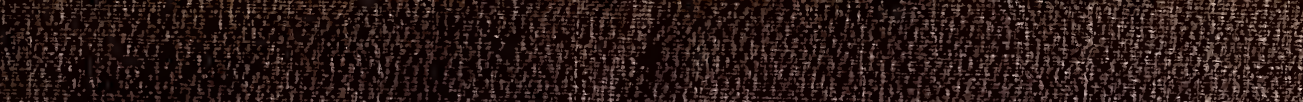
(5) 4 , it.

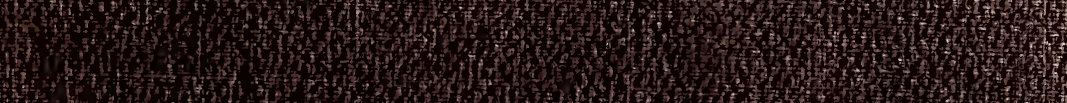

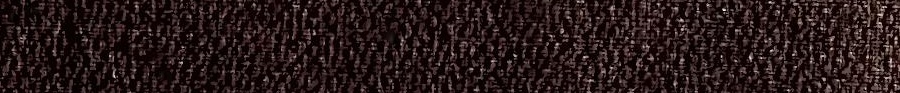

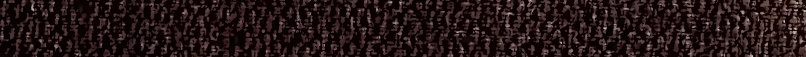

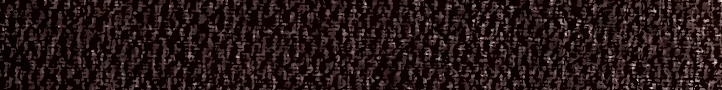
(3)

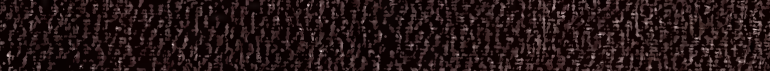

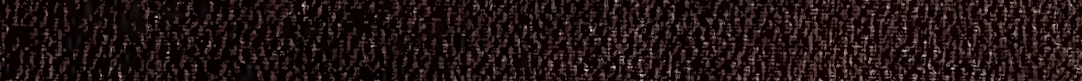
(1) His

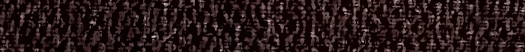

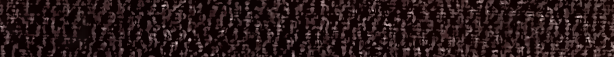

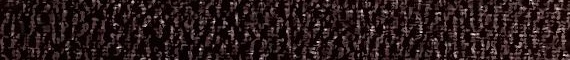

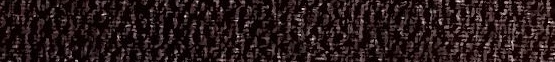

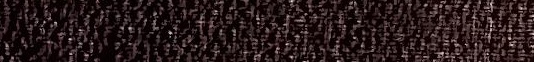

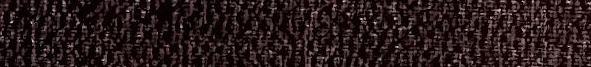

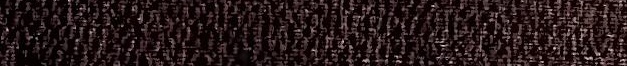
How

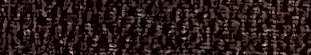

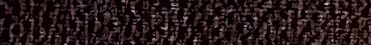

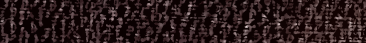
(W) How 1.7.

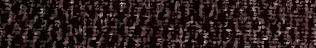
HW Whothom

(1)

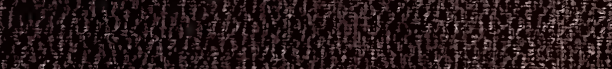
(1) 3 . (10)

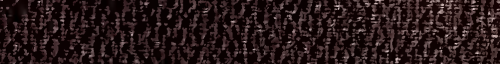

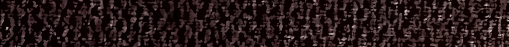

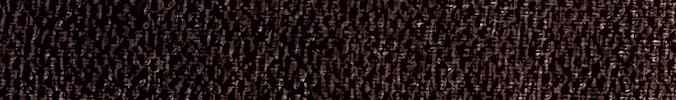

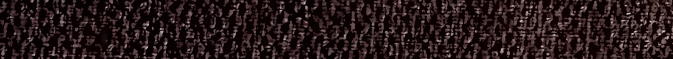

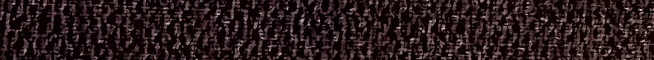
the 1)

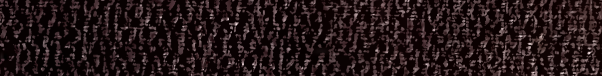

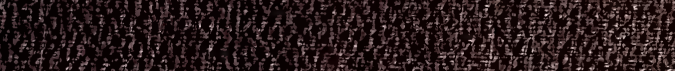

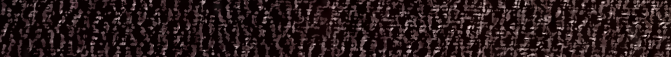
Whow

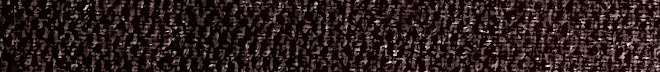

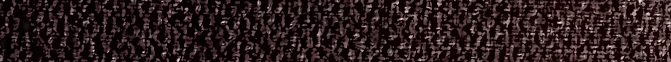

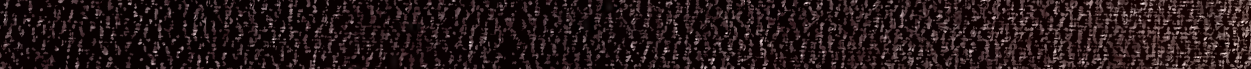

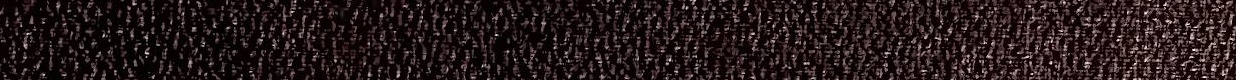
W.

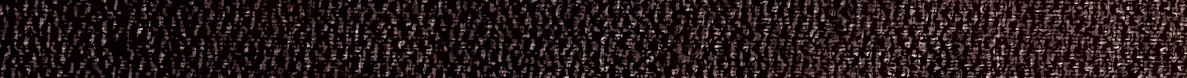
H. W How

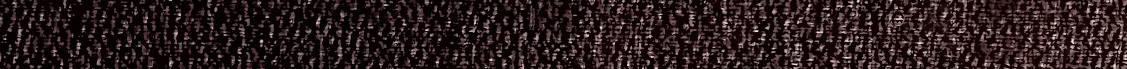

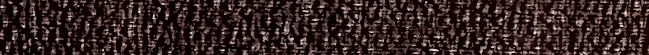


Michèle TROCHON

Spécialiste
du TIERS MONDE

76, r. du Cherche-Midi 75006 PARIS 




\title{
I OEURS,
}

\section{USAGES ET COSTUNES}

DE TOUS LES

\author{
PEUPLES DU MONDE.
}



$G T$

70

w $2 x$

1843

MOEURS,

V. 2

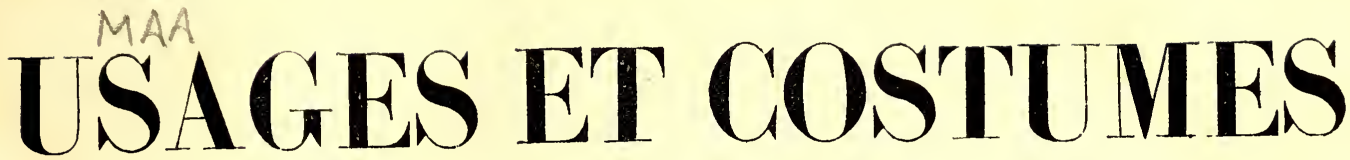

DE TOUS LES

\section{PEUPLES DU MONDE,}

D'APRĖS dES DOCUMENTS AUTHENTIQUES ET LES VOYAGES LES PLUS RÉCENTS;

PUBLIE

par a Ueus'te Wh mane.

CHEVALIEL DE PLUSHEH OHDHES

\section{AFRIQUE - AMÉRIQUE.}

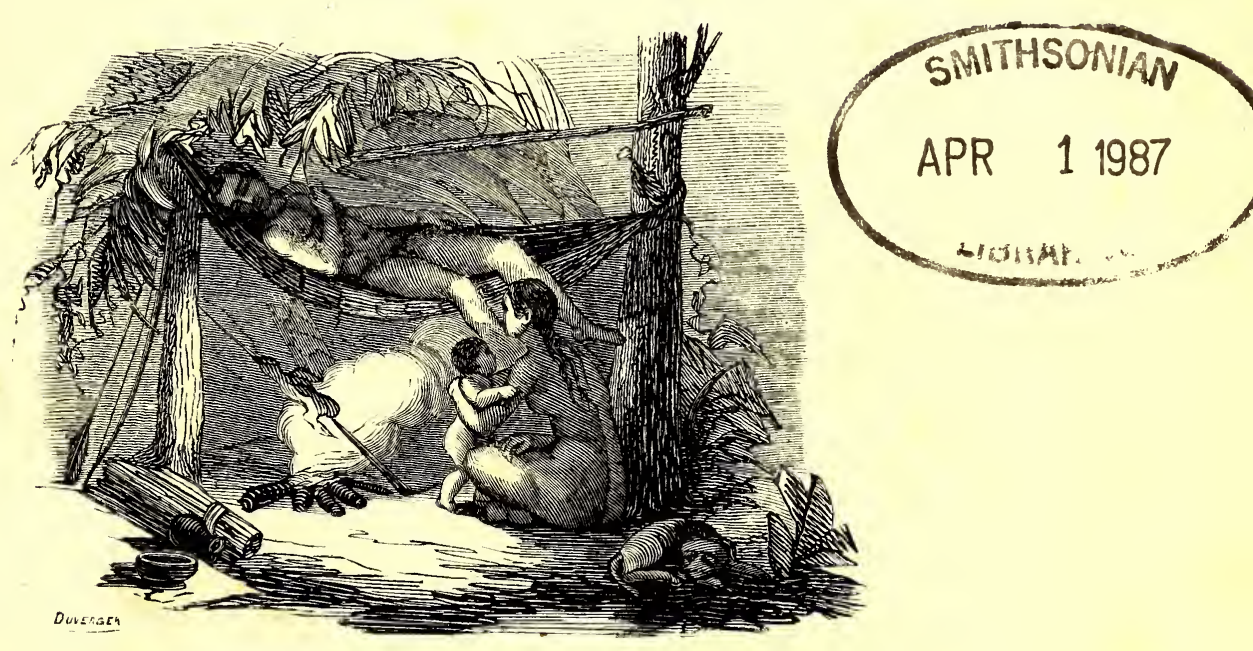

\section{Brutelles}

A LA LIBRAIRIE HISTORIQUE-ARTISTIQUE,

RUE DE SCHAERBEFK, 12 . 



\section{AFRIQUE.}

\section{- \\ APERG̣U GÉNÉRAL.}

L'Afrique, la troisième partie du monde par l'étendue, et la dernière sous le rapporí de la civilisation, présente l'aspect d'une presqu'île immense, liée au continent par l'isthme de Suez, situé à son extrémité nord-est, entre la mer Rouge et la Méditerranée. L'Afrique est séparée en deux parties presque égales en longueur par la ligne équinoxiale : ce continent a près de 72 degrés du nord au sud, et 69 degrés de l'est à l'ouest; il s'étend en largeur du cap Guardafui par $49^{\circ}$ de longitude est, au cap Vert par $19^{\circ}$ $50^{\prime} 4 \mathbf{5}^{\prime \prime}$ de longitude ouest, ce qui produit une largeur de 1650 lieues; et du cap Bon par $37^{\circ} 4^{\prime} 45^{\prime \prime}$, au cap de Bonne-Espérance par 34.24' de latitude sud, ce qui donne une longueur de 1,820 lieues. La superficie est évaluée à 1,750,000 lieues carrées, el le circuit des côtes à 7,000 lieues.

Ce n'est point à l'indifférence des géographes ni à la timidité des voyageurs que l'on doit attribuer l'obscurité qui enveloppe encore une grande partie du continent. intérieur de l'Afrique. En effet, on ne pourrait que difficilement offrir un résumé exact de toutes les tentatives qui ont eu lieu pour explorer les côtes et l'intérieur de cette division du globe, depuis les navigateurs phéniciens, contemporains de Néchos, jusqu'à nos jours. Ces premiers explorateurs, qui franchirent les colonnes d'Hercule, paraissent avoir doublé le cap de Bonne-Espérance. L'antiquité nous apprend encore que Sataspes, courtisan persan qui avait été disgracié par Xercès, et condamné au crucifiement, n'échappa à cet affreux supplice qu'en offrant d'entreprendre une périlleuse navigation : il traversa le détroit de Gibraltar, et fit voile vers les côtes d'Afrique; mais cet audacieux voyageur ne nous a laissé aucun renseignement. - Eudoxe, natif de Cyzique, entreprit, sous le règne de Ptolémée-Évergète, d'aller dans l'Inde par mer; il était accompagné d'un Indien qui avait fait naufrage à l'entrée du golfe Arabique; mais, contrarié par les vents, il fut poussé mainte fois sur les côtes africaines, où il aperçut les débris d'un bâtiment de Cadix. Cette découverte fit naître en lui le désir de se rendre dans cette ville, qui dès lors florissait par son commerce, pour s'y procurer des renseignements sur les moyens d'accomplir le projet de navigation qu'il avait conçu. Il parvint à organiser deux expéditions considérables : l'indiscipline des matelots fit échouer la première, et le sort de l'autre ne fut point connu; mais on ne saurait douter qu'il n'ait visilé plusieurs portions des côtes occidentales de l'Afrique. 
Le peuple carthaginois, essentiellement commerçant et navigateur, fit vraisemblablement de plus grandes tentatives; cependant la seule dont on ait recueilli quelques détails est celle de Hanon, dont nous possédons la relation. Elle s'accomplit à une époque très-reculée, et son but consistait à faire des opérations commerciales, et à fonder des colonies. On y employa soixante gros vaisseaux, montés par 30,000 personnes de sexe différent; ils dépassèrent le détroit de Gibraltar, fondèrent plusieurs villes sur les côtes de Libye où ils édifièrent un temple; parcourant une vaste étendue de côtes, ils abordèrent sur celles d'Éthiopie, où ils aperçurent une race d'hommes d'une si grande timidité, qu'ils s'enfuirent à leur aspect. Après avoir navigué assez longtemps, le manque de provisions les contraignit à revenir sur leurs pas, après être parvenus jusqu'à la Gambie et même ${ }^{\mathrm{r}}$ jusqu'à la Sierra-Léone.

Nous apprenons par le Périple de Scylax, qui n'est qu'une espèce de compilation, que les navigateurs phéniciens avaient des relations commerciales avec les Éthiopiens qui, en échange de drogues d'Égypte, de vêtements athéniens, et d'un grand nombre d'ustensiles de ménage, leur fournissaient une quantité considérable d'ivoire. Les Phéniciens servirent probablement, de guides aux expéditions que les monarques juifs envoyèrent à Ophir et à Tarse, que l'on suppose avoir été situées dans l'océan Indien. Les expéditions de Cambyse et d'Alexandre dans les oasis n'ont pas plus contribué à nous faire connaître l'intérieur de l'Afrique que celles des conquérants musulmans sur les côtes orientale et septentrionale, et dans l'intérieur de la même partie du monde. Il était réservé aux Portugais de déterminer l'extrémité méridionale de l'Afrique. Ce fut en 1486 qu'un de leurs amiraux, Barthélemy Diaz, découvrit le cap dit aujourd'hui de Bonne-Espérance, mais qu'il nomma d'abord Cap des Tourmentes. Le même amiral avait reconnu aussi plusieurs parages de la côte occidentale de l'Afrique. Le premier voyageur musulman, à notre connaissance, qui ait pénétré dans l'intérieur des terres, est Ebn-Batoutah, marchand, natif de Tanger, qui, dans le xıv ${ }^{0}$ siècle de notre ère, visita Timbouctou, Melly, et autres royaumes d'Afrique. Sa relation prouve qu'au XIv ${ }^{e}$ siècle le commerce était bien plus florissant dans l'intérieur de l'Afrique qu'il ne l'est maintenant; la religion musulmane y était très-répandue. Peu de temps après, les Portugais, qui se montraient alors les plus hardis navigateurs de l'Europe, furent aussi les premiers Européens qui procurèrent des notions directes sur Timbouctou. Ils envoyèrent le Vénitien Cada Mosto, qui recueillit des renseignements précieux sur Timbouctou et sur le commerce de l'intérieur de l'Afrique. Cette natiọn eut bientòt de grandes facilités pour exploiter ce commerce, par le moyen de son établissement dans l'île d'Arguin. La Description circonstanciée et authentique de l'Afrique, que Léon, surnommé $l$ 'Africain, composa en arabe, et qu'il traduisit ensuite lui-même en italien, en 1526, renferme de précieux documents sur l'Afrique. C'est à lui que nous devons la principale masse des connaissances que nous possédons sur cette partie du monde, et auxquelles les voyageurs et les écrivains qui lui sont postérieurs ont fait des additions nombreuses. Les documents, sinon les plus authentiques, du moins les plus certains, relatifs à la découverte des sources du Nil, sont dus aux pères Paëz et Lobo, missionnaires de la société de Jésus. En comparaut les cartes des PP. jésuites gravées par Échinard et jointes à la Description de l'empire du Prêtre-Jean (Paris, Billaine, 1674, in-4', avec celles du voyageur anglais Bruce, on serait bien tenté d'accuser celui-ci de plagiat. Les discussions auxquelles la relation de Bruce donna lieu, les doutes qu'elle inspira, et les relations qu'on exhuma à cette occasion inspirèrent à plusieurs Anglais l'idée de

1 C'est du moins l'opinion de M. le major Rennell; mais, selon M. Gosselin, iIs n'allèrent pas au delà du cap Moun. 
former, en 1788, une société pour faire des recherches dans l'intérieur de l'Afrique. Le triste sort de leurs premiers voyageurs, MM. Ledyard et Houghton, n'effraya pas M. Browne. Ce jeune et riche Anglais, animé de la passion des découvertes, exécuta le même projet à ses frais, de 1792 à 1798. Sans secours étranger, il entra en Afrique par l'Égypte, et pénétra dans le Darfour. Il obtint en outre des naturels de ce pays des détails intéressants sur différents pays voisins. Quoique Seetzen n'ait point pénétré dans l'intérieur de l'Afrique, le résultat de ses recherches mérite qu'il soit placé au nombre de ceux qui ont contribué à nous la faire connaître. Seetzen allait s'assurer lui-même de l'exactitude des rapports que lui avait faits un jeune Arabe, quand il périt victime de la rapacité d'un cheyk arabe. Un sort non moins funeste était réservé à son digne émule Mungo-Park, justement célèbre par deux hardis voyages également utiles pour la connaissance de l'intérieur de l'Afrique. Chargé par la compagnie africaine, en 1795, de faire de nouvelles recherches dans l'intérieur de l'Afrique, il découvrit le Niger ou Djoliba coulant de l'ouest à l'est. Sa relation a jeté un grand jour sur les vastes contrées de la Sénégambie. Les succès que Mungo-Park avait obtenus enflammèrent l'imagination de plusieurs jeunes Anglais et Allemands. Frédéric Hornemann, élève de l'université de Gœttingue, qui partit de Londres en 1798, aux frais de la société africaine, pénétra en Afrique par l'Égypte, et a été perdu pour l'Europe depuis son aŕrivée à Mourzouk, capitale du Fezzan; son long silence donne tout lieu de croire que ce zélé voyageur n'existe plus. Nous lui devons des renseignements beaucoup plus précis et plus authentiques que tout ce que l'on possédait jusqu'alors sur les oasis de Syouah et d'Audjélah, et sur le désert situé entre l'Égypte et le Fezzan. La société africaine envoya depuis deux autres voyageurs, MM. Nichols et Roentgen, en Afrique, où ils périrent, le premier en remontant le Calabar, que certains géographes croient être l'embouchure du Djoliba ou Niger, l'autre en sortant de Mogador pour se rendre au Soudan. Découragée par la perte successive de presque tous les voyageurs qu'elle avait expédiés en Afrique, la société se borna pendant quelque temps à demander aux consuls de sa nation dans les États Barbaresques tous les renseignements qu'ils pourraient recueillir sur l'intérieur des terres. MM. Cabil de Rabath et Grey Jackson de Mogador, en procurèrent surtout de précieux sur Timbouctou, ville immense située sur les bords du Niger. Entre Timbouctou et Cachemes, que l'on nomme aussi $\boldsymbol{B} \hat{e} b$ Haoussa, se trouvait, disait-on, une race d'hommes aussi blancs que les Anglais, etc. La lecture de ce rapport réveilla la curiosité de Mungo-Park, retiré alors en Écosse, sa patrie. Animé d'une noble émulation, il proposa, non à la société africaine, mais à son gouvernement, de l'envoyer une seconde fois dans l'intérieur de l'Afrique. Sa proposition fut accueillie, et on lui fournit abondamment tout ce qui était nécessaire pour ce grand voyage; le 18 août 1805, Mungo-Park eut le plaisir de revoir pour la seconde fois le Niger. Arrivé à Sansanding, ville située sur le fleuve, et moins avancée dans les terres que le point où il était parvenu dans son précédent voyage, il s'embarqua sur le fleuve après avoir chargé un nègre fidèle de porter ses journaux au comptoir anglais de la Gambie. Depuis cetle époque, il n'a plus donné de ses nouvelles, et l'on ne sait pas très-positivement de quelle manière il a péri près d'un lieu nommé Boussa. Au reste, ce second voyage n'a pas été, à beaucoup près, inutile pour la science, n'eût-il contribué qu'à ne plus nous laisser aucun doule sur l'existence du lac de Dibbie, et à nous faire connaître les rivières qui s'y jettent. Après Mungo-Park, un des voyageurs qui a le mieux mérité de la géographie est M. Bowdich, à qui un séjour de cinq mois parmi les Achantins en 1817, a permis de donner une description détaillée de leur pays; il a visité les rives du Gabon. Nous devons citer aussi MM. Badia, qui a parcouru l'empire de Maroc, Tripoli et l'Égypte; Ritchie, qui de Tripoli est allé à Mourzouk, où il 
est mort; Tuckey, qui, après avoir remonté le Zaïre, a péri victime de l'insalubrité du climat; Mollien, qui de l'embouchure du Sénégal est allé par terre à Timbou, situé par $10^{\circ}$ de latitude nord, et $13^{\circ}$ de longitude ouest, et est revenu heureusement dans sa patrie, etc. Ces voyageurs, soit par leurs observations, soit par les renseignements qu'ils ont reçus des naturels, ont jeté un nouveau jour sur les relations de leurs prédécesseurs, et ont ajouté aux connaissances que l'on possédait déjà. Des ténèbres non moins épaisses ont longtemps couvert la partie méridionale de l'Afrique. Les courses aventureuses de Levaillant firent connaître plus de bêtes curieuses que de points géographiques. Avant lui, Sparrmann et Thunberg, naturalistes suédois, et Paterson, Anglais, avaient parcouru le pays à l'est, et au nord du Cap, et leurs courses avaient enrichi la géographie de renseignements précieux. Depuis 1797, Barrow visita cette contrée jusqu'à la rivière Orange, à $30^{\circ}$ de latitude sud. En 1801, Trutter et Somerville pénétrèrent jusqu'à Litakou, capitale des Bouchouanas, située par $26^{\circ}$ de latitude. MM. Lichtenstein, Allemand, qui voyagea de 1803 à 1806, Campbell en 1813 et en 1820, Burchell en 1813, La Trobbe en 1819, ont, par leurs excursions, jeté un nouveau jour sur cette contrée. Alberti, officier au service de Hollande, a donné des détails intéressants sur les Cafres. Le jésuite allemand Thomann voyagea en 1757 dans le pays de Mozambique, qui a été observé en 1809 par M. Salt. Ce voyageur anglais a aussi visité en 1805 et en 1810 l'Abyssinie, où son compatriote Bruce avait séjourné de 1769 à 1772. Enfin, en 1824, M. Caillaud, qui avait précédemment découvert une nouvelle oasis à l'ouest de l'Égypte, et la mine d'émeraudes à l'est de ce pays, a, dans une nouvelle excursion, parcouru la Nubie et des pays peu connus. Il a suivi les bords du Nil; il ne s'est arrêté qu'au $10^{\circ}$ degré de latitude nord. Quant à nous, c'est surtout dans les revues, dans les brochures et les journaux que nous puisons pour compléter autant que possible tout ce qui a été dit sur cette contrée; et nous terminerons cet aperçu en formant les vœux les plus sincères pour que la Société africaine de Londres, et la Société géographique de Paris dirigent spécialement leur attention vers les sources du Nil, le cours du Niger, la mer du Soudan, la situation et la population des villes de Timbouctou et d'Ouessanah, et emploient tous les moyens qui sont en leur pouvoir pour parvenir à la solution des grands problèmes géographiques que présente encore l'intérieur de l'Afrique. 


\section{ÉGYPTE.}

L'Égypte, cette partie unique dans la nature et dans les fastes de l'histoire, rattache l'Afrique au monde civilisé. Cette contrée est celle qui mérite la description la plus détaillée de toutes les parties africaines. L'Égyple offre une vallée que le Nil arrose après l'avoir en partie formée, et que resserre, à l'ouest et à l'est, la stérile immensité des déserts. Nous commencerons donc par le Nil le tableau physique de cette contrée, qui doit aux dons de son fleuve l'avantage de pouvoir se passer du reste de la terre, et du ciel lui-même.

Le plus grand fleuve de l'ancien monde, le Nil, dérobait encore naguère ses véritables sources aux regards de la science. Les voyageurs les plus récents ont confirmé presque entièrement l'opinion d'Ératosthène, le savant bibliothécaire d'Alexandrie, qui distinguait trois branches principales du Nil, dont la plus importante est le Bahrel-Abiad, ou rivière Blanche, venant des montagnes de la Lune; la seconde est le Bahrel-Azrak, ou rivière Bleue, sortant d'un plateau d'Abyssinie, et traversant le lac Dembea dans sa partie méridionale; la troisième, qui est la plus orientale, le Tacaz-zé, ou l'Albarak, n'est considérée que comme un afluent de ce fleuve, auquel elle se réunit après un parcours de 200 lieues.

L'Égypte, en arabe Massr ou Missir, Egyptus, est située au nord-est de l'Afrique, entre $23^{\circ} 23^{\prime}$ (golfe Immonde), et $31^{\circ} 37^{\prime}$ (cap Bourlos) de latitude septentrionale, et entre $25^{\circ} \breve{5}^{\prime}$ (al Baretoun) et $33^{\circ}$ 22' (cap Nosi) de longitude orientale. La Méditerranée au nord, la mer Rouge et l'isthme de Suez à l'est, la Nubie au sud, les déserts de Libye et de Barcah à l'ouest forment les limites de l'Égypte, dans lesquelles ne sont pas comprises la Grande-Oasis, l'oasis de Dakhel, celle de Farafré, et la Petite-Oasis.

L'Égypte a environ 197 lieues de longueur, et 110 lieues dans sa largeur moyenne. On peut partager l'Égypte en deux parties distinctes : la vallée du Nil, ou la partic habilée, et le désert. Nous offrons ici le tableau de l'étendue et de la population de ce pays :

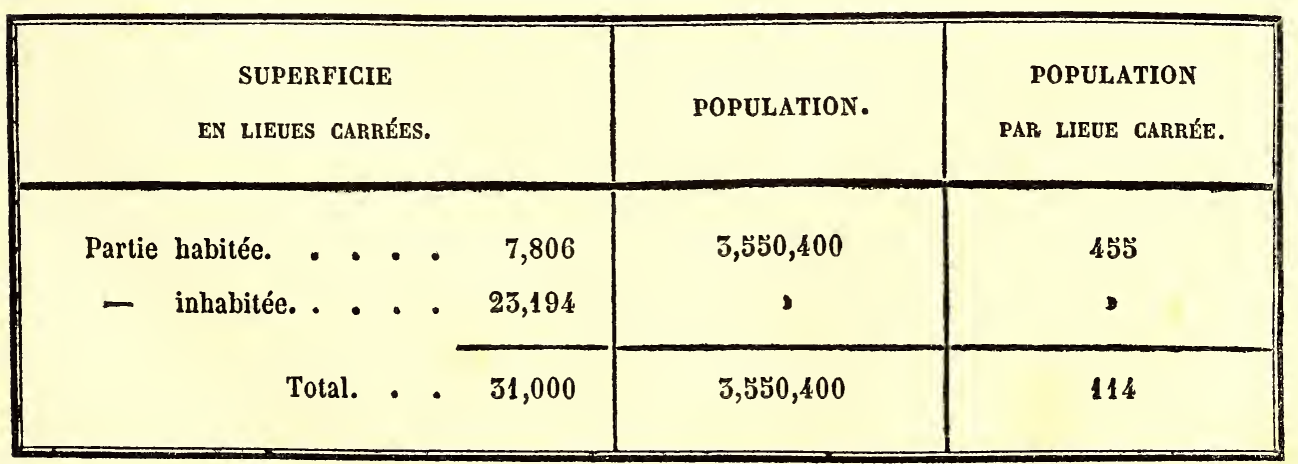


Le Nil, depuis l'île de Philoé (240 $1^{\prime}$ de latitude) jusqu'au Caire $\left(30^{\circ} 2^{\prime}\right)$, coule dans un bassin étroit, resserré par deux montagnes; il s'élargit alors, et, à Daraouéh, ce fleuve se sépare en deux branches principales (celle de Damiette ou orientale, et celle de Rosette ou occidentale), qui, avec le littoral de la Méditerranée, forment l'île triangulaire appelée par les anciens Delta. Un grand nombre de deltas, artificiels ou naturels, dont les principaux sont ceux de Bahgoûrah, de Saoûaqi, de Joseph, qui communique au Birket-el-Geroun (ancien lac Mœris), entretiennent la fertilité dans cette vallée.

Des deux chaînes qui limitent en Égypte le bassin du Nil, celle de l'est est connue sous le nom de chaîne Arabique, et celle de l'ouest sous le nom de chaîne Libyque. Elles sont non-seulement incultes dans toute leur étendue, mais encore absolument nues.

La chaîne orientale présente dans sa partie septentrionale des escarpements semblables à de longues murailles formées d'assises horizontales; on y voit de toutes parts une multitude de grottes et de carrières. Cette chaîne se termine d'une manière abrupte au-dessus de la citadelle du Caire, et présente des escarpements aussi bien du côté de la ville que du côté du fleuve.

La chaîne Libyque laisse voir dans sa partie septentrionale un talus peu rapide, des formes arrondies, et parfois descend par larges degrés jusqu'à la plaine cultivée; elle se termine par un éperon dont la base s'avance pour former le plateau sur lequel sont bâties les pyramides, et qui va se perdre dans les plaines sablonneuses qui se prolongent à l'ouest du Delta. Cette chaîne est moins élevée que sa parallèle, la chaîne Arabique. Elles sont entrecoupées par un nombre infini de gorges et de vallées, qui toutes, à l'exception de celle de Fayoum, s'inclinent vers le Nil, pour y verser le peu d'eau qui tombe dans les déserts voisins. Ces différentes gorges sont habitables, parce que les pluies d'hiver y entretiennent la végétation pendant quelque temps, et forment des sources qui suffisent aux besoins des Arabes. Dans la pente douce qui termine la partie septentrionale de la chaîne Libyque, il y a deux vallées remarquables, presque parallèles à la branche voisine du Nil : la première, à 15 lieues $3 / 4$ du Delta, est celle des lacs de Natron; la seconde, un peu plus à l'ouest, est celle du fleuve sans eau (Bahrbelâ-mâ). On trouve aussi dans cette chaîne la vaste coupure d'environ 6 lieues $3 / 4$ de largeur, inclinée du côté opposé au Nil, vers le Fayoum, où elle conduit par le canal Joseph la dérivation du Nil qui se rend dans le Birket-el-Geroun.

L'Égypte n'a pas de mines exploitées. Les mines d'émeraude, ouvertes et abandonnées successivement par les Égyptiens, les Grecs et les califes, et plus récemment par Méhémet-Ali, ne paraissent avoir jamais rien produit de quelque valeur. Quelques parcelles de prime d'émeraude, de la grosseur d'une tête d'épingle, voilà tout ce que l'on trouve en fouillant les veines de mica et de quartz. Les autres pierres précieuses paraissent y être aussi très-rares. Aux environs de Syout, il y a du cuivre et du fer, et des salines dans l'île du Phare, devant Alexandrie. On ramasse du sel tout formé le long de la côte et dans l'intérieur de l'isthme de Suez. Le natron, une des productions les plus singulières de la contrée, se forme en abondance dans les lacs de la vallée de ce nom. La haute Égypte a toujours été renommée pour ses carrières de granit, de syénite et de porphyre.

Les champs offrent trois tableaux différents, suivant les trois saisons de l'année égyptienne. Dès le milieu du printemps, les récoltes déjà enlevées ne laissent voir qu'une terre grise et poudreuse, si profondément crevassée qu'on ose à peine la parcourir. A l'équinoxe d'automne, ils présentent une immense nappe d'eau rouge ou jaınâtre, du sein de laquelle sortent des palmiers, des villages et des digues étroites qui servent de communicalion. Après la retraite des eaux, qui se soutiennent peu de temps 
à ce degré d'élévation, on n'aperçoit plus qu'un sol noir et fangeux. C'est pendant l'hiver que la nature déploie toute sa magnificence : durant cette saison, l'Égypte n'est, d'un bout à l'autre, qu'une magnifique prairie, un champ de fleurs ou de verdure, fertilité que relève le contraste de l'aridité absolue qui l'environne.

Dans la haute Égypte, les maisons, élevées de trente pieds au-dessus de la plaine, sont d'une teinte sombre, semblable à celle du sol, toujours basses et sans toit. Leur forme est celle de pyramides tronquées, terminées pour la plupart par quatre masses carrées et blanchies servant de colombiers. Bâties en briques crues du limon du Nil, elles ont un aspect aussi misérable que celles du Delta; cependant les minarets légers construits en pierres qui sortent de ces habitations écrasées, de ces murs de terre bruns en talus, et qui élèvent leurs longues aiguilles blanches au-dessus des têtes verdoyantes des sycomores et des dattiers, donnent quelque chose de pittoresque aux villages. L'aspect est à peu près le même dans la basse Égypte.

Les maladies particulières au climat, et qui sont très-funestes à la population, ont été l'objet des savants mémoires de M. le baron Larrey. Ce sont une ophthalmie endémique, le tétanos traumatique, la peste, l'hépatite, l'atrophie des testicules, le sarcocèle; la lèpre et l'éléphantiasis sont aussi particulières à ce pays.

Le climat est, dans l'été, d'une chaleur excessive; mais les nuits sont très-fraîches. Dans la vallée même du Nil, au-dessous du confluent du Tacazzé (vers $17^{\circ} 40^{\prime}$ de latitude nord), il ne pleut jamais; au sud de ce point, les pluies commencent chaque année en juillet. Dans les parties montagneuses de l'est, il tombe quelques pluies à des époques indéterminées. Le khamsyn commence à se faire sentir dans la Nubie vers la fin d'avril, et dure jusque vers l'équinoxe d'été; ce vent pernicieux entraîne une grande quantité de sable, et est accompagné de tonnerre et d'éclairs. La rive droite du Nil, périodiquement inondée par les eaux de ce fleuve, est beaucoup plus fertile que la rive gauche. L’agriculture est en général assez soignée.

Le blé est cultivé dans toute l'Égypte : les parties qui en produisent le plus sont les provinces de Thèbes, de Girgéh, de Syout, de Minyéh, de Gizéh, de Menouf et de Mansourah. Le dourah fournit la nourriture ordinaire du paysan; il est cultivé depuis l'île Éléphantine jusqu'au Caire. Le maïs, qui, dans la haute Égypte, n'est en quelque sorte que subsidiaire, remplace le dourah dans quelques cantons du Delta. Le riz n'est cultivé que dans la partie septentrionale de la basse Égypte. L'orge est Ia plante céréale le plus généralement cultivée. Les lentilles sont particulières à la partie entre Edfou et Gizéh, en y comprenant le Fayoum. On sème aussi des pois chiches et des lupins: les tiges presque ligneuses de ces derniers sont employẻes comme combustibles, et particulièrement à faire l'espèce de charbon qui entre dans la fabrication de la poudre à canon du pays. Les fèves sont récoltées en abondance dans les provinces centrales de Girgéh, de Syout, et de Minyéh. L'oignon est un objet de grande culture dans presque toute l'Égypte, à l'exception de la partie méridionale de la province de Thèbes et des parties inférieures du Delta : ce comestible sert à la nourriture des habitants des campagnes, et est assez doux pour être mangé cru. La pastèque est aussi fort abondante partout. Les champs cultivés en plantes potagères sont ordinairement bordés par des lisières de chanvre, de carthame, etc. Il n'y a pas de prairies naturelles en Égypte; le trèfle est le fourrage le plus généralement semé. Dans les provinces de Syout et de Girgéh, on récolte une espèce de colza appelée selgam, dont la graine est employée à faire de l'huile. Aux environs de Qénéh et dans presque tout le Delta, on fait avec le sésame une huile comestible. Le carthame, cultivé dans la vallée d'Égypte depuis Esné jusqu'au Caire, a une graine dont on tire de l'huile, et une fleur qui est employée pour la teinture : sa culture est une des plus avantageuses. Le lin est un des produits les plus 
importants des provinces de Syout et de Minyéh, du Fayoum et de l'intérieur du Delta ; une partie est employée par les tisserands du pays, et le reste est exporté en filasse dans l'Archipel. On trouve dans toutes les parties de l'Égypte quelques champs de coton; un Français nommé Jumel a introduit depuis quelques années le coton du Brésil : celte espèce a réussi, et conserve le nom de coton Jumel. Les parties méridionales de la haute Égypte paraissent les plus propres à la culture de l'indigo. Bien que toutes les parties de l'Égypte puissent produire la canne à sucre, cette plante est, pour ainsi dire, concentrée dans la province de Girgéh. Le tabac est spécialement cultivé dans les provinces de la haute Égypte. Toule l'eau de rose qu'on fabrique en Égyple provient des rosiers de la province de Fayoum, la seule où ils soient l'objet d'une grande culture. C'est un trait du site de l'Égypte d'ètre dénué d'ombrages, sans être pourtant privé d'arbres. Le dattier, l'arbre le plus universellement répandu dans toute l'Égypte, ne jette sur la terre qu'une ombre pâle et incertaine : on en tire un très-grand parti pour les constructions et l'économie domestique; son tronc fournit des poutres et des solives; ses feuilles des paniers et des meubles à l'usage des habitants de la campagne, ainsi que des cordes. La vigne est, après le dattier, l'arbre le mieux soigné; la province de Fayoum et la langue de terre de Bourlos la produisent spécialement. On cultive dans quelques jardins des grenadiers, des orangers, des citronniers; l'olivier vient en plein champ dans le Fayoum, et a disparu du reste de l'Égypte. On trouve aussi dans cette province les lotus, si révérés des anciens; ils y sont aussi communs que dans les canaux et les terrains inondés de la basse Égypte. Le nopal ou roquette épineuse y forme des clôtures semblables à de hautes murailles. Il n'y a pas en Égypte d'arbres forestiers proprement dits : l'espèce d'arbre la plus commune est le figuier sycomore, dont le bois est employé à la construction des barques du Nil; on en fait aussi des planches et des madriers. La graine du mimosa nilotica remplace l'écorce de chêne pour le tannage des cuirs. On trouve aussi dans la haute Égypte, plus souvent que dans le Delta, le tamarin, le rhamnus, le cassier. La sensitive croît spontanément aux environs d'Assouan; le séné, qui vient aussi sans culture, n'habite que le sol pierreux des environs de la cataracte.

Tous les travaux de l'agriculture sont exécutés, dans la partie supérieure de l'Égypte, par des bœufs. Les troupeaux de buffles que l'on rencontre dans cette partie ne sont entretenus que pour le lait qu'ils fournissent : le climat y est trop chaud pour qu'ils puissent être employés aux travaux de l'agriculture comme ils le sont dans la basse Égypte; la chair de ces animaux est celle dont les boucheries des villes sont le mieux approvisionnées. Les chameaux sont plus grands dans la basse Égypte que dans la haute Égypte, dont ils forment la principale richesse; diverses tribus arabes amènent dans cette partie le hégyn, petit dromadaire svelte et léger. Les chèvres fournissent dans la haute Égypte une partie du lait qui se consomme dans les villages. C'est dans le Fayoum qu'on élève le plus de moutons, et ceux dont la laine est la plus estimée. Le cheval n'est pour l'Égypte qu'un objet d'utilité pour la guerre, de luxe ou d'agrément; on ne l'emploie pas pour le trait. Au reste, c'est aux Arabes devenus cultivateurs, qui habitent encore sous des tentes à l'entrée du désert, que l'éducation des chevaux est réservée; ce sont eux aussi qui approvisionnent de bétail les différents marchés. Les fellahs ou paysans élèvent une grande quantité de pigeons et de poules. On se livre presque dans toutes les provinces à l'éducation des abeilles. Vers les confins du désert, on voit errer des chiens sauvages; le chacal habite les ruines.

Les canards, les pluviers, etc., sont abondants sur la côte de la Méditerranée. Dans les mois de septembre et d'octobre, les cailles y sont si nombreuses, qu'elles sont l'objet d'une espèce de récolte. Le Nil est très-poissonneux, et il y a dans tous les endroits 
situés sur ses bords des pêcheurs de profession; mais ce n'est que sur les rives des lacs Bourlos et Menzaleh qu'il y a des établissements de pêche proprement dits. Le poisson dont les œufs donnent la poutargue, y est abondant. Les crocodiles, l'hippopotame et l'ichneumon se trouvent dans la haute Égypte.

Dans les campagnes l'industrie se borne aux arts de première nécessité, et à la manipulation de quelques produits du sol servant à la consommation journalière; les travaux d'agriculture sont peu pénibles, tant est grande la fécondité du sol. Il y a de la chaux presque par toute l'Égypte. Le Fayoum est la seule province où l'on fabrique du vin, mais d'une manière très-imparfaite.

Les Égyptiens tirent du maïs, du millet, de l'orge, et même du riz, une liqueur fermentée qui ressemble un peu à la bière douce. Les chrétiens tirent des dattes une autre liqueur qu'on nomme araki; on en fait aussi avec ce que nous appelons raisin de Corinthe.

Le lin, la soie, la laine, le sel ammoniac sont les principales productions de l'Égypte.

On trouvera dans nos Monuments les plus remarquables des renseignements intéressants sur les curiosités architecturales de l'Égypte. Nous nous bornerons ici à offrir le tableau des lieux principaux de cette contrée, afin de simplifier notre travail et de ne pas dépasser le cadre de notre ouvrage.

\section{BAHARI OU BASSE ÉGYPTE.}

(2 gouvernements et 13 départements.)

\begin{tabular}{|c|c|c|}
\hline $\begin{array}{l}\text { GOUVERNEMENTS } \\
\text { ET DÉPARTEMENTS. }\end{array}$ & VILLES ET VILLAGES. & POPULATION. \\
\hline 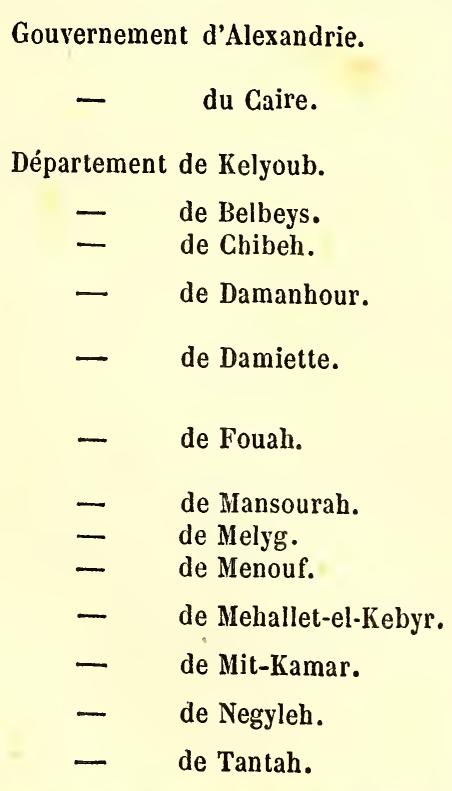 & $\begin{array}{l}\text { Iskanderyeh ou Alexandrie. } \\
\text { Aboukir, ville. } \\
\text { El-Kaïra ou le Caire. } \\
\text { Boulak. } \\
\text { Kelyoub. } \\
\text { Matarieh, vill. } \\
\text { Belbeys. } \\
\text { Chibeh, b. } \\
\text { Damanhour. } \\
\text { Rahmâniéh, b. } \\
\text { Damiette. } \\
\text { Menzaleh. } \\
\text { Fouah. } \\
\text { Rosette. } \\
\text { Deïrout, b. } \\
\text { Mansourah. } \\
\text { Melyg, b. } \\
\text { Menouf. } \\
\text { Mehallet-el-Kebyr. } \\
\text { Abousyr, b. } \\
\text { Mil-Kamar, b. } \\
\text { Negyleh, b. } \\
\text { Terraneh. } \\
\text { Tantah. }\end{array}$ & $\begin{array}{r}36,000 \\
900 \\
336,000 \\
18,000 \\
1,500 \\
600 \\
5,000 \\
1,000 \\
6,000 \\
2,000 \\
30,000 \\
2,000 \\
7,000 \\
14,000 \\
1,200 \\
6,000 \\
1,100 \\
4,000 \\
8,000 \\
900 \\
800 \\
800 \\
1,500 \\
2,000\end{array}$ \\
\hline
\end{tabular}


SAiID OU HAUTE ÉGYPTE,

COMPRENANT LA MOYENNE ÉGYPTE.

(11 départements.)

\begin{tabular}{|c|c|c|}
\hline DÉPARTEMENTS. & VILLES ET VILLAGES. & POPULATION. \\
\hline $\begin{array}{ll}\text { Département d'Atfieh. } \\
\text { _ } & \text { de Beni-Soueyf. } \\
\text { de Bouch. } & \text { d'Esneh. } \\
- & \text { de Fayoum. } \\
\text { de Gizeh. } \\
\text { - } & \text { de Girgeh. } \\
- & \text { de Kénéh. } \\
- & \text { de Minieh. } \\
- & \text { de Manfalout. } \\
- & \text { de Syouth. }\end{array}$ & $\begin{array}{l}\text { Atfieh. } \\
\text { Beni-Soueyf. } \\
\text { Bouch, vill. } \\
\text { Esneh. } \\
\text { Edfou. } \\
\text { Assouan. } \\
\text { Médinet-el-Fayoum. } \\
\text { Gizeh ou Djizeh. } \\
\text { Girgeh ou Djirgeh. } \\
\text { Akhmin. } \\
\text { Denderah, vill. } \\
\text { Kénéh. } \\
\text { Coptos, b. } \\
\text { Louxor, ville. } \\
\text { Minieh. } \\
\text { Achmouneïn, vill. } \\
\text { Manfalout. } \\
\text { Sanâbou, b. } \\
\text { Syouth. } \\
\text { Aboûtig, b. }\end{array}$ & $\begin{array}{r}4,000 \\
11,000 \\
1,200 \\
4,500 \\
2,000 \\
1,600 \\
12,000 \\
3,000 \\
10,000 \\
4,000 \\
4,500 \\
5,000 \\
1,200 \\
1,000 \\
5,000 \\
1,200 \\
2,000 \\
3,000 \\
25,000 \\
1,500\end{array}$ \\
\hline
\end{tabular}

\title{
DIVISIONS ADMINISTRATIVES ACTUELLES.
}

\author{
MOYENNE ÉGYPTE, \\ FORMANT UN SEUL MOUDYRLIK.
}

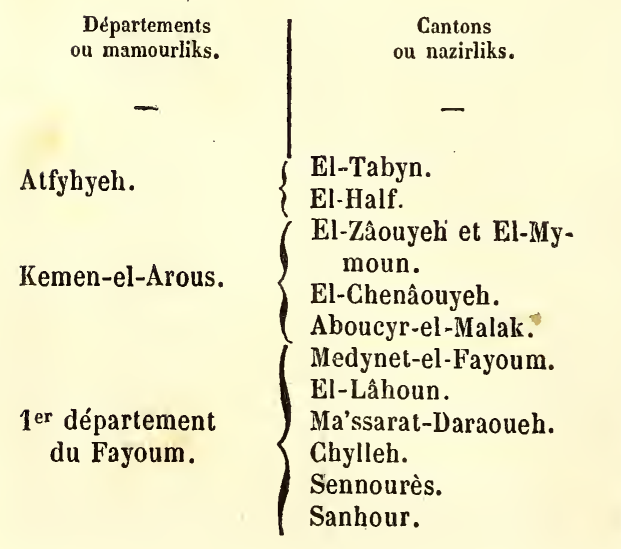
Départements ou mamourliks.
$2^{\mathrm{e}}$ département $\mathrm{du}$ Fayoum:
El-Adjâmin.
Bény-Soueyf.
El-A'ouâounél.
El-Fechn.
El-A'ouâou
Abou-Girg' ou Abou-
El-A'douah.
Girge.
Cantons
ou nazirliks.




\section{IAUTE ÉGYPTE,}

DIVISEE EN DEUX MOUDYRLIKS.

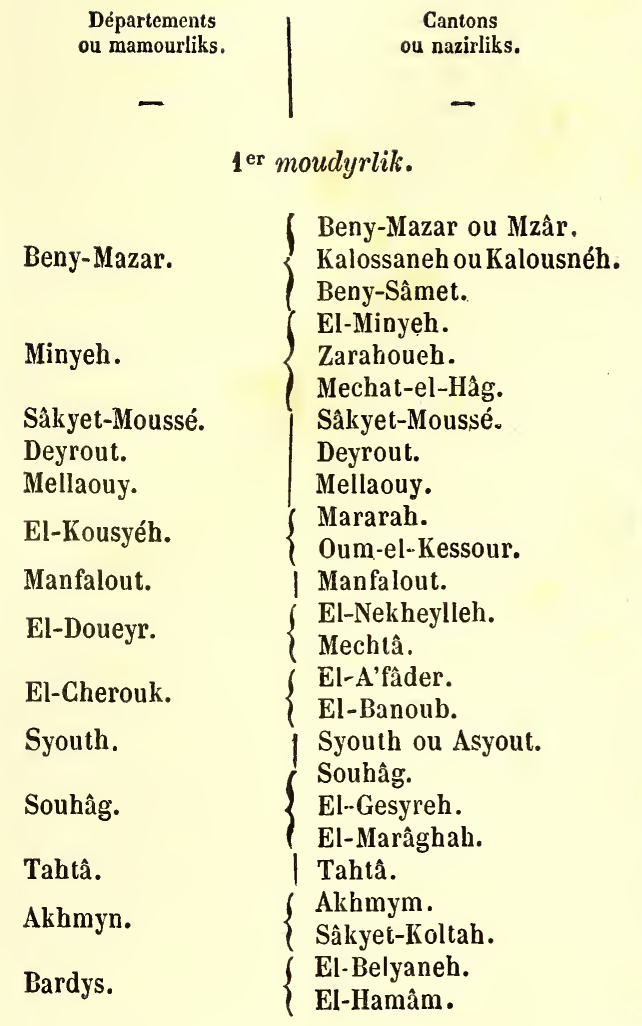

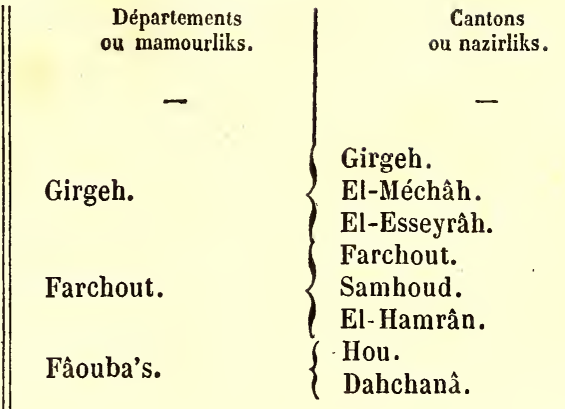

$2^{\circ}$ moudyrlik.

$\begin{array}{ll}\text { Kénéh. } & \left\{\begin{array}{l}\text { Oulad·A'mr. } \\ \text { Eyssour. } \\ \text { Keft. } \\ \text { EI-Ballàs. }\end{array}\right. \\ \text { Kous. } & \left\{\begin{array}{l}\text { Kous. } \\ \text { Ghâmoulleh. } \\ \text { Nakâdeh. }\end{array}\right.\end{array}$

Esnéh.

Erment.

Esnéh. $\quad$ El-Mettaneh.

Essulamyeh.

Koum-Myr ou Koum-

Edfou. $\quad\left\{\begin{array}{l}\text { Edfou. } \\ \text { El-Allamyeh. } \\ \text { Byban. }\end{array}\right.$

\section{BASSE ÉGYPTE.}

\section{$1^{\text {er }}$ MOUDYRLIK.}

Province de Gizeh.

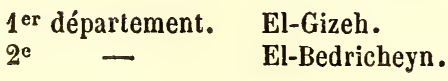

Province de Kélyoubyeh.

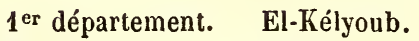

$2^{\circ} \quad-\quad$ El-Mary.

Benna-el-A'sal.

$\begin{array}{lll}3^{\mathrm{e}} & - & \text { Benna- } \\ 4^{\mathrm{e}} & - & \text { Tahâ. }\end{array}$

Choubra-Chahâb.

,

Province d'el-Bahyreh.
$1^{\mathrm{er}}$ département.
El-Ramânyeh.
2e - El-Néguyléh.
$3^{\circ}$ - $\quad$ Chebrekhyt.
$4 \mathrm{e}$ - Damanhour.

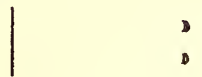


AFRIQUE. - ÉGYPTE.

$2 \cdot$ MOUDYRLIK.

Province de Menoufyíh.

1 er département. Achmoun-Gireys.

$2^{\mathrm{c}}$ - $\quad$ El-Beydjour.

Chybyn-el-Kouon.

Melyg.

Ebyâr.

Girey.

Menouf.

Mehalhet-Menouf.

Fichéh-Selym.

Kafr-el-Zayât.

Tanoub.

Province de Gharbyeh.

$\begin{array}{lll}1^{\text {er }} \text { département. } & \text { Fouah. } \\ 2^{\mathrm{e}} & - & \text { Zefteh. } \\ 3^{\mathrm{e}} & - & \text { Tantâ. } \\ 4^{\mathrm{e}} & - & \text { El-Djafaryeh. } \\ 5^{\mathrm{e}} & - & \text { El-Chabâsât. } \\ 6^{\mathrm{e}} & - & \text { El-Mehallet-el-Kebyreh. } \\ 7^{\mathrm{e}} & - & \text { Nabaro. } \\ 8^{\mathrm{e}} & - & \text { Cherbyn. } \\ 9^{\mathrm{e}} & - & \text { Damyat. }\end{array}$

Kafr-el-Cheykh.

Meytbr.

Myt-el-Meymoun.

Choubra-el-Yemen.

Kafr-Madjar.

Sâri.Hadjar.

$3^{e}$ MOUDYRLIK.

Province de Mansourah.

1 er département. Mit-Kamar.

$2^{e} \quad-\quad$ El-Senbellâoueyn.

$3^{\mathrm{e}} \quad-\quad$ El-Mansourah.

$4^{\circ} \quad-\quad$ El-Ouâdy.

$5^{\circ} \quad-\quad$ Mehallet-el-Daméneh.

$6^{\circ}$ - El-Menzaléh.

\begin{tabular}{|l} 
Chanfâ. \\
\\
\end{tabular}

$4^{e}$ MOUDYRLIK.

Province de Charkych.

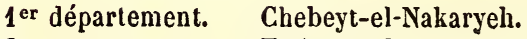

$2^{\circ} \quad$ El-A'zyzyeh.

Belbeys.

Hehyâ.

Abou-Kebyr.

Kofour-Nedjem.

Machtoul-Essouk.

Menâ-el-Kamih.

Abou-Hamâd.

Cbyha.

El-Dakhalye.

N. $\boldsymbol{B}$. Rosette, Damiette et le Caire forment des gouvernements particuliers. 
RÉGION ORIENTALE.

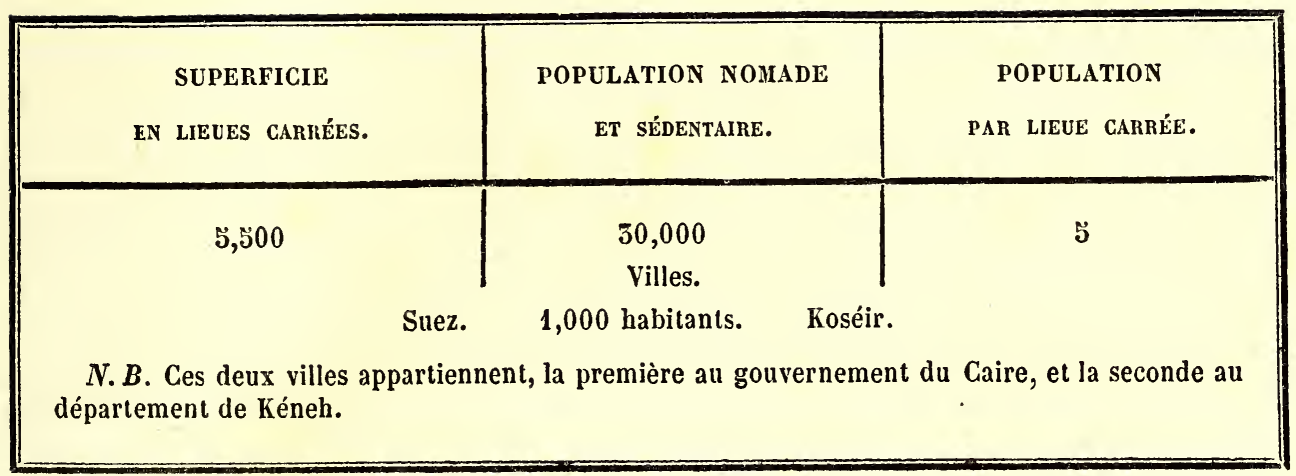

RÉGION OCGIDENTALE.

\begin{tabular}{|c|c|c|c|}
\hline \multicolumn{2}{|c|}{$\begin{array}{l}\text { SUPERFICIE DES OASIS } \\
\text { EN LIEUES CARRÉES. }\end{array}$} & POPULATION DES OASIS. & $\begin{array}{c}\text { POPUlation } \\
\text { PAR LIEUe CarréE. }\end{array}$ \\
\hline $\begin{array}{l}\text { Grande-Oasis. } \\
\text { Petite-Oasis. } \\
\text { Oasis de Dakhel. } \\
\text { Oasis de Syonah. } \\
\text { - de Farafré. }\end{array}$ & $\begin{array}{r}175 \\
30 \\
100 \\
41 \\
260\end{array}$ & $\begin{array}{l}5,000 \\
2,400 \\
5,000 \\
6,000 \\
2,000\end{array}$ & $\begin{array}{r}28 \\
80 \\
50 \\
144 \\
7\end{array}$ \\
\hline Total & 606 & 20,400 & 33 \\
\hline
\end{tabular}

On a bien conjecturé sur l'origine des premiers habitants de l'Égypte; et toutes ces conjectures n'ont servi qu'à prouver la haute antiquité de ce peuple, que quelques-uns font descendre des Chinois, d'autres des Hindous. Au reste, que cette opinion soit vraie ou que les Égyptiens aient eux-mêmes peuplé ces pays, toujours est-il qu'ils ont occupé le premier rang parmi les nations civilisées de l'antiquité, vérité clairement prouvée par les restes de leurs monuments, leurs usages et leurs mœurs. Il est aussi démontré que de temps immémorial ce peuple eut des rois qui firent fleurir leurs États par des lois sages, ainsi que par les arts, l'industrie et le commerce.

On regarde généralement comme fabuleuse l'histoire des premières dynasties de ces rois, auxquels on a donné le nom de dieux, et de demi-dieux ou héros, et qui régnèrent environ 34,201 ans.

Le premier de ces rois-hommes paraît avoir été Menès (sans doute le même que le Mezraïm de l'Écriture sainte) : on prétend qu'il vint de l'Asie, vers l'an 1816 avant Jésus-Christ, pour fonder un royaume dans ce pays; et c'est à lui que l'on attribue généralement la fondation de cette fameuse religion, dont les prêtres ne révélèrent jamais entièrement les mystères, et dont le peuple ne connaissait qu'une multitude de signes extérieurs qu'il adorait. Ce fut, dit-on, sous le règne de son fils Athotès, que prirent naissance les caractères hiéroglyphiques, qui ne furent cependant employés 
symboliquement que longtemps après : ce fondateur fut mis au rang des dieux sous le nom d'Osiris, ainsi que ses deux fils, Athotès, sous le nom de Mercure, et Tosorthrus, sous celui d'Orus ou d'Esculape. Peu de temps après Menès, l'Égypte paraît avoir été divisée en plusieurs royaumes qui prirent les noms de leurs capitales : ainsi Thèbes, Memphis, This, Éléphantine, Heliopolis, et Diospolis, furent les siéges de plusieurs dynasties de rois; plusieurs de ces royaumes ont ensuite été conquis par les pasteurs phéniciens, qui y ont régné peu de temps. Les anciens rois finirent par expulser ces rois pasteurs, et furent ensuite vaincus par Sésostris, qui régna sur toute l'Égypte, depuis l'an du monde 2514 jusqu'en 2572 , époque à laquelle cetle contrée fut de nouveau partagée en trois royaumes : Thèbes, Memphis, et Diospolis, dont les rois, outre leurs noms particuliers, portèrent celui de Pharaons, c'est-à-dire souveraine puissance. En 2898, le dernier se divisa en deux parties, dont l'une conserva le nom de Diospolis et l'autre prit celui de Tanis; mais en 2924, les quatre royaumes furent réunis en un seul sous Phunésès, deuxième roi de Tanis. Cette unique monarchie en Égypte eut six dynasties, et succomba l'an 3478 sous les efforts de Cambyse, qui fit cette conquête sous prétexte d'anéantir l'idolâtrie des Égyptiens : telle fut la fin de ce grand empire égyptien, dont la durée, selon M. d'Origny, n'a été que de 1,662 ans, mais qui, selon d'anciennes chroniques dont l'autorité est loin d'être incontestée, embrasse une grande période de 36,525 ans, y compris les dynasties persanes. L'Égypte sous ses Pharaons devint très-florissante, et fut souvent l'heureuse rivale des plus grandes monarchies du monde. Cette contrée resta 193 ans sous la domination des Perses, tantôt comme sujetle, tantôl comme vassale, et souvent en rébellion contre ses oppresseurs.

Alexandre le Grand l'arracha sans peine aux Perses, et parut avoir le dessein d'y établir le siége de son empire, ce qui, au dire de Napoléon, illustra plus Alexandre, en y fondant Alexandrie, et en voulant y transporter le siége de son empire, que par ses plus éclatantes victoires. Cette ville devait être la capitale dı monde; située entre l'Asie et l'Afrique, à portée des Indes et de l'Europe, son port est le seul mouillage que présentent les cinq cents lieues de côtes depuis Tunis (l'ancienne Carthage) jusqu'à Alexandrette.

La mort de ce conquérant en laissa maître Ptolémée, fils de Lagus. Sous ce prince et sous ses successeurs, l'Égypte recommença à briller d'un nouvel éclat, et durant trois siècles, les sciences et les arts y fixèrent leur empire; la faiblesse et l'indolence des derniers descendants de ces princes préparèrent aux Romains la conquête de ce royaume, dont Auguste s'empara après une assez longue résistance, et pendant 666 ans il fut au pouvoir des empereurs d'Occident et d'Orient. Ce fut à la fin de cette époque que le fanatique Omar, un des successeurs de Mahomet, y porta la dévastation et le carnage, et le réduisit à son obéissance. Vers l'an 1171, les Turkomans chassent les califes successeurs d'Omar, et en 1250, ils sont à leur tour chassés par les mameluks, dont ces souverains avaient récemment composé leur garde; cette audacieuse milice substilue aux Turkomans un de leurs chefs avec le titre de sultan ou soudan, et cette nouvelle dynastie règne sur l'Égypte jusqu'en 1517. Sélim Ier s'empara alors de l'Égypte, et abolit la monarchie des mameluks; il crut y établir d'une manière plus certaine son autorité, en y introduisant une espèce de gouvernement aristocratique composé de vingt-quatre beys ou chefs de mameluks, à la tête duquel il mit un pacha : cette forme de gouvernement répondit assez bien aux intentions des sultans pendant plus de 200 ans; mais vers la fin de cette époque, les liens en étaient relâchés, et les pachas n'avaient plus qu'un simulacre de pouvoir : les beys et les mameluks seuls exerȩaient un empire absolu, et la malheureuse Égypte, pillée et dévastée, languissait dans le plus affreux esclavage. 
Bonaparte y débarqua alors (1798) avec une armée envoyée par le gouvernement français. Sa conquête fut. rapide et brillante; après plusieurs combats, les mameluks, anéantis ou dispersés, laissèrent à la France le gouvernement de ce pays, où on crut voir naître une grande colonie européenne. Quelle espérance pour la civilisation, et combien les sciences, la géographie surtout, ne durent-elles pas applaudir à ce noble projet! Mais l'Angleterre, haineuse et jalouse, fit que des hordes nombreuses venues du Gange, du Bosphore et des îles Britanniques, fondirent sur cette poignée de Français, qui, pendant trois années, et par des efforts inouïs, se maintinrent dans ce pays, qu'ils furent forcés d'abandonner en 1800, ne pouvant se recruter. La barbarie ressaisit alors sa proie. Les Anglais, espérant être plus heureux que leurs prédécesseurs, débarquèrent de nouveau en Égypte, le 17 mars 1807, dans l'intention de subjuguer ce pays; mais, le 14 septembre de la même année, ils se rembarquèrent sans avoir pu y réussir. Dès ce moment l'Égypte devint le théâtre de la plus affreuse anarchie. Les mameluks, essayant de ressaisir leur autorité, et les pachas envoyés par la Porte, se livrèrent de terribles combats, qui achevèrent de ruiner ce pays, épuisé par la conquète des Francais et par les tentatives infructueuses des Anglais.

Enfin le choix de la Porte tomba sur un de ces hommes doués de cette fermeté de caractère, de ces grandes vues, qui rendent capables de gouverner les empires. Cet homme c'est Méhémet-Ali, le vice-roi actuel, ou plutôt le véritable souverain de l'Égypte. Par son adresse autant que par son énergie, il sut s'emparer du pouvoir que ses prédécesseurs avaient vainement tenté de saissir; et pour éviter qu'à l'avenir il ne lui fùt ravi par les mameluks, si justement redoutés, il employa un de ces terribles expédients dont l'Orient a été si souvent le théâtre, et qui d'ailleurs n'était que l'exécution du projet que la Porte avait depuis longtemps conçu. Le $1^{\text {er }}$ mars 1811, sous le prétexte d'une fête, il fit rassembler dans son palais tous les mameluks qui résidaient au Caire, et les fit impitoyablement massacrer. L'ordre fut donné en même temps de détruire tous ceux qui étaient répandus dans les provinces. Après s'ètre ainsi défait de cette milice turbulente, l'Égypte se trouva pacifiée. Le pacha porta ensuite la guerre en Arabie contre les Wahabis, dont il avait projeté d'affaiblir la puissance, et à la fin de la guerre de 1819, ce peuple fut presque entièrement détruit. A peine celte expédition élait-elle terminée qu'il envoya son fils Ismayl soumettre les peuples de la Nubie, du Dongolah, du Sennaar et du Kourdofan. Dans la terrible lutte des Grecs contre leurs oppresseurs, le pacha d'Égypte se montra le fidèle vassal de la Porte, en lui prètant le secours de ses soldats et de ses flottes, et en exerçant sur les malheureux insurgés des cruautés que la différence de croyance religieuse ne pouvait autoriser. Mais par les victoires de son fils Ibrahim, ses conquêtes sur la Porte en 1855, il a prouvé que l'empire ottoman n'était plus qu'un corps énervé et languissant que le moindre choc peut renverser.

L'Égypte, dont nous allons retracer l'état politique, était censée jusqu'ici faire partie de l'empire ottoman. Cette contrée, comme toutes les divisions de cet empire, était gouvernée par un pacha, dont l'autorité n'était pas grande, mais dont en revanche les revenus étaient fort considérables; aussi cette place, vivement sollicitée à Constantinople, se payait fort cher aux intrigants du sérail. Le pacha occupait cette place un ou deux ans.

A son arrivée, on lui rendait de grands honneurs, et il présidait le divan à quelques cérémonies publiques. Les beys, ces chefs militaires, maîtres de l'autorité, pouvaient, selon leur volonté, renvoyer le pacha, s'ils n'en étaient pas satisfaits; et plus d'une fois la Porte a dû dévorer cette injure.

Les multéegnis, espèce de noblesse appelée en Turquie timariots, possédaient les 
terres de l'Égypte sous le nom de fiefs, qui, presque tous, étaient possédés par des mameluks, milice commandée par les beys, lesquels ne reconnaissaient que pour la forme la suzeraineté du Grand Seigneur.

Pour l'administration intérieure, l'Égypte était divisée en vingt-quatre juridictions, nommées hirrats. Les beys recevaient chaque année le commandement de quelque province, y faisaient une tournée, pour forcer le payement des impositions, soumettre les Arabes, et maintenir l'ordre. Le plus puissant des beys résidait ordinairement au Caire, avec le titre de cheik-el-beled, ou cheik du pays.

a Les revenus se composaient de ceux du gouvernement et de ceux qui appartenaient aux mameluks.

จ Les premiers comprenaient le miri ou impôt territorial, perçu en argent ou en nature; les douanes, les droits sur le commerce intérieur, la ferme de certaines exploitations, le kharadje, ou capitation des étrangers. Ces revenus étaient affectés aux dépenses du gouvernement, et l'excédant devait être envoyé à Constantinople; mais les agents, depuis les receveurs jusqu'aux beys, s'arrangeaient si bien que le Grand Seigneur ne touchait presque jamais rien de toutes ces impositions. Il y a plus, on lui portait en compte des dépenses pour des réparations de bâtiments et de canaux qui n'avaient pas eu lieu.

\Les revenus des beys se composaient non-seulement de tout ce qu'ils recevaient des villages qui leur étaient attribués, mais aussi de ce qu'ils pouvaient extorquer de mille manières. On croit généralement que les mameluks tiraient de l'Égypte, en revenus publics et particuliers, environ $55,000,000$ à $40,000,000$ de francs. Ils ont varié chaque année sous les Français, selon les circonstances de la guerre; mais le général Reynier les évalue, l'un parmi l'autre, à 20 ou 25 millions. ๖

L'ancienne division en quatorze provinces est encore en usage parmi ce peuple; cependant, en 1826, l'Égypte fut divisée en vingt-quatre mamourliks ou préfectures, sans comprendre Alexandrie et le Caire, qui, avec leur territoire, formaient deux juridictions à part. Dans cette division, l'Égypte est partagée en haute et basse, ainsi qu'on l'a vu précédemment.

Le vice-roi a depuis quelques années changé ces divisions administratives, afin d'assurer la centralisation du pouvoir, et l'unité de son action.

Chaque moudyrlik est administré par un moudyr ou gouverneur, ayant le nom de bey, quoique plusieurs aient le grade de pacha, et d'autres celui d'aga. Ces moudyrs visitent les départements, veillent à l'exécution des ordres du vice-roi el du conseil, ainsi qu'aux opérations du cadastre, à la division des terres, à la répartition des impôts, à l'entretien et à la construction des canaux et des digues.

Le namour ou préfet doit déterminer les travaux agricoles, et surveiller les ouvriers de sa juridiction. Il doit punir ses administrés quand ceux-ci n'exécutent pas les ordres du gouvernement; indiquer dans chaque village la quantité de terres à affecter aux diverses sortes de culture. Il doit aussi exiger des fellahs les contributions en nature ou en argent; faire les levées d'hommes pour le service militaire et les travaux publics, et surveiller les fabriques. Le mamour porte une croix de diamants.

Le cheik-el-beled exerce une action directe sur tous les individus qui ont recours à ses décisions dans leurs démêlés, et répond du payement des contributions; il se distingue par une décoralion en argent.

Le moubasch ou inspecteur, Copte de nation, est préposé à l'administration des finances de chaque mamourlik, et choisit lui-même les agents placés sous ses ordres. Dans chaque canton il place un receveur qui perçoit les impôts à l'aide du maire ou cheil, et de l'arpenteur appelé kholy, et les envoie au caissier: ou seraff, qui est chargé 
de les faire parvenir au receveur général du mamourlik, qui verse lui-même les fonds chez le receveur du moudyrlik. Celui-ci, après avoir acquitté les bons sur le trésor, envoie au Caire les fonds qui lui restent.

Dans chaque mamourlik il y a une force armée aux ordres du mamour, et commandée par un kascheff, qui distribue ses troupes dans toute la juridiction.

Le chahed, délégué du kady, est chargé de rendre la justice, et remplit les fonctions de notaire, pour passer les actes publics. Il y a un chahed dans chaque village.

Alexandrie, la résidence du gouvernement, est la seule ville qui ne dépende d'aucun département; elle est sous l'administration immédiale du pacha et de ses ministres.

La haute administration de l'Égypte est confiée à des agents supérieurs ou ministres, chargés de rendre compte des affaires au pacha. Tout ce qui est relatif à l'armée de terre est du domaine du ministère de la guerre. La marine constitue un département spécial; les rapports de l'Égypte avec les autres États constituent les attributions du ministre des affaires étrangères; le commerce forme aussi un département particulier; les affaires intérieures ont également leur ministère; il en est de même de tout ce qui a rapport à l'instruction. Les finances sont confiées à un ministre appelé hasnader ou trésorier, ayant sous ses ordres un grand nombre de Cophtes, d'Arabes et de Syriens ou Grecs, auxquels il confie les différents emplois de son administration; le ministère de la justice comprend tout ce qui se rattache à l'ordre judiciaire et à l'administration civile : il est confié au kiaja-bey.

La surveillance des domaines de l'État est entre les mains du rousnamasch, administrateur; mais depuis que le pacha s'est emparé, au profit du gouvernement, des biens qui appartenaient aux mosquées et aux pauvres, et des fondations de toute espèce, les fonctions de cet administrateur se bornent à tenir compte des dédommagements et des pensions à payer par l'État, des frais qu'occasionnent les caravanes de la Mecque, et de ceux qui concernent le cadastre.

Pour chaque branche de l'administration, Méhémet-Ali a créé des conseils composés d'hommes spéciaux : tels sont le conseil de guerre, de la marine, de l'agriculture, de l'instruction publique, le conseil de santé, et plusieurs autres encore.

Un conseil d'Élat, institué en 1826, domine tous ces conseils. Il est chargé d'examiner et de faire exécuter les changements proposés par les mamours dans leurs juridictions respectives : ce conseil soumet ses propositions au pacha, qui les adople ou les rejelte : Méhémet-Ali, dans la crainte de se laisser entraîner trop facilement à l'arbitraire que sa position lui permet, a attaché à sa personne un conseil privé, au sein duquel il discute toutes les affaires du gouvernement.

En 1829, on a établi des assemblées provinciales et un divan général (assemblée centralc) composée de 180 députés de toutes les provinces, chargés de discuter sur les intérèts des affaires intérieures de l'Égypte : réunions qui rappellent le régime des États constitutionnels de l'Europe. Ces réunions sont publiques; chacun des membres y parle en toute liberté; on y traile de l'intérèt général, et l'on y reçoit les réclamations des administrés.

Un conseil général est chargé dans chaque mamourlik de s'occuper des intérêts locaux.

Ces grandes institutions, tout à fait nouvelles en Orient, ne sont pas les seules établies par le gouvernement égyptien, qui a cherché surtout à travailler pour l'avenir, en formant des administrateurs éclairés et capables de comprendre ses vues; c'est dans ce but que l'on a fondé au Caire une école d'administration, d'où sortiront à l'avenir les préfets et sous-préfets, et où l'on enseigne la science administrative, l'agriculture pratique, et la statistique agricole des provinces. La comptabilité clle-même a subi de 
grands changements. Le mode adopté dans les bureaux du gouvernement est celui de la tenue des écritures en partie double. Les places de finances, occupées jusqu'à ce jour par des étrangers, le seront à l'avenir par les habitants du pays, quelle que soit d'ailleurs la religion à laquelle ils appartiennent.

Le système judiciaire, qui, chez les mahométans, est intimement lié au Coran, d'où il tire même son origine, a subi peu de changements en Égypte; mais il y a perdu une grande partie de sa rigueur : il en résulte que les habitants se décident avec moins de peine à obéir aux lois. Cependant en 1826, Méhémet-Ali a fait traduire en turc et en arabe le code Napoléon, et a ordonné la mise en vigueur du code de commerce. Un changement plus important est l'abolition de la peine de mort pour les crimes d'assassinat et de fabrication de fausse monnaie. D'après une nouvelle loi pénale, les hauts fonctionnaires de l'État, comme les derniers agents de l'administration, accusés de concussion ou d'abus de pouvoir, sont condamnés à la prison, après avoir restitué aux particuliers ce qu'ils ont pris ou reçu : si les fonds détournés appartiennent à l'État, les coupables subissent une année de galères; les assassins et les faux-monnayeurs sont condamnés aux galères à perpétuité ou pour un temps plus ou moins considérable, selon la gravité de leurs crimes. Si l'accusateur ne peut, dans l'espace de quinze jours, prouver la culpabilité du prévenu, celui-ci est mis en liberté sous caution. Mais si le prévenu est accusé de nouveau du même crime et jugé coupable, ceux qui s'étaient porlés pour lui servir de caution subissent une année de galères. Les peines portées contre les crimes que nous venons d'indiquer ne peuvent ètre prononcées que par le divan général, devant lequel l'accusé se présente el se défend.

L'Européen, dans la nouvelle organisation de l'Égypte, rencontre un assemblage hétérogène de l'antique système administratif des Pharaons, et d'institutions empruntées à la civilisation de l'Europe moderne. L'organisation attribuée dans la Genèse à la sagesse de Joseph ${ }^{x}$ a été renouvelée par le pacha, avec cette seule différence, qu'il n'a pas plus ménagé les biens des prêtres que ceux des particuliers. Il a déclaré l'Élat propriétaire des biens fonciers, et en a assigné l'usufruit aux possesseurs actuels, qui en touchent le revenu sur le trésor public. Les fonds provenant des biens des mosquées, des églises et des couvents, des biens communaux et des établissements militaires, servent à acquitter ces charges, qui ne sont plus que des rentes viagères. L'État, d'après cetle organisation, est le véritable propriétaire; les nazirs sont les régisseurs, et les fellahs ou cultivateurs, les ouvriers. L'intérêt du gouvernement est donc de faire

1 On lit dans la Genèse, ch. Xlvir, v. 17, 18 et 19, qu'après une grande famine le peuple proposa à Joseph de lui vendre pour le compte de l'État toutes les terres pour du pain, à la condition de fournir au cultivateur les semences nécessaires à la culture. - 20. "Ainsi Joseph acquit à Pharaon toutes les terres n d'Égypte; car les Égyptiens vendirent chacun son champ, parce que la famine s'était augmentée, el la D terre fut à Pharaon. - 22. Seulement il n'acquit point les terres des sacrificateurs, parce qu'il y avait \une portion assignée pour les sacrificateurs, par l'ordre de Pharaon; et ils mangeaient la portion que

\Pharaon leur avait donnée : c'est pourquoi ils ne vendirent point leurs terres. - 25. Et Joseph dit au

D peuple : Voici, je vous ai acquis aujourd'hui, vous et vos terres, à Pharaon; voilà la semence pour - semer la terre. - 24. Et quand le temps de la récolte viendra, vous en donnerez la cinquième partie " à Pharaon, et les quatre autres seront à vous, pour semer les champs et pour votre nourriture, et pour " celle de ceux qui sont dans vos maisons, et pour la nourriture de vos petits enfants. - 25. Etils dirent: 》 Tu nous as sauvé la vie; que nous trouvions grâce devant les yeux de notre Seigneur, et nous serons ᄁ esclaves de Pharaon. - 26. Et Joseph en fit une loi qui dure jusqu'à ce jour, à l'égard des terres de

" l'Égypte de payer à Pharaon un cinquième du revenu; les terres seules des sacrificateurs ne furent - point à Pharaon. ग

Les saint-simoniens, dans leurs prédications, n'ont fait qu'étendre ce système qu'ils ont dû regarder comme praticable, puisqu'il a été exécuté en Égypte il y a $\mathbf{3 7}$ siècles, et que le gouvernenient actuel l'a remis en vigueur. 
cultiver le sol par ceux qui en tirent le meilleur parti, et d'en éloigner les oisifs. D'un autre côté, les fellahs trouvent leur avantage à soigner la culture des terres qui leur sont allouées, et qu'ils peuvent considérer comme des emphytéoses qui doivent assurer l'avenir de leurs enfants; d'autant plus, que leur aisance est plus grande lorsqu'ils déploient plus de zèle et d'activité.

On est prêt, en jugeant cette organisation d'après les vues européennes, à en faire la critique; mais lorsque l'on considère combien les différentes races qui constituent le peuple égyptien sont loin d'avoir l'activité et l'instinct de bien-être qui caractérisent l'Européen, et que les fellahs, naturellement indolents et presque sans besoins, ainsi que l'ont prouvé les siècles antérieurs, laisseraient tomber en décadence l'agriculture, poussée si haut par les Égyptiens, s'ils étaient livrés à eux-mêmes, on conçoit que ce système, réalisé par Méhémet-Ali, est celui qui convient le mieux à l'Égypte.

C'est à ce système, dit M. Clot-Bey, qu'il faut attribuer les immenses progrès que l'agriculture a faits dans ces derniers temps, l'introduction de riches plantations inconnues jusqu'alors au sol égyptien, et qui lui étaient éminemment propres, et l'augmentation des produits. C'est aussi ce système qui a donné au vice-roi les moyens de porter à $60,000,000$ les revenus de l'Égypte, chiffre qui se bornait à $35,000,000$ en 1799.

Le miri, ou impôt sur les céréales, est fixé par le gouvernement, après qu'il a reçu des mamours la quantité de terres cultivées, et l'approximation presque certaine de la récolte, après laquelle les nazirs en font transporter les produits dans les greniers publics, ou dans tout autre lieu désigné par le conseil d'État. Le cultivateur, pouvant payer avec du papier, n'a pas le droit de demander de l'argent. Après avoir fait sa livraison au gouvernement, et conservé les semences qui lui sont nécessaires, il peut faire ce que bon lui semble des grains qui lui restent. Les impôts sont partout les mêmes; quelles que soient du reste la race et la religion des sujets, ils ont droit d'obtenir des terres à cultiver.

Le pacha perçoit en outre un impôt sur les dattiers et sur les maisons. En 1826, 618,600 maisons étaient imposées, et produisaient 39,300,000 francs; les dattiers, au nombre de 6,000,000, supportaient un impôt de 20 à 65 paras par arbre, et donnaient un produit de 400,000 talaris, ou environ 1,800,000 francs.

Le gouvernement, pour augmenter ses ressources, lève encore d'autres impôts et se réserve même la culture d'un certain nombre de plantes, et l'exploitation de divers genres d'industrie. En 1827, les droits régaliens, les taxes et douanes produisirent plus de $65,000,000$ de francs.

Le feddan ${ }^{\mathrm{r}}$ est évalué en moyenne à $10 \mathrm{fr}$. Les terres les plus fertiles se payent 14 à $16 \mathrm{fr}$., et les qualités inférieures 6 à $8 \mathrm{fr}$. De temps en temps, les terres incultes sont données par le vice-roi à des individus en état de les faire valoir; et il affranchit ces terres du miri.

Le fidel-el-rouss, impôt personnel, est fixé au douzième du revenu supposé du contribuable; tous les individus mâles, musulmans ou rayas, y sont soumis dès l'âge de douze ans. Dans les villes, cet impôt se lève par individu, et dans les villages par maison. Ce revenu forme le sixième des revenus du trésor égyptien.

Le bétail est également soumis à un impôt. Les bœufs et les vaches sont taxés à

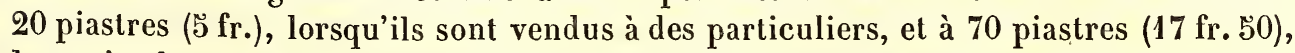
lorsqu'on les vend aux bouchers. Les chameaux et les brebis sont imposés à 4 piastres; les barques du Nil à 200. Ces droits sont affermés par le gouvernement.

1 Le feddan égale 40 ares. 
Voici comment Glot-Bey classe la population de l’Égypte : Égyptiens musulmans, 2,600,000; Égyptiens chrétiens (cophtes), 150,000; Osmanlis ou Turcs, 12,000; Arabes bédouins, 70,000; nègres, 20,000; Barabras, 5,000; Abyssiniens, 5,000; esclaves circassiens, mingréliens, géorgiens, 5,000; juifs, 7,000; Syriens, 5,000; Grecs raïas ou rayas, 3,000; Arméniens, 2,000; Grecs francs, 2,000; Italiens, 2,000; Maltais, 1,000; Français, 700 à 800 ; Anglais, 80 à 100; Autrichiens, 60 à 100; Russes, 20 à 30 ; Espa- . gnols, 15 à 20; Belges, Hollandais, Suédois, Prussiens, Danois, environ 100. Cette évaluation, nous devons le faire observer, n'est qu'approximative et nullement officielle.

En décrivant les différents peuples de l'Égypte, nous ne ferons qu'indiquer la religion ou la secte à laquelle ils appartiennent, renvoyant nos lecteurs, pour tout ce qui concerne les cultes, à notre Histoire et cérémonies religieuses de tous les peuples.

Le fondateur de l'islamisme n'a point établi de distinction sociale entre les musulmans; l'empire ottoman n'admet point de castes privilégiées : et cependant deux races qui, malgré leur communauté de religion, ne se sont point mélangées, existent en Égypte et sont en présence l'une de l'autre : l'une, la race turque, a le pouvoir avec les honneurs et les profits qui en résultent; l'autre, la race égyplienne ou arabe, subit la honte, supporte les charges de la dépendance.....

D'où vient cela?... D'un passé de quarante siècles qui a produit cet état de choses qu'une soudaine révolution n'a pu, ne pouvait pas renverser instantanément. Doit-on accuser Méhémet-Ali? Non : il a fait tout ce que lui ont permis les circonstances; il est le seul Osmanli qui se soit appliqué à relever la race arabe. C'est à lui qu'elle doit l'instruction qui doit l'éclairer, la féconder; c'est lui qui a fait battre par les Arabes, les Turcs qu'une servitude de trois siècles leur avait appris à craindre; c'est MéhémetAli qui a choisi parmi les Égyptiens indigènes la plupart des mamours, et presque tous les officiers de ses armées jusqu'au grade de chef de bataillon.

Le vice-roi ne pouvait pas faire plus : les Égyptiens ont les vices et les défauts des peuples qui ont vécu longtemps dans la servitude : ils n'ont pas l'instinct du commandement, et, malgré une grande intelligence, ils ne savent rien mener à fin s'ils ne sont pas dirigés.

Il n'en est pas de même des Turcs qui, accoutumés à la supériorité, ont la tenue, la dignité, la confiance en soi, qui sont indispensables à ceux sur qui repose l'autorité. Méhémet-Ali a donc dù réserver à ceux-ci les principaux emplois dans l'administration, les grades les plus éminents dans l'armée : le contraire eût été une maladresse, un défaut de génie ou même de simple raisonnement qui aurait pu amener des conséquences fâcheuses.

La race égyptienne proprement dite est divisée en plusieurs classes :

Les ulémas, les hommes de la loi et de la religion, occupent le premier rang. Ils doivent la considération dont ils jouissent à l'importance et à la noblesse des fonctions qui leur sont confiées, à l'instruction qui leur est nécessaire pour les remplir. Bien que tout musulman puisse être admis dans le corps des ulémas, ils se transmettent pourtant leurs charges par voie d'hérédité, et forment comme une caste aristocratique. Mais le haut ascendant qu'ils avaient autrefois sur l'esprit du peuple a été détruit par le vice-roi, qui les a sagement dépouillés des immenses richesses territoriales qu'ils devaient aux superstitions et à l'ignorance de leurs compatriotes.

Les propriétaires, les négociants et marchands forment la seconde classe, peu nombreuse et qui ne possède que des fortunes médiocres. Cependant la crise à laquelle l'Égypte vient d'être en proie a relevé son importance; c'est à ses membres les plus influents qu'ont été remis les principaux commandements de la milice nationale improvisée dans les provinces de la basse Égypte par le vice-roi. 
Les artisans composent la troisième classe, qu'on peut regarder comme une véritable caste. Tous les métiers, toutes les petites industries, sont divisés en corporations qui se régissent elles-mèmes dans le cercle qu'elles embrassent, et qui ont leurs statuts, leurs coutumes et leurs chefs. La corporation des domestiques entre aussi dans cetle catégorie.

La dernière classe comprend les agriculteurs, les fellahs ou paysans, qui forment la masse de la population.

De même que dans toutes les civilisations orientales, la loi, chez les musulmans, a son principe dans la religion; et si pour ce peuple le péché est souvent un délit, le délit est toujours un péché. Leurs lois civiles et criminelles émanent surtout du Coran; s'il se présente un cas sur lequel le livre ne prononce pas, le juge cherclie alors la lumière dans les traditions religieuses suivantes:

$1^{\circ}$ Le Sunnet, ou recueil des actions et des paroles du prophète : les préceptes qu'il a donnés sur certains actes, le silence qu'il a gardé sur d'autres, sont ici interprétés;

$2^{\circ}$ Les lois orales de notoriété publique, qui furent connues dans les trois premiers siècles du culte mahométan : on observe aussi des lois orales moins sacrées, que l'on considère comme une sorte de droit coutumier;

$3^{\circ}$ Les recueils des gloses et interprétations des premiers disciples du prophète;

$4^{\circ}$ Le recueil des décisions canoniques prononcées par les imans des siècles primitifs, et principalement par les quatre grands imans fondateurs des quatre rites orthodoxes.

La majorité pour les deux sexes est fixée à l'époque de la puberté, c'est-à-dire à douze ans pour l'homme, à neuf ans' pour la femme, si à cet âge ils affirment par serment être en état de puberté. S'ils ne remplissent pas cette formalité, ce n'est qu'à l'expiration de leur quinzième année que les jeunes gens sont déclarés majeurs. L'homme de condition libre est alors maître de ses actions; s'il n'a plus son père, le tuteur peut administrer les biens jusqu'à ce que le pupille ait vingt-cinq ans révolus; mais si le jeune homme a la disposition de sa fortune, l'emploi qu'il en fait conformément aux lois est valide.

Le mariage est légalement constitué par une déclaration de consentement faite devant témoins, ainsi que par le payement, intégralement ou partiellement effectué, d'une dot à l'épouse. - La polygamie est permise, mais restreinte; le Coran défend expressément d'avoir plus de quatre épouses légitimes; et, dans le cas où un homme appréhende quelque inconvénient de ce nombre de femmes libres, il lui est recommandé de se borner à en avoir une seule, ou de se contenter d'esclaves au lieu de femmes libres. - La faculté du divorce repose principalement dans la volonté du mari : de là un abus énorme parmi les Arabes, dont quelques-uns ont changé de femmes plus de cinquante fois. Les Osmanlis, au contraire, se montrent fort sobres du divorce. Après deux divorces, le mari peut encore reprendre sa femme; mais une troisième séparation accomplie, il ne lui est permis de l'épouser de nouveau que si, dans l'intervalle, elle a été mariée à un autre homme qui l'ait répudiée. - On doit remarquer que la condition des femmes a été améliorée en Orient par la loi de Mahomet; on ne peut épouser une femme sans lui assurer une dot en cas de répudiation; les sœurs héritent conjointement avec les frères, et reçoivent une demi-part; l'esclave rendue mère devient libre.-Le Coran proclame la supériorité de l'homme sur la femme; mais il exige que cette supériorité se témoigne par une protection bienveillante. \& Les hommes, dit-il, sont supérieurs aux femmes parce que Dieu leur a donné la prééminence sur elles, et qu'ils les dotent de biens. Les femmes doivent être obéissantes et taire les secrets de leurs époux. Les maris qui ont à souffrir de leur désobéissance peuvent les 
punir, les laisser seules dans leur lit et même les frap̧per. La soumission des femmes doit les mettre à l'abri des mauvais traitements; attachez-les par des bienfaits. ๖

Le père a le droit de marier ses enfants mineurs, sans qu'ils puissent jamais élever une réclamation contre cet acte d'autorité paternelle; mais le consentement des enfants majeurs est indispensable. Le père n'est point responsable des accidents qui peuvent survenir pendant son administration des biens de ses enfants mineurs; il a la faculté de les engager s'il a des besoins réels ou des dettes.

Ces deux derniers droits exceptés, le tuteur, qui est de droit le plus proche parent de l'orphelin, a la même autorité que le père; si l'enfant n'a point d'alliés, son tuteur naturel est le magistrat du lieu.

L'incarcération du débiteur est facultative jusqu'à ce qu'il ail été déclaré insolvable. Le failli formellement interdit ne peut se passer de l'autorisation du magistrat pour tout acte civil ou relatif à ses biens.

Les cas d'interdiction sont : la minorité, l'imbécillité, la folie, l'esclavage, la prodigalité et l'état de banqueroute.

En Égypte, ainsi que dans tout l'empire ottoman, les fils héritent également de leurs pères, qu'ils soient issus d'épouses légitimes, de concubines ou d'esclaves. La femme a droit à la moitié de la part dévolue à l'homme, lorsqu'ils sont parents au même degré. Si le mort laisse des filles, quel qu'en soit le nombre, elles ont à partager les deux tiers de la succession; s'il n'y a qu'une fille, on lui accorde la moitié : le Coran le veut ainsi. Mais si le défunt ne laisse point de parents à qui ils puissent être distribués, la moitié ou le tiers en question sont reportés sur lesdites filles. En cas de survivance, le père et la mère du mort ont droit à un sixième des biens; s'il n'y a pas d'enfants, le père a les deux tiers et la mère le surplus; si le défunt laisse des frères, ils ont un sixième, ce qui diminue de moitié la portion de la mère. L'épouse ou les épouses ont un huitième si le mari laisse postérité; autrement elles ont un quart. Un mari a le quart si la femme laisse des enfants, la moitié s'il n'y en a point. - Un homme ne peut disposer en legs que du tiers de sa fortune.

Les factieux, les pirates, les brigands, les faussaires encourent la peine capitale; on sait que le blasphémateur est puni de mort par la loi musulmane.

Le meurtre, presque inconnu en Égypte, y encourt la peine du talion; il peut se racheter par une amende au profit des ayants droit, si ceux-ci y consentent. - Il en est de même à l'égard des coups et blessures.

L'adultère non marié est fustigé; il est lapidé dans le cas contraire.

Selon le Coran, la main du voleur doit être tranchée; mais une loi du Sunnet n'inflige ce châtiment que si le vol a eu lieu avec circonstances aggravantes.

En causes civiles, les faux témoins doivent être notés d'infamie, et promenés publiquement dans la ville; les mêmes coupables, dans les affaires criminelles, encourent, outre la fustigation, la peine que leur faux témoignage a fait subir à l'accusé.

L'apostasie de l'islamisme est punie de mort, à moins qu'après triple serment l'apostat ne revienne à la religion musulmane.

La justice émane uniquement du souverain, qui nomme les premiers juges. Ceux-ci, à leur tour, choisissent leurs subordonnés en hiérarchie. Le sultan envoie donc chaque année au Caire un grand cadi dont la juridiction s'étend sur tonte l'Égypte, et qui a sous lui les cheiks, les muflis (docteurs de la loi), et les naïbs (espèce de substituts). - L'instruction et la vertu sont deux qualités principalement réclamées du juge doni la charge, qui n'est point inamovible, ne peut se refuser.

Un greffier, kiatib, est toujours attaché au mehkemé, tribunal; ce fonclionnaire dresse les protocoles des plaidoiries. - Il n'y a point d'avocats; chaque partie défend 
sa cause ou la fait défendre par la personne qu'elle choisit. En général, la déposition de deux témòins suffit pour établir une preuve certaine; l'adultère seul en demande quatre, et les dépositions doivent être parfaitement identiques. Dans le jugement de ce crime, l'aveu quatre fois répété des accusés emporte condamnation; mais le désaveu détruit tout. Le témoignage d'un seul homme n'est jamais admissible; celui de la femme ne l'est qu'en matière civile. - Les appels ont rarement du succès.

Quoique, dans les recueils juridiques ou dans le droit coutumier musulman, il se trouve des lois assez bonnes, la justice n'est nulle part plus mal rendue que chez les musulmans.

Le cadi cumule avec ses fonctions celles de notaire; c'est lui qui, moyennant un droit de 2 pour 100, passe les contrats de ventes d'immeubles entre les particuliers. Ces contrats, ou heggeh, sont revêtus de son sceau, et les archives du tribunal en conservent les minutes.

Les frais de procédure n'excèdent pas 4 pour 100. Le condamné les paye aussitôt le jugement rendu.

Méhémel-Ali, en organisant son armée, a fait adopter le code militaire français. Il a aussi établi un tribunal de commerce mixte, composé de nationaux et d'Européens.

L'Égyptien musulman conserve, même sous les haillons, un caractère de distinction; son port est droit, bien cambré; sa démarche est posée, sans affectation ; ses mouvements sont pleins de calme; el, bien qu'elles ne soient pas étudiées, on dirait que toutes ses manières sont calculées avec précision; jamais la vivacité et l'enjouement n'en troublent la lenteur et la régularité. Impassible, le regard sérieux, le visage sévère, il ne trahit extérieurement aucune des impressions intérieures qu'il ressent, et laisse s'agiter en lui, sous un masque également froid, les sentiments les plus opposés. Sa voix est forte et perçante; il parle d'un ton très-haut, ce qui ferait croire qu'il se dispute lorsqu'il ne fait que causer tranquillement. Au reste, il est sobre de ses paroles, qui paraissent toujours réfléchies.

L'Égyptien a de l'intelligence, conçoit rapidement, apprend sans difficulté; mais, soit insouciance ou défaut de mémoire, il oublie vite ce qu'il a appris. Il est doué d'une très-grande adresse manuelle, et son caractère malléable permet de l'employer aux travaux les plus divers. Pendant son enfance, l'Arabe de ce pays semble enjoué, vif, spirituel; parvenu à l'âge viril, il prend ce sérieux, cette froideur dont nous avons parlé plus haut.

La sobriété, la frugalité même distinguent les Égyptiens, parmi lesquels l'ivresse esı fort rare. Le pain est considéré par eux avec un grand respect; ils lui ont donné le nom de keysch (littéralement vie), parce que, dans leur pensée, il se lie étroitement avec l'existence dont il est le principal soutien.

L'hospitalité est religieusement observée en Égypte; les mousafirs (voyageurs), de quelque pays qu'ils soient, sont parlout accueillis et hébergés. Lorsque le visiteur arrive au moment où le musulman prend son repas, celui-ci l'invite à le partager. Les gens de la classe moyenne, qui soupent quelquefois devant la porte de leurs demeures, invitent à s'asseoir à leur table le passant dont l'extérieur est décent. Cependant, si les Éyyptiens se témoignent entre eux une grande affabilité, il faut reconnaître que, lout en se montrant parfois généreux, ils mettent plus de réserve dans leurs rapports avec les Européens.

Accoutumé à l'oppression, ce peuple, dans les circonstances ordinaires, semble timide, el craint, dirait-on, d'altirer le danger sur sa tête. Mais devant le péril, son cou rage se réveille, et nul plus que lui n'a de résignation dans la souffrance; nul n'est plus 
soumis aux décrets de la Providence, et il accueille les revers par ces mots stö̈ques: Allah-Kerim! (Dieu est bon!).

L'amour de la patrie est si fort enraciné chez eux qu'on les voit rarement se résoudre à abandonner volontairement le sol qui les a vus naître; ils conçoivent si peu l'existence ailleurs que chez eux, qu'ils demandent souvent aux Européens s'il y a aussi dans' nos contrées un Nil et'des palmiers.

Mais si jusqu'à présent nous avons fait voir ce peuple à travers un prisme avantageux, il nous faut bien aussi montrer ses défauts et ses vices, car toute médaille a son revers. Un cupide amour de l'argent bannit presque tout orgueil du cœur de l'Égyptien; lorsqu'on lui remet de l'argent à titre de cadeau ou de payement, il a pour habitude d'agiter l'index de la main droite en disant : Käman ouâhed (encore une autre pièce de monnaie), et il n'hésite pas à mendier quelques misérables paras ${ }^{\mathrm{x}}$. Il ne faut pourtant pas trop en vouloir à ces malheureux de cette honteuse cupidité; c'est un instinct méprisable et qui ne les porte que trop à l'escroquerie et au vol; mais qu'on ne perde pas de vue que pendant dix siècles ces infortunés ont été en butte à toutes les extorsions qu'il a plu à leurs oppresseurs de leur faire subir, et que, sans cesse volés par ces tyrans, l'argent leur est devenu d'autant plus précieux qu'il leur était plus difficile de le conserver. Aussi les Égyptiens ont-ils pour mettre leur trésor une cache nommée mekhba.

Au reste, ils sont menteurs, dissimulés, envieux, jaloux, défiants, et se montrent bien rarement reconnaissants. La paresse est innée chez eux; et s'ils étaient leurs maîtres, ils passeraient leur vie dans la plus honteuse indolence. L'Égypte leur offrant le moyen de satisfaire leurs besoins, très-bornés d'ailleurs, leur prévoyance ne va pas jusqu’à penser au lendemain; le présent est tout pour eux, et l'intérêt même se tait devant l'apathique léthargie à laquelle ils sont en proie.

L'Égyptien, se considérant comme sectateur d'une religion privilégiée, est fier de sa croyance, et ne regarde qu'avec mépris ceux qui ne professent point son culte. Un juif est pour lui un chien, un chrétien un infidèle, et il ne connaît pas d'injure plus grande, d'outrage plus sanglant à lancer à la face d'un homme que de l'appeler chrétien ou juif. Mais si jamais le doute n'a effleuré sa foi, il n'en est pas moins à tous autres égards dans une ignorance complète. L'esprit des Égyptiens en général n’a aucune espèce de culture; et aujourd'hui encore, il n'y a, à part les sujets sortis des écoles récemment fondées, que quelques personnes lettrées; et encore leur instruction ne s'étend pas au delà de la connaissance des livres religieux et d'un petit nombre de poésies. Mais ce n'est pas à l'islamisme qu'il faut attribuer cet état de ténèbres où reste leur intelligence : c'est aux mameluks qu'on doit s'en prendre, car ce sont eux qui ont étouffé les lumières en Égypte.

L'entêtement est un des traits caractéristiques des Égyptiens, à ce point qu'on en a vu plusieurs préférer recevoir jusqu'à deux cents coups d'une sorte de cravache en cuir d'hippopotame, appelée courbach, plutôt que d'acquitter leurs impôts. Ils sont aussi très-querelleurs, surtout dans les classes inférieures; et cependant on ne voit que bien rarement les coups succéder aux injures. Un des antagonistes cède toujours en disant : "La justice est contre moi; "à moins qu'un tiers intervenant ne s'écrie : "Bénédiction sur le prophète; que Dieu le favorise! » Les deux adversaires répètent ces paroles, récitent ensemble quelques versets du Coran, et un embrassement scelle souvent la réconciliation. Le ressentiment est encore un vice fort ordinaire chez ce peuple. Il existe parmi eux des vengeances héréditaires entre familles : Le sang appelle le sang,

1 Il faut 40 paras pour égaler une piastre qui représente 25 centimes. 



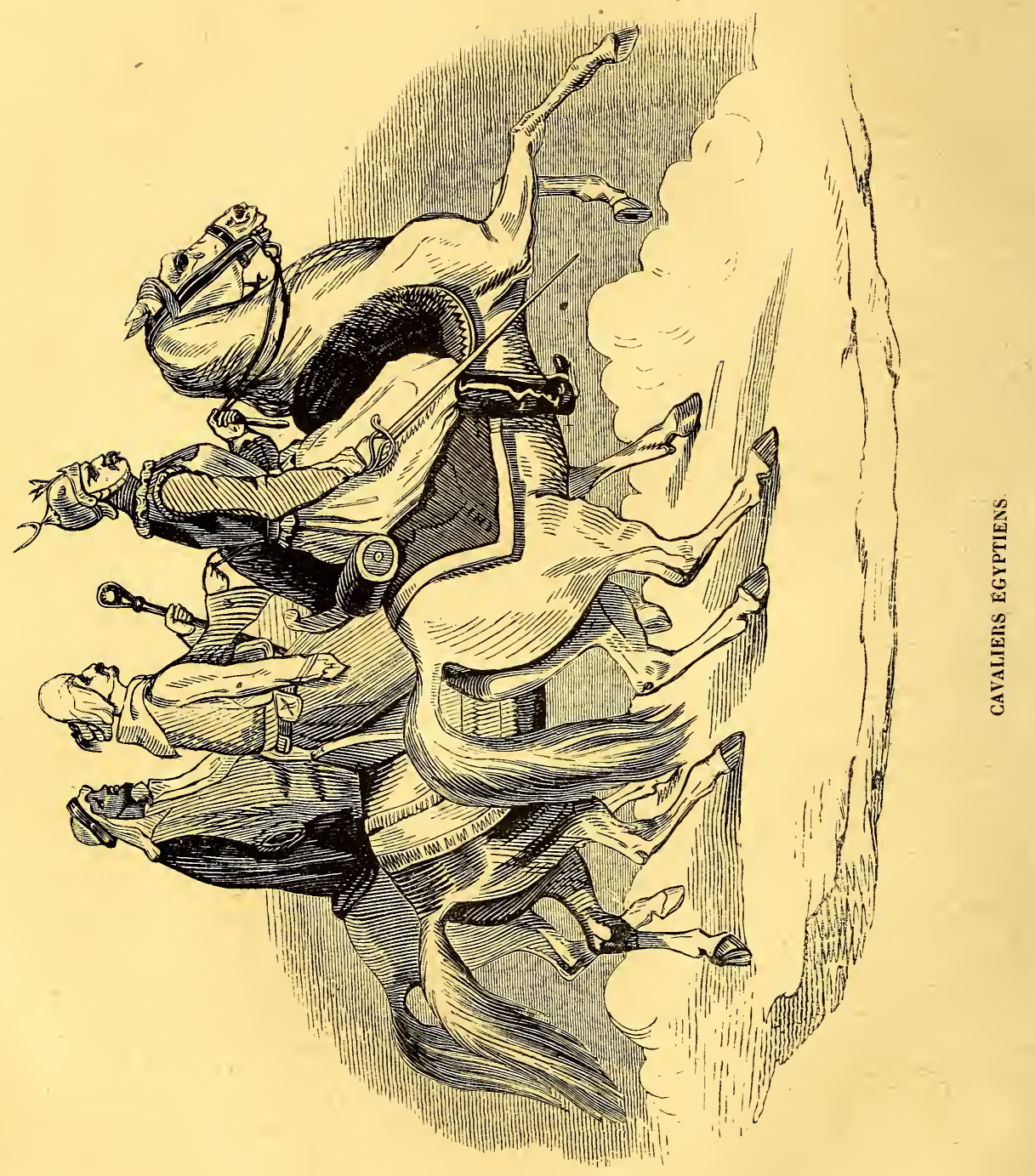


disent-ils. Heureusement les coutumes barbares disparaîtront inévitablement devant les progrès de la civilisation.

Les Égyptiens sont naturellement satiriques, et souvent spirituels; leur langue admet les ambiguïtés, les mots à double sens, qui abondent dans leurs conversations, fréquemment licencieuses. Les idées ne sont pas moins scabreuses que les expressions; et peu de femmes, même entre les plus vertueuses, savent bannir de leur langage l'indécence et les obscénités. Les Turcs d'Égypte sont adonnés au vice odieux de la pédérastie; mais si ce crime est moins commun chez les Arabes, ils en commeltent un plus repoussant, s'il est possible : nous voulons parler du crime de bestialité.

Nous ne devons rien dire ici du costume musulman primitif, encore en usage il y a peu d'années chez les mahométans de l'Égypte, el dont la description trouvera sa place lorsque nous parlerons des Turcs d'Europe; mais nous devons mentionner la métamorphose qui s'est opérée dans l'habillement des Égyptiens vers l'année 1823, et qui fut la conséquence de l'organisation des troupes réglées. La suppression du turban commença la réforme; trois ans plus tard on procéda à de nouvelles modifications; tout en laissant subsister la culotte large jusqu'au genou, et que termine une espèce de guêtre, on adopta un gilet à manches, par-dessus lequel on portait une carmagnole, à peu près semblable, quoique plus ample, aux vestes de nos hommes du peuple. On s'est bientôt aperçu combien les manches ouvertes de çtte espèce de dolman, qui flotlaient par derrière, entravaient les évolutions des militaires, et on les a mises à l'index.

L'influence de l'armée, devenue alors l'institution la plus importante de l'Égypte, devait s'étendre à tout, même au costume traditionnel. Qu'ils appartinssent ou non à l'armée, les dignitaires de l'État adoptèrent peu à peu l'habillement militaire : IbrahimPacha donna l'exemple et le premier prit le tarbouch; tous l'imitèrent bientôt, et le vice-roi lui-même adopta le vêtement qu'il avait intronisé.

Aujourd'hui les couleurs éclatantes, si chères aux anciens Orientaux, ne sont plus portées que par le peuple; les gens de distinclion ne font cas actuellement que des beaux draps noirs, bleus, marrons, etc. Si le tarbouch avait une visière, il serait analogue aux bonnets des chasseurs d'Afrique, et, quoique moins gracieux que le turban, il aurait du moins l'avanlage de préserver le front et les yeux des ardeurs du soleil, chose fort utile dans un pays où la lumière est très-vive. Mais la visière donnerait au tarbouch une certaine ressemblance avec le chapeau européen, et il est douteux que les musulmans consentent à l'adopter : ils ont un tel mépris pour notre coiffure, que lorsqu'ils veulent exprimer qu'ils sont capables de tout, ils s'écrient qu'ils prendront le chapeau, ce qui pour eux équivaut à changer de religion ou à renoncer à leur nationalité.

Le mezz, espèce de chausson en peau jaune, remplace, chez les personnes aisées, les bas dont peu de musulmans font usage; le mezz est placé dans un soulier de maroquin jaune ou rouge, qu'on nomme markoub, et qui est porté en pantoufle. Jadis les musulmans seuls pouvaient porter la couleur jaune; le noir était principalement affecté aux chrétiens qui, néanmoins, avaient droit de se passer la fantaisie des souliers rouges. Grâce à la double chaussure, les Orientaux sont libres, en entrant dans une mosquée ou dans un appartement, de déposer leurs souliers à la porte, ce qui leur permel de fouler les nattes, les tapis, les divans, sans crainte de les salir, et en mème temps sans avoir les pieds nus : on s'explique facilement son utilité.

Le législateur, qui sans doute connaissait le goût passionné des Arabes pour la parure, s'est efforcé d'y remédier par une prohibition spéciale; mais ce fut en vain : l'influence religieuse, quoique immense, ne fut pas assez forte pour vaincre ce penchant. Mais si nul peuple ne fait autant profusion d'or et de pierreries, nul n'harmo- 
nise plus mal les richesses qu'il prétend déployer; on a vu souvent un Oriental unir l'or aux guenilles. La garde-robe des Égyptiens est moins bien fournie que celle des Européens aisés; ils n'ont pas autant d'habillements; les riches pourtant en changent assez souvent. Le linge du corps est renouvelé plusieurs fois par semaine, excepté parmi le peuple qui se montre peu fidèle aux règles de propreté. Le linge n'est pas, comme chez nous, plissé, repassé, etc. Tout est lavé à l'eau et au savon; on n'y fait pas usage de la lessive.

Le costume du fellah est très-simple : il se compose d'une chemise et d'un caleçon de toile de lin, par-dessus lesquels on revêt une grande chemise bleue nommée herie, qui descend au-dessous du genou, et que serre autour du corps une ceinture de peau ou d'étofle. La coiffure du fellah est le tarbouch et le turban, ou une calotte feutrée, de couleur blanche ou grise, appelée lebdeh. L'hiver il porte le zabout ou capote à manches amples.

En général, les Égyptiens musulmans ne laissent subsister de leurs cheveux qu'une petite touffe nommée choucheh, au sommet de la tête; cette infraction aux lois du Coran, qui ordonne de raser entièrement la chevelure, vient de ce qu'ils craignent que, venant à être pris par les infidèles, ceux-ci ne leur tranchent la lête, et ne trouvant pas de cheveux pour la saisir, n'introduisent leur main impure dans la bouche, la barbe ayant souvent trop peu de longueur pour la saisir. On sait que les Égyptiens, comme tous les peuples des climats chauds, ont la barbe peu fournie; ils n'en laissent guère que ce que nous appelons la royale, et jamais sa longueur ne dépasse un travers de main. Ils coupent la moustache au niveau de la lèvre supérieure, tandis que les Osmanlis la laissent croître librement. Quoique la barbe soit un symbole de virilité et de puissance physique et morale, le vice-roi l'a supprimée dans l'armée aussi bien pour les officiers que pour les soldats. Un jeune homme, s'il n'est pas majeur, ne peut porter de barbe qu'autant que son père le lui permet. Les esclaves ne peuvent que bien rarement obtenir cet honneur. L'absence de moustaches, chez ceux qui n'ont point de barbe, est stigmatisée par une épithète qui frise souvent l'outrage. Les chrétiens du pays ont pour la barbe une considération aussi grande que celle dont les musulmans font profession. A l'exception de la barbe, toutes les parties chevelues du corps sont soigneusement soumises à l'épilation qui se fait au moyen du rasoir, ou en arrachant les poils, ou en les faisant tomber à l'aide d'un cosmétique composé de chaux et d'orpiment. Quelques hommes de la basse classe se tatouent les mains et les bras. Les bains et les ablutions sont les mêmes que chez les Turcs proprement dits; aussi n'en parlerons-nous pas ici. Il en sera de même pour tout ce qui appartient positivement aux mœurs ottomanes.

Les domestiques égyptiens sont avides, et l'on ne saurait se reposer sur leur fidélité. Dans les pays musulmans, il n'était jamais permis aux chrétiens d'avoir des serviteurs de Mahomet pour domestiques; l'Égypte seule a fait infraction à cette absurdité religieuse.

Les femmes arabes qui forment la plus grande partie de la population féminine de l'Égypte, sont de taille moyenne et de formes élégantes. Elles ont la colonne vertébrale arquée, les membres réguliers et arrondis, les mains et les pieds petits et potelés. On sait que souvent elles surpassent en vigueur l'homme dont elles partagent les fatigues. Leur nez est petit, souvent épaté légèrement, et leurs lèvres un peu épaisses. Leurs dents, parfaitement alignées et d'une blancheur éclatante, contrastent assez agréablement avec la teinte basanée de leur peau, et plus ou moins foncée selon qu'elles appartiennent à la ville ou à la campagne, à la haute ou à la basse Égyple. Mais ce qui surtout embellit leur physionomie, ce sont de grands yeux noirs, étincelants de viva- 
cité, et ombragés de longs cils. Leur sein, puissamment développé, ferme et bien placé, ne cède jamais aux artifices souvent funestes de la coquetterie européenne. Leur démarche élégante, leur pas sûr et allongé, leurs poses majestueuses rappellent de gracieux souvenirs de l'antiquité. La douceur de leur voix s'harmonise admirablement avec l'adorable tendresse de leurs expressions familières : Iah heny (mes yeux), Iah kholbi (mon cœur), Iah rohihi (mon âme). Elles se servent toujours du nom de frère ou de celui de maître lorsqu'elles adressent la parole à un homme.

La toilette préoccupe beaucoup les Égyptiennes, et leur excessif désir de plaire enfante mille pratiques curieuses : par exemple, au lieu de laisser croître librement leurs sourcils, elles en diminuent la largeur et n'en laissent qu'une ligne très-mince. Elles teignent en noir le bord de leurs paupières au moyen d'une poudre noire qu'elles nomment khol (antimoine), qu'elles renferment dans un petit flacon en cristal ou en argent; elles introduisent dans ce flacon un stylet, qu'elles promènent ensuite sur le bord des paupières, et lorsqu'elles ne surchargent pas trop la teinte, le résultat qu'elles se sont proposé, et qui consiste à rendre les yeux plus brillants, est assez bien atteint. Elles parsèment leur visage, leur cou et leur gorge de mouches noires, et se teignent communément les ongles, l'extrémité de la lace palmaire des mains, et la plante des pieds en noir ou en rouge avec des feuilles de henneh. Les femmes du peuple ont la lèvre inférieure, le menton, les mains et les bras tatoués.

Les femmes turques sont les plus belles de l'Égypte; ce sont pour la plupart des esclaves venues de Géorgie ou de Circassie, et c'est parmi elles qu'on choisit les odalisques du sérail.

Lorsqu'elles ont atteint sept ou huit ans, on fait subir aux jeunes filles une espèce de circoncision; pour cela, on les conduit au bain, et ce sont les baigneuses qui les mutilent. Cet usage, que la religion ne prescrit pas, était, dit-on, pratiqué dans l'antique Égypte; son but probable paraît être de modérer dans son principe mème un penchant trop prononcé à la volupté. Dans ce pays, les femmes sont nubiles vers leur dixième ou onzième année; elles sont souvent mères à douze ans, grand'mères à vingtquatre, bisaïeules à trente-six, trisaïeules à quarante-huit, et on en voit mème qui sont contemporaines de leur cinquième génération. Mais leur précocité et leur fécondité déterminent une vieillesse hâtive, et une Européeune à cinquante ans est souvent moins fanée qu'une Égyptienue à vingt-cinq. Il n'est aucun moyen qu'elles ne mettent en pratique pour devenir mères, car la stérilité n'est vue qu'avec mépris.

La richesse et la variété de l'habillement distinguent la femme de l'homme puissant. Elle porte une chemise de mousseline, de toile très-fine, de crêpe ou d'autre tissu recherché; cette chemise est blanche, de couleurs éclatantes, quelquefois noire; quelques-unes sont parsemées de paillettes brillantes; plus fréquemment elles ont une bordure de soie ou d'or. Elles sont amples, ont des manches larges, ne tombent pas tout à fait jusqu'au genou, et recouvrent un caleçon de toile ou de mousseline. Un chintyan (pantalon) fort large, fixé par une gaîne à la ceinture et lié à la jambe, retombe sur les pieds, offrant ainsi l'aspect d'une jupe. Une grande robe (yalek) serre la taille sur les hanches et descend jusqu'aux pieds; elle est échancrée de façon que la gorge n'est couverte et retenue que par la chemise; elle est boutonnée par devant jusqu'audessous des hanches, et ouverte des deux côtés à partir des hanches. Les manches pressent les bras, s'élargissent au coude et tombent ensuite jusqu'au bas de la robe, ou s'arrètent au poignet. La taille est entourée d'une ceinture faite d'un châle de cachemire ou d'un carré de mousseline, d'indienne, selon le rang el la fortune. Le carré est plié diagonalement et placé sur le bas des reins; un de ses angles reste derrière, tandis que les deux extrémités, ramenées sur le devant, y sont fixées par un nœud ou une 
ganse. Une espèce de surtout (gebbeh), en drap pendant l'hiver, avec ou sans broderies, est placé par-dessus le yalek; les manches s'arrêtent au coude; quelques dames le remplacent par le saitah ou spencer.

La coiffure consiste en une petite calotte de laine rouge, autour de laquelle sont roulés, en forme de turban, un ou plusieurs mouchoirs de crêpe, de mousseline blanche ou autre, brodée suivant la fantaisie. Une plaque ronde, bombée, de trois pouces environ de diamètre, et nommée gours, est fixée à la partie postérieure dı bonnet; cette plaque est en or, ou garnie de pierreries, suivant que les femmes occupent un rang inférieur ou élevé. Les cheveux de la partie antérieure de la tête sont arrangés en boucles ou en bandeaux sur les tempes. De mème qu'en Europe, les dames égyptiennes rejettent la masse des cheveux en arrière, mais avec cette différence qu'au lieu de les arrêter sur la tête, elles les laissent retomber sur le dos et les divisent en petites tresses dont le nombre, toujours impair, varie depuis onze jusqu'à trente-cinq. Dans la composition de ces tresses, on fait entrer trois petits cordons de soie noire, auxquels on attache de petites pailletles ou des bijoux en or. Chaque tresse se termine par un ornement en or, une grappe de perles, ou une simple pièce de monnaie percée à son bord. L'ensemble de cette coiffure a reçu le nom de sefé.

Ce costume est celui des dames du harem; elles ne portent point de bas; la peau de leurs pieds, souvent lavés dans une eau parfumée, est aussi douce que celle de leurs mains; les ongles sont teints avec le henneh, et quelques-unes vont jusqu'à garnir leurs orteils d'anneaux non moins précieux que ceux qui brillent à leurs mains. Le mezz, en maroquin jaune ou en velours richement brodé, chausse ce pied dont la beauté naturelle est rehaussée par l'éclat et le luxe de cette chaussure très-découverte, et qui en cache à peine les extrémités; le mezz, sans rebord par derrière, laisse au talon toute sa liberté. Pour marcher ailleurs que sur les divans et les tapis, les dames ont des babouches dont la pointe aiguë est recourbėe; lorsqu'elles sortent, elles ont, pour soustraire leurs jambes aux regards, de petites bottes en maroquin jaune; dans ce même cas, elles s'affublent du sableh, vaste chemise de soie noire, semblable à peu près au domino de nos bals masqués, et par-dessus laquelle elles ont un habbarah, immense voile en taffetas, noir pour les femmes mariées, blanc pour les jeunes filles, et qui enveloppe tout le corps. Un autre voile en mousseline dérobe entièrement le visage, à l'exception des yeux. Les femmes de moindre condition portent le milayeh : c'est la même chose que le habbarah, si ce n'est qu'il est en tissu de fil et de coton à fond bleu, et à carreaux.

Bien que les caprices de la mode aient peu d'empire en Égypte, le costume des femmes a, comme celui des hommes, subi quelques changements dans ces dernières années, et il n'y a rien perdu certainement. Ainsi la coiffure aujourd'hui n'est plus alourdie par des turbans massifs, surchargés de bijoux. Les cheveux tressés et relevés sur la tête ont remplacé le sefé. On ne laisse plus, comme autrefois, les chemises pardessus le pantalon. Le yalek est moins long; ses manches ne dépassent pas le poignel; il n'est plus échancré sur la poitrine, et se boutonne ou se croise sur l'estomac comme les robes des dames européennes. Le gebbeh, entièrement délaissé, n'est plus porté que par les vieilles femmes. Les dames d'une classe distingnée ont adopté l'usage des bas, et les éloffes en mousseline simple sont justement préférées aux tissus brochés d'or. Si la prodigalité inintelligente y a perdu, le bon goût y a considérablement gagné.

Les femmes de la classe moyenne portent une chemise de soie et des marqoubs (souliers) dans lesquels leurs pieds sont loin d'être gênés. Beaucoup plus simple, le vêtement des femmes du peuple consiste en une chemise de toile bleue, à manches très- 
larges, et sur laquelle elles ont une chemise blanche et un caleçon. Elles ne font point, en général, usage de chaussures.

Les femmes égyptiennes sont très-portées aux plaisirs voluptueux; et si l'honneur des maris est plus en sûreté dans les contrées orientales qu'en Europe, c'est moins à des principes de morale qu'il faut l'attribuer qu'à la vigilance et aux précautions dont elles sont constamment entourées.

L'Égypte, qui se distingue des autres parties de l'Orient par un grand nombre de points, ne s'est point conformée à la loi du prophète, laquelle défend la prostitution, qui, rare en Turquie, est plus que tolérée chez les Égyptiens. Les femmes publiques, qui y étaient très-répandues, formaient une corporation qui avait ses chefs, ses règlements, et payait au trésor une redevance considérable. Dans ces dernières années, le gouvernement, en supprimant la prostitution, a volontairement renoncé à ce revenu. Mais cette mesure, prise dans un but moral, a produit un effel qui l'est peu, en faisant faire des progrès à la pédérastie, vice plus repoussant mille fois que le liberlinage. D'ailleurs, il existe encore un grand nombre de femmes publiques, qui, quoique d'une manière occulte, n'en exercent pas moins leur triste métier. "Je crois, dit Clot-Bey, que cette plaie sociale est alimentée plus encore par l'abus du divorce que par le tempérament voluptueux des Égyptiennes. „Et cette opinion est vraisemblable, si l'on considère que les prostituées sont, en général, des femmes répudiées auxquelles la servitude conjugale a inspiré du dégoût, ou qui, ne trouvant pas occasion de se remarier, n'ont que la prostitution pour ressource.

Quoique notre intention ne soit pas de placer ici la description du harem, nous devons parler des eunuques, puisque c'est en Égypte que la mutilation est aujourd'hui pratiquée exclusivement; cel acte ne s'accomplit que dans les villes de Syout el Girgeh. Le village de Zawy-el-Dyr, près de Syout, est la métropole des exécutions de cette œuvre ignoble. Les victimes sont de jeunes nègres de six à neuf ans, amenés par les caravanes du Sennaar ou du Darfour; ces infortunés sont vendus de 1,500 à 5,000 piastres ', suivant les chances de vie ou les qualités qu'on leur reconnaît. Les mutilateurs sont des chrétiens, des prètres même, des Cophtes... bourreaux de l'humanité, honte et opprobre de la religion du Christ qu'ils déshonorent! Aussi le mépris qu'ils inspirent est-il universel, et l'opinion les flétrit aux lieux mêmes où ils exercent leur ignominieuse industrie.

L'automne est regardé comme la saison la plus favorable à l'opération. On aurait tort de croire que les mutilateurs se bornent à la castration : ils tranchent avec un rasoir toutes les parties extérieures de la génération; puis ils versent de l'huile bouillante sur les blessures qu'ils ont faites, et placent un tuyau dans la portion restante du canal de l'urètre. Ils répandent ensuite sur la plaie de la poudre de henneh, et enfin ils enterrent le patient jusqu'au-dessus du ventre, et le laissent ainsi durant vingt-quatre heures; après quoi, ils le retirent et le pansent avec un onguent composé d'huile et d'argile. Le quart des enfants ne survivent pas à celle opération; ceux qui n'en meurent point sont condamnés à une vie étiolée et souffrante!

De leur état naissent des signes distinctifs au physique et au moral : l'eunuque est sans barbe, sa voix est féminine, et il a de l'obésilé; il est orgueilleux, mais sa fierté est sombre, méchante, ombrageuse, irascible..., car il a la conscience de son infériorité; il est dévot, mais sa dévotion a moins pour but d'honorer Dieu, que de chercher dans les pratiques austères du culte une sorte de dédommagement à sa dégra- 
dation. Et cependant, chose étrange, on voit des eunuques qui aiment les femmes, et plusieurs sont engagés par le mariage !...

Les Égyptiens font usage de beaucoup de nos mets, avec cette différence qu'ils font toujours la cuisine au beurre, et qu'ils mettent peu de soins dans la préparation de leurs plats. L'huile habituellement consommée est de qualité inférieure, et il n'y a que les Européens ou les indigènes fort riches qui emploient de l'huile de Provence ou de Lucques. Le vinaigre, fait de dattes, ne vaut pas mieux que l'huile. Le citron est communément employé. Le riz est un aliment national qui se mange en pilau (rouz moufelfel); ils le mêlent aussi à de la chair hachée, en font des boulettes qu'ils recouvrent de feuilles de vigne, et que l'on appelle ouarouk machie et doul mâ.

Ils sont friands de pâtisseries, qu'ils composent de différentes manières et qui n'ont aucune ressemblance avec les nôtres; la plupart consistent en gâteaux plats et ronds, garnis intérieurement de viande, de crème, d'herbages, de fromage blanc ou de confitures. Mais quoique leur pâte soit assez bien feuilletée, ils sont loin d'être aussi avancés que les Européens dans l'art du pâtissier. On rencontre communément des boutiques où l'on vend des gâteaux plats, appelés foulyrs. Les Arabes aiment les confitures qu'ils font avec du miel. Les hors-d'œuvre ne sont pas communs chez eux; néanmoins ils ont du poisson salé (fessyr), du caviar, des anchois, des olives noires, des concombres au vinaigre, des salades, etc.; mais outre que ces entremets sont trop fortement salés et poivrés, les Européens refuseraient d'en manger, ne fùt-ce que parce qu'ils sont arrangés avec de l'huile rance. Les desserts sont composés de fruits du pays, que les Égyptiens cueillent avant leur maturité, car autrement ils les trouvent trop fades.

L'usage de l'eau-de-vie est plus répandu et moins nuisible en Égypte que celui du vin; la plus commune, extraite des dattes, est de qualité médiocre; la meilleure est faite avec du raisin sec, tiré de la Syrie ou de Ia Grèce; dans sa plus grande force elle a 30 degrés.

Une espèce de bière, produite de la simple fermentation de l'orge, est fort goûtée des indigènes, quoique les Européens la trouvent très-désagréable au palais.

Le café est la boisson de prédilection dans ce pays : pauvres et riches en prennent le matin et après chaque repas; les personnes aisées en prennent quinze ou vingt fois dans la journée. Le café est brûlé à peu près comme chez nous; mais ils ne le mettent point dans un moulin et le réduisent en poudre en le pilant, prétendant extraire ainsi plus sûrement son huile essentielle. Pour le préparer, ils font bouillir l'eau dans une cafetière, l'écartent du feu aux premiers bouillonnements, y versent la dose de café nécessaire, et le retirent après une forte ébullition. Après l'avoir laissé infuser quelques instants, on le verse dans les tasses en le remuant.

Avant ou après le café, on prend des sorbets; le plus simple est de l'eau sucrée mêlée à de l'eau de rose, à de la fleur d'orange, ou dans laquelle on exprime le jus de l'orange ou du citron. Des amandes, des graines de melon, de pastèque, de courge, etc., servent à fabriquer une espèce d'orgeat. Le kouscheff est une eau sucrée, bouillie avec des raisins, des cerises, et à laquelle on joint ensuite de l'eau de rose. Le sorbet le plus recherché est celui qu'on prépare avec la violette (schareb-el-benefseg). On dépouille de leurs pistils les violettes, dont on pétrit les pétales avec du sucre; la pâte ainsi formée, on la fait sécher, on la réduit en poudre, et l'on obtient ensuite le sorbet en la délayant dans l'eau.

Le peuple égyptien, auquel on vend dans les rues une décoction de réglisse ou de karroub, estime fort une autre boisson nommée haschich. C'est une préparation enivrante, tirée du chanvre d'Égypte. On broie les fruits de ce végétal, qu'on réduit en une pâte que l'on fait cuire avec du miel, du poivre, de la muscade et des essences 
odoriférantes; après quoi on en forme de petites tablettes d'une teinte verdâtre et un peu fades au goût; il suffit d'en avaler un morceau de la grosseur d'une noisette pour en ressentir bientôt les effets. C'est surtout en boisson qu'il est employé. Quelquefois aussi on le réduit en une poudre, que l'on fume dans une espèce de narghileh. Le haschich produit ordinairement une sensation de bien-être qui arrive jusqu'à une exhilaration extravagante, désordonnée; il aiguise l'appétit, et, la période d'exaltation terminée, il procure un sommeil doux et des songes heureux.

L'opium, appelé afioun par les Arabes, est peu en usage en Égypte.

Dans les repas, plusieurs grands seigneurs veulent aujourd'hui copier les habiludes européennes; et c'est chose curieuse lorsqu'ils oublient nos usages pour les coutumes musulmanes. Ils font preuve d'une gaucherie vraiment grotesque dans leurs contrefacons; les uns mangent leur potage dans le service affecté au dessert et réciproquement, boivent le vin ordinaire dans les verres à champagne; d'autres, unissant plaisamment les façons orientales aux manières européennes, prennent la viande dans le plat avec leurs doigts, tout en ayant soin, avant de la porter à leur bouche, de la planter aux dents de leurs fourchettes; il en est encore qui, dans un diner à la frangaise, s'emparent du plat qu'on leur présente, et le gardent avec sang-froid devant eux.

Les fellahs ou paysans sont très-sobres; leur principale et quelquefois unique nourriture se réduit au pain de dourah. Quand leurs moyens le permettent, ils y joignent des fèves bouillies assaisonnées de sel et de beurre, et quelques autres végétaux. L'eau du Nil et le café sont les seules boissons dont ils fassent usage.

Les maisons sont généralement plus spacieuses, plus belles dans les villes que dans les villages; les premières sont construites en pierres calcaires, en grès, en briques cuites ou desséchées au soleil; elles sont rarement vastes, par la raison que chacune est occupée par une seule famille. Leur apparence extérieure est presque toujours misérable, et elles n'ont pas même un crépi sur la façade. On entre par des portes trèsbasses, formées d'une seule pièce, ouvrant en dedans, fermées intérieurement par une barre en bois qui court transversalement dans le mur, où on la fait glisser pour ouvrir et d'où on la tire pour fermer. Il y a aussi parfois des serrures de divers genres. Les façades sont percées de grandes fenêtres fermées de grillages très-serrés qui permetment au vent et à la lumière de pénétrer dans les appartements, en dérobant aux regards les personnes et les objets qui s'y trouvent. Les parties supérieures de l'édifice, dans lesquelles des baies sont ouvertes, avancent de deux ou trois pieds, et forment ainsi des balcons couverts. Les muscharabyeh, ou jalousies, sont en treillis formés de petits morceaux de bois tournés adaptés ensemble et offrant des dessins gracieux. Ces grillages sont en roseaux ou branches de palmier dans les maisons pauvres. L'intérieur des maisons riches est protégé contre le vent et la poussière par des vitrages qui ferment les croisées.

Une terrasse, bordée d'un parapet à hauteur d'homme, recouvre la toiture qui est horizontale. Cette terrasse sert d'étendoir, et surtout de lieu de récréation, dans les maisons qui sont dépourvues de cour et de jardin; le plancher en est recouvert d'un mastic léger, formé d'un mélange de chaux et de plâtre avec de la cendre des fours.

Une cour intérieure a le double avantage de procurer à la fois à la maison de la lumière el de l'air; autour d'elle se trouvent toutes les pièces accessoires, et notamment le lieu où le maître reçoit les visiteurs, et qui est appelé manclarah.

Des différents appartements qui composent une habitation égyptienne, il n'y a guère que le mandarah (salle de réception des hommes) qui mérite de fixer l'atlention. C'est une pièce carrée ou rectangulaire, avec une ou deux fenêtres donnant sur la cour. Une petite partie du sol, plus basse de cinq à six pouces que le reste du parquet, et qui 
s'étend de la porte au mur opposé à l'entrée, est appelée dourkah; une fontaine jaillissante (fiskych) est placée, dans les maisons riches, au centre de cet espace, qui est pavé en mosaïque de marbres dont les différentes couleurs offrent d'ingénieuses combinaisons. A l'extrémité qui fait face à la porte s'élève une console de pierre semblable à une cheminée; c'est la soufah, haute de trois à quatre pieds, adossée au mur, et soutenue par des arches, supportées elles-mêmes par des colonnettes. Elle sert à recevoir les urnes à parfum, le bassin et le pot à l'eau dont on fait usage pour les ablutions, et différents autres ustensiles.

Le lewan est la partie du sol plus élevée que le dourkah; il est pavé en pierres communes, et ordinairement recouvert d'une natte durant l'été, et d'un tapis pendant l'hiver. Le divan garnit ses trois murs.

On appelle divan un sofa composé d'une série de matelas de longueur arbitraire, larges de deux pieds et demi, épais de quatre à cinq pouces, et qui sont placés sur le sol ou sur des bancs de pierres, de bois, ou de grillages de dattiers, hauts de cinq à six pouces; ce qui, vu l'épaisseur des matelas, donne au divan l'élévation d'une chaise. Des coussins sont appuyés au mur dans tout le pourtour du divan.

Les parois des murs ne sont jamais tapissées, mais seulement blanchies à la chaux dans les maisons pauvres, et peintes à l'huile dans les riches habitations; le plafond est boisé et présente des cercles, des polygones, etc., comme les peintures des murs.

Le pourtour du lewan est ordinairement garni d'étagères et de petites armoires; dans celles-ci on renferme les ustensiles de table; sur les autres on place des porcelaines de Chine.

Nous ne pouvons nous arrêter à décrire les villes de l'Égypte; nous dirons seulement que les principales sont le Caire, Alexandrie, Aboukir, Damiette, Rosette, Damanhour, Ramanyeh, Fouah, Mansourah, Mehallet-el-Kebir, Tantah, etc. On y trouve des bains publics, des hôpitaux, des palais, des arsenaux, des mosquées, etc. Alexandrie est la clef de l'Égypte; ses ports sont les seuls que possède ce pays.

La tolérance de Méhémet-Ali a permis aux Européens d'avoir des esclaves; voici ce que dit à ce propos M. Clot-Bey : « On croirait volontiers, pour l'honneur de notre civilisation, que ce doit être un bonheur pour les esclaves d'appartenir à des maîtres qui viennent de contrées où l'esclavage n'existe pas et dont le sol hospitalier donne la liberté à quiconque le touche; en général, on se tromperait. Ces Européens, qui, en parlant de la barbarie musulmane, ont toujours le mépris à la bouche, maintiennent peu souvent leur conduite au ton de leur verbeuse philanthropie; beaucoup vendent ou troquent leurs esclaves. Ces actes peuvent être justifiés jusqu'à un certain point et dans certains cas, tant qu'ils ne dégénèrent pas en trafic. Ce serait, en effet, une cruauté que de donner la liberté à un jeune esclave qui ne pourrait subsister par son travail et dont on serait forcé néanmoins de se débarrasser. En l'affranchissant, on serait aussi barbare qu'un père qui chasserait son enfant du foyer domestique. Mais vendre un esclave qui peut gagner sa vie en travaillant, c'est faire un marché qui déshonore, et pourtant bien des Francs spéculent sur cette infamie. On en voit qui vendent des femmes enceintes de leurs œuvres, et qui abandonnent ainsi à l'esclavage leurs propres enfants, sur la naissance éventuelle desquels ils ne rougissent pas de percevoir une prime. Pour qualifier de si horribles immoralités, la langue est trop pauvre ou le ccur de l'homme d'honneur trop riche d'indignation. En les voyant, les Orientaux doivent s'enorgueillir de leur vertueuse barbarie, et prendre en mépris notre civilisation, souillée par des misérables qui couvrent leurs bassesses de ses oripeaux. Hâtons-nous de dire que des Européens hommes de cœur traitent leurs esclaves, hommes et femmes, avec bienveillance, adoptent tous les enfants qu'ils ont 



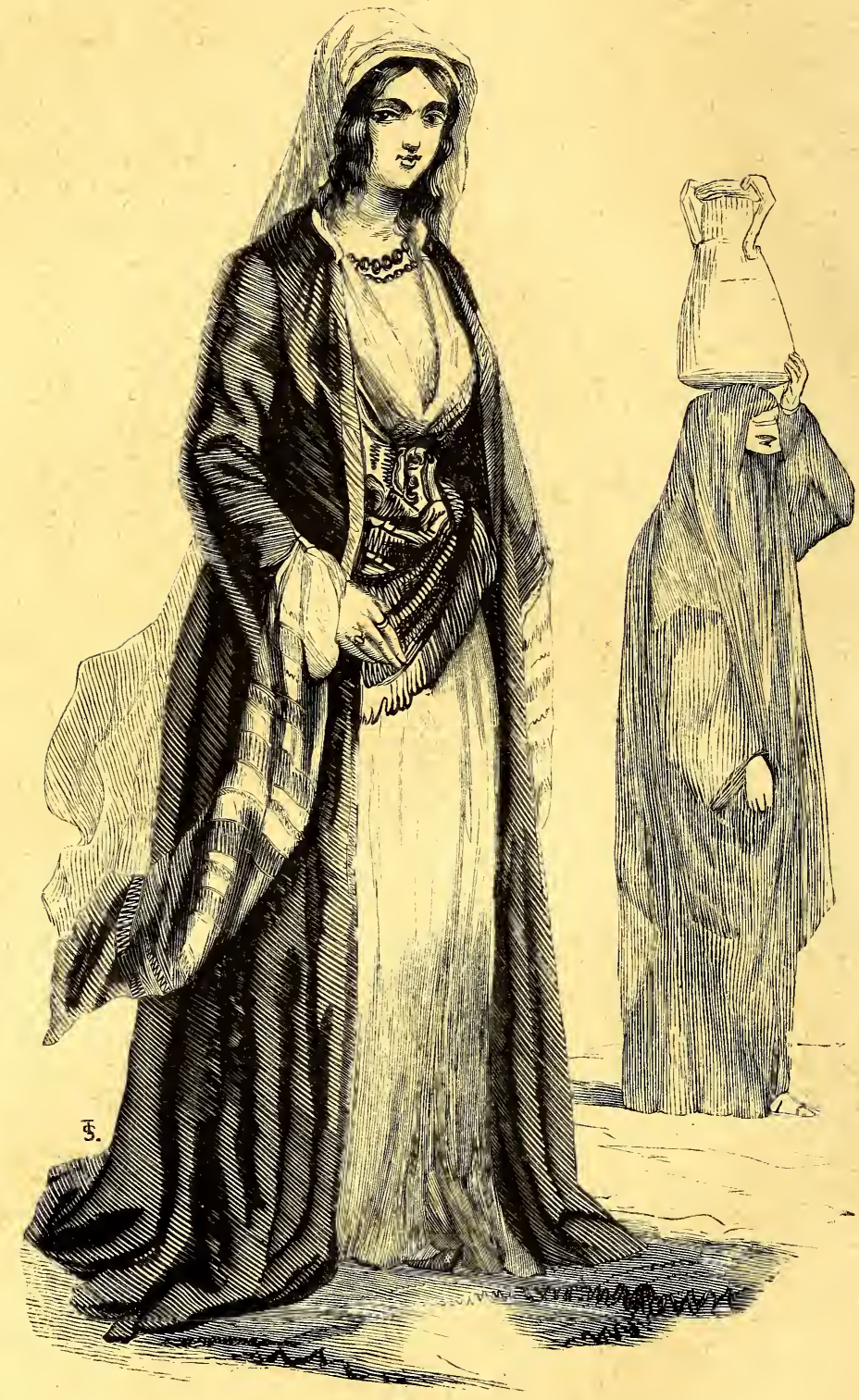

FEMME RICHE ET FEMME DU PEUPLE AU CAIRE.

(Ëgypte.) 
de celles-ci, et ne poussent point jusqu'au crime une faute que condamnent nos mœurs el notre religion.

- La légèreté de plusieurs des voyageurs qui viennent en Égypte amène quelquefois des résul tats aussi fâcheux que ceux dont je viens de parler. En visitant les bazars d'esclaves, curiosité dont le touriste est très-avide, si une négresse ou une Abyssinienne leur plaît, ils achètent avec un peu d'argent le moyen de satisfaire leur caprice; puis, cette boutade sensuelle apaisée, ils croient être généreux envers l'infortunée, sur laquelle ils ont assouvi leur passion éphémère, en lui donnant la liberté. Mais, dans un pays où la femme ne peut vivre que sous la tutelle de l'homme, la liberté place l'esclave affranchie dans la déplorable alternative de la misère ou de la prostitution. C'est ainsi que l'étourderie égoïste de quelques Européens nomades contribue à entretenir cette espèce de mépris que les musulmans ont pour nos mœurs. »

Les Égyptiens sont essentiellement amis du merveilleux. L'une de leurs superstitions les plus répandues est la croyance aux génies. Race intermédiaire entre l'ange et l'homme, les djinns, créés avant Adam, sont nés du feu et vivent plusieurs siècles; ils peuvent revêtir toutes les formes et se rendre invisibles. Les bons génies sont révérés; on craint les mauvais. Ces derniers sont connus sous le nom d'efrits, et il n'est sorte de méfaits qui ne leur soient attribués. Il y a des sautous, des omleys, des derviches, le mauvais oeil, des hejahs (charmes); mais c'est en décrivant les mœurs des Turcs que nous en parlerons.

Les songes sont regardés avec respect par les Égytiens, qui ont des jours heureux et néfastes : le dimanche, la nuit de ce jour au lundi (pendant laquelle est mort le prophète), sont des jours malheureux; mais le samedi, et surtout le mardi, appelé jour du sang, parce que plusieurs martyrs de l'islamisme ont péri ce jour-là, sont particulièrement sinistres. Le lundi, consacré au mariage; le jeudi, el moubarac (ou le béni), sont les jours heureux. Il y a encore le vendredi, el faclilch (l'excellent), choisi de préférence pour la consommation du mariage. Le pire des jours néfastes est le derniev mercredi du mois de $s a f e r$, pendant la durée duquel peu de personnes osent s'aventurer hors de leurs demeures.

L'Égypte est fertile en astrologues, magiciens, alchimistes, bohémiens, enchanteurs de serpents (psylles), etc. Les harvis forment une classe de sorciers qui n'ont pas le don de seconde vue comme ceux du Tyrol ou de l'Écosse; leur science consiste à évoquer, dans le creux de la main d'un enfant pris au hasard, telle personne absente dont le nom est prononcé dans l'assemblée, et de la faire dépeindre par cet enfant, sans qu'il l'ait jamais vue, et sous des traits qu'on ne puisse méconnaître. Voici, à ce sujet, la relation d'un voyageur, M. Th. Pavie, qui nous parait trop curieuse pour ne pas la rapporter :

"Le plus célèbre des harvis a eu l'honneur de travailler devant plusieurs voyageurs européens dont les écrits ont été lus avec avidité, et il a généralement assez bien réussi pour que sa gloire n'ait eu rien à souffrir de ces rencontres périlleuses. Voir cet homme, assister à une séance de magie, juger par mes propres yeux de l'état de la sorcellerie en Orient, trois choses qui me tentaient violemment : l'occasion s'en présenta.

„ C'était au Caire, dans une des hôtelleries de cette capitale de l'Égypte. A la suite de quelques discussions qui s'étaient élevées entre nous au sujet du grand harvis, il fut unanimement résolu de le faire appeler. La table était presque toute composéc d'Anglais.

"Vers la fin du dîner, le sorcier arriva. Il entre, fait un léger signe de tête, et va s'asseoir au coin du divan, dans le fond du salon; bientôt, après avoir accepté le café et la pipe comme chose due à son importance, il se recueille, tout en parcourant l'assemblée d'un regard scrutateur. Le devin est né à Alger; sa physionomie n'a rien de 
gracieux, son œil est perçant et peu ouvert, sa barbe grisonnante laisse voir une bouche petite, à lèvres minces et serrées; ses traits, plus fins que ceux d'un Égyptien, n'ont pas non plus le calme impassible et sauvage d'un Bédouin; il est grand, fier, dédaigneux, et se pose en homme supérieur.

- Tandis que nous achevions de fumer, celui-ci son chibouk, celui-là son narguilé, le harvi, immobile dans son coin, cherchait à lire sur nos visages le degré de croyance que nous étions disposés à lui accorder; puis tout à coup il tira de sa poche un calan (sorte de plume) et de l'encre, demanda un réchaud, et se mit à écrire ligne à ligne, sur un long morceau de papier, de mystérieuses sentences. Dès qu'il eut jeté dans le feu quelques-unes de ces lignes, déchirées successivement, le charme commençant à opérer, un enfant fut introduit. C'était un Nubien de sept à huit ans, esclave au service de l'un de nos convives, récemment arrivé de son pays, noir comme l'encre du harvi, et affublé du plus ample costume turc. Le sorcier prit la main de l'enfant, y laissa tomber une goutte du liquide magique, l'étendit avec sa plume de roseau, et, abaissant la tête du patient sur ses doigts, de manière à ce qu'il ne pût rien voir, il le plaça dans un coin de l'appartemènt, près de lui, le dos tourné à l'assemblée.

\-Lady K...! s'écria le plus impétueux des spectateurs. Et l'enfant, après avoir hésité quelques instants, prit la parole d'une voix faible.-Que vois-tu? lui demanda son maître, tandis que le harvi, de plus en plus sérieux, marmottait des vers magiques, tout en brùlant ses papiers, dont il tira une grande poignée de dessous sa robe.-Je vois, répondit le petit Nubien, je vois des bannières, des mosquées, des chevaux, des cavaliers, des musiciens, des chameaux... - Toutes choses qui n'ont rien à faire avec lady K..., me dit tout bas un esprit fort. - Shouf $t a^{\prime} i b$ ! Shouf $t a^{\prime} i b$ ! regarde bien! criait le spectateur qui voulait évoquer lady K... L'enfant se taisait, balbutiait; puis il déclara qu'il voyait une personne.-Est-ce une dame, un monsieur? - Une dame! Le harvi s'aperçut à nos regards qu'il avait déjà converti à moitié les plus incrédules. - Et comment est cette dame? - Elle est belle, reprit l'enfant, bien vêtue el bien blanche; elle a un bouquet à la main; elle est près d'un balcon, et regarde un beau jardin.

$₫$ - On dirait que ce négrillon a vu quelquefois les portraits de Lawrence, dit le maître de l'esclave à son voisin; il a deviné juste, et pourtant jamais rien de semblable ne s'est présenté à ses yeux. - Et puis, reprit l'enfant après quelques secondes, car il parlait lentement et par mots entrecoupés, cette belle dame a trois jambes!

- L'effort que fit le harvi pour ne pas anéantir le négrillon d'un coup de poing se trahit par un sourire forcé. Il lui répéta avec une douceur contrainte, une grâce pleine (le rage : Shouf $t a^{\prime} i b$ ! regarde bien! L'enfant tremblait; toutefois il affirma que le personnage évoqué dans le creux de sa main avail trois jambes.

\Aucun de nous ne put se rendre compte de l'illusion; mais on fit retirer le petit nègre, qui fut remplacé par un autre en tout semblable. Durant cette interruption, le sorcier avait marmotté bon nombre de phrases magiques et brùlé force papiers. L'assemblée fumait, le café circulait sans cesse; l'animation allait croissant. On convint d'évoquer cette fois sir F. S..., facile à reconnaître, puisqu'il a perdu un bras. Le nouveau négrillon prit la place du premier, abaissa de même sa tête sur la goutte d'encre, et l'on fit silence.

- - Sir F. S...! dit une voix dans l'assemblée, et l'enfant répéta, syllabe par syllabe, ce nom tout à fait barbare pour lui. Ainsi que son prédécesseur, il déclara voir des chevaux, des chameaux, des bannières et des troupes de musiciens : c'est le prélude ordinaire, le chaos qui se débrouille avant que la lumière magique de la goutte d'encre éclaire le personnage demandé. 
๖ Le harvi ne comprend ni le français, ni l'anglais, ni l'italien; mais, habitué à lire dans les regards du public, il devina qu'on lui proposait un sujet marqué par quelque signe particulier. Jadis on lui avait demandé de faire paraître Nelson, à qui, comme chacun sait, il manquait un bras et une jambe, et il avait rencontré juste, grâce à la célébrité du héros. Cette fois, il eut vent de quelque tour de ce genre; aussi, après bien des réponses confuses, l'enfant s'écria : - Je vois un monsieur! c'est un chrétien, il n'a pas de turban; son habil est vert... Je ne vois qu'un bras! A ces mots, nous échangeâmes un sourire, comme des gens qui s'avouent vaincus : il fallait croire à la magie... Mais mon voisin l'esprit fort, après avoir fait bouillonner l'eau de son narguilé avec un bruit effroyable, regarda le harvi. Je remarquai que notre pensée avait été mal interprétée par le devin, et qu'il chancelait dans son affirmation, supposant que nous avions ri de pitié. Il demanda donc à l'enfant : - Tu ne vois qu'un bras? Et l'autre? L'enfant ne répondit pas, et il se fit un grand silence. On entendit les petits papiers s'enflammer plus vivement sur le réchaud._L'autre bras, reprit le négrillon... je le vois : ce monsieur le met devant son dos, et il tient un gant de cette main!

- La première personne évoquée avait trois jambes; la seconde, au lieu d'un bras de moins, se trouvait être au grand complet.

- Le harvi avait donc échoué complétement; mais enfin que voyait ce négrillon dans le creux de sa main? Comment la farce se jouait-elle? Par hasard, je pus l'apprendre.

\Un mois après, à bord de la Zénobie, en route pour Bombay, je retrouvai le lieutenant St... et son négrillon, le même qui avait servi de compère au harvi. C'était assurément une soirée magique : le flot calme de la mer Rouge baignait mollement la ligne de sable qui s'allonge au pied des grands monts de la côte d'Arabie; les étoiles, reflétées dans les eaux, semblaient des lumières phosphorescentes se jouant à la proue du navire. L'instant ne pouvait être mieux choisi... Le lieutenant St... me donna donc l'explication suivante :

) Le grand art du harvi, c'est de savoir se faire entendre de l'enfant sans que personne de l'assemblée puisse distinguer un seul mot de ce qu'il dit, tandis qu'il semble murmurer des paroles mystérieuses. D'abord il effraye le compère improvisé, le menace de lui montrer le diable, lui dicte les réponses que parfois celui-ci entend de travers (comme dans le cas de la dame aux trois jambes), et, pour le forcer à parler, de son orteil il lui presse le pied d'une façon horrible; manœuvre dissimulée aux yeux du public par la longue robe dont s'enveloppe le sorcier. S'il devine juste, la gloire de la réussite lui revient de droit; s'il se trompe, on s'en prend à l'enfant; souvent le hasard l'a merveilleusement servi. Aussi la goutte d'encre est-elle considérée comme infaillible par les Égyptiens, dont le harvi est depuis longtemps en possession d'amuser les soirées. D

Il y a au Caire environ cinquante choaras (poëtes); des moadditins (conteurs d'histoires), et des anteriyeh (trouvères d'Antar). Les poëtes de ce pays comparent leurs amantes à la lune, et ils trouvent d'abondantes figures dans les douces teintes de la rose, les parfums du jasmin, la force et la majesté du lion, la délicate élégance, l'agilité, les beaux yeux de la gazelle, la fécondité du Nil, la patience du chameau, etc. Il y a aussi des poëles titrés qui composent une romance par mois. Ces compositions sont chantées par les almées dans les fètes publiques ou particulières; le peuple les apprend ensuite.

La musique des Égyptiens n'est actuellement qu'un art dégénéré; les divisions et subdivisions de la gamme la caractérisent; et la notation, dans laquelle le système des clefs est inconnu, est aussi toute différente de la nôtre. Leurs instruments sont le tambour et les orgues qu'ils ont inventés; des timbales (noukakir), des kas (cymbales), cn 
usage lors des processions; des castagnettes de cuivre, assez semblables à de petites cymbales, et dont les danseuses se servent pour accompagner leurs mouvements: un tambour de basque (tar); le daraboukals, autre tambour, généralement de forme conique, et terminé par une espèce de manche creux que l'on tient d'une main, tandis que de l'autre on frappe sur la peau qui couvre la grande ouverture; on en tire des sons assez agréables et combinés avec beaucoup d'originalité.

Les Arabes ont quelques instruments à vent : le chalumeau, le zamir (hautbois), une sorte de flageolet à double pipeau, nommé zoumarah, pour lequel les mariniers du Nil ont une grande préférence, et une flûte appelée nay.

L'instrument à corde le plus simple est le rebab, monocorde sur lequel s'accompagnent les improvisateurs et les conteurs : c'est une espèce de basse sans caisse qui rend des sons mélodieux imitant souvent la voix humaine; on en joue avec un archet. Le kemengeh est un violon dont la caisse est faite avec les trois quarts d'une noix de coco, percée de petits trous; il a trois cordes, composées chacune de plus de cinquante crins de cheval. Le kissar, lyre éthiopienne, ressemble au luth antique. Ils ont une espèce de harpe appelée canoun, el dont on joue avec le plectrum; et l'oud, ou guitare à sept cordes, dont les vibrations sont également dues au plectrum.

Les alatyeh (alaty au singulier), ou chanteurs de profession, forment une caste méprisée et de mœurs dissolues. Les cantatrices sont appelées avualem (au singulier almée $^{\mathrm{I}}$ ), mot que les Européens appliquent, à tort, à toutes les danseuses.

En même temps artistes et courtisanes, les almées sont ordinairement de jeunes et jolies femmes. Leur costume est à peu près celui que nous avons décrit pour les dames ćlégantes; mais il a ce cachet particulier qui partout distingue la femme galante : il dessine davantage leurs formes, laisse la gorge et les bras à découvert, et se fait remarquer par la profusion de bijoux et d'étoffes précieuses, ridicule affectation de fausses richesses.

Ces femmes dansent par groupe de deux ou quatre. Quoiqu'elles mettent une certaine symétrie dans leurs mouvements, elles ne forment point de figures et de tableaux réguliers comme nos danseuses de théâtre. Quant à la nature de leurs danses, elle est tellement licencieuse, qu'on ne peut en parler qu'en termes généraux.

En se présentant sur le dourka, elles commencent par quelques pas, en agitant au-dessus et autour de leur tête leurs castagnettes de cuivre dont elles jouent avec beaucoup d'expression. Elles se troussent ensuite en avant, en arrière, à droite, à gauche, et, ce prélude achevé, commencent la danse : Alors, dit Clot-Bey, les jambes demeurent immobiles, de mème que la partie supérieure de leur corps, excepté les bras qu'elles écartent, arrondissent, abaissent ou élèvent selon les diverses phases du sentiment lascif qui paraît les animer. Agités par une trépidation incessante, qu'elles accélèrent tour à tour avec une audacieuse énergie ou ralentissent langoureusement, leurs hanches et leurs reins, assouplis à toutes les contorsions, feignent avec impudeur les émotions physiques les plus sensuelles; c'est le

Vibrabunt sine fine prurientes

Lascivos docili tremore lumbos,

dont se servit Martial pour dépeindre la danse des filles de Gadès.

Les almées ont du reste plusieurs sortes de danses : l'une, hardie et brutale, est exclusivement empreinte du génie égyptien; une autre, mêlée de quelques pas, paraît

1 La traduction du mot almcie est fomme leltréc. 
combinée avec la danse grecque. Il en est une que l'on appelle nahleh (danse des guêpes ); les danseuses feignent d'avoir été piquées par une guêpe, qu'elles cherchent dans leurs vêtements en criant : Nalleh-oh! nalleh-oh! (ah! la guêpe! ah! la guêpe!), et pour saisir l'insecte imaginaire, elles dépouillent peu à peu leurs vêtẻments et ne restent bientôt couvertes que d'un voile qu'elles font flotter et laissent s'entr'ouvrir de temps en temps. On comprend ce qu'un tel spectacle peut inspirer à ceux qui y assistent...

Lorsque la danse est arrivée à son plus haul degré de lasciveté, il y a des instants de repos, dont les almées profitent pour venir faire aux spectateurs des agaceries qui s'adressent surtout au principal invité; elles s'asseyent sur les genoux de celui-ci, et prennent avec lui des licences dont on s'effaroucherait dans le mystère quand on n'y est pas habitué.

Quelques-unes de ces femmes arrivent à acquérir une certaine opulence; mais elles forment une caste à part, comme en Europe la race des Gitanos.

Les gaouasyrs étaient d'autres danseuses qui exécutaient en plein vent des scènes chorégraphiques non moins licencieuses. Mais depuis peu une ordonnance leur a défendu de parader comme autrefois dans les rues du Caire et d'Alexandrie.

Le but moral qu'on s'était proposé par la prohibition des danseuses publiques est loin d'avoir été atteint, car ce qui n'était qu'immoral dans la danse de ces dernières, devient infâme dans celle des kowals ou danseurs.

Les jeux que préfèrent les Égyptiens sont le dahmeh (jeu de dames), le taoutah (trictrac), et surtout le setreng (jeu d'échecs), auxquels ils passent des journées entières. Ils estiment peu les cartes; ils connaissent pourtant quelques parties qu'ils appellent lib-el-koumar (jeu de hasard ou de gain), parce qu'ils les intéressent avec de l'argent.

Ils considèrent peu les exercices gymnastiques; cependant on voit quelques lutteurs, et, dans les fêtes publiques, on voit parfois les fellahs s'escrimer avec des nebouts, longs bâtons dont ils s'efforcent de frapper leurs adversaires. Mais leurs luttes sont peu habiles et témoignent de leur nonchalance et de leur mollesse.

Ils préfèrent l'équitation, qu'ils regardent comme un amusement noble. Un de leurs exercices favoris est le djerid, qui rappelle nos anciens tournois et carrousels. Pendant que deux cavaliers courent au galop l'un sur l'autre, un d'eux lance avec force et comme ún trait, à son adversaire, un bâton de palmier de quatre à six pieds. L'adresse consiste à éviter le djerid ou à le recevoir dans la main.

Les Égyptiens ont des marionnettes, et surtout des jongleurs, escamoteurs, etc. On voit aussi des individus qui montrent des animaux savants.

Quelques comédiens donnent des représentations dans des maisons particulières. Les pièces qu'ils jouent sont dépourvues d'intrigue autant que de naturel et d'esprit. C'est l'enfance de l'art dramatique, et sous une forme élémentaire entièrement privée d'attraits.

Différents Peuples QUi habitent l'Égypte. - Nous ne parlerons point des ArabesBédouins dont nous avons déjà dit un mot à l'article Turquie d'Asie, et que nous aurons occasion de retrouver en arrivant à la description de l'Algérie. Il en est de même des Turcs d'Europe, des Albanais et des autres peuples qui ne sont point aborigènes de l'Égypte.

Cophtes. - Ces peuples, appelés aussi Gobthes, peuvent être regardés comme les propriétaires de l'Égypte, dont ils furent les habitants primitifs, puisqu'ils descendent des anciens Égyptiens mêlés aux Perses, depuis Cambyse, et aux Grecs depuis Alexandre et les Ptolémées. Répandus dans le Delta, ils habitent surtout la haute Égyple; dans le Saïd ils habitent presque exclusivement des villages entiers. 
Les Cophtes ont le teint basané, le front plat, les yeux relevés aux angles et peu couverts ; les joues hautes, le nez plutôt court qu'épaté; la bouche grande, plate, éloignée du nez, bordée de larges lèvres; les cheveux demi-laineux, la barbe rare et pauvre. Leurs jambes sont arquées, sans mouvements dans le contour; ils ont les doigts des pieds allongés et plats. En somme, leur corps est peu gracieux.

Leur caraclère n'a aucune des conditions qui pourraient les faire aimer des Européens. Ils sont mélancoliques, taciturnes, sombres, dissimulés surtout comme toute race qui a vécu longlemps sous l'oppression; bas, rampants, serviles envers leurs supérieurs, il semble qu'ils veulent s'en venger sur leurs subalternes envers lesquels ils sont d'une dureté, d'une arrogance extrême. Fins, sobres, avares, ils ont une rare aptitude pour tout ce qui a rapport à la comptabilité. C'est ce qui avait déterminé les mameluks, ces hommes qui se faisaient un point d'honneur de leur ignorance, à remeltre la plupart des fonctions administratives entre les mains des Cophtes, et ceux-ci en profilèrent pour se venger des vexations de toute sorte que leurs dominateurs exerçaient à leurs dépens. Le maniement des fonds, l'arpentage des terres leur ayant été confiés, ils pouvaient aisément frustrer le trésor de leurs chefs, et il faut avouer qu'ils ne se firent pas faute de ces concussions, qui du reste ne leur inspiraient aucun scrupule.

Les Cophles sont extrêmement superstilieux et d'une grande dévolion aux saints, dont chacun est invoqué par eux pour un objet particulier, ainsi que nous le verrons dans notre Histoire et Cérémonies religieuses de tous les peuples.

Ils ont un grand nombre d'écoles, mais destinées aux garçons seulement; peu de leurs femmes savent lire. On y enseigne principalement les psaumes de David, les Évangiles, les épîtres et les Apôtres. Il est peu de Cophtes, surtout dans la basse Égypte, qui parlent encore la langue de leurs ancêtres; l'arabe est la seule en usage aujourd'hui parmi eux. De même qu'au temps des mameluks, beaucoup de ces hommes sont employés dans l'arpentage et la comptabilité. Dans les villes ils sont artisans : tailleurs el orfévres au Caire; fabricants de nattes dans la province de Menouf; ils distillent de l'eau de rose dans le Fayoum, tissent le lin à Syout, el enfin sont agriculteurs dans les villages.

Ils marient leurs filles très-jeunes et ne forment d'alliance qu'entre eux. On conduit l'épouse au bain trois jours avant la cérémonie, qui a lieu ordinairement à minuit, et qui est célébrée par une messe. La consommation du mariage n'a lieu que le lendemain de la consécration, après que le prêtre, qui a prononcé les paroles sacramentelles, est venu lui relirer une espèce de lien nommé zennar, qu'il lui a passé au cou pendant la cérémonie.

Les enfants ne sont baptisés que trois jours après leur naissance. Les familles sont, dit-on, fort unies.

Les Cophles ont adopté l'habillement des musulmans; mais ils préfèrent les nuances sombres, et se distinguent, dans les villes, par la couleur de leur turban, qui est noire, grise ou bleue. Les femmes cophtes, que ce soit en public, ou chez elles, même devant leurs plus proches parents, ont toujours le visage soigneusement voilé.

Les JuIFs, qui ont la même physionomie que ceux d'Europe, habitent principalement le Caire, où ils ont un quartier à part dont les rues sont étroites, sombres, sales, infectes, et fermées par des portes guichetées; ils peuvent s'y séquestrer, et rester, si cela leur convient, entièrement étrangers au reste de la population. Les beaux individus de celle race, les jeunes surtout, rappellent ce caraclère de tête que la peinture a consacré à Jésus-Christ. Au reste, toujours méprisés et repoussés sans jamais être chassés, ils sont, en général, mal vêtus, et semblent faire ostentation de leur misère. 
Ils ont la figure hâve, des habits sales et déchirés; on attribue leur apparence maladive à la consommation excessive qu'ils font de l'huile de sésame.

Les juifs ont en Égypte le caractère et les mœurs qui les firent abhorrer au moyen âge. Avares jusqu'à la plus sordide cupidité, ils s'efforcent de dérober à tous les yeux la fortune qu'ils peuvent avoir, en affectant des dehors misérables. Ignorants, religieux jusqu'au fanatisme, ils sont actifs, d'une souplesse insinuante, et ne reculent devant aucun moyen pour réaliser le plus mince bénéfice. Il faut leur reconnaître d'ailleurs des mœurs pures et sévères; il n'y a point de courtisanes parmi leurs femmes, qui, de même que celles des Cophtes, se voilent scrupuleusement le visage.

Les familles d'Arméniens qui se trouvent en Égyple y sont venues à la suite des conquérants turcs. Ces hommes, qui n'ont pas de quartier particulier, ont exercé, par leurs richesses et les services pécuniaires qu'elles leur permettaient de rendre aux pachas, une si grande action sur l'administration des provinces, et une influence si prépondérante sur les affaires du gouvernement ottoman, qu'on eût pensé que l'empire était exploité de compte à demi par les Turcs et les Arméniens. Du reste, ils ont envers les indigènes les mêmes sentiments de hauteur que témoignent les Turcs. Ils exercent particulièrement des professions financières ou mercantiles, pour lesquelles ils montrent une grande aptitude et beaucoup d'activité.

Les Raïas (peuples indigènes qui ne professent pas l'islamisme) ne forment qu'une partie assez minime de la population, et leur influence politique n'a sur les affaires présentes et sur l'avenir de l'empire qu'une médiocre influence, tandis que c'est le contraire en Turquie.

C'est, dit M. Clot-Bey, une chose qui frappe l'observateur et mérite d'être considérée comme une donnée très-importante, que le caractère transitoire que les Turcs ont imprimé à tout dans leur établissement politique. Il y a longtemps que l'on a dit qu'ils ne font que camper dans leurs possessions; nous avons vu, en parlant des mœurs des musulmans, que cette assertion n'est pas seulement une métaphore, qu'elle est encore vraie dans son acception propre.

Les Osmanlis n'ont donné à l'empire qu'ils ont fondé aucun élément de durée. Ils ont livré au caprice du hasard ou à l'arbitraire de la force, leurs institutions administratives et militaires, si l'on peut appeler de ce nom une organisation grossièrement ébauchée. Ils n'ont pas compris que, pour prendre de solides racines dans leurs nouvelles conquêtes, il ne s'agissait pas seulement d'occuper le sol, mais surtout d'en absorber les habitants par la fusion des religions, des institutions, des races. Les barbares qui envahirent l'Europe lors de la chute de l'empire romain se convertirent à la religion des vaincus, inspirèrent leurs codes de leur législation, s'assimilèrent leur langue, et de celte fusion féconde, vivifiée par l'incubation du temps, sont sortis, avec notre état social actuel et les progrès modernes, les génies divers des nationalités curopéennes. Les Ottomans, au contraire, infatués de la supériorité de leur croyance, ne firent aucune concession aux vaincus, qu'ils tinrent humiliés sous leur joug, et demeurèrent complétement séparés d'eux. Il n'y eut donc pas, dans l'empire turc, combinaison d'un élément de force, d'énergie vivace, promesse d'avenir, apportée par les conquérants, et d'un élément de civilisation, héritage du passé, conservé par les vaincus; il n'y eut pas, comme cela s'était passé en Europe, au moyen âge, infusion d'un sang neuf et généreux dans un corps d'où la vie s'en allait; mais il y eut juxtaposition stérile d'uu élément barbare immobilisé dans sa présomptueuse ignorance, à côté des ruines d'une société détruite par une décadence de plusieurs siècles.

Ainsi établi, l'empire ottoman s'était fermé toute voie au progrès; il n'avait aucune garantie intrinsèque de durée. Il renfermait deux races placées en présence l'une de 
l'autre, en contact quotidien, mais avec des intérêts contraires, des mœurs différentes, des idées opposées, se méprisant ou se haïssant. Il n'y avait pas dans l'empire un peuple unique, mais, dans le même État, deux nations, dont l'une possédait, à défaut de la puissance dans le présent, la supériorité du nombre.

Or, l'unité nationale est la condition exclusive de la vitalité des empires; il n'y a d'avenir que là où elle se trouve.

Les conséquences que peul avoir la profonde division qui scinde en deux grandes parts les populations de la Turquie, ont frappé tous les esprits sérieux. « La population des raïas, dit M. Urquhart ${ }^{x}$, a une importance et une puissance politique telles, qu'elle peut arrêter la régénération de l'empire ottoman. ๖

Que l'on remarque la différence qu'il y a, sous ce rapport, entre l'Égypte et le reste de la Turquie. L'Égypte n'a pas de dissensions intérieures à redouter, elle ne peut craindre que la moitié de ses habitants appelle à son aide l'invasion étrangère pour renverser la domination de l'autre moitié. Je suppose, ajoute M. Clot-Bey, qu'il y ait quelques raisons dans les accusations que les ennemis de l'Égypte portent contre sa situation actuelle; mais je veux qu'ils reconnaissent qu'elle forme une partie bien distincte de l'empire ottoman, la seule partie qui ait de l'avenir, parce que c'est la seule dans laquelle on trouve l'unité de race.

Les raïas ne participent ni aux mêmes charges, ni aux mêmes avantages politiques que les musulmans. Ainsi, ils ne contribuent pas de leur personne à la défense du pays. En revanche, ils ne jouissent pas de l'égalité civile, et payent des impôts particuliers, etc. Opérer un rapprochement entre les raïas et les musulmans en accordant à ceux-là l'égalité des droits, tel est le but que doit se proposer en Turquie toute la polilique prévoyante qui veut sincèrement la régénération de l'empire ottoman. C'est vers ce résultat que paraît tendre celui des conseillers du sultan qui se distingue le plus par ses idées libérales, Reschid-Pacha. Je souhaite ardemment que les projets généreux dont le hati-chérif de Gul-Hané a été l'expression, puissent être menés à bonne fin. Pour ma part, dit M. Clot-Bey, si j'avais à donner un avis au vice-roi d'Égyple, je lui conseillerais d'établir l'égalité civile et politique entre ses sujets musulmans et ses sujets raïas. Celte œuvre aurait pour lui moins de difficultés et d'embarras que pour la Porte; car dans ses États les raïas sont bien moins nombreux, bien moins puissants, bien moins redoutables aux musulmans que dans le reste de la Turquie; sa tentative serait très-utile comme expérience pratiquée sur une échelle peu considérable; elle préparerait le reste de l'empire otloman à une révolution qui, dans son intérêt, doit s'opérer le plus tôt possible. Ici encore, Méhémet-Ali prendrait l'initiative de l'exéculion d'une mesure progressive et réformatrice, et commencerait pour la Turquie un nouvel ordre de choses. D'ailleurs il ne ferait que se continuer lui-même; il a déjà fait beaucoup pour l'émancipation des raïas en les admettant à remplir des charges importantes dans l'administration, et en choisissant parmi eux les préfets de ses départements.

Il nous reste à parler des différentes nations chrétiennes auxquelles on a donné, non-seulement en Égypte, mais dans tout le Levant, le nom générique de Francs. Cette population comprend diverses catégories dont chacune forme un groupe distinct.

La première, et la plus honorée des indigènes, est celle des consuls, des chanceliers et des attachés aux consulats.

Les consuls généraux résident à Alexandrie : les puissances représentées par des

${ }^{x}$ La Turquie et ses ressources. 
dignitaires de ce grade sont la France, la Russie, l'Autriche, l'Angleterre, l'Espagne, la Belgique, la Suède, la Hollande, la Sicile, la Prusse, la Sardaigne, le Danemark et la Toscane. Le drapeau national flotte à l'extrémité d'un mât placé sur le faîte de la maison de ces hauts dignitaires, et les armes de leur gouvernement sont blasonnées sur la porte de leurs hôtels.

Le Caire a des vice-consuls; les principales puissances ont à Damiette, à Rosette, à Suez, à Kenneh et à Kosseyr des agents choisis pour l'ordinaire parmi les chrétiens indigènes.

Le rang que l'Égypte a pris dans le monde politique, depuis que Méhémet-Ali dirige ses destinées, a élevé la position du consul général d'une grande puissance, auprès du vice-roi, au niveau des postes diplomatiques de première importance. Ce sont de véritables ambassadeurs qui ne se bornent pas à protéger les intérèts civils ou commerciaux de leur's compatriotes; ils entretiennent des rapports avec le vice-roi, auquel ils ont fréquemment à faire des communications de la part des cabinets qu'ils représentent, et avec lequel ils traitent des questions politiques difficiles et de haut intérêt.

Les négociants forment la seconde catégorie; leur résidence la plus commune est Alexandrie; il faut y joindre les commis qui vivent ordinairement chez leurs patrons.

La troisième classe se compose des marchands et des restaurateurs.

Il y a ensuite la classe des industriels, et, en dernier lieu, celle des hommes de peine, domestiques, etc.

Quant aux Européens au service du gouvernement, ils forment une catégoric particulière.

Tous ces groupes forment une espèce de colonie réunie presque tout entière dans les mêmes quartiers. La distinction des rangs y est rigoureusement observée; l'étiquette. poussẻe très-loin, et les membres de chaque classe ne dépassent pas dans leurs relalions le cercle qui leur est tracé par leurs fonctions, leur profession ou leur fortune. Les Francs sont hospitaliers, généreux, et, pour secourir leurs compatriotes nécessiteux, ils font souvent entre eux des collectes qui ne tardent pas à produire des sommes importantes. A Alexandrie, les Européens ont élevé à leurs frais un hôpilal où sont recueillis les Francs qui ne peuvent se faire soigner chez eux. Les mœurs sont, il faut l'avouer, assez relâchées dans la société franque; les intrigues d'amour y sont communes; néanmoins, il ne manque pas de personnes honorables qui observent soigneusement les convenances et les lois de la morale.

Les voyageurs sont bien trailés en Égypte; ceux qui ont un nom illustre sont reçus avec distinclion. Le vice-roi leur donne souvent pour logement un de ses palais ou les fait héberger dans la demeure d'un de ses grands ofliciers; ceux qui, sans avoir un grand nom, sont dans l'aisance, peuvent parcourir en liberté le pays, au moyen d'un firman ou passe-port, que l'on obtient toujours par l'intermédiaire du consul de la nation à laquelle on appartient.

Ce firman est conçu en ces termes :

* De notre divan, l'an de l'hégire, le...

"Notre ancien ami (nom de sa nation), M. N., se rendant dans nos domaines pour visiter les lieux d'antiquités et autres lieux curieux et utiles à ses recherches, il nous a été présenté par son consul, en foi de quoi nous lui avons délivré notre firman pour lui servir et valoir pendant son voyage dans l'étendue de nos domaines. Les moudyrs, mâmours et tous magistrats civils ou militaires, à qui ce firman sera présenté, ne doivent pas négliger de lui accorder les égards, les soins et les services qui pourraient lui 
être agréables, afin qu'aucune plainte ne nous soit portée par le voyageur. Nous vous recommandons qu'aucune insulte ni tort ne lui soit fait par les fellahs ou autres, et de lui procurer tout ce dont il pourra avoir besoin en ne payant qu'au taux du pays pour les montures, barques, provisions, etc.; je regarderai comme rendus à moi-même tous les services que vous lui rendrez. 


\section{NUBIE.}

Cette partie de l'Afrique est située entre $9^{\circ}$ et $24^{\circ}$ de latitude nord, et entre $26^{\circ}$ et $57^{\circ}$ de longitude est. Ses bornes sont : au nord l'Égypte, à l'est le golfe Arabique, au sud-est l'Abyssinie, au sud-ouest la Nigritie, et à l'ouest cette même contrée et le Sahara. Elle a environ 350 lieues du nord au sud, 170 lieues de largeur moyenne, et 60,000 lieues carrées.

Le caractère principal de la géographie de ce pays est le Nil qui, dans la partie méridionale, y est formé par la réunion du Bahr-el-Abiad avec le Bahr-el-Arrak, que grossissent le Toumât, le Dender et le Bahad. Ce fleuve reçoit vers le milieu de la contrée le Tacazzé ou Atharah. La vallée du Nil constitue la Nubie proprement dite; le sol y est fertile; les maisons, les villages y sont en grand nombre, et c'est là que la population s'est concentrée. Hors de la vallée, dans les parties moyenne et septentrionale, presque tout est désert et stérile.

Dans l'été, le climat est d'une excessive chaleur, mais les nuits sont très-fraîches au-dessous du confluent du Tacazzé dans la vallée même du Nil (par $17^{\circ} 40^{\prime}$ de latitude nord) il ne pleut jamais, tandis qu'au sud de ce point les pluies tombent chaque année, à partir du mois de juillet, et ont lieu à des époques indéterminées dans les parties montagneuses de l'est. Le khamaya ${ }^{\mathbf{x}}$ commence à souffler en Nubie vers la fin d'avril, et règne à peu près jusqu'à l'équinoxe d'été. Périodiquement inondée par les eaux de ce fleuvre, la rive droite du Nil offre une plus grande fertilité que la rive gauche.

En général l'agriculture est assez soignée. Les principales productious de ce pays sont le dourah, le maïs, le dokhoum, l'orge, les lentilles, lupins, haricots, melons d'eau, tabac et coton; on cultive la vigne vers Deyr, les palmiers sont communs, les dattes d'lbrym et du Sokkot sont renommées. Dans la Nubie méridionale, il croît surtout un grand nombre d'arbres qui donnent la gomme arabique. Les animaux domesliques, tels que le cheval, qui est très-estimé, le dromadaire et l'âne, servent de montures; le bœuf et le buffle sont employés aux transports ainsi qu'à l'arrosement des terres; on rencontre dans les forêts et les déserts des sangliers, des éléphants, des ligres, des panthères, des rhinocéros, des girafes, des hyènes, des renards, des chats sauvages, des gazelles, quantité de singes et d'autruches, ainsi que de gros serpents et autres reptiles qui ne sont pas venimeux; le bouquetin existe dans les montagnes à l'est, et le lièvre en assez grand nombre dans les lieux couverts. Partout on voit des perdrix, des oies sauvages, des vanneaux, des cigognes, des corneilles. Les crocodiles et les hippopotames abondent dans le Nil et sur ses bords. La pêche dans le fleuve est

\footnotetext{
1 Vent pernicieux qui entraîne une grande quantité de sable, et qui est accompagné de tonnerre et
d'éclairs.
} 
peu active, si ce n'est vers Deyr. Il y a des mines d'or à l'est, dans le mont Elbéh; des mines d'alun à l'ouest, dans le désert de Nubie, et du sel gemme dans les montagnes de l'est.

Le sol de cette terre est couvert de magnifiques restes d'antiquités qui peuvent soutenir la comparaison avec les plus beaux monuments de la Grèce antique, et qui diffèrent de ceux des Égyptiens en ce qu'ils sont ou sous terre ou creusés dans le roc vif. Un des plus remarquables de ces débris est le temple d'Ebsamboul, taillé dans le roc vif, sur les bords du Nil, et parfaitement conservé.

Circonscrite dans ses limites, la Nubie correspond à l'AEthiopià supra AEgyptum des anciens, région sur laquelle se répandent quelques rayons épars de l'histoire ancienne, et que font connaître les récits d'Hérodote, les recherches de Strabon, les voyages d'Artémidore et d'Agatarchide, par les inscriptions d'Adulis, monuments des expédilions d'un Ptolémée, ou plutôt d'un roi d'Abyssinie, et par l'érudition de Pline le naturaliste.

La Nubie est peu peuplée eu égard à son étendue. Nous jetterons un coup d'œil sur les différents peuples qui l'habitent.

Ce pays est divisé en un grand nombre de petits États, dont chacun est gouverné par un chef indépendant et absolu qui prend ordinairement le titre de malek.

Le principal commerce est celui des esclaves qu'on importe du centre de l'Afrique au nombre d'environ 5,000 par an. On exporte en Égypte beaucoup de dattes, de la gomme et des plumes d'autruche. Le seul port remarquable de la Nubie est celui de Souakem. Le moud, petite mesure de dourah, est le terme de comparaison le plus fréquemment employé dans les échanges du commerce. On ne connaît guère d'autre monnaie que les dollars, les piastres et les paras.

Les Barabras ou Kenous. - Les Barabras sont maigres, grêles, el n'ont que des nerfs, des muscles et des tendons plus élastiques que forts; leur peau luisante offre une teinte bronzée; leurs sourcils surbaissés laissent étinceler des yeux profonds. Ils ont la bouche évasée sans que leurs lèvres soient grosses, les narines larges, le nez pointu, les cheveux et la barbe rares et par petits flocons. Toujours agiles, on ne saurait deviner lẹur âge, malgré leurs rides précoces, si ce n'est par la blancheur de leur barbe. Leur physionomie respire la gaieté; leur caractère est vif et bon. En Égypte, on les emploie généralement à garder les magasins ou les chantiers de bois. Leurs gains sont minimes, mais leurs besoins sont modérés; ils se nourrissent de peu, et gardent à leurs maîtres de l'attachement et de la fidélité.

Leurs vêtements consistent en une pièce de laine bleue ou blanche, retenue sur les reins et passant entre les jambes, et à laquelle ils ajoutent parfois une chemise de toile. Il en est qui portent les cheveux courts et bouclés; les autres les réunissent en tresses, comme on représente leurs ancêtres dans les monuments de l'antiquité; ces tresses formant plusieurs petits chignons, sont rassemblées sur le sommet de la tête, et retenues par une broche en bois assez longue. Leur costume est complété par une espèce de bracelet, attaché près de l'épaule au bras gauche, et dans lequel ils placent un petit couteau courbé. On les dit sobres, laborieux, d'un tempérament sec et peu sujets aux maladies. Ils considèrent comme un remède souverain contre presque tous les maux, la brûlure à l'aide d'un fer rouge. Ces peuples élèvent des bœufs, des moutons, et particulièrement des chèvres très-communes dans leur pays. Leur récolte se compose de dourah, d'orge, de tabac, de coton, de dattes, de bois d'acacia et de sycomore. Ils vont. vendre, quelquefois jusqu'au Caire, ces denrées qu'ils transportent, à l'époque de la crue du Nil, sur de grands radeaux qu'ils construisent eux-mêmes.

Leurs femmes sont loin d'ètre belles. Elles portent une chemise de toile blanche ou 
bleue, ouverte des deux côtés, fermée par devant, et flottant sur un pantalon de même éloffe. Souvent elles s'enveloppent dans un manteau court dont elles se couvrent la tête.

Les Barabras ou Kenous habitent à l'occident du Nil et vivent dans un état d'indépendance presque complète.

Les Ababdèus. - Ces naturels occupent les déserts situés à l'orient du Nil, depuis la vallée de Koséir en Égypte, jusque fort avant dans la Nubie. Ils diffèrent entièrement par leurs contumes, leur costume et leur langage, des Arabes que l'on rencontre en Égypte. Les Ababdèhs sont presque noirs, mais la conformation de leur tête est celle des Européens; ils ont les cheveux longs et la tête toujours découverte; la graisse de mouton leur sert à oindre leur corps, et surtout leur tète, d'un enduit assez épais. Leur religion est le mahométisme, mais ils témoignent plutôt de la tiédeur que de l'amour pour leur croyance. Ils enterrent leurs morts en les couvrant de pierres. Leurs amusements guerriers sont animés par une musique moins triste et moins monotone que celle des Égyptiens. Le mème homme cultive la poésie el la musique : il chante en s'accompagnant d'un instrument qui ressemble à la mandoline. Ils ne font point usage d'armes à feu, et ne se servent que rarement de chevaux. Ils élèvent une espèce de chameaux qu'ils appellent aguina, et qui est plus petite, plus svelte et plus prompte que l'espèce ordinaire. Leurs ennemis habituels sont les Arabes qui, comme eux, habitent à l'orient du Nil, mais au nord de la vallée de Koséir jusqu'à l'isthme de Suez.

Leurs femmes portent une petite jupe attachée sur les hanches, et qui ne descend que jusqu'au milieu des cuisses. Elles se parent de colliers ; mais l'ornement par excellence est, pour elles, un tatouage élégant qu'elles dessinent sur les bras et sur la partie antérieure du corps.

Habitants du Dongolah. - Le Dongolah fut, vers le milieu du dernier siècle, ruiné par les Chaykyéhs, ce qui obligea les habitants à s'expatrier; c'est pour cela que la population est si faible et la culture si négligée. Dès qu'on entre dans celte province on découvre des myriades de ces insectes auxquels on a donné, dans ce pays, le nom de gourda, et que nous appelons vulgairement fourmis blanches; c'est une espèce du genre termès. Ils détruisent tout : grains, papier, linge, et jusqu'au bois qu'ils piquent et rongent en peu de temps. Les habitants sont forcés d'élever sur des pieux, des planchers qui servent à recevoir les provisions, pour les soustraire aux ravages de ces insectes dont les phalanges innombrables, aux attaques desquelles il est difficile de se soustraire dès que descend la nuit, instant où ils quittent leurs retraites, sont un véritable fléau pour ce pays déjà si pauvre.

Les hommes se distinguent par une chevelure épaisse et touffue, et par leur costume qui se compose d'une longue chemise ou robe à manches, et d'un long collier qui descend sur la poitrine. Ils n'ont habituellement pour armes qu'une lance. Ils sont apathiques, malingres, fainéants, et ne cultivent la terre qu'autant que leurs besoins les plus impérieux les y contraignent.

L'unique vêtement des femmes est un morceau de toile dont une extrémité est portée en trousse à la ceinture, tandis que le reste se drape sur les épaules ou autour du corps.

- Quelquefois, surtout dans leur ménage, elles suppriment cette dernière partie de leur ajustement. Celles qui sont aisées ont des bracelets d'argent ou d'ivoire, souvent même en cuir garni de quelques boutons d'argent ou d'étain : elles portent quelquefois des ornements de la même forme au bas des jambes. Leur cou et leur chevelure sont aussi parés d'ouvrages en verroterie et de petites plaques d'argent. Les femmes pauvres 
se contentent de bracelets de bois ou de verre. Il est du bon ton, pour les premières, d'avoir les ongles longs et teints en rouge. Des sandales en cuir, comme celles des anciens, sont la chaussure des habitants des deux sexes : leur nourriture ne diffère pas de celle des autres Arabes.

M. Ruppel nous apprend que la démoralisation est telle dans le Dongolah qu'en général les femmes se prostituent pour de l'argent. Le maître partage le prix de la prostitution de ses esclaves.

Les Cinykýsins. - En entrant dans la province de Chaykyéh, on est frappé d'un aspect bien différent de celui que présente le Dongolah : les champs bien cultivés prouvent l'industrie et l'activité des habitants.

La tradition rapporte que cette province était, vers le milieu du xiII siècle, une république gouvernée par trois chefs principaux qui avaient sous leurs ordres trois autres chefs chargés du commandement des troupes. Trop considérable pour l'étendue de terres en culture, la population conserva des habitudes guerrières; ce qui fait que la plupart des Chaykyéhs sont presque constamment armés de leur lance. Ils sont de taille moyenne, plus robustes que les Barabras, et pleins de bravoure et de fierté. Leur arme défensive est un bouclier long et étroit en peau de crocodile ou d'hippopotame. Avant qu'ils se fussent soumis au pacha d'Égypte, ces peuples exerçaient leurs brigandages sur les caravanes qui traversaient leurs parages. Leur territoire, qui n'a pas une lieue de largeur, en a trente de longueur, et ils peuvent mettre sur pied environ 600 hommes.

Leur habillement se compose d'une sorte de jupon qui descend jusqu'aux genoux, et l'une longue pièce d'étoffe jetée sur leurs épaules; leurs cheveux, tressés à la manière des anciens Nubiens, sont rabattus sur le col et le front en une infinité de petites nattes.

Les femmes ne démentent pas l'ardeur belliqueuse des Chaykyéhs : en 1812, elles provoquèrent les mameluks, se mesurèrent avec eux, et les vainquirent parfois. En général, on les dit jolies, mais elles ont la réputation d'être fort dépravées. Leur vêtement principal consiste en une simple pièce de toile drapée autour du corps.

Habitants du Barbar ou Berber.-Le pays de Barbar a environ 20 lieues de longुueur; la plus grande partie de son étendue est en plaines dont les deux tiers environ renferment des cultures de dourah, de cotonniers et autres productions. L'arbre le plus répandu est l'acacia; mais on y voit aussi quelques palmiers. L'atmosphère y est pure. Le chameau, le bœuf à bosse et le cheval y sont assez nombreux. Les chevaux renommés du Dongolah se tirent en général du Chaykyéh et du Barbar.

Les habitants des deux sexes sont de taille élevée et bien prise; mais ils ont les jambes trop minces. Les hommes ont habituellement des cheveux courts, frisés et formant une huppe sur le devant de la tête. Ils sont armés et vêtus comme les Chaykyéhs.

Les femmes réunissent leur chevelure en tresses comme les Barabras; dans leur maison, elles n'ont qu'une toile d'un seul lé roulée autour de la ceinture et dont les extrémilés descendent un peu au-dessous du genou; mais lorsqu'elles vont dehors, elles se drapent dans cette pièce de toile. Le seul vêtement des jeunes filles est une trousse en lanières.

- Le divorce, dit Cailliaud, est une institution en vigueur chez les Barbars. Toutefois, si un homme, après avoir répudié sa femme et s'être marié à une autre, s'en repent et témoigne le désir de reprendre sa première femme, il le peut, pourvu que celle-ci y consente; un délai de quelques jours est réservé pour procéder aux formalités du second divorce : mais durant cet intervalle, la coutume autorise l'épouse rentrée en faveur à se choisir, par forme de représailles, un mari provisoire, avec lequel elle 
habite jusqu'au jour indiqué pour sa réunion avec celui qui l'avait délaissée. Il n'est point rare de voir des femmes, dans cette position, user, dans l'intérêt de leur sexe, de la prérogative que la loi leur accorde. Bien plus, si le mari par intérim paraît à une femme mériter la préférence sur l'homme dont elle a déjà éprouvé l'humeur inconstante, libre à elle d'opter; et de deux compagnes, l'époux volage se trouve n'en avoir aucune.»

Le goût du commerce et des spéculations qui y ont rapport a été répandu dans la province de Barbar par les caravanes qui la parcourent assez souvent, ce qui contribue à donner plus de valeur aux productions agricoles et manufacturières du pays. Aussi les Barbars font-ils de fréquents voyages en Égypte, où ils exportent les marchandises qu'ils reçoivent des caravanes, en échange de leurs toiles et de leurs autres produits, principalement le dourah. G'est de là, sans doute, que vient l'air d'aisance qu'on remarque dans le pays où l'on compte plusieurs personnages fort riches.

En général, les villages ne méritent pas une description; mais celui d'el-Mekheyr, situé sur la rive droite et à trois cents pas du Nil, est regardé comme la capitale du Barbar; son étendue est d'à peu près un quart de lieue. F. Cailliaud, dans son Voyage ¿ Méroé et au fleuve Blanc, en parle ainsi :

a Les maisons y sont sur trois lignes, séparées par deux larges rues; elles sont en lerre crue et n'ont en général qu'un rez-de-chaussée. Quelques-unes seulement, en partie isolées les unes des autres et éparses sans ordre et sans alignement, ont trois ou quatre pièces et sont surmontées le plus souvent de terraśses avec des conduits pour l'écoulement des pluies; une cour, enceinte de murs, est destinée aux animaux domestiques, et il y a des espèces de petites étables où, la nuit, on les met à couvert. Une ou deux pièces obscures servent de magasins pour les provisions, les vases à boire et autres ustensiles. Le luxe de la chambre à coucher consiste dans le lit conjugal : il est très-élevé et entouré de nattes de paille, quelquefois très-fines et de diverses couleurs. Une pièce est consacrée aux travaux du ménage; elle n'est souvent qu'à moitić couverte : c'est là que sont les pierres pour triturer les grains; le feu se fail contre la muraille; enfin, c'est la cuisine proprement dite. Un grand nombre de maisons ont des portes faites de pièces de bois assemblées avec des lanières, et dans lesquelles il n'entre aucune espèce de ferrure; la serrure mème est en bois et fixée de la même manière. D

Peuples du Ghendy. - Les indigènes du Chendy ont plus de méchanceté, plus de perfidie que leurs voisins les Barbars, avec lesquels ils offrent d'ailleurs beaucoup de ressemblance sous les rapports physiques et sociaux; leur teint varie du basané noir au basané clair, et leur langue est ordinairement l'arabe. Ce sont des descendants des Arabes de l'Hedjaz, des compatriotes des Chaykyéhs, avec lesquels ils forment la race des Arabes Jahelin.

La ville de Chendy, située sur la rive droite du Nil, à un demi-quart de lieue du fleuve, renferme environ 6,000 à 7,000 habitants, dispersés dans 800 à 900 maisons. Les habitations sont de forme carrée et surmontées d'une terrasse. De petites ouverlures, pratiquées dans le haut des murailles, servent de fenêtres. Les rues sont larges, assez bien alignées; mais le vent y accumule une si grande quantité de sable, que les piétons n'y circulent qu'avec peine.

- Nulle part en Nubie, dit M. Cailliaud, les mœurs ne sont aussi corrompues qu'à Chendy. Les femmes y sont l'objet d'un trafic public dont on stipule hautement les conditions dans les rues et les marchés. Les absences fréquentes que les hommes sont obligés de faire pour leur commerce, la chaleur du climat, la nudité des deux sexes, l'excès des boissons fermentées, tout tend à y entretenir le déréglement et l'exaltation des sens. Je pourrais, saus craindre d'être taxé d'exagération, évaluer au-dessous du 
quart les femmes qui conservent quelques sentiments de pudeur : la vertu mème des dames d'un certain rang n'est pas, à beaucoup près, exempte de tout reproche. 》

Le pays dont Chendy, que l'on regardait alors comme l'entrepôt principal du commerce de la Nubie, et son plus grand marché d'esclaves, était la capitale, se trouvait tributaire du roi de Sennaar, et était gouverné, depuis 235 ans, par une dynastie de princes arabes, lorsque le dernier de ceux-ci, Nimir ou Nemir, se vit, en 1821, dépossédé par Ismayl-Pacha. Voici les détails que nous avons recueillis à ce sujet. Un jour que Nimir s'était permis de faire au chef égyptien, qui avait pénétré dans la Nubie en vainqueur, quelques observations touchant une contribution de 1,000 esclaves, exigée dans les quarante-huit heures par Ismayl-Pacha, ce dernier le menaça de le faire rôtir s'il ne se soumettait à son ordre. Exaspéré par cetle menace, Nimir jura d'en tirer vengeance. Quoique privé de ses États, il n'avait rien perdu de son crédit sur ses sujets. A son retour de Sennâh, Ismayl, avec quelques-uns de ses partisans, célébrait, dans un banquet nocturne, la joie de rentrer dans son pays; l'ivresse la plus complète appesantissait ses paupières, lorsque Nimir, qui avait accumulé des matières combustibles autour de la cabane de son ennemi, le fit périr au milieu des flammes. A cette nouvelle, le pacha d'Égypte chargea un de ses généraux du soin de venger la mort de son fils. Cet ordre fut rempli de la manière la plus horrible par le général Méhémet-Bey; les habitants de Chendy furent brûlés vifs dans leurs maisons; ailleurs il fit massacrer les femmes et les enfants; le pays tout entier fut ravagé par le fer et le feu. Après ces atrocités, le pacha fit peupler Chendy par des familles de Chaykyéhs; mais il est plus facile de soulever l'insurrection que de l'étouffer, et il fallut plusieurs années pour ramener le calme parmi les habitants.

La province d'El-Ayze est peuplée d'Arabes mahométans dont les quatre tribus principales portent les noms de Djenelyes, Hassanyeh's, Hetsenats et Mohamedyens. Celles-ci habitent la rive orientale, tandis que sur l'autre rive on rencontre les MAGDyens, les Hellahouyens et quelques autres tribus. Ces peuplades nomades n'ont d'autres habitations que des cabanes de paille. Leur nourriture se compose, en général, de poissons, et leurs mœurs passent pour ètre douces.

Les Kererats, les Kenaouys, les Kenehabes et principalement les Kababychs, qui habitent le désert de Bahiouda, bornent leurs occupations à la recherche et à l'exploitation du sel gemme.

La partie orientale de l'île Meroé renferme les Choukryens et les Kaouahleh, ennemis irréconciliables des DJaLerns, dont la tribu est la plus nombreuse. Ces derniers passent pour les plus perfides des Arabes. Parmi leurs coutumes, il en existe une qui permet de racheter le sang versé moyennant une quantité déterminée de tamarin. Ce rachat assoupit, au moins pour un temps, les haines de famille. Ces Djaleyns, hommes robustes et bien constitués, se reconnaissent aisément, dans les marchés de Chendy, au large chapeau de feuilles de palmier qu'ils attachent sous le menton, et à leur barbe épaisse et courte.

La parlie connue sous le nom de royaume de Sennaar ou Sennâr, paraît être l'antique Macrobe du temps de Cambyse, laquelle, après ce prince, fut régie par douze reines et dix rois. On rapporte que l'an 1480 , une nation nègre, inconnue jusque-là, sortit du Soudan ou des rives du fleuve Blanc, et vint s'étendre sur les terres des Arabes de la Nubie. Ces peuples abdiquèrent le nom de Chillouks qu'ils portaient, dit-on, chez eux, pour prendre celui de Foungis (vainqueurs), dénomination qu'ils avaient méritée, puisque, arrivés à Arbaguy `, une victoire les rendit maîtres du pays. Après leur

1 Cette ville n'offre plus que des ruines. 
établissement en Nubie, ils renoncèrent à l'idolâtrie et embrassèrent l'islamisme. Ils obligèrent les vaincus à leur donner annuellement la moitié de leurs troupeaux. Ce sont eux qui ont bâti la ville de Sennaar, et fondé la monarchie dont le trône, occupé successivement par vingt-neuf rois, fut détruit en 1821 par le fils du pacha d'Égypte.

Les indigènes du Sennaar ont les cheveux crépus, sans ressembler néanmoins à ceux des nègres; ils n'ont pas non plus, comme ces derniers, le nez, les joues et les lèvres saillants; leur physionomie n'est point sans agrément, et leurs traits offrent une certaine régularité. Ce qui frappe en eux, c'est une étonnante diversité de nuances dans le teint et la couleur, ce qui vraisemblablement a pour cause le mélange du sang arabe avec celui des nègres et des Éthiopiens.

Ces peuples se divisent eux-mèmes en six races, qu'ils désignent par les noms suivants : el-asfar (les moins colorés) sont des Arabes venus primitivement du Hedjaz; el-hamar (les rouges) sont originaires du Soudan; et les moins nombreux, el-Soudan. azrak (les bleus) sont les Foungis : leur teint est plutôt cuivré que noir ; el-ahcdar (les verts) ont les cheveux comme ceux des Foungis, mais leurs traits se rapprochent beaucoup plus de ceux des nègres. On donne le nom de $e l$-kat-Fatelolem à une race qui tient de la première et de la quatrième, c'est-à-dire qui sont à demi jaunes et à demi verts; le sang qui domine en eux est celui des Éthiopiens, c'est-à-dire de la race la plus nombreuse dans l'ancienne Égypte. Enfin les Ahbits, Ahbd ou Nouba, sont des peu= plades nègres venues de l'ouest, et qui vivent isolées dans les montagnes du pays de Bertât.

Les hommes sont de haute taille, robustes et bien faits; les femmes sont belles et conservent longtemps leur fraicheur et leurs charmes. Nais si leur physique est digne de louanges, il n'en est pas de même de leurs mœurs : les Sennaariens sont fourbes, dépravés, et adonnés à la superstition quoique témoignant fort peu de zèle à l'endroit de la loi mahométane. Ils sont tellement enclins à la débauche et dépourvus de propreté, que les maladies honteuses y font de grands ravages et sont héréditaires dans les familles.

L'habitude de fumer est commune aux deux sexes, mais plus parliculièrement aux femmes, qui font preuve d'une soumission servile envers leurs maris. On a observé qu'un des points les plus importants de leur toilette est celui-ci : elles se frottent longtemps de la tête aux pieds avec du beurre ou de la graisse de chameau; puis elles restent environ une heure exposées, sous une grande pièce de toile, à la fumée de copeaux odorants que l'on fait brùler sans flamme... C'est là une manière de se parfumer qui, nous le pensons, serait peu goûtée en Europe.

Le costume des Sennaariens ne diffère presque point de celui des indigènes du Barbar ou du Chendy. De même que les Chaykyéhs, les militaires n'ont pour armes que la lance, le sabre à deux tranchants et le long bouclier en peau de crocodile ou de rhinocéros. On remarque quelques cavaliers qui portent des cottes de maille et une espèce de casque qui, à vrai dire, n'est autre chose qu'une calotte en fer.

Ces peuples se nourrissent principalement de dourah, et leur boisson la plus habituelle est la bulbul et la méryse, espèces de bière qu'on obtient au moyen de la fermentation de la graine du dourah.

Les maisons sennaariennes offrent beaucoup d'analogie avec les ruches; elles consistent en de petites enceintes circulaires faites en pièces de bois et en terre, sur lesquelles on pose la toiture qui se compose d'un grand chapeau formé de cercles de différentes grandeurs.

Ces indigènes sont adonnés au commerce et à l'agriculture.

Outre que leur pays est l'entrepôt de toutes les marchandises que l'on tire de l'intéAFRIQUE. 
rieur de l'Afrique et que les caravanes y apportent, les Sennaariens expédient en Égypte des esclaves, du tamarin, de l'ivoire, des cornes de rhinocéros, des plumes d'autruche, de la civette, de la gomme, de l'encens, du séné, et des outres en peau de bœuf qui servent à porter l'eau sur les chameaux. Ils prennent en échange des toiles, des lames de sabre, du savon, du sucre, du riz, du papier, du girofle, du poivre, des rasoirs, de petits miroirs, et d'autres objets de quincaillerie.

La monnaie d'argent qui a cours dans le pays est la piastre d'Espagne; mais les achats se font généralement à l'aide du dourah : tout s'évalue en mesures de cette espèce de céréale. La mesure de longueur est le dera, qui signifie bras; elle équivaut à l'étendue comprise entre le coude et l'extrémité de la main, à laquelle on ajoute les quatre travers de doigt de l'autre main. Ce qu'il y a de remarquable, c'est que cette mesure est exactement conforme à l'ancienne coudée égyptienne, dont la longueur est de 52 centimètres, et qu'elle porte le mème nom.

Leur industrie n'est pas très-avancée; cependant ils travaillent le fer dont ils fabriquent des clous, des couteaux, des lances et quelques instruments très-simples pour le menuisier, qui cumule avec ce métier ceux de tourneur et de charpentier. L'état d'arpenteur ne demande pas des connaissances bien profondes : celui qui cullive cet art, mesure une pièce de terre en jetant une pierre qu'il lance de toute sa force. Au reste, on n'y regarde pas de si près dans un pays où les terres, presque toutes en friche, ne présentent qu'une valeur fort minime.

Au Sennaar, on ne fait point usage de la charrue : pour se livrer à l'opération du labour, les naturels attendent l'époque où elles sont imprégnées de l'eau des pluies, et se servent d'une espèce de houe. C'est au mois d'août qu'on sème le dourah, et la récolte a lieu trois mois après. Comme chez les anciens Égyptiens, on ne coupe ici que l'épi : la tige de la plante demeure en terre où on la coupe à mesure que cela devient nécessaire pour la nourriture des bestiaux. Lorsqu'on veut en extraire la graine, les épis du dourah sont foulés aux pieds par les bœufs. On conserve ensuite le grain dans des fosses enduiles d'argile.

Ici, comme dans le Barbar, la principale occupation des femmes est de trilurer le dourah, et d'apprèter le pain et la boisson. Elles font aussi des tissus de paille et des naltes très-fines sur lesquelles on couche, et qui servent encore d'ornements dans l'inlérieur des habitations.

On fabrique aussi de larges toiles de coton appelées dammour, des vases grossiers en terre, et d'autres en calebasses que l'on nomme garahs.

La capitale de la province est Sennaar : c'est une ville à laquelle M. Cailliaud donne 9,000 habitants, mais dont les ruines annoncent qu'elle fut autrefois plus considérable. Sa forme est oblongue et présente une circonférence de plus de trois quarts de lieue d'étendue. On ne peut donner le nom de maisons à des cabanes couvertes en chaume, dont quelques-unes seulement ont un étage et une terrasse en mauvais élat. Au centre domine l'ancienne résidence du roi, construction en briques cuites, élevée de quatre élages, et qui est inhabitée comme ses dépendances. Une mosquée contiguë à ce palais, et assez bien conservée, est le seul édifice consacré au culte.

\section{ANNEXES DE LA NUBIE.}

Le Dâr-el-Keyl (province des chevaux), et le Kamamyl, au sud du précédent, sont deux districts dont les habitants appartiennent à la race nègre. Le dernier passe pour le plus riche en sables aurifères; les indigènes en retirent par le lavage des paillettes 



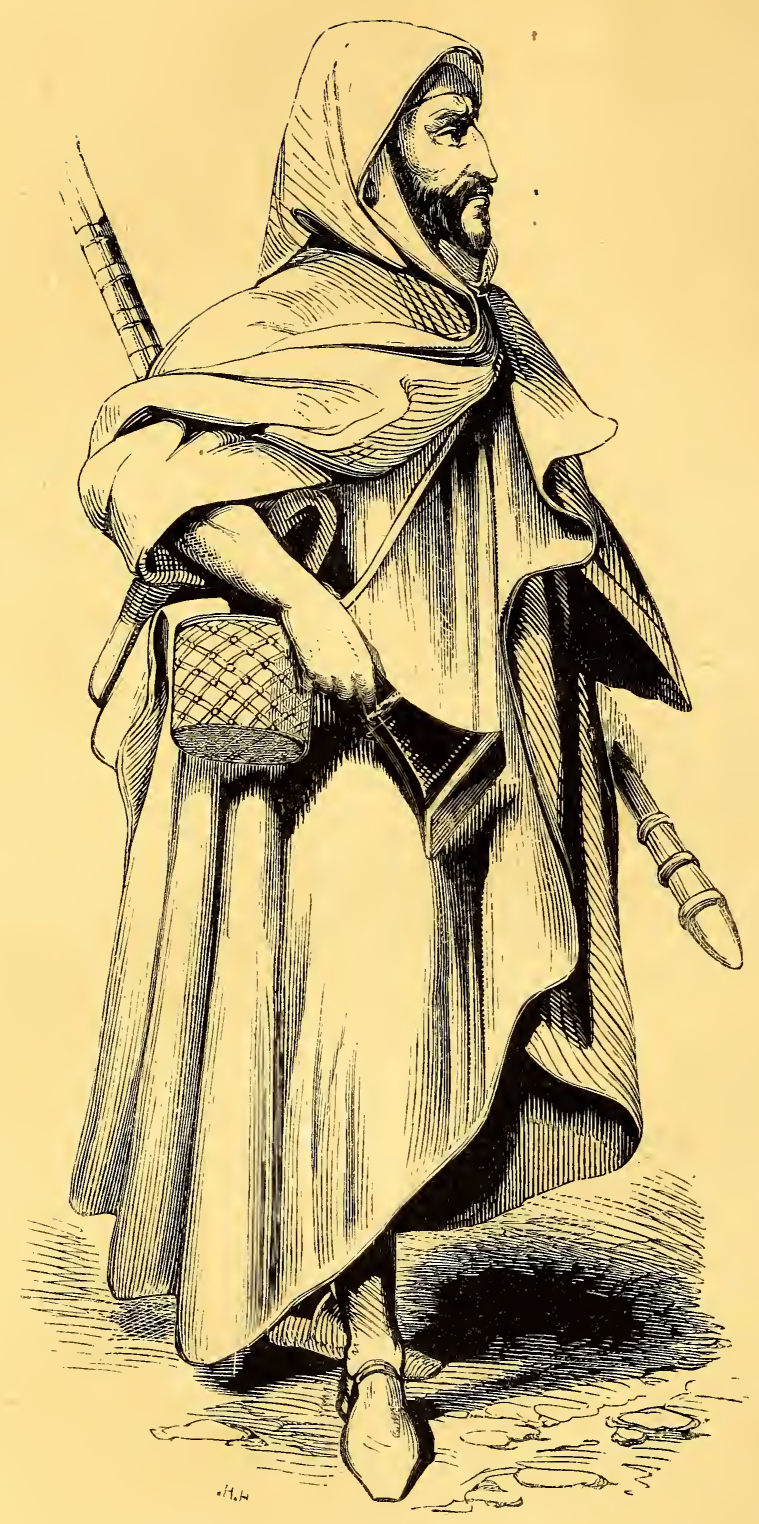

Arabe Bedouin.

(Afrique.) 
d'or qu'ils placent dans des tuyaux de plumes, et qu'ils vendent aux Arabes; ceux-ci en font des anneaux qui circulent dans le commerce.

Les nègres qui occupent le pays de Denka, sur la rive droite du Bahr-el-Abiad, méritent une mention particulière. Ils sont bien faits, vigoureux et vont dans un état complet de nudité. Ils paraissent adorer les astres. Leur courage et leur nombre en font des ennemis redoutables à leurs voisins. Leurs armes sont des lances très-lourdes, garnies d'un fer long d'un pied et demi, et d'une largeur de trois pouces; une massue grosse d'un bout, pointue de l'autre, qu'ils lancent à une distance assez éloignée, de manière que l'une des extrémités atteigne le but qu'ils ont choisi. Ils emmanchent encore sur des bâtons des cornes droites et pointues, et des dards en fer.

Les femmes sont d'une fécondité remarquable; elles mettent ordinairement au monde deux enfants à la fois. On voit assez communément une mère allaiter un enfant, en porter deux ou trois sur le dos dans une espèce de havre-sac en cuir, et être suivie d'un autre qui marche à peine.

La coiffure distinctive du chef est un turban blanc orné d'un panache en plumes d'autruche; les femmes s'enveloppent d'une peau dont la forme est celle d'un jupon court; les jeunes filles ne mettent d'antres vêtements qu'une peau qui ne couvre que la chute des reins et s'attache par devant. Les personnes âgées portent une clochette suspendue au bras; et ce qui est plus étrange, c'est que les enfants des familles riches portent cette clochette attachée au derrière.

Suivant leur aisance, les femmes, et surtout les filles, se parent d'un nombre plus ou moins considérable de colliers et de ceintures en verroterie, de boutons et de bracelets d'ivoire ou de fer, et de bagues de ce métal. Lorsque les enfants sont parvenus à l'âge de puberté, on leur arrache les quatre dents incisives inférieures, qui, suivant ces nègres, sont inutiles et déparent la figure. Les hommes et les femmes se rasent la tête; les uns et les autres s'épilent tout le reste du corps. Le nombre de femmes que peut prendre un homme est proportionné à sa fortune. Le jour des noces, les nouveaux époux se couvrent le corps et la figure d'une couche épaisse de graisse; ils sortent de la cabane conjugale pour faire fondre cet enduit à la chaleur du soleil, et pour se frotter. Ces frictions ne sont pas seulement salutaires, elles sont pour les hommes une jouissance, et pour les femmes une affaire de coquetterie. Lorsqu'un nègre devenu vieux a des femmes jeunes encore, il confère à son fils le soin de le suppléer auprès d'elles.

Laissant de côté une foule de petites peuplades dont on ne connaît guère que le nom, nous terminerons la description des peuples nubiens par celle des habitants du Kourdofan.

Ruppel a reconnu trois races différentes d'individus dans ce pays : les NoubaHs (nègres), qui sont indigènes, et dont le chef siége à Obéid; les Dongolars, qui s'établirent à diverses époques dans cette province; et enfin, les Arabes-Bédouins.

Les Noubahs sont, en général, agriculteurs; ils élèvent des chameaux, des bœufs, des troupeaux de moutons et de chèvres, et se montrent fort adroits dans la préparation du cuir. Chacun de leurs villages a son chef, dont la dignité paraît se transmettre par voie d'hérédité. Quatre langues sont en usage parmi eux : le chaboun, le dë̈er, le koldagi et le takèle; chacune de ces langues est divisée en plusieurs dialectes.

Les nègres des montagnes sont partagés en une multitude de peuplades, dont chacune occupe communément une seule hauteur ou un groupe de montagnes. Leur taille est ordinairement bien prise et de hauteur moyenne; ils ont les cheveux laineux, le nez court et les lèvres épaisses.

Ces hommes se couvrent de boucliers en cuir; ils fabriquent eux-mêmes des sabres 
courbés, et lancent avec adresse leurs javelots dont la pointe est empoisonnée.

La coutume adoptée par les femmes de porter leurs enfants sur les reins nuit beaucoup à leurs formes, et leur donne cette protubérance qui distingue les Hottentotes. Les objets de parure qu'elles recherchent sont des bracelets d'ivoire et d'émail.

L'islamisme est suivi par quelques peuplades du sud; les autres sont livrées au paganisme et déifient la lune : tous néanmoins croient à une seconde vie.

Ces peuples ont généralement une existence paisible et heureuse; mais l'insuffisance des récoltes apporte souvent le trouble et le désordre dans les familles. La misère alors cnfante des maux cruels : les mères vendent leurs enfants; les frères cèdent leurs sœurs pour quelques mesures de dourah.

Selon M. Ruppel, c'est à la disette seulement qu'il faut attribuer l'esclavage : a Tant que les progrès de la civilisation, dit-il, n'auront pas enseigné aux Africains à prévenir la famine, il est à craindre que la traite des esclaves ne dure.,

Les Dongolais sont surtout adonnés au commerce; ils parlent le berber et l'arabe, et les Noubahs leur fournissent presque toujours des épouses.

Autrefois, les Arabes du Kourdofan comptaient douze tribus; mais le despotisme égyptien les réduisit à sept, qui portent les noms suivants : Derihamat, el-Giomme, Habanie, Hemasmé, Liserra, Hammer et Mousirir. On a donné aux cinq premières, qui habitent au sud d'Obéid, le nom général de Bakara (bergers), parce qu'elles se livrent presque exclusivement à l'élève du bétail.

Tous ces Arabes font la chasse aux éléphants, qui se montrent par troupeaux durant la saison pluvieuse. En temps de guerre, ils se revêtent de casques, de cottes de maille et de brassards en fer. On voit même certains chefs couvrir leurs chevaux d'une housse en maille, usage que nous verrons se renouveler dans plusieurs contrées de l'Afrique.

Les marchands du Kourdofan tirent du Dar-four de l'encens, du tamarin, du natron qu'ils vont vendre en Nubie, ainsi que des cordes en cuir, des sacs de peau, des outres, des vases en bois, des plumes d'autruche et des esclaves. En échange, ils rapportent des verroteries, des aromates, des clous de girofle, du café, de la toile d'Égypte, des tissus de coton et de soie.

Pour le commerce intérieur, le dourah et les étoffes fabriquées dans le pays sont employés comme moyen d'échange; mais pour les petits achats on fait usage d'une monnaie en fer, qui est appelée haschaseh, et qui a presque la forme d'un marteau. 


\section{ABYSSINIE.}

On ne saurait indiquer avec précision la situation de cette vaste contrée qui occupe la limite septentrionale de l'Afrique, et dont les bornes ne sont fixées que par le sort toujours incertain des armes. Toutefois nous donnerons ici les limites qui lui sont attribuées par la carte de Salt :

L'Abyssinie est comprise entre $9^{\circ}$ et $15^{\circ} 40^{\prime}$ de latitude nord, et entre $33^{\circ} 40^{\prime}$ et $41^{\circ}$ de longitude est; elle confine : à l'est au golfe d'Aden et à la mer Rouge; au nord au Sennaar (Nubie); à l'ouest au pays des Chilouks; au sud à ceux des Gallas, des Samanlys et au mont Tchakha (prolongement des monts de la Lune).

Les forêts, les lacs, les vallées profondes et les rivières de ce pays produisent un immense tableau d'une magnificence sauvage; et si les voyages y sont périlleux, ils offrent aussi bien des charmes par la variété des scènes pittoresques qui se déroulent à chaque pas aux yeux de l'observateur.

Les montagnes sont peu élevées; on ne découvre de la neige que sur celles du Samen dans le Tigré, et sur celles de Naméra dans le Godjam; les monts Fanaches sont les plus élevés et les moins inaccessibles; les plus petits sont ceux d'Amhara.

Le climat de l'Abyssinie est moins chaud que sa position géographique ne semblerait l'indiquer; ce qu'il faut attribuer à la multiplicité des rivières, à l'abondance des pluies et à l'élévation du sol. L'hiver, ou plutôt la saison des pluies, dure depuis avril jusqu'en septembre : pendant les autres six mois où le soleil est vertical et le ciel sans nuages, la chaleur du jour devient insupportable. Sur les bords de la mer Rouge, entre les montagnes et la côte, la saison des pluies commence quand elle finit dans le reste de l'Abyssinie.

Quoique ni Bruce ni Salt n'indiquent des mines dans l'Abyssinie, il est probable que les montagnes renferment des métaux. Le premier des auteurs que nous venons de citer, parle d'or très-fin qui se trouve dans les provinces occidentales, au pied des montagnes de Dyre et de Tegla.

Indépendamment du maïs, de l'orge et du blé, on trouve encore en Abyssinie un autre grain nommé teff, graminée du genre des poa, dont ils font un pain blanc, léger, et facile à digérer. Le teff réussit dans tout le pays, quelle que soit la qualité du terrain. Lorsqu'on a réduit ce grain en farine, dans un moulin de pierre, on en fait des gâteaux fort estimés du peuple, et que le roi lui-même ne dédaigne pas. L'enselé est une espèce de bananier qui fournit un aliment précieux pour les indigènes. On recueille communément deux moissons en Abyssinie, et même trois dans certains cantons. La vigne n'y est pas étrangère; mais on y fait peu de vin, parce que les naturels préfèrent une espèce d'hydromel. Les jardins offrent plusieurs espèces d'arbres fruitiers et de légumes : des plantes oléagineuses inconnues en Europe croissent en abondance dans les champs : enfin, l'atmosphère est embaumée de l'odeur suave qu'exhalent les roses, les jasmins, les lis et les æillets. 
Nous ne pouvons donner une nomenclature de tous les animaux qu'on rencontre en Abyssinie; nous dirons seulement que nulle part ils ne sont ni plus nombreux, ni plus variés.

S'il nous fallait écrire en entier et dans ses moindres détails l'histoire de l'Abyssinie, ce ne sont point quelques pages qui seraient suffisantes; aussi nous bornerons-nous à indiquer quelques faits, quelques époques mémorables.

Il est à remarquer d'abord qu'à partir de la huitième année du règne de Brazen (laquelle coïncide avec l'année de la naissance de Jésus-Christ) jusqu'à la quatorzième du règne d'Abreha (époque présumée de l'introduction du christianisme en Abyssinie), le nombre des années des règnes intermédiaires entre ces deux monarques s'élève à 350 , nombre égal à celui des années qui, suivant les chroniques indigènes, séparent ces deux événements. Quelques historiens prétendent que les Axoumites n'embrassèrent la foi chrétienne que du temps de Constantin le Grand, sous le règne d'Abreha que nous avons nommé plus haut; s'il en est ainsi, ce dernier souverain n'est pas le même qui, pen de temps avant la naissance de Mahomet, conduisit une armée nombreuse d'Abyssiniens contre la Mecque, et dont la défaite miraculeuse faisait époque parmi les anciens Arabes. Quoi qu'il en soit, il paraît que, dès le Ive siècle de l'ère vulgaire, la puissance des empereurs abyssiniens était bien établie, et qu'ils avaient porté leurs armes victorieuses dans une partie de l'Arabie, et depuis Zeilah jusqu'à la jonction du Nil et du Tacazze.

Vers l'an 550 ou 540 de notre ère, des missionnaires chrétiens revinrent en Abyssinie pour ranimer le christianisme qui allait s'affaiblissant. A peu près dans le même temps, El-Eschaas, roi des Axoumites, soumit une partie de l'Yémen; mais soixante ou quatre-vingts ans plus tard, les Abyssiniens durent abandonner le territoire del'Arabie, devant les Persans, qui les repoussèrent au delà de la mer Rouge, et étendirent même leurs envahissements jusque sur une grande partie de la rive africaine de cette mer.

C'est au séjour plus ou moins long des Persans dans cette contrée, qu'il faut attribuer l'introduction d'un assez grand nombre de mots de leur langue dans celle des Alyssiniens. On ne sait pas bien précisément combien subsista la domination des Persans en Abyssinie, mais on a tout lieu de croire qu'elle fut anéantie par les fanatiques et invincibles musulmans, qui portèrent le Coran, leur langue et leur écriture, dans les contrées les plus barbares et les plus reculées de l'Afrique. Leurs montagnes et la disposition physique de leur pays préservèrent de ce fléau les Abyssiniens qui purent même conserver leur religion.

Les expéditions des croisades parvinrent sans doute à la connaissance des Abyssiniens, puisque tous les ans une multitude d'entre eux s'y rendait; cependant la haute noblesse sut les en détourner, et à la place des pèlerins on fit partir un évêque, qui, en revenant, tomba entre les mains des musulmans; ceux-ci lui imposèrent, par la force, la circoncision, circonstance qui amena, vers la fin du xiIr ${ }^{\mathrm{e}}$ siècle, une guerre terrible entre les Abyssiniens et les Mores, et dont le souverain de l'Abyssinie profita pour agrandir ses États.

Du $x^{\prime}{ }^{e}$ au $\mathrm{xv}^{\mathrm{e}}$ siècle, les rois abyssiniens entretinrent constamment des relations avee l'Europe.

En 1439, l'empereur Zara Yacob envoya un ambassadeur au concile de Florence, et écrivit des lettres remarquables à ses prêtres de Jérusalem. Les rapports avantageux que ces prêtres abyssiniens firent de leur pays et de son commerce avec le sud de l'Afrique, engagèrent les Portugais à envoyer des émissaires en Orient pour y faire des découvertes. C'est ainsi que le cap de Bonne-Espérance fut doublé, et l'Inde découverte : ces expéditions par terre et par mer procurèrent aux Européens une connaissance plus 
positive de l'Abyssie. Pierre Gorilhan, un des agents portugais, parvint, en 1490, à la cour du négus, ou roi d'Abyssinie, qui résidait alors dans la province de Choa, et détermina l'iléghé, ou reine mère, à envoyer une espèce d'a mbassadeur à la cour de Portugal. Cetle démarche produisil une grande sensation dans toule l'Europe; la cour de Portugal y répondit par une magnifique ambassade, et quelques années après envoya à l'empereur d'Abyssinie, d'après ses propres sollicilations, un corps de 400 hommes avec une grande quantilé d'armes pour l'aider à repousser les altaques d'un féroce musulman qui régnait sur le royaume d'Arras ou Harrar, situé à l'est de la province de Choa. Les Portugais parvinrent en effet à délivrer l'Abyssinie de son mortel ennemi; mais le zèle immodéré que leur chef montra pour ramener l'empereur dans le giron de l'église catholique, le fit tomber dans la disgrâce de ce monarque. Il perdit même la confiance de ses propres compatriotes, qui finirent par refuser de lui obéir. Différents missionnaires catholiques profitèrent du séjour des Portugais en Abyssinie pour s'y introduire; mais à la fio du $x_{v 1}{ }^{e}$ siècle, l'Abyssinie devint de plus en plus inaccessible par la conquête que les Turcs firent des places littorales de Suakem et de Massouah, et par les incursions des Gallas. Cependant des ecclésiastiques y pénétrèrent encore isolément de temps à autre. C'est ainsi que s'y introduisit en 1599, déguisé en faquir, ou moine musulman, le moine catholique Melchior de Sylva, qui resta dans le pays jusqu'à l'arrivée du P. Paez, en 1603. Celui-ci, doué de plus de talents que tous les autres, s'acquil une grande influence à la cour d'Abyssinie, et atteignit le but des jésuites, qui élait de faire embrasser à l'empereur el à sa famille la religion catholique romaine, et de les soumeltre au siége de Rome. Cependant l'empereur Socinius abjura la religion catholique; el son fils, qui lui succéda bientôt, chassa en 1652 le patriarche avec toute sa suile, à l'exception de deux individus qui furent mis à mort, parce qu'ils avaient osé rester : cet événement se passait en 1640. En 1648 et en 1679 , d'autres missionnaires de la propagande eurent un destin pareil, et reçurent, à Suakem, la palme du martyre!

Pendant une période de cent quatorze années, on vit se soutenir la lutte entre les souverains qui avaient embrassé le catholicisme, et les sujets qui ne voulaient pas abandonner l'hérésie d'Eutyches, que leur avaient transmis leurs ancêtres. L'Abyssinie ne jouit de quelque calme que depuis l'expulsion des jésuites. Ce fut alors que la résidence de l'empereur, qui avait élé successivement à Coja, à Ibaha, à Gorgora, à Aukeber, à Dancaz et en d'autres lieux, fut tranférée à Gondar, où elle est toujours restée depuis, et la cour impériale recouvra une partie de son ancienne splendeur.

A l'époque où Salt visita l'Abyssinie, elle était partagée en trois Élats indépendants les uns des autres : le Tigré, l'Amhara et les deux provinces réunies d'Efat et de Choa. Depuis, elle a été divisée en six provinces ou ràs qui ont reçu le nom de royaumes, gouvernées chacune par un chef indépendant; ce sont les royaumes d'Hururgué, de Tigré, de Lasta, d'Amhara, de Semen el de Choa. Ces princes sont en guerre ouverte et continuelle les uns contre les autres; et comme il est vraisemblable que l'un d'eux, vainqueur de tous les autres, rendra à l'Abyssinie son ancienne unité, nous suivrons dans la description de ce pays les premières divisions que nous avons indiquées.

La partie la plus au nord-esı de l'Abyssinie, el qui répond à l'ancien royaume de Tigré, est habilée par une race d'hommes sanguinaires, féroces, perfides et corrompus.

Trois provinces avoisinent, à l'ouest, le Tigré; ce sont: Ouodjerat, Siré et Sémen. Si la première est un des greniers de l'Abyssinie, la seconde doit à ses plaines humides la quantité de palmiers el autres arbres fruitiers qui y croissent; on remarque dans la troisième plusieurs chaînes de montagnes : les principales sont le Lamalmon et l'Amba-Gidéon. Ce dernier, plateau escarpé, presque inaccessible de tous points, mais 
vaste et assez fertile pour subvenir aux besoins d'une armée, était la forteresse des Falasjan ou Falasyan ${ }^{x}$, juifs abyssiniens, jadis maîtres de la province de Salem.

Selon l'opinion du savant Marcus, c'est entre les années 643 et 830 avant notre ère que les juifs établirent leur colonie. Il paraît qu'à l'époque de la conquête de la Judée par Nabuchodonosor, vers l'an 596 avant Jésus-Christ, un grand nombre d'habitants se réfugièrent en Arabie et en Égypte, d'où ils purent passer en Abyssinie. Dès le temps d'Alexandre le Grand, ces juifs portaient dans ce pays le nom de Fulasjan. Ils y ont conservé jusque dans ces derniers temps leur langue, leur religion, leurs lois, leurs mœurs, el, ce qu'il y a de plus remarquable, leur indépendance. Lorsque Bruce visita l'Abyssinie, ils étaient assez nombreux, selon lui, pour pouvoir mettre sur pied une armée de 50,000 hommes : il paraît cependant que depuis l'année 1800, la partie du Samen qu'ils occupent est devenue une dépendance du Tigré.

Ces hommes ont le teint brun olivâtre assez foncé, le nez courbe, les lèvres moins bordées que celles des Gallas, le front saillant, l'ovale de la tête rétréci à la partie inférieure; l'ensemble de leur physionomie est peu agréable. Ils ne font preuve ni de force ni de courage.

Afin d'éviter tout contact avec des étrangers, ils n'ont recours qu'à eux-mêmes pour confectionner leurs vêtements et leurs instruments de travail. Ils confient les travaux aģricoles et la surveillance de leurs troupeaux à des esclaves chrétiens. L'industrie métallurgique et la construction paraissent être leur spécialité; ils fabriquent les fers de charrue, les haches, les couteaux, les sabres, les fers de lance, etc.; ils construisent les maisons et les églises, ce qui leur a valu la protection des princes abyssiniens.

La province d'Amhara ou Gondar est peuplée d'une race d'hommes que l'on dit les mieux partagés de l'Abyssinie en bravoure et en beauté. M. Coffin évaluait, en 1814, à 20,000 âmes la population de Gondar, résidence royale et chef-lieu de la province. Les maisons de cette ville sont construites, les unes en torchis, les autres en pierres rouges, et n'ont qu'un toit de chaume. On y compte quarante et une églises chrétiennes, dont la principale, qui porte le nom de Quosquum, est construite avec beaucoup de luxe et a des murs tapissés de soie bleue, et ornés de glaces. L'un des quartiers de la ville est habité par des mahométans.

Les Camaountes, petit peuple païen, habitent au milieu des montagnes qui environnent Gondar. On ne connaît rien de la religion de ce peuple, dont la langue est l'ambarique. Les hommes ne viennent que rarement à Gondar; les femmes y apportent du bois le samedi; elles ont d'immenses pendants d'oreille de fer ou de tout autre métal, ce qui rend leurs oreilles si longues qu'elles tombent jusque sur leurs épaules.

Le Gojam, qu'entoure le Nil, ce qui lui donne l'apparence d'une grande presqu'île, est un des plus beaux pays de la contrée que nous décrivons. Certains auteurs prétendent que la population, qui vit dans les montagnes où le Bahr-el-Azrak prend sa source, est autochthone, et qu'elle n'a janais subi aucun mélange avec les autres Abyssiniens. Les femmes sont remarquables par leur beauté.

La petite province de Maїсна ou Maїтсна, autrefois habitée par des Agaous, l'est actuellement par des Gallas qui ont embrassé la religion et les mœurs abyssiniennes.

Les Galfates habitent la province de Damiet; ils parlent une autre langue que les Abyssiniens.

Les individus qui peuplent le royaume de Choa sont ceux qui ont le mieux conservé dans toute leur pureté, l'ancienne civilisation et la littérature éthiopienne. Les pro-

1 Ce nom signifie exilé. 
vinces les plus méridionales se trouvent, pour la plupart, dans la dépendance des féroces Gallas; on cite surtout les royaumes d'Angot et une partie de celui de Narea. Les habitants de ce dernier sont d'une couleur moins foncée que les Siliciens, selon Bruce; d'autres voyageurs réfutent cette opinion et assurent que les Naréens sont seulement moins bruns que les Abyssiniens.

On voit, d'après l'esquisse topographique qui précède, combien la population de l'Abyssinie est mélangée. Aussi, faisant abstraction des habitudes particulières à chacune de ces peuplades, nous ne pouvons que décrire les mœurs générales des Abrssiniens proprement dits, ou, comme ils s'appellent entre eux, des Agazians.

Les Abyssiniens ont la taille élevée, bien prise, les membres vigoureux, les cheveux longs, la barbe rare, les traits du visage se rapprochant de ceux des Européens. Toutefois, ils se distinguent des autres peuples connus par une teinte qui leur est propre, et que Bruce compare tantôt à l'encre pâle, tantòt au brun olivâtre, tandis que les Français de l'Institut la rapprochent du bronzé. Au reste, on peut remarquer chez ce peuple des nuances assez tranchées : selon l'Anglais Pearce, cenx des plateaux élevés ont la peau claire, ceux du Tigré sont presque blancs; au contraire, ceux qui habitent les contrées marécageuses sont noirs, ou presque noirs. Cette dernière nuance paraît c̀tre regardée comme un trait de beaulé, puisque ceux qui ont la peau claire la noircissent en la tatouant.

La défiance et les obstacles physiques séparent les Abyssiniens de l'Europe; il en résulte pour eux un isolement au milieu de peuples mahométans ou païens qui empèche à la civilisation de faire des progrès, malgré l'esprit et les talents naturels dont ils sont doués. Comme on le verra dans notre Histoire et Cérémonies religieuses, trois partis religieux divisent l'Abyssinie, et ne contribuent pas peu à augmenter l'anarchie qui déchire ce pays.

L'Abyssinie n'est plus aujourd'hui cette contrée gouvernée par un prince qui prenait le titre de négous nagast za Ithyopya (roi des rois d'Éthyopie) : parmi les chefs qui prennent celui de roi, il en est bien qui reconnaissent en apparence l'autorité du grand négous, mais qui, de fait, déposent à leur gré un monarque qui n'a point d'armée et dont ils règlent à volonté la liste civile. Ces monarques, despoles absolus, vendent les gouvernements à des subalternes non moins despotes. Le vizir ou premier ministre est appelé ras. La noblesse se compose des descendants de la famille royale dont le nombre s'accroîl singulièrement par la polygamie que le culte défend et que l'usage maintient. Les princes qui peuvent avoir'des prélentions au trône sont tenus en prison; et tandis que quelques auteurs nous apprennent que le droit de propriété est à peu près nul, d'autres nous parlent de l'existence d'une espèce de magistrat chargé de taxer les récoltes et de fixer la redevance du fermier envers le propriétaire, mesure qui supposerait des égards pour le peuple. Ce qui parait plus certain, c'est que la justice est aussi prompte que harbare. Il y a des tribunaux formés de douze assesseurs, présidés par un juge, et dont les séances ont lieu en plein air.

Les revenus du roi consistent en fournitures de grains, de fruits, de miel; les tributs en or sont rares et peu considérables.

L'armée, payée par des concessions de terres, s'élevait autrefois à 40,000 hommes, dont 4,000 cavaliers. Quelques soldats ont de courts fusils dont ils font usage en les appuyant sur un pieu. La bravoure de ces hommes n'étant point dirigée par la tactique, n'a guère d'autre résultat que de les faire massacrer en plus grand nombre. La victoire les rend féroces, et dans leurs triomphes peu fréquents, ils portent en trophée les parties naturelles de leurs ennemis morts.

Les habitations sont des cabanes rondes, avec un toit dont la forme conique est 
nécessité par la violence des pluies. Celles des chefs se composent de plusieurs corps de logis.

Les Abyssiniens sont d'un naturel excellent et enclins à la piété; ils on t moins de vices que les Européens, mais on ne peut en dire autant des habitants du royaume de Tigré, qui sont très-vindicatifs, surtout pour cause d'homicide. Au reste, les divers auteurs qui ont parlé du caractère de ces hommes ne sont pas tous d'accord sur ce point, et il y a une telle divergence d'opinions entre les voyageurs qu'il y aurait témérité à porter un jugement définitif.

Ces peuples sont rigoureux observateurs des règles de la civilité et de leurs devoirs. En général, lorsqu'ils se présentent au ras, ils se découvrent jusqu'à la ceinture; il en est d'autres qui ne mettent que la poitrine à nu et replacent aussitôt leur vêtement; il ne leur est permis de s'asseoir qu'après les premiers mots échangés. Dans les réunions particulières, tous sont assis en cercle, et confondus sans distinction de rang. Ils se témoignent réciproquement des sentiments affectueux et sont remplis d'égards les uns envers les autres. La manière de se saluer entre égaux consiste à se baiser la main et à se répéter plusieurs fois le même compliment.

Les Abyssiniens font preuve d'une indolence orgueilleuse jusque dans leur manière de manger. Les grands seigneurs se font mettre dans la bouche les aliments grossièrement apprêlés dont leur table est couverte. Après de nombreuses discussions, il paraît certain que les viandes crues avec une sauce de sang frais, au lieu de répugner aux Abyssiniens, excitent leur appétit. Ces viandes sont servies sur un gâteau apprêté par les femmes avec du froment ou autres grains, et qui leur sert en même temps de serviette. Les aliments liquides se servent dans des vases de terre noire à couvercles de paille. Comme leurs doigts remplacent la fourchette, les Abyssiniens ont la coutume fort louable de se laver les mains avant de se mettre à table. Leur principale boisson, appelée maïz ou boriza, est une espèce de bière qui anime la sauvage gaieté de leurs festins. Les deux sexes s'y livrent publiquement, sinon à la débauche, au moins à des plaisanteries qui pèchent par une grande licence.

Les rois et les ras ont auprès d'eux des bouffons qui plaisantent tout le monde, el des poëtes qui n'ont d'autres moyens d'existence que de réciter ou d'improviser des vers pendant les soirées ou veillées. Il y a même des Corinne : Pearce cite une femme qui s'était adonnée de bonne heure à l'étude de la poésie, et qui était parvenue à une grrande célébrité. Elle allait aux veillées, non pour aucun salaire, car elle était riche, mais pour accroître sa réputation.

Les hommes n'ont qu'une épouse légitime, ce qu'il est aisé de comprendre, car le mariage n'est qu'un lien civil, facile à rompre, et qui ne reçoit aucune sanction religieuse. Cependant les gens à qui leur fortune le permet, entretiennent des concubines, quoique la religion désapprouve ces déréglements. Ce qui doit surprendre après ce que nous venons de dire du mariage, c'est que celui qui manque à la foi conjugale est repoussé de sa communion : c'est là un non-sens étrange, puisque le mariage n'est pas consacré.

A la mort d'un individu, fût-il étranger, tous les voisins témoignent une grande douleur, et s'empressent d'apporter chez le plus proche parent du défunt, des provisions de bouche en quantité considérable, d'où il résulte que l'ivresse ne tarde pas à remplacer les témoignages d'aflliction dont on faisait parade une heure auparavant. L'enterrement ne coûte rien : ce sont les voisins qui aident à creuser la fosse. Mais, en revanche, les prêtres font payer cher les prières des morts : on a vu des familles entières ruinées pour se conformer à l'usage qui veut que les prêtres reçoivent pendant six mois, à titre de salaire, les viandes et le maïze nécessaires à leur consommation. 
Pearce rapporte que deux ecclésiastiques se disputèrent la robe d'une pauvre femme, seul objet passable qu'elle eût encore après sa mort.

Dans les fètes qui succèdent aux rigueurs du carême, le principal amusement des classes inférieures est le jeu du kerra, qui a beaucoup d'analogie avec le mail : de nombreuses troupes de jeunes gens se réunissent, et il arrive que des villages entiers se défient. Il n'est pas rare alors de voir le sang couler.

Les denrées sont au prix le plus modique dans ce pays : un bœuf vaut 2 ou $\mathbf{3}$ talari ${ }^{1}$; une poule se vend 5 centimes. Quant aux objets de moindre valeur, on se les procure par voie d'échange.

Jusqu'à l'âge de quinze ans, les enfants restent dans un état de nudité complète; les adultes ont un costume qui rappelle l'élégance et la simplicilé antiques. Il consiste en un caleçon, une large tunique à manches, et une sorte de manteau de toile blanche de coton, dans lequel ils se drapent avec beaucoup d'aisance, mais qu'ils laissent quelquefois de côté. La coiffure ordinaire est un large turban. Les femmes ont des robes qui tantôt voilent leur sein, et tantôt partent seulement de la hauteur des hanches.

Les gens du commun portent en outre une ou deux peaux sous leur robe, dans laquelle ils s'enveloppent la nuit; ils ont pour oreiller une espèce de fourche, dans laquelle ils passent la tête pour ne pas déranger leur chevelure dont ils prennent grand soin, ainsi que nous le verrons plus tard. Quant à ceux d'un rang élevé, sans déployer un grand luxe, ils ont cependant des coussins en soie, qu'ils placent sur des sofas. Ils ont aussi des tapis de Perse, et, dans l'intérieur des maisons, ils font usage d'une jolie poterie de terre un peu transparente.

Après ce que nous venons de dire sur les chrétiens, rien ne doit étonner de la part des nations sauvages de l'Abyssinie.

Les Gallas paraissent descendre des tribus nomades de l'Afrique centrale méridionale; ils sont divisés en une multitude de tribus, comprises en trois corps de nations. Ceux du midi sont peu connus; ceux de l'occident ont reçu le nom de Bertuma-Galla, et appellent leurs chefs de guerre loubo; ceux de l'est s'appellent Borena-Galla, et leurs chefs mooty. Ces chefs, dont l'autorité n'est que temporaire, donnent audience dans de misérables cabanes, el ont des courtisans et des gardes qui assaillent à coups de bâton l'étranger qui les visite, el qu'ils présentent ensuite au roi, en le complimentant d'être un homme brave et intrépide qui ne s'est pas laissé renvoyer.

Les Gallas adorent la lune, quelques astres, des arbres, des pierres, etc.; cependant les plus civilisés ont, dit-on, embrassé le mahométisme. Le mariage, l'entretien des parents âgés, le droit de propriété, sont consacrés par des lois. L'exposition des enfants est permise aux guerriers. Dans leurs excursions, ils se nourrissent de café réduit en poudre; mais chez eux, ils ne mangent que de la viande crue, se barbouillent le visage du sang de l'animal tué, et en suspendent les intestins autour de leur cou, à moins qu'ils n'en entrelacent leur chevelure. Leurs incursions ont toujours lieu subitement, et les suites en sont désastreuses. Tout tombe sous leurs coups : l'enfant périt dans les entrailles de sa mère, et les adolescents, après avoir été privés de virilité, sont emmenés en esclavage. Ces peuples, nomades et pasteurs, se distinguent des autres nègres par une petite taille, de longs cheveux et la teinte brun foncé de leur peau.

Les Changallas ou Schangallas sont divisés en tribus qui se subdivisent en familles, dont chacune est gouvernée par le plus ancien des membres que l'on nomme cheba. Ces individus étaient déjà connus des anciens, qui les désignaient sous le nom de mangeurs

19 fr. à 13 fr. 50 o. 
de sauterelles, d'éléphants, d'autruches, parce qu'en effet ils se nourrissent de ces animaux. A l'exception de quelques-uns qui se sont faits musulmans ou qui ont cmbrassé le christianisme, ils sont tous idolâtres. Le visage de ces nègres se rapproche de celui des singes; ils vont nus et ont pour armes des flèches empoisonnées, des lances, des sabres et des boucliers. Ils n'ont d'autre demeure que l'ombrage des arbres pendant une partie de l'année, el des cavernes creusées dans les rochers quand la saison devient pluvieuse ou froide. Ils n'ont qu'une femme; le cheba seul peut en posséder deux. Le mariage n'est d'ailleurs chez eux qu'une sorte d'échange; le frère donne sa sœur à celui qui lui offre la sienne; s'ils n'ont pas de sœur, ils se procurent à la guerre une femme à laquelle ils donnent cette qualité, et qu'ils échangent ensuite contre la femme qui leur plaît. Les femmes sont très-précoces, et deviennent mères dès l'àge de dix ans. Les Abyssiniens chassent comme des bêtes fauves les Changallas qu'ils réduisent à l'esclavage.

Le nom d'Agaours ou Agauws appartient à deux nations de l'Abyssinie; l'une habite dans la province de Lasta, l'autre occupe les environs des sources du Bahr-el-Azrak. La plupart sont devenus chrétiens. Possesseurs de contrées fertiles et inaccessibles, pourvus d'une armée que l'on porte à 4,000 hommes de cavalerie et à un plus grand nombre de fantassins, les Agaouys disputent avec succès leur indépendance aux Gallas et aux Abyssiniens qui cherchent en vain à les soumettre.

On ne sait rien des Gafates, si ce n'est qu'ils sont nombreux, vivent dans le Damot dont le territoire produit du beau coton, et parlent une langue à part.

Quant aux Guragues, ce sont des voleurs intrépides èt rusés qui n'habitent que dans le creux des rochers qui se trouvent au sud-est de l'Abyssinie.

\section{GOTE D'HABESCH.}

Les voyageurs anciens et modernes se sont accordés pour comprendre toutes les côtes africaines, depuis l'Égypte jusqu'au Bab-el-Mandeb, sous le nom générique de Troglodytique, de côte d'Abex ou d'Habesch, ou de Nouvelle-Arabie.

Selon le témoignage des anciens et l'opinion des écrivains arabes, la chaîne de montagnes qui longe le golfe Arabique est riche en pierres fines et en métaux, et on y aurait exploité une mine d'or. Mais la chaleur et la rareté de l'eau rendent la partie basse à peu près inhabitable.

Les habitants y sont retenus dans l'état sauvage par la nature du sol et du climal. Divisés en tribus, sous des chefs léréditaires, ils vivent encore, comme jadis, des produits de la pêche et de leurs troupeaux de chèvres. Ils habitent toujours dans le creux des rochers, ce qui leur a fail donner par les anciens le nom grec de Troglodyte. Bruce comprend sous le nom général d'Agazi ou Ghéz (c'est-à-dire pasteurs) ces peuples qui, d'après les anciens, sont d'origine arabe. Ils parlent la langue ghéz; et l'on sait qu'elle offre beaucoup de similitude avec la langue arabe dont elle paraît dériver. C'est le son rudè et bizarre de cet idiome qui a fait dire, dans l'antiquité, que les Troglodyles sifflaient et hurlaient au lieu de parler. La circoncision paraît avoir été jratiquée par les deux sexes. Les femmes étaient en commun, excepté celles des chefs de tribus; elles passaient sur leur corps une couche de blanc de céruse, et suspendaient à leur cou des coquillages qui devaient éloigner les sorts qu'on pouvait leur jeter. Quelques tribus ne tuaient pas leurs bestiaux, et se nourrissaient de lait; d'autres 
mangeaient des serpents et des sauterelles. Les plus misérables se rendaient, en troupes comme les bestiaux, au bord des lacs ou des mares d'eau pour y étancher leur soif. Néanmoins, ils composaient avec des fruits sauvages une espèce de liqueur vineuse. Si nous nous sommes étendu sur ce portrait des anciens Troglodytes, c'est qu'il est encore applicable au moins en grande partie aux habitants actuels de la côte d'Habesch.

Après la Baie-Sale ou le golfe immonde formé par l'enfoncement de la côte, et au fond duquel se trouve le port des Abyssiniens, on trouve la côte Baza, Beja, Bedjah ou Bodscha, qui, suivant les géographes arabes, est un royaume séparé de la Nubie par une chaîne de montagnes riches en or, en argent et en émeraudes.

Les hommes qui peuplent cette contrée ont reçu le nom de Bugihas par Léon l'Africain, de Bogaïles dans l'inscription d'Aksoum, et de Bedjahs chez la plupart des Arabes. Ils ne sont soumis à aucune espèce de gouvernement, et ne reconnaissent que l'autorité patriarcale, religieusement conservée dans chaque famille. Pleins de loyauté entre eux, d'hospitalité envers les étrangers, ils pillent les peuplades agricoles et les caravanes. Leurs bœufs ont d'énormes cornes, leurs brebis sont tigrées. Ils se nourrissent du lait et de la chair des animaux domestiques. Tous les hommes sont monorchides; il y a des tribus qui se font arracher les dents de devant. En signe de paix ou pour commander le silence, ils élèvent une robe au bout d'une pique. On voit aussi une société de femmes qui fabriquent des armes et vivent à la façon des amazones. Ils parlent un dialecte dérivé de la langue ghẻz, suivant Bruce; mais, selon un historien arabe, ils appartiendraient à la race des Berbers ou Barabras.

Laissant de côté Aïdab ou Djidyd, Fedjah, Dorho ou Deroura, Suakem ou Souâkin, la côte voisine, le promontoire de Ras-Ageeg ou Ahehas, l'île Duhalac ou Dalhac, la petite île ou plutôt le rocher stérile de Massaouah (lieux qui n'ont rien d'assez intéressant pour nous arrêter), nous arriverons à la contrée qui porte le nom de Dankali; elle est arrosée par des pluies périodiques qui commencent à l'époque où elles ont complétement cessé en Abyssinie. Les habitants portent le nom générique de Danakils.

La partie septentrionale est appelée Samhar; le reste porte le nom de DumhoëtaChoho. Les Chonos sont pasteurs; ils cultivent quelques champs, mais leur récolte ne peut suffire à leur consommation. On les dit cruels et sanguinaires, et l'obéissance qu'ils gardent envers leur chef disparaìt dès que leur intérêt n'y est plus subordonné. Non contents d'exercer leurs brigandages sur les étrangers, leurs diverses tribus sont entre elles dans un état d'hostilité permanente. Ils professent l'islamisme et ont un langage particulier qui renferme beaucoup de mots arabes.

Plusieurs tribus nomades errent sur la côte de Samhar ou Samhara; on remarque les Chilos, très-noirs de peau, et peu connus; les Hazortas, petits de taille et qui ont le teint cuivré. Ces derniers obéissent à des chefs dont le plus puissant habite Zoulla; ils peuvent mettre sur pied trois mille guerriers. Des creux de rochers forment leurs habitations. Ils sont pasteurs, et changent de localité suivant que les pluies font éclore un peu de verdure sur le sol brûlé qui les vit naitre; car, lorsqu'elles ont cessé dans les plaines, elles commencent dans les montagnes. Lorsqu'ils abandonnent ces dernières, ils en rapportent des provisions de sel qu'ils ont recueilli et qu'ils échangent contre des grains.

$\mathrm{Au}$ sud des Chilos on rencontre les Davakils; ils forment plusieurs tribus, dont la principale, appelée Dumhoëta, peut mettre un millier d'hommes sous les armes, et possède les villages de Douroro et d'Ayth. Les hommes en état de faire la guerre pourraient s'élever à 6,000 ; mais ils sont si pauvres qu'ils ne peuvent acheter les armes 
qui leur seraient nécessaires. Ces hommes ont le teint noir, les cheveux crépus. La forme pyramidale qu'ils donnent à leurs tombeaux ferait supposer qu'ils appartiennent à un ancien peuple qui aurait fait jadis partie de l'empire de Méroé. Tous parlent la même langue et ont embrassé le culte de Mahomet.

Le territoire nommé Bahar-Nagaeh (roi de la mer) dans les vieilles relations, s'étendait depuis Souâkin jusqu'au delà du détroit de Bab-el-Mandeb. Les NÉBaras, qui habitent entre Débaroa et Massaouah, sont les seuls chrétiens du Dankali. Nous ne savons rien des Belessouas, des Hadarems, des Kedemts et des Ouimas.

A l'est de l'ancien royaume d'Adal, s'étendaient celui de Mara, ainsi que les pays d'Angot et de Gedem, tous soumis depuis longtemps aux Gallas qui ont adopté la religion et les mœurs des vaincus. Les Gallas qui occupent l'ancien royaume d'Adal sont appelés Adal-Gallas; mais leur j̧lus puissante tribu a reçu le nom d'Assoubho-Galla ${ }^{x}$, et habite une vaste contrée qui comprend le pays d'Angot et celui des Dohas pasteurs, et qui est bornée à l'est par la mer, au nord par le Dankali et les tribus nommées Taltal et Mantilli, à l'ouest par les Dobas-Changalas et la rivière de Sabaletté, au sud par la rivière d'Anazo.

Il y a encore beaucoup d'autres tribus que nous ne pourrions que nommer. Nous terminerons cetle partie de l'Afrique par quelques mots sur les Soumoulis el les habitants du royaume de Ilururgué. Les premiers jouissent des avantages d'une civilisation moins arriérée que celle des Gallas, qui ne sont pas encore parvenus à les soumeltre; quant aux autres, ils parlent trois langues : le somouli, le hururgué et l'ancien adal. On peut en dire autant des tribus de Mara et d'Adal, qui jusqu'ici n'ont point été envahies par les Gallas.

1 La dénomination de assoubho signifie sel, en langage somouli. 


\section{BARBARIE.}

La Barbarie s'étend entre $25^{\circ} 30^{\prime}$ et $37^{\circ} 50^{\prime}$ de latitude nord, et entre $26^{\circ}$ de longilude est et $14^{\circ}$ de longitude ouest. Elle a 900 lieues de l'est à l'ouest, et 200 lieues dans sa plus grande largeur. Ses bornes sont : à l'est l'Égypte, au nord la Méditerranée, à l'ouest l'océan Atlantique, au sud le Sahara. L'Atlas, qui est compris en entier dans celte vaste partie de l'Afrique, donne naissance à une multitude de rivières dont les unes, après avoir fertilisé des campagnes, vont se jeter à l'ouest dans l'Atlantique, au nord dans la Méditerranée, et dont les autres abreuvent le désert ou forment des lacs considérables.

Le climat est plutôt chaud que tempéré. Le sol, excepté sur l'Atlas où il offre une nature calcaire, est léger et sablonneux. Il renferme une grande quantité de sel et de nitre. Au reste, il est d'une telle fertilité partout où il est suffisamment arrosé, que, sous l'empire romain, cette région était déjà le grenier de l'Italie. Actuellement encore, malgré une administration tyrannique, l'impéritie et la paresse des habitants, ce pays se couvre de riches récoltes, et fournit des blés à l'étranger. Toutes les productions végétales de l'Europe méridionale y croissent à côté de celles qui lui sont particulières. Le blé, l'orge, le maïs, le riz, le tabac, le dattier, l'olivier, l'oranger, le figuier, l'amandier, la vigne, le pêcher, l'abricotier, le pistachier, le jujubier, les melons, le mûrier et la canne à sucre, sont les principaux végétaux que l'on cultive. L'avoine croît spontanément. Les flancs des montagnes se couvrent de belles forêts, principalement composées d'oliviers sauvages, de pins de Jérusalem, de liéges, de peupliers blancs, de genévriers de Phénicie, de térébinthes et de différentes espèces de chène; l'une d'elles porte un gland qui égale en douceur nos châtaignes, et sert de nourriture aux habitants. Le lentisque, le pistachier atlantique, le thuya articulé, le cyprès, le laurier-rose, l'arbousier, l'if, la bruyère en arbre, etc., ornent aussi les forêts. Les plantes aromatiques abondent sur les coteaux et dans les plaines.

Les animaux féroces, tels que le lion, la panthère, l'hyène, y sont très-nombreux. Les serpents, les vipères, les lézards et les scorpions abondent partout. D'autres animaux encore plus nuisibles sont les sauterelles, qui ravagent en peu de jours des régions très-étendues.

Les animaux domestiques sont à peu près les mêmes qu'en Europe. L'âne et le mulet sont employés à la culture des terres, à l'exclusion du cheval et du bœuf : celui-ci est nourri seulement pour sa chair et pour sa peau; le cheval sert uniquement de monture. Quoiqu'un peu dégénéré, le cheval de Barbarie est encore très-beau. Les chameaux sont remarquables par leur vitesse; quelques-uns parcourent jusqu'à 75 lieues en un jour. Parmi les moutons, il faut distinguer la variété à queue grasse, et celle dont la toison ressemble au poil de chèvre. Les campagnes éloignées des habitations sont couvertes de troupeaux de différentes espèces d'antilopes. 
Malgré l'absence de notions positives, on sait que le sein de la terre en Barbarie renferme de l'argent, du cuivre, du plomb, du fer, de l'antimoine, du gypse et de grosses calcédoines. Les carrières dont les Carthaginois et les Romains tiraient leur beau marbre d'un jaune uni ou tacheté de diverses couleurs ne sont pas encore épuisées. La pierre à chaux abonde dans l'Allas; elle est recouverte, sur les monts de Barkah, par du basalte. Le sel y est tellement commun qu'il forme des montagnes, et que la plupart des rivières et des lacs sont salés.

Cette contrée comprend: $1^{\circ}$ le royaume de Tripoli avec ses dépendances; $2^{\circ}$ le royaume de Tunis; $3^{\circ}$ le territoire d'Alger; $4^{\circ}$ l'empire de Maroc.

Nous décrirons tour à tour chacun de ces pays, et nous donnerons ensuite un apercu du grand désert de Sahara; mais nous devons avant jeter un coup d'œil général sur l'espèce humaine disséminée dans toute l'élendue de la Barbarie.

Les habitants des villes et des plaines cultivées sont désignés sous le nom de Mores. Bien qu'ils parlent un dialecte arabe rempli d'idiotismes, leur ensemble physique, la peau plus blanche que celle des Arabes, le visage plus plein, le nez moins saillant, et lous les traits de la physionomie moins énergiques annoncent qu'ils descendent d'un mélange d'anciens Numides, avec les Phéniciens, les Romains et les Arabes. S'il faut en croire les voyageurs européens, le caractère propre de cette nation serait la réunion de tous les vices, et ils ne rachèteraient par aucune qualité, l'avarice, la làcheté, la débauche, l'esprit vindiratif, la paresse qui les distinguent. Cependant, la haine que les Mores repoussés hors de l'Espagne ont vouée à leurs persécuteurs chrétiens, n'a-t-elle pas fait naître chez les voyageurs un sentiment semblable... Les Mores qui professent l'islamisme appartiennent particulièrement à la secte fanatique appelée maleki; ils ont des saints qui se font remarquer, les uns par le repos, les autres par une manie turbulente et destructive; on a vu de ces derniers assommer des ànes et en dévorer la chair sanglante. On cite dans le nombre des cérémonies du mariage la procession solennelle dont le but est d'attester la sagesse virginale de la fiancée. Il n'est point de peuple aussi jaloux que les Mores avant et après l'hymen. Les Mores s'habillent simplement dans tout l'intérieur; mais à Tunis, à Alger, les femmes rehaussent l'élégance de leurs costumes par l'or et les diamants. Quoiqu'ils aient des astrologues, et qu'ils témoignent beaucoup de goût pour l'histoire et la poésie, les Mores regardent la lecture comme le comble de la science. Leurs maisons carrées et à toits plats sont quelquefois ornées à l'intérieur de riches tapis et de fontaines jaillissantes. Les exercices à cheval, et le tir d'armes à feu composent, avec les tours d'équilibre, leurs plus chers passe-temps. Lors des funérailles, un grand nombre de femmes accompagnent le mort jusqu'à sa dernière demeure en pleurant et en hurlant, probablement suivant l'importance de la rétribution qui leur est allouée, car elles sont payées pour simuler le désespoir.

Les Arabes nomades, venus d'Asie depuis l'établissement du mahométisme, conservent leur sang pur. Dans quelques tribus les femmes se peignent le corps de diverses lignes et figures noires, sur les joues et la poitrine. Les tentes sont couvertes d'étoffe grossière ou de feuilles de palmier, et ont conservé la forme d'un bateau renversé, attribuée par Salluste au Mapalia des Numides. Une cabane semblable est nommée chaima, et un groupe de quelques-unes de ces huttes compose un douar (hameau), souvent entouré d'une haie d'épines pour en repousser les lions qui rôdent à l'entour. De même que les Mores, les Arabes envoient à la Mecque des caravanes de pèlerins. Ces deux peuples portent en Asie le nom de Magrebi ou Maugrabins (Occidentaux).

Entièrement distincte des deux précédentes, la race des Berbers passe pour indigène de l'Afrique septentrionale, et forme quatre nations séparées : $1^{\circ}$ les Amazygh, que les Mores appellent Chillah ou Choullah, dans les montagnes du Maroc; 20 les Kabyles 


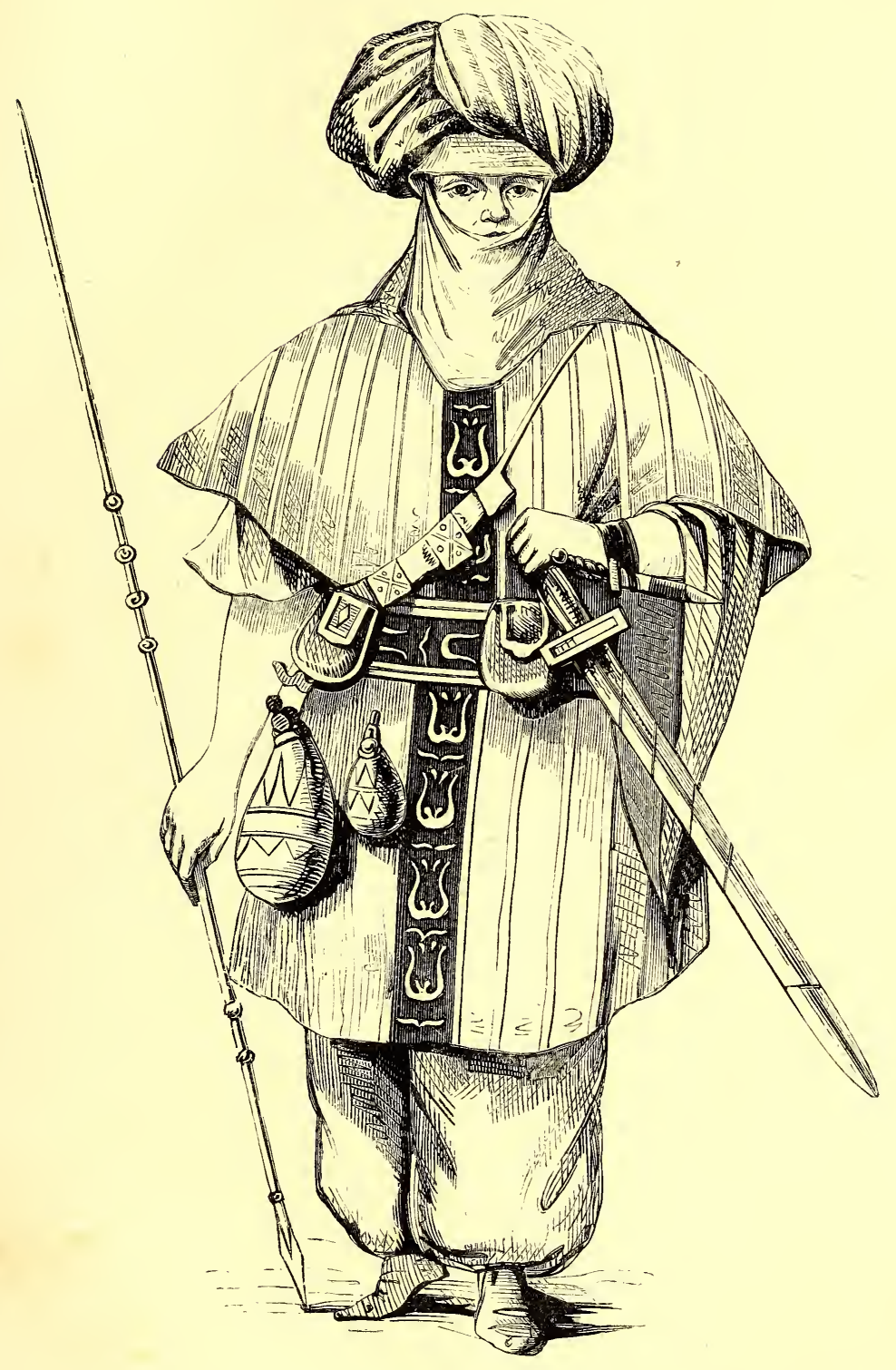

GLERRIER IE TUARICK 

ou Cabaïls, dans les montagnes d'Alger et de Tunis ; $3^{\circ}$ les Tibbous, dans le désert entre le Fezzan et l'Égypte; $4^{\circ}$ les Touariks, dans le grand désert.

La comparaison des vocabulaires a fait reconnaître l'identité de la langue que parlent les Berbers, et c'est là une des découvertes les plus importantes dont l'histoire ethnographique ait pu s'enrichir.

Les Berbers ont le teint rouge et noirâtre, la taille haute et svelte, et le corps grêle ct maigre. Ils laissent croître leurs cheveux, et leur seul vêtement consiste en une large tunique de laine. La vengeance est chez eux une passion; le fanatisme religieux qu'ils poussent plus loin encore que les Mores, les rend cruels, et ils apaisent cette soif de vengeance quand l'occasion se présente, dans le sang des juifs et des chrétiens; ce qui n'empêche pas les Chillahs de boire du vin et de manger la chair du sanglier. Les marabouts, sorte de prêtres hypocrites qui distribuent des amulettes et font des miracles, exercent une autorité despotique, et sont vénérés comme des saints dans beaucoup de villages des Kabyles. Dans certaines contrées, notamment chez les Chillahs, ce sont des cheiks héréditaires qui gouvernent les petites tribus qui forment les divisions de cette nation. Celles qui habitent les hautes vallées de l'Atlas sont presque absolument indépendantes. Dans le Maroc, quelques tribus sont réunies sous la puissance d'un chef appelé amargar, dont l'autorité patriarcale se borne à réprimer les vols et les assassinats, et qui sont choisis quelquefois par l'empereur. La misère et la malpropreté des Berbers leur donnent une apparence sauvage; cependant ils font preuve d'activité dans la culture de leurs champs, et montrent une intelligence susceptible de développement. Ils procurent au More indolent du blé, des olives et d'autres denrées, et fabriquent eux-mêmes la poudre à feu dont ils font usage. Leur nourriture consiste en pain bis et en olives; pour boisson ils ont de l'eau. Dans leurs villages, dont quelquesuns ont l'étendue et la population d'une ville, on voit des tours de garde d'où ils découvrent l'approche de l'ennemi. A la moindre alerte, tous les hommes prennent les armes; ils manient parfaitement le fusil, le lancent en l'air, le raltrapent et le déchargent avec une adresse, une rapidité surprenantes.

L'Afrique septentrionale renferme, outre ces véritables nations, des colonies étrangères, parmi lesquelles on remarque surtout les Turcs, autrefois dominateurs à Alger, à Tunis, à Tripoli, et les juifs répandus dans toute la Barbarie, mème dans les vallées des Cabaïls.

Salubre et favorable à la propagation de l'espèce humaine, ce pays, par suite de l'irrégularité du gouvernement, se trouve exposé à tous les fléaux. M. Jackson, consul anglais à Mogador, a tracé l'effrayant tableau d'une peste qui, au commencement de ce siècle, a dévoré 50,000 individus dans la seule ville de Maroc; 65,000 à Fez; 4,500 à Mogador; 5,000 à Saffi. On n'eut pas le temps d'enterrer les morts, et ceux qui survécurent jetèrent les cadavres dans de grandes fosses que l'on recouvrait de terre quand elles étaient à peu près pleines. Les hommes jeunes, sains et musculeux furent les premiers atteints; puis les femmes, les enfants; et enfin les gens maigres, épuisés, les valétudinaires et les vieillards. Quand le fléau eut cessé, on put s'apercevoir qu'une révolution soudaine avait eu lieu dans la situation et dans la fortune des individus : de simples ouvriers étaient devenus opulents, et achetaient des chevaux qu'ils ne savaient pas monter. Les vivres étaient à vil prix ; les troupeaux et leurs gardiens erraient sans maîtres dans les pâturages, et tentaient les diverses tribus de ces contrées, généralement portées au vol, mais retenues par l'appréhension de la maladie; car la peste (el khere) est regardée comme un jugement de Dieu, et il était important de régler sa conduite de manière à mériter le paradis. Bientôt le prix des travaux fut exorbitant, et les travailleurs étaient en si petit nombre qu'il en résulta, pour presque 
tous, la nécessité de vaquer eux-mêmes aux petits travaux domestiques. D'immenses terrains restèrent abandonnés, et les Arabes du désert vinrent s'y établir.

Nous croyons devoir dire un mol de la chasse aux autruches, qui offre un spectacle assez curieux : Une vingtaine d'Arabes, montés sur des chevaux du désert, qui sont dans leur espèce ce que sont les heiries parmi les chameaux, vont contre le vent, cherchent la trace de l'autruche, et quand ils l'ont trouvée, la suivent avec la plus grande rapidité, en ne's'écartant pas l'un de l'autre de plus d'un demi-mille anglais. Fatiguée de courir contre le vent qui s'engouffre dans ses ailes, l'autruche se retourne espérant passer à travers leur ligne. C'est alors qu'ils entourent l'animal et tirent tous à la fois sur cet oiseau qui bientôt tombe mort. On ne saurait prendre l'autruche sans cette ruse, car, quoique n'ayant pas la faculté de voler, cet oiseau dépasse à la course les animaux les plus véloces.

\section{ROYAUME DE TRIPOLI,}

\section{ET SES DÉPENDANCES.}

Partie la plus orientale de la Barbarie, le royaume de Tripoli, situé entre $23^{\circ} 45^{\prime}$ et $33^{\circ}$ de latitude nord, et entre $7^{\circ} 40^{\prime}$ et $26^{\circ}$ de longitude est, se compose : $1^{\circ}$ du Tripoli propre au nord-ouest; $2^{\circ}$ du Fezzan au sud; $3^{\circ}$ du Barcah à l'est. Ses bornes sont : au nord la Méditerranée, à l'est l'Égypte, au sud le Sahara, et à l'ouest le royaume de Tunis. Sa longueur est d'environ 400 lieues de l'est à l'ouest, et sa plus grande largeur est de 230 lieues.

BarGaH. - Ce pays est sous la dépendance d'un gouverneur ou bey qui relève du souverain de Tripoli, et dont la résidence est une masure décorée du nom de château, à Beng'hazy (ou Bernik), ville de 5,000 à 6,000 âmes, avec un port médiocre, sur une còte poissonneuse, et dans un territoire fertile, où l'on exporte des laines. Les États européens ont des consuls dans cette cité, qui occupe l'emplacement de l'antique Bérénice.

Fezzan. - La capitale du Fezzan est Mourzouk où réside le sultan, qui est tributaire de Tripoli. Cette ville est le rendez-vous des caravanes du Caire, de Tripoli, de Tunis, et de Tembouctou, à l'arrivée de chacune desquelles le sultan, placé sur un siége d'honneur, la reçoit hors de la ville, et donne sa main à baiser à tous ceux qui la composent.

Quoique depuis le $\mathrm{xv}^{\ominus}$ siècle le sultan paye en or, en séné et en esclaves, un tribut au pacha de Tripoli, il est néanmoins indépendant; son pouvoir est absolu et son trône héréditaire. Selon Hornemann, ces revenus proviennent de ses domaines; d'autres relations mentionnent trois ou quatre impôts légers, et notamment un droit d'entrée sur les marchandises transportées par les caravanes. La place de cadi, ou juge suprême, et celle de chef du clergé, sont héréditaires. Le sultan n'a point d'armée régulière; en temps de guerre il fait un appel aux hommes en état de porter les armes, et réunit ainsi de 15,000 à 20,000 soldats.

Bien que cette force armée indique environ 150,000 habitants, composés en partie de Touariks, de Tibbous et d'autres peuples africains, Hornemann n'évalue pourtant la population du Fezzan qu'à 75,000 individus. La couleur de ces hommes, par sa variété, annonce bien une population mélangée; cependant la race indigène conserve des traits qui lui sont propres: elle est de stature ordinaire, dénuée de vigueur; la peau est très-brune, les cheveux sont noirs et courts, le nez moins aplati que chez les nègres, 



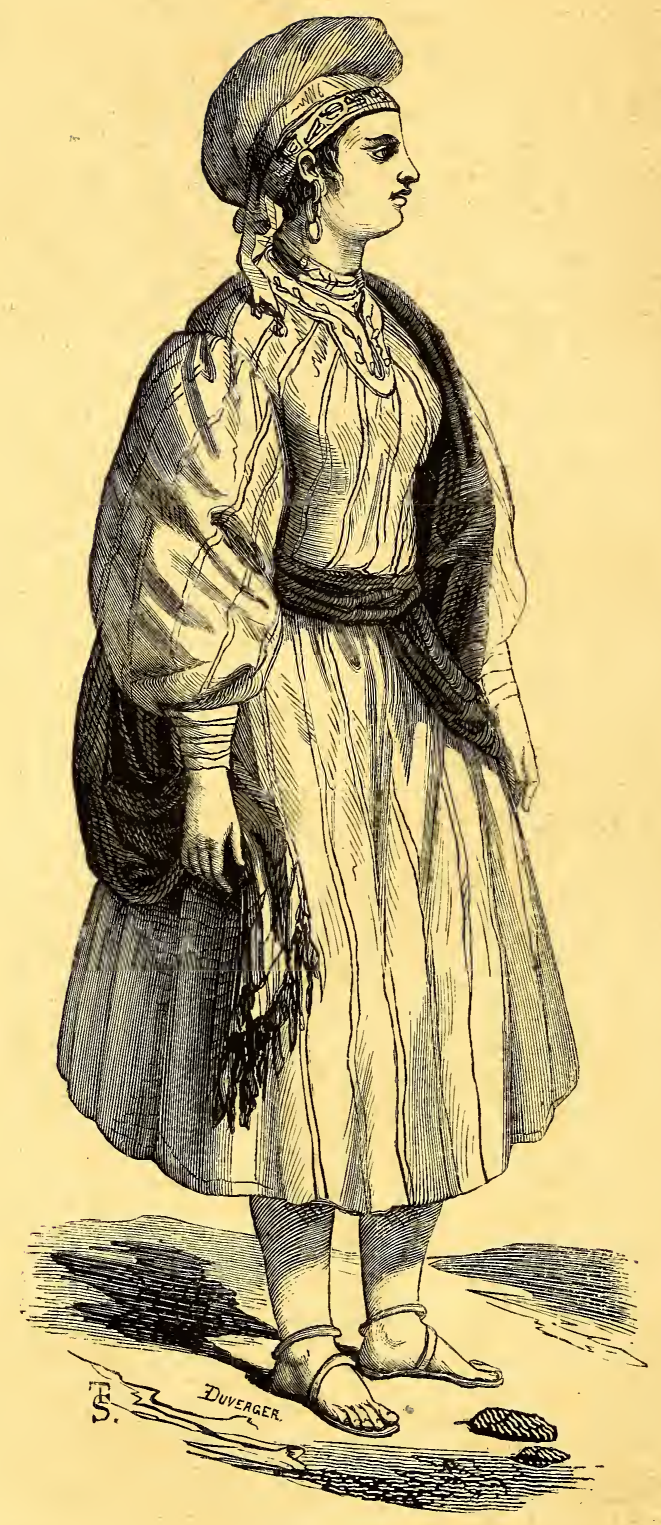

JEUNE FILLE SOCKNANAISE. 
et la forme du visage est telle, qu'elle passerait pour régulière en Europe. Les femmes, comme dans toute l'Afrique, aiment passionnément la danse; elles sont plus libres que dans les autres contrées, ce qui rend les mœurs plus dépravées. Sobres par nécessité, les Fezzanis s'enivrent pourtant de jus de dattier. Les maisons du Fezzan, extrêmement basses et ne recevant de jour que par la porte, sont construites en briques calcaires et en glaise séchée au soleil.

L'industrie des Fezzanis est peu étendue. Ils fabriquent d'assez bons tapis, des tissus grossiers de laine et de coton; mais le peuple seul emploie ces étoffes que les riches font venir de Tripoli. Ce peuple connaît la coquille appelée porcelaine cauris, ce qui fait supposer qu'ils ont des relations avec la côte de Guinée, où cette coquille sert de monnaie.

A Soka les femmes portent des chemises rayées de soie ou de toile, de larges hou= cles d'oreilles d'argent, des bracelets et des ornements de jambes de même métal. Chez les femmes d'une classe inférieure, ces objets de parure sont de verre ou de corne.

Royaume de Tripoli. - Le royaume de Tripoli proprement dit est, de tous les États barbaresques, le plus avancé dans l'échelle de la civilisation; la population y est plus éclairée et le gouvernement mieux établi. On a remarqué que cette marche civilisatrice date surtout de l'époque où l'esclavage des prisonniers chrétiens fut aboli, c'est-à-dire en 1817.

Après avoir fait partie des possessions carthaginoises, ce pays fut occupé par les Romains, puis par les Sarrasins. Sous le règne de Charles-Quint, il appartint pendant quelque temps aux chevaliers de Malte; mais en 155̆1, Sinan-Pacha, vizir de Soliman II, s'en rendit maître, et les Turcs le gardèrent comme une partie de leurs provinces jusqu'en 1713, époque où le bey Hamet-Pacha secoua le joug de la Porte, et fit de Tripoli un État indépendant. On sait que ce prince était originaire de Caramanie, et chef de la dynastie des Caramanlis qui y règnent encore.

Quoique très-important, le commerce de Tripoli serait bien plus considérable sans les divers monopoles qui y sont établis. Le pacha se réserve la vente de certaines denrées, telles que l'eau-de-vie de dattes, le sel et la potasse; celle des vins, savons et peaux, est affermée aux juifs; les autres se vendent librement. C'est avec le centre de l'Afrique, et par les caravanes du Fezzan et de Ghadamès, que se fait la principale branche de commerce. Par ces caravanes le Tripoli reçoit un grand nombre d'esclaves noirs, beaucoup de poudre d'or, de séné, de plumes d'autruche, d'ivoire, de carbonate de soude et d'alun. Ces marchandises arrivent généralement à Tripoli à dos de chameau : les caravanes dont elles font partie se composent de musulmans se rendant à la Mecque en pèlerinage; mais depuis qu'un préjugé religieux ne s'oppose plus à ce que les musulmans s'embarquent sur des bâtiments chréliens pour Alexandrie, elles sont devenues beaucoup plus rares et moins nombreuses. On en a vu pourtant d'assez considérables dans ces dernières années arriver de Maroc à Tripoli : elles étaient composées de 2,500 à 3,000 hommes, de plusieurs centaines de femmes et enfants, et d'environ 2,000 chameaux. Ces caravanes, à leur retour de la Mecque, qui a lieu un an après, apportent à Tripoli de l'opium, du café, des parfums, du naphte, des étoffes de l'Inde, des châles de Cachemire, des perles fines et des pierres précieuses.

On exporte de Tripoli divers objets, dont les principaux sont : la laine brute, les tapis, l'huile, le cuir de bœuf, les bœufs, les moutons et les chèvres, la potasse et la garance.

Le produit des droits de douane s'élevait, il y a peu d'années, à plus de 500,000 fr.; ils n'en rapportent plus aujourd'hui que 200,000 .

Le bey de Tripoli est tributaire de la Porte Ottomane, ce qui n'empêche en rien le 
despotisme de son pouvoir; les emplois sont à sa disposition, et sa volonté fait loi au divan mème qu'il n'assemble que pour la forme.

\section{REGENCE DE TUNIS.}

Le pays appelé régence ou royaume de Tunis est situé entre $31^{\circ}$ et $37^{\circ} 20^{\prime}$ de latitude nord, et entre $5^{\circ} 40^{\prime}$ et $9^{\circ}$ de longitude est. Il a une étendue de 160 lieues en longueur, et 70 lieues dans sa plus grande largeur.

De tous les États barbaresques, celui de Tunis est le plus favorablement placé pour le commerce, surtout avec l'Europe : c'est cette situation qui fut le fondement de la puissance et de la richesse de Carthage. Des caravanes mettent ce pays en rapport avec la Nigritie, l'empire de Maroc el l'Égypte.

Cet État n'est point divisé en provinces. Sa capitale est Tunis dont les rues sont étroites, tortueuses et sales. Les maisons, blanchies à l'extérieur, et construites en amphithéâtre, se découvrent d'une très-grande distance et produisent un effet pittoresque. L'intérieur, toujours propre, est orné avec luxe chez les grands. Un appartement séparé, qu'elles ne quittent jamais tant qu'un étranger se trouve dans la maison, est réservé aux femmes. Il y a de beaux édifices à Tunis; les principaux sont les mosquées; quelques quartiers renferment des bains publics. On y fabrique des toiles, des étoffes de soie, de laine, etc., et le commerce y est très-actif, surtout comme exportation.

Le chef de la régence a le titre de bey; à son avénement, il reçoit de l'empereur turc le caftan, avec le titre de pacha à trois queues : ce sont les seuls droits que la Porte Ottomane ait conservés sur ce pays. Le prince réside dans le joli château de Bardo, situé au milieu d'une grande plaine, à trois quarts de lieue au nord de Tunis. La cour du bey est très-nombreuse; les officiers qui l'entourent sont en général très-honnêtes el très-polis envers les étrangers. Le prince dicte et réforme les lois, juge les affaires de ses sujets, les condamne ou les absout sans rendre compte de sa conduite; dans les affaires imprévues et délicates, il consulte le divan; mais il est toujours libre de suivre sa volonté.

Le gouvernement tunisien, sous les successeurs des califes, et depuis sous les beys qui ont exercé le pouvoir, après l'établissement dans la régence de la suprématie du Grand Seigneur, était tombé dans l'erreur la plus grave et la plus contraire à ses propres intérêts, en se servant des Arabes pour opprimer la population des villes et des villages. C'est ainsi que les habitations ont été dévastées, que l'industrie et l'agriculture ont été ruinées. Un long état de paix exlérieure pourra seul permettre à un gouvernement réparateur et ferme de protéger les habitants sédentaires, en comprimant avec persévérance la population nomade, celte véritable plaie du pays.

Depuis plusieurs générations, les princes de la maison régnante protégent ouvertement une amélioration intellectuelle très-remarquable parmi les populations tunisiennes, au risque de s'exposer, en agissant ainsi, aux excès d'un fanatisme qu'ils bravent, non sans de sérieux dangers. La régence de Tunis, depuis que nous sommes maîtres d'Alger et de Constantine, n'a plus à redouter les incessantes incursions de ses anciens voisins. Du côté de la mer, elle est protégée par nos escadres contre les prétentions de la Porte, entretenues et excitées par les menées de la politique anglaise. Aussi Ahmed, le bey actuel, met-il habilement à profit la sécurité que notre voisinage et notre protection assurent à ses États, pour leur donner tous les développements possibles de culture, de civilisation et de puissance. 
Sa volonté à cet égard s'est manifestée dès les premiers jours de son règne, et pendant six années sa persévérance n'a jusqu'à ce jour été rebutée par aucun obstacle. Pour soumettre le pays à une organisation générale et homogène qui fìt à la fois sa force et celle du gouvernement, Ahmed-Bey a compris que le meilleur moyen était de créer une armée régulière sur le modèle des armées européennes, avec leur administration, leurs grades hiérarchiques, leur discipline sévère, leur instruction : véritable et première école de civilisation pour le pays. C'est à la France surtout qu'il a fait ses plus utiles emprunts, et il peut déjà regarder son ouvrage avec orgueil. Avant lui, la régence de Tunis ne comptait que deux régiments d'infanterie de 2,000 hommes chacun. Son armée comprend aujourd'hui cinq régiments d'infanterie, chacun de 3,000 hommes, un régiment de cavalerie de 1,100 hommes et un régiment d'artillerie de $\mathbf{3 , 0 0 0}$ hommes.

Quoique l'islamisme répande une teinte uniforme sur toute la population, on y remarque pourtant des nuances assez tranchées. Outre les juifs et les chrétiens, il existe une foule de races mêlées qui n'ont rien de commun entre elles, soit sous le rapport des mœurs, du caractère, soit même par l'apparence extérieure. On voit des Turcs de la Morée et de Constantinople, d'anciens Mores espagnols, des nègres de l'intérieur de l'Afrique, des Bédouins des frontières de l'Atlas, des Berbers, elc.

Les musulmans de Tunis se montrent de jour en jour plus négligents à accomplir leurs devoirs religieux; la plupart boivent du vin et de l'eau-de-vie; et, malgré leurs fréquentes ablutions, ils sont plus sales que les juifs. Durant le baïram, ils se dédommagent du jeûne qui leur est imposé le jour, en se livrant la nuit à toutes sortes de débauches; ils ont presque abandonné le pèlerinage de la Mecque, et il n'y a guère que leur haine contre les chrétiens qui n'ait subi aucune altération.

Cependant ils sont très-superstitieux : ils croient aux sorcières, aux magiciens, aux vampires, au mauvais œil, aux présages, et ils font des sacrifices. Quand ils posent la première pierre d'un édifice, ils mettent à mort un agneau dont ils laissent égoutter le sang sur la pierre; s'ils lancent un vaisseau à la mer, ils jettent dans les flots la chair de l'animal qu'ils ont tué. On dit même qu'ils ne se contentent pas toujours d'animaux. Lorsqu'ils croient quelqu'un possédé du démon, ils excitent un bouc à aller frapper de la tête contre la porte du patient, dans la persuasion que le démon est ainsi mis en fuite.

Les Turcs de Tunis sont d'une avidité qui égale au moins leur superstition; il y a un proverbe qui les caractérise ainsi : « Donnez de l'argent d'une main à un Tunisien, et il vous permettra de lui crever un œil de l'autre. ,

Les femmes, qu'on ne peut jamais apercevoir, ne sont ni belles ni jolies; leur peau est blanche, mais huileuse; si leurs cheveux sont d'un beau noir, si leurs prunelles brillent d'un vif éclat sous des sourcils arqués et d'une extrême délicatesse, l'excessif embonpoint dont la plupart sont affectées forme une ombre fâcheuse à ces avantages. Assises, elles ne manquent pas de grâce; mais leur ignorance est inqualifiable : elles savent à peine lire quelques versets du Coran, et encore est-il bien rare qu'elles en comprennent le sens. Comme on les marie fort jeunes, les soins du ménage et la reclusion perpétuelle où elles vivent ne sont guère propices à développer leur intelligence, et leurs connaissances se bornent en général à tricoter et à faire des confitures.

Les nouveaux mariés ne peuvent habiter sous le même toit que huit jours après la célébration du mariage; on leur accorde seulement une entrevue d'une demi-heure, pendant laquelle les parents des deux époux se tiennent devant la porte de la chambre nuptiale; c'est dans ce court espace de temps que l'union est consommée. Lorsque l'époux pénètre dans l'appartement, la femme lui baise la main en signe de respect, et se laisse marcher sur le pied. Le jour suivant, les preuves matérielles de la virginité de la jeune femme sont exposées solennellement. 
Les hommes sont en général d'une constitution sèche, ont du caractère et de la fierté dans la physionomie; leur taille commune est de cinq pieds trois ou quatre pouces; on en voit peu d'infirmes et de contrefaits; quand ils mènent une vie sobre (et c'est le plus grand nombre), ils vivent aussi longtemps que les habitants des climats tempérés. Ils laissent croître la barbe et se rasent la tête; quelques-uns se rasent aussi le visage, et ne conservent que leurs moustaches; mais tous les grands ont la barbe longue; lorsqu'on veut dégrader quelqu'un d'eux, on lui coupe la barbe. On laisse croître les cheveux des enfants jusqu'à l'âge de puberté.

Les troupes tunisiennes, organisées à l'européenne, ont adopté un costume qui se rapproche assez de celui des soldats d'Europe. Ces militaires ont la tête couverte du $f e z$ rouge, dont la façon ne diffère des bonnets des autres habitants qu'en ce que, outre le long gland bleu, toute la forme est encore entourée d'une frange basse de même couleur. L'uniforme est un kutka ou veste bleue, avec un gilet de drap bleu, coupé comme le sont les nôtres. Dans d'autres régiments la veste est de couleur garance. Ils ont autour des reins un ceinturon rayé de rouge et de bleu; leur pantalon de drap bleu, à la turque jusqu'au genou pour la largeur, va en s'étrécissant plus bas comme ceux d'Europe, et s'attache autour de la cheville avec un ruban. Des bas blancs et des souliers à cordon complètent ce costume, dont le disgracieux contraste d'une manière fâcheuse avec l'élégant costume des mameluks.

Les pantalons de drap en hiver sont de couleur garance, et les pantalons d'été en toile blanche. Le collet et les parements des vestes, et les bandes des pantalons sont de teintes tranchantes.

Les officiers portent la capote et le pantalon droit, avec broderies et bandes en or. La coiffure seule est restée orientale; cependant le turban a élé remplacé par la chichia rouge, élevée et garnie d'un flot bleu en soie. La différence des grades est signalée par l'étoile et par le croissant, en argent pour les sous-officiers, en or pour les officiers subalternes, et en diamant pour les officiers supérieurs. Les officiers portent en outre des épaulettes distinctives. Les armes sont celles de nos armées. Dans la cavalerie, la selle arabe a été conservée, mais avec des modifications. Plusieurs officiers ont adopté la selle française. Le bey, les princes, les officiers, ressemblent beaucoup, on le voit, à nos officiers, à l'exception de la coiffure; ils portent même des gants jaunes et des bottes vernies.

L'habillement des Tunisiens est le même sans distinction de rang; ils portent le fez. rouge dont nous venons de parler, moins la frange; une jaquette ronde et une veste bleue sans ornement; le pantalon de même couleur, et semblable pour la forme à celui que nous avons décrit plus haut; la ceinture rayée rouge et blanche, les bas de coton blancs, et les souliers pointus. Le sapatapa, ou ministre, et les autres dignitaires, ne se distinguent des gens du commun que par une longue chaîne de montre et plusieurs breloques qui paraissent indiquer leur qualité de grands.

Le commandant des camps (titre qui correspond à celui de feld-maréchal) porte une espèce d'uniforme européen à collet brodé d'or. Sa coiffure est le fez, et ses mains sonl surchargées de bagues en brillants.

Le prince de Puckler-Muskau put assister à une audience dans la salle de justice; voici comment il rend compte de cette cérémonie :

c On revêtit d'abord le bey d'un manteau de soie cramoisie, après quoi il se rendit, entouré de ses nombreux courtisans, en procession, à la salle de justice, en traversant la grande cour. En avant du corlége marchaient, vêtus d'un riche costume blanc et rouge, les quatre shtershetes, ayant à leur tête le shaushsalam, qui se distinguait des autres par un costume plus riche et plus bigarré encore et par un énorme turban. 


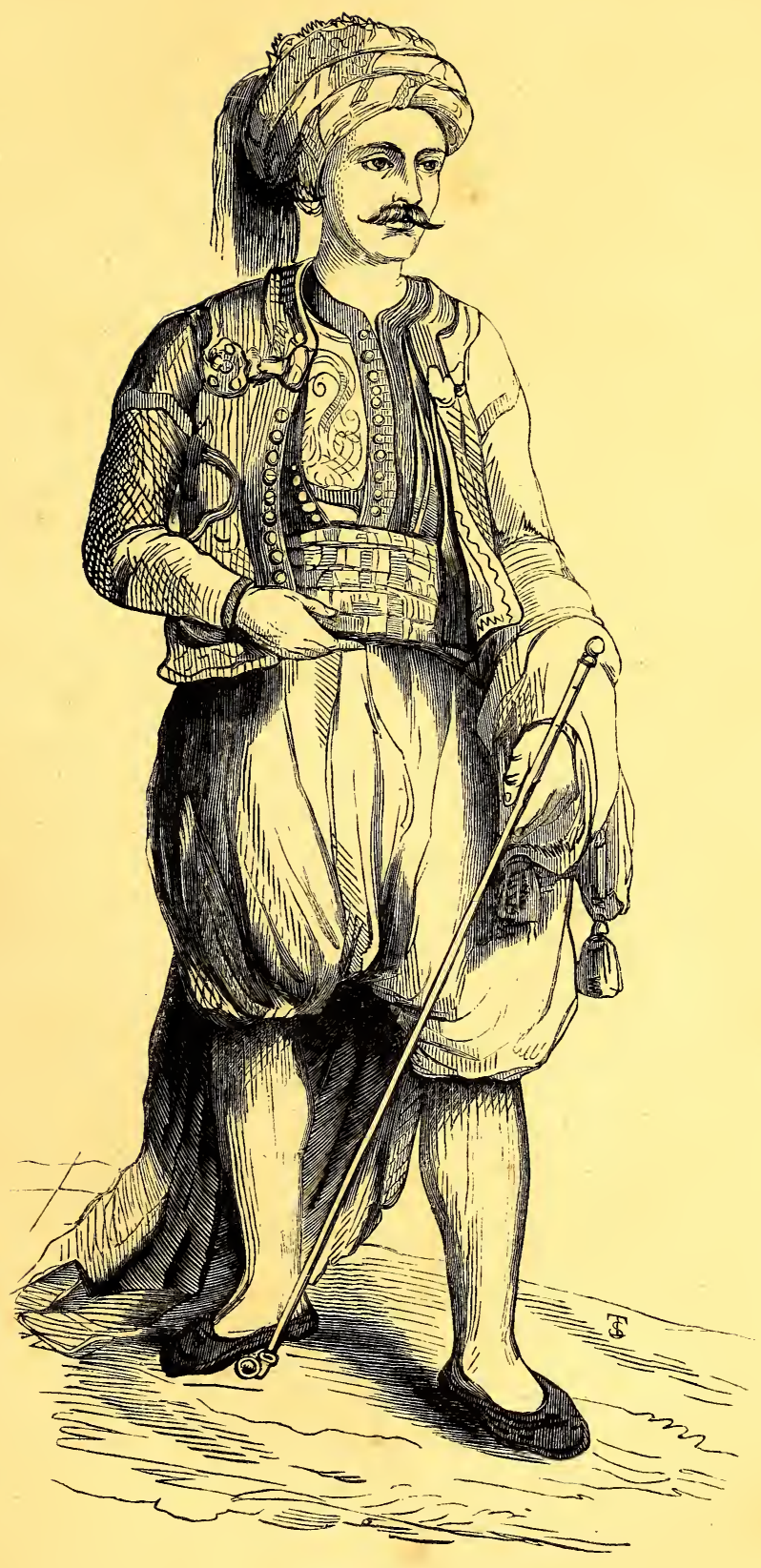

NORE D'ALGER 



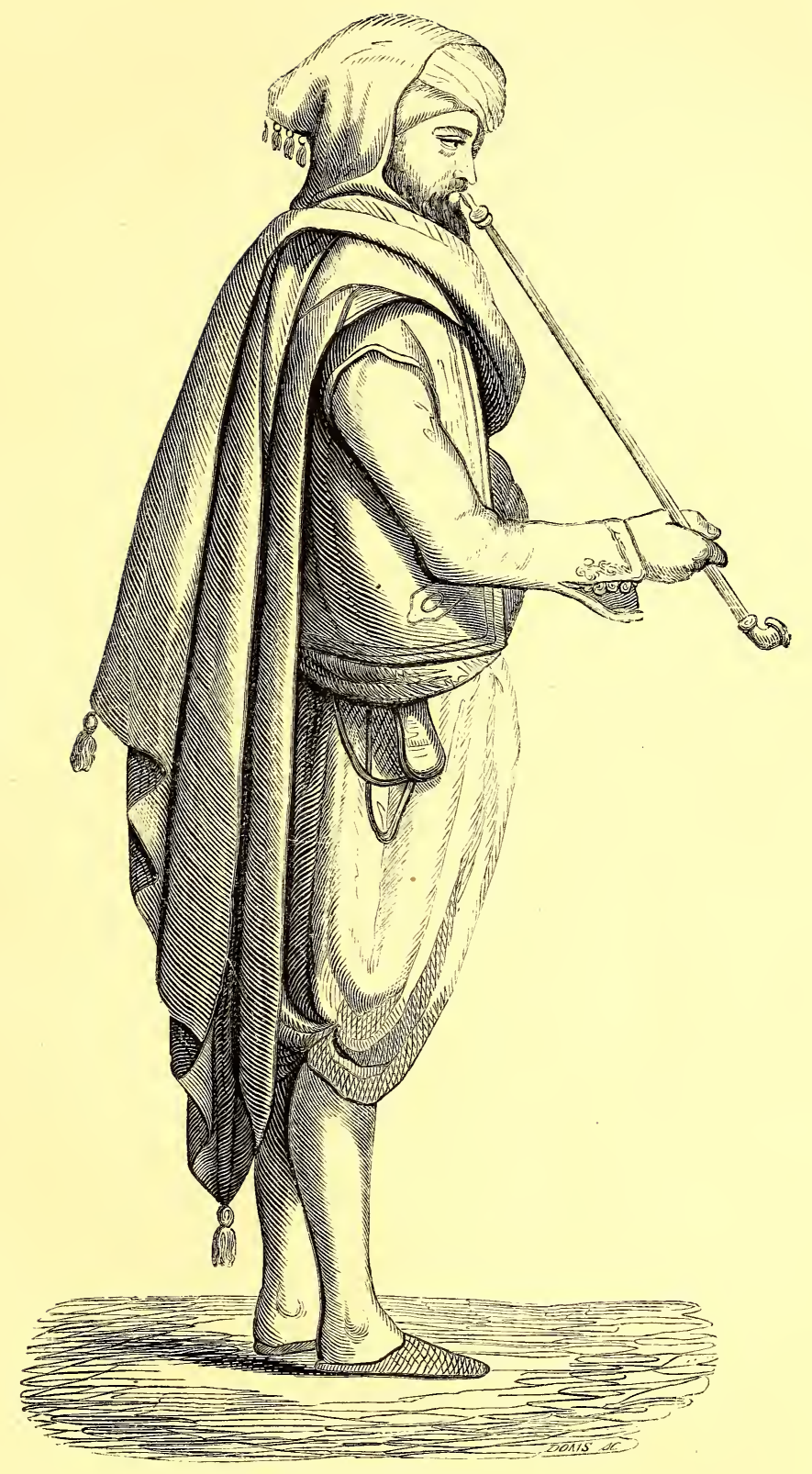

MARCHAND MAURE. 

Ces shaushs étaient autrefois des personnages d'une haute importance; car c'étaient eux qui, lorsqu'un pacha avait été condamné par le sultan, devaient lui appliquer le fatal cordon. A cet effet ils portent encore aujourd'hui une ceinture de métal au-devant de laquelle se trouve une grande boîte qui servait autrefois à serrer le cordon. Maintenant elle est vide, ce dont nous pûmes nous convaincre nous-mêmes; car la cérémonie terminée, les shaushs ne firent aucune difficulté d'ôter leur ceinture et de nous la laisser examiner de près.

\ Dès que le bey entra dans la salle de justice, le shaushsalam annonça son arrivée d'une voix de stentor, en langue turque, et salua le prince. Le shaush salua ensuite tous les membres du divan à mesure qu'ils entraient dans la salle. Le bey seul était assis ainsi que les greffiers; tous les autres assistants sont obligés de se tenir debout, quoique l'audience dure souvent plusieurs heures. On me donna cependant, ainsi qu'aux personnes qui étaient venues avec moi, en notre qualité d'étrangers, des chaises de jonc, et nous nous assîmes à la droite du trône. La cérémonie commença par un baise-main général de tous les assistants, au nombre desquels se trouvaient cette fois plusieurs chefs arabes, ce qui fit durer plus d'une demi-heure cette partie de la cérémonie. Le bey tenait la main étendue et le coude appuyé sur la hanche; car il doit présenter à ses sujets non le dos, mais la paume de la main; c'est tout le contraire pour les chrétiens. Il arrive parfois que les consuls, par une grâce particulière, obtiennent aussi l'honneur de baiser la paume de la main; ce dont ils sont aussi fiers que lorsque nos ministres daignent sourire à leurs protégés. Du reste, Son Altesse prêtait fort peu d'attention à la cérémonie, et s'entretenait sans cesse avec les personnes qui se trouvaient à côté d'elle. Les plus intimes se contentaient de baiser une seule fois la main ; mais, pour beaucoup d'autres, l'affaire devenait bien plus compliquée : ils pressaient leur front sur la main du prince, qu'ils baisaient ensuite à deux ou trois reprises; mais tous y mirent la même ardeur et la mème tendresse que s'ils eussent baisé la main d'une maîtresse adorée. Néanmoins, le bash hamba (général des hambi, corps composé de 300 officiers à cheval), qui se tenait debout à la gauche du trône, avait soin de s'emparer du bras de chaque nouvel arrivant, afin de prévenir toute tentative d'homicide. Le dernier qui passa fut le boulanger de la garnison; après avoir, à son tour, baisé la main du pacha, il lui présenta, en poussant un grand cri, quatre petits pains, formant la ration militaire qui lui revenait en qualité de soldat du Grand Seigneur. Le bey baisa le pain, en mangea une bouchée et dit ensuite avec un accent d'humilité : « Puisse Dieu m'en donner autant chaque jour!

๖ Cette cérémonie terminée, on présenta à la cour et aux personnes de distinction du café; le bey reçut en outre une pipe magnifique qui avait au moins dix pieds de long. Aussitôt qu'il en eut tiré quelques bouffées, l'audience commença. Sous tous les rapports elle ressembla à celle à laquelle j'avais assisté chez le gouverneur de la ville; le sujet des procès était souven l de la plus mince importance, sans pour cela que la patience du souverain parût se lasser. M. Raffo ', qui avait eu la bonté de se placer à côté de moi, m'expliqua quelques-uns des cas; mais, comme il avait lui-même des devoirs à remplir, et que le bey l'appelait souvent auprès de lui, les renseignements qu'il me donna furent trop incomplets pour que je puisse en rien rapporter ici. Quoi qu'il en soit, je crus m'apercevoir que les plaideurs se retiraient, en général, satisfaits de l'arrêt.

- Tout à côté du bey, à sa droite et sur les marches du trône, se tenait son fils aîné, Sidi-Achmet, jeune prince de vingt-six ans, qui, avec cet air de profond respect que

1 Italien et chrétien, secrétaire du bey. 
tous les enfants de ce pays montrent pour leurs parents, tantôt présentait à son père ses lunettes pour qu'il pût lire les requêtes qui lui étaient adressées, tantôt lui tendait un crachoir d'argent. A gauche, ainsi que je l'ai déjà dit, il y avait le bash hamba, et un peu plus loin le nouveau sapatapa, qui quittait souvent sa place pour aller causer avec les plaideurs un peu éloignés, et venait ensuite rapporter au bey ce qu'ils lui avaient dit. A mesure qu'une affaire était jugée, et il y en avait fort peu à l'égard desquelles une remise parût nécessaire, le sapatapa déchirait sur-le-champ la requête présentée.

Les habitants des parties du désert, où le sol est composé de sables mouvants, acquièrent une grande dextérité à courir sur ces sables sans y enfoncer les pieds. Pour porter le corps avec l'aplomb nécessaire, on assure qu'ils se lestent d'un certain poids. Quoi qu'il en soit, un cavalier ne peut les atteindre à la course à travers ces sables. Ils vivent de lait de chameau et de dattes; ils entassent des fruits dans des jarres, mettent un poids par dessus, et les laissent fermenter : il en découle une liqueur qu'eux seuls peuvent supporter. Ils sont d'ailleurs très-habiles à flairer, pour ainsi dire, l'eau sous les sables. Lorsqu'ils creusent pour en chercher, ils ont grand soin, après.en avoir puisé, de recouvrir la source; aussi le voyageur étranger n'y rencontre-t-il jamais autre chose que le sable sec et aride.

Les environs de Tunis, quoique mieux garnis de villages et de fermes qu'aucune autre partie de la régence, ont aussi leur population nomade; elle n'est cependant pas organisée en arch (tribu) ou en nouadja (branches de tribu), mais elle se compose de familles occupant quatre, six, huit tentes, et appartenant à la même tribu. Ces Arabes sont souvent au service du bey ou d'un propriétaire quelconque du sol sur lequel ils campent et qu'ils labourent; quelquefois aussi ils louent des champs à l'année et les cultivent pour leur compte.

\section{ALGERIE.}

Cet ancien royaume de la Barbarie est borné au nord par la Méditerranée, à l'ouest par l'empire de Maroc, à l'est par les royaumes de Tunis et de Tripoli, et au sud par le désert. Il a 227 lieues géographiques de longueur, sur une largeur encore mal déterminée, mais qui ne dépasse pas 20 à 20 lieues, et s'étend de $7^{\circ} 50^{\prime}$ de longitude est, à $4^{\circ} 30^{\prime}$ de longitude ouest. Cette contrée est traversée par le Lovat et l'Ammer, qui sont les ramifications de l'Atlas; les rivières les plus considérables sont le Chélif et le Ouad-Djidi. Le climat est tempéré; les pluies sont assez abondantes, les sources nombreuses, et la végétation riche et variée : les tremblements de terre sont fréquents sans être redoutables. Le sol est généralement très-fertile; indépendamment des animaux domestiques de l'Europe, il y a le chameau, le lion, le léopard, l'autruche, et autres animaux sauvages.

On fabrique dans ce pays des étoffes de soie, particulièrement des ceintures, des mouchoirs, des tapis moins beaux, mais plus doux et à meilleur marché que ceux de Turquie. Le commerce d'exportation consiste en laine, cire, ceintures de soie, plumes d'autruche, grains, peaux de chèvre et de mouton, poils de chameau, bêtes à cornes et moutons; on y porte des marchandises manufacturées et des denrées coloniales.

Les prinipales villes sont : Alger, que les Arabes appellent Al-Djézä̈r (les îles), ce repaire de pirates qui depuis des siècles mettait à contribution toutes les nations chrétiennes. Le 14 juin 1830, l'armée française s'empara de cette ville et de son territoire, 


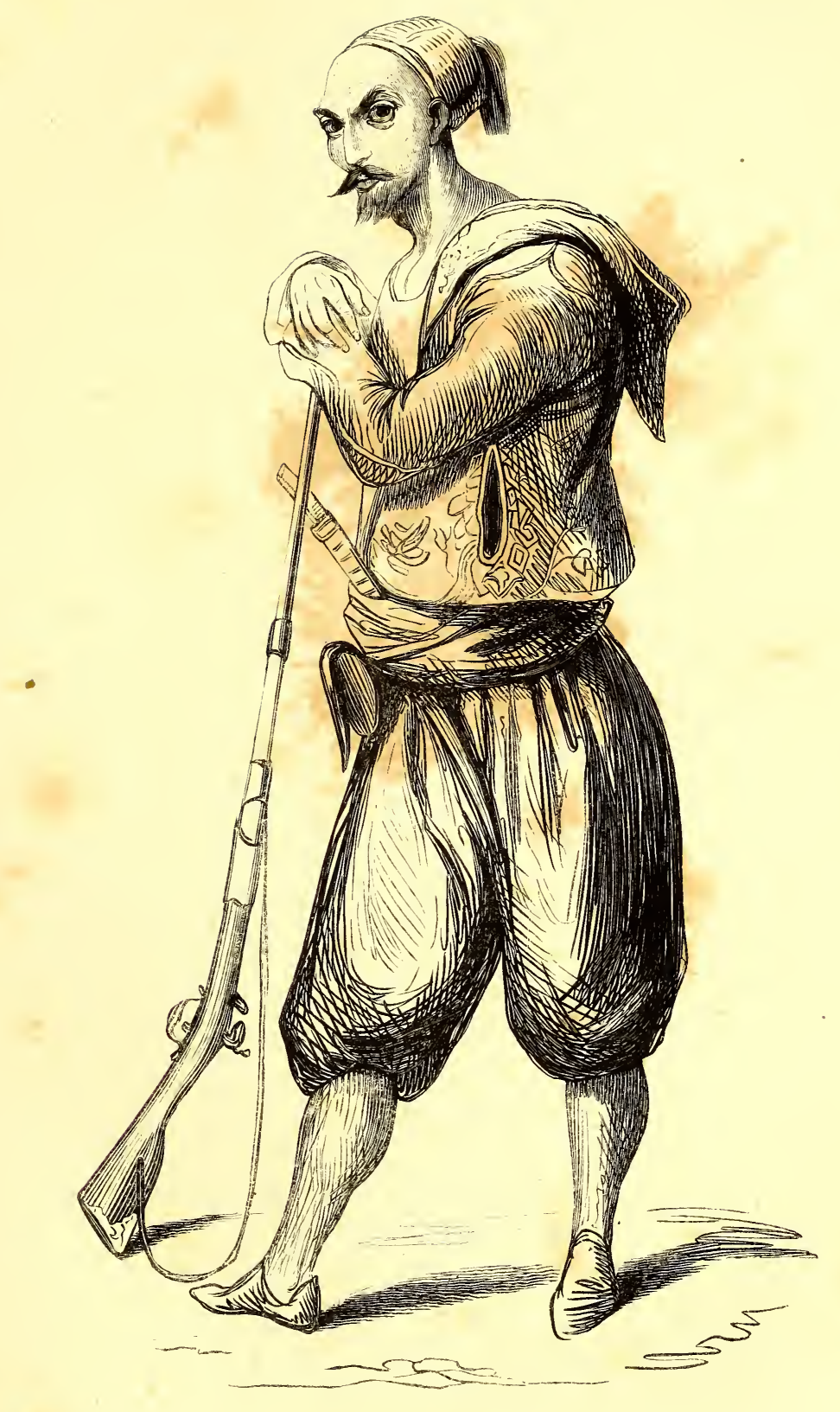

FANTASSIN REGULIER DABDEL-KADER.

Algérie 


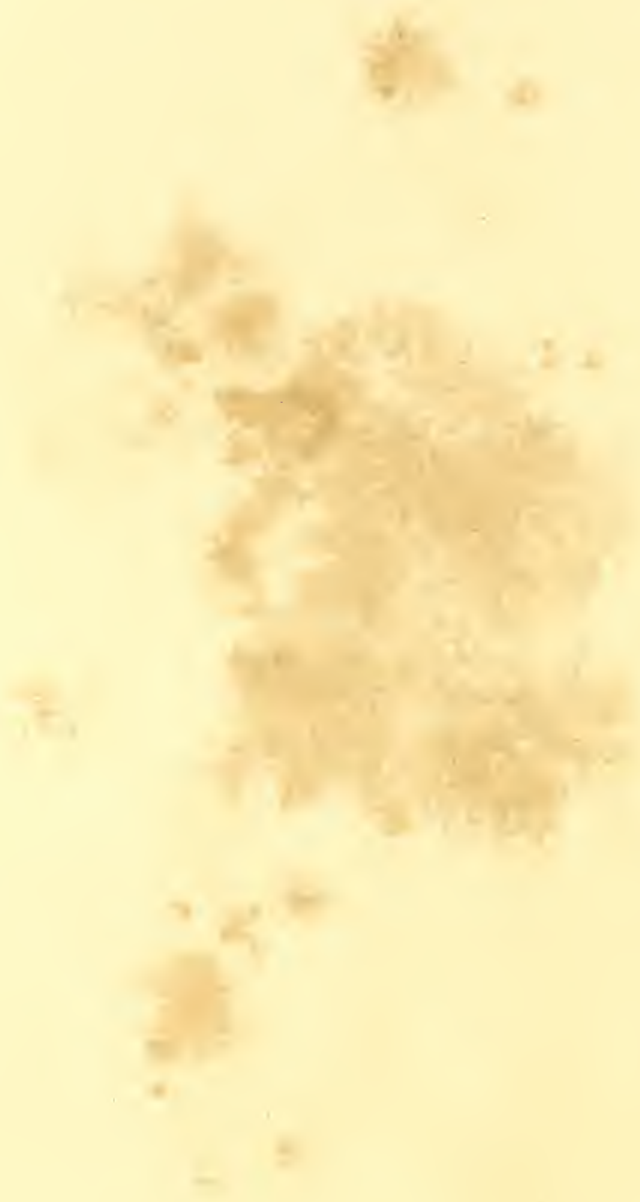

it 


et affranchit ainsi la chrétienté d'un fléau redoutable et du tribut qu'elle payait à un chef de barbares; KolÉaH, à 8 lieues sud-est d'Alger; BLIDAH, dans une position délicieuse, au pied de l'Allas; MÉvéAII, où résidait de bey de Titteri, bâtie sur un plateau situé au delà de la première chaîne de l'Atlas; Miliana, qui parait ètre l'antique Malliana de l'itinéraire d'Antonin, et qui n'offre rien de remarquable; Bugra, en français Bovgie, sur l'emplacement d'une antique cité appelée Choba; Constantine, au centre de la vaste province de ce nom, qui, par suite des injustes agressions de son bey, a élé conquise, en 1837, par l'armée française. Elle est assise sur un plateau élevé, à 600 mètres de la mer; elle est environnée d'une muraille de brique; Collo, appelée par les Arabes Calla ou Coullou, est une ville de 2,000 âmes, située au bord de la mer; Stora, au fond d'un golfe auquel elle donne son nom, et à trois quarts de lieue de laquelle s'élève la nouvelle cilé de Philippeville, construite en 1838, et dont la population est d'un millier d'individus; Bona ou Bone, en arabe Beled-el-Areb, située à environ 17 lieues à l'est de Philippeville; Bone est une ville sale et mal bâtie, mais son port est vaste et commode; Mechan autrefois célèbre et florissante, mais aujourd'hui peu peuplée et peu commerçante; la moderne Cherchelle, dans la partie occidentale de l'Algérie ou province d'Oran : ses maisons sont couvertes en tuiles; MAtMoura, éloignée d'un quart de lieue de Moslaganem, est devenue un point militaire important; MaZaGran, sans fortification et entourée de maisons crénelées, où la $10^{\circ}$ compagnie du 1 er bataillon d'Afrique, commandée par le capitaine Lelièvre, soutint, du $\mathbf{3}$ au 6 février 1840, l'assaut donné à ces braves par un corps de 12,000 Arabes, qui fut repoussé; Oran, remarquable par ses solides fortifications; Tlemsen, à quelques lieues des frontières de l'empire de Maroc : on y compte un grand nombre de mosquées; Maskarah, à 23 lieues au sud-est d'Oran : elle est située sur le versant méridional des montagnes appelées Chareb-el-Rirh; ELL-KALLAH, ville sale et mal bâtie, mais très-industrieuse.

Nous ne dirons rien de l'ancienne Algérie, et nos renseignements historiques se borneront à une courte nomenclature des changements apportés dans celte contrée depuis quelques années.

La chute du gouvernement turc, en brisant les liens qui rattachaient les chefs principaux des tribus au gouvernement central, rendit pour un instant les tribus arabes à leur existence originelle. Mais depuis longtemps, dans la province d'Alger, l'autorité française a, à cet égard, rétabli les anciennes dispositions administratives, en rattachant à elle le principe d'une constitution sociale qui suffira longtemps encore aux races purement indigènes. Dans la province d'Oran, le territoire restreint, administré directement par la France, n'a dû que faiblement attirer, sous ce rapport, l'attention du gouvernement; mais dans la province de Constantine, le fil des anciennes traditions a été tout à fait renoué, el, sauf le changement de souverain et l'amélioration réelle de leur condition, les sociétés arabes, ménagées et protégées, conservent une organisation que le temps n'est pas venu modifier.

Les sacrifices d'hommes et d'argent que la France a faits dans l'Algérie doivent un jour porter leurs fruits. Pour donner une idée des importantes améliorations que cette contrée a éprouvées, il suffit de dire que d'immenses travaux ont déjà été exéculés. Ces travaux consistent en canalisation, desséchement de marais, construction d'édifices publics et particuliers, etc.

Le gouvernement, en prètant son actif concours au mouvement de migration qui porte vers l'Algérie des populations françaises et même étrangères, le gouvernement a dû s'attacher à régulariser ce mouvement en n'appelant dans cette colonie qu'une population laborieuse. 
L'augmentation de la population européenne a été, en 1839, de 2,945 individus. La population européenne fixéc en Algérie pouvait être évaluée, en 1840, à plus de 26,000 habitants.

La population indigène, à la même époque, répartie dans les villes, s'élevait à 27,734 individus.

Les produits des impôts se sont élevés, en 1839 , à $4,469,000 \mathrm{fr}$., et les dépenses à $32,345,000 \mathrm{fr}$.

Le domaine géuéral comprend deux genres d'immeubles : ceux qui sont affectés à des services publics, et ceux dont les produits entrent dans les caisses du gouvernement colonial. Cette partie du domaine a donné lieu dans les trois dernières années à une recette d'environ $200,000 \mathrm{fr}$. par an.

Les bois de l'État, dont la reconnaissance n'a point encore été faite complétement, se composent, dans leurs parties reconnues, de 12,000 hectares de haute futaie, et de 7,כ00 hectares de broussailles susceptibles de devenir taillis.

Quant au rapport commercial, l'Algérie présente des résultats qui donnent de grandes espérances pour l'avenir.

Des corps indigènes à la solde de la France ont été organisés en 1833, sous le nom de spahis auxiliaires. On a fait marcher, dans plusieurs circonstances, en leur donnant des vivres seulement, tous les cavaliers des trois outhans des Beni-Mouça's et Khachna, bien qu'ils ne fussent pas inscrits comme spahis auxiliaires.

Le service des Arabes considérés comme spahis auxiliaires, est utile en temps de guerre et même en temps de paix. Ces spahis font aussi un service de police, comme auxiliaires des gendarmes mores. Ces derniers sont principalement chargés de la garde des blockhaus et autres postes situés dans des lieux malsains pour tous autres que des indigènes.

On a formé un bataillon d'indigènes sous le titre de tirailleurs de Constantine. Dans la province de ce nom, dans celle d'Alger, 300 jeunes Koulouglis forment un corps irrégulier. Enfin, la province d'Oran renferme 950 cavaliers douairs et zmela's.

La conquête de l'Algérie et les sacrifices de la France pour la conserver sont nonsculement favorables à la civilisation de cette contrée, mais encore au commerce que peuvent y entretenir toutes les nations du globe.

Les différents peuples qui habitent l'ancienne régence d'Alger sont les Mores, les juifs, les Turcs, les Berbers, les Arabes et les Koulouglis.

Les Mores paraissent descendre des anciens Mauritaniens et des anciens Numides, habitants aborigènes de l'Afrique. Ils ont la peau un peu basanée, mais cependant plus blanche que celle des Arabes; les cheveux noirs, le nez arrondi, la bouche moyenne, les yeux très-ouverts, mais peu vifs; les muscles bien prononcés, et le corps plutôt gros que maigre; leur taille est au-dessous de la moyenne, et leur démarche est grave et fière. Les femmes moresques sont assez jolies de figure; l'embonpoint étant une beauté aux yeux des Mores, elles font tout ce qu'elles peuvent pour l'augmenter; les mères ont l'habitude de tirer la gorge des jeunes filles pour l'allonger; leur taille, par suite de cette pratique, est tout à fait déformée avant l'àge de trente ans.

Le costume des hommes diffère peu de celui des Turcs; mais celui des femmes s'en éloigne beaucoup. Dans la maison, la femme est à peine vêtue; sa tête est nue; une petile chemise à manches courtes, et un caleçon fixé sur les reins lui cachent le ventre et une partie des cuisses; un fichu de coulcur et ordinairement en soie, noué par devant de manière à former un petit jupon ouvert, complète l'ajustement; car, dans ce négligé, avec lequel les Moresques ne se font aucun scrupule de se montrer sur les balcons de leurs terrasses, elles n'ont ni bas ni souliers. Le costume paré de l'intérieur 



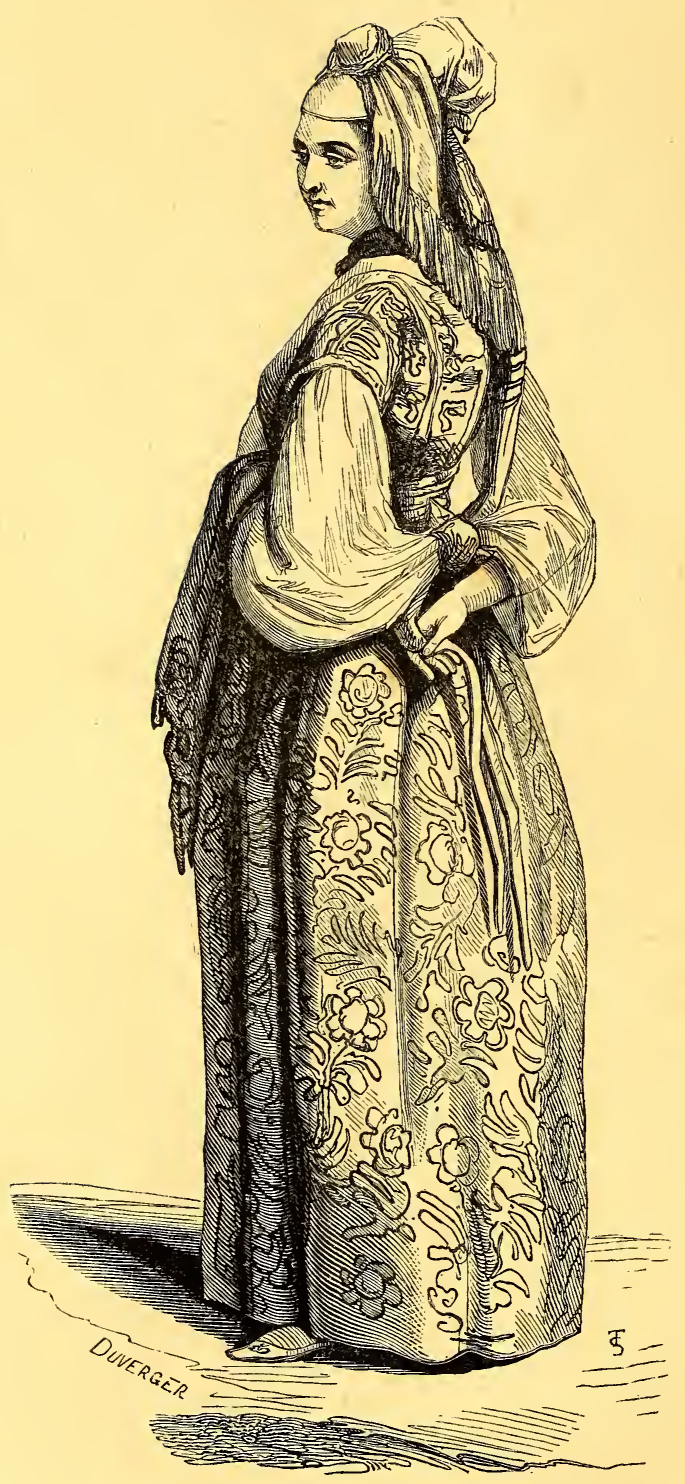

DEMOISELLE JUIVE D'ALGER. 


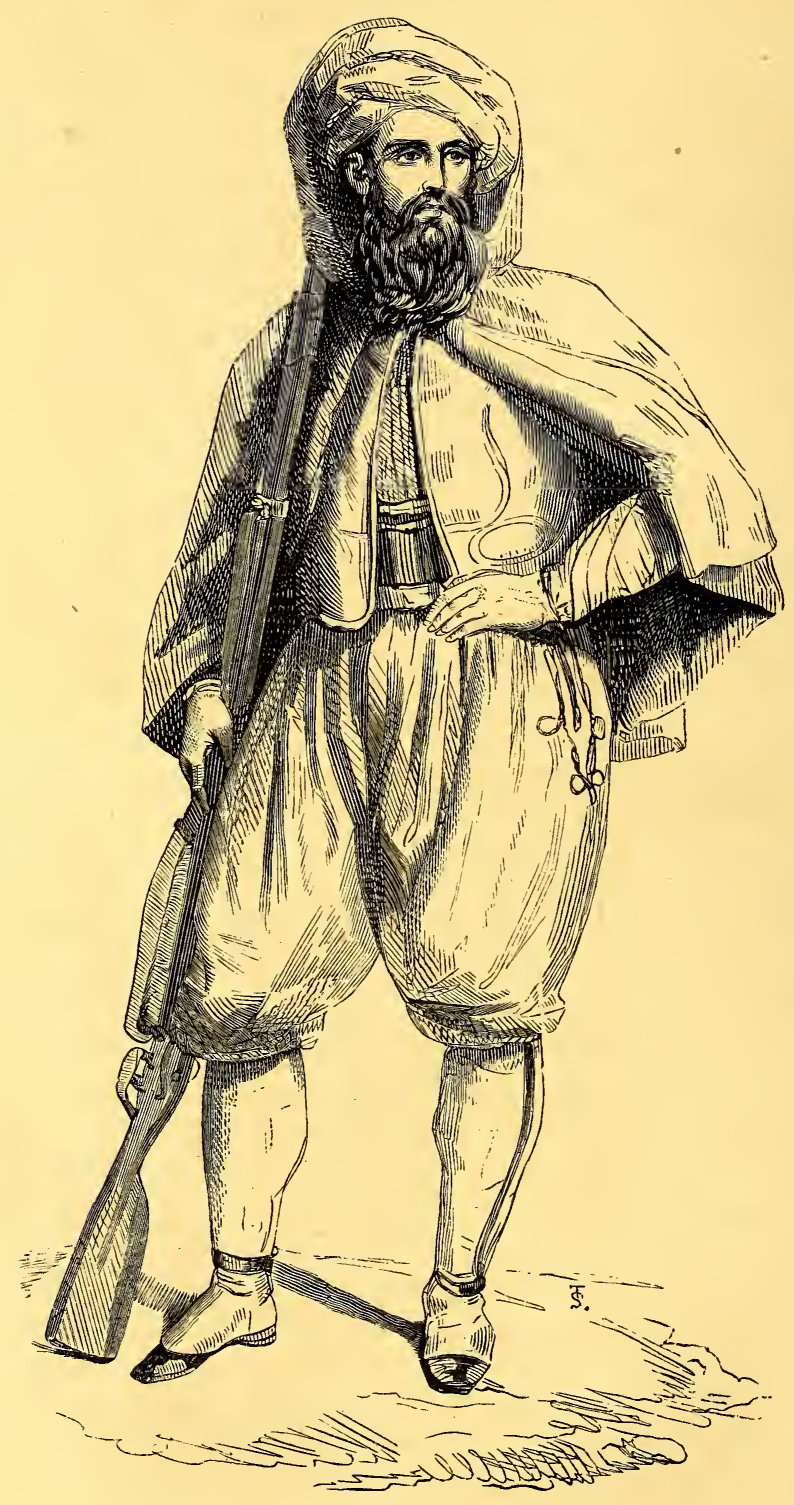

ZOUAVE.

(Algérie.). 
est très-riche, et même élégant. Elles ont les cheveux tressés, et, sur le sommet de la tête, un grand bonnet, pointu comme celui des Cauchoises, orné de lames de métal et de rubans, s'élève en s'inclinant en arrière. Du bas de ce bonnet tombe jusqu'à terre une large bande de drap d'or terminée par des franges. De leurs oreilles pendent des boucles plus ou moins belles, selon leur fortune; leur cou est chargé de colliers, dont la richesse varie aussi suivant les rangs. Sur une chemise très-blanche, fixée aux poignets par des bracelets, elles ont une veste à manches courtes richement ornée de broderies d'or; un pantalon, qui descend jusqu'à mi-jambe et qui est brodé comme la veste, passe par-dessous celle-ci, tandis qu'une riche ceinture les arrête tous les deux sur les hanches; enfin un grand châle de soie, passé par derrière et noué élégamment par devant, entoure le bas du corps, cache une des jambes et vient traîner à terre. A ce costume vraiment éblouissant se joint le contraste d'une jambe nue, ornée sur le coude-pied d'un grand anneau doré, tandis que le pied est à peine maintenu dans des souliers de velours brodés d'or. Quand les Moresques sortent, elles mettent un large pantalon de toile ou de calicot blanc qui vient s'attacher en fronçant au-dessus de la cheville ; par-dessus le pantalon, un foulard qui leur sert de jupon; une chemise courte qui entre dans le pantalon, et sur la chemise une ou deux vestes assez semblables à celles des hommes. Sur tous ces vêtements, elles jettent une tunique de gaze de laine blanche; elles portent sur la figure un petit mouchoir blanc attaché par derrière, et qui la cache depuis le menton jusqu'aux yeux. Coiffées de leur grand bonnet métallique, elles s'enveloppent d'un manteau de laine blanche qui descend jusqu'aux genoux et dans lequel elles cachent leurs mains, ne laissant voir absolument que leurs yeux. Elles marchent d'un pas grave et lent dans les rues.

L'établissement des Turcs dans l'Algérie date de l'époque où, envoyés au secours des Mores sous le commandement du fameux corsaire Barberousse, et de l'Arabe Sélim-Eutem, ils chassèrent les Espagnols d'Alger. Ce nouvel État se mit sous la protection de la Porte Ottomane. Ces Turcs ont le regard sévère, les traits du visage fortement prononcés, et la peau aussi blanche que celle des Européens.

Les caractères physiques des juifs africains sont absolument les mêmes que ceux des juifs qui habitent l'Europe. Leur costume est assez semblable à celui des Mores, aux couleurs près. Un turban plus petit, deux vestes, dont une à manches longues, un bernous, petit châle de drap qu'ils jettent sur l'épaule, une ceinture, une large culotte qui descend jusqu'aux genoux, les jambes nues et des souliers en peau de couleur. Celui des femmes, qui sont généralement jolies, a quelque analogie avec celui des paysannes de certaines parties de la Normandie. Leur haute coiffure est le seul ajustement qu'elles aient emprunté aux Moresques; le reste se compose d'une robe de laine noire ou bleue très-large, à manches courtes, qui laissent dépasser celles de la chemise. Elles portent aussi des caleçons; mais leurs longues jupes ne laissent voir que le bas de la jambe nue, et que leurs pieds chaussés avec une espèce de pantoufle sans quartier qui ne couvre que les doigts du pied. Lorsqu'elles sortent, elles s'enveloppent, depuis le haut du bonnet jusqu'au talon, d'une gaze légère de laine blanche, qu'elles relèvent de la main gauche de manière à laisser voir la moitié du visage, et surtout les yeux, qu'elles font jouer avec art el coquetterie.

Les nègres du pays d'Alger, dont le costume est absolument le même que celui des Mores, sont originaires du centre de l'Afrique; quant à l'habillement des femmes, il ne diffère de celui des Moresques que par le grand bonnet poinlu qu'elles ne portent pas.

Les Arabes se divisent en deux grandes classes : les cultivateurs et les nomades, ou Arabes-Bédouins. Ils sont généralement grands, bien faits et d'une couleur un peu 
brune. Ce que leur costume a de particulier, c'est le bernous, grand manteau de laine auquel tient un capuchon.

Quelques femmes se tatouent les membres et la poitrine; leur habillement se compose d'une chemise de laine blanche, fort large, à manches courtes, qui est liée avec une corde au milieu du corps.

Les Berbers vivent dans les montagnes, depuis le royaume de Tunis jusqu'à l'empire de Maroc. Ils se divisent en un grand nombre de tribus. Leur taille est moyenne; leur leint est brun, quelquefois même noirâtre; leurs cheveux sont également bruns et lisses; et bien que leur corps soit maigre, ils sont généralement bien faits. Leur tête est plus ronde que celle des Arabes; mais rarement on trouve chez eux ces beaux nez aquilins, si communs chez ces derniers. Ce qui les distingue surtout de ceux-ci, c'est l'expression de leur figure qui a quelque chose de sauvage et même decruel. Ils sont les plus belliqueux des habitants des États barbaresques.

" L'habit le plus simple des Berbers, dit Malte-Brun, est une chemise ou tunique à manches courtes, et le chaïk, longue pièce de laine blanche dont ils se drapent à la manière des anciens; leur tête est couverte d'une petite calotte blanche en feutre; et lorsqu'il fait froid, ils mettent le bernous comme les Arabes. Les femmes s'habillent à peu près comme les hommes.

La partie méridionale de la province d'Oran est soumise au gouvernement d'Abdel-Kader; elle se divise, d'après les naturels, en deux régions : l'orientale ou le Cherk, et l'occidentale ou le Gharb, peuplées l'une et l'autre par un grand nombre de petites tribus.

Les Algériens regardent comme un péché de porter l'Alcoran sous la ceinture, de laisser tomber une goutte d'urine sur leurs vêtements. La croyance où sont les Barbaresques que c'est une pollution de se salir avec de l'urine, a donné lieu chez eux à une coutume singulière, c'est que les hommes s'accroupissent comme les femmes pour uriner, et il est défendu de paraître en justice comme témoin à quiconque a été vu uriner debout. Il est encore défendu de se servir de plume au lieu de pinceau pour écrire, d'avoir des livres imprimés, des peintures ou images quelconques qui représentent des hommes ou des animaux, de se servir de cloches, de laisser entrer des chrétiens ou des femmes dans les mosquées, d'échanger un Turc pour un chrétien, de toucher de l'argent, de tirer du sang et de panser une plaie avant d'avoir fait la prière du matin; de manger des escargots qu'ils regardent comme sacrés; de châtier les enfants en d'autres parties du corps que sous la plante des pieds; et de fermer les portes pendant la nuit.

Les Algériennes, celles surtout qui sont riches, mènent une vie oisive, et passent tout leur temps à leur parure, sur un sofa, à aller au bain, à visiter les tombeaux de leurs parents et de leurs saints, et à s'amuser dans les jardins où leurs maris viennent fumer leur pipe et prendre le café.

Les Algériens mènent un genre de vie fort rude en mer : ils ne prennent avec eux ni lits ni malles; et toutes leurs provisions consistent en biscuit, en eau, en un peu de riz et d'autres denrées communes d'assez mauvais goût.

L'uniforme des Zouaves consiste en une large culotte rouge, tombant au-dessous du genou, sur de grandes guêtres en cuir; une veste bleue à parements rouges, et pardessus un petit bernous qui couvre la tête. Les Zouaves portent la barbe fort longue.

Nous avons donné le costume d'un grand chef arabe du désert, et celui d'une esclave servante à Alger.

Jusqu'à ce jour, on n'a pas encore pu obtenir le chiffre exact de la population de la ville d'Alger. Le maire ayant projeté un dénombrement qu'il s'efforça de rendre plus. 



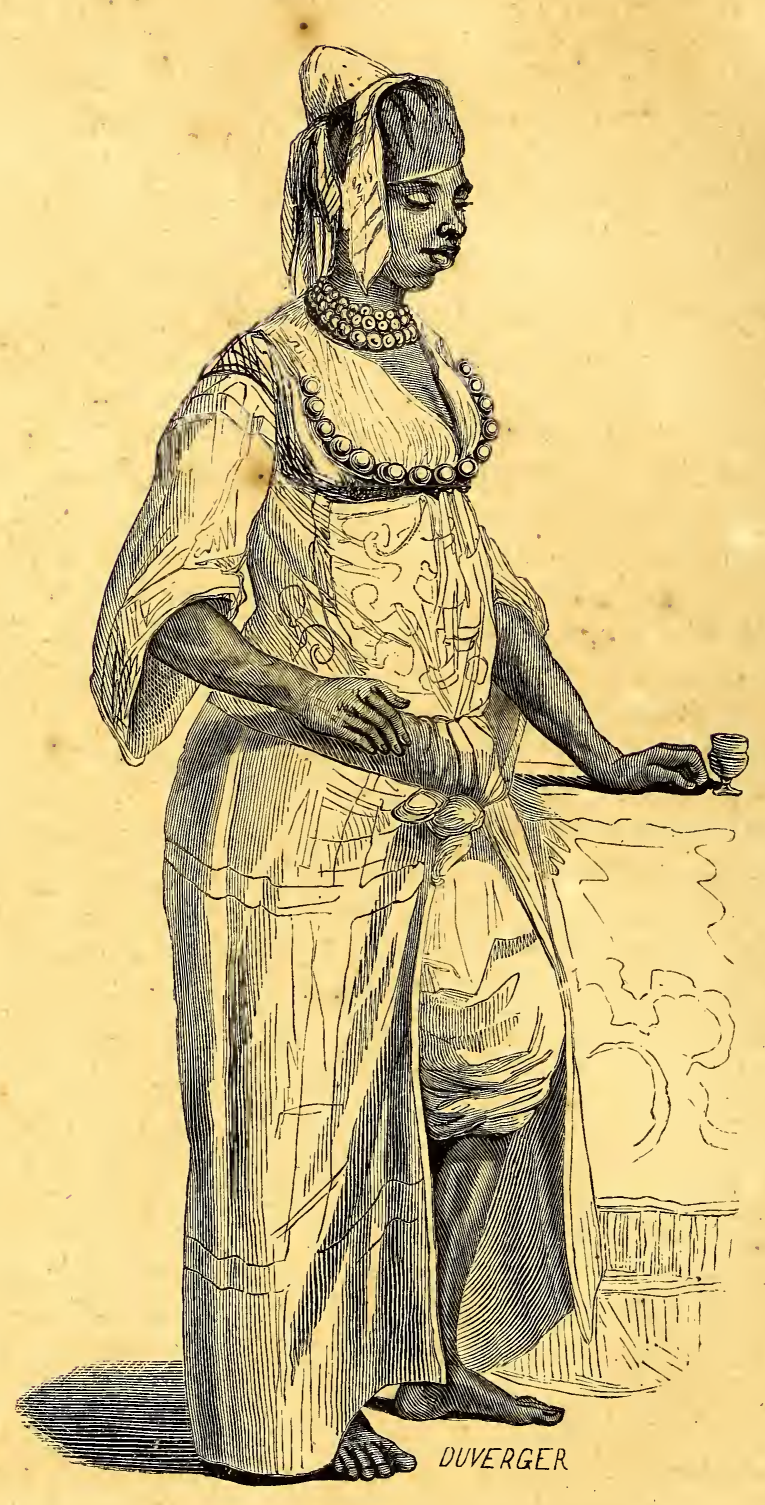

ESCLAVE SERVANTE A ALGER. 
exact que ccux qui avaient été tentés jusqu'à ce jour, et qui étaient venus échoner devant les mœurs des indigènes, et surtout devant celles des Mores, qui sous aucun prétexte ne laissent pénétrer chez eux. On sait qu'ils reçoivent les hommes dans la skiffa, espèce de vestibule de leurs maisons, mais ne laissent jamais franchir le seuil intérieur, de sorte qu'on ne sait pas quelle est leur population. N'ayant pas voulu forcer la consigne pour vérifier le nombre des habitants de chaque maison, le maire se contenta de la déclaration du More, chef de la famille. Depuis, il a obtenu dans l'intérieur des maisons la présence d'un médecin français pour constater, après un décès, la nature de la maladie et de la mort. La première fois que celui-ci se présenta, ce fut au lit d'une femme; à sa vue, toutes celles qui pleuraient autour du lit se sauvèrent effrayécs de cette infraction inusitée; mais après leur avoir fait entendre que c'était une mesure de santé publique qui intéressait toute la cité, la raison eut plus d'empire sur leur esprit que la coutume, et dès lors le docteur français fut admis dans toutes les maisons où l'appelait ce triste ministère.

Les Mores ont un usage à peu près analogue à celui de la visite du médecin après la mort : le beit-el-mal doit recevoir la déclaration de chaque décès.

Chez les Mores, l'administration municipale n'a pas la même nature et la même existence que chez nous; les pouvoirs correspondants à ceux du maire sont disséminés en plusieurs autorités, ainsi : un magistrat est chargé du service des canaux souterrains, qui remplacent dans chaque maison les lieux d'aisance, et qui tous communiquent aux égouts dans lesquels toutes les immondices ont un commun rendez-vous. Un autre démembrement du pouvoir municipal est la police, qui est fort bien faite du reste. Quand un vol ou un assassinat est commis dans une rue, tous les habitants sont frappés d'une contribution pour n'avoir pas livré le coupable; par ce moyen, ils sont tous intéressés à veiller à la sûreté publique; aussi se commet-il rarement un crime dans ces rues qui, cependant, sont toutes étroites et obscures.

La nuil, de nombreuses patrouilles, revêtues d'obscurs costumes, sans armes apparentes, parcourent toutes les rues, se glissent dans l'ombre, et sont aussi redoutées présentes qu'éloignées. Elles vont sondant chaque porte; et si par hasard elles en trouvent une ouverte, on monte dans la maison, on en réveille le maître, puis clles continuent leur tournée. Le lendemain, un des gardes de la nuit vient demander au propriétaire négligent l'amende d'usage en faveur de la vigilante patrouille.

Les Mores ne sortent presque jamais la nuit; les juifs, qui sont à leurs yeux en état permanent de suspicion, sont exposés à des peines graves, s'ils circulent dans les rues après le coucher du soleil. Ceux qui veulent obtenir cetle permission se présentent au bureau de la police, et on leur donne, comme aux agents de celle-ci, une lanière de nerfs de bœufs, qui sert à les faire reconnaître par la ronde de nuit, à laquelle ils produisent celte espèce de mot d'ordre muet.

Rien n'est plus surprenant pour un étranger que la vue des rues d'Alger pendan la nuit. Comme nous l'avons dit, les rues sont fort étroites, au point que beaucoup d'entre elles ne permeltent point le passage d'un cheval. Elles ne sont éclairées, çà et là, que par de petites lanternes en papier, que chaque passant porte à la main, et qui forment autant de petits fanaux ambulants. Ces rues sont tapissées à droite et à gauche de petites boutiques fermées, et sur le devant desquelles sont des auvents ouverts qui n'ont pas plus de huit ou dix pouces de largeur. Ces auvents servent de couche à des indigènes auxquels on donne quelques sous par mois; de sorte que vous traversez la ville au milieu d'une double rangée d'hommes endormis ou éveillés, qui rèvent à haute voix, se remuent, et jouissent d'un fort bon sommeil sur ce lit dur et incommode, mais qui par là procurent à la ville une grande sécurité; au 
moindre bruit, au moindre cri d'alarme, cette population tout entière est sur pied.

a La garde de la ville, dit le docteur Shaw, est confiée à la tribu des Biscaras, répartie, lous les soirs, par leurs émirs, dans les rues, où ils couchent devant les boutiques sur des nattes, des matelas, voire même sur le pavé; si par hasard il arrive qu'on parvienne à volér sans qu'ils s'en aperçoivent, ils répondent de la valeur des objets enlevés, payent et sont punis sévèrement. L'émir qui les commande doit au dey un tribut annuel qu'il prélève ensuite sur chacun de ses subordonnés.,

\section{MAROC.}

Le Maroc, appelé par les Arabes Mogh'rèb-oul-Akssa, c'est-à-dire l'extrême Occident, est un débris des grandes monarchies africaines fondées par les Arabes. Cet empire du nord-ouest de l'Afrique se trouve entre $28^{\circ} 20^{\prime}$ et $35^{\circ} 50^{\prime}$ de latitude nord, et entre $3^{\circ} 40^{\prime}$ et $12^{\circ} 40^{\prime}$ de longitude ouest. Il est borné au nord par la Méditerranée et le détroit de Gibraltar, à l'ouest par l'Atlantique, au sud et au sud-est par le Sahara, et à l'est par le royaume d'Alger. Sa superficie est d'environ 24,379 lieues carrées; sa longueur, du nord au sud, est de 190 lieues, sa largeur moyenne de 190 lieues. Il est traversé du sud-ouest au nord-est par le grand Atlas, cette majestueuse chaîne de montagnes qui y montre ses sommels les plus élevés, couverts de neiges continuelles, et qui le coupe en deux parties, dont l'une, sur le versant occidental de la chaine, comprend les deux royaumes de Fez au nord et de Maroc au sud, et dont l'autre, sur le versant opposé, renferme ceux de Tafilett et de Souze, et les provinces de Sidjelmessa et de Draha.

On vante la fertilité de cet empire; le climat en est agréable et sain : de mars en septembre, le ciel est rarement couvert, et dans la saison pluvieuse, qui comprend les autres mois de l'année, les pluies ne tombent pas sans interruption; il se passe même peu de jours sans que le soleil se montre. La culture est très-négligée; la fécondité du sol est en général telle, que les productions croissent avec une vigueur et une abonlance extraordinaires. Ce pays, qui produit jusqu'à trois récoltes dans l'année, exporte une grande quantité de céréales, principalement en Espagne. Il pourrait approvisionner l'Europe entière de froment, d'orge et de riz; l'avoine y croît spontanément. On voit partoul dans les plaines et sur les collines, l'olivier et le figuier dans leur plus grande force, le citronnier, l'oranger, l'amandier, le dattier, le mûrier blanc, le colonnier, etc. On cultive avec succès plusieurs variétés de la vigne dans les parties septentrionales de l'empire. Cette contrée nourrit une grande quantité d'animaux; on y remarque principalement plusieurs espèces de chameaux, de beaux chevaux de race arabe, et des chèvres, parmi lesquelles celles de Tafilett sont renommées pour fournir les peaux les plus estimées des fabriques de maroquin. On compte parmi les animaux sauvages le lion, la panthère, la gazelle, l'hyène, le furet, quelques singes, et une espèce de marmotte; presque tous ces animaux ne fréquentent guère que les forêts et les frontières du Sahara où l'on rencontre aussi beaucoup d'autruches. Il y a des mines de fer, de cuivre, d'étain, d'antimoine, etc.; mais on en tire un très-faible parti. On extrait l'antimoine avec assez de soin, pour la fabrication des cosmétiques d'Orient. Le sel gemme s'y trouve en abondance et forme un article considérable d'exportation.

L'industrie se réduit à la fabrication d'objets de nécessité : les manufactures les plus importantes sont celles de maroquin rouge et jaune qui est très-estimé; on fabrique aussi quelques étoffes de soie et de laine. 
Le Marocain a le maintien grave el silencieux; il est peu communicatif; l'orgueil national lui fait mépriser les autres peuples; cependant on ne trouve chez lui aucun sentiment d'honneur individuel. Il est strict observateur de la foi musulmane. La reclusion des femmes est des plus rigides dans les villes. Les femmes des Arabes errants el des Berbers sont assujetties aux travaux les plus durs, et leur continuelle exposition aux ardeurs du soleil détruit bientôt toute trace de beauté et les garantit ainsi d'une rigueur inutile. La condition des esclaves chrétiens chez ce peuple cruel et inhumain est affreuse.

Les Marocains sont très-scrupuleux dans l'observance de leur carême appelé ramadan, pendant lequel ils se garderaient bien de prendre une seule goutte de café, et de fumer depuis le lever jusqu'au coucher du soleil.

Les chérifs ${ }^{2}$ ou empereurs fondent l'absolutisme de leur pouvoir sur l'aveugle superstition de leurs sujets. Ce monarque prend les titres les plus pompeux, mais sa cour n'a aucune magnificence; il ne se distingue de ses courtisans que parce qu'il ne va jamais qu'à cheval, et qu'il porte un parasol, attribut de la souveraineté. Dans les jours d'audiences publiques ou de cérémonies seulement, il est entouré d'un cortége plus nombreux que brillant.

Comme les Mores en général, ces souverains sont naturellement sombres; ils ont une nourriture uniforme, et les restes de leur table servent à leurs officiers. Le service intérieur du palais est confié à des Mores qui sont habillés à neuf tous les ans, et ne recoivent qu'un modique salaire. Les ouvriers qui travaillent pour l'empereur ne reçoivent aucune rémunération.

Une garde nommée hariffe, composée et commandée par des femmes, est chargée de se rendre dans les provinces pour faire subir la torture aux épouses des grands qui ont été arrêtés, afin d'obtenir d'elles les renseignements que l'empereur désire connaître.

Les femmes de l'empereur ne se font pas remarquer par leur luxe, et il en est qui reslent oubliées dans la ville impériale, abandon étrange si l'on considère que ces femmes, ayant le titre d'épouses d'après la loi, ne sont point esclaves, ont souvent le titre de princesses, ou sont filles de chérifs ou d'autres grands. La première épouse a la prééminence sur les autres, et est appelée grande reine.

Mariées ordinairement à des fils de chérifs auxquels elles apportent une dot considérable, les filles du monarque restent maîtresses d'elles-mêmes et continuent à habiter le palais durant la vie de leur père. Quant aux enfants mâles, l'empereur les investit, aussitôt qu'ils sont mariés, d'un gouvernement de ville ou de province, dans lequel ils ne se font pas faute d'exercer toutes sortes d'exactions. Lorsqu'ils poussent les choses trop loin, ils encourent des confiscations au profit du trésor; mais bientôt ils recommencent les extorsions, et c'est toujours le peuple qui souffre.

Il n'y a pas de loi qui assure la succession au trône, et, quoique l'opinion des Mores y porte de préférence le fils aîné en qui on suppose plus d'expérience que chez ses frères, l'élection du souverain ne repose guère que sur des éventualités.

Quel que soit le lieu où l'empereur se trouve, il donne quatre audiences par semaine; le public y est admis, et les plaintes sont écoutées sans aucune distinction. Les magisIrats qui prennent part aux soins du gouvernement sont ecclésiastiques ou militaires: le mufti et le cadi ont la juridiction des affaires civiles et religieuses; les pachas, les

1 Les Marocains nomment quelquefois leur souverain iman; les Mores l'appellent sultan, plus souvent sidna ou scidna (notre seigneur); ils ajoutent encore emphatiquement à ce titre celui de moulana (maltre). 
alcades et autres officiers militaires décident de celles qui ont rapport à l'État ou à l'armée. Mais les uns et les autres, servilement soumis au chérif, n'ont en réalité aucune espèce d'influence ni de volonté.

Le respect des Marocains pour la loi qui prohibe les jeux de hasard est tel qu'ils ont les cartes et les dés en aversion. Peut-être cela provient-il de ce que, en cas d'infraction à la loi, le cadi, outre qu'il oblige le gagnant à la restitution, le condamne à une amende ou à un certain nombre de coups de bâton.

Les chrétiens et les juifs ne peuvent pénétrer dans les mosquées, ni avoir aucun rapport avec les femmes du pays, à moins de se faire mahométans; ils on tencore le droit d'opter entre l'empalement ou le bûcher. Les supplices sont cruels dans ce pays, et beaucoup sont analogues à ceux en usage au Japon.

L'armement et la solde de l'armée ne coûtent rien à l'empereur, puisque chaque ville et chaque village sont dans l'obligation d'entretenir un nombre de soldats toujours prêts à marcher. Les cavaliers sont tenus de subvenir à l'entretien de leur monture. Les hommes mariés sont de préférence appelés à servir' en cas d'urgence on prend des jeunes gens; mais on ne leur donne pour arme qu'une lance ou un sabre, et quelquefois un simple bâton.

La marine est peu considérable, et la moitié à peu près appartient à l'empereur. Les Marocains sont moins pirates que leurs voisins de Tunis.

Comme presque tous les Barbaresques, les habitants du Maroc sont mahométans. Ils croient que ceux qui meurent, à quelque secte qu'ils appartiennent, sont sauvés s'ils meurent avant l'âge de quinze ans; mais que plus tard ils sont damnés à moins qu'ils ne professent l'islamisme. Les femmes étrangères au giron mahométan et qui meurent vierges avant leur quinzième année, sont destinées à complimenter les soixante et dix femmes que Mahomet promet à chacun de ses sectateurs dans son paradis.

Les Marocains portent une chemise fort courte avec des manches larges, pendantes ou retroussées. Ils ont sous cette chemise des caleçons de toile qui n'arrivent que jusqu'au genou, et leur laissent la jambe nue : leur chaussure consiste en pantoufles qui n'ont ni tirants ni talons. Ils portent pour vêtement une espèce d'habit à la turque qui se serre sur le devant, et est garni de cordons qui leur servent d'ornement. Cet habit, appelé hayke, est d'une étoffe de laine blanche, et a par derrière un capuchon avec un gland au bout. Il se serre sur les reins avec une écharpe de soie, à laquelle est adaptée une gaîne qui renferme deux ou trois couteaux dont le manche est un objet précieux. Leur coiffure se compose. d'un simple bonnet de laine, entouré quelquefois d'un morceau de mousseline pour en faire un turban.

Les femmes font usage d'une robe fermée jusqu'à la ceinture, aux manches de laquelle sont attachés plusieurs morceaux de mousseline. Les caleçons leur cachent tout le gras de la jambe. Elles arrangent leurs cheveux comme les Espagnoles, et les laissent tomber par derrière en deux tresses entremêlées de rubans. Elles portent des pendants d'oreilles d'or ou de pierres précieuses, des bracelets, et des pantoufles de maroquin rouge quelquefois enrichies d'or. Lorsqu'elles sortent, elles se couvrent la lète d'un voile blanc, qui ne leur laisse que les yeux à découvert. Dans les rues elles ne parlent jamais aux hommes, pas même à leur mari, auquel il est impossible de les reconnaître. Quand elles vont rendre visite à quelqu'une de leurs amies, elles laissent leurs pantoufles à la porte de l'appartement, ce qui en interdit l'entrée au maître même de la maison, et alors elles ôtent leur voile. 


\section{SÉNÉGAMBIE.}

A l'ouest de l'Afrique est située la Sénégambie, qui doit son nom à ses deux principaux fleuves : le Sénégal et la Gambie; elle est comprise à peu près entre $10^{\circ}$ et $18^{\circ} \mathrm{de}$ latitude nord, et entre $6^{\circ}$ et $20^{\circ}$ de longitude ouest; elle est bornée au nord par le Sahara, à l'est par la Nigritie, au sud par la Guinée supérieure, el à l'ouest par l'Allantique. Elle a 54,000 lieues carrées; sa longueur, de l'est à l'ouest, est d'environ 300 lieues, et sa largeur, du nord au sud, de 200 lieues.

Son climat est peut-être le plus chaud du globe; la cause en doit être attribuée aux vents d'est, qui y arrivent après avoir traversé le sol brûlant de l'Afrique dans toute sa largeur. Ces chaleurs sont heureusement tempérées par des nuits fraîches et par des pluies abondantes, qui ont lieu de juillet en octobre : c'est la saison nommée hivernage; des vents de sud-ouest règnent alors presque constamment.

Les végétaux acquièrent, sous le ciel de feu et sur le sol très-fécond de ce pays, des dimensions gigantesques : c'est là que le baobab, l'adansonia digitata de Linné, qui, de son fruit, surnommé pain de singe, nourrit abondamment les nègres, et le bombax, déploient toute leur grosseur; on y voit en abondance les palmiers, les cocotiers, divers mimoses, les cés ou arbres à beurre, les orangers, les citronniers, les tamariniers, l'ébénier, etc.

On trouve dans la Sénégambie beaucoup d'éléphants, de singes, d'antilopes, de gazelles, d'hippopotames, de lions, de panthères, de léopards e $t$ d'hyènes. Il y a des chacals; la giraffe se montre quelquefois. Le cheval et l'âne des bords du Sénégal sont beaux; on voit quelques chameaux dans le nord. Les indigènes élèvent des bœufs, des buffles, des moutons et des chèvres. D'énormes serpents se cachent dans les forèts herbacées, et le crocodile est commun dans les fleuves. Parmi la inultitude des oiseaux, on remarque l'aigrette et de jolis perroquets. On est affligé par d'innombrables insectes dégoûtants ou venimeux, et par des nuées de sauterelles; les caméléons sont communs; les abeilles sauvages abondent. Les richesses du règne minéral sont peu connues; il y a de célèbres mines d'or dans le Bambouk.

La côte, généralement très-basse et bordée d'immenses terrains d'alluvion, présente deux principales directions, du nord-est au sud-ouest, jusqu'au cap Vert, ensuite du nord-nord-ouest au sud-sud-ouest, jusqu'au cap Verga, limite de la Guinée; les parties les plus hautes sont les monts Badet, Courx et Tangé, dans le sud; c'est là que se trouvent les sources des trois principaux fleuves du pays, le Sénégal, la Gambie et le Rio-Grande; tous trois se jettent dans l'Atlantique.

Les plaines fertilisées par le Sénégal et la Gambie comprennent une multitude de petits États, dont quelques-uns sont habilés par les nègres indigènes, tandis que les autres ont été envahis par les Mores. En reconnaissant les avantages qu'offrait la position, on a tenté d'y fonder des colonies; mais ces établissements ont été abandonnés à l'exception de l'île Saint-Louis, qui en fut le principal et qui forme encore le cheflieu des possessions françaises dans la Sénégambie. 
Arrondissement de Saint-Louis. - L'arrondissement de Saint-Louis comprend l'île de ce nom, les îles voisines de Babaghé, de Safal et de Ghiber, divers établissements sur le fleuve, les escales ou lieux de marché pour la gomme, et partie des côtes depuis le cap Blanc, sur la côte du Sahara, jusqu'à la baie d'Iof, voisine du cap Vert. La population est de 10,305 habitants, dont 220 blancs, 642 hommes de couleur libres, 1,475 nègres libres, et 7,968 nègres esclaves.

Les habitants, selon Durand, sont polis, bons, humains et vivent heureux; ils sont grands, bien faits, robustes, courageux, infatigables, intelligents, sensibles et reconnaissants. Les femmes ont en partage la modestie, la tendresse, et leur beauté est encore rehaussée par un air d'innocence qui leur prête un grand charme. Toutefois, elles ont un vif penchant à l'amour et à la volupté, et expriment leurs sentiments avec un accent de mollesse et de force à la fois, qui passe pour inimitable. Elles ont les yeux grands et vifs, la peau noir d'ébène, le nez bien fait et généralement aquilin, les lèvres minces et vermeilles, les dents d'une blancheur éclatante.

Tous les habitants ne sont pas catholiques; on dit même que la majeure partie professe le mahométisme. Mais, malgré la différence des cultes, ils vivent en bonne intelligence. Les mariages se font suivant le rit de la religion à laquelle les fiancés appartiennent; quand il s'agit de l'union d'un blanc avec une négresse ou une mulâtre, la cérémonie a un caractère de convention tout à fait particulier; il n'est pas indissoluble et n'a de durée qu'autant que les parties se trouvent satisfaites. Si l'époux fait une absence temporaire, la femme reste seule et attend le retour sans manquer à ses devoirs; et il ne faut rien moins que la nouvelle de sa mort ou la certitude qu'il ne reviendra plus pour la déterminer à contracter un nouvel hymen.

Les deux sexes s'habillent d'une toile de coton qu'ils fabriquent eux-mêmes. Les hommes ont en outre un caleçon qui s'arrête à mi-jambe, et une tunique flottante assez semblable à un surplis; ils vont la tête et les pieds nus. Les femmes ont un vêtement qui consiste en deux morceaux dont l'un leur ceint les reins et tombe jusqu'à la cheville, et l'autre leur enveloppe négligemment le haut du corps. Les signare ou femmes de qualité (c'est-à-dire celles qui sont unies à des blancs ou à des mulâtres), portent une chemise et des robes à la française; des pantoufles en maroquin rouge, vert ou jaune, des bracelets d'or aux poignets et aux jambes, des colliers et de gros pendants d'oreilles de corail, et une ceinture garnie de plusieurs fils de gros grains de verre. Elles ont habituellement pour coiffure un simple bandeau long et étroit dont elles entourent leur tête, et qu'elles remplacent les jours fériés par un mouchoir des Indes ou de mousseline arrangé avec art.

Les esclaves célibataires vont nus jusqu'au jour de leur mariage, n'ayant pour vêtement qu'un morceau de toile passé entre les jambes, et attaché des deux bouts à une corde qu'ils ont autour des reins. Après le mariage, ils portent un morceau de toile qui part des hanches et descend au genou, et un autre sur les épaules.

Cet habillement est à peu près le même pour tous les habitants de cette partie de I'Afrique; et nous ne ferons que mentionner les légères différences que nous aurons occasion de remarquer.

ILE DE GoréE. - Cette île est peuplée d'environ deux mille cinq cents individus nègres ou mulâtres qui ont les mêmes religion, mœurs et usages que ceux de l'île Saint-Louis.

Les Anglais ont eu ou ont encore quelques établissements sur les rives de la Gambie; mais ils ne méritent aucune description.

Divers peuples occupent les rives du Sénégal : celle de droite au nord est habitée par des Mores; celle de gauche par des nègres. Toutefois il y a des exceptions, et les Mores vont quelquefois sur le territoire des nègres qui usent de réciprocité. 
Royaume D’Houal. - Ce royaume est gouverné par un prince qui prend le titre de brak (roi des rois), ce qui ne l'a pas empêché de reconnaître, en 1830, la suzeraineté de la France. Sa résidence est Baghana, où les Français ont un comptoir.

Cet État renferme l'ancien Panié-Foul, aujourd'hui N'gher, qui passe, à tort, pour devenir une plaine fertile dans la saison sèche.

Le voyageur Durand rapporte que le roi d'Houal, qui vint le visiter à bord de son bâtiment, était vêtu d'une chemise blanche, tombant jusqu'au genou, serrée sur les hanches avec une écharpe rouge, et recouverte d'une espèce de tunique jaune fort large. Il avait la tête et les jambes nues, et sa chaussure se composait de pantoufles de même couleur que la tunique. La sobriété ne paraissait pas être la vertu de ce monarque, car il s'enivra deux fois en un jour.

La principale île du lac N'gher est Ghealam, large d'une lieue, longue de deux, et sur laquelle on trouve quelques villages dont les habitants sont doux, affables et paisibles.

M. Perrottet dit que ces Africains sont bien faits, bien constitués, vigoureux et pouvant supporter la fatigue. Leur taille est bien prise, au-dessus de la médiocre; leurs cheveux sont noirs, crépus, laineux et souvent très-fins. Ils ont les yeux noirs, bien fendus, les traits de la figure assez agréables, et leur barbe est peu forte. La taille des femmes est encore plus belle que celle des hommes, et elles ont la peau d'une douceur et d'une finesse extrêmes. Leurs yeux ressemblent à ceux des hommes; leur bouche et leurs lèvres sont petites, et leurs traits d'une grande régularité. Leurs manières sont vives, aisées, gracieuses ; malheureusement elles ont l'habitude de graisser leurs cheveux avec du beurre souvent rance, ce qui ne laisse pas de diminuer l'admiration qu'elles excitent tout d'abord.

Les habitations de cet État ne sont que des cabanes qui ressemblent pour la forme à des colombiers; les parois extérieures ou topades sont construites en roseaux; la couverture est en paille.

Royaume de Dacar. - C'est une petite souveraineté de la presqu'île du Cap-Vert, ou plutôt une espèce de république dont le chef est un roi assisté d'un conseil, et qui est vassal de la France. On perçoit une dìme sur la récolte du millet, du sucre, du café, etc., et chaque habitant paye un contribution annuelle qui consiste en une barre de fer équivalanı à une somme de quatre francs. Le roi fixe le jour du labour, de l'ensemencement et de la récolte qui, après le prélèvement des dìmes, se partage entre tous les habitants. Déposé dans des caisses de prévoyance et d'épargne, le produit des dîmes sert à racheter les esclaves tombés sous le joug de mauvais maîtres et à atténuer les effets de la disette qui résulte parfois de la sécheresse et des dégâts causés par les sauterelles.

Royaume de Cayor. - Le chef de cet État, qui comprend la côte depuis l'embouchure du Sénégal jusqu'au cap Vert, a le titre de damel. Quoique Ghighis soit la capitale, la résidence royale est Makayé et quelquefois Embohl. La population est d'environ 100,000 habitants, sur lesquels le damel a droit de vie et de mort.

Royaume de BAOL. - Le souverain est appelé teyn, et la capitale est Lambaye.

Royaume de Syn.-Le chef de ce royaume prend le titre de bour. La capitale est Ghiakhaôu, et l'une des principales villes est Joal, où l'on faisait autrefois un commerce considérable d'esclaves.

Yolof. - Cet État est encore appelé Ghiolof et Bour-bé-Ghiolof. Son monarque prend le même titre que celui du Syn. Ouamkrore (Huarcor ou Ouarkhogh) en est la capitale.

Ces cinq États sont les débris du grand empire Yolof, autrefois gouverné par le 
Bour-bé-Ghiolof qui avait un pouvoir très-étendu, et qu'aujourd'hui encore on n'aborde qu'en se prosternant devant lui.

Les YoLofs sont les plus beaux nègres de l'Afrique occidentale; ils ont les cheveux laineux, la lèvre épaisse : ils sont grands, bien faits; leurs traits sont réguliers, et leur couleur est très-noire. Si l'on en croit Golberry, ils sont doux, hospitaliers, généreux et fidèles; et leurs femmes ont autant de charmes qu'on peut en avoir avec une peau d'ébène. Ces peuples se disent mahométans; mais leur religion est mêlée d'un peu d'idolâtrie et de superstition. Ils parlent une langue gracieuse et facile. Leur pays est riche en denrées, en bestiaux, en volailles; les habitants fabriquent des étoffes de coton ${ }^{x}$.

La couronne est héréditaire dans quelques-uns de leurs États; elle est élective dans d'autres. A la mort d'un prince héréditaire, c'est le frère et non le fils qui succède; mais après la mort du frère, c'est le fils du premier qui est appelé au trône, et qui ensuite le laisse à son frère. Ailleurs, c'est au premier neveu par les sœurs qu'échoit la succession. Dans les États électifs, les plus grands personnages s'assemblent, après la mort du roi, pour lui choisir un successeur, se réservant la faculté de le déposer s'il y a lieu.

Les Yolofs ont un grand respect pour les morts, qu'ils enterrent avec soin. Chaque tombe est défendue par des arbrisseaux qui forment des abris impénétrables aux atteintes des bêtes féroces. C'est à l'ombre de ces buissons que les graines se développent et que la fertilité s'étend peu à peu sur des sables arides. Chaque habitant a deux cases dont l'une sert de cuisine et l'autre de chambre à coucher.

Royaume de Fouta-Toro. - L'un des plus grands de la Sénégambie, ce royaume est divisé en trois provinces principales : au centre le Fouta, à l'ouest le T'oro, à l'est le Damga.

Royaume de Bondou. - La couronne de cet État est en quelque sorte élective, mais sans sortir de la famille royale, et c'est généralement le frère du défunt qui est préféré.

Royaume de Fouta-Dialon. - Il comprend la contrée montagneuse où le Sénégal, la Gambie et le Rio-Grande prennent naissance; la capitale est Timbo ou Timbou. Le souverain peut mettre sur pied 16,000 hommes de cavalerie.

Les mines de fer de ce pays sont exploitées par les femmes, et il y existe quelques manufactures où l'on travaille le bois, le cuivre et l'argent.

Les habitants de ce royaume sont mahométans, ce qui ne les empêche pas de faire la guerre pour se procurer des esclaves. Ils forment une espèce de confédération républicaine, et ils ont une association secrète, offrant beaucoup d'analogie avec le tribunal vehmique du moyen âge, et qui maintient l'ordre et rend la justice: il est désigné sous le nom de pourrah; chaque canton a le sien, où les hommes ne sont admis qu'après avoir alteint leur trentième année; l'élite des membres qui ont dépassé leur cinquantième année compose le suprême pourrah. C'est dans une forêt sacrée que l'on célèbre les mystères de l'initiation, qui sont accompagnés d'épreuves terribles. Il paraît qu'on a recours à tous les éléments pour éprouver le courage du récipiendaire qui, assure-t-on, se voit assailli par des lions rugissants, mais retenus par des liens invisibles; la forêt retentit d'un hurlement effroyable, et l'inviolable enceinte est rendue inaccessible par un feu dévorant qui brille autour d'elle. Le membre qui s'est rendu coupable d'un crime ou d'une indiscrétion importante ne tarde pas à voir arriver des émissaires armés qui, en l'approchant, s'écrient : "Le pourrah t'envoie la mort! A ce cri, les parents, les amis de la victime fuient en abandonnant celle-ci au

\footnotetext{
Irancis Moore : Travels, etc.
} 
glaive vengeur. On dit même que des tribus entières qui se font la guerre contre l'ordre du suprême pourrah, sont mises au ban, et punies par un corps d'armée envoyé contre elles par les neutres.

État de Kasson ou Casso. - Le prince de cet État prend le titre de sagedova. Il a sa résidence à Mamier, et peut mettre 4,000 hommes sous les armes.

État de Fouladou ou Fouladougou. - C'est un pays peu connu, qui a pour capilale Sabourira; cette ville passe pour une des mieux fortifiées de la Sénégambie.

Les cinq royaumes que nous venons de nommer sont habités par les Peules ou Poules, qu'on nomme aussi Pholeys, Felans et Foulahs, qui sont divisés en cinq corps de nations.

Les traits des Poules ou Foulahs indiquent un mélange de nègres et de Berbers; ils ont le teint rouge noir ou brun jaunâtre, les cheveux plus longs, noirs et moins laineux que ceux des nègres, le nez moins épaté et les lèvres moins épaisses. Cette nation mixte, qui rappelle les Leucoethiopes des anciens, paraît avoir reçu des Arabes nonseulement l'usage religieux et civil du Coran, mais encore le nom qu'elle porte; car c'est évidemment le même que celui des fellahs ou cultivateurs de l'Égypte. Les Foulahs ont l'esprit facile, le caractère doux, beaucoup de goût pour l'agriculture; mais ceux qui vivent de l'entretien des bestiaux transmigrent d'un pays à l'autre, plutôt que de souffrir l'oppression.

Néanmoins, dans les cinq royaumes que nous venons de passer en revue, il faut distinguer deux races bien distinctes, premièrement celle dont il vient d'être question, ct qui, fixée originairement dans une fertile contrée de l'Afrique seplentrionale, en fut chassée par les Arabes, et vint s'établir dans les contrées habitées par les Serrères, lesquels, à la vue de ces hommes montés sur des chameaux et sur des chevaux, s'enfuiren t effrayés vers le sud-ouest, où il formèrent les royaumes de Syn et de Baoi. Les Mores continuant à poursuivre les Foulahs, ces derniers furent forcés d'acheter la paix en leur payant tribut et en embrassant l'islamisme. Depuis cette époque, leur union avec les Serrères et les Yolofs a formé une race de mulâtres nommée Torodos, qui a donné son nom à la province de Toro, dans le pays de Fouta.

Ainsi, les Poules sont partagés en deux races, les rouges ou bruns jaunâtres et les mulâtres; mais, par leurs conquêtes successives, ceux-ci ont forcé les premiers à mener la vie nomade.

Les Foulahs mahométans montrent le plus grand mépris pour les Poules purs et pour les nègres; ils élèvent leur race au-dessus de tous les autres peuples de l'Afrique. Cet esprit national les empêche de se vendre entre eux, et les engage à tirer leurs compatriotes de l'esclavage. Ils parlent très-bien l'arabe, et l'on cite chez eux plusieurs écrivains dont les ouvrages écrits en cette langue sont estimés des Mores eux-mêmes. Les écoles publiques y sont célèbres. Ce peuple est très-industrieux; il fabrique des tissus ornés de dessins délicats et gracieux, des ouvrages en maroquin, et de la bijouterie.

La polygamie y est en vigueur; ils prennent autant de femmes qu'ils peuvent en nourrir. Celles-ci sont coquettes et assez jolies; elles savent profiter de leurs charmes pour exercer une espèce d'autorité sur leurs époux. Rarement leur vertu résiste à un grain de corail. Voici le portrait qu'en fait Mollien : "Un visage un peu allongé, des traits pleins de finesse, des cheveux longs qu'elles tressent aulour de leur tête, un petit pied et un embonpoint moins volumineux que celui des autres négresses, sont les traits caractéristiques de ces femmes, dans lesquelles on peut cependant critiquer les jambes un peu arquées.

Les Foulahs obéissent pour la plupart à un souverain qui porte le titre de siratick, 
plus puissant que le brak, et qui a une cavalerie bien plus nombreuse; ses États sont partagés en provinces, gouvernées chacune par un lieutenant dont le pouvoir est absolu, et qui commande à la milice. La couronne, qui est héréditaire, passe au fils aîné du roi, pourvu qu'il ait épousé une princesse du sang royal : dans toute autre occurrence, elle est dévolue au frère aîné du roi défunt, ou au neveu de ce dernier. Souvent il arrive pour ces nominations de grandes contestations; alors les grands se réunissent et nomment un souverain qui doit cependant toujours être pris dans la famille régnante.

Ces peuples sont robustes et laborieux; ils cultivent bien leurs champs et font d'abondantes récoltes de riz, de miel, de coton, de tabac, de fruits, de racines, etc. Ils élèvent aussi beaucoup de bétail, qui fait leur principale richesse. Le grand nombre de lions, de tigres, d'éléphants et de crocodiles dont leur pays est infesté, les tient dans la nécessité de veiller sans cesse à leur propre sûreté et à celle de leur bétail.

Les Foulahs sont passionnés pour la chasse, dans laquelle ils montrent une trèsgrande habileté, principalement dans celle des éléphants dont le pays est rempli ; ils se servent à merveille du sabre et des armes à feu dont ils ont appris l'usage des Francais. Ils sont aussi amateurs de musique, et jouent de plusieurs instruments : les airs qu'ils exécutent n'ont rien de désagréable. Comme tous les nègres, ils sont également très-portés à la danse.

Royaume DE Bambouk. - Ce royaume a un souverain comme tous les États voisins, et la couronne y est élective. Les indigènes (appelés Malincops) ont dû s'unir aux Mandings qui se sont répandus chez eux. Aujourd'hui les Bamboukains suivent les mœurs, les usages, et ont adopté le costume de leurs vainqueurs.

Nous ne ferons que mentionner les États de Dentruia, Tenda, Oulli, Katoba, Saloum (et ses annexes Sanjalli, Badibou, Barras et Kobar).

Le royaume de KABOU a pour tributaires les Biaffares, près de l'embouchure du Rio-Grande; les Papels, près du Rio-San-Domingo; les Balantes, entre les deux précédents. La capitale de cet État est Schimisa.

Les Papels adorent des arbres, des cornes de bœuf et un grand nombre d'objets visibles. Un voyageur ${ }^{\mathrm{I}}$ rapporte que lorsque leur roi est mort, les grands entourent le cercueil, qui est lancé en l'air par quelques nègres robustes; celui sur lequel retombe la bière, s'il n'est pas écrasé, est élu en remplacement du défunt monarque. Ce peuple entretient des hostilités perpétuelles avec les Biaffares, qui sont plus traitables et plus doux.

Les îles des Bissagos forment un archipel riant et fertile; c'est dans Boulama, l'une d'elles, que les Anglais, ayant eu connaissance du projet de l'habile Brue, qui avait trouvé cette île favorable à un établissement, s'empressèrent de le mettre à gáexécution. Mais, en même temps qu'ils ont choqué les indigènes, ils ont négligé les précautions exigées par le climat, leur colonie n'existe plus.

Les Bissagos ou Bidjougas sont grands, robustes, belliqueux, et se sont fait redouter de leurs voisins par leurs cruautés. Ils abandonnent quelquefois la piraterie pour la pèche. Ils sont idolâtres, et le coq est leur animal sacré. Le vêtement de ces individus paraît consister en un tablier à franges fait de cannes. Les gens de quelque distinction oignent leurs cheveux avec de l'huile de palmier, ce qui les fait paraître tout à fait rouges. Outre le tablier qu'elles portent tout l'été, les femmes, lorsque arrive l'hiver, ont un vêtement de même composition que l'autre, mais qui prend du cou et va jusqu'à la ceinture; quelques-unes en ajoutent un troisième qui tombe de la tête sur

M. Schad, cité par Brum, page 289. 
les épaules. Leurs jambes et leurs bras sont ornés de bracelets de cuivre ou d'étain.

Le royaume de Fourn (Foini, Foni ou Fouana) passe pour très-peuplé et d'une grande fertilité. Il comprend le ci-devant royaume de Jereja et de Kaen. Les habitants sont idolâtres; on les dit courageux et habiles à manier les armes.

Sous la domination du roi de Fouini, les Feloups s'étendent depuis l'embouchure de la Gambie jusqu'à celle de San-Domingo. Ils sont petits et robustes; ils ont la peau d'un noir foncé, les traits fins et les cheveux crépus et plus longs que ceux des autres nègres. Sauvages, vindicatifs, mais fidèles à leurs amis, ils reconnaissent difficilement une souveraineté, et n'ont d'autre culte que le fétichisme. Ils se tressent la barbe, se tatouent le visage et le corps, et n'ont pour vêtement qu'un petit tablier.

Depuis le pays qui porte leur nom, et qui est voisin des sources du Niger, dans les États de Barbara à l'est, et dans ceux d'Oulli et Bambouk à l'ouest, les Mandings ou Mandingues se sont très-répandus. D'un noir moins beau que les Yolofs, ces naturels rendent leurs dents pointues en les limant; ils se servent de l'alphabet arabique, font usage de beaucoup de mots arabes, et professent une espèce de mahométisme. Les ermites ou marabouts font de très-longs voyages de commerce; les marabouts marocains et barbaresques vont aussi les visiter; ils connaissent parfaitement l'Afrique; la traite des nègres est dans leurs mains. Depuis 1100 , cette nation règne sur le riche royaume de Bambouk.

La nation mandingue est la plus nombreuse de toutes celles des bords de la Gambie. Ces nègres sont vifs et enjoués, et passent quelquefois la journée à danser en faisant des sauts et se livrant à des postures bizarres au son de leurs balafos et de leurs tambours. Un grand nombre portent une épée sur l'épaule droite; d'autres n'ont que leur sagaie et un dard long de trois pieds, ou un arc et des flèches. Tous portent un couteau à la ceinture. Ils manient ces armes avec beaucoup d'adresse. Les Mandings et les Feloups se distinguent aussi facilement à leur nez plat et à leurs grosses lèvres, que les Yolofs à la beauté de leurs traits. Un enfant en venant au monde est plongé dans l'eau trois ou quatre fois par jour, et, après l'avoir fait sécher, on le frotte avec de l'huile de palmier. Les Mandings riches affichent un grand luxe d'esclaves, auxquels ils rendent la vie très-douce. Lors du voyage de Moore dans les pays arrosés par la Gambie, il y avait près de Brouko, dans le royaume de Kabou, un village entier de 200 personnes qui n'étaient que les femmes, les enfants et les esclaves d'un seul Manding. La plupart des seigneurs sont considérés comme les rois des villes ou villages où ils résident dans un grand nombre de contrées mandingues. Dans chaque ville il y a un gouverneur, juge de tous les différends qui s'élèvent entre les habitants; il est aussi chargé de régler le travail du peuple.

L'habillement des Mandings est en toile de coton fabriquée dans le pays : les hommes portent un surtout imitant à peu près un surplis, avec un bonnet de forme conique, des caleçons très-larges qui leur viennent jusqu'au genou, et des sandales. Les femmes ont une pièce de toile roulée autour des reins en forme de jupe, qui leur descend jusqu'aux pieds; et une autre jetée sur les épaules leur cache négligemment le sein. Ces vêtements sont communs à tous les peuples de cette partie de l'Afrique. Dans les pays qu'arrose la Gambie, les femmes portent un bandeau étroit, appelé jalla, qui leur ceint la tête de plusieurs tours. Celles du Kassar savent arranger avec élégance de petites coquilles blanches dont elles se parent. Dans le Kaarta et le Ludamar, elles rehaussent leur chevelure avec un petit coussin placé par dessous et parsemé de grains de corail pêchés dans la mer Rouge, que les pèlerins à leur retour de la Mecque vendent assez cher.

Sorti d'un État républicain, ce peuple n'a formé que des monarchies. Leurs rois 
n'ont point un pouvoir illimité. Dans les affaires importantes, ils doivent convoquer une assemblée des vieillards les plus sages, dont ils suivent l'avis. L'alkaïd ou premier magistrat, dont l'emploi est héréditaire, est chargé de la perception des droits sur les voyageurs et du maintien de l'ordre dans les villes. Il préside le tribunal de justice qui se compose de vieillards de condition libre; ses palavers ou séances se tiennent en plein air et avec beaucoup d'appareil. Ils y traitent les affaires avec la plus grande liberté : leurs décisions sont quelquefois approuvées par les parties elles-mêmes.

Tout se règle d'après d'anciens usages, les nègres n'ayant point de lois écrites. Cependant, depuis que la loi de Mahomet a fait des progrès considérables dans ce pays, il s'est mêlé plusieurs institutions civiles du prophète aux principes de religion : si l'Alcoran ne paraît pas assez clair en certains cas, on consulte un commentaire appelé Al-Scharra, et qui donne l'explication des lois de l'islamisme. De cette ignorance des lois écrites, il résulte que les nègres encore païens ont souvent besoin de recourir à des gens qui se font passer pour avocats et qui ont la faculté de haranguer devant le tribunal.

Ces indigènes sont rigides observateurs des préceptes de la religion musulmane; ils jeûnent pendant tout le radaman, et ne boivent jamais ni vin ni eau-de-vie. Il leur est défendu de se nourrir de cochons qu'ils n'élèvent point. Il y a chez eux beaucoup d'attachement et de bienveillance réciproques. Dans plusieurs endroits ils ont des missuras ou mosquées, où ils se rassemblent pour la prière. Ceux qui vivent à l'état libre ont plusieurs femmes; mais ils ne peuvent épouser deux sœurs.

Dans chaque ville il y a une maison commune appelée bentang, faite de cannes entrelacées, placée souvent sous un grand arbre pour être à l'abri du soleil. C'est là que se traitent les affaires commerciales et que les habitants se rassemblent pour fumer leur pipe et recueillir les nouvelles.

Les nègres, tant païens que kafirs, dont le nombre de femmes plus ou moins grand donne lieu entre elles à des jalousies et quelquefois à des querelles que le chef ne peut pas toujours apaiser, ont recours au mambo-jombo, dont l'intervention n'est jamais vainement réclamée. Mungo-Park nous a donné une description de cet office. En entrant à Kolor, ce voyageur vit suspendu à un arbre un habit de masque fait d'écorce qui était celui du mambo-jombo. Dans toutes les villes il y a de ces fantômes extravagants.

Lorsqu'ils ont recours au mambo-jombo, le mari ou une autre personne à qui il a fait la leçon se cache sous l'habit dont nous venons de parler, armé d'une verge marquant son autorité, et, par des cris épouvantables, annonce son arrivée dans les bois voisins. Ce n'est jamais que le soir que s'entendent ces hurlements, et ce n'est qu'à la nuit close qu'il entre dans la ville et se rend au bentang où l'on ne tarde pas à le rejoindre.

Comme on peut le penser, cette apparition n'est pas agréable aux femmes : car celui qui fait ce rôle étant inconnu, chacune craint que sa visite ne soit pour elle. L'on commence par des chansons et des danses qui durent jusqu'à minuit : alors la femme coupable est désignée par le mambo-jombo, et l'on s'empare aussitôt d'elle, on la met nue, et on l'attache à un poteau où le mambo-jombo la fouette rudement avec sa verge au milieu des cris et des huées des spectateurs. L'infortunée que l'on punit reçoit ordinairement le plus d'outrages des femmes.

Pour prévenir les querelles entre ses femmes, le Manding construit pour chacune une hutte particulière. Toutes les huttes d'une même famille forment une enceinte défendue par un treillage de bambou d'un beau travail. Quelques-unes de ces enceintes, séparées par de simples sentiers, forment une ville. Le principal soin qu'ils ont dans la construction de ces huttes est d'en faire la porte au sud-ouest, pour y donner accès à une petite brise de mer. 
Les Mandings libres ne forment que le quarl de la population des pays qu'ils habitent; les autres sont nés dans l'esclavage et ne peuvent en sortir. Comme les nègres d'Amérique, ces malheureux sont dévoués à la culture des terres et à la garde des troupeaux. Leurs maîtres n'ont cependant aucun droit sur leur vie, et ils ne peuvent les vendre à un étranger sans y être autorisés par un jugement public, rendu contre l'esclave pour cause de dèlit. Ceux nés dans le pays ont le droit d'invoquer l'autorité des lois contre ces arrêts d'expulsion. Les condamnés pour cause de délit ou de dettes, et les prisonniers de guerre que l'on traîne vers les côtes pour y être vendus, n'ont aucun moyen de réclamation contre l'injustice de leurs maîtres.

Les Serakhalès ou Serracolets, selon quelques voyageurs, sont une des plus anciennes nations de la Sénégambie; mais il paraît certain qu'on doit comprendre sous ce nom des marchands qui appartiennent à quelques tribus du Sénégal, et qui ont échelonné leurs comptoirs depuis la côte jusque dans la Nigritie. Cependant Mungo-Parc, et plus récemment le major Gray, ont parlé d'un peuple (les Serawoulès ou Serawoulis) qui, par la ressemblance de son nom avec celui des Seralshalès, pourrait bien avoir donné licu à la méprise que nous venons de signaler. Les Serawoulis habitent principalement le royaume de Galau, dont le nom véritable est Kayagà ou Kadjaaga, et qui, divisé en haut el bas Galam, renferme, dans le premier, le poste français de BAKEL, et dans l'autre, l'ancien fort de Sarnt-Joseph. Chacune de ces divisions est gouvernée par un prince qui a le titre de tonka.

La majorité des Serawoulis ont renoncé au paganisme en faveur du culte mahométan. Plusieurs de leurs villes sont exclusivement habitées par des prêtres qui sont ordinairement les plus riches et les plus recommandables du pays.

Ces peuples sont moins bien partagés que les Foulahs sous le rapport des proportions du corps, et ils n'ont pas autant de vivacité que les habitants du Bondou; leur maintien est grave, et leur caractère apathique. Ils ont la peau d'un beau noir, et la rendent brillante par l'emploi du beurre rance. Ils se nourrissent de poisson, et ont pour la viande, même très-avancée, un goût si prononcé qu'il est passé en proverbe. " J'ai vu, dit le major Gray, des habitants prêts à se battre pour le partage d'un hippopotame mort, flottant sur la rivière, et dans un tel état de putréfaction que l'air en élait infecté. ১ Les habitants du Galam savent tisser et teindre les étoffes de coton; la teinture bleue qu'ils obtiennent de l'indigo passe pour la plus belle de celles que fournit l'Afrique.

Les Ghialonkès ou Jellonkas habitaient autrefois le Fonta-Dialon, d'où ils furent chassés par les Foulahs, et vinrent occuper le GHialonkadou.

C'est dans l'espace douteux existant entre les limites de la Sénégambie et de la Guinée (limites abandonnées au caprice des géographes) que se trouve la nation des Sousous, appelés à tort Foulahs de Guinée; ils font partie de la grande nation des Mandings.

En terminant la Sénégambie au Rio-Nugnez, nous trouvons sur les deux rives de ce fleuve, les Nallok̀s ou Naloubès, nègres pleins de douceur el d'intelligence, tellement confondus avec les descendants des premiers Portugais, qu'il est impossible de faire une distinction entre eux. Ils fabriquent des pagnes recherchés des nations voisines à cause de leur extrême finesse el de la beauté de leurs couleurs. Leurs terres bien cultivées fournissent d'excellent indigo, et des cotons de belle qualité. 



\section{GUINÉE.}

En arrivant au territoire de BAGos ou BAGoĖs, à l'est des Nalloès, nous entrons dans la Guinée, que M. Balbi a nommée Nigritie maritime. Cette contrée a 780 lieues de l'est à l'ouest, et 140 dans sa moyenne largeur. On en évalue la superficie à 110,000 lieues carrées.

L'établissement anglais de Sierra-Leone se trouve sur la côte de ce nom; nous ne pouvons nous occuper de cette colonie ni de tous les autres comptoirs en grand nombre sur ces côtes; les nations indigènes seules arrêteront notre attention.

Le Trunani a 90 milles de longueur et מ̋ milles de largeur; il est partagé en quatre gouvernements dont les chefs prennent le titre de roi; la capitale de la plus importante division est Kamba ou Kambia. Le Logo ou Loco vient ensuite; le nom des deux autres États n'est pas connu. Les rois sont soumis à l'autorité du pourrah dont nous avons parlé plus haut.

Les chefs portent en général le costume manding; quant aux nègres de condition ordinaire, ils n'ont pour vêtement qu'une étroite pièce d'étoffe nommée tatungué, attachée à la ceinture avec un cordon; les femmes ne sont pas autrement vêtues tant qu'elles sont filles; mais une fois mariées, elles nouent autour de leur corps quelques aunes de toile bleue dont elles font une sorte de jupon. Elles aiment à se parer la tète, le cou, les poignets et les chevilles de chapelets de corail ou d'une petite graine jaune qu'elles nomment masarabunto.

Lorsqu'un homme veut se marier, il va trouver les parents de la fille qu'il a choisie, auxquels il porte un présent qui consiste en une jarre de vin de palme, ou en un peu de rhum s'il a pu s'en procurer. Si sa demande est accueillie, il est invité à revenir, et, cette fois, à une nouvelle jarre de vin il joint quelques kolas, quelques brassées d'étoffe et de chapelets. Ces dons terminent la négocialion : le jour du mariage est fixé, et on instruit la fiancée de la résolution prise. Si les parents, au contraire, font au poursuivant des observations sur ses moyens d'existence, il doit travailler jusqu'à ce qu'il soit en mesure de répondre aux exigences de la famille dans laquelle il veut entrer, ce qui n'empêche pas que si, dans l'intervalle, un parti plus avantageux se présente, la fille puisse disposer d'elle. Les cérémonies nupliales n'offrent aucune particularité intéressante, et ne se font remarquer que par une scène de débauche et d'orgie qui commence à l'heure du coucher des époux', et se continue durant plusieurs jours, si l'état pécuniaire des contractants le permet.

Ces individus sont très-superstitieux, et le prouvent surtout dans les cérémonies des funérailles, à propos desquelles ils se livrent à mille pratiques ridicules. Au reste, ils ont, comme la plupart des Africains, un grand respect pour les morts.

Le Kouranko, auquel nous passons sans nous arrêter au Liba ou Liban, est un pays très-vaste, divisé en plusieurs petits États. La capitale du Kouranko du sud-ouest est Simera; celle du nord-ouest, Kolakonka; celle du Kouranko septentrional, Kamato. 
Les Kourankoniens sont moins civilisés que les Mandings, mais ils leur ressemblent pour le langage, les mœurs, et le costume. Toutefois l'habillement des femmes, avant et après le mariage, est le même que dans le Timanni.

Les Kourankoniens aiment la danse avec passion. Tout homme d'un certain rang a dans sa maison trois ou quatre maîtres qui, de même que ceux de Jimara, se font moins remarquer par leurs grâces que par leur agilité.

Dans les grandes fètes, les danseurs à gages, vêtus d'une manière bizarre, se promènent dans toute la ville, et vont rendre successivernent visite aux chefs qu'ils amusent par la souplesse de leurs mouvements, et dont ils reçoivent quelques présents. Au coucher du soleil, le taballa ou tambour les appelle à la danse générale. Les musiciens se tiennent au centre, comme dans le Timmani, et l'on danse autour d'eux. Leur musique et leurs mouvements sont également monotones. Le major Laing a vu une danse de ce genre durer deux jours et trois nuits; ceux qui se retiraient étaient aussitôt remplacés par de nouveaux champions.

Les Soulimas, qui habitent le Soulma ou Soulmana, sont les plus policés des nègres de la Sierra-Leone. Le roi a le monopole des produits comme en Égypte, et le major Laing y a, dit-il, reconnu différentes coutumes qui rappellent celles des anciens Romains. Le souverain consulte sur les affaires importantes les anciens qu'il appelle pères; la maison des palabres ou maison commune, siluée sur la grande place de la capitale, est comme le forum romain : c'est là que les orateurs discutent publiquement les affaires; le chef qui commande l'armée ne peut entrer dans la ville que lorsqu'il en a obtenu la permission; en y entrant, il perd son titre el les prérogatives qui y sont attachées; des poëles sont chargés de transmettre dans leurs chansons le souvenir des événements publics; un Soulima débiteur insolvable devient l'esclave de son créancier. D'autres coutumes distinguent encore ce peuple : les femmes peuvent abandonner leurs maris pour leurs amants, en restituant le présent que leurs parents ont reçu du mari; mais si, l'infidélité prouvée, elles ne peuvent remplir la condition ci-dessus, elles ont la tête rasée et sont regardées avec mépris, tandis que l'amant devient l'esclave de l'époux outragé.

Le pays d'AQUAPIM n'offre rien de particulier, si ce n'est que les nègres ne louent ni n'achètent de terres; les ventes ont lieu exclusivement au profit des Européens.

Les Achantis ou Assianthès, qui paraissent être les Argentains d'un écrivain français, M. Pommegorge, parlent une langue qui règne sur la plus grande partie de la côte d'Or, au nord-ouest de laquelle ils habitent.

Ils forment l'empire le plus puissant de la Guinée, puisqu'il s'étend, de l'est à l'ouest, depuis le $1^{\text {er }}$ degré de longitude jusqu'au $7^{e}$, et, du sud au nord, depuis la côte jusqu'aux monts Sarga, sur une largeur de 5 degrés. Il a une superficie d'environ 10,000 lieues carrées. Le principal Élat de cet empire a pour capitale Coumassie.

Parmi les tributaires, il comprend : le pays d'AQUapim ou d'AQUapiem, celui d'Agouna, l'État d'Apollonia, la république des Fantis et le pays des Aminas; ainsi que plusieurs autres États dont les principaux sont le petit royaume d'Accra ou d'ANkran, le fertile pays de Ningo ou d'Adampi, le royaume d'Ouarsa, celui de Dankara, celui d'Assin, celui de Coranza, le pays de l'Amina, le royaume d'Inta, et celui de Dagoumba.

Chez les Achantis, après la mort du souverain, le pouvoir passe au frère de celui-ci, et est ensuite transmis au fils de la sœur, puis après le fils, au premier vassal de a couronne. Les sœurs du roi se marient ou vivent avec qui bon leur semble, pourvu que ce soit un homme remarquable par les qualités corporelles, afin que les héritiers soient dignes, sous ce rapport, de commander à leurs compatriotes. Le roi hérite de l'or de tous ses sujets quel que soit leur rang. Lorsqu'un prince du sang se rend coupable 
d'un crime, on le noie; jamais on ne verse le sang royal. - Après trois ans d'absence du mari sans qú'elle en ait entendu parler, la femme peut se remarier; mais si le premier revient, les enfants du second deviennent sa propriété, et il peut les mettre en gage. - On sacrifie un grand nombre d'officiers du prince et d'esclaves, dans les grandes fètes. Quelques esclaves sont aussi immolés à la mort de leur maître. Ils font un massacre général à la mort d'un roi; toutes les cérémonies funèbres qui ont eu lieu pendant son règne se renouvellent avec leurs sacrifices humains; les sœurs et les neveux du roi affectent une folie passagère, se précipitant hors du palais et courant dans les rues de Coumassie en tirant des coups de fusil sur tous ceux qui se trouvent sur leur passage; l'on immole enfin à peu près 100 esclaves sur la tombe du défunt. Le roi peut avoir 3,333 épouses, nombre que la loi lui accorde et qui est toujours complet; mais il en a rarement plus de six dans son palais.

De tous les peuples tributaires des Achantis, il n'y a que les Fantis qui méritent une description. Ces nègres ont des mœurs qui offrent quelques particularités remarquables: leur religion est une espèce de fétichisme; ils reconnaissent deux principes, l'un bon (souman), l'autre mauvais (alastor). Ils pensent que tous les grands célacés proviennent d'un peuple qui aurait été détruit par un déluge, et lorsqu'un de ces animaux échoue sur leurs rivages, c'est pour eux un fâcheux pronostic. Les hommes sont nubiles à douze ans, les femmes à dix ; lorsqu'elles sont parvenues à l'état de puberté, elles doivent sortir de leur maison et marcher d'une manière déterminée par la coutume. Les Fantis peuvent avoir plusieurs épouses, et ils sont dans l'usage de tuer en l'honneur d'un riche défunt, la crabba ou la plus jeune de ses femmes restée vierge, ainsi que le cransa, jeune esclave qui portait sa pipe au moment où il rendit le dernier soupir. Ils enterrent leurs morts dans leurs propres maisons.

Les Fantis sont robustes; leurs femmes sont bien constituées, ont les traits délicats, les pieds petits, les dents blanches, bien rangées, et les formes gracieusement arrondies. Les deux sexes portent une jupe qui, chez les femmes seulement, forme une protubérance dont la grosseur varie selon le rang de la personne. Les hommes âgés ont les cheveux entièrement rasés, à l'exception d'une boucle ou deux qui tombent par derrière et auxquelles ils suspendent un morceau d'or.

La Còte des Esclaves comprend les États de Coto, Popo-Ouyda et Ardra, qui n'ont rien d'assez important pour nous arrêter; ils dépendent tous du royaume de DAHOMEY, dont le chef, du rang d'un petit cabossier, s'est élevé à celui d'un grand monarque africain. Ce roi peut armer 8,000 hommes, mais, entouré d'ennemis, il serait promptement détrônẻ s'il n'était soutenu par les forts européens. Le roi a deux palais qui se composent de chaumières distinguées, enfermées par des murs de terre dans un enclos d'un quart de lieue, où sont logées 800 à 1,000 femmes, lesquelles, armées de fusils ou de flèches, forment la garde légère du souverain, qui choisit dans ce corps ses aides de camp et les messagers de ses ordres. le despotisme et la férocité de ces monarques sont hors de toute expression : les ministres ne peuvent les approcher qu'après avoir déposé à la porte leurs vêtements de soie, et en rampant ventre à terre et roulant leur tête dans la poussière; un gouverneur anglais, M. Dalzel, trouva le chemin de la cabane du roi semé de crânes humains, et les murs incrustés de mâchoires. Le roi marche en cérémonie sur les tètes sanglantes des princes qu'il a vaincus ou des ministres qui sont tombés en disgrâce. A la fète des tribus, où tous les sujets apportent leurs dons, il arrose de sang humain le tombeau de ses ancêtres : cinquante cadavres sont jetés autour du sépulcre royal, et les têtes fixées sur autant de pieux. Dans les constructions élevées en son honneur, on mêle le sang à l'argile. Les veuves royales se tuent les unes les autres jusqu’à ce que le successeur du défunt metle un terme au massacre; le peuple 
applaudit à ces cruelles scènes et déchire les victimes en s'abstenant pourtant de dévorer leur chair. L'objet de leur culte est un léopard.

Ce peuple se distingue des autres nègres de la Guinée par ses mœurs féroces et perfides, et par son amour implacable de la vengeance. La distinction nationale des Dahomeys consiste en une ligne qui descend du haut du front à la racine du nez. Les femmes sont réduites à une condition abjecte; elles ne se présentent devant leurs maris qu'en témoignant la soumission la plus servile, et se mettent à genoux pour leur offrir leur nourriture. Ces femmes passent pour fort jolies.

Le royaume de Benin ou d'Adou, à l'est du précédent, peut mettre 100,000 hommes sur pied. Les habitants ont les mêmes usages que ceux des Dahomeys; seulement ils adorent un lézard.

Les Lagos, qui occupent le royaume de ce nom, sont très-superstitieux; dans la croyance qu'ils rendront la navigation de la rivière favorable à leurs communications commerciales, ils lui immolent une jeune fille qu'ils empalent. Cette coutume offre des circonstances repoussantes de barbarie. Les Lagos sont tributaires de Benin.

Les habitants du royaume d'OuAry sont très-noirs, et leurs mœurs offrent beaucoup d'analogie avec celles des Fantis.

Le royaume de Calabar ou Kalbary ne présente qu'une particularité intéressante : la ville du Nouveau-Calabar formait un important entrepôt de commerce lorsque Peppel, riche marchand de l'île de Bonny, surprit la ville pendant une nuit, et y fit mettre à mort le plus grand nombre des habitants dont les crânes lui servirent à paver une maison qu'il a consacrée au culte de son dieu; il montre aussi avec orgueil aux Européens, comme le plus beau trophée de sa victoire, une pyramide qu'il a fait élever au centre de la ville avec la plus grande partie des ossements de ses victimes. Bonny, dans l'ìle de ce nom, était la capitale d'un petit État que l'on pouvait considérer comme une république oligarchique; Peppel en a fait le siége dê son gouvernement despotique et sanguinaire.

Les nègres qui habitent le royaume de QUA ou QUOUA sacrifient des victimes humaines dans les grandes fètes; ils ont une association (egho) qui se rapproche du mambo-jombo des Mandings et du pourrah des Foulahs, mais dont le but est à la fois de favoriser la liberté du commerce et de punir les femmes infidèles. Cet État a pour capitale la ville du Vieux-Calabar dont les habitants sont les plus civilisés de tous ces nègres.

Les Galbongos sont partagés en plusieurs États peu connus. Le cap d'Esteiras (das Serras) a pour habitants des hommes à demi sauvages, redoutés des navigateurs. Les nègres de la côte de Gabon sont remarquables par leur hardiesse; ils forment plusieurs nations dont on sait à peine les noms. 



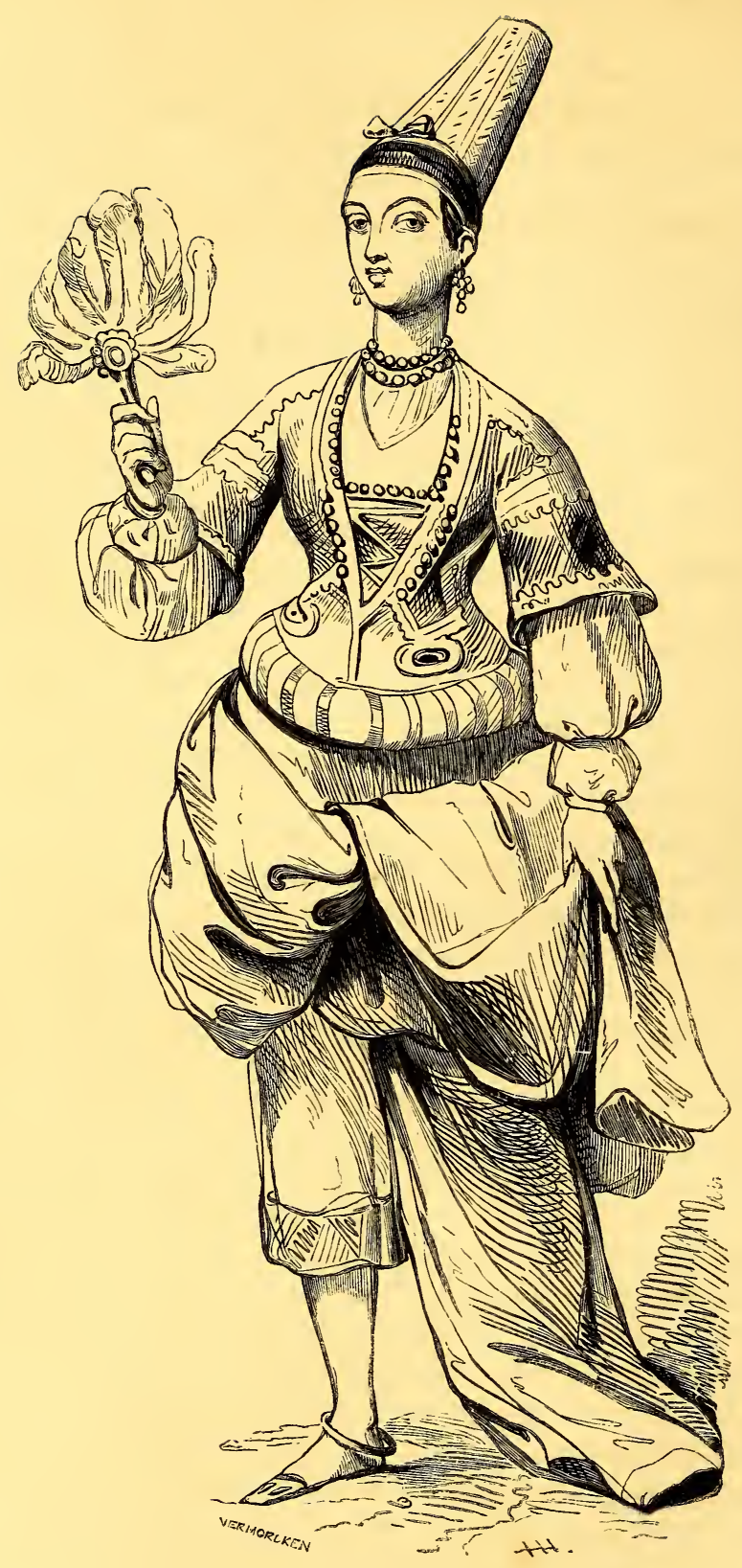

Jeune fille de Timbouctou.

(Afrique.) 


\title{
NIGRITIE,
}

\author{
APPELÉE AUSSI SOUDAN OU TAKROUR.
}

Cette contrée est entre $6^{\circ}$ et $17^{\circ}$ de latitude nord, et entre $10^{\circ}$ de longitude ouest et $30^{\circ}$ de longitude est. Elle est composée d'un grand nombre de royaumes dont les principaux sont : à l'ouest, le Bambara, le Tembouctou et le Kong; au centre, le Haoussa, le Borgou, l'Yourriba, le Nyffé, le Funda, le Bournou, le Mandara, le Baghermé et le Kanem; à l'est, le Bergou ou Darszaléh, le Darfour, le Kordofan, le Donga et le pays des Chilouks.

Pour simplifier la description de ce pays, nous donnerons un aperçu sur les nègres cn général, afin de ne plus avoir à nous occuper que des coutumes particulières à chacun des pays de l'Afrique que nous passerons en revue.

Chez toutes les nations nègres, l'indolente légèreté, l'insouciance puérile sont perpétuées par la nature du sol; vingt jours dans l'année leur suffisent pour assurer la récolte des productions nécessaires à leur frugal repas, et leur goût peu délicat ne les laisse jamais sans ressource pour leur nourriture; leur appétit grossier ne recule devant aucune viande gâtée, aucun poisson passé à l'élat de putréfaction ; les bouillies épaisses dont ils se nourrissent ne demandent que peu de soin; et s'ils repoussent la salade, c'est, disent-ils, " pour ne pas ressembler aux animaux herbivores. "Ils obtiennent, par un art facile, le vin de palmier ou de bananier, et la bière de millet dont ils font leur boisson habituelle; l'Europe lcur fournit ces eaux-de-vie dont le résultat funeste est de les faire passer de l'ivresse à l'esclavage. Les habitations ne les préoccupent guère : elles ne sont pas autre chose que la cabane à son état primitif; un amas de cases semblables forment les villes où l'on ne voil d'autre édifice public qu'une grande case ouverte de toutes parts et nommée bourrée, servant aux délibérations publiques désignées sous le nom portugais corrompu de palaver. Les souverains, qui ont quelquefois pour trône un morceau d'or massif, n'ont d'objets de luxe que des tapis, des armes à feu, et de la vaisselle européenne; toute la pompe qui les distingue consiste à marcher en pantoufles à l'ombre d'un parasol. L'ameublement des pauvres ne se compose souvent que de deux ou trois calebasses.

Quant au costume, ils s'en tourmentent médiocrement : le coton vient sans culture, et les femmes en tirent la quantité d'étoffes nécessaires à la famille; l'indigo, production indigène abondante, sert à teindre ces étoffes.

Isert cite un trait qui fait ressortir l'indolence du nègre : l'éléphant, si commun en Afrique, et susceptible de devenir l'utile, l'intelligent auxiliaire de l'homme, n'a pas été apprivoisé; le nègre ne l'emploie que dans le Dagoumbah, pays peu connu, dans l'empire d'Achanti. Chasseur timide, il ne se montre actif que dans l'exercice de la pêche : à la nage ou à la rame, il brave les flots et ramène des filets chargés d'un butin 
inmense; mais l'abondance même de cette ressource le replonge dans sa paresse et nuit au développement de ses dispositions naturelles pour l'industrie, dont il fait preuve dans la fabrication des étoffes, des couvertures, des voiles pour les bateaux, des poteries, des pipes à fumer, et des ustensiles en bois. Les forgerons et les orfévres prouvent aussi beaucoup d'adresse, et les nègres savent encore donner à l'acier une bonne trempe, et réduire le fil d'or à une extrếme finesse.

Malheureusement cette industrie reste stationnaire par suite de leur peu de besoins, et l'on ne voit pas un nègre qui travaille plus qu'il ne faut pour sa subsistance. N'éprouvant aucun de nos sentiments d'avarice ou d'ambition, ils considèrent la vie comme un court moment dont il faut jouir autant qu'il est possible. Dès le coucher du soleil, les sons rauques de la trompette d'ivoire et les roulements du tambour se mêlent aux accords de plusieurs espèces de guitares et de lyres : jeunes et vieux accourent prendre part à la danse qui se continue toute la nuit. Les jeux de hasard sont recherchés avec passion par les nègres; quant aux ingénieuses combinaisons de l'ouri (espèce de jeu de dames plus compliqué que le nôtre), il n'offre d'intérêt qu'aux femmes.

La barbe de ces nègres, peu abondante, a le caractère laineux de leurs cheveux; mais, malgré cette apparence d'une virilité peu prononcée, ils ont l'avantage sur toutes les races humaines lorsqu'il s'agit d'amour physique, et nulle part la polygamie n'est poussée plus loin que chez eux.

Toutes les nations nègres qui ont conservé leur caractère primitif maintiennent, avec des nuances, l'usage des incisions sur la peau.

La circoncision est admise parmi beaucoup de nations nègres idolâtres.

Le nègre prend pour son fétiche, pour son idole tout ce qui frappe son imagination déréglée : un arbre, un rocher, un œuf, une arête de poisson, un grain de datte, une corne, un brin d'herbe, etc. Il y a des nègres qui ont un fétiche national et suprême.

Chez quelques nations, ils se rendent les dents pointues en les limant; toutefois, Isert aflirme qu'il a vu des nègres dont les dents étaient naturellement en pointe. Il en est qui se vantent d'être anthropophages, et qui arrachent un lambeau de chair du bras de leurs camarades afin d'en fournir la preuve.

A l'occasion des funérailles, ils ont une coutume superstitieuse étrange : les porteurs du corps du défunt l’interpellent pour savoir s'il a été empoisonné ou ensorcelé, et prétendent recevoir une réponse par le mouvement du cercueil, provoqué sans doute par le jongleur le plus audacieux d'entre ces hommes. Et malheur au prétendu sorcier que le mort accuse : il est vendu comme esclave. Des scènes plus déplorables encore ont lieu lors des enterrements des princes, ainsi que nous l'avons vu chez les Dahomeys.

Mais le despotisme n'est pas le seul, n'est pas même le principal malheur de l'Afrique; car les actions féroces de ces petits tyrans ne peuvent révolter un peuple aussi sanguinaire que ses chefs; c'est bien plutôl aux guerres éternelles qui règnent entre les divers Étals qu'il faut attribuer l'étal de stagnation où restent ces peuples, malgré les relations de plusieurs tribus avec les Européens.

On exagère encore quand, en condamnant la traite, on donne pour principal motif de son improbation la funeste influence de ce trafic sur la prospérité des Africains. Quel bonheur public ou particulier peut-il y avoir dans une contrée où règnent des lois et des mœurs aussi barbares? A ces hommes qui chez eux vivent dans un état d'esclavage héréditaire, ou peuvent y être réduits d'un instant à l'autre par un mot de leurs despoles, que peut importer la contrée qu'ils devront arroser de leur sueur el de leurs larmes!... Cependant, il faut avouer que l'aspect de tant d'individus vendus avec une apparence de droit, excite les marchands d'esclaves à tenter d'enlever mème des hommes libres. Parmi plusieurs exemples, en voici un qui est rapporté par quelques 
voyageurs: Un de ces marchands, connu sous le nom anglais de Ben-Johnson, avait ravi une jeune fille libre, et venait de la vendre à un capitaine anglais. Il s'en retourne avec le prix de son crime; mais près du rivage, d'autres nègres, apostés par le prince ou les chefs du village, l'attaquent, le lient, et, en criant au voleur, le ramènent au vaisseau et l'offrent en vente. Ben-Johnson eut beau invoquer l'amitié du négrier européen, et lui rappeler qu'il était un homme libre et son plus habile fournisseur d'esclaves: "C'est égal, répondit l'iusensible Anglais, puisque ces hommes te venden l, je t'achète; » et aussitòt il lui fait mettre les fers.

Quoi qu'il en soit, la race nègre n'est pas dépourvue des sentiments qui honorent et élèvent la nature humaine ; l'Afrique a eu ses Pylade, et les liens de la tendresse maternelle et filiale y sont aussi fortement resserrés qu'ils peuvent l'ètre là où la polygamie est en usage. Le plus beau trait dans le caractère du nègre, c'est cette héroïque fidélité envers un maître juste, et mème envers un maître sévère. On en a cité divers exemples; mais en voici un des plus authentiques : Quagié, nègre inspecteur, avait joui de toute la confiance de son premier maître, qui, en mourant, le recommanda à son fils et successeur : ayant été élevé avec celui-ci, il pouvait espérer la continuation de la même faveur; cependant il encourut une disgrâce momentanée; le jeune maître, sévère et violent, le menaç, pour la première fois dans sa vie, d'une punition déshonorante. Quagié se cache, dans l'intention de faire demander son pardon. Pour son malheur, le naître, en se promenant, découvre le même jour sa retraite; jeune et vigoureux, il s'élance sur l'esclave et le maltraite cruellement. Entraîné de son côté par un premier mouvement, le robuste nègre saisit l'Européen, l'abat sous lui, et tirant de sa ceinture un large couteau : a Massa, dit-il, j’ai été le compagnon de votre enfance, je vous chéris plus que moi-même; je vous jure que je suis innocent; mais eussé-je même été coupable, j'aurais dû pouvoir compter sur votre indulgence; cependant vous m'avez condamné sans m'entendre; vous voulez me livrer à une peine déshonorante. Non, non! je m'y soustrairai. » A ces mots, il plonge le couteau dans son propre cœur, et tombe, baigné dans son sang, sur son maitre, qui, trop tard, lui offrait le pardon.

Passant maintenant à la description particulière de la Nigritie, nous nous proposons de ne parler que des États qui pourront offrir à nos lecteurs quelque intérêt par les usages et le costume de leurs habitants.

Ainsi, nous laisserons de côté le Sangara, le Kankan, le Ouassouls, l'Amara et le Bouri, pour nous occuper du Bambarra, aujourd'hui partagé en deux États que l'on a proposé d'appeler le haut et le bas Bambarra, et que l'on nomme aussi royaume de Sego et royaume de Jenné ou Djenny.

La population de la capitale (Ségo) du haut Bambarra est évaluée à 30,000 habitants; la forme de leurs canots, composés de deux grands arbres creusés et joints par les extrémités, prouve combien la civilisation a fait peu de progrès.

Le roi du bas Bambarra ou du royaume de Jenné ne réside pas à Jenné, capitale de cet État; il a fait élever une ville à laquelle il a donné le nom de El-Khando-l'Illah (la louange de Dieu). Les JennéEns sont mahométans; ils prennent plusieurs femmes et les traitent mieux que ne le font les nègres situés plus au sud; elles sortent sans voile; mais elles ne mangen $i$ pas avec leurs maris ni avec leurs enfants du sexe masculin. Les habitants de Jenné sont très-industrieux; il y a parmi eux des tailleurs qui font des habits que l'on envoie à Tembouctou; des maçons, des cordonniers, des forgerons, des pêcheurs, des emballeurs et des portefaix. Les Mores y font un grand commerce et y sont fort riches.

Le royaume de MASSINA est habité par des Foulahs mahométans; ils ont les cheveux nattés en tresses très-fines, et se coiffent d'un chapeau de paille à larges bords. Leur's 
armes sont des arcs, des flèches et quelques javelots; peu d'entre eux ont des fusils.

Les royaumes de Ludamar (ou Eli-oud-Amar), de Birou et de Banan-Dagou n'ont aucune importance, quoique les nègres du dernier s'adonnent au commerce et à l'industrie.

Le pays des Dirmans a pour chef-lieu Alcodia; ces hommes ont le teint noir, de beaux traits, de grands yeux, le nez aquilin, les lèvres minces, et les cheveux crépus. Outre les piques, les arcs, les flèches et le poignard, ils sont quelquefois armés d'un sabre et d'un fusil. Les femmes placent quelques grains de verre dans les tresses de leurs cheveux; elles ont le cartilage du nez traversé par des boucles en verroterie.

Le royaume de Tembouctou ${ }^{x}$ a pour capitale la ville de ce nom, cité myslérieuse qui fut longtemps l'objet des recherches des Européens, et qui est loin de répondre aux idées de grandeur et de richesse qu'on s'en était faites. \& Au premier aspect, dit M. Caillé, elle n'offre qu'un amas de maisons en terre, mal construites; dans toutes les directions, on ne voit que des plaines immenses de sable mouvant, d'un blanc tirant sur le jaune et de la plus grande aridité. Le ciel, à l'horizon, est d'un rouge pâle; toul est triste dans la nature; le plus grand silence y règne; on n'entend pas le chant d'un seul oiseau. Cependant il y a je ne sais quoi d'imposant à voir une grande ville élevée au milieu des sables, et l'on admire les efforts qu'ont eus à faire ses fondateurs. »

Les habilants de Tembouclou suivent avec zèle les pratiques de l'islamisme; ils sont doux, hospitaliers, intelligents, industrieux, et d'une grande propreté dans leurs vètements. Les hommes, de taille ordinaire, sont bien faits, ont la démarche assurée, le teint d'un beau noir foncé, le nez un peu plus aquilin que celui des Mandings, et, comme ceux-ci, de beaux yeux et les lèvres minces. Les femmes, généralement jolies, sont libres et peuvent sortir sans être voilées; elles tressent leur chevelure avec art, et ornent leur cou, leur tête et leurs oreilles de faux ambre, de verroteries et d'autres petits objets, élevés à la qualité de bijoux par les peuples qui sont encore dans l'enfance de la civilisation; elles portent aussi des bracelets d'argent, et des anneaux de fer argenté aux chevilles. Le costume est celui des Mores.

Le roi, très-respeclé de ses sujets, est simple dans ses habiludes, et ne déploie pas, dans son habillement ou dans son habitation, plus de luxe que les Mores négociants. II est commerçant lui-même, ainsi que ses enfants, et jouit d'un riche patrimoine qu'il lient de ses ancêtres. Il n'a pas de ministres; c'est un père qui règne sur ses enfants el qui ne prélève aucun tribut sur ses sujets ni sur les marchands étrangers. S’il s'élève quelque contestation entre les habitants, ils se rendent auprès du prince qui, après en avoir référé au conseil des anciens, prononce un jugement que les parties accueillent sans murmure.

De même que chaque chef de maison, le roi a quatre femmes; mais il se distingue des autres par un plus grand nombre d'esclaves.

Le Kayri ou Kayouerri renferme un peuple qui, dit-on, ne vit que de brigandages.

Le royaume de Kong ou Conge est peuplé de nègres mahométans qui se teignent en bleu les sourcils et les paupières.

Les royaumes de Calama, Dagoumbai, Fobi, Masi, Filladou et Gago sont à peine connus; ces deux derniers sont séparés par des déserts du Tembouctou et du vaste empire des Fellahs ou Fellatahs, dans lequel nous allons entrer.

Les Fellatans n'ont conservé aucune idée de leur origine; ce peuple est disséminé dans les diverses provinces que nous allons visiter, et parle la même langue que les Foulahs des environs de Sierra-Leone.

1 Plus exactement Ten-buktoue. 


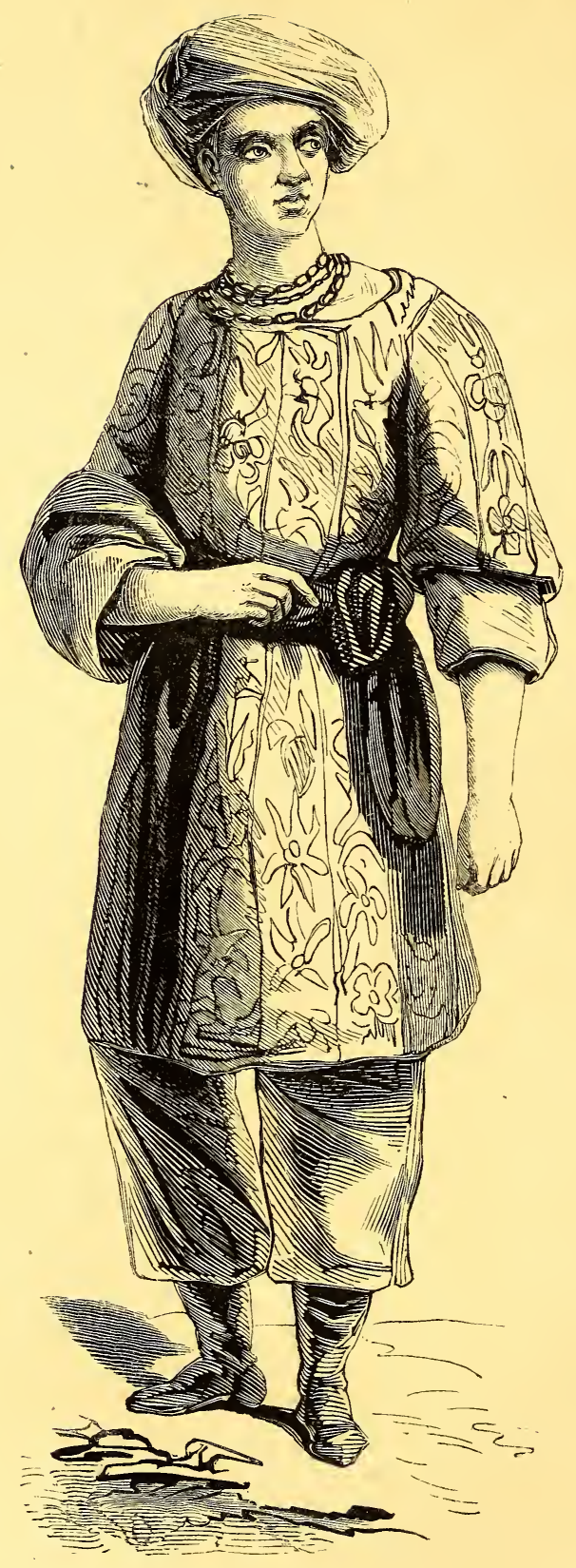

ROI DE BOUSSA. 
Le Mali ou Melli est, dit-on, riche en mines d'or. Selon un voyageur more (EbnBathouthah), personne ne peut entrer dans Mali, capitale du pays, sans la permission du monarque, petit prince despotique devant lequel tous les autres nègres s'humilient. " Si quelqu'un de ces nègres, dit ce voyageur, est appelé à comparaître devant le roi, il quitte sur-le-champ ses vêtements ordinaires, se revêt d'habits usés et d'un sale manteau, et paraît en sa présence comme un mendiant, les vêtements retroussés jusqu'à mi-jambe; il frappe la terre de ses deux coudes et conserve la posture d'un suppliant. Quand le roi adresse la parole à quelqu'un, celui-ci rejette ses vêtements en arrière et couvre sa tête de poussière; tant que le prince parle, tous les assistants restent la tête couverte.

Mais ce qui, selon Ebn-Bathouthah, parait le plus choquant dans leurs coutumes, c'est qu'ils laissent leurs enfants des deux sexes entièrement nus, de même que leur's esclaves mâles et femelles. Les femmes libres ne portent de vêtements qu'après le mariage. Enfin, la plupart de ces hommes mangent des viandes corrompues.

Les habitants du SANGHI sont mahométans et passent pour avoir atteint un certain degré de civilisation.

Le royaume de Haoussa est partagé en quatorze provinces (sept à l'est et sept à l'ouest), dont chacune est gouvernée par un prince. Zirmie, capitale du Zamfara, dans le Haoussa occidental, a pour habitants les plus fameux voleurs du pays; c'est dans cette ville que se réfugient les esclaves fugitifs de toutes les parties du pays.

Les principales divisions de la partie occidentale sont le Yaourc, le Noufé ou Nyffé, le Yarriba, le Barghou et le Gourouma. Nous donnons le costume du roi et de la reine de Boussa.

Le costume du roi consiste en un bonnet rouge et un ample turban de même couleur; une tunique de soie damassée verte et cramaisie, un large pantalon de drap rouge et des bottines arabes. La nuance des divers vètements, et surtout la coiffure, varie souvent.

Celui de la reine se compose d'une simple chemise de manufacture indigène, d'un morceau de cotonnade bleue attachée autour de la tête, et qui cache entièrement sa chevelure : un morceau d'étoffe semblable est jeté sur son épaule gauche, et un troisième, noué autour de la ceinture, lui descend jusqu'au milieu de la jambe. Ses pieds et ses bras sont nus jusqu'au coude; ses poignets sont ornés chacun de huit bracelets d'argent dont le moindre pèse environ un quart de livre; chacun de ses orteils est orné d'un anneau de cuivre; elle porte au cou un collier de corail et de morceaux d'or, et le cartilage de ses oreilles est percé de trous dans lesquels sont passés de petits tubes de corail.

YaOURI, capitale de la province de ce nom, est d'une étendue prodigieuse; ses murailles hautes et en très-bon état, bien que construites en terre, ont environ 8 à 10 lieues de circonférence; on y entre par huit portes, qui sont bien fortifiées à la manière du pays. Les habitants fabriquent une espèce de poudre à tirer, très-grosse et fort mauvaise, mais qui cependant est le meilleur des autres produits de cette espèce fabriqués par les indigènes. Les YAOURIENS fabriquent encore une étoffe particulière à ces contrées; ils cultivent l'indigo, le tabac, les oignons, le blé, différentes sortes de grains, et récoltent une énorme quantité de riz d'une qualité supérieure.

Un marché assez considérable se tient chaque jour dans la ville, sous des hangarã commodes. Malgré leur industrie et les avantages dont ils jouissent, les habitants de cette ville sont pauvrement vêtus, ont peu d'argent, et se plaignent toujours de la misère.

Les Yaouriens possèdent des chevaux, des bœufs, des chèvres, etc. La résidence du sultan, de mème que les maisons de la plupart des principaux habitants, est élevée 
d'un étage, auquel on arrive par un lourd et disgracieux escalier en terre; mais les appartements de ce premier étage ont d'ordinaire de hauts plafonds, et leurs portes, ainsi que celles du rez-de-chaussée, ont une grandeur suffisante pour qu'il ne soit pas nécessaire de se baisser quand on passe dessous. En général, les maisons sont construites sur un plan circulaire; il y en a pourtant quelques-unes de carrées. Celles du sultan n'ont aucune forme régulière. Pour maintenir la fraîcheur dans ces habitations, on humecte les planchers et les murs intérieurs, deux ou trois fois par jour, ou du moins aussi souvent que possible, avec une solution de bouse de vache et d'eau.

Entre les différents groupes d'habitations s'étendent des espaces considérables de terre, sur lesquels paissent les bestiaux, ou qui sont destinés à l'agriculture et au jardinage. Dans l'enceinte de la ville, il y a aussi une grande variété d'arbres dont les principaux sont le palmier, le micadonia, le citronnier et le dattier; mais ce dernier, bien qu'il paraisse y pousser à merveille, n'a jamais porté de fruits.

Les femmes les plus distinguées de Yaouri portent leurs cheveux très-artistement tressés et teints en bleu, ce qui leur donne un air des plus étranges; elles se noircissent aussi le tour des yeux avec de la poudre d'antimoine, ou quelque autre drogue qui a la même propriété, et que les indigènes tirent de Jacoba.

Dans le Haoussa oriental, les provinces ne sont pas moins importantes : on cite celles de Kachénah, Zez-Zeg, Ghoubir et Kano ou Kanou.

Jusqu'à l'époque de leur mariage, les jeunes gens des deux sexes, dans la dernière ville que nous venons de nommer, portent par décence un long tablier bleu et blanc, avec une bordure dentelée d'étoffe de laine rouge; ils l'attachent au moyen de deux larges bandes, ornées de la même manière et qui retombent par derrière jusqu'aux talons; les jeunes filles ont des colliers de verroterie. Les deux sexes se colorent les dents et les lèvres avec les fleurs du goerjie ou du tabac, ce qui leur donne une teinte rouge de sang, fort appréciée dans ce pays; ils se teignent en bleu les bras et les jambes.

L'empire de Bournou a pour capitale Birnie ou Akumbo, qui est la résidence de l'empereur. Il comprend, outre le Bournou proprement dit, le Kanem el le Mandara.

Les Bournouars ${ }^{1}$ se donnent le nom de Kanory; ils ont le visage large, le nez gros, le front haut, la bouche très-fendue et ornée de belles dents. Leurs manières sont polies, affectueuses; leur caractère est indolent. Moins tolérants que les Arabes, ils suivent rigoureusement les préceptes de l'islamisme qu'ils professent. Les riches Bournouais ont rarement plus de deux ou trois femmes à la fois; les pauvres n'en ont qu'une. Celles-ci se distinguent moins par la beauté que par la propreté; elles se drapent gracieusement dans une pièce d'étoffe bleue qui, attachée sur l'épaule, contourne la taille et forme une jupe ouverte par devant, et qui laisse voir une espèce de chemise de toile blanche qu'elles portent en dessous; leur chevelure est partagée en une infinité de petites nattes qui retombent au bas du cou; un bandeau de couleur rouge orné d'une espèce de cocarde de métal ceint leur front, du milieu duquel partent en sens contraires deux chapelets à grains de cuivre ou d'argent.

M. de Seedzen ne fut pas médiocrement surpris d'apprendre que le sultan de Bournou avait plusieurs esclaves français, dont quelques-uns conservaient même leur costume européen; ils lui ont établi une fonderie de canous de bronze, dont il se sert dans ses guerres avec les nègres païens au sud de l'empire.

Le commerce de Bournou est très-actif, et on y voit constamment une multitude de négociants étrangers : les principales affaires sont faites par les Tunisiens; mais les Tripolitains, les Égyptiens, les Fezzanais et les nègres d'Affanoh y apportent aussi beau-

1 Pour la religion des Bournous, voyez notre Histoire et Céremonies religieuses, etc. 


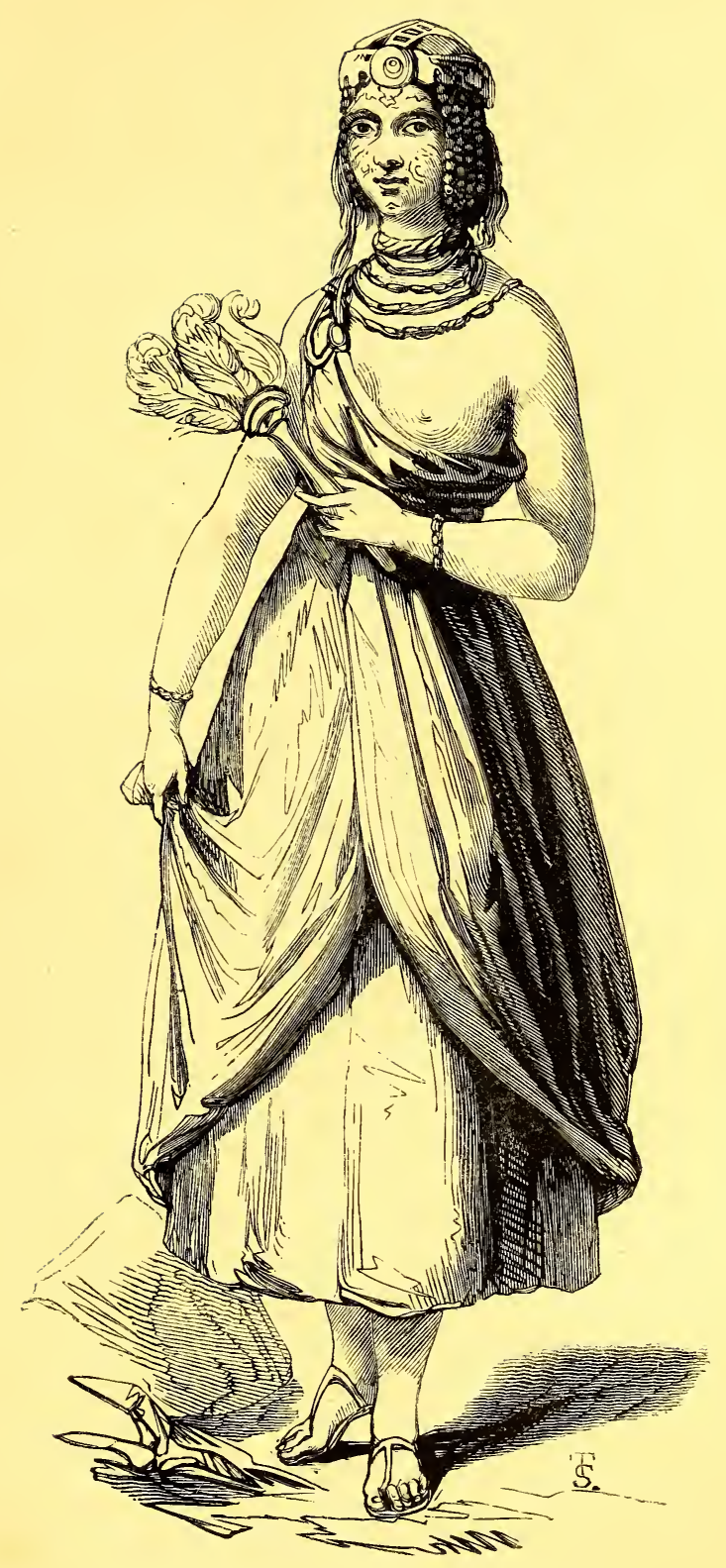

BOURNOUAISE 



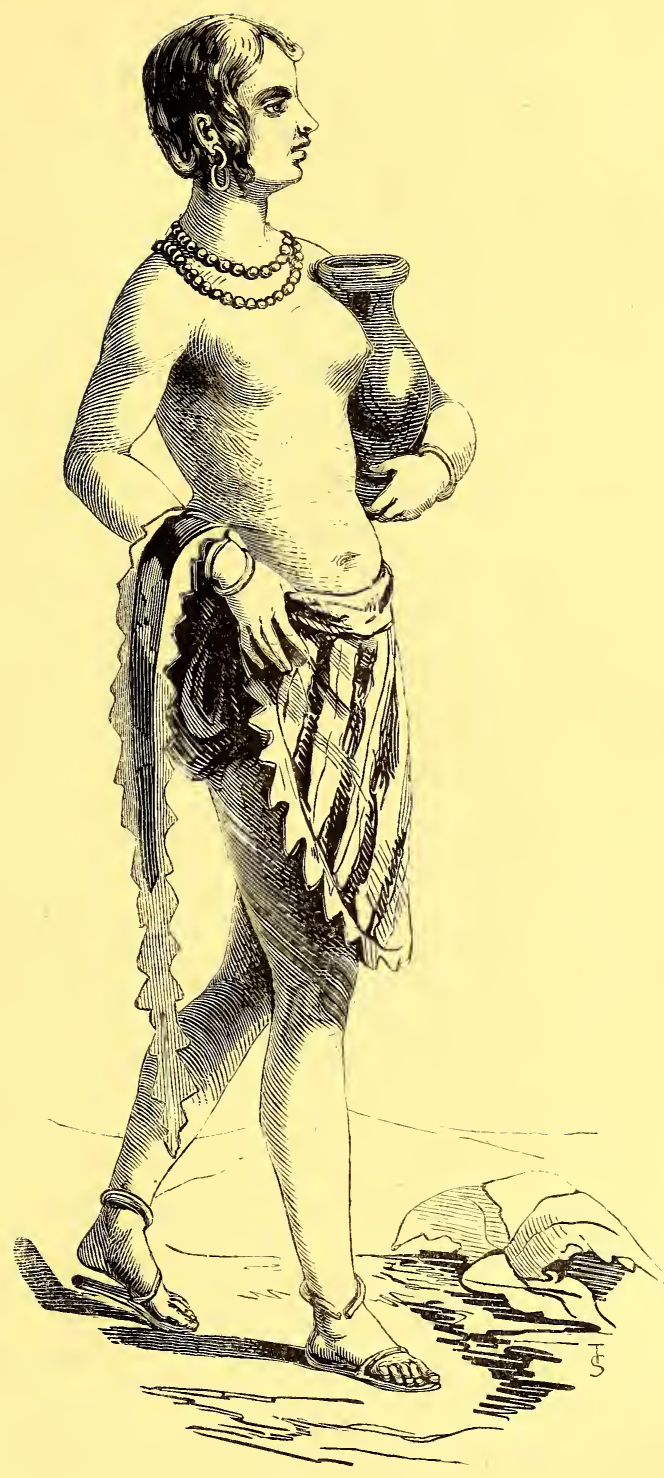

JEUNE FILLE DE KANO. 

coup de marchandises. On fabrique à Bournou des bagues ou anneaux d'or, d'argent et de cuivre jaune; des aiguilles, des couvertures de lit et des étoffes. Il y a aussi des graveurs en pierres fines et en cachets.

Le Bournou est très-peuplé : on y compte treize villes principales, et l'on y parle dix dialectes différents de la même langue. Les Chouaa y ont apporté un arabe assez pur. Ils sont divisés en tribus qui portent encore les noms de quelques-unes des hordes de Bédouins qui parcourent l'Égypte; ils se prétendent doués du don de prophétie; l'une de leurs tribus offre la plus grande ressemblance avec les bandes de bohémiens qui parcourent la terre. Ils fournissent à l'armée du Bournou 15,000 hommes de cavalerie.

Les Mandarans sont mieux partagés que les Bournouais sous le rapport physique. Ils ont le front haut et plat, le nez presque aquilin, et la physionomie pleine d'expression. l.es femmes sont jolies, et leurs mains et leurs pieds sont d'une petitesse charmante. l.e costume est le même que celui des Bournouais.

Les Kanembous ou Kojam sont en partie mahométans, en partie idolâtres; ils sont armés d'une lance, d'un bouclier et d'un poignard fixé sur le bras gauche par un anneau qui entoure le poignet. Le costume de leurs femmes est semblable à celui des Bournouaises.

Les habitants du Baghermeh ou Baghirmah passent pour être chrétiens; on peut en dire autant des habitants du pays d'ANDAM, qui ont les dents naturellement pointues. Cette forme de dents est commune aux Jemsens, qui sont païens et anthropophages. On ne dit rien des KendiLs, si ce n'est qu'ils ont les cheveux longs.

Le pays de Baghermeh relevait jadis de l'empereur du Bournou, lorsque ce dernier était dans sa toute-puissance, ainsi que le prouve le fait suivant, rapporté par un habilant de Mobba, nommé Hassan : Le sultan de Baghermeh avait épousé sa sœur. Une action aussi contraire à la loi ne pouvait rester cachée; elle parvint à la connaissance du sultan de Bournou, qui, outré de colère, lui ordonna de renoncer de suite à cette alliance, et le menaça de la vengeance d'Allah et de la sienne. Le sultan de Baghermeh ne se laissa pas intimider, et renvoya la lettre, en écrivant sur le revers \& que l'usage d'épouser sa, sœur avait subsisté longtemps avant la naissance du prophète, et qu'il ne voyait pas de raison pour qu'il ne subsistât pas après lui. 'Cette réponse laconique de la part d'un vassal mit le sultan de Bournou en fureur. Il ordonna de suite au sultan vassal de Mobba d'entrer avec une armée dans le pays de Baghermeh. Ce prince remplit sa mission, vainquit le sultan rebelle, et l'envoya prisonnier à Mobba.

Le LougGoun, pays qui doit son nom à l'une de ses villes les plus méridionales, et qui a pour capitale Kernok, est peuplé d'une race d'hommes qui passent pour être plus beaux que les Bournouais. Les Lougroniens des deux sexes sont intelligents et industrieux; dans presque toutes les maisons on trouve un métier à tisser. Les femmes sont les plus belles négresses que l'on puisse voir, mais aussi très-dépravées. La langue de ce pays est un mélange de baghermien et d'arabe.

Le Kossery est un petit État indépendant dont on n'aborde le sultan qu'en lui tournant le dos.

Les habitants de Maffataï sont indolents et aiment beaucoup la danse.

Les naturels du Koulla appartiennent à deux races d'hommes, les uns noirs et les autres cuivrés ou rouges; ceux du nord-est reconnaissent l'autorité d'un roi; les autres sont divisés en petites tribus indépendantes.

Le royaume de MOBBA$^{x}$ est habité, en général, par des nègres mahométans. La circon-

1 Les Arabes établis dans ce royaume l'appellent Dar-Szaley. Les Fezzains le nomment Ouadaï, et les Bournouais Bergou. 
cision est en usage pour les deux sexes. Les femmes ne sont pas voilées. Ces nègres ont pour armes des lances, des boucliers, des arcs et des flèches; les fusils y sont en petit nombre. La petite vérole exerce de grands ravages parmi eux, mais la peste y est peu connue.

Le Dar-Four est un groupe d'oasis entouré de déserts, dont la superficie est évaluée à 9,500 lieues, et la population à 200,000 habitants.

Les Dar-Fouriens ou Fouriens ont la peau noire et très-épaisse; les fibres musculaires d'un rouge éclatant, une force de contraction singulière qui paraît résider dans leurs nerfs, la vue excellente, les dents blanches et fortes, les cheveux courts et laineux. Ils sont mahométans; mais ils ne se montrent ni rigoureux observateurs des préceptes du Coran, ni sévères dans leurs relations d'un sexe avec l'autre. La circoncision et l'excision sont pratiquées par eux. La langue berbère paraît être celle du pays. Ils s'enivrent fréquemment avec une boisson fermentée appelée merissah; ils voient d'un œil indulgent les infidélités de leurs femmes, pourvu qu'ils en retirent quelque avantage. Quoiqu'ils puissent avoir autant de femmes qu'ils en veulent, que le souverain en ait plus de cent, et les grands plus de trente, il arrive fréquemment que, sourds à la voix de la morale la plus naturelle, le frère épouse sa sœur et le père sa fille. Et chez eux il est permis de tromper ceux avec qui on a des rapports, et de s'emparer du bien d'autrui si l'on peut le faire impunément.

Les Dar-Fouriens ne connaissent pas les monnaies, et font le commerce d'échange. La capitale, nommée Cobbé, renferme 600 habitants, deux mosquées et cinq moctebs ou écoles publiques. Le souverain n'y réside point; il habite aux environs, dans un endroit appelé $E$-Facher. Ce prince est absolu; il fait le commerce, perçoit des impôts sur toutes les marchandises, et chaque village lui fournit annuellement une quantité de millet que ses esclaves sont chargés de recueillir. Le seul corps qui ait le droit de faire des remontrances à ce despole (presque toujours sans effet, il est vrai) est celui des foulkaras ou ministres de la religion; mais une institution redoutable pour lui est l'armée, car s'il encourt la haine des troupes, il périt bientôt par la strangulation. L'effectif de cette armée est porté à 30,000 hommes répartis en trois corps : les hommes montés sur des dromadaires, la cavalerie et l'infanterie. 


\section{ROYAUME DU GONGO.}

La côte de l'Afrique occidentale, comprise entre le cap Lopez de Gonzalvo, et le cap Negro, est connue dans le commerce sous le nom générique de côte d'Angola, nommée Éthiopie occidentale par quelques auteurs italiens et français; elle est située dans la hasse Éthiopie des Portugais, vaste division qui commençait près du fort de la Mina, au nord de l'équateur. Tandis que les meilleurs géographes l'ont appelée basse Guinée ou Guinée méridionale, M. Balbi lui a donné le nom de Nigritie méridionale. Il paraît lonc plus convenable de donner à cette région le nom de Congo, puisque la langue de ce royaume, dont la domination a jadis embrassé le pays presque en totalité, est regardée comme la tige de tous les idiomes qu'on y parle.

Sans prétendre entrer ici dans une description partielle de toutes les petites divisions politiques, résultat naturel des usurpations des gouverneurs auxquels obéissait autrefois le Congo, nous tracerons l'historique du costume de chacun des principaux pays qui formaient naguère ce grand empire, afin d'éviter toute espèce de confusion dans la description de ces immenses contrées.

Placé près de l'équateur, le Congo est naturellement sujet aux chaleurs qui règnent dans les contrées de la zone torride. On n'y connaît à la rigueur que deux saisons, celle de la sécheresse et celle des pluies; les mares d'eaux stagnantes qu'occasionnent celles-ci, remplissent l'air de méphitismes et rendent le séjour de la côte dangereux pour les Européens.

On n'a que de faibles notions sur la direction des différentes chaînes de montagnes, ainsi que sur l'origine et le cours des fleuves. Parmi ces derniers, le Congo ou Coango ${ }^{\mathbf{x}}$, qui se jette dans la mer avec tant de violence qu'on en ressent la secousse à trois lieues, et qu'on peut encore en apercevoir les effets à douze; car, outre que la mer y conserve la teinte de ses eaux noirâtres, elle est encombrée d'îles flottantes de bamhous qu'elle y a entraînées. On prétend que ses cataractes, qui sont à cent vingt lieues de son embouchure, semblent plus majestueuses que celles du Nil.

Si le règne minéral n'y offre que des richesses médiocres, la nature, en revanche, y déploie un caractère de fécondité et de magnificence dont nulle description n'approchera.

Zucchelli et Cavazzie parlent du poisson-femme (ou pesce-donna), qui paraît ètre le phoque, peut-être le lamentin. Les reptiles y abondent, et les insectes y sont innombrables. Quant aux oiseaux, la description des espèces qui peuplent ces contrées for. merait la matière de plusieurs chapitres.

A partir du cap Lopez jusqu'à la baie de Sainte-Catherine, où se trouve un port rare. ment visité, la côte peu connue est basse et couverte d'arbres. Les naturels sont misérables, passent pour traîtres et obéissent à un chef qui est sous la dépendance de

${ }^{1}$ Les indigènes l'appellent le Zaïre ou Zahire. 
celui de Loango. A l'embouchure du grand fleuve Banno, on rencontre la baie de Mayomba, dont les habitants sont doux, hospitaliers, et plus intelligents que ceux des États voisins. Ce peuple paraît adonné au commerce : il fournit la plus grande partie de l'ivoire qui s'achète dans les ports des environs, travaille le cuivre, et recueille la meilleure gomme; mais supposer que les montagnes du Mayomba recèlent de l'or, est une prétention purement gratuite. Les chefs des Mayombas relèvent du royaume de LOANGO.

Ce dernier pays, dont la capitale est appelée Bouali, selon les indigènes, ne renferme pas plus de 600,000 âmes, lant la traite a épuisé la population. Les esclaves qu'on amène au marché de Bouali sont Mayombes, Quibongas ou Montéquès : les Mayombes sont inférieurs en qualité, mais supérieurs en nombre; les Quibongas, qui appartiennent à une petite peuplade de l'intérieur, sont les plus beaux nègres qu'on puisse voir; ils sont bien faits, très-noirs, d'une jolie figure, et ont les dents admirables; les MoNTÉQuÈs sont beaux aussi, mais ils se gâtent les dents en les limant pour les rendre pointues; leur corps, et surtout leurs joues, sont ornés de longues cicatrices. Ce pays, selon Oldendorp, renferme des juifs noirs.

Le royaume de CAcongo, appelé Malembé par les marins, fournissait autrefois les meilleurs esclaves. Le roi dîne seul en public, et lorsqu'il se dispose à boire, tout le monde se jette à terre dans la crainte qu'il ne mourût si quelqu'un de ses sujets le regardait en ce moment. Lorsqu'il exerce les fonctions de juge, il est tenu de sceller chacun de ses arrêts par un coup de vin.

LeroyaumedeN'Goyo, EN-Goyo ou Goy, emprunte souvent le nom de sa capitale Cabinde. Les nègres qui sont vendus dans ce port sont des Congues, des Sognes et des Mondongères (ou Mondongonès). Les Sognes ou Sonhos sont généralement bien faits, grands et rouges. Les Mondongonès sont beaux et bons; mais ils ont les mêmes habitudes que les Montéquès; de plus, ils se déchirent la poitrine en dessins symétriques, font gonfler les chairs avant de les cicatriser, de manière qu'elles forment, en surmontant les bords de la blessure, une broderie dont ils tirent vanité. Les femmes ont en outre la manie de s'inciser le ventre de trois larges blessures, et de faire renfler les chairs jusqu'à ce qu'elles forment trois grosses excroissances sur cette partie.

Le royaume du Congo a été divisé en six provinces, Sogno, Pemba, Batta, Pango, Bamba et Soundr, par les Portugais, qui, pour familiariser les nègres avec les formes de la civilisation européenne, ont fait prendre aux grands les noms de ducs, marquis, comtes, etc., au lieu de l'ancien titre de mani (seigneur). Mais, soit faiblesse, soit négligence, les Portugais, qui sont parvenus à soumettre ce pays à leur suzeraineté, le laissent en proie aux dissensions intestines. La capitale du Congo est San-Salvador qui, avec sa banlieue, forme un district à part, soumis à l'autorité immédiate du roi.

Indépendamment des six provinces que nous venons de nommer, il y en a d'autres moins considérables qui sont incultes, désertes ou occupées par des sauvages.

Les provinces d'Ouando et de Dembi se sont soustraites à l'autorité du roi du Congo, et sont placées sous la protection des Portugais.

Ces derniers n'ont pu parvenir à convertir au christianisme les habitants du royaume d'Angola (Dongo ou N'Gola); ils ont dû se contenter de les enrôler pour le service militaire. C'est sur la côte d'Angola que se trouve la colonie portugaise de LaondaSan-Paolo, capitale des établissements de cette nation dans l'ouest de l'Afrique.

La province de Soumbi et celle de Goloungo n'ont rien de remarquable.

Quoique sous le joug portugais, le Benguela a conservé le titre de royaume, et quelques priviléges insignifiants.

Le royaume de Mattemba ou Ginga est gouverné par une reine qui s'est rendue 
célèbre par ses exploits guerriers. Le nom de cette femme, appelée Zinga, a fait donner aux habitants le nom de Zingas ou Gingas.

Après avoir nommé les contrées connues et civilisées, ou du moins régulièrement habitées, nous jetterons un coup d'œil sur les nègres qui les occupent.

Les Congues sont inférieurs, sous le rapport de l'intelligence, à beaucoup de races africaines : à l'exception d'une mémoire assez heureuse, leur ineptie est complète; ils n'ont que des sentiments, des instincts grossiers; des mœurs et des habitudes tellement rapprochées de l'animalité, qu'ils ont regardé eux-mèmes les singes comme faisant partie de leur race. Le temps est divisé chez eux en jour et nuit; le jour en trois parties. Ils comptent par lunaisons, et n'ont aucune idée de l'écriture. Leur courage est aussi nul à la guerre qu'à la chasse : le chasseur ajuste longtemps la pièce, tourne la tête, fait feu, laisse tomber son fusil, s'enfuit au bruit de l'explosion, et ne revient que longtemps après pour ramasser le gibier qu'il apporte en triomphe s'il le retrouve. Leur navigation se borne à la pêche; ils n'ont que des pirogues faites avec des troncs d'arbres qui ne sont même pas façonnés et qui sont creusés à l'aide dı feu; il est impossible de trouver des filets plus mauvais que ceux dont ils se servent. Tous les travaux utiles sont délaissés aux femmes et à de nombreux esclaves.

Quoique nés dans l'abrutissement, ces êtres dégradés sont pleins d'orgueil; et nulle part on ne saurait trouver cie maîtres plus capricieux, plus durs, plus barbares: les esclaves ne les approchent qu'à genoux; et les grands, qui seuls portent des pantoufles, déploient une morgue insupportable dans leurs relations avec le peuple, qui se courbe servilement devant eux. Tous considèrent comme les plus grands monarques de l'univers, leurs rois, fiers de la prérogative de chausser des bottes... quand ils en possèdent, ct souvent affublés ridiculement de débris d'uniformes européens qui couvrent mal leur dégoûtante nudité.

On ne saurait indiquer toutes les superstitions indigènes des Congues, tant elles sont variées et nombreuses. Cependant nous en faisons connaître bon nombre dans nos Cérémonies religieuses de tous les peuples, où l'on trouvera le détail des ridicules momeries de leurs prêtres et de leurs magiciens et jongleurs religieux ou fétichistes.

Parvenu à faire de sa cour une nauvaise copie de celle de Lisbonne, le roi du Congo, assis sur un trône à l'européenne, est servi par des comtes et des marquis noirs dont le costume étale des ornements grossièrement imités de ceux d'Europe. Les monarques païens ont conservé la barbarie de leur pompe. Jadis, celui de Loango se rendait une fois par an à une réunion de la nation pour ordonner solennellement à la pluie d'arroser la terre; et comme il arrivait parfois aux nuages d'obéir, le peuple s'en allait convaincu du pouvoir divin de son roi. Cependant, devenu moins crédule par le contact l'hommes civilisés, le peuple est plus difficile à tromper, et le roi s'est résigné à ne plus commander aux éléments; il a cédé cetle fonction à un de ses ministres qui, pour mettre à couvert sa responsabilité, attend prudemment pour appeler la pluie qu'il ait commencé à pleuvoir.

Tous les souverains des provinces comprises entre le cap Lopez et le fleuve Zaïre r'econnaissent la suzeraineté du roi de Loango, et lui payent un tribut en femmes. Leur jouvoir est d'ailleurs exercé despotiquement et sans contrôle; dans un accès de mauvaise humeur, ils vendent aux Européens jusqu'à leurs ministres, taxent leurs sujets suivant leur caprice, et disposent de leur vie quand la fantaisie leur en prend. Ceci n'empêche pas qu'ils ne plient devant leurs vassaux lorsqu'ils les craignent. Une loi fondamentale de l'État leur défend de faire usage d'aucune production étrangère, excepté les métaux, les armes et les ouvrages en bois. Le domaine royal se compose de 'quelques villages et de tout le terrain qui n'est point occupé. 
Au Congo le tròne se transmet partout par voie d'hérédité. Mais il faut excepter le royaume de Loango. Ici, lous les princes nés dans les divers États dépendants peuvent aspirer à l'honneur de régner; ils sont choisis par un corps électoral, composé des sept officiers principaux de la couronne, y compris deux seigneurs adjoints, et qui forme le gouvernement provisoire. Il résulte de celle disposition que les feudataires se trouvent vivement intéressés au maintien d'un trône auquel tous ont des droits, et qu'ils rompraient difficilement les liens qui les y rattachent. C'est la mère qui anoblit, et non le père, que l'on connaîtrait difficilement; aussi, pour être prince-né, il faut être issu d'une princesse : de là vient le droit qu'a celle-ci d'épouser qui lui convient, et de le répudier à volonté pour appeler à l'honneur de sa couche un nouveau mari. Les princes font de même, mais leurs enfants nés d'une femme de condition inférieure peuvent être vendus par leurs frères ou sœurs qui ont pour mère une princesse. Le mari de celle-ci est prince tant qu'il vit avec elle, et conserve celte qualité si elle meurt dans cet intervalle. Le divorce n'est plus permis entre un prince et une princesse. Les princes ne peuvent remplir aucune charge du gouvernement, mais ils jouissent généralement d'importantes prérogatives.

Après le roi, les principaux officiers du gouvernement sout, à Loango, le grand capilaine (premier ministre et grand juge); le mafouc (ministre du commerce); le maquimbe (inspecteur général de la côte); le monibanze (ministre des finances); le monibele (messager d'État); le soldat-roi (généralissime de l'armée et grand exécuteur).

Dans les autres États, le second personnage est le manbouc, l'héritier présomptif du trône. Après lui vient le macage, premier ministre, dont l'autorité est limitée par celle du manbouc el des princes-nés; puis le mafouc, le maquimbe, le monibèle, et le grand capitaine, dont les fonctions sont les mêmes que celles du soldat-roi de Loango; enfin les gouverneurs et les suzerains.

Abstraction faite des charges, les rangs de la société se suivent ainsi : le roi et sa famille, les princes-nés, les maris des princesses, les suzerains, les courtiers, les marchands d'esclaves, les clients. Les suzerains sont de riches propriétaires, serfs du roi el princes-nés, quoique non attachés à la glèbe. Les courtiers sont les individus qui reçoivent des marchands les captifs, qu'ils transmettent aux Européens; la distinction avec laquelle ceux-ci les traitent, les font considérer de leurs compatriotes. Les clients sont obligés de servir et défendre leur maître, qui, de son côté, les loge, les habille et les protége.

Bien que le roi soit juge suprême, il est rare qu'une plainte lui parvienne. Les seigneurs des plaignants et des prévenus sont les premiers juges, et rendent la justice a vec empressement. Il faut, selon les circonstances, la décision du mafouc, du maquimbe, du gouverneur, ou le concours de tous les magistrats. L'audience est publique; si l'affaire n'est pas criminelle, les spectateurs n'ont point d'armes; ils se rangent en cercle autour d'un tapis, sur lequel on dépose, aux frais des parties, des flacons d'eaudo-vie en nombre proportionné à celui des assistants. Il n'y a pas d'affaires sans eaude-vie; tout le monde peut pérorer, et chaque plaidoyer est accompagné de libations el de chansons. On achève de vider les flacons après le prononcé de la sentence.

Il n'y a pas de lois écrites; l'usage et la tradition en tiennent lieu. Si le coupable a volé, il faut qu'il paye; s'il a fait des dettes jusqu'à concurrence de la valeur d'un esclave, il le devient lui-même à défaut de payement; s'il a commis un adultère, l'époux outragé a droit à la valeur d'un esclave; s'il a blessé au sang, il doit un esclave; s'il a vendu un esclave sur lequel il n'avait aucun droit, ou commis un homicide, il est mis en pièces sur-le-champ, et son corps est abandonné aux oiseaux. L'esclavage étant commun, il y a égalité de droit entre les hommes. Cependant les princes-nés ne sont 
pas vendables, et les suzerains condamnés peuvent livrer à leur place un de leurs mainmortables.

Quand la culpabilité du prévenu paraît contestable, on le soumet aux épreuves du poison ou du feu. Une coutume bizarre consiste à faire prendre aux deux parties l'infusion d'une racine nommée imbondo; cette boisson a deux effets; elle fait évacuer et uriner, ou elle agit sur la tète comme un poison narcotique. Le peuple attend lequel de ces effets aura lieu; celui qui rend promptement le breuvage est proclamé vainqueur; l'autre est impitoyablement massacré.

La polygamie la plus effrénée règne au Congo, et toute l'influence de la religion chrétienne n'a pu que prohiber les unions incestueuses. L'intelligence du Congue ne va pas jusqu'à comprendre la saintelé du mariage, l'affection mutuelle des époux, et les jouissances d'un ménage bien uni; il n'éprouve aucun attachement pour ses enfants, qu'il verra vendre avec la plus complète indifférence. L'ivrognerie, une musique bruyante, des danses grossières, le sommeil : tels sont les plaisirs qu'il affectionne. Les hommes riches donnent quelquefois un vingaré (sorte de dîner public) où tout un village s'enivre du melaffo ou vin de palmier qui coule à flots.

Au nombre des usages étranges du Congo, nous devons faire remarquer celui qui oblige les hommes à se mettre au lit lorsque leurs femmes viennent d'accoucher; ainsi placé, il reçoit les félicitations de ses amis, car ici les femmes ne sont que des esclaves, et la naissance d'un enfant étant regardé comme un événement heureux, c'est au maître que les compliments doivent être adressés.

La langue des Congues passe pour une des plus belles de l'univers.

Le costume de ces peuples offre diverses singularités; les princes et les seigneurs du Congo, de Batta, de Sogno tiennent à honneur de se coiffer d'un bonnet blanc; ceux de Lubola attachent des sonnettes à leur ceinture. Dans le royaume de Mattemba, on conserve en général l'usage de se faire des incisions dans la peau.

Les hommes du peuple ne portent qu'une espèce de tablier d'une étoffe grossière; leurs femmes et les esclaves ne sont couvertes que d'une espèce de jupe, et ont le haut du corps entièrement nu.

Les femmes d'un rang distingué ont trois de ces tabliers, chacun de longueur différente, ornés de franges; celui de dessous leur descend jusqu'aux pieds; elles ont aussi une espèce de corset qui leur vient jusqu'à la ceinture, et ont pour coiffure un bonnet pareil à celui des hommes et dont la forme se rapproche de nos casquetles rondes à plis. Les femmes de condition moyenne s'habillent de même, excepté que les étoffes sont plus communes, et qu'elles n'ont qu'un tablier. La plupart des grands ont adopté l'habillement portugais; mais les dames ne portent point le manteau.

Les soldats du Congo ont pour coiffure un bonnet garni de plumes d'autruche, de paon, de coq, etc.; ils sont nus de la ceinture en haut, et ont des chaînes de fer avec des anneaux de la grosseur du petit doigt qui leur tombent du cou sur les flancs. Ils portent des caleçons de toile ou de tafetas, et par-dessus une pièce d'étoffe qui descend sur les talons et dont ils relèvent les bouts dans la ceinture; celle-ci, d'un travail délicat, est garnie de sonnettes. Leur chaussure se compose de bottes à la portugaise. Leurs armes sont un mélange ridicule d'arcs, de sabres de bois dur et de quelques mousquetons. Ils empoisonnent leurs flèches, et leurs haches, arrondies en forme de faux, seraient redoutables si elles étaient conduites par un bras nerveux. Il y en a qui se couvrent d'un bouclier ou de peaux d'animaux; d'autres cherchent à se donner un aspect terrible en chargeant leur corps de peintures de serpents et d'autres animaux dangereux.

Les soldats de Loango se peignent le corps en rouge pour marcher aux combats. 
Les troupes du Congo sont divisées en plusieurs corps, portent leurs étendards déployés, et combattent ordinairement à pied; elles exécutent leurs évolutions suivant les divers sons qu'elles entendent et qui sont produits par trois instruments : le premier est une espèce de timballe dont la caisse de bois est recouverte d'un cuir sur lequel on frappe avec de petits maillets d'ivoire; le second a la forme d'une pyramide renversée, et forme par le bas un triangle qui va en s'élargissant par le haut; il se compose de plaques de fer minces jointes ensemble, sur lesquelles on frappe avec des baguetles de bois; le troisième est fait avec des dents d'éléphant de dimensions différentes; elles sont percées dans leur longueur, et on en tire des sons en soufflant dans un trou qui se trouve sur le côté.

Des diverses tribus sauvages qui occupent les confins du Congo, il n'y a que les Anziquois qui puissent nous arrêter.

Les AnziQuors sont loyaux, courageux, agiles, intrépides, mais d'une barbarie si révoltante, qu'ils vendent publiquement la chair humaine dans les marchés. Quelquefois les naturels, dégoûtés de la vie, dit-on, ou égarés par un faux point d'honneur, s'offrent eux-mèmes à la boucherie. Les parents et les fils même se dévorent les uns les autres. Cette assertion est combattue par M. de Grandpré, qui nie même que l'anthropophagie existe en Afrique. Il soutient ainsi son opinion : "Si le voyage de Mungo-Park dans đles pays où le mahométisme a pénétré, ne détruit pas sans réplique l'imputation faite aux Africains d'être cannibales, que pourrait-on répondre au témoignage de Levaillant, dont les pas se sont dirigés vers des peuples entièrement sauvages, absolument étranģers à toute espèce de civilisation, et parmi lesquels il n'a rien trouvé qui pût justifier une accusation aussi injuste? Je puis, de mon côté, certifier qu'il est faux que les noirs Congues mangent de la chair humaine : ces peuples sont doux, timides et paresseux; ils ont en général horreur de verser le sang, et celui d'entre eux qui blesse un autre au sang, est condamné à donner un esclave ou la valeur en marchandises, et si l'agresseur n'en a pas le moyen, il est pris lui-même et vendu. »

Les grands portent un bonnet de velours ou de soie bleu, rouge ou noir, des robes de soie ou des habits de drap. Les femmes sont vêtues de la tête aux pieds. Tous vont pieds nus, à l'exception des gens de distinction; les individus de basse classe ont. la partie supérieure du corps nue et les cheveux nattés.

\section{CIMB E B A S I E .}

Cette contrée de la côte occidentale de l'Afrique a environ 275 lieues de longucur. Elle s'étend depuis le cap Frio jusqu'aux îles des Oiseaux, sur les limites de la Hottentotie. Elle est habitée par les Cimbebas et les Makosses ou Macasses, peuples sur lesquels on a peu ou point de renseignements.

1 Notre marche géographique exige que nous placions ici la Cimbebasie. 



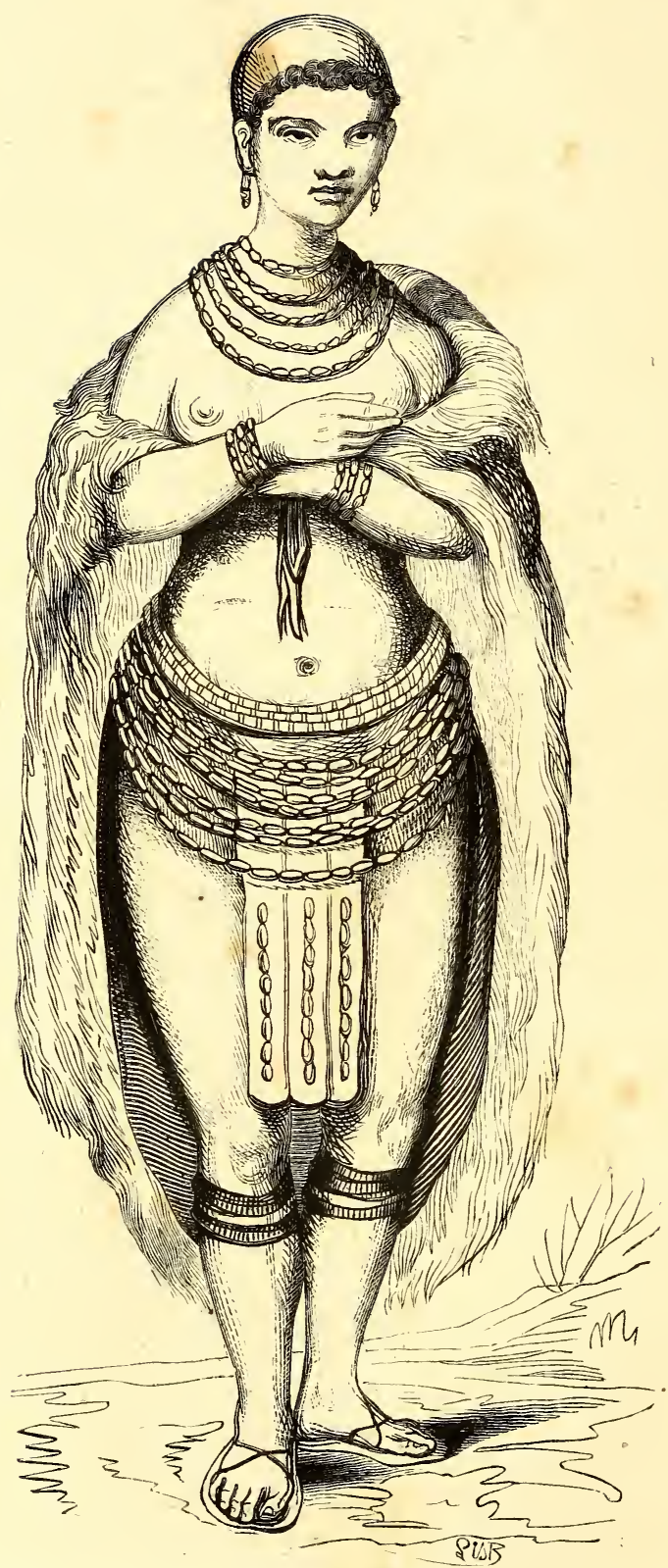

HOTTENTOTE. 



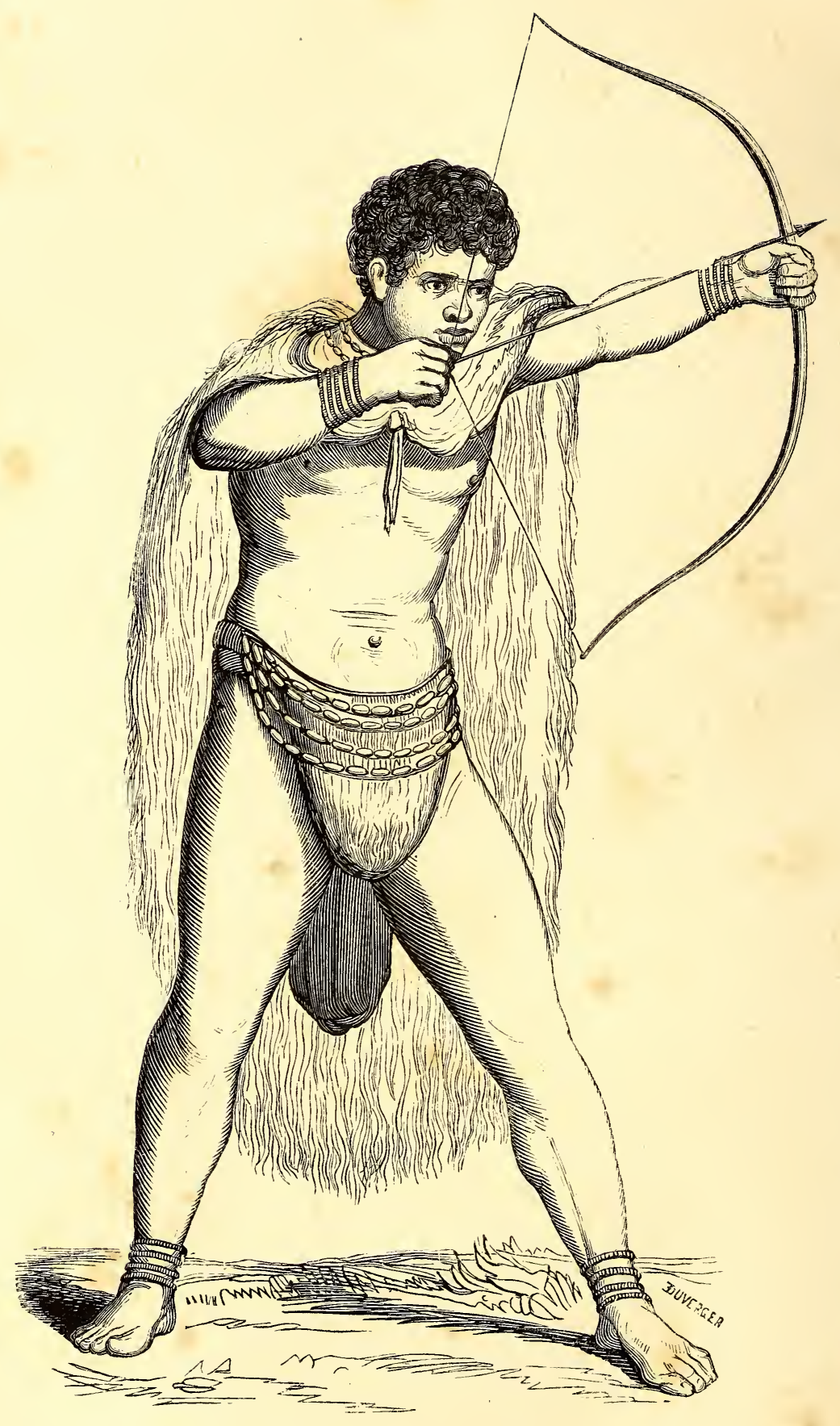

HOTTENTOT. 


\section{HOTTENTOTIE.}

Cette région tire son nom du peuple qui l'häbite; elle est située entre $25^{\circ}$ et $32^{\circ}$ de latitude sud, et entre $13^{\circ}$ et $25^{\circ}$ de longitude est.

Les Hottentots sont aborigènes de l'Afrique méridionale; ils en ont occupé toute l'extrémité, car les noms des cours d'eau et des montagnes de la Cafrerie propre, tirés de leur langue, prouvent assez qu'ils ont été chassés de ce pays et refoulés à l'ouest, comme ils l'ont été successivement au nord par les Européens depuis le milieu du $\mathrm{Xvir}^{\mathrm{e}}$ siècle. Ils se divisent en nations, qui présentent quelques légères différences quant au physique, mais de plus grandes dans le caractère et la manière de vivre. Ce sont : au nord, les Damaras et leurs voisins méridionaux les Kabobiquas; à l'ouest, les Namaquas, séparés en grands et petits par le fleuve Orange; au centre et voisins des Karamankeys, situés à l'est, les Koranas : ces deux divisions se trouvent entre l'Orange el la Kouroumana, son affluent. Au sud des Karamankeys, entre les deux branches de l'Orange et les limites de la Cafrerie, vivent les Gonaquas, et au sud-est de ceux-ci, sur la limite de la colonie anglaise, les Bosjesmans ou Houzouanas, et enfin l'ensemble des tribus qui retiennent le nom de Hotlentots, et qui habitent au sud de l'Orange, entre les Bosjesmans et les Namaquas, et occupent encore la plus grande partie du gouvernement du cap de Bonne-Espérance. Ces tribus sont plus ou moins soumises aux Anglais, et c'est d'après elles qu'on a pu donner quelques détails sur les mœurs, les couturnes, etc., de ces peuples.

Les Holtentots sont de couleur brun foncé ou jaune brun ; mais cetle nuance n'atteint pas le blanc des yeux qui reste pur; ils ont la tête, le visage fort large d'en haut et finissant en pointe; les pommettes des joues très-proéminentes, les yeux en dedans, le nez plat, les lèvres épaisses, les dents très-blanches, la main et le pied petits en comparaison du reste du corps; ils sont bien faits, d'une taille grande et droite; leurs cheveux, de couleur noire, sont frisés ou laineux, et ils n'ont presque pas de barbe. Les femmes ont réellement la difformité connue sous le nom de lablier, et que la décence nous empêche de décrire.

Le Hottentot sauvage erre en chantant et en dansant au milieu des troupeaux qui forment toute sa richesse; il est couvert d'une peau de mouton, de gazelle ou de lion; inondé de graisse mèlée d'une couleur noire ou rouge, et armé d'une courte massue. Un usage bizarre parmi ces peuples, c'est la cérémonie par laquelle un jongleur ou magicien sanctifie l'union des nouveaux époux en les aspergeant d'une eau chaude et malpropre; elle sert encore à initier à la qualité d'homme fait, l'adolescent qui atteint sa dix-huitième année. Le tempérament de ces individus leur fait repousser la polygamie; ils ont en horreur l'inceste et l'adultère, et la veuve qui veut se remarier doit perdre une phalange d'un doigt. On ne leur connaît aucune idée de la Divinité; cependant ils considèrent une espèce de mante (mantis fousta) comme un animal sacré, el se livrent à diverses opérations de sorcellerie.

La langue de toutes les tribus hottentotes est une, y compris celle des Bosjesmans, 
quoique celle-ci présente quelques différences avec l'idiome des autres tribus. Toutefois, nous devons ajouter que les tribus sauvages changent continuellement leur idiome, chaque nouveau chef voulant introduire quelques locutions nouvelles. Il en résulte une multiplicité de dialectes qui déroute toutes les observations.

Les Damaras sont réunis en communautés plus nombreuses que les Koranas et les Namaquas, et gouvernés par des chefs héréditaires; ils pratiquent la circoncision et habitent des villages; car, bien qu'ils sachent exploiter les mines de cuivre, ils sont trop misérables et trop grossiers pour bâtir des villes.

Les Namaquas, divisés en grands el petits Namaquas, sont un peuple pasteur chez lequel on retrouve les traits caractéristiques des Koranas. Leur naturel est doux, apathique et peu entreprenant. Les grands Namaquas vivent sous l'autorité patriarcale du missionnaire Anderson.

Les Kabobiquas et les Geissiquas paraissent être des branches de Namaquas.

Les Koranas ou Kora-Hottentots se divisent en un grand nombre de clans indépendants ou de kraals, dont chacun est gouverné par un chef ou capitaine qui est ordinairement l'individu le plus riche, mais dont l'autorité est à peu près illusoire, puisqu'on ne lui obéit qu'autant que ses ordres ont l'approbation générale. Ils transportent leurs huttes mobiles partout où ils vont s'établir, coutume commune aux Namaquas. Leur habillement est fail de peau de mouton; les femmes y ajoutent un tablier de peau, et les hommes une espèce de poche qui ne satisfait qu'imparfaitement au vœu de la pudeur. Les Koranas sont les plus beaux Hottentots.

Les Gonaquas ou Channaquas sont aussi très-beaux comparativement aux races du pays. Comme les Koranas, ils ont l'esprit plus étendu que les autres tribus.

Les Bosjesmans ${ }^{1}$ paraissent être une branche des Hotlentots, séparée anciennement. Ils se trouvent incontestablement placés au dernier point de dégradation où puisse descendre l'espèce humaine : un regard incertain, farouche et sinistre; des traits confus, mous et insidieux; un embarras visible dans toute leur manière d'être et d'agir, annoncent, à la première vue, la dépravation de leur âme. Leur excessive maigreur fait singulièrement ressortir dans leur visage les caractères propres à la race hottentote. La couleur naturelle jaunâtre de leur peau n'est reconnaissable qu'audessous des yeux, où les larmes, provoquées par la fumée du feu autour duquel ils aiment à se blottir, enlèvent quelquefois l'enduit épais de cendre et de suif qui recouvre entièrement leur corps. Cependant, comparés à leurs femmes, les hommes peuvent passer pour beaux; celles-ci font vraiment horreur. Des seins flasques, allongés el pendants, un dos creux, rentrant et décharné comme le reste du corps, en contraste avec la partie inférieure qui est gonflée, très-éminente, et où, de même que chez les brebis d'Afrique, toute la graisse paraît s'être concentrée; tel est le portrait de la femme bosjesmane. La piqûre du scorpion, fort dangereuse dans ce pays pour tous les autres individus, n'a aucun effet sur ces sauvages. La plupart du temps, munis d'un arc, d'un carquois rempli de flèches, d'un bonnet et d'un ceinturon, d'une toison de mouton, de sandales de cuir, d'une calebasse ou de la coque d'un œuf d'autruche pour contenir l'eau, de leux ou trois nattes d'herbe, qui, étendues sur des bâtons, forment leur tente, accompagnés quelquefois de chiens barbets, ces indigènes infortunés traînent la plus déplorable existence, en rôdant seuls ou par petites bandes dans les arides déserts qui bordent au nord la colonie. Ils vivent ordinairement de baies, de racines, de larves, de sauterelles, d'œufs de fourmis, de crapauds, de souris, de lézards, et du rebut de la chasse des colons.

1 On les appelle aussi Boschismans et Ouzonanas; les Koranas les appellent Saabs. 
Tantôt voleurs et brigands, tantôt mendiants, toujours cruels et làches, sans demeure fixe, sans forme sociale, sans gouvernement, sans aucune espèce d'intérêt commun, vivant au jour le jour, ils ont fait jusqu'ici échouer toutes les tentatives faites pour adoucir leurs mœurs brutales; aussi la haine des peuples voisins s'appesantissait-elle sur eux bien longlemps avant l'arrivée des Européens dans leur pays; ceux-ci, au lieu de leur donner la chasse, comme on l'a supposé gratuitement, accueillent au contraire ceux d'entre les Bosjesmans qui circulent près des frontières de la colonie, et leur font souvent des largesses en bestiaux, volaille, tabac, corail, eau-de-vie, boutons, elc., pour les engager à la paix. Dans les derniers temps, plusieurs colous septentrionaux s'étaient colisés pour distribuer à une troupe de ces naturels, seize cents brebis et trente pièces de gros bétail; peu de temps après, il n'en restait plus aucune trace, grâce au concours des hordes éloignées, accourues pour partager le festin, et qui ne désemparèrent que lorsque tout fut consommé. Les Cafres et mème les Hottentots les plus civilisés leur font sans relàche une guerre à mort; la vue seule d'un Bosjesman les met en fureur. Un Cafre député d'une petite horde de sa nation se trouvant, en 1804, au Cap, reconnut, dans l'hôtel du gouvernement, parmi les autres domestiques, un Bosjesman âgé d'environ onze ans; soudain il s'élança sur lui pour le percer d'un coup de hassagaie, et l'on eut toutes les peines du monde pour l'empêcher d'accomplir son dessein. Les Bosjesmans sont les seuls peuples de l'Afrique qui se servent de flèches empoisonnées; c'est avec cetle arme qu'ils guettent le passage des karrous, en se cachant derrière les roches ferrugineuses, d'avec lesquelles on les distingue fort difficilement. Bien souvent, après avoir reçu le tribut qu'on est forcé de leur accorder, ils viennent la nuit, fondent sur les habitations dont ils ont reconnu les approches, enlèvent tout le bétail et se sauvent avec la plus grande rapidité dans leurs inaccessibles montagnes. S'il leur arrive d'être alteints dans la fuite, ils ne làchent leur butin qu'après avoir tué ou du moins estropié tous les bestiaux volés; quelquefois même, ils se contentent de massacrer tout ce qui se trouve dans le parc, bœufs, moutons, chevaux, chiens, et jusqu'au berger, sans en tirer le moindre profit. Semblables à l'hyène, l'odeur des cadavres et la vue du sang leur procurent d'agréables émotions.

La Colonie du Cap renferme une population de 64,000 blancs ou de nègres libres, 32,000 Holtentots et 36,000 esclaves. Aujourd'hui celle colonie est divisée en sept districts. La parlie méridionale du district de Stellenboscin a conservé le nom de Hollande hollentote.

Nous ne pouvons terminer la description de la Hotlentolie sans parler des colons de la Ville du Cap. Fondée en 1652 par Van Riebeck, elle fut d'abord peuplée de mauvais sujets exilés de Hollande, de soldats libérés du service, de matelots qui, ayant amassé quelque argent à Batavia, avaient pu rompre leur engagement. A l'époque de la révocation de l'édit de Nantes, un grand nombre d'infortunés Français qu'une marâtre repoussait de son sein, trouvèrent l'hospitalité en Hollande; beaucoup d'entre eux allèrent s'établir au Cap et peuplèrent un petit canton qui fut nommé le Coin Français, et que leurs descendants habilent encore; ils n'ont conservé que les noms français défigurés, ont presque oublié leur langue, et ont adopté les usages des Hollandais. L'éducation de ceux-ci est très-négligée; les jeunes gens parlent assez bien le français et l'anglais, mais là paraît se borner leur instruction. Quoiqu'ils excellent dans les arts d'exercice, les trois quarts de leur vie se passent à fumer; ils boivent continuellement du thé, du café et du genièvre. Un voyageur, M. Collin, parle ainsi des habitants du Cap :

- Les femmes, jusqu'à l'âge de vingt à vingt-cinq ans, restent charmantes : des yeux bleus, des cheveux d'un châtain clair, un teint de rose, et leur extrème propreté, voilà 
des charmes qui font oublier leur mise peu élégante : après cet âge, elles perdent ordinairement leur légèreté; un embonpoint épais remplace la finesse de leur taille, elles deviennent alors très-dignes de leur mari, dont le flegme, l'air gauche et la démarche lourde, contrastaient auparavant avec leur délicatesse. On trouve au Cap des femmes qui, sous des dehors de simplicité, sont très-aimables et très-instruites. Parny, qui a peint les mœurs du Cap dans de jolis vers, dit dans une note : aous êtes accueilli avec un air d'intelligence et d'amitié qui, parmi nous, signifierait beaucoup. Vos yeux peuvent s'expliquer en toute assurance, on leur répond sur le mème ton. \Ces observations étaient très-justes dans le temps où Parny écrivait (1773). Mème à une époque plus rapprochée, les demoiselles avaient des airs fort libres; un baiser était complé pour rien : on le prenait en jouant, en jouant on vous le rendait, lors même que le père et la mère se trouvaient présents; ces bonnes gens riaient de tout leur cœur. Ils attachaient peu d'importance à ces libertés qui, chez les Français, semblent attaquer l'honneur et la vertu : mème un étranger arrivé de la veille pouvait aller le lendemain se promener avec la demoiselle de la maison où il logeait. Elle avait soin de lui faire remarquer les belles allées du jardin de la compagnie, et surtout l'allée couverte; ils y allaient même ensemble, ils pouvaient s'y trouver seuls, s'asscoir l'un près de l'autre, rire, folâtrer, et ressortir encore animés de leurs jeux, sans que personne ait eu l'idée d'une réflexion maligne. Aujourd'hui cette simplicité de mœurs est un peu altérée; les filles sont plus réservées, et les mères les veillent de plus près, el cependant les aventures fâcheuses sont beaucoup plus fréquentes qu'autrefois. ”

M. Collin ajoute que le séjour des Anglais au Cap y a apporté de grands changements et lui fera perdre peu à peu le caractère d'une contrée hollandaise.

Cette colonie est susceptible de beaucoup d'accroissement, et, en temps de guerre, la Ville du Cap est le centre d'une station maritime qui commande la navigation des Indes orientales par son union avec les îles Sainte-Hélène et Mauritius. 


\title{
COTES ET ILES AFRICAINES.
}

\section{COTES SUD-EST,}

\author{
OU GAFRERIE, MIONOMOTAPA ET MOZAMBIQUE.
}

Cette vaste contrée est divisée en quatre parties : la Cafrerie propre, le pays des Betjouanas, celui des Barrolous, et le Monomotapa. Elle a 225 lieues de largeur sur une longueur de plus du double.

Cafrerie propre. - La taille des Cafres ${ }^{x}$ est haute; leur corps robuste, leurs proportions sont belles. Par la forme de leur tête el par leur physionomie, ils se rapprochent bien plus des Européens que des Hottentots, ou des nègres de l'Afrique occidentale; une chevelure laineuse, crépue et noire, ombrage un visage de couleur brune, mais dont le teint cuivré ne manque pas de transparence. Chez eux, rien de cette défiance, de cette perfidie et de cette férocité cachée qui caractérisent les nations non civilisées. Leur abord est franc; il y a de la gaieté dans leurs mœurs, et quelque chose de noble, de généreux, d'ouvert dans leurs relations sociales. Les femmes, moins bien douées de la nature que les hommes, sont petites, ont le système musculaire plus développé, la taille plus courte et ramassée, les membres forts, la physionomie en geénéral peu régulière, mais agréable et bienveillante. Lorsqu'elle n'a pas atteint l'àge de la caducité ou qu'elle n'est pas malade, la femme du Cafre est vive, aimable, riante; et, en général, les femmes cafres, les plus laides même, ont de très-belles dents.

Toutes ces femmes ont le dos, les bras et le milieu de la poitrine sillonnés de lignes parallèles à égale distance. Ces incisions, qui, dans leur opinion, servent à relever la beauté, se font en introduisant un poinçon, en guise de bistouri, sous l'épiderme qui se déchire à mesure que l'on relève l'instrument.

Les Cafres sont très-braves, et s'ils étaient unis, ils pourraient devenir fort dangereux pour leurs voisins. C'est à la chasse et à la guerre qu'il faut les voir déployer leur énergie. Ils y vont par troupes nombreuses; les filles nubiles et les femmes assistent même quelquefois à ces parties, qui durent jusqu'à deux ou trois mois. Pour forcer un lion, ils commencent par former un cercle autour de lui, et se rapprochent peu à peu du centre. L'animal blessé ne manque pas de se précipiter sur l'un des chasseurs, qui l'évite en se jetant subitement à terre, et en se couvrant de son bouclier; alors les autres accourent et percent l'animal de leurs zagaies. Le vainqueur rentre en triomphe dans son hameau. La chasse des éléphants est la plus pénible. Rarement les Cafres parviennent à les percer assez profondément pour rendre la blessure mortelle.

Le sentiment religieux est peu développé chez ces peuples; ils professent le fétichisme.

1 Ils se donnent à eux-mêmes le nom de Koussas. 
Ils croient à un mystérieux rapport entre un Être dont ils ont une idée bien imparfaite et qui exprime sa colère par le tonnerre ou par une famine venue à la suite de la sécheresse, et un monde peuplé d'esprits. Ils croient à la sorcellerie et à l'apparition de la mort. Ils rendent aussi un culte à un bon génie, Tiko, qui a été métamorphosé par les missionnaires en Outiko (bon génie tout-puissant), nom qu'ils donnent à ce dieu qu'on leur enseigne maintenant, et que dans leur ignorance ils regardent plutôt comme leur ancien génie que comme le Dieu des chrétiens. Tikaloski, démon bizarre et invisible, du genre des farfadets et des sylphes, est, disent-ils, le mauvais génie des femmes; c'est lui qui les porte à troubler la paix du ménage, à se mal conduire et à oublier leurs maris. Quand un de ceux-ci croit avoir à se plaindre de sa femme, il réunit ses amis, et tous ensemble attaquent une hutte vide dans laquelle le démon Tikaloski est supposé résider, et, lorsqu'ils ont remporté une victoire facile, ils poussent des cris de joie et de triomphe. Ils pratiquent beaucoup de cérémonies superstitieuses; entre autres, ils immolent une génisse aux mânes d'un ancêtre que l'on veut rendre propice au mariage d'une jeune vierge. La circoncision est généralement adoptée chez les Cafres, sans qu'elle se mêle à aucun vestige d'islamisme. Quand arrive l'âge de puberté, les jeunes gens sont séparés de leurs camarades, vivent isolés pendant trois mois, et sont ensuite réunis dans une grande cérémonie où la circoncision est pratiquée. Les circoncis portent des vêtements fantastiques, bizarres, prononcent certaines paroles, et sont admis au nombre des guerriers. Les femmes, lorsqu'elles deviennent nubiles, subissent une cérémonie analogue.

Le christianisme n'a civilisé qu'imparfaitement ces régions presque ignorées. Tous les cadavres du bas peuple sont abandonnés à la dent des hyènes; ceux des chefs et de leurs femmes sont enterrés dans l'oumzi ou village. Les Cafres pensent en général que la présence de la mort est cantagieuse. Malgré les efforts des missionnaires, les magiciens ont conservé leur pouvoir sur la nation. Quand un magicien accuse un individu qui possède une grande quantité de bestiaux, aucune preuve n'est nécessaire, aucune protestation d'innocence admise; l'accusé est attaché à terre avec une courroie, traîné par les pieds et pan les bras, qui sont liés à des pieux; des pierres brùlantes sont posées sur lui, et des nids brisés de grosses fourmis noires et venimeuses placés sur les parties écorchées de son corps. Dans ces tortures, il avoue tout ce qu'on exige de lui; alors on lui intime de se défaire du pouvoir par lequel il fait le mal; il donne quelque chose, quoi que ce soit, un fil de grains ou tout autre ornement; ensuite il est mis à mort, ou il est banni de la tribu, et devient mendiant et vagabond.

Le gouvernement des Cafres est patriarcal, et ressemble à celui de toutes les hordes primitives. Le chef est héréditaire; mais le père a le droit de choisir parmi ses enfants celui qu'il veut pour successeur. Dans tous les cas, ce ne peut être que l'un des fils de sa première femme, qui appartient ordinairement à une autre tribu. Les nobles, l'aristocratie s'appellent amagapati (vieillards, sénateurs); ce sont toujours eux que l'on consulte dans les occasions difficiles, et qui servent de contre-poids à l'autorité, d'ailleurs absolue, du chef.

Ces peuples si sauvages ne manquent pas d'une certaine politesse grave, apanage de la vie primitive, et qui préside à leurs discussions. Le Cafre parle peu, mais avec dignité, aplomb, et comme s'il s'acquittait d'une tâche importante. Les petits enfants eux-mêmes, lorsque la question la plus ordinaire leur est adressée, font un pas en avant, étendent la main, comme pour donner plus de poids à leurs paroles, et prononcent leur réponse d'un ton solennel. Le vol, l'adultère et le meurtre sont châtiés par une amende, qui, tantôt équivaut à la propriété totale de l'accusé, tantôt ne consiste qu'en quelques pièces de bétail. Rarement le criminel est puni de mort. 


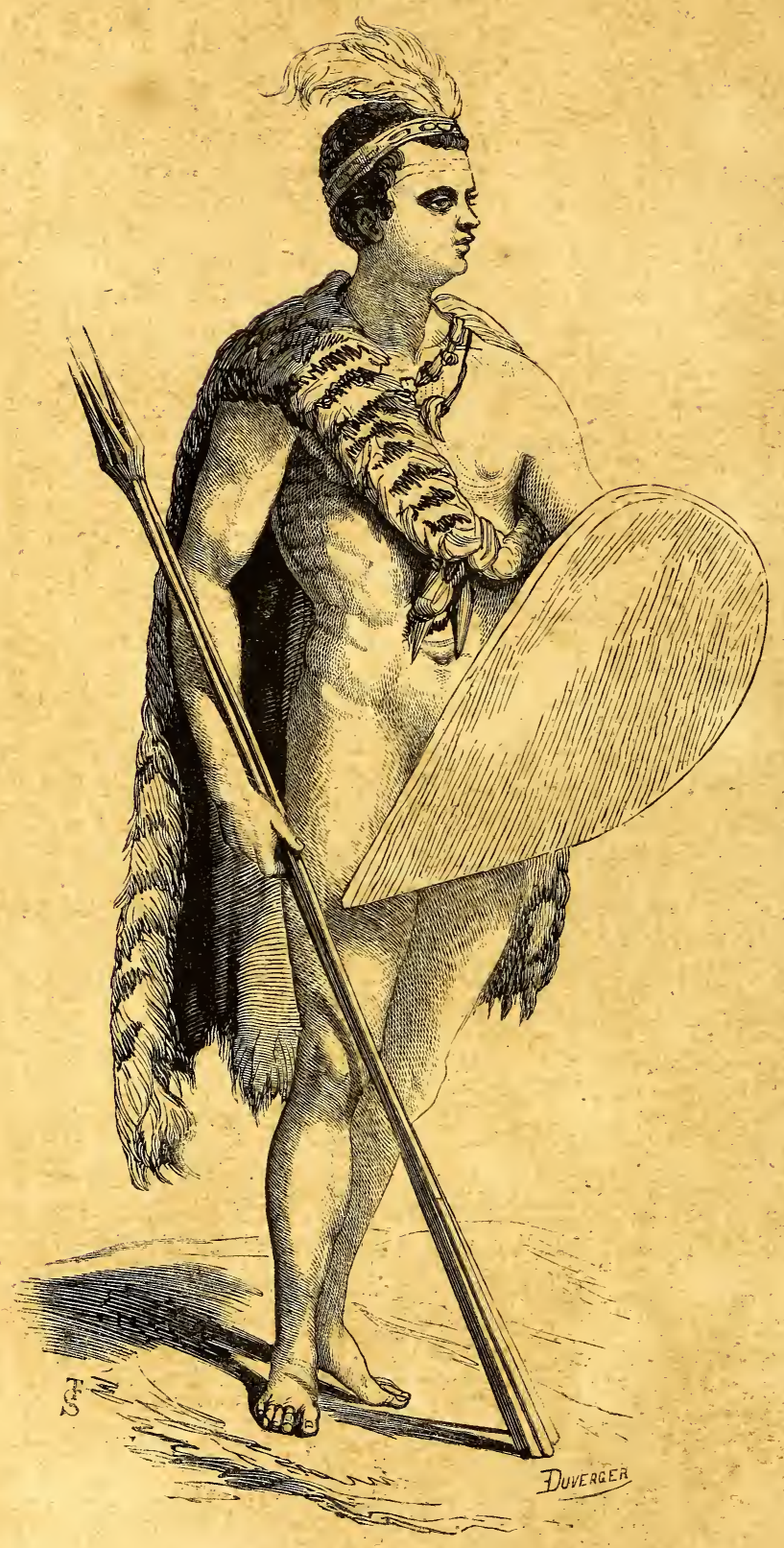

GUERRIER CAFRE 
Le droit du plus fort ne règne pas chez les Cafres; il n'est permis à personne d'être son propre juge, le cas excepté où un homme surprend sa femme en adultère. Malheureusement l'exemple de la corruption européenne exerce déjà une influence funeste sur les mœurs de ce peuple pasteur. L'arrogance des colons, les fraudes commises dans le trafic, l'abus de la force, joints aux instigations de quelques mauvais sujets de la colonie et à celles des Hottentots révoltés, ont amené des guerres désastreuses entre les Cafres et les colons; guerres qui ont laissé un ressentiment profond et funeste : cependant rien de plus facile que de traiter avec ces peuples, en invoquant leur équité naturelle.

Un sentiment universel de bienveillance unit tous les Cafres, et chaque individu considère le tort fait à un autre comme s'il était fait à lui-même; ils s'entr'aident dans le besoin avec un dévouement sans bornes. Quoique très-intéressés, ils mettent la plus grande bonne foi dans le commerce. L'hospitalité est à leurs yeux un devoir sacré qu'ils s'empressent de remplir avec la plus aimable prévenance : tout étranger est accueilli et fêté; on va, dit-on, jusqu'à lui donner une compagne pour la nuit.

Le costume des Cafres consiste en peaux d'animaux, préparées et tannées de manière à conserver le moelleux de la fourrure et sa souplesse. La peau d'un bœuf ou d'une vache, coupée dans une certaine forme consacrée, forme l'ingoubo ou carosse, manteau à la grecque qui flotte sur les épaules et que portent tous les Cafres. Les chefs et les princes ont des peaux de léopard et de panthère destinées au même usage; mais ils confient ordinairement ces belles dépouilles au soin d'un domestique qui porte à la main le manteau royal de son maître, dont les épaules sont simplement couvertes de l'ingoubo ordinaire. Autrefois on portait aussi, dans certaines occasions, quand il fallait jeter bas l'ingoubo, une espèce de petit tablier; mais cette coutume a été abandonnée comme trop féminine. Le Cafre pense qu'il doit se présenter debout et nu à son ennemi; il n'attache aucune idée de décence ou d'indécence à la nudité entière; il doit se montrer à son adversaire, sans voile, sans armure, sans défense. C'est une sorte d'héroïsme qui lui fait reléguer parmi les femmes jusqu'à ce petit tablier qu'ont eu soin de conserver cependant quelques tribus de l'Afrique intérieure.

L'aspect d'un Cafre dans son costume de guerre offre quelque chose de sauvage et de singulier; son carosse ou manteau est jeté de côté pour qu'il ne gêne pas ses mouvements. Son bouclier, formé d'un cuir très-fort et taillé en forme ovale, est suspendu à son bras gauche, tandis qu'il porte dans la main droite un faisceau de cinq zagaies. Deux plumes grises de grue, attachées par une lanière de cuir, lui ceignent la tête.

La vie du Cafre est une vie d'indolence parfaite ou d'exercice violent. La culture est abandonnée aux femmes, à qui l'entrée du kraal est expressément interdite. Les hommes seuls peuvent traire les bestiaux. Armés d'une seule zagaie, les Gafres attaquent l'éléphant et l'hippopotame; mais rien ne pourra les forcer à cet exercice; ils resteront des heures entières autour du feu, écoutant les fables de leurs conteurs.

L'habillement des femmes cafres est plus compliqué, plus modeste et plus gracieux que celui des hommes. Elles portent aussi l'ingoubo, dont le collet est enrichi par derrière d'une espèce de queue ou de basque, ornée de plusieurs rangées de boutons. Leur poitrine est couverte de l'imbeka, espèce de gorgeret de cuir souple, que l'étiquette leur défend de déposer, excepté lorsqu'elles allaitent ou qu'elles sont malades. Un petit tablier de cuir, appelé kaïo, et l'ïpouri, coiffure singulière, sont encore indispensables. L'ïpouri est une espèce de casque ou de turban, formé avec la peau de l'antilope bleue, dont le nom est ïpouri chez les indigènes. Des grains de verroterie blanche et bleue $y$ sont disposés, non pas selon le caprice ou la fantaisie des femmes, mais bien d'après un modèle dont il n'est pas permis de s'éloigner. Les couleurs bleue et blanche dont ces bonnets sont nuancés s'harmonisent fort bien avec le teint bronzé de ces femmes. 
Les femmes cafres sont traitées comme des esclaves; ce sont elles qui chargent les bœufs, les attèlent, les nourrissent; ce sont encore elles qui font des paniers, des tapis et de la faïence grossière pour l'usage de la maison; qui cultivent la terre, qui bêchent, qui hersent, qui défrichent, qui moissonnent; et cependant, malgré toutes ces diverses occupations, elles ont trouvé le moyen d'être encore coquettes à leur manière. Elles portent des bracelets d'ivoire, qui distinguent les femmes de la haute classe des femmes du peuple; des anneaux de cuivre et de fer pour le cou-de-pied et les bras; des boucles d'oreilles de verre et de cuivre, des festons de petits coquillages; enfin des colliers de verroterie, dont le nombre est souvent considérable. C'est surtout du grand nombre de ces colliers que la femme cafre tire vanité; il n'est pas rare d'en trouver qui en portent jusqu'à cent cinquante. Tous les devoirs domestiques leur sont dévolus; et, comme nous l'avons dit, elles laissent aux hommes la chasse, la guerre et le soin des troupeaux.

Il règne beaucoup d'ordre dans les ménages. La pluralité des femmes est permise, mais il n'y a que les gens aisés qui en prennent deux, et rarement davantage. Les femmes en général sont très-fécondes; cependant on trouve le plus d'enfants chez celles qui ne partagent pas la possession de leur mari avec une autre, et la polygamie n'y favorise pas la population autant qu'on pourrait le croire. Le bétail tient lieu de tout au Cafre; il est, pour ainsi dire, l'unique objet de ses pensées et de ses affections. Ce sont les vrais Arcadiens de Théocrite. Quelquefois le beuglement particulier d'une vache a quelque chose de si flatteur pour l'oreille d'un Cafre, qu'il n'a pas de repos qu'il n'en ait fait l'acquisition, et que, pour l'avoir, il la paye beaucoup au-dessus de sa valeur. Aussi le chien le mieux dressé n'obéit-il pas plus ponctuellement à son maître que les bêtes à cornes n'obéissent, chez les Cafres, à la voix de leur conducteur. Un coup de sifflet arrête soudain un nombreux troupeau de bœufs; un autre coup de sifflet suffit pour les remettre en mouvement.

Les Cafres habilent des espèces de huttes qu'ils nomment inhbous; ce sont de véritables tanières, moins bien construites que celles des autres tribus de l'intérieur, et particulièrement que les chaumières des Betjouanas. Des branches d'arbres sont planlées en terre par un bout; les extrémités supérieures se rapprochent à peu près comme le couronnement d'une ruche. Point de cheminée ni de fenêtre. Un homme un peu grand ne peut s'y tenir debout. Une douzaine de ces cabanes, dont les plus larges et les plus longues ont quinze pieds de profondeur, tandis que d'autres n'en ont que six, réunies et groupées forment un oumzi ou village. L'emplacement de cet oumzi est généralement choisi pour produire un effet pittoresque. La hulte des chefs ne diffère aucunement de celles des indigènes; seulement une queue d'éléphant est suspendue à l'entrée de son kraal, que quelques auteurs appellent oubouhlanti; c'est une espèce de place, de lieu de réunion, et destiné aussi à parquer les troupeaux. Le Cafre attache surtout beaucoup d'importance à la bonne situation et à la commodité de cet oubouhlanti. Vivant très-peu dans son intérieur, et ne se réfugiant dans ce trou, qu'il appelle sa hutte, que pendant la nuit et le mauvais temps, il préfère un beau soleil et un air pur et chaud qui l'appellent dans les vallées et dans les bois. C'est là qu'il soigne ses troupeaux qui font sa seule richesse.

La nourriture des Cafres est très-simple; ils font cailler du lait dans des sacs de cuir noirs et sales, que les Européens ne peuvent regarder sans dégoût, et qui soir et matin sont altachés au pis de la vache; cet aliment, qu'ils nomment amuraz, est leur grande ressource en tout temps; le lait, dans son état naturel, est réservé aux enfants. Ils mêlent au lait caillé la farine d'une espèce de millet ou blé de Guinée appelé amazimbre par les Cafres, et mabali (bouilli) par les Betjouanas. On sert ce mets dans de petits 
paniers où chaque convive plonge ses doigts; quelquefois on en fait une sorte de potage et on le détrempe avec du lait; d'autres fois aussi on le fait cuire sur des charbons à la manière des anciens Grecs, et on le sert sous la forme de gâteau. Le maïs et quelques légumes servent encore à la nourriture des Cafres, qui n'en font jamais provision, et qui se contentent de rôtir le maïs et de le manger tant qu'il est sur l'épi. Ils mêlent souvent à leur potage de millet une liqueur qu'ils tirent d'une espèce de canne à sucre nommée imfe, et dont le goût est fort agréable. Rarement ils mangent de la viande. Ce peuple, l'un des plus robustes de la terre, est très-sobre; il se contente d'un repas par jour, et n'y ajoute qu'une lasse de lait. Comme les Arabes, ils ont leurs préjugés sur le choix des aliments; ils repoussent avec dégoût le poisson, la volaille, les œufs et la chair de porc, qu'ils regardent comme immondes. Dans leurs jours de fète, ils boivent avec excès d'une boisson fermentée, qu'ils font avec du miel, quand les vaches ont beaucoup produit, et qui est la seule liqueur spiritueuse qu'ils fabriquent.

Les Cafres ne manquent pas d'adresse et d'habileté industrielle; ils ne savent pas fondre le fer; mais une fois qu'ils sont en possession de la matière première, ils la façonnent à leur gré avec un fragment de rocher pour enclume, et une pierre pour marteau. Ils fabriquent ainsi des bracelets, des chaines, des haches, des épées et des fers de lance.

Outre les zagaies dont nous avons parlé plus haut, et qu'ils lancent à soixante ou soixante et dix pas, en leur imprimant un mouvement de vibration qui en augmente la vélocité, les Cafres emploient encore à la guerre une massue courte et noueuse qui sert lantôt à repousser le trait que l'ennemi vient de lancer, tantôt à le frapper lui-mème. Malgré ces armes, leurs guerres, en général, sont peu sanglantes; le vol d'une pièce de bétail peut être suivi de représailles; mais après le jet de quelques lances, une ou deux blessures peu graves terminent le combat. Pourtant quelques tribus, entre autres les Zoulous et les Mantaties, sont beaucoup plus féroces; elles se forment en bataillons serrés, et se précipitent, la zagaie et la massue à la main, sur le village condamné, en détruisant tout sur leur passage.

Pays des Betjouanas. - Les Betjouanas sont moins élancés que les Cafres, mais leurs formes sont plus élégantes. Ils sont bruns et ont quelque chose de la physionomie des Hottentots. Leur langue est sonore, riche et accentuée. Ils mangent la chair des animaux tués à la chasse, et ont le poisson en horreur.

Les Betjouanas sont avides d'instruction; ils accablent les étrangers de questions, et les importunent souvent par l'excès de leur curiosité. Pour mieux examiner, ils touchent à tout ce qui leur est nouveau, et, pour peu qu'un objet leur convienne, ils le demandent; mais un refus ne les offense pas. La facilité de leur mémoire se manifeste par la promptitude avec laquelle ils retiennent toutes les dénominations hollandaises, et même des phrases entières, qu'ils prononcent beaucoup mieux que les Hottentots nés dảns la colonie. Beaucoup plus éloignés de l'état de nature que les Cafres, ils connaissent l'art de la dissimulation, et savent ménager avec adresse leurs intérêts personnels. Remuants et toujours actifs, même sans occupation déterminée, ils ne dorment jamais le jour; en temps de pleine lune, ils passent même souvent les nuits à danser et à chanter. Très-bornés dans leurs appétits, ils s'endurcissent à la fatigue, en courant des jours entiers sans prendre d'autre nourriture que celle qui s'offre sous leurs pas dans les plaines incultes et découvertes de quelques contrées arides. Chez eux, ils vivent communément de lait caillé. La cendre dans laquelle ils rôtissent les viandes remplace le sel, dont leur pays manque absolument. Ce n'est qu'au dernier besoin qu'ils boivent de l'eau; ils ne s'en servent pas non plus pour se laver. Ils ignorent l'art que possèdent 
les Cafres d'extraire des grains une boisson fermentée; mais le vin et l'eau-de-vie, présentés par les Européens, les ont sur-le-champ séduits. L'emploi de certaines herbes en fumée ou en poudre leur était familier longtemps avant l'arrivée des Européens; aussi ils ont conservé au tabac le nom particulier de montiouko, tandis que les tribus hottentotes, qui fument également des herbes sauvages, notamment du dakha (phlomus leonuris), ont adopté dans leur langue le mot estropié twak.

Pour travailler l'ivoire, ils le mettent amollir dans du lait, et le taillent ensuite péniblement avec le couteau. Ils paraissent posséder l'art de faire du fil d'archal; car le fil fin de cuivre qu'ils entortillent très-ingénieusement autour d'une mèche de queue de girafe pour faire leurs bracelets, est d'un métal tout particulier, et cette sorte de marchandise n'entre point dans les objets d'échange qui composent les pacotilles des vaisseaux européens destinés au commerce d'Afrique.

La construction de leurs maisons et des enclos de leurs étables les distingue surtout avantageusement des autres peuples de l'Afrique méridionale; mais les femmes seules en ont le mérite. La forme de ces maisons est généralement circulaire; la distribution des parties paraît varier selon les localités et les saisons : l'intérieur en est clair, frais et bien aéré. La poterie forme un autre genre d'industrie réservé aux femmes : elles y emploient la même argile ferrugineuse mêlée de mica, qui leur sert pour s'enduire le corps. Les pots, d'une forme exactement hémisphérique et sans pieds, sont très-forts malgré leur peu d'épaisseur. Elles font aussi des cruches qui ont le cou très-étroit et dans lesquelles le lait se conserve longtemps frais. Les Betjouanas montrent encore beaucoup d'intelligence dans le métier de forgeron. Leurs instruments sont des marteaux et des tenailles de la même forme que les nôtres, seulement un peu plus grossiers; une grande pierre leur sert d'enclume. Ils savent aussi tremper le fer. L'écorce de plusieurs arbres et les filaments de quelques espèces de joncs leur fournissent de quoi faire des ficelles très-fortes. L'art avec lequel ils taillent des figures sur les gaînes de leurs couteaux, qu'ils portent au cou, sur leurs hassagaies, sur leurs cuillers et autres ustensiles de bois, prouve qu'ils ne manquent pas de dispositions pour la sculpture.

Lorsqu'un jeune homme songe à s'établir, il achète une femme moyennant une douzaine de bœufs; celle-ci est obligée de bâtir elle-même une maison et une étable entourées d'un enclos. Ils peuvent avoir autant d'épouses qu'ils le désirent; ce sont elles qui, assistées d'esclaves pris dans la guerre, font tous les travaux agricoles.

Le vêtement des Betjouanas est fait de peaux d'animaux tannées; leurs ornements se composent d'anneaux de cuivre jaune, qu'ils suspendent à leurs oreilles; de bracelets de même métal, et de grands anneaux d'ivoire qu'ils mettent à la partie inférieure du bras.

Les Betjouanas ont pour armes une hassagaie qui diffère peu de celle des Cafres, et une massue. Depuis quelques années, ils se servent aussi contre les Boschismans des mêmes flèches empoisonnées qu'ils enlèvent à ces implacables brigands, car ils ne savent pas les faire. La population, au lieu de diminuer par les fréquentes guerres, s'accroît chez les tribus victorieuses du nombre des femmes ennemies qu'on emmène prisonnières, ainsi que les enfants en bas âge. Sans avoir aucune connaissance de la traite des esclaves, les Betjouanas semblent déjà deviner les avantages qu'ils pourraient retirer de la vente de leurs prisonniers; et en plusieurs circonstances, ils ont offert aux voyageurs qui les ont visités, d'échanger des enfants de dix ans contre des moutons ou d'autres animaux domestiques.

Les Betjouanas se distinguent de tous les peuples situés dans leur voisinage, par la douceur de leur caractère, leur industrie et leur probité. Une constitution libre et 
populaire leur garantit l'indépendance et la paix, et leur fournit, lorsque le besoin l'exige, le moyen de défendre leur liberté.

Les Borrolous, qui habitent au nord des Betjouanas, à dix journées de marche, ont de grandes villes; ils savent fondre le fer et le cuivre; ils sculptent avec art le bois et l'ivoire; leur sol fertile est ombragé d'arbres et arrosé de rivières.

Les Machâous et les Maroutzis habitent probablement l'intérieur des terres aux derniers postes portugais du Monomotapa, car c'est d'après leurs relations avec eux que les autres Betjouanas ont eu la première connaissance d'hommes blancs.

Les Machâous mangent avec délices toute espèce d'animaux, mème en putréfaction; ils divisent le temps par nuits et non par jours. Les Maroutzis se barbouillent le corps d'argile blanche, depuis les pieds jusqu'à la tête; ils se couvrent les épaules de peaux de panthère, et se coiffent d'un turban fait de peau de sanglier. Ce sont ces derniers qui fournissent aux autres tribus de Betjouanas les aiguilles, couteaux, bracelets de fer et de cuivre, et les boucles d'oreilles que les voyageurs ont été si étonnés de trouver chez ces indigènes. Ils tirent le métal d'une chaîne de montagnes qui les sépare des Moukhouroûzis, lesquels forment encore une des tribus du Betjouana.

Ces diverses peuplades sont soumises à des chefs particuliers qui se font souvent la guerre. Ils sont unis par les mœurs, les habitudes et le langage. Les Betjouanas sont grands voyageurs, ce qui fait qu'ils se connaissent très-bien. Les fils de famille, et particulièrement ceux des chefs qui prétendent à la succession, sont tenus de faire des courses lointaines pour former des liaisons d'amitié et des alliances utiles à leur tribu respective en cas de coalition avec les autres.

Le Sofala était le nom d'un royaume situé près de la côte, et qui n'existe plus aujourd'hui. Le roi de Sofala se faisait précéder par quatre cents bourreaux, et quatre ministres parcouraient tous les ans le royaume, l'un représentant la personne du monarque, le second ses yeux, le troisième sa bouche, et le dernier ses oreilles.

Le nom de Sofala en hébreu et en arabe veut dire pays bas. Le sol de la tribu qui porte actuellement ce nom est fertile, le climat tolérable. De nombreux récifs et bancs de sable font redouter les approches de la côte. On prétend que parmi les habitants il y a une race d'une taille gigantesque, qui livre ses prisonniers à une nation de l'intérieur pour être dévorés. Les habitants de la côte ont adopté en partie la langue arabe et le mahométisme. Ils ne savent pas teindre les étoffes de coton qu'ils fabriquent.

Le Monomotapa se trouve derrière le Sofala; il est, comme ce dernier, arrosé par le Zambèze ou Couama, l'un des grands fleuves de l'Afrique, qui se jette dans la mer par quatre embouchures ou branches. Les naturels disent que cette grande rivière sort d'un vaste lac, et reçoit son nom d'un village peu éloigné de l'endroit où il prend sa source. Le Zambèze inonde le pays comme le Nil, mais c'est dans le mois d'avril. En naviguant sur ce fleuve, il ne faut plonger dans l'eau ni le pied ni le bras, car on n'est pas sûr de l'en retirer sain et sauf, à cause de l'innombrable quantité de crocodiles qui s'y trouve. Le Monomotapa abonde en riz, en maïs, en fruits et en bestiaux; il est cultivé le long des fleuves; mais le reste du terrain, quoique inculte, paraît fertile, puisqu'on y trouve de vastes forèts peuplées d'éléphants, de rhinocéros, de bœufs sauvages appelés mérous, de tigres assez forts pour emporter un veau, de zèbres, d'antilopes et de singes. Les hippopotames et les tortues y parviennent à une énorme grosseur. Les Portugais établis dans ces contrées y ont élevé un petit nombre de bêtes à cornes; mais les chevaux ne peuvent pas y réussir.

Les mines d'or du.Monomotapa consistent principalement en dépôts de transports ou d'alluvion, entrainés par les eaux du haut des terrasses que forment les montagnes qui entourent ce pays. Ces dépôts consistent en sables aurifères mêlés à une terre rou- 
geâtre, que l'on exploite par le lavage. L'or y est en lingots ou en paillettes. On trouve aussi de ces mines dans le pays de Manica; on en ramasse même dans les champs et dans le sable des rivières. Au delà de ce dernier pays, dans la direction du sud, on n'a encore jusqu'à ce jour trouvé aucune trace d'or; mais le fer s'y montre assez abondamment.

Les habitants du Monomotapa savent très-bien le travailler; ils en font des haches fort tranchantes, des piques et autres instruments domestiques.

Le nom de Monomotapa désigne, suivant quelques voyageurs, le roi de Motapa; d'autres l'écrivent Béno-Motapa, ce qui paraît signifier en arabe, d'après une observation ingénieuse : "Les peuples de soldats mercenaires, " et n'être par conséquent qu'un appellatif donné à ces nations par les Arabes qui ont conquis les côtes maritimes. Quoi qu'il en soit, le souverain, qualifié d'empereur par les Portugais, étendait autrefois sa domination sur un grand nombre de vassaux. Par suite de guerres civiles, l'empire se parlagea, en 1759 , en plusieurs petits États rivaux, où dominent les chefs de plusieurs peuples cafres : les Bororos, les Cazembes, les Moriza's, les Maravi's, les Mongas et les Merapoua's.

Les Bororos habitent la partie nord de l'ancien Monomotapa. On les représente comme assez avancés en civilisation.

Les Cazembes sont peu connus. Ils sont gouvernés par un roi qui paraît être un des princes les plus puissants de l'ancien empire. Les soldats sont bien disciplinés; ils manœuvrent au moyen de signes; ils sont armés de lances et de couteaux courts, de forme oblongue, fabriqués dans le pays. Ils se couvrent de boucliers légers faits en écorce d'arbre. La capitale de ce petit royaume est entourée d'un fossé profond et d'une haie épaisse. Le pouvoir du roi est tellement absolu qu'il fixe les heures de repos de son peuple et celles de ses divertissements.

Les Mori $\approx a$ 's, qui sont limitrophes des précédents et leurs tributaires, sont paisibles, industrieux et commerçants.

Les Máravi's sont possesseurs de la plus grande des divisions de l'ancien territoire impérial. Ils sont gouvernés par un chef qui prend le titre de quitero ou quitere, et qui passe pour un des plus puissants de cette contrée de l'Afrique. Sa résidence est à $Z$ imbaoé ou Zimbao, l'ancienne capitale de l'empire. Le pays des Maravi's abonde en fer dont ils fabriquent les instruments nécessaires à l'agriculture.

Les Mongas habitent la rive droite du Zambèze; ils sont très-belliqueux et n'ont jamais pu être soumis à l'empereur du Monomotapa.

Les Merapoua's sont les moins connus de tous les peuples que nous venons de décrire; cependant ils ne sont pas moins importants que les Mongas.

Les habitants du Monomotapa vont presque nus, comme ceux de la côte d'ouest; ils sont très-superstitieux et croient aux enchantements et à la magie.

Le Jambara et le Mocanda sont à peu près inconnus et n'offrent rien de bien intéressant. Au nord de ce dernier pays se trouve le Mouloua, État puissant et populeux où la civilisation a fait plus de progrès que dans le reste de l'Afrique orientale. Les habitants emploient pour se vêtir des produits de manufactures européennes apportés des comptoirs portugais; ils livrent aux Cassanges, situés dans leur voisinage, le cuivre que ceux-ci vendent aux Portugais. La capitale est appelée aussi Mouloua; elle est grande et propre.

Au nord de ce pays se trouvent les Monjous ou Mondjous, qui sont plus doux que la plupart de leurs voisins; ils entretiennent des relations commerciales avec Mozambique. Les Monjous sont une des plus laides races nègres de toute l'Afrique. Ils ont les pommettes saillantes, les lèvres grosses et pendantes, les cheveux courts, laineux et crépus, 
et la peau très-noire. Leurs armes, qu'ils empoisonnent, sont l'arc, la flèche et une courte lance. Chaque Monjou porte toujours sur lui de quoi faire du feu; leur appareil se compose de deux morceaux de bois noir qu'ils savent frotter de manière à les mettre en combustion en très-peu de temps. Ce peuple habite la pente méridionale des montagnes de Tégla et de Dyre.

La Côte de Mozambique présente partout des récifs dangereux entremêlés d'un grand nombre d'îlots. Les rivières, quoique très-larges à leur embouchure, ne viennent pas de loin; elles ont leurs sources aux pieds d'une longue et haute chaîne de montagnes, qui doit son nom portugais de Picos Fragosos, qu'elle porte, aux pics dont elle est hérissée.

L'insalubrité qui règne à Mozambique a engagé les habitants à bâtir, au fond de la baie, l'agréable et vaste bourg de Mesuril ou Mossoril. Le palais du gouverneur s'élève majestueusement au-dessus d'une forêt de cocotiers, de mangoustiers et de cachous.

La ville de Mozambique avec ses habitants présente un mélange bizarre d'usages curopéens, indiens et arabes. Les habitants de cette ville se divisent en deux classes principales : les Portugais et les descendants des cultivateurs indigènes; leur nombre est évalué à 300 personnes. On y trouve aussi des descendants des anciens Arabes, qui sont presque tous marins, et des Banians, c'est-à-dire des artisans et des marchands indiens qui travaillent les métaux et font le petit trafic comme les juifs; ces deux autres classes forment environ 800 personnes. Le reste de la population se compose de noirs affranchis et de mercenaires indigènes.

La colonie de Mozambique est administrée par un gouverneur, dont le conseil se compose de trois personnes : l'évêque, le commandant des troupes et le ministre.

La vie déréglée que mènent les Européens dans cette colonie fait chez eux autant de ravages que l'insalubrité du climat. On peut admettre que sur ceńt soldats européens il n'en reste que sept après les cinq ans qu'ils doivent y séjourner; il en est de même des fonctionnaires civils. On peut juger par là du triste état dans lequel se trouve cette colonie.

La principale nation sur cette côte est celle des Makouas ou Macouanas, peuple dont la peau est très-noire, et dont les femmes ressemblent un peu aux Hottentotes. Les Makouas ont, comme les Monjous, les lèvres grosses et pendantes, et sont généralement très-laids. Les femmes ont l'épine dorsale très-courbée, et la partie postérieure saillante presque autant que chez les Hottentotes. Les Makouas sont très-féroces dans l'état sauvage; esclaves, ils sont, au contraire, très-soumis ; fidèles et braves lorsqu'on les emploie comme soldats. Ils se passent des anneaux daus le nez, et se liment les dents de manière à les rendre aussi aiguës que de grosses dents de scie; enfin ils se défigurent par de fortes incisions sur le front, le menton et le nez.

Les Makouas sont aussi robustes que les Cafres; comme ces derniers aussi ils sont toujours prêts à faire des excursions sur les possessions des Portugais, contre lesquels ils nourrissent une implacable haine.

Ces peuples ont pour armes des lances et des javelots avec des pointes empoisonnées; pourtant ils commencent à acheter des Arabes et des Portugais des mousquets et autres armes à feu. Ils s'en sont même déjà servis pour attaquer les Portugais de la péninsule de Caboreiro, qui ne purent leur résister qu'avec le secours d'autres Makouas de la côte et des troupes portugaises de Mozambique.

Les autres tribus de Makouas habitent les còtes, et, soumises autrefois aux Arabes, forment à présent trois petits États nègres dans le voisinage de Mozambique, et qui portent les noms de Quintagona, Saint-Coul et Serecma. Ils sont soumis à des chefs connus sous le titre arabe de cheik, et placés sous la surintendance des Portugais. 


\section{COTES ORIENTALES,}

OU ZANGUEBAR ET AJAN.

Le Zanguebar × s'étend, selon les Arabes, depuis l'Abyssinie jusqu'au territoire d'Ouakouak, c'est-à-dire jusqu'au pays des Makouas ou la côte de Mozambique. Le roi de ce pays, qui, dit-on, prend le titre de Walk-Iman, ou fils du seigneur suprême, marche à la tèle de 3,000 guerriers qui ont des bœufs pour montures.

Cette partie de l'Afrique est divisée en six principaux États; ce sont, en allant du sud au nord : Quiloa, Zanzibar, Mombaza, Mélinde, Brava, et Magadoxo. On évalue à 2,000,000 d'individus la population, composée d'Arabes et d'indigènes.

On ne connaît guère que les îles et quelques places maritimés du Zanguebar.

Le roi de Quiloa est nègre, et ses sujets ont pour lui un grand respect. Néanmoins il est sous la tutelle d'un vizir arabe nommé Malindane, lequel gouverne souverainement au nom du monarque titulaire, et peut déposséder celui-ci et conférer la dignité à un autre de son choix.

"Les habitants de cette île, dit Blancard, voyaient avec dépit que Quiloa faisait à elle seule tout le commerce de la côle; ils envahirent cette ville en 1787. Le roi de Quiloa céda à celui de Zanzibar la moitié de tous les droits qui se percevaient annuellement sur le commerce des esclàves.

Cette île renferme à peu près 3,000 habitants; la ville, du même nom que l'île, n'est qu'un assemblage de cabanes misérables; elle est défendue par un fort qui domine la mer, et des vestiges d'anciennes murailles et des ruines en grand nombre attestent ses richesses et son importance d'autrefois.

Les hommes chassent, pêchent ou dorment; les femmes cultivent les patates et le miel autant par habitude que par nécessité; elles tressent encore des nattes et quelques étoffes pour l'usage des hommes.

La langue de Quiloa a plusieurs points de ressemblance avec celle du Congo.

Zanzibar, ou Souayeli, pour l'appeler de son véritable nom, se fait remarquer entre toutes ces îles par son importance, son étendue et sa beauté. Elle a 17 à 18 lieues de long sur 5 de large, et une population de 60,000 habitants dont 500 Arabes et les autres de race mixte. Le cheik, vassal de l'iman de Mascate, a, dit-on, exprimé le désir de se mettre sous la protection de l'Angleterre. Zanzibar est la capitale, et, depuis quelques années, une riche place de commerce.

Les habitants de l'île Pamba sont d'un caractère timide. Ils s'habillent d'éloffes de soie et de coton provenant de l'Inde.

On n'a sur Monbaza, Mélinde, Brava, et le pays de Lano que des renseignements incertains.

Non loin de ces États maritimes et civilisés on trouve les tribus sauvages de MoseGuexos, qui, dans l'enfance, remplacent les bonnets par une couche épaisse d'argile dont ils se couvrent la tête.

Au nord de ceux-ci, on indique les Maracatas, peuple moins grossier, qui n'est pas dépourvu d'avantages physiques, observe la circoncision, et dont les filles conservent le trésor de l'innocence au moyen d'une couture que l'époux seul a le droit d'enlever.

Le royaume de Magadoxo ou MaKadochou occupe sur la côte une longueur d'environ

1 Ou la côte de Zangues, ou le pays des Zingues ou Zindges. 
80 lieues. La population, parmi laquelle on voit quelques Abyssiniens, se compose d'hommes blancs, olivâtres et noirs qui, pour la plupart, ont adopté l'idiome de leurs maîtres les Arabes.

On y compte aussi quelques Abyssiniens chrétiens. Le roi et les grands sont vêtus depuis la poitrine jusqu'aux pieds; les gens du peuple vont à peu près nus; la reine porte, pour marque distinctive, une robe de soie verte, et des cheveux ornés de plumes de diverses couleurs. Le roi rend justice en public, assisté de quelques conseillers. Les criminels sont livrés aux bêtes féroces, ou assommés avec une massue. Dans les voyages seulement, le roi est accompagné d'une suite; du reste il n'a ni cour, ni garde, et personne ne le salue. La religion mahométane, qui domine, paraît s'allier au paganisme; car on voit différentes idoles dans les temples aussi bien que dans les maisons. Les violences exercées jadis sur cette côte par les Portugais, qui venaient y chercher des esclaves, ont laissé des souvenirs profonds, et l'on n'y accueille plus les Européens qu'avec méfiance et avec une très-grande réserve.

Bâtie à peu de distance du port de la mer, la capitale, grande et belle ville, porte le nom du royaume.

La côte d'AJan s'étend depuis le Zanguebar jusqu'au cap d'Orfoui ; elle prend, en tournant autour du cap Gardafoui, une teinte de stérilité moins absolue que partout ailleurs. Mais les Européens fréquentent peú le port du cap Fellis, le mons Felix, le Raz-el-Fil des Arabes, et les côtes du golfe d'Aden. Le royaume d'Adel est le principal Élat de toute cette côte, dont les peuples, nommés Berbers par les géographes arabes, et Somaulis par les Européens, ont le teint olivâtre, les cheveux longs, et ne ressemblent en rien aux Cafres. Ils sont surtont remarquables par la beauté de leurs traits et par leur coutume de teindre leurs cheveux en jaune. Presque tous sont pasteurs.

Les Jagas ou Cassanges occupent les régions à l'ouest du Congo. Ce peuple ne cultive point la terre et ne possède d'autres bestianx que ceux dont il s'empare en guerre; il envahit les contrées fertiles de ses voisins, il y consume les fruits de la terre, et, après avoir tout dévasté, il va chercher une nonvelle proie. Les Jagas dévorent leurs prisonniers; on frotte de graisse humaine le généralissime, qui d'ailleurs porte une ceinlure d'œufs d'autruche, et des espèces d'anneaux de cuivre au nez et aux oreilles. Les femmes des Jagas enterrent vifs leurs propres enfants; la nation ne continue son existence qu'en élevant les enfants des nations voisines, ravis à leurs parents à l'âge de douze ans. Le généralissime, dans les grands sacrifices, immole de sa main les victimes humaines. On assure que, dans une certaine fète, ce chef fait lâcher au milieu de ses sujets un lion furieux et affamé. Les Jagas, loin de l'éviter, tiennent à honneur de périr sous ses dents meurtrières. Les vieillards et les malades sont abandonnés sans pitié. Les morts, enterrés vêtus de leurs plus beaux habits dans des tombeaux voùtés, ont pour compagnes deux de leurs femmes qu'on y enferme vivantes. Les Jagas qui n'ont point de chevaux combattent à pied avec une intrépidité extrême; ils retranchent leurs camps avec soin. Cetle nation affreuse a eu son Alexandre et sa Sémiramis. Sous les ordres de Zimbo, elle a parcouru l'intérieur de l'Afrique méridionale, et esít venue dévaster Quiloa et assiéger Mozambique. Arrivée devant Mélinde, l'armée de Zimbo essuya une défaite totale, qui fut suivie de la dissolution de son empire; mais Temba. Nclamba, petite-fille d'un de ses généraux, essaya par ses lois ou quixilles de relever la puissance de la nation. Pour donner l'exemple de la soumission à ses préceptes inhumains, elle saisit son jeune fils, le jeta dans un mortier, l'écrasa, le pila, et fit ensuite extraire de ces restes horribles un onguent, duquel elle mettait quelques gouttes sur son corps chaque jour de bataille.

Le royaume de NiNÉANAI n'offre rien d'intéressant. 
L'État de Grngiro ou Zendero a été visité par les Européens; il est situé sur les bords du Zebee ou Zebi, rivière qui roule un plus grand volume d'eau que le Nil. Lorsqu'ils veulent le traverser dans leur pays, les Gingirains tuent une vache, enveloppent les bagages dans la peau, qu'ils remplissent d'air en y soufflant avec force, et, après y avoir attaché deux perches en forme de brancards, ils s'accrochent à celles-ci deux à deux de chaque côté pour tenir en équilibre la machine qu'un bon nageur placé en tête traîne au moyen d'une corde, tandis que deux autres, placés derrière, la poussent devant eux.

Les Gingirains ont le teint d'un noir moins foncé que celui des nègres. Ils ont les traits fins et aussi réguliers que les Abyssiniens et les Européens. Toute la nation est esclave; tout est la propriélé absolue du roi. Lorsqu'il veut acquérir quelque objet précieux apporté par des marchands étrangers, il leur donne en échange le nombre d'esclaves qu'ils désirent. A cet effet, il fait tout uniment enlever dans les maisons qu'il plaît à ses gens de choisir, les fils et les filles des habitants. C'est un droit du Irône consacré par le temps; et celui qui désapprouverait cette barbarie, serait mis à mort sans rémission. La couronne est héréditaire dans la même famille, mais non par ordre de primogéniture. Le successeur est pris de force aux périls de la vie des électeurs, qui passent pour de grands sorciers, et paraissent être une caste de prêtres. Après son inauguration, le nouveau souverain fait comparaître devant lui tous les favoris de son prédécesseur, et ordonne de les envoyer rejoindre leur maître chéri dans l'autre monde. La maison du défunt est brûlée avec tout cee qu'elle renferme. On en fait de même après le décès d'un particulier : on brûle même les arbres et les végétaux qui se trouvent dans le voisinage, afin que le mort, habitué à cet endroit, ne soit pas tenté de revenir y faire sa promenade. Avant d'abattre un arbre choisi pour former le pilier qui doit soutenir le trône dans la nouvelle demeure du roi, on coupe le cou au premier homme qu'on rencontre d'une certaine famille du royaume qui, par là, se trouve exemple de toute autre charge, et à laquelle beaucoup d'autres envient cet honneur. Lorsque le roi va être installé dans son palais, on tue, selon le nombre des portes, un ou deux autres hommes de la même famille privilégiée, pour peindre avec leur sang les seuils et les poteaux. Le jour où il prend les rênes du gouvernement, son premier acte esı de donner des ordres tendant à faire rechercher dans le royaume entier tous les hommes et toutes les femmes qui ont la teigne, pour empêcher la propagation de leur mal qui pourrait finir par gagner Sa Majesté. Il les guérit en envoyant la troupe entière au delà du Zebee, où on leur coupe la tête.

Le roi, assis sur son trône, qui a l'air d'un ballon établi en forme de cage au haut de sa maison, porte une robe de soie blanche, de fabrique indienne. Un jësuite voyageur qui a visité ce prince, dit que gingiro veut dire singe, et il trouve que les gestes et les attitudes du monarque dans sa cage lui donnent beaucoup de ressemblance avec cet animal; le même voyageur ajoule qu'à l'instar de ce que font les singes, le roi, blessé au combat, est tué sur-le-champ par ceux qui l'entourent, ou, à leur défaut, par ses parents, pour qu'il ne périsse pas d'une main ennemie. Il est considéré comme un être divin, rival du soleil et de sa puissance dévorante. Il ne sort que le matin au clair de l'aurore. Si le soleil est levé avant lui, il se tient toute la journée dans l'intérieur de sa maison, et ne monte point à sa cage, ni ne fait aucune affaire; car, disent les Gingirains, deux soleils ne peuvent briller à la fois, et quand l'autre a pris les devants, la dignité du roi serait compromise s'il s'abaissait jusqu'à le suivre en second.

Le corps du roi est revètu, après sa mort, des étoffes les plus riches, et enveloppé d'une peau de vaché; on le traîne par-dessus les champs au lieu de sépulture des souverains, et là on le dépose dans une fosse qu'on laisse ouverte; la terre n'étant pas 
jugée digne de couvrir les restes du rival du soleil, qui ne peut avoir que le pavillon du ciel pour mausolée. Mais on inonde le corps du sang d'une quantité de vaches immolées sur le bord de la tombe; et par la suite, on y en tue une chaque jour, jusqu'au décès du roi alors régnant : la chair des victimes appartient aux prêtres sacrificateurs, et, comme nous l'avons dit, le sang coule dans la tombe.

Il y a encore parmi les autres cérémonies d'inauguration, qu'il serait trop long de décrire, un usage que nous allons rapporter ici : le nouveau roi est obligé d'écraser entre les dents un ver qu'on lui apporte, et qui est censé sorti du nez du précédent souverain.

\section{ILES AFRICAINES ORIENTALES.}

L'île de Socotra ou Socotara est une terre aride, pierreuse, presque entièrement dépourvue de végétation. Thomas Roe donne des détails satisfaisants sur les habitants qu'il divise en quatre classes : les Arabes, dominateurs du pays, leurs sujets ou esclaves musulmans; les Bediognes, anciens habitants isolés dans les montagnes, et qui professent la doctrine des chrétiens jacobites; enfin, une tribu sauvage qui, cachée dans les bois, vit sans vêtements et sans maisons. Les habitants actuels ont paru ignorer l'usage du fusil; mais sous les rapports de commerce et d'intérêt, ils partagent les vices des nations civilisées.

Les deux groupes d'iles comprises sous les noms d'Aurrauté et Seychelles sont trop peu intéressants pour que nous nous y arrêtions. Il en sera de même pour une multitude d'autres îles que nous ne nommerons même pas.

Les îles Comones sont au nombre de quatre : Anjouan ', proprement Hinzouan; Angazija, ou la grande Comore; Mounilly ou Moëly ${ }^{2}$; et Mayotre, qui est la plus petite.

Les habitants des îles Comores sont un mélange de nègres et d'Arabes. De grosses lèvres, des pommettes avancées rapprochent les gens de la basse classe des noirs de Mozambique; mais le sultan et les nobles ont conservé la figure belle et spirituelle de leurs ancêtres arabes. En général, tous ont les yeux grands, le nez aquilin, la bouche bien dessinée, et l'on voit parmi eux des têtes d'un grand caractère.

Les Comorors sont pour la plupart doux, pleins d'honnêteté et d'hospitalité, trèsaffables et déjà parvenus à un degré de civilisation que l'on ne trouve pas dans les habitants de la partie du continent et de la grande île dont ils sont voisins. Ils ont beaucoup de politesse dans les manières, un excellent bon sens, l'esprit cultivé et une certaine tournure poétique qui donne à leur conversation une grâce orientale. Mais quoique plusieurs d'entre eux sachent lire et écrire, ils ne tiennent pas note des événements publics ou particuliers, et ce sont les plus anciens qui, dans les disputes, décident de la vérité des faits et de leur date. Les Européens naufragés y ont toujours éprouvé les traitements les plus généreux. Quelques Arabes se livrent à l'agriculture et possèdent de grandes propriétés dans l'intérieur de l'ìle. Il en est d'autres qui s'adonnent aux arts mécaniques, tels que la tisseranderie, l'orfévrerie, etc.; et l'adresse dont ils font preuve dans leurs travaux n'est pas moins étonnante que la médiocrité des outils qu'ils emploient. On en voit aussi qui sont navigateurs, et entreprennent des voyages jusqu'à Surate et Bombay.

Cependant les naturels sont généralement làches, pusillanimes, et par conséquent

1 Appelée aussi Joanna.

2 On la nomme encore Mohilla. 
mauvais soldats. Il en résulte que les Madécasses font chez eux de fréquentes descentes, enlèvent les troupeaux, et réduisent à l'état d'esclaves les habitants qu'ils font prisonniers.

Leurs maisons sont simples et même misérables. L'appartement des femmes est séparé du corps de logis par une petite cour intérieure et inaccessible aux étrangers. La seule apparencẻ de luxe que l'on remarque parmi eux est l'usage immodéré qu'ils font du musc, dont l'odeur infecte les maisons; ils tiennent aussi beaucoup à la coutume orientale de teindre leurs ongles d'une couleur orangée, tirée du henneh (Lausonia inermis) tant célébré par les poëtes de l'Orient. Le vêtement des hommes n'a rien de remarquable. Le costume d'une femme du haut parage, que M. Collin, de l'île de France, eut occasion de voir au-dessus de la terrasse d'une maison, se rapprochait beaucoup de celui des Indiens de la côte de Malabar. Elle avait un grand nombre de colliers et de bracelets de corail, de longs pendants d'oreilles et un anneau d'or passé au cartilage du nez; sa chevelure était parsemée de bijoux. Elle paraissait jolie, mais son teint était fort brun.

L'île de Madagascar ${ }^{\text {I }}$ a près de 3500 lieues de, longueur, 85 lieues de largeur (120 dans quelques endroits), et 25,000 lieues carrées de superficie.

La population de cette île embrasse un total d'un million et demi, selon les uns, et de quatre millions, d'après d'autres. Elle est formée de plusieurs races. Quelques tribus, ou plutôt castes peu nombreuses, sont évidemment d'origine arabe. Les $Z_{\mathrm{AFFE}}$ Ramini prétendent descendre d'Imina, la mère de Mahomet. C'était le chef de cette famille qui était reconnu souverain de la plus grande partie de l'île, mais la ligne directe de ces princes est éteinte. Les Rhoandriens sont leurs descendants les plus proches et nés sans aucun mélange. Les Anacandriens et les Ondzassis proviennent d'un mélange avec les indigènes. Le teint olivâtre de ces descendants d'Arabes leur vaut le titre de blanc ou malate. Les ZaFFe-Iвrahm descendent, soit des Juifs, soit des Arabes, sortis de leur patrie antérieurement à Mahomet. Dans le district de Matatane, une troisième caste moins belliqueuse, mais lettrée et bien faite de corps, est venue s'établir à une époque plus récente; elle se nomme Kassi-Mambou, et reçoit des indigènes le nom d'Anta-Mahouri, qui, selon M. Collin, signifie habitants du pays des Mores. Leur teint, plus rapproché du noir, et la nature un peu laineuse de leurs courts cheveux, indiquent les colonies arabes du Zanguebar comme leur patrie. Mais toutes les tribus, vraiment considérables et qui forment la presque totalité des habitants, ont ou le teint basané et les cheveux plats des Indiens, ou la peau noire et les cheveux crépus des Cafres. Il paraît que des émigrations très-anciennes de la Cafrerie et du Malabar ont peuplé cette île, que sa situation rapproche de l'Afrique, mais que les vents périodiques et une chaîne d'îles rattachent à l'Asie. Le nom de MALEGaches, que les anciens habitants se donnent, ceux de MaLe-Drves, de Male-Bar et autres, indiquent cette filiation qui, à l'égard de l'émigration asiatique, est encore parfaitement démontrée par la composition générale de la langue de Madagascar.

En général, les Madécasses ou Malegaches vivent dans une liberté turbulente. Les Séclaves, les Antancayes et les Ovas gémissent pourtant sous le joug d'un gouvernement tyrannique. Hors de ces États, le Madécasse ne reconnaît d'autorité suprême que dans les cabares, ou assemblées publiques; c'est là que se décident les affaires publiques et que se jugent les procès. Les discours qui y sont prononcés brillent souvent d'une éloquence naturelle et énergique. Chez plusieurs tribus on reconnaît des classes héréditaires, dont les priviléges ne sont pas bien déterminés. Les Voadrisi sont les sei-

1 Le nom indigène est Madécasse. 
gneurs suzerains indigènes, subjugués en quelques cantons par les Arabes. Les Lohavohits sont des seigneurs qui commandent dans leurs villages. Les Oudzoa forment le peuple. Il y a en outre de nombreux esclaves. Comme dans les îles de la mer du Sud, le droit de tuer certains animaux, et de manger certaines viandes, est réservé aux classes supérieures.

L'espace nous manque pour donner tous les renseignements que nous avons recueillis sur les Ovas et plusieurs des peuples que nous devons nous borner à nonmer.

Les îles Mascareignes ${ }^{x}$ comprennent : l'île de Bourbon ou la Mascareigne proprement dite; l'île de France, nommée Cerne par les Portugais, et Maurice ou Mauritius par les Anglais; enfin les îles Rodrigue et Cargados.

L'île de Bourbon a environ 20 lieues de long, 15 de large et 48 de circonférence. Elle fut acquise à la France en $\mathbf{1 6 4 2}$, et sept ans plus tard elle reçut le nom qu'elle porte aujourd'hui. Le régime républicain lui imposa celui de Réunion; ensuite on la nomma Bonaparte. Les Anglais, qui s'en étaient emparés en 1810 , la restituèrent à la France en 1815, époque à laquelle elle reprit sa première dénomination. La populalation, en 1837, était de 108,000 individus, au nombre desquels se trouvaient 69,500 esclaves.

Cette île comprend onze communes administrées comme en France, et formant autant de paroisses dont tous les curés ont pour chef un préfet apostolique. Sous le rapport judiciaire, elle forme quatre justices de paix qui dépendent d'un tribunal de première instance et d'une cour royale. La ville de SaInT-Denis est le chef-lieu, la résidence du gouverneur et le siége des principales autorités. Sa position entre la mer et le pied d'une montagne est fort agréable; ses maisons, quoiqu'en bois, sont construiles avec élégance. Elle a une église, un collége, des casernes, un beau jardin botanique qui sert de promenade, 10,000 habitants dont environ 2,000 blancs, 1,200 affranchis et 6,800 nègres esclaves. Elle a un petit port défendu par quelques batteries; mais sa meilleure défense est la difficulté d'aborder dans l'île autrement qu'avec des barques du pays. Ce que l'administration y a fait de plus utile, ce sont des fontaines qui répandent dans chaque quartier une eau vive et limpide; ce sont des étuves pour la dessiccation des graines et des farines, et un canal de dérivation, de la rivière de Saint-Denis, pour donner le mouvement aux moulins de la boulangerie du gouvernement et à des usines appartenant à des particuliers.

L'île de France, aujourd'hui nommée officiellement Maurice, quoique moins fertile et moins étendue que celle de Bourbon, doit à ses ports et rades une grande importance commerciale. Elle a pour capitale Port-Louis.

\section{ILES AFRICAINES OCGIDENTALES.}

Parmi le grand nombre d'îles comprises sous le nom d'îles africaines occidentales, il en est à peine quelques-unes qui méritent une description.

L'île SaInte-HÉLÈne, à jamais célèbre par l'illustre prisonnier qu'elle renferma, a 5 à 4 lieues de long, 2 1/2 de large, 10 de circonférence, et 9 de superficie; la population se compose d'environ 4,000 à 5,000 habitants, dont environ 1,000 blancs et 3,000 nègres, non compris la garnison. Jamestown, sur la côte du nord-ouest, est la seule ville et le seul port de Sainte-Hélène. De bonnes fortifications en défendent les approches.

* Ce nom leur vient de celui de Mascarenhas, navigateur portugais qui les découvrit en 1545. 
L'île de Sarnt-Thomas ou SAN-Thomé a 15,000 à 20,000 habitants, la plupart nègres ou mulâtres. Elle est commandée par un gouverneur mulâtre, et administrée par un conseil de douze indigènes. Tout y respire le plaisir et la mollesse. Les esclaves ne connaissent point la servitude, et travaillent à peine deux ou trois jours par semaine. Des prêtres noirs desservent les églises ou chapelles, disséminées au nombre de huit ou neuf dans l'île. La plupart ne savent pas seulement lire; mais ils ont chacun deux ou trois concubines. Quelques capucins blancs ou mulâtres, fixés dans un petit couveńt, n'ont pas des mœurs plus rigides. Des évêques que la cour de Lisbonne avait résolu d'y envoyer à plusieurs reprises pour rétablir la discipline, moururent tous en peu de jours.

L'archipel des îles du CAP-Vert appartient aux Portugais et comprend dix îles, outre les îlots et les rochers. La principale est SANT-IAGo, dont les habitants sont dans un état misérable qui attriste l'âme ; ils ont le teint si foncé, que l'on ne soupçonnerait guère dans leurs veines le moindre mélange de sang européen, s'ils ne se vantaient pas eux-mêmes d'être Portugais. Le clergé est composé de gens de couleur et même de nègres. La misère générale dérive, partie de la mauvaise administration, partie des sécheresses qui quelquefois accablent l'île pendant plusieurs années de suite.

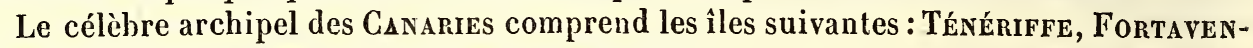
ture, Canarie, Palma, Lancerote, Gonère, Fer.

Les habitants des Canaries, connus sous le nom d'Iscenos (les insulaires), émigrent en grand nombre à la côte de Caraccas et aux Philippines. Vifs et spirituels comme des Andalous, ils aiment l'instruction et le travail comme des Biscayens; ils prononcent l'espagnol avec une douceur particulière. Des philosophes, comme Clavijo, des poëtes, comme Yriarte, ont illustré cette peuplade, qui compte encore dans son sein quelques savants estimables, et chez lesquels les bons livres français sont loin d'être inconnus.

L'île de MADĖRE ' est riche en ressources de toutes sortes. Eu 1826, on évaluait à 100,000 âmes la population qui se compose d'un mélange de Portugais, de mulâtres et de nègres. Les créoles ont le teint basané, la stature petite, sont malpropres et mal vêtus. Le peuple y mène en grande pariie une vie misérable, et l'étranger boit la majeure partie du vin qu'ils récoltent. Les femmes, douées de beaucoup d'avantages naturels, sont accablées de peines et de fatigues, puisque la loi défend d'employer les nègres esclaves aux travaux champêtres. Parmi les classes moyennes, les mœurs ne sont pas très-pures. Les gens de qualité promènent leur indolence dans des maisons de campagne ou quintas, dont les jardins n'ont rien d'attrayant, mais qui ont chacune leur chapelle, ordinairement desservie par un chapelain particulier. Les seuls véritables riches sont les négociants anglais et les Irlandais catholiques établis dans la capitale.

Nous l'avons dit déjà plusieurs fois, nous n'avons mentionné que les lieux qui méritent quelque attention sous le rapport des mœurs. On ne devra donc point s'étonner si beaucoup d'îles n'ont pas même été nommées ici. Quant aux îles Açores, par lesquelles beaucoup d'écrivains terminent la description de l'Afrique, nous les avons rejetées dans l'Europe, parce qu'elles sont plus près de cette dernière partie du monde.

1 Cette île forme, avec celle de Porto-Santo et quelques îlots déserts, un groupe particulier, et un gouvernement appartenant aux Portugais.

FIN DE L'AFRIQUE. 


\section{AMÉRIQUE.}





\section{AMERIQUE.}

\section{APERCQU GÉNÉRAL.}

Cette division du globe, nommée aussi Nouveau-Monde et Nouveau-Continent, s'étend depuis le cap Horn, sous $55^{\circ} 58^{\prime} 30^{\prime \prime}$ de latitude sud, jusque vers $70^{\circ}$ de latitude nord; ses limites, de ce dernier còté, ne sont pas exactement connues; l'océan Atlanlique baigne ses côtes orientales, le grand Océan ses côtes occidentales. L'isthme de Darien, situé entre $8^{\circ}$ et $9^{\circ}$ de latitude nord, partage naturellement cette partie du monde en deux continents : l'Auérique SEPTENTRIONALE et l'AMÉrique méridionale. On évalue la population générale à $33,000,000$ d'habitants.

Cette contrée n'est pas seulement remarquable par sa vaste étendue, par les variétés de climats qui y existent; ses traits généraux lui donnent un caractère de grandeur tout à fait extraordinaire: outre les productions qui lui sont particulières, elle peut fournir toutes celles des autres parties du monde; ses montagnes sont colossales et se prolongent sur une portion considérable de sa surface; ses lacs ont une étendue démesurée; ses fleuves immenses forment un vaste système de navigation et d'irrigation, et donnent naissance à des cataractes qui excitent l'admiration; ses forêts prodigieuses s'enorgueillissent de produire quelques-uns des géants du règne végétal; enfin ses entrailles recèlent en abondance l'or, l'argent et les pierres précieuses.

M. de Humboldt explique ainsi les différences que présente le climat de l'Amérique :

( Le peu de largeur du continent, sa prolongation vers les pôles glacés; l'Océan, dont la surface non interrompue est balayée par les vents alisés; des courants d'eau Irès-froide qui se portent vers le détroit de Magellan jusqu'au Pérou; de nombreuses chaînes de montagnes remplies de sources, et dont les sommets couverts de neige s'élèvent bien au-dessus de la région des nuages; l'abondance de fleuves immenses, qui, après des délours multipliés, vont toujours chercher les côtes les plus lointaines; des déserts non sablonneux, et par conséquent moins susceptibles de s'imprégner de chaleur; des forêts impénétrables qui couvrent les plaines de l'équateur, remplies de rivières, et qui, dans les parties les plus éloignées de l'Océan et des montagnes, don- 
nent naissance à des masses énormes d'eau qu'elles ont aspirées, ou qui se forment par l'acte de la végétation; toutes ces causes produisent dans les parties basses de l'Amérique un climat qui contraste singulièrement par sa fraîcheur et son humidité avec celui de l'Afrique.

Dans les évaluations qu'on a cherché à faire de la différence de chaleur qui existe entre l'Amérique et les autres parties du monde, diverses expériences ont prouvé qu'elle est égale à $10^{\circ}$ de latitude, c'est-à-dire qu'il fait aussi chaud en Afrique à $20^{\circ}$ de l'équateur qu'à $10^{\circ}$ en Amérique.

On sait que le navigateur qui a découvert l'Amérique est le Génois Christophe Colomb. Partide Palos (Andalousie) le 3 août 1492, avec trois vaisseaux espagnols, pour chercher un passage aux Indes par l'ouest, il découvrit, le 12 octobre suivant, dans les Lucayes, l'île San-Salvador, dont il prit possession au nom du roi d'Espagne. Il trouva ensuite Cuba et Espagnola, aujourd'hui Saint-Domingue. Dans un second voyage, en 1493, il reconnut plusieurs autres îles; et, supposant qu'elles faisaient partie de l'Inde, il les nomma Indes occidentales. Elles ont conservé ce nom, et c'est de là qu'est venu le nom d'Indiens donné aux naturels de l'Amérique. Le $1^{\text {er }}$ août 1498, Colomb découvrit le continent de l'Amérique méridionale, vers l'embouchure de l'Orénoque, et nomma la Trinité une île qu'il vit dans ces parages. L'année précédente, Sébastien Cabot, envoyé par Henri VII à la découverte de contrées qui ne fussent occupées par aucune puissance chrétienne, était parti de Bristol, avait trouvé l'île de Terre-Neuve et reconnu les côtes du continent américain, depuis $56^{\circ}$ jusqu'à $58^{\circ}$ de latitude nord. 0 jeda, officier qui avail accompagné Colomb dans son second voyage, partit, en 1497 ou 1499, avec quatre vaisseaux, et fit quelque commerce avec les habitants de la côte de Paria. Un Florentin, Améric Vespuce, accompagnait Ojeda dans cette campagne; à son retour en Espagne, il se vanta d'avoir découvert le premier le continent du Nouveau-Monde; il publia une relation de son voyage, et eut la gloire de donner son nom à cette partie du globe. Dans la même année, Alonzo Pigna rapporta d'Amérique beaucoup d'or et de perles. Yanes Pinzon, compagnon de Colomb, partit en 1500 avec quatre vaisseaux, et fut le premier Espagnol qui passa la ligne. Vers le même temps, Pedro Alvarez Cabral, commandant une flotte portugaise destinée pour les Indes orientales, s'avança tellement à l'ouest, qu'il aborda à la partie de l'Amérique connue maintenant sous le nom de Brésil. Cette découverte, due au hasard, prouve que l'Amérique ne nous serait pas restée longtemps inconnue, quand même Colomb n'eût pas réussi dans son projet. En 1502, ce dernier navigateur fit un quatrième voyage, qui fut pour lui fertile en accidents; il découvrit néanmoins toute la côte du continent, depuis le cap Gracias a Dios jusqu'au havre de Porto-Bello. De retour de ce voyage, il termina sa carrière en 1506, après avoir éprouvé toute l'ingratitude de Ferdinand V, qui lui doit une grande partie de l'éclat de son règne. En 1509, Juan Dias de Solis découvrit le Rio de la Plata; Ponce de Léon, la Floride, en 1512. L'année suivante, Balboa, parvenu sur la cime des montagnes de l'isthme de Darien, vit le grand Océan, dont il prit ridiculement possession au nom de son souverain. De celte époque à 1518 , on reconnut le Rio Janeiro, l'Yucatan et Campêche. En 1519, Cortès entreprit la conquête du Mexique, où l'on avait touché l'année précédente; elle fut achevée en deux ans. Deux ans après, Magellan découvrit le détroit qui a conservé son nom, et le premier traversa le grand Océan. Vers la fin de 1524, Pizarre partit pour la découverte des pays au sud de Panama; et, après plusieurs expéditions sans succès, il parvint enfin au Pérou en 1526 : quelques années lui suffirent pour le soumettre à la domination espagnole. Cependant les Anglais, toujours animés du désir de trouver un- passage aux Indes par le nord-ouest, avaient fait plusieurs tentatives infructueuses sous ce rapport, mais qui eurent pour résultat quelques 
découvertes. En 1534, Cartier, envoyé par François Ier, entra dans le golfe et le fleuve Saint-Laurent; et, l'année suivante, il bâtit un fort à 300 lieues au-dessus de l'embouchure de ce fleuve. François Drake, dans son voyage autour du monde, chercha vainement sur la côte occidentale de l'Amérique une communication entre les deux mers; il visita les côtes découvertes en 1542 par Gali et Cabrillo, et les appela NouvelleAlbion. En 1578, Élisabeth accorda à sir Humphrey Gilbert une charte pour l'établissement d'une colonie en Amérique; ce fut la première que les Anglais y fondèrent, mais elle fut bientôt suivie de plusieurs autres. La recherche du passage aux Indes à travers le continent américain a donné lieu à un grand nombre d'expéditions, qui nous ont fait connaître les golfes et les baies par lesquels on crut y parvenir. En 1607, Davis découvrit le détroit qui porte son nom. En 1610, Hudson donna son nom au détroit et à la mer où il entra le premier, et où il périt. Quelques années après, la mer de Baffin fut parcourue par le navigateur de ce nom. Vers le milieu du xviri ${ }^{\mathrm{e}}$ siècle, Béhring et Tchirikof découvrirent le détroit de Béhring. En 1774, Pérez trouva l'entrée de Noutka; el, en 1795, Quadra et Vancouver reconnurent presque toutes les îles qui forment l'archipel auquel ils ont donné leurs noms, ainsi que les baies qui les avoisinent. En 1819, le capitaine Parry s'est avancé par le détroit de Barrow dans la mer Polaire, au nord de l'Amérique, par le parallèle du $74^{\circ}$ jusqu'à $115^{\circ}$ de longitude ouest. En 1821, Franklin, descendu par le fleuve Copper-Mine jusqu'à la mer Polaire, a exploré environ 180 lieues de la côte au nord-est de ce fleuve. Nous devons à d'intrépides voyageurs la connaissance de beaucoup de parties de l'Amérique septentrionale. Hearn, en 1772, découvrit l'embouchure du Copper-Mine. Mackenzie a visité, en 1789, les pays arrosés par le fleuve auquel il a donné son nom, et ensuite a pénétré le premier par terre jusqu'aux côtes du grand Océan. Pike est remonté jusqu'aux sources du Mississipi. Les capitaines Lewis et Clarke ont découvert les sources du Missouri; et, après avoir traversé les monts Rocailleux, ils sont parvenus à l'embouchure de la Colombia dans le grand Océan. Pour la connaissance de l'Amérique septentrionale, on doit beaucoup aux travaux des missionnaires et des aventuriers français, tels que Hennepin, Lejeune et Charlevoix, la Hontan, Lasalle et une foule d'autres. Les PP. Dutertre et Labat ont les premiers donné une bonne description des Antilles. Au nombre des voyages les plus importants qui nous font connaître l'Amérique méridionale, nous devons placer celui de la Condamine, qui a décrit le cours de l'Amazone; celui d'Azara, qui nous a laissé des détails sur diverses parties; celui du prince Maximilien Wied-Neuwied, qui a parcouru la côte du Brésil. M. de Humboldt, par ses voyages entrepris de 1799 à 1804, a étendu le domaine de la géographie du Nouveau-Monde. Enfin, diverses relations insérées dans des publications périodiques nous fournissent des documents plus récents.

Sans nous préoccuper des nombreuses discussions relatives à l'origine des Américains, nous nous bornerons à dire que la race américaine forme aujourd'hui une classe essentiellement différente des autres portions du genre humain, soit par ses caractères physiques, soit par ses idiomes.

Nous trouvons dans la Géographie universelle de Malte-Brun le résumé de longues observations physiologiques empruntées à divers savants; résumé que nous copions ici afin de faire connaître les peuples de l'Amérique :

- Les naturels de cette partie du globe sont en général grands, d'une charpente forte, bien proportionnés et sans vices de conformation. Ils ont le teint bronzé ou d'un rouge cuivré, comme ferrugineux et très-semblable à la cannelle ou au tanin; la chevelure noire, longue, grossière, luisante et peu fournie; la barbe rare et semée par bouquets, le front court, les yeux allongés et ayant le coin dirigé par en haut vers les 
tempes, les sourcils éminents, les pommetles avancées, le nez un peu camus, mais prononcé, les lèvres étendues, les dents serrées et aiguës; dans la bouche, une expression de douceur qui contraste avec un regard sombre et sévère ou même dur; la tête carrée, la face large sans être plate, mais s'amincissant vers le menton; les traits, vus de profil, saillants et profondément sculptés; la poitrine haute, les cuisses grosses, les jambes arquées, le pied grand, tout le corps trapu. L'anatomie nous fait encore reconnaître dans leur crâne des arcs sourciliers plus marqués, des orbites plus profondes, des pommettes plus arrondies et mieux dessinées, des tempes plus unies, les branches de la mâchoire inférieure moins écartées, l'os occipital moins bombé, et une ligne faciale plus inclinée que chez la race mongole, avec laquelle on a voulu quelquefois les confondre. La forme du front et du vertex dépend le plus souvent d'efforts artificiels; mais indépendamment de l'usage de défigurer la tête des enfants, il n'y a pas de race sur le globe dans laquelle l'os frontal soit plus déprimé en arrière. Le crâne est ordinairement léger.

a Tels sont les caractères généraux et distinctifs de toutes les nations américaines, à l'exception peut-être de celles qui occupent les régions polaires aux deux extrémités. Les Esquimaux hyperboréens, ainsi que les Puelches méridionaux, sont au-dessous de la taille moyenne, et présentent dans leurs traits et dans leur conformation la plus grande ressemblance avec les Samoyèdes; les Abipons, et plus encore les Patagons au sud, ont une stature presque gigantesque. Cette constitution forte et musculeuse, jointe à une forme élancée, se retrouve en quelque sorte chez les habitants du Chili, ainsi que chez les Caraïbes qui habitent les plaines du delta de l'Orénoque jusqu'aux sources du Rio-Blanco, et chez les Arkansas, que l'on compte parmi les sauvages les plus beaux de ce continent. $)$

a Les raisonnements sur les causes de la variété des couleurs de la peau humaine échouent ici contre l'observation, puisque la même teinte cuivrée ou bronzée est commune, avec de très-petites nuances, à la généralité des nations d'Amérique, sans que le climat, le sol ou la manière de vivre paraissent y exercer la moindre influence. Citera-t-on les Zambos, appelés jadis Caraïbes, à l'île Saint-Vincent? ils exhalaient en effet cette odeur forte et désagréable qui semble appartenir aux nègres; leur peau noirâtre présentait au toucher la même mollesse soyeuse qu'on observe notamment sur les nations cafres; mais ils descendaient d'un mélange des naturels avec la race africaine : les véritables Caraïbes sont rouges. Le coloris des indigènes du Brésil et de la Californie est foncé, quoiqu'ils vivent, les uns dans la zone tempérée et les autres près du tropique. Les indigènes de la Nouvelle-Espagne, dit M. de Humboldt, ont le teint plus basané que les Indiens de Quito et de la Nouvelle-Grenade, qui habitent un climat entièrement analogue : nous voyons même que les peuplades éparses au nord du RioGila sont plus brunes que celles qui avoisinent l'ancien royaume de Guatimala. Les peuples de Rio-Negro sont plus basanés que ceux du Bas-Orénoque, et cependant les bords du premier de ces deux fleuves jouissent d'un climat plus frais. Dans les forêts de la Guyane, surtout vers les sources de l'Orénoque, vivent plusieurs tribus blanchâtres qui ne se sont jamais mêlées avec les Européens, et se trouvent entourées d'autres peuplades d'un brun noirâtre. Les Indiens qui, dans la zone torride, habitent les plateaux les plus élevés de la cordilière des Andes, ceux qui, sous le $45^{\circ}$ de latitude australe, vivent de la pêche entre les-îles de l'archipel des Chonos, ont le teint aussi. cuivré que ceux qui, sous un ciel brûlant, cultivent des bananes dans les vallées les plus étroites et les plus profondes des régions équinoxiales. Il faut ajouter à cela que les Indiens montagnards sont vêtus et l'ont été longtemps avant la conquête, tandis que les indigènes qui errent dans les plaines sont tout nus, et par conséquent toujours 
exposés aux rayons perpendiculaires du soleil. Partout on s'aperçoit que la couleur de l'Américain dépend très-peu de la position locale dans laquelle nous le voyons actuellement; et jamais, dans un même individu, les parties du corps couvertes ne sont moins brunes que celles qui se trouvent en contact avec un air chaud et humide. Les enfants ne sont jamais blancs en naissant; et les caciques indiens qui jouissent d'une certaine aisance, qui se tiennent vêtus dans l'intérieur de leurs maisons, ont toutes les parties de leur corps, à l'exception de l'intérieur de leurs mains et de la plante des pieds, d'une mème teinte rouge brunâtre ou cuivrée. "

"Cette couleur foncée se soutient jusqu'à la côte la plus proche de l'Asie. Seulement sous le $54^{\circ} 10^{\prime}$ de latitude boréale, au milieu d'Indiens à teint cuivré et à petits yeux très-allongés, on a cru distinguer une tribu qui a de grands yeux, des traits européens et la peau moins brune que les paysans de nos campagnes. Michikinakou, chef des Miamis, a parlé à Volney d'Indiens du Canada qui ne brunissent que par le soleil et par les graisses et les sucs d'herbes avec lesquels ils se frottent la peau. Selon le major Pike, les intrépides Ménomènes se distinguent par la beauté de leurs traits, par des yeux grands et expressifs, et par un teint plus clair que celui des autres bandes de Chipeouays. Leur physionomie respire à la fois la douceur et une noble indépendance. Ils sont tous bien faits et d'une taille moyenne. Les Li-Panis ou Panis-Loups, qui errent, au nombre d'environ 800 guerriers, depuis les bords du Rio-Grande jusque dans l'intérieur de la province du Texas, au Nouveau-Mexique, ont les cheveux blonds et sont généralement de beaux hommes. D'après Adolphe Decker qui, en 1624, accompagna l'amiral hollandais L'Ermite autour du cap Horn, il y aurait également, dans la Terre-de-Feu, des habitants qui naissent blancs, mais qui se peignent le corps en rouge et de diverses autres couleurs. Ces faibles anomalies, bien avérées, ne tendraient qu'à mieux prouver que, malgré la variété des climats et des hauteurs qu'habitent les différentes races d'hommes, la nature ne dévie pas du type auquel elle s'est assujettie depuis des milliers d'années. "

« La barbe qu'on avait voulu refuser aux Américains, leur est assurée aujourd'hui. Les Indiens qui habitent la zone torride de l'Amérique méridionale en ont généralement un peu, et elle augmente lorsqu'ils se rasent; cependant beaucoup d'individus naissent dénués de barbe et de poils. Galeno nous apprend que parmi les Patagons il y a plusieurs vieillards qui ont de la barbe, quoique courte et peu touffue. Presque tous les Indiens, dans les environs de Mexico, portent de petites moustaches que des voyageurs modernes ont aussi retrouvées chez les habitants de la côte nord-ouest de l'Amérique. En rassemblant et comparant tous les faits, il semblerait en définitive que les Indiens sont plus barbus à mesure qu'ils s'éloignent de l'équateur. D'ailleurs, ce manque apparent de barbe est un caractère qui n'appartient pas exclusivement à la race américaine. Plusieurs hordes de l'Asie orientale, les Aléoutes et surtout quelques peuplades des nègres africains, en ont si peu, qu'on serait tenté d'en nier entièrement l'existence. Les nègres du Congo et les Caraïbes, deux races d'hommes éminemment robustes, souvent de structure colossale, prouvent que c'est un rêve physiologique que de regarder un menton imberbe comme un signe certain de la dégénération et de la faiblesse physique de l'espèce humaine. »

"Ces caractères physiologiques rapprochent sans doute la race américaine de celle des Mongols qui peuple le nord et l'est de l'Asie, ainsi que celle des Malais ou des hommes les moins basanés de la Polynésie et des autres archipels de l'Océanie. Mais ce rapprochement, qui ne s'étend qu'à la couleur, n'embrasse pas les parties les plus essentielles, le crâne, les cheveux, le profil du visage. Si, dans le système de l'unité de l'espèce humaine, on veut considérer la race américaine comme une branche de la race 
mongole, il faudra supposer que, pendant une suite de siècles sans nombre, elle a été séparée de son tronc et soumise à la lente action d'un climat particulier. » Après avoir parlé de l'Amérique en général, nous ferons connaître chacune de ses parties; et cette description particulière complétera les caractères généraux que nous venons d'énoncer sur cette division du globe et les peuples qui l'habitent. 


\section{AMÉRIQUE MÉRIDIONALE.}

L'Amérique méridionale est bornée au nord par la mer des Antilles, à l'est par l'océan Atlantique, et à l'ouest par le grand Océan. Elle a environ 1,650 lieues en longueur du golfe de Maracaïbo au détroit de Magellan, et 1,250 lieues dans sa plus grande largeur du cap Saint-Roque au cap Blanc.

Ses côtes ne renferment qu'un petit nombre d'îles dont les plus grandes et les moins connues bordent la partie sud. Ses golfes sont également peu remarquables; on cite ceux de Panama, de Guayaquil et de Guaiteca, sur la côte occidentale; ceux de SanJorge et San-Autonio, sur la côte orientale; et ceux de Paria et de Maracaïbo au nord. La principale chaîne de montagnes de cette partie de l'Amérique se rapproche de la còte haignée par le grand Océan, et ne s'en éloigne même que d'une distance peu considérable; elle part de l'isthme de Darien et se prolonge sans interruption jusqu'au cap Froward, dans le détroit de Magellan.

Celte chaîne est la fameuse cordilière des Andes, et s'élève sous l'équateur à sa plus grande hauteur. Elle se divise en plusieurs branches, dont l'une se rattache, au nord, à lá Sierra de Santa-Martha, qui suit la côte en se dirigeant, à l'est, jusque sous la ligne. Vers le $20^{\circ}$ degré de latitude sud, la chaîne fléchit vers le sud-est, et ses rameaux de ce côté s'abaissent en plateaux qui vont rejoindre les montagnes du Brésil, lesquelles courent en plusieurs branches parallèles à la côte orientale, sous le nom de Sierra de Mangaveria, de Bom-Jardin, de Mantiqueira, de Geral et de Tape.

Les plaines immenses qui s'étendent entre ces montagnes sont arrosées par une multitude de cours d'eau. Le principal, l'Amazone ou le Maragnon, sort des Andes et reçoit toutes les eaux qui descendent de la partie orientale de cette grande cordilière, entre $3^{\circ}$ de latitude nord et $20^{\circ}$ de latitude sud; il se jette dans l'océan Atlantique après un parcours de plus de 1,000 lieues. On cite encore le Rio de la Plata; l'Orénoque, qui a pour affluents le Cassiquiari, le Tocantin, qui communique avec l'Amazone par le Rio das Boncas, et le San-Francisco. Les rivières, parmi lesquelles on distingue le Rio Madalena, sont en grand nombre; mais celles qui descendent du versant occidental des Andes n'ont pas un long cours, et ne sont en général que des torrents. Les lacs les plus importants sont le Maracaïbo au nord, le Titicaca dans l'ouest, et le Patoz sur la còte sud-est.

Cette moitié du Nouveau-Monde possède les productions minérales les plus précieuses; les montagnes renferment l'or et l'argent; le cuivre abonde dans le Chili et la Colombie; on trouve aussi dans ce dernier pays le platine et les émeraudes, tandis que le Chili a des montagnes d'aimant. Les mines de mercure ont rendu célèbre Guancavelica, dans le Pérou qui est riche en sel gemme. La pèche des perles s'exerce avec succès sur plusieurs parties des côtes. 
Les productions végétales ne sont pas moins précieuses. La nourriture principale des indigènes est le manioc, et les Européens l'ont adoptée. On cultive, suivant les climats, le riz, le maïs, le froment, etc.; ainsi que la canne à sucre, le café, le cacao, le coton, le tabac et l'indigo. On y recueille aussi la vanille el les épiceries qui viennent de l'Asie, telles que la cannelle, le girofle, la muscade, et beaucoup de drogues médicinales. Les forêts donnent des bois de teinture et de marqueterie; celles des régions équatoriales se font admirer par leur vigoureuse végétation. L'arbre du quinquina croìt dans une zone particulière aux environs de la ligne, mais seulement à une certaine hauteur, et ne s'approche pas des cimes des montagnes. Des palmiers gigantesques ornent les plages, et même les hauteurs de cette partie du monde. Les régions hautes de l'occident fournissent la pomme de terre; on leur doit aussi la capucine et le tournesol, et une grande quantité de plantes qui font l'ornement de nos jardins. Les bètes fauves et les animaux les plus remarquables sont les cerfs, les lamas, les guanacos, les alpacos, les singes de diverses espèces, le jaguar, le coati, le cougouar, le tigre noir de l'Orénoque, le tapir, le pécari, les tatous, le paresseux et les fourmiliers. Quelquesuns de ces quadrupèdes se distinguent par leurs formes bizarres. De nombreux troupeaux de bœufs et de chevaux sauvages errent dans les vastes plaines de la zone tempérée. Le condor, les toucans au bec énorme, les colibris, les perroquets, dont les espèces sont très-variées, et parmi lesquels les aras se distinguent par leur grosseur et la richesse de leurs couleurs; le camichi à la voix retentissante; l'agami, remarquable par son intelligence; les hoccos et le maraïl, dont la chair est si délicate; le nandou, qui approche de la grosseur de l'autruche; le jabiru, fléau des reptiles, sont les oiseaux les plus dignes d'altention. On en voit une infinité d'autres dont le plumage est extrêmement brillant, et offre les teintes les plus belles. Les abeilles sont communes, particulièrement dans le Brésil. Les rivières et la mer sont très-poissonneuses, et les tortues fourmillent dans l'Orénoque et l'Amazone, ainsi que dans la mer. On trouve beaucoup de crocodiles dans les fleuves et les marais. Les serpents sont nombreux, et quelquesuns d'une grosseur énorme. Des lézards, des insectes, les uns incommodes, les autres curieux par leurs belles couleurs et leurs proportions gigantesques, pullulent dans les régions humides et voisines de l'équateur. 


\section{ILES MALOUINES,}

\section{TERRE-DE-FEU ET PATAGONIE.}

Iles Malouines. - Les îles Malouines, nommées Falkland par les Anglais qui les appellent encore Hawkin's Maidenland, se composent de deux grandes îles : FalkLand et Soledad, séparées l'une de l'autre par un large canal auquel les Espagnols ont imposé le nom de détroit de San-Carlos, et que les Anglais appellent Falkland. Elles sont situées entre $51^{\circ} 5^{\prime}$ et $52^{\circ} 46^{\prime}$ de latitude australe, et entre $60^{\circ}$ et $63^{\circ} 30^{\prime}$ de longitude ouest.

La république argentine a récemment fondé une colonie dans ces îles; el les Brésiliens ont établi un poste dans les États de la Trinité " et de Saint-Paul.

Ces îles ne peuvent nous arrêter, puisqu'elles n'offrent rien d'intéressant sous le rapport des mœurs. Cependant on trouvera dans notre Nouvelle Collection de voyages le récit d'une aventure éminemment dramatique dont Neuw-IsLand ${ }^{2}$ fut le théâtre, el que, faute d'espace, nous ne pouvons rapporter ici.

Terre-de-Feu. - Le nom de Terre-de-Feu ${ }^{3}$ fut donné à cette terre à cause de la fuméc que les premiers explorateurs virent s'élever des huttes des indigènes.

Parmi les îles qui font partie de cette terre, nous nommerons les îles l'Ermite, de la Cathédrale-d'Yorck, des Nigauds, des Oies, de l'OEuf, l'île Brûlée, etc. Le point le plus important de la Terre-de-Feu est le cap Horn.

Les FuÉgrens ou habitants de la Terre-de-Feu passent pour les plus misérables de l'espèce humaine. Ils ont la tête grosse, les joues proéminentes, le nez plat. Ils sont plus petits, plus mal faits et plus sales que les Patagons; mais ils ont plus de douceur dans la physionomie. Un mélange de charbon, d'ocre rouge et d'huile de phoque, dont ils imprègnent quelquefois leur corps, exhale une odeur tellement insupportable qu'on ose à peine les approcher.

Leurs vêtements consistent en peaux de guanaques ou de phoques; lous se talouent la figure et d'autres parties du corps d'une manière grotesque. Les femmes se couvrent en partie de peaux, et s'ornent le cou de colliers faits de dents de poissons. Les indigènès de la Terre-de-Feu ont pour demeures des huttes coniques couvertes soit de peaux, soit d'écorces ou de feuilles d'arbre. Ceux que le capitaine Weddel a visités avaient l'air doux et timide, et vivaient dans un état d'abrutissement profond, ne s'occupant que de pêcher quand la saison le permet; ils ont pour cet usage des canots qu'ils manœuvrent avec une grande dextérité, mais qui ne sont pas aussi artistement travaillés que ceux des Samoyèdes. Les habitants de la côte méri-

1 Nommée aussi île de l'Ascension.

${ }^{2}$ L'île nouvelle.

3 En espagnol Tierra del Fuego. Le capitaine anglais King la nomme King Charles Southland. 
dionale sont sauvages, traîtres et cruels. Tous ont pour armes l'arc, la fronde et une sorte de lance armée d'un os pointu; ils paraissent n'avoir aucun chef et aucune espèce de croyance religieuse.

Outre les occupations du ménage qui leur sont entièrement dévolues, les femmes ont le pénible soin de ramer sur mer, et les hommes ne les remplacent que lorsqu'une trop grande fatigue les oblige au repos.

On divise les Fuégiens en plusieurs tribus : les Yacana-Kunny, qui habitent le nordest du groupe, et qui sont peu connus; les Tekrnica, petits, mal faits, et dont la teinte varie entre la couleur du cuivre et celle du bronze; les Alikhoulip qui, après les Yacana-Kunny, sont les moins repoussants des Fuégiens; les Pecherais, pauvres et chétifs; enfin les Fuégiens du havre Merie, dont la physionomie est dépourvue d'expression.

On prétend que les Fuégiens sont anthropophages; ils mangent leurs plus vieilles femmes lorsqu'ils craignent de manquer de vivres. Malgré cela, le sentiment de la famille est développé chez eux à un assez haut point, et ils accueillent bien le voyageur qui les visile.

Patagonie. - Cette contrée est comprise entre $35^{\circ} 38^{\prime}$ et $53^{\circ} 54^{\prime}$ de latitude sud, sur une longueur d'environ 465 lieues. Sa configuration présente un vaste triangle, dont les trois points extrèmes sont le cap Corientes à l'est, le cap Frosard au midi, et à l'ouest le promontoire qui s'avance dans le grand océan Austral, en face de l'ile de Chiloë.

Les Patagons proprement dits sont divisés en deux tribus, celle des Tehuelches au nord, et celle des Inaken, répandus sur les bords du détroit de Magellan. Mais nous ne pouvons entrer, relativement à la distinction de ces races, dans des dissertations toujours arides et qui ne sauraient convenir dans un ouvrage comme celui que nous offrons au public.

La population de la Patagonie ne dépasse pas 8,000 à 10,000 âmes, disséminée dans une étendue de 26,000 lieues carrées, ce qui donne une moyenne d'un homme pour trois lieues à peu près. Pourtant on ne s'étonnera pas des chiffres que nous venons de poser si l'on considère l'aridité des terres de la Patagonie, l'espace nécessaire à l'établissement de chaque tolderia '. Les familles doivent d'ailleurs, sur ce sol avare, s'étendre assez loin pour trouver leur nourriture. Et de plus, il faut à un peuple chasseur une plus grande surface qu'il n'est nécessaire à un peuple versé dans l'agriculture ou dans l'industrie.

La taille des Patagons du nord est en moyenne ${ }^{2}$ de cinq pieds quatre pouces. Ils ont les épaules larges et effacées, le corps robuste, les membres bien nourris, les formes massives et herculéennes; la tête grosse et un peu aplatie par derrière; la face large et carrée, les pommettes peu saillantes, les yeux horizontaux et petits; leur front, leurs sourcils, et les lèvres épaisses qui bordent leur grande bouche, sont très-proéminents; leur nez est épaté et à narines ouvertes. Les femmes jeunes ont une expression spirituelle qui annonce chez elles de la vivacité, de la douceur, et les rend quelquefois assez agréables. Elles ont la main et le pied petits; leur taille ne manque pas d'élégance; elles ont les dents égales et d'une blancheur extraordinaire. Leur teint ressemble plus à celui des mulâtres qu'à la couleur du cuivre rouge.

On n'est point d'accord sur le caractère des Patagons : les uns les ont vus humains et sociables; d'autres les accusent de perfidic et de cruauté. Mais ce peuple est sus-

1 Village formé de quelques tentes.

2 Les plus grands Patagons ont cinq pieds onze pouces. 
ceptible de civilisation, puisque, malgré le peu de rapports continus qui existent entre les Espagnols et les naturels du nord, on remarque une différence notable entre ceux-ci et les indigènes du midi. On leur reproche d'être faux, arrogants et enclins au vol; mais leur discrétion est, dit-on, à toute épreuve, surtout lorsqu'il s'agit d'un secrel qui intéresse la sûreté de leur tribu.

Les Patagons sont d'une paresse extrême : ils ne s'occupent que de leurs armes, el passent leur temps dans une stupide oisiveté. Ils n'ont aucune aptitude pour la pêche; les habitants de la Terre-de-Feu sont les seuls navigateurs de toute la pointe de l'Amérique méridionale. Chasseurs et nomades, ils n'ont aucune industrie, tandis que les Araucanos sont beaucoup plus avancés sous ce rapport, et leur fournissent le peu de tissus de laine dont ils font usage. La conséquence de cette paresse et de cette sorte de dédain pour ce que nous appelons le confortable, est une malpropreté inimaginable. Ils ne balayent jamais leurs huttes ou toldos, faites de branches plantées en rond, retenues par le haut et couvertes de peaux de guanaques; quand les immondices les incommodent, ils enlèvent leur demeure et vont la porter plus loin. Ils ne se baignent que durant les chaleurs et uniquement dans le but de se rafraîchir. Ils n'ont soin, dit M. d'Orbigny, que de leur figure et de leurs cheveux : de la première pour la couvrir de couleurs mélangées et de graisse de jument, et des seconds pour les peigner avec une espèce de brosse faite de racine.

Les amusements des Patagons sont très-bornés. Indépendamment d'un jeu pour lequel ils se servent de dés semblables à ceux qu'on emploie au trictrac, ils en ont un autre exclusivement réservé aux jeunes gens, et que les Français désignent sous le nom de pilma. En voici la description : Les joueurs se rangent sur deux lignes, vis-àvis les uns des autres; un champion de chacune d'elles est muni d'une balle de peau rémplie d'air; l'un la tient du côté gauche et l'autre du côté droit, et bientôt ils commencent à jeter ensemble leur balle, non devant eux, comme on le fait ordinairement, mais en arrière du corps, de manière à ce que, pour qu'elle revienne librement en avant, ils doivent immédiatement lever la jambe gauche; ils reçoivent la balle dans la main, et la renvoient à l'adversaire, qu'ils doivent atteindre au corps, sous peine de perdre un point; ce qui oblige le vis-à-vis à faire, pour l'éviter, mille contorsions, se baissant ou sautant, afin que la balle ne le touche pas et sorte du cercle, ce qui fait perdre deux points au premier joueur, alors obligé d'en sortir lui-même pour l'aller chercher. Si, au contraire, le second est touché, il faut qu'il saisisse la balle et la renvoie au premier joueur, qu'il doit aussi frapper, sous peine de perdre lui-même une marque; puis c'est à celui qui suit, du côté opposé, à recommencer. On sent bien qu'une telle combinaison doit amener les mouvements les plus singuliers tant de la part de ceux qui jettent la balle sous la jambe, que de ceux qui cherchent à se plier, comme des serpents, pour l'éviter; ce qui leur fait prendre les postures les plus grotesques, aux grands éclats de rire du parti opposé. Les Indiens déploient au jeu de pilma la joie bruyante de nos écoliers : rien de plus plaisant à voir d'un peu loin, que les contorsions des joueurs en faisant leurs gambades et en agitant les bras et les jambes; on prendrait vraiment cet exercice pour une danse. Il a sans doute été inventé par eux pour se réchauffer, pendant l'hiver, au sein des régions glacées qu'habitent quelques-unes de leurs tribus; mais dans le mois de février, au milieu du jour, par une chaleur excessive, on ne conçoit pas comment ces athlètes peuvent y résister.

La nourriture du Patagon consiste en viande crue ou cuite, surtout la chair de jument; il mange énormément, mais il est capable de supporter un long jeûne. La graisse et le suif le plus rance sont ses mets de prédilection.

Les armes offensives se composent d'un arc et de flèches. L'arc, long de quatre- 
vingt-dix centimètres, est sans aucun ornement : il est fabriqué avec du bois blanc fortement recourbé, et muni de cordes faites avec des tendons d'animaux. Les flèches, en bois et très-courtes, sont garnies à une de leurs extrémités de plumes blanches d'oiseaux de mer courtes et roides; l'extrémité opposée est armée d'un fragment de silex, ou pierre à fusil, artistement taillé en fer de flèche, avec deux crocs recourbés en sens inverse. Celte pointe est faiblement attachée, de sorte que quand on cherche à retirer le trait de la blessure, elle s'élargit considérablement et le dard se sépare de la hampe. Ils s'en servent avec adresse. Ils font usage aussi d'un javelot assez court, et d'une fronde des plus simples faite en peau, élargie vers la moitié de sa longueur pour recevoir la pierre qu'ils lancent à une grande distance et avec une dextéritě presque sans égale. Mais, de toutes leurs armes, la plus redoutable est celle qu'ils appellent bolas; elle consiste en deux pierres, du poids d'environ une livre chacune, recouvertes de cuir et attachées aux deux bouts d'une corde de sept à huit pieds de long. Pour s'en servir, ils tiennent une des pierres dans la main, font tournoyer l'autre au-dessus de leur tête, jusqu'à ce qu'elle ait acquis une force suffisante, et la dirigent alors en làchant la première; on les a vus atteindre des deux pierres à la fois, et à une distance assez considérable, un but d'un pouce à quinze lignes de diamètre. Ils s'en servent aussi pour la chasse; mais les bolas sont doubles, et même triples.

Les armes défensives des Patagons sont appropriées aux moyens d'attaque, et contribuent singulièrement à rendre ce peuple hideux. Au jour du combat, dit M. d'Orbigny, ils restent presque nus, avec leur espèce de ceinture de cuir à laquelle sont attachées leurs armes; mais les grands guerriers, ou les chefs, sont couverts d'une armure assez originale qu'ils ont empruntée aux Aucas. Ils s'affublent d'une longue cuirasse à manches, ressemblant à une ample chemise, et composée de sept à huit doubles d'une peau souple parfaitement préparée, peinte en dessus en jaune, et munie d'une large bande rouge sur la ligne médiane; le col de cette cuirasse s'élève jusqu'au menton et couvre une partie de la figure. Avec cette armure, ils portent une espèce de casque formé de deux peaux épaisses cousues ensemble, représentant un grand chapeau à larges bords, orné de plaques d'argent ou de cuivre, attaché par derrière au col de la cuirasse, et retenu par devant au moyen d'une mentonnière de cuir. La cuirasse descend jusqu'aux genoux et est fort gênante à cheval. Ceux qui n'en portent pas, ou qui n'ont pas le droit d'en porter, laissent flotter leurs cheveux sur les épaules. En dépit de cet appareil belliqueux, les Patagons sont loin d'être aussi redoutables que les Araucans. Ils ont été la terreur des peuples de ces contrées; mais, décimés par une maladie épidémique qui régna de 1809 à 1811, et attaqués ensuite par les Araucans qui en firent une horrible boucherie, ils ont perdu à la fois leur importance nationale et leur courage, et ne sont plus fort redoutés de leurs voisins.

Ils déploient la ruse et l'astuce en temps de guerre comme tous les sauvages de l'Amérique. Ils n'attaquent jamais sans que le chef ait fait préalablement une longue harangue pour exciter l'ardeur de ses compagnons. Il faut aussi, et avant tout, qu'ils reconnaissent la position de l'ennemi, et ils envoient, à cet effet, des éclaireurs à dix ou douze lieues de distance. Cette précaution et l'usage des surprises constituent pour eux tout l'art de la guerre. Ils se montrent d'une patience et d'une adresse merveilleuses, quand ils veulent assaillir leurs adversaires à l'improviste; ils attachent leurs chevaux au loin, afin de ne laisser aucune trace de leur passage; ils se traînent souvent sur les pieds et sur les mains, et rampent même quelquefois sur le ventre, de peur d'être aperçus. Pour entendre le moindre bruit, ils appliquent leur oreille contre terre, et ils distinguent approximativement le nombre des guerriers qu'ils auront à combattre. Lorsqu'ils sont suffisamment préparés, ils attendent le retour de la nuit, 
et dès que la lune est levée, ils tombent avec fureur sur leurs ennemis, qu'ils égorgent sans pitié. Ces surprises n'ont jamais lieu qu'au temps des pleines lunes, parce qu'alors les assaillants n'ont pas à craindre de funestes erreurs et qu'ils ont, en cas d'échec, deux jours et deux nuits de marche non interrompue. On reconnaît dans ces ruses de guerre les habitudes et l'admirable instinct des Américains de l'hémisphère boréal; mais ceux-ci portent l'adresse et l'habileté à un degré beaucoup plus remarquable.

Il y a moins d'un siècle, les Patagons combattaient encore à pied. En effet, le cheval n'est pas originaire de l'Amérique; il y a été naturalisé par les Européens, à qui les Indiens ont emprunté, avec une supériorité merveilleuse, le moyen de maitriser ce superbe animal et de s'en servir utilement. Les Patagons du nord sont presque inséparables de leurs montures, à ce point que la plupart des voyageurs ne les ont vus qu'à cheval. Les selles dont ils se servent n'ont rien de remarquable. Les étriers sont de bois, et à peine assez larges pour recevoir le gros orteil; ils sont même quelquefois remplacés par un nœud qui sert de point d'appui et qui passe entre le gros doigt et le second. Les éperons sont faits le plus souvent de deux petits morceaux de bois mobiles réunis par une courroie. La selle des femmes consiste en deux rouleaux de joncs, recouverts d'une peau très-mince et ornés de peintures variées. Lorsqu'une Indienne veut seulement se promener, elle ne met sur son cheval qu'un morceau de cuir, sur lequel elle s'assied. Elle a un étrier des plus singuliers, et pour lequel elle épuise tout le luxe que lui permet sa position. Cet étrier, nommé kéka-kénohué, est commun à loutes les Indiennes des parties australes du Pampas; il se compose d'une forte pièce de tissu de laine, ornée de couleurs vives, et large de trois à six pouces, dont les deux extrémités, réunies ensemble et fixées par le tissu même, viennent se séparer ensuite, pour former des franges en dehors de leur jonction. Il est passé au cou du cheval et pend sur sa poitrine; quand l'Indienne veut monter, elle y pose un pied, tout en saisissant une poignée de crins au garrot, et se trouve ainsi, d'un saut, sur le dos de sa monture, où elle reste comme encaissée entre les deux bourrelets, les genoux trèsélevés et les jambes pendantes en avant; position des plus gênantes, mais qui ne l'empêche pas de galoper aussi vite que les hommes. Souvent, dans ces promenades, elle se couvre de son chapeau de voyage, qui ressemble à un très-large plat renversé, formé de jeunes pousses de saule et de laine artistement croisées, et qu'elle orne quelquefois de plaques d'argent ou de cuivre; ce chapeau singulier, nommé joa, presque toujours réservé pour les voyages, est fixé derrière la tète par deux petits fils attachés aux cheveux, et par une mentonnière qui passe sous la gorge.

Les Patagones ne vont jamais nues, même avant l'âge nubile, et sont d'une chasteté remarquable. La polygamie n'est pas en usage parmi eux comme chez les Araucans.

Le mari n'abandonne jamais sa femme légitime; un homme ne peut mème quilter une concubine que quand il n'en a pas d'enfants. S'il fait des captives dans une guerre, elles deviennent les domestiques et non les rivales de sa femme. Les femmes jouissent d'une liberté entière avant le mariage; mais l'infidélité conjugale est sévèrement punie.

"Dès qu'une jeune fille, dit le savant voyageur d'Orbigny, s'aperçoit des premiers indices de sa nubilité, elle en prévient sa mère ou sa plus proche parente; celle-ci en avertit le chef de la famille, qui choisit immédiatement sa jument la plus grasse, afin d'en régaler ses amis. La jeune fille est placée au fond d'un toldo (tente), nommé puéténuca, séparé des autres et décoré à cet effet; là, sur une espèce d'autel, elle reçoit les visites successives de tous les Indiens et Indiennes de la tolderia, qui viennent la féliciter d'être femme et recevoir d'elle un morceau de la jument, proportionné à leur rang ou à leur degré de parenté. Aussitôt que tous les visiteurs sont venus, et que per- 
sonne n'ignore dans la tribu que la jeune fille est nubile, on l'assied sur une manne de laine que sa mère prend par le devant, sa plus proche parente par derrière, et, ainsi soulevée, on la promène, tandis qu'une vieille femme remplissant les fonctions de devin ou de prêtre, marche en tête en chantant, sans doute pour conjurer le malin esprit. Ce cortége s'achemine lentement vers un lac voisin, sans que personne le suive; la prètresse entre la première dans l'eau, en prend un peu et la jette en l'air, en parlant longtemps, sans doute afin de prier le dieu du mal de protéger la jeune Indienné dans sa nouvelle position. Les autres femmes entrent aussi au sein de la lagune; la conjuration terminée, elles y plongent la jeune fille à trois reprises différentes, l'essuient bien, étendent quelques pièces de tissus à terre sur la rive, l'y couchent, en la couvrant de ce qu'elles ont de meilleur; puis, plus tard, lorsque la prêtresse a terminé et recommencé ses prières, la néophyte revient vers la tolderia, où, dès lors, elle doit jouer un rôle. Cette coutume est générale parmi les peuples de l'Amérique méridionale; seulement, les cérémonies diffèrent suivant le pays."

A l'époque du mariage, le prétendant est tenu de faire des présents aux parents de la future, qui souvent même fixent le prix auquel ils estiment leur fille; et s'il n'est pas au-dessus de la fortune de l'Indien, tout s'arrange facilement; bien entendu qu'il n'est pas question de la conduite antérieure de la future : comme il est reconnu qu'elle est maîtresse de sa personne, on ne s'occupe pas de ce qu'elle a fait, n'étant obligée d'ètre fidèle qu'à son mari. Dès que les parties sont d'accord, la mère de la fulure et ses amis construisent le toldo de mariage que doit occuper le nouveau ménage; on y renferme les deux époux, puis tous les devins ou parentes se réunissent autour. Les devins commencent par donner des conseils au mari sur la conduite qu'il doit tenir avec sa femme, sur ses devoirs; puis ils en font autant à celle-ci, en lui prêchant surtout la soumission. Une fois que tous les conseils sont donnés, les devins avec lès parents chantent et dansent autour de la tente, tout en exécutant une musique diabolique avec de grandes calebasses, ou en soufflant dans de grandes coquilles. Les hommes, dans cet intervalle, allument un grand feu et font rôtir de la viande, dont ils offrent de temps en temps quelques petits morceaux aux époux, en leur faisant encore de nouvelles recommandations. La nuit se passe ainsi, et, le lendemain matin, ils ne sont considérés comme définitivement mariés que lorsque tous les habitants de la tolderia les ont visités au lit. Aussitôt après, la nouvelle épouse aime à se parer de tout ce qu'elle a reçu de plus précieux de son mari : ainsi, elle prend ses énormes boucles d'oreilles, et la plus grande jcuissance qu'elle puisse éprouver, c'est si son mari, à l'exemple des Aucas, lui a donné un bonnet fait de perles de verre de couleur, enfilées dans des tendons d'autruche et réunies par mailles, comme des filets. Les bijoux consistent en verroteries; si elle a un cheval, elle le selle, l'orne de tont ce qu'elle possède, et va ainsi se promener, étalant toutes ses richesses aux yeux de ses voisins.

Lorsqu'une femme, pour suivre son amant et aller vivre avec lui, abandonne le toit conjugal, l'époux, s'il est d'un rang élevé, ou s'il a des amis plus puissants que le ravisseur, se fait rendre sa femme; mais si, au contraire, celui-ci appartient à une classe supérieure, le mari doit patiemment se voir enlever sa compagne sans se plaindre. Le plus souvent les intéressés entrent en composition et transigent au moyen d'une indemnité au profit de l'époux outragé.

Les occupations des femmes sont multipliées et leur condition est très-dure, même pendant leur grossesse; ce sont elles qui font tout, excepté la chasse et la guerre. Lorsqu'elles accouchent, à peine leur accorde-t-on deux ou trois jours de repos. Une devineresse leur sert de sage-femme, et la naissance de l'enfant est célébrée quelquefois par des danses, des chants et des festins; souvent même ces circonstances donnent 
lieu à des conjurations contre les mauvais esprits. Les Patagons aiment leurs enfants jusqu'à l'adoration; ils sont pour eux d'une si grande faiblesse qu'on a vu des tribus abandonner un parage, ou y séjourner plus longtemps qu'elles ne le devaient, sur le simple vouloir d'un enfant.

Les Patagons conservent longtemps la mémoire de ceux qu'ils ont aimés, et souvent on les entend șe lamenter et retracer les vertus et les bonnes qualités du défunt. Dès qu'ils apprennent la mort d'un chef de famille, les amis se teignent de noir et viennent successivement consoler sa veuve et ses enfants. Le corps du défunt est immédiatement dépouillé de ses vêtements par les parents; puis, tandis qu'il est encore chaud, on lui croise les bras sur les jambes que l'on dispose de façon à ce que les genoux touchent au menton, et les talons à la partie inférieure du tronc. Aussitôt après, une partie de ce qui lui a appartenu est brûlée en signe de deuil. Sa demeure est anéantie; sa femme et ses enfants sont dépouillés de tout ce qui ne leur est pas propre; et la veuve, sans asile, souvent presque nue, attend aux environs que quelque parent vienne lui donner des vêtements. Elle se barbouille de suite la figure de noir, se coupe les cheveux de devant, peigne les autres qu'elle laisse tomber sur les épaules, et se renferme dans une vieille tente, d'où elle ne sort pas pendant une année, gardant des habits lugubres, la figure teinte en noir, sans pouvoir se la laver qu'un an après, et astreinte dans cet intervalle à la conduite la plus austère. La moindre infraction à cette règle serait un affront pour la mémoire du défunt, et que les siens auraient le droit de punir par la mort de la coupable et de son complice.

Le corps du défunt ainsi ployé, et lorsque sa tente est brûlée, ses proches immolent à ses mânes tous les animaux qui lui ont appartenu; on ne réserve que son meilleur cheval, qui est destiné à porter son corps jusqu'à la sépulture, avec ses bijoux et ses armes, qui doivent être ensevelis avec lui, afin qu'il les retrouve dans l'autre vie. Le mort est accompagné jusqu'à sa dernière demeure par ses fils ou ses neveux; ils marchent au loin dans la campagne, surtout lorsqu'il y a aux environs une nation différente de la leur, ou des chrétiens, afin de ne pas être aperçus d'eux. Ils creusent une fosse circulaire, de deux pieds de diamètre et assez profonde pour que le corps, déposé assis, puisse avoir quelques pieds de terre sur la tête. Lorsqu'il est enseveli, ils immolent le coursier sur sa tombe, afin que le défunt s'en serve quand il voudra; puis ils reviennent tristement, en faisant de grands détours, pour ne pas indiquer où ils sont allés; précautions qui sont des plus nécessaires, car si dans la même tolderia un Indien n'était pas assez hardi pour aller profaner la tombe de son frère, de son ami, les autres tribus, toujours peu scrupuleuses sur ce point, et surtout les chrétiens qui peuvent se trouver parmi elles ou aux environs, ne manqueraient pas de rechercher ces tombes afin d'en enlever les vêtements et les ornements d'argent qu'on y place; violence qui souvent amène entre les nations des rixes et des haines mortelles. Lorsqu'une Indienne meurt avant son mari, on n'anéantit que ce qui lui appartient en propre, ce qui se réduit à des habits et à quelques ornements. Du reste, la cérémonie est la même; mais le veuf ni les enfants ne portent aucun deuil extérieur, et le premier peut immédiatement se remarier.

Leur costume se compose de fourrures; ils emploient de préférence la peau du guanaque; ils ne font usage que des parties du dessous du cou et des jambes, parce que la laine en est plus douce. Ils réunissent ces morceaux au moyen de tendons d'autruche, dont ils se servent en guise de fil, et parviennent à en composer de vastes manteaux carrés. La peau du renard et de la mouffette constitue leurs vètements de luxe. Sous cet âpre climat, tout devant être calculé pour l'utilité, le côté du poil et le côté de la peau sont, tour à tour et suivant la température, mis en dedans ou en dehors. Les Patagons 
décorent le côté de la peau du manteau, de desseins de couleur rouge, afin qu'il soit d'un aspect moins repoussant. Ils portent, indépendamment de ce manteau, un vêtement composé également de fourrures, et qui, attaché autour de la taille, se termine en pointe par devant, pour passer entre les cuisses, et remonter s'attacher par derrière. Ce costume simple est complété par des espèces de bottes formées d'un morceau de yeau relevé et fixé autour de la cheville. Leurs cheveux, attachés sur la tête avec un cordon de cuir ou un ruban de laine, sont noirs. Quoique le tatouage ne leur soit pas connu, leur figure reste rarement de sa couleur naturelle; ils la peignent le plus souvent en rouge, en noir ou en blanc. Le rouge occupe presque toujours l'espace compris entre les yeux et la bouche, à l'exception d'un espace d'un pouce, au-dessous de la paupière inférieure, consacré au noir. Le blanc forme une tache au-dessus de chaque œil. Les femmes font usage des mêmes couleurs, à l'exception du blanc; elles ont, avec le manteau et la pièce de devant qu'elles ne font point remonter par derrière, une autre pièce semblable qui s'étend des aisselles aux genoux. Leurs cheveux sont tantôt flottants sur leurs épaules et séparés seulement par le milieu, tantòt réunis en deux tresses qui retombent sur chaque épaule, et auxquelles elles suspendent de menus objets de verroterie, entremêlés de petites plaques de cuivre et de monnaie. Elles ont des boucles d'oreilles en argent, ornées de morceaux de même métal carrés et extrêmement lourds. Les Patagons, comme plusieurs peuplades de l'Amérique, s'épilent la barbe.

La taille des Patagons du sud ou Inaken paraît être la même que celle des indigènes du nord. Ils ont de cinq à six pieds anglais; la largeur de leurs épaules et la longueur de leur buste leur donnent, au premier coup d'œil, l'apparence d'une race gigantesque; mais la partie inférieure de leur corps n'est nullement en harmonie avec les proportions de la partie supérieure. Leurs cuisses et leurs jambes sont courtes et grêles.

Les toldos des Inaken sont de forme rectangulaire : ils ont environ douze pieds de long, dix de large, sept de haut sur le devant et six seulement sur le derrière. Ces toldos sont formés par des perches fixées dans le sol, et fourchues à leur extrémité supérieure, pour soutenir les chevrons qui supportent le toit. Cette sale demeure est couverte de peaux si bien cousues les unes aux autres, qu'elles sont presque impénétrables à la pluie et au vent. Les naturels les emportent et les traînent avec eux dans leurs excursions. Le centre est occupé par le foyer. Les Patagons du nord ne regardent jamais le feu comme les Européens, mais ils lui tournent le dos, afin de mieux voir ce qui se passe autour d'eux.

Chez les Patagons du sud la polygamie est fréquente; ils achètent les femmes trèsjeunes; elles sont vêtues, comme les hommes, de peaux de guanaque. La mante qu'elles se font de la dépouille de cet animal est retenue par devant au moyen d'une épinglette d'argent; leurs cheveux sont disposés comme ceux des Indiennes du nord.

Leur manière d'enterrer leurs morts est différente de celle des naturels du nord. Voici la description que Parker King donne de la tombe d'un enfant près de la baie Grégoire : "C'était, dit-il, un monceau conique de branches sèches et de broussailles, ayant dix pieds de haut et vingl-cinq de circonférence, le tout entouré de bandes de cuir. Le sommet de la pyramide était couvert d'un morceau d'étoffe rouge, orné de clous de cuivre, et surmonté de deux bâtons supportant des drapeaux rouges et des sonnettes qui, agitées par le vent, ne cessaient de tinter. Un fossé de deux pieds de large et d'un pied de profondeur était creusé autour du tombeau, excepté à l'entrée qui avait été remplie de buissons. En face de cette entrée étaient étendues les peaux de deux chevaux, récemment tués, lesquelles étaient soutenues par quatre pieux. Les têtes des chevaux étaient ornées de clous de cuivre, semblables à ceux du sommet de la 
pyramide. Enfin, en dehors du fossé, on voyait six bâtons portant chacun deux petits drapeaux, l'un au-dessus de l'autre.

Les Patagons du sud sont plus affables et plus familiers que ceux des autres parties du pays, parce qu'ils n'ont pas appris à leurs dépens combien le voisinage des Européens est dangereux; ils accueillent même les étrangers avec cordialité ; mais lorsqu'ils sont en nombre, ils imposent aux visiteurs un large tribut de tabac, de pain, de fusils, de poudres et d'autres articles dont ils raffolent; ils sont indifférents et apathiques.

A propos de cette apathie, nous citerons le fait suivant rapporté par le capitaine Wallis, qui, lors de son voyage au détroit de Magellan, fit amener plusieurs naturels à son bord, et ne put parvenir à faire naître chez eux le moindre sentiment de surprise :

"Je les menai dans toutes les parties du vaisseau, dit-il; ils ne regardèrent avec attention que les animaux vivants que nous avions à bord. Ils examinaient avec assez de curiosité les cochons et les moutons, et s'amusèrent infiniment à voir les poules de Guinée et les dindons. Ils ne parurent désirer de tout ce qu'ils voyaient que nos vêtements, et un vieillard fut le seul d'entre eux qui en demanda. Nous leur offrîmes des feuilles de tabac roulées; ils en fumèrent un peu, mais ne parurent pas y prendre plaisir. Je leur donnai du bœuf, du porc, du biscuit et d'autres provisions du vaisseau; ils mangèrent indistinctement de tout ce qu'on leur offrit, mais ils ne voulurent boire que de l'eau. Je leur montrai les canons; ils ne témoignèrent pas avoir connaissance de leur usage. Je fis mettre les soldats de marine sous les armes et leur fis exécuter une partie de l'exercice : à la première décharge de mousqueterie, nos Américains furent frappés d'étonmement et de terreur; mais voyant que nos gens étaient de bonne humeur et qu'ils n'avaient d'ailleurs reçu aucun mal, ils reprirent bientôt leur gaieté, et entendirent sans grande émotion une deuxième, puis une troisième décharge. 》

Après avoir parlé des détails, nous devons entrer dans les généralités communes aux peuplades des deux régions.

Les Patagons ne manquent pas d'intelligence, et leur génie national mérite d'être pris en considération. Leurs discours sont empreints d'un caractère d'énergie remarquable; ils sont très-éloquents, et ils ont surtout le talent de parler très-longtemps, sans hésiter et sans sortir du sujet de la conversation. Ce qui les distingue surtout, c'est l'emploi fréquent de la comparaison; cette tournure d'esprit les rapproche des peuples orientaux, qui, comme on sait, font consister la poésie dans l'usage exagéré de la métaphore.

Leur langue est plus gutturale que celle des Araucans, difficile à prononcer, et pleine de sons que nos lettres ne sauraient exprimer; elle est très-riche et a des combinaisons remarquables. Les indigènes peuvent compter jusqu'à cent mille; cette quantité de désignations numériques atteste la multiplicité des combinaisons de calcul auxquelles ils peuvent se livrer.

Les Patagons ont un système de politique des plus simples. Ils sont gouvernés par un chef, qu'ils désignent sous le titre de caras-ken, et dont le pouvoir ne s'exerce qu'en temps de guerre. En temps de paix, on a pour lui beaucoup de respect, mais il ne jouit d'aucun privilége. Ce poste n'est pas héréditaire de droit : il faut que le fils, pour succéder à son père, ait fait preuve de courage et d'éloquence; autrement la place est donnée à un autre.

Ces peuples n'ont point de lois; chacun vit à sa guise, et le plus voleur est le plus estimé comme étant le plus adroit.

Ils ne connaissent point le partage du territoire entre les membres de leur société; les richesses ne peuvent être chez eux que mobilières; et l'usage d'anéantir, à la mort 
de chacun, tout ce qui lui a appartenu dans ce monde, les met dans la nécessité de trouver de nouveaux moyens d'existence.

L'habitude de la chasse et la nécessité de pouvoir se diriger, pendant leurs longues excursions, d'après le soleil et les étoiles, firent naître parmi les naturels de ces contrées quelques idées astronomiques. Ils transformèrent la partie du firmament qui leur était connue en un immense tableau représentant la chasse de l'Indien. Ainsi la voie lactée ne fut pas pour eux le chemin parcouru par la chèvre Amalthée, mais celui du vieil Indien chassant l'autruche. Les trois rois furent les boules (tapolec) qu'il jetait à cet oiseau, dont les pieds sont la croix du Sud, tandis que les taches australes qui accompagnent la voie lactée ne sont à leurs yeux que des amas de plumes formés par le chasseur. Ces allégories n'ont pas détourné les indigènes du but pratique de l'astronomie : c'est ainsi qu'ils ont adopté une division du temps très-rationnelle; ils ont partagé l'année en douze mois; et au printemps, quand les plantes recommencent à pousser, ils rectifient et règlent les jours supplémentaires. Ce qui prouve que les nations qui habitent l'extrémité sud du continent américain sont loin d'être dépourvues d'intelligence. 


\section{CHILI.}

Ce pays est borné au nord par la Bolivie dont il est séparé par le Rio Salado et le grand désert d'Aracama; il confine au sud avec la Patagonie, et occupe le revers occidental des Andes entre $23^{\circ}$ et $4^{\circ}$ de latitude australe.

L'origine du mot Chili est expliquée de trois manières : selon Zarate, il vient de chil, qui en péruvien signifie froid; d'autres le font dériver du mot quile, dénomination indienne du Rio Quillota, un des principaux fleuves du pays; enfin, d'après l'opinion des indigènes et du savant Molina, il vient du nom de certains oiseaux de la famille des grives, très-communs dans cette contrée, et dont le cri ressemble au son du mot tchil ou tchili (turdus ater, turdus thilius). Les Espagnols prononcent Tchilé.

Le Chili fut longtemps uné province du Pérou, sous le règne des Incas. Quelques années après la conquête de ce dernier État par les Espagnols, sous les ordres de Pizarre, c'est-àdire vers 1536, Almagro fut envoyé pour réduire les provinces méridionales. La plus grande partie de son monde périt; cependant Almagro traversa le Chili, et s'empara de l'or qui y abondait. L'Araucanie seule résista. Pierre Valdivia entreprit en 1540 une nouvelle expédition, soumit le Chili non sans difficulté, et fonda l'année suivante la ville de Santiago; en 1550, il bâtit la Concepcion, pénétra aussi dans l'Araucanie, y construisit des forts, et fonda la ville qui a reçu et conserve son nom. Cependant les Araucaniens détruisirent les forts, Valdivia fut battu, fait prisonnier, et mis à mort. Ils restèrent libres, et sebattirent souvent contre les Espagnols. Pendant la paix, ils trafiquaient avec les créoles du Chili, auxquels ils vendaient des chevaux et des lainages grossiers. Les jésuites furent assez adroits pour former dans l'Araucanie deux missions. L'árchipel de Chiloé fut découvert, en 1558, par don Garcia de Mendoza. Le poëte Ercilla, qui a chanté les guerres de l'Araucanie, faisait partie de l'expédition qui prit possession de ces îles au nom de l'Espagne. Cette puissance annexa le Chili à la vice-royauté du Pérou. Elle bâtit partout des églises et des couvents en les dotant richement. Elle distribua des terres aux conquérants, exploita des mines, et fit au reste très-peu de chose pour la prospérité du pays. Avant la dernière révolution, il n'y avait pas d'imprimerie dans tout le Chili; les habitants recevaient de Lima des livres de dévotion ou d'instruction. Lorsqu'au commencement de ce siècle la puissance espagnole, déchirée par les guerres, tomba en décadence, le Chili, à l'exemple d'autres colonies, s'occupa en 1810 de son affranchissement. Une armée de Buenos-Ayres vint au secours du parti des indépendants. Le vice-roi du Pérou rétablit pour quelque temps l'autorité de l'Espagne; mais la bataille de Maypo gagnée par les républicains en avril 1818, brisa son pouvoir. Les vainqueurs nommèrent un directeur suprême, et celui-ci donna, en 1818, au Chili une constitution provisoire. Elle fut abolie en 1822, et l'année suivante, les députés de la nation formèrent un congrès pour dresser un nouvel acte constitutionnel qui a 
été promulgué depuis, et d'après lequel le Chili forme une république représentée par un congrès.

Le tableau ci-contre présente la statistique de l'État que nous décrivons :

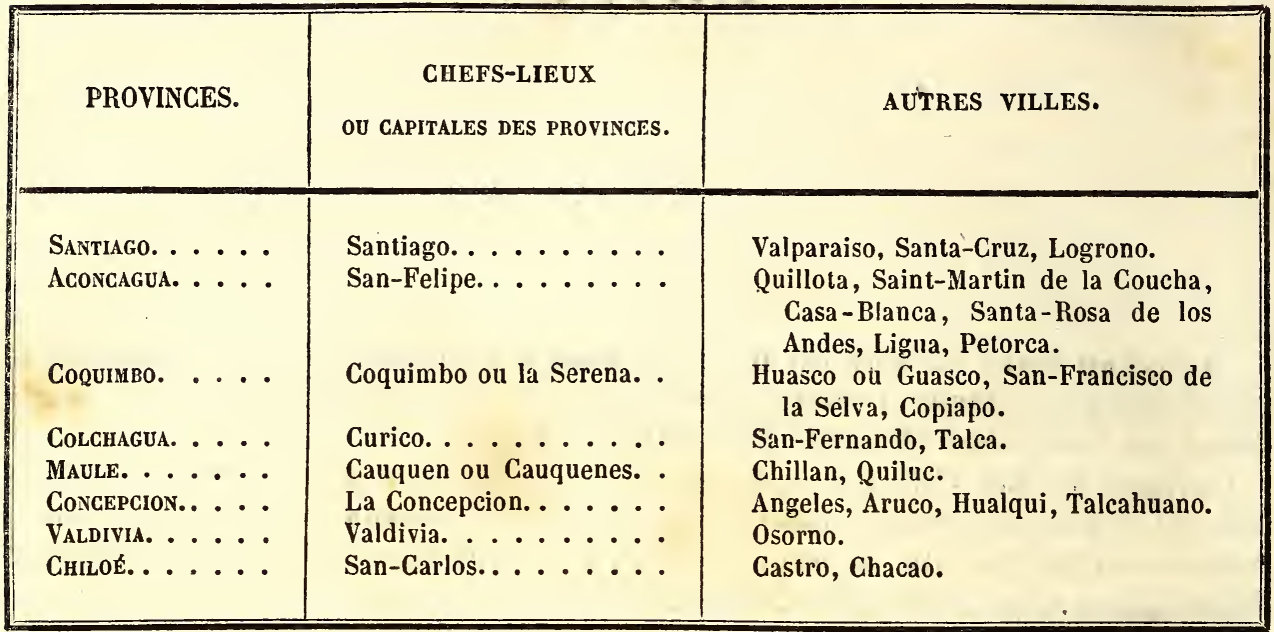

La population du Chili est de 1,500,000 âmes; l'armée consiste en 29,400 hommes dont 8,400 de troupes régulières, et le reste appartenant à la milice. La marine se compose d'une frégate et de cinq bâtiments inférieurs. La dette publique est de $36,000,000$ de francs; les revenus s'élèvent à $12,000,000$ de francs.

Le pouvoir exécutif de la république est confié à un président élu pour quatre ans, et le pouvoir législatif à un sénat de neuf membres nommés pour six anš, et à une chambre nationale composée de cinquante membres au moins et de deux cents au plus, ćlus pour huit ans et renouvelés par huitième chaque année. Un conseil d'État permanent est chargé de tous les projets de loi, de toutes les affaires importantes et de la nomination des ministres. Pour être électeur, il faut être citoyen, être âgé de vingt et un ans, posséder un immeuble de la valeur de mille francs, ou exercer une industrie exigeant un capital de deux mille cinq cents francs, ou bien être à la tête d'une fabrique, ou enfin avoir importé dans le pays une industrie, une invention dont l'utilité ait été reconnue et approuvée par le gouvernement.

Le Chili proprement dit, ou la partie basse de cetle contrée, forme deux divisions, dont la première s'étend, au nord, depuis le Pérou jusqu'au fleuve Biobio : c'est le Chili espagnol; la seconde partie commence au Biobio, va jusqu'à l'archipel de Chiloé, c'est-à-dire qu'elle est située entre $36^{\circ} 49^{\prime}$ et $41^{\circ}$ de latitude : c'est le Chili indien, ou partie indépendante.

Ce dernier pays est habité par les Araucans ou Molouches '. Ce sont les fils aînés de la famille chilienne; jamais on n'a pu les dompter; ils sont le seul peuple qui ait repoussé l'invasion en opposant la force à la force. Les Espagnols avaient élevé des

1 Le mot Araucans, tiré de la langue chilienne, équivaut aujourd'hui, chez les Espagnols, à une injure; il est synonyme de brigands, hommes féroces, etc. Quant à la dénomination de Molouches, comme ils s'appellent entre eux, elle signifie guerriers. Ces Indiens se donnent encore le nom d'Aucas, qui veut dire hommes libres, et traitent les Espagnols de chiapi, ou mauvais soldats, et de huinca, ou assassins. 
villes importantes sur leur territoire; telles furent: Villarica, Impériale, Canette, Angol, Chillan, Osorno et Valdivia. Ces deux dernières sont les seules que possèdent encore la république. Parmi les autres, il en est dont il serait difficile de retrouver même l'emplacement : les trois premières que nous avons nommées sont de ce nombre.

Les Araucans sont d'une taille élevée, mais de formes peu agréables; ils ont le visage aplati, les pommettes saillantes comme les Mongols, le regard féroce, méfiant; le teint cuivré ou brun rougeâtre, le nez court, la bouche fort grande, le menton épilé; ils portent très-longs leurs cheveux noirs; ils sont robustes, adroits et excellents cavaliers; les premiers ils se sont adonnés à dompter ces chevaux espagnols dont la race sauvage s'était prodigieusement augmentée depuis la conquête. Une simple lanière de cuir leur sert de bride, une peau ou un morceau d'étoffe remplace la selle; quelques-uns cepen. dant, mais en très-petit nombre, se servent d'étriers de bois et de selles grossières, assez semblables à celles dont on fait usage pour les mulets. Leurs armes de guerre consistent en lances, flèches, massues et laços. Les Espagnols leur ont procuré quelques armes à feu, mais ils en font rarement usage; c'est la lance qu'ils préfèrent à tout; aussi s'en servent-ils avec une adresse prodigieuse. Cette arme, dont le fer a quelquefois deux pieds de longueur, est emmanchée d'une longue tige de bambou. Ils manient le laço avec la même habileté, le faisant tournoyer sur leur tête jusqu'à ce qu'ils aient jugé le moment favorable pour lancer les terribles bolas, et arrêter ainsi dans sa fuite l'ennemi qui se croyait à l'abri de leurs atteintes. Les Araucans, ainsi que les Llaneros de la Colombie, combattent sans ordre et sans tactique, à la manière des Cosaques. Ils se suspendent à la crinière de leur cheval, se cachent derrière son flanc, et, la lance en arrêt, ils se précipitent sur leurs adversaires, et les frappent avant de se montrer. Leurs armes défensives consistent en cuirasses, casques de cuir et boucliers.

Le gouvernement des Araucans est celui d'une aristocratie militaire. Les emplois y sont héréditaires de mâle en mâle, mais cependant par élection et non par ordre de primogéniture. Le pays, divisé en tétrarchies, appelées uthal-mapus, est gouverné par des toqués ou caciques. Les tétrarchies sont les suivantes : $1^{\circ}$ le pays de la mer, Languen-Mapu; $2^{\circ}$ le pays de la plaine, Lelbun-Mapu; $3^{\circ}$ la basse cordilière, Mapire-Mapu; $4^{\circ}$ la cordilière, Pire-Mapu. Ces gouveruements sont autant de zones parallèles avec la mer d'un côté, la cordilière de l'autre, et à peu près égales entre elles. Chacune d'elles embrasse cinq provinces ou allarégues, et chaque province neuf districts ou régues. Les gouverneurs des cinq provinces d'une tétrarchie prennent le titre de apo-ulmènes, et les chefs de districts celui d'ulmènes. On voit que ce mot indique à la fois un pouvoir spirituel et une autorité temporelle; dans les cieux, les ulmènes sont les divinités bienfaisantes; sur la terre, ce sont des hommes revêtus du pouvoir. La marque distinctive de l'autorité des toqués est une hache de porphyre ou autre pierre; les apo-ulmènes portent un bâton surmonté d'une tête d'argent; un anneau du mème métal est enchâssé dans le milieu du bàton. Les simples ulmènes portent également cette marque d'honneur, mais sans anneau. Les divers fonctionnaires d'une tétrarchie forment le conseil simple ou yog, chargé de statuer sur les affaires civiles ou militaires qui ne concernent que la province. L'assemblée, composée des fonctionnaires de toutes les tétrarchies, constitue le grand conseil, appelé ciucaco ou butaco-yog. C'est là que se débattent les affaires qui intéressent la confédération, telles que les traités de paix, les déclarations de guerre, les alliances, etc.

Lorsque le grand conseil a résolu de faire la guerre, il envoie de côté et d'autre des messagers ou guerchénis, en porter la nouvelle. Alors les guerriers se rassemblent au son de la trompe, chacun apportant avec lui ses provisions et ses armes. Les lances, les piques, les dards, les flèches, les frondes, les massues hérissent la plaine. Les fantassins, 
namunılicos, s'organisent en régiments; les chevaux hennissent et caracolent, et les femmes courent gè et là afin de tout préparer pour le départ des guerriers. Bientôt le cacique paraît, tout rentre dans le silence et dans l'ordre, et la troupe, affamée de carnage, enthousiaste, se dirige à marche forcée vers le lieu désigné pour le rendez-vous général. Le commandement en chef est déféré à l'un des quatre toqués; mais il n'est cependant pas rare de le voir confié à un simple ulmène, quand celui-ci en est jugé plus digne. Ces expéditions militaires se font ordinairement avec tant de célérité, que l'ennemi n'a pas le temps de prendre ses mesures de défense. Autrefois les Araucans ne faisaient pas de prisonniers; mais aujourd'hui la coutume barbare de les immoler est à peu près entièrement éteinte, et peut-être doit-on cette circonstance à l'introduction qui s'est opérée parmi eux d'une population métisse, provenant de l'union des indigènes purs avec les femmes espagnoles qu'ils ont enlevées. Des couvents de religieuses ont plus d'une fois servi de motifs à la guerre. La passion de ces Indiens pour les femmes blanches est si grande, qu'on n'a pas d'exemple de prisonnières rendues à leur famille. Les hommes faits prisonniers sont emmenés dans l'intérieur du pays et réduits à l'esclavage. L'étendard des Araucans porte une étoile blanche sur champ d'azur.

Le mari a droit de vie et de mort sur sa femme, et le père sur ses enfants ; la société n'en exige aucun compte. Le thaulonco est la peine du talion, qu'ils infligent dans les circonstances les moins graves; l'homicide prémédité, la trahison, l'adultère, le vol et la sorcellerie sont punis de mort, mais le coupable a la faculté de racheter sa vie en transigeant avec la famille qu'il a offensée.

La polygamie est permise chez les Indieus de l'Araucanie; mais la première femme est seule considérée comme épouse en titre; les autres habitent séparément, et chacune a sa cabane; aussi compte-t-on les femmes d'un guerrier par le nombre de ses cabanes. Quand un Araucan veut se marier, il rassemble ses parents et ses amis pour enlever sa fiancée, et, à cette occasion, les deux familles se livrent des combats de convention, qui dégénèrent quelquefois en mêlées sanglantes.

La condition des femmes est des plus malheureuses; ce sont elles qui sont chargées des soins les plus pénibles, non-seulement dans l'intérieur du ménage, mais encore dans les travaux de l'agriculture, à la chasse et mème à la guerre. Partout, elles remplissent un rôle de servitude cruel et humiliant; ce sont elles qui pansent les chevaux, nettoient les armes, portent les fardeaux et préparent les aliments, pendant que leurs maris se promènent, fument, ou se reposent. Le mème usage existe d'ailleurs chez bien d'autres nations sauvages, et il est à remarquer que, parmi celles où cette coutume n'est pas établie, l'infériorité de la femme diminue d'autant plus que la civilisation tend à s'améliorer.

Lorsqu'un guerrier vient à mourir, ses amis et ses parents enlèvent son corps processionnellement; les femmes se joignent au cortége et chantent les hauts faits d'armes de celui qui n'est plus. Le convoi funèbre se dirige vers l'eltun, ou cimetière de famille, dans lequel une fosse a élé préparée. Le guerrier mort est mis en terre avec ses armes, ses habits de luxe, des provisions de bouche, et quelques objets de valeur destinés à payer le prix du passage à la vieille Tempu-Laggi, le nocher des enfers, qui conduira l'àme au séjour de l'immortalité. Si c'est une femme qui a succombé, on enferme avec elle des ustensiles de ménage ou autres objets à son usage; puis les assistants comblent la fosse, élèvent au-dessus un tertre en pierres, et l'arrosent de chicha, leur boisson de prédilection. Les jeux commencent ensuite, et la cérémonie se termine par un festin auquel tous les parents et amis du défunt prennent part. Les Indiens araucaniens appellent celte cérémonie le curica-huin, ou divertissement noir. Cette coutume res- 
semble beaucoup aux jeux funèbres de la Grèce; mais on a pu s'apercevoir déjà que les Molouches ont plus d'un point de ressemblance avec les Spartiates : leurs vices les plus détestables ne sont en quelque sorte que l'exagération de la vertu.

Les Araucans ne se sont jamais élevés au mème degré de civilisation que les Mexicains, les Péruviens et les Muyscas. Cependant on ne saurait nier que, de toutes les nations indiennes qui vivent encore indépendantes dans l'Amérique du sud, il n'en est pas d'aussi avancée dans les voies de la civilisation. La passion de ce peuple pour la guerre a imprimé à ses mœurs un caractère de cruauté et de violence qui le rend l'effroi de ses voisins; mais il a plusieurs qualités estimables, parmi lesquelles il faut surtout remarquer la bonne foi dans les traités, les devoirs de l'hospitalité, le respect du serment et l'urbanité pour les étrangers qui voyagent sur son territoire avec la permission des chefs. Quand un marchand étranger veut trafiquer avec les Araucans, il se rend directement chez l'ulmène, et s'assied devant lui sans prendre la parole; ce qui serait une infraction à l'étiquette et aux habitudes de ces peuples. Après un instant de silence, le chef lui dit : Es-tu venu? A quoi le marchand répond : Je suis venu.-E - $\iota$ que m'apportes-tu?-Du vin, des étoffes, etc. Ici l'étranger fait le détail des présents qu'il destine à l'ulmène. La cérémonie terminée, le chef fait publier dans son district qu'un marchand étranger est arrivé, et qu'il apporte avec lui des objets d'échange. Aussitôt chacun accourt, choisit ce qui lui convient, et retourne à ses occupations. Au bout de quelques jours, quand le marchand veut partir, l'ulmène fait avertir ses administrés qu'ils aient à venir payer le prix de la marchandise qu'ils ont choisie, et chacun alors, avec une exactitude religieuse, vient remettre à l'étranger la valeur en nature des articles qu'il a achetés. Ce commerce d'échange consiste, pour l'importation, en étoffes européennes, en couteaux, haches, boutons, colliers, bracelets, etc., et, pour l'exporlation, en ponchos, bœufs, chèvres, moutons, etc.

Plusieurs voyageurs ont dit que les Araucans avaient des notions en géométrie, qu'ils cultivaient la poésie, la médecine et la rhétorique. La vérité est qu'ils ont dans leur langue des mots pour exprimer la ligne, le point, l'angle, le cube, le cône et la sphère; que les poëtes, appelés gempir ou seigneurs de la parole, improvisent des chansons guerrières; que leurs amfibes, décorés par les Espagnols du nom de médecins, connaissent assez bien les qualités de certaines plantes médicinales, et qu'ils ont enfin des chirurgiens, ou gularves, habiles à guérir les plaies et les blessures; mais on peut faire ces mêmes observations chez d'autres peuples dont l'ignorance n'est pas mise en question, et l'on ne saurait voir en cela qu'une simple tendance vers le progrès. Du reste, les Araucans ne connaissent ni l'art d'écrire, ni celui de la lecture. C'est á l'aide de nœuds, semblables aux quipos péruviens, qu'ils conservent leurs traditions historiques et leurs souvenirs domestiques. La connaissance des quipos passe chez eux pour une science importante, et ce n'est souvent qu’à son lit de mort qu'un père dévoile à son fils les mystères des nœuds de famille. A ce sujet, nous citerons le fait suivant, rapporté par W. B. Stevenson :

an l'année 1792, on arrèta à Valdivia des Indiens soupçonnés de tramer une conspiration. L'un d'eux, nommé Marican, avoua qu'un des principaux instigateurs du complot lui avait envoyé une pièce de bois longue d'environ un quart de verge; que ce bois avait été fendu, et qu'on y avait trouvé, dedans, un doigt humain. Ce doigt était entouré d'un cordon, au bout duquel se trouvait une frange de laine rouge, bleue, blanche et noire. Sur la laine noire on remarquait quatre nœuds, ce qui indiquait que le porteur de ce message était parti de Paqui-Pulli le quatrième jour après la pleine lune. Sur la laine blanche on voyait dix nœuds, e'est-à-dire que dix jours après le départ du messager la révolte éclaterait. Si l'Indien à qui le message était adressé con- 
sentait à prendre part à cet événement, il devait faire un nœud sur la laine rouge; dans le cas contraire, il en devait faire un sur la laine bleue et la rouge réunies ensemble, afin que les conjurés pussent connaître, au retour du chasqui ou héraut, le nombre d'amis sur lesquels ils pouvaient compter.

Le salut de ces Indiens consiste dans les mots marry-marry; et lorsqu'un chef envoie le marry-marry à un Espagnol, celui-ci peut compter sur son amitié, et même sur son alliance en temps de guerre.

Les femmes indiennes fréquentent les villes espagnoles voisines de leur territoire; elles y apportent des fruits, des légumes, de la volaille et du poisson qu'elles échangent contre d'autres marchandises à leur usage, et principalement contre le sel, dont la plupart des tribus manquent entièrement.

Les jeunes gens, désignés sous le nom de mosotones, fréquentent également les mêmes villes, en temps de paix, dans l'espoir d'y rencontrer des étrangers qui les prendront pour guides, moyennant un salaire convenu. Ces jeunes gens sont des conducteurs fidèles et intelligents; ils sont surtout utiles pour un voyage dans les montagnes, ou pour le passage des rivières à ponts suspendus.

Les Araucans cultivent le blé, le maïs et autres céréales, quelques plantes potagères et plusieurs arbres utiles. Les hommes et les femmes bêchent la terre; celles-ci seules ensemencent et récoltent. La principale occupation des premiers, en temps de paix, est de courir, le laço à la main, après les chevaux et les taureaux sauvages. Comme nous l'avons déjà dit, les chevaux sont issus de ces beaux coursiers castillans que les Espagnols introduisirent dans le Nouveau-Monde. Ils y ont multiplié considérablement, et n'ont rien perdu ni de leur beauté ni de leurs qualités; mais on remarque une vieillesse plus précoce chez ceux que les Araucans ont domptés. Les soins qu'ils donnent à leurs grands troupeaux de bœufs prennent encore une large part de l'existence des Indiens. Les intrépides Araucans, les Guaycurus, les Pehuenches, les Huilliches, et bien d'autres encore, montés sur de rapides chevaux, armés de longues lances, et poussant devant eux de nombreux troupeaux de bœufs, ressemblent plus aux Tatares ou aux Arabes qu'à leurs propres ancêtres, dont l'indolente existence végétait sur les bords des rivières ou se traînait sous les hautes graminées des Pampas.

Les femmes des Araucans se livrent avec quelques succès à la fabrication des étoffes. Les ponchos, qui forment la principale pièce du vêtement des guerriers, sont leur ouvrage. Le poncho est un morceau d'étoffe de laine quadrilatère, de trois aunes de long sur deux de large, percé au centre d'une ouverture pour y passer la tête, et destiné à couvrir les épaules et le haut du corps jusqu'aux hanches. Ce vêtement, qui peut servir de manteau pendant le jour et de couverture pendant la nuit, a maintenant été adopté dans tout le Chili. Les ponchos araucaniens, tissus avec la laine du guanaco, le chamois des Alpes, sont très-estimés. La fabrication d'un poncho de luxe occupe une femme pendant près de deux ans, et vaut cent dollars (environ 500 francs). Il est ordirement bleu-turquoise; c'est la couleur favorite des Chiliens, qui l'extraient de diverses substances végétales. Les autres couleurs sont le jaune, le vert et le rouge. Cette nation se livre encore à la fabrication d'une grossière poterie, et à celle des armes. Avanl l'arrivée des Européens, les Indiens se servaient, au lieu de fer, de pierres dures ou d'une sorte de bronze natif, appelé campanile par les Espagnols, mélange de zinc, de cuivre et d'antimoine. Cependant ils connaissaient l'art d'extraire l'or et l'argent du minerai qu'ils faisaient fondre dans des vases d'argile au moyen d'un courant d'air. l.es Araucans connaissent encore l'art de se servir du coton pour tisser de la toile et des hamacs, ouvrages grossiers, il est vrai, mais qui prouvent que ce peuple a déjà fait plus d'un pas dans la voie de la civilisation. La chasse et la guerre étant l'occupation 
favorite des hommes, la navigation et la pêche tiennent peu de place dans l'histoire de leur industrie. Ils font usage sur les côtes et les rivières d'une sorte d'embarcation appelée balsa. Elle consiste en deux peaux de phoque cousues avec soin et ballonnées au moyen de l'air atmosphérique, de manière à former deux énormes vessies qui conservent encore assez bien la forme de l'animal. Ces deux ballons supportent des bandes transversales, recouvertes de peaux de bêtes fauves et de branches d'arbre. Le navigateur s'assied sur ce pont en tâchant de maintenir en parfait équilibre sa frêle embarcation.

Le territoire araucan est une vaste contrée aussi riche que fertile, et bien propre à éveiller la convoitise des Européens. Arauco est la seule ville du territoire indépendant; partout ailleurs, les Araucans ne possèdent que des villages ou des campements provisoires. Arauco est entourée de murs; mais sa principale défense consiste dans une fortification peu importante, élevée sur une colline, au pied de laquelle la ville est bâtie. Du temps que cette ville appartenait aux Espagnols, la population n'excédait pas 400 âmes. Les maisons, couvertes en chaume, sont divisées intérieurement en plusieurs cases, où l'on trouve quelques meubles qui rappellent le voisinage de la civilisation. Dans les autres résidences, les habitations indiennes ne sont que des cabanes grossières ou des tentes en peaux disposées circulairement. La place du milieu est réservée au pacage des bestiaux; et dès que ceux-ci n'y trouvent plus une nourriture suffisante, la peuplade enlève ces tentes et va camper ailleurs.

Les Araucans mangent peu d'herbages et de fruits; leur nourriture habituelle se compose de viande de mouton ou de bœuf, de charque (viande broyée), de poisson, de volaille, et de milcow, pâte faite avec des citrouilles ou des pommes de terre pétries dans du lait. Ils assaisonnent leurs mets avec du piment et du poivre. Dans leurs expéditions, ils emporient de la viande desséchée au soleil et coupée en minces lanières, et du maïs. Ils mangent également dans ces circonstances de la chair de cheval et de mulet. Le cici et la chicha sont des boissons faites avec du maïs ou des fruits fermentés. La préparation de la chicha est réservée aux vieilles femmes, qui trilurent et mâchent le maïs, leur salive ayant une propriété convenable à cette opération. Avant l'arrivée des Espagnols, les Indiens du Chili ne connaissaient ni le blé, ni l'orge, ni l'avoine, ni les légumes, ni les fruits qu'ils cultivent aujourd'hui avec succès. Ils aiment passionnément l'eau-de-vie et les liqueurs fortes qu'ils se procurent à Valdivia et à la Concepcion.

Quoique farouche et sérieux, ce peuple aime la danse avec passion. La sapátera, qui est leur danse favorite, offre des allusions éroliques telles, qu'il semble qu'une femme ne saurait les tolérer sans un excès d'impudence, ou sans une grande ingénuilé.

Au poncho, qui est la partie essentielle des vêtements d'un Araucan, il faut joindre une veste qui descend jusqu'à la ceinture, une culotle courte, une ceinture de cuir, un chapeau en pain de sucre, des sandales de peau appelées ojoles, et quelquefois une paire d'éperons. Les femmes vont la tête et les pieds nus; elles portent des robes longues, de couleur bleue, ouvertes sur le côté et sans manches. Un manteau de la mème couleur, retenu sur les épaules par des agrafes d'argent; des pendants et des bracelets de même métal, complètent à peu près leur costume. Leurs cheveux, qu'elles portent très-longs par derrière, sont tressés et coupés courts sur le front. Ces Indiens sont assez propres; ils se baignent souvent, et nettoient leurs cheveux avec l'écorce du quillay. Les hommes s'arrachent la barbe au moyen de pinces faites avec des coquilles.

Un grand nombre de tribus habitent le Chili; mais on n'en dit rien de remarquable. Quant aux Puelches et aux Pampas, dont quelques peuplades errent sur le territoire chilien, nous en parlerons dans la description des provinces unies du Rio de la Plata. 
Quoique pleins de vivacité, d'enjouement, d'avidité pour les plaisirs, les Chrrrens sont, en général, insouciants, paresseux, et chérissent les procès et le jeu. Ces vices datent d'un temps où l'on pouvait penser que le travail des esclaves suppléerait à la nonchalance des hommes libres; cependant ils vont chaque jour en diminuant, et, selon toute apparence, les nouvelles institutions restitueront à ce peuple son énergie primitive : alors seulement ils apprécieront toute la richesse du sol qu'ils occupent.

Aujourd'hui, les bourgades de la campagne ont un aspect déplorable : à côté de maisons de chétive apparence, construites en boue, on voit des huttes en bambous qui ne sauraient même garantir leurs misérables propriétaires de l'intempérie des saisons. Étendue sur le plancher intérieur, une natte sert de lit commun à toute une famille.

Depuis l'établissement des Espagnols au Chili, la race européenne s'est mêlée à la race indienne, el de ce mélange est née une race intermédiaire qui constitue aujourd'hui une partie considérable de la population du pays, et dans laquelle l'orgueil espagnol avait introduit les distinctions subtiles de demi-blanc, tiers, quart, huitième de blanc, suivant que les familles s'étaient mêlées avec les Indiens ou avec les blancs. On voit en effet au Chili toutes les teintes, depuis le rouge foncé jusqu'à l'incarnat du plus beau teint européen. Les esclaves africains ont introduit une autre race, la noire; elle est peu considérable, et heureusement l'esclavage cessera au Chili, en vertu d'une loi qui a affranchi les enfants des esclaves. Il en résulte que la population se compose de créoles, d'Européens, d'Indiens, de nègres, de mulàtres el de métis ou guassos.

Toutefois, le teint des Chiliens est, en général, légèrement basané; ils sont bien faits, de taille moyenne, robustes, adroits, excellents cavaliers. Élevés à l'école de la guerre, ils ont pour eux la bravoure, la sobriété, la patience, la résignation après la défaite; mais la victoire les rend cruels. Ils aiment avec toute la jalousie des Espagnols et toute l'ardeur des créoles. Les femmes sont généralement fort agréables; elles sont vives, légères, ardentes et crédules; elles ont été en butte aux sarcasmes les plus méchants de la part de quelques voyageurs ingrats. Les Chiliens ont fait de rapides progrès dans la voie de la civilisation, depuis leur indépendance; ils sont respectueux devant les vieillards, hospitaliers et polis. On est certain d'ètre bien reçu chez eux. Ils mellent un grand empressement à offrir à l'étranger qui les visite un siége, de la liqueur, de la limonade glacée et des fruits, qu'ils présentent de très-bon cœur.

Les jeux chevaleresques, de hasard, les combats de taureaux, les danses, etc., absorbent une grande partie de leur existence. Il est rare que dans les combats de taureaux ces animaux soient tués. Cependant, lorsque dans une circonstance solennelle on veut sacrifier un taureau, les torreadores s'attachent à le mettre en fureur et le poursuivent avec des perches de douze pieds de long, surmontées d'un instrument en forme de croissant, appelé lune. C'est au moyen de celte arme qu'ils arrêtent l'animal en lui coupant les jarrets avec une cruelle dextérité, et le jettent, sanglant, dans le milieu de l'arène, aux applaudissements de la multitude. Les élégantes viennent, dans ces occasions, étaler tout ce que leur garde-robe offre de plus riche; leurs ramadas ou loges sont de petits salóns de réception, convertis quelquefois en salles à manger. Dans le carnaval, elles y viennent masquées; les hommes fument le cigare et parient, dans des pièces voisines, à la rouge et noire, tandis que des joueurs de harpe, de tambour et de guitare font assaut d'énergie et de dextérité, le plus souvent aux dépens des oreilles de l'auditoire. Les chanteurs entonnent leurs airs sur un ton élevé, auxquels un étranger a de la peine à s'habituer; mais généralement ils ont la voix juste.

Parmi leurs danses nationales qui sont nombreuses, on cite, entre autres, la sapatera, le menuet, le quando, le pericon, et d'autres qui ressemblent à la tarantelle 


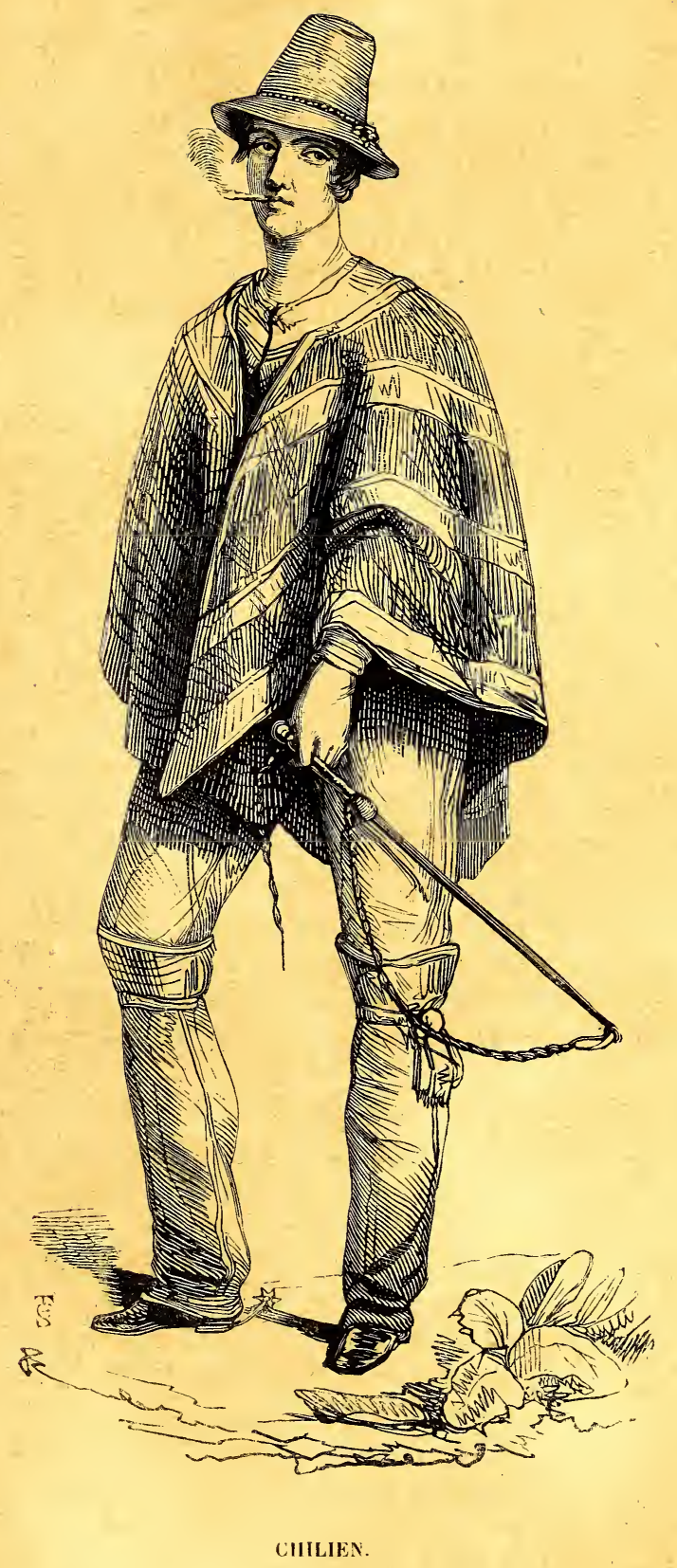



des Napolitains. Quelquefois, à un mouvement très-lent, triste et monotone, succède un air vif et animé, accompagné de coups de tambour et de chorus de voix. Les pieds des danseurs touchent la terre avec une extrême rapidité; ils se présentent leurs mouchoirs d'une façon affectueuse, mais à une certaine distance, et décrivent des ronds autour d'un mât surmonté de banderoles ou de fleurs. Les orgies du carnaval des Chiliens durent trois jours, pendant lesquels les grâces du sexe perdent de leurs charmes : les cheveux ẻpars, la figure barbouillée d'un mélange de terre, de farine, de noir de fumée, et même de bouse de vache, elles ressemblent à des furies qui courent les unes après les autres pour se jeter à la figure ce qu'elles trouvent sous leur main, en criant : Chaia. Le dernier jour on se rend à la campagne; et sur le gazon, à l'ombre du feuillage, on sert un modeste repas; point de nappes, point de serviettes, quelques couleaux et une ou deux fourchettes. Chacun se sert, et on dévore à qui mieux mieux. On verse le vin à rasade, et les femmes rivalisent avec les hommes, qui ne quittent le festin que lorsqu'ils n'ont plus rien à boire. Le repas fini, on se jelte réciproquement à la figure des sauces et la lie de vin; puis on recommence la chaia, et la fète se termine en se rendant sur le bord de l'eau, où les hommes s'emparent des demoiselles pour les y plonger......

La ciueca est leur jeu de prédilection. Le nombre des joueurs est indéterminé, et ils se divisent en deux troupes. Chacun est armé d'un bâton recourbé à son extrémité, qui lui sert à pousser une balle vers un but donné, tandis que le parti contraire cherche à l'en empêcher, et à faire passer sur son propre champ l'objet en litige.

Le jeu de los porotos n'exige que deux joueurs. Les porotos sont des fèves blanches teintes en noir d'un côté; il s'agit de les faire tomber, selon les conventions, sur la partie blanche ou sur la partie noire, en les faisant passer par un anneau adapté à un bâton planté en terre. Les deux adversaires sont nus jusqu’à la ceinture, et se frappent la poitrine avec force.

Les habitants de la campagne se livrent encore aux plaisirs de la danse et du jeu en le certaines occasions qui, partout ailleurs, sont accompagnées de deuil et de pleurs. Quand un enfant meurt avant l'âge de sept ans, ses parents, persuadés que son âme va droit au paradis, célèbrent cet heureux événement par une fête à laquelle concourent les voisins et les amis. La jeune victime, parée et couverte de fleurs, est placée sur un petit lit de parade entouré de flambeaux, dans une pièce où se réunissent les conviés, et ceux-ci passent la nuit à jouer, à danser, à rire et à boire en présence du cercueil !...

Les Chiliens ont adopté une grande partie des usages anglais. Les personnes riches ont des équipages, des gens à livrée, des habits de luxe, et se parent volontiers de titres nobiliaires.

Ils ont en outre les assemblées nocturnes appelées chinganas, uniquement consacrées aux divertissements. Là, ainsi que dans nos estaminets, les hommes fument et passent le temps à jouer et à boire. Les tertulias sont des réunions où la bonne société se livre aux plaisirs des jeux européens, de la danse et de la conversation.

Généralement l'éducation est fort négligée, surtout pour les femmes; mais il y a d'honorables exceptions.

Les habitants de Santiago se distinguent de ceux des autres villes du Chili par un plus grand degré de culture intellectuelle, et sont d'une amabilité charmante.

Les Guassos vivent dans la campagne; ils forment la partie la plus inculte de la population chilienne. Ce sont des métis issus de l'union des anciens colons espagnols et des Indiens indigènes.

Depuis plusieurs années, l'agriculture a fait au Chili de rapides progrès. Indépendamment du blé, l'orge et le maïs y sont cultivés avec succès. Le chanvre et le lin y 
réussissent bien. La vigne, l'olivier, la canne à sucre, les orangers, les citronniers et la plupart des arbres fruitiers de l'Europe donnent à peu près les mêmes produits que sur leurs terrains primitifs. Le vin est généralement sucré; dans certains districts on fait un vin muscat très-estimé.

Le cheval a été importé au Chili par les Européens, ainsi que l'âne, le bœuf, le mouton, la chèvre et divers autres animaux domestiques. Il n'est pas rare d'y voir des troupeaux de dix à douze mille têtes. Les chevaux ne le cèdent point, pour l'apparence, aux plus beaux andalous. Les mulets et les ânes y ont acquis un développement supérieur à celui de la race primitive. Les bœufs, et généralement les bêtes à cornes, sont de la plus grande taille.

Les articles du commerce d'exportation sont : les métaux, le blé, le vin, les laines, le suif, la graisse, les bois de construction, les cordages, les fruits, les légumes, la viande sèche, et autres. L'exportation de l'or ou de l'argent en lingots est prohibée. Ceux d'importation sont : les étoffes d'Europe, les articles de modes, la quincaillerie, le coton, le riz, le sucre, etc.

Les ports du Chili sont ouverts aux navires de toutes les nations neutres et amies.

Récemment quelques manufactures se sont établies au Chili, telles que des papeteries, des fabriques d'étoffes, de flanelle et de gros draps, etc. De nombreuses imprimeries ont succédé à celles qui, la première, fut introduite au Chili en 1811.

Il n'y a au Chili que trois routes praticables pour les voitures; la première est celle qui de Santiago mène à Valparaiso. La seconde, également ouverte entre ces deux villes, passe à Mélepilla. La troisième, enfin, conduit de Santiago à la Concepcion.

Le costume le plus remarquable est celui des habitants de la Concepcion. Les hommes ajoutent à l'habit européen un élégant poncho ou un riche manteau. Les femmes portent un corsage très-orné ; leur jupon plissé, de flanelle aux vives couleurs, de velours noir ou de brocart, est supporté par un large panier. Les dames couvrent leur tête d'une pièce de flanelle, ou quelquefois d'un chapeau assez semblable à celui des hommes; mais le plus souvent elles vont nu-tête, pour étaler les longues tresses de leurs cheveux. Ce riche habillement est complété par des rosaires, des bagues et des bijoux de toutes les formes. Dans les autres parlies de la république, le costume des hommes appartenant à la classe aisée est généralement anglais ou français, à l'exception du poncho. Celui des dames tient à la fois de l'européen et du péruvien; elles portent de petits ponchos d'un travail exquis, des chapeaux ornés de plumes, des paniers de petite dimension, et des robes de couleurs variées.

Le costume des Guassos se rapproche beaucoup de celui des Araucans. Ils ont des guêtres de serge et des éperons d'une grandeur démesurée; on en voit même qui portent l'éperon sans chaussure. 


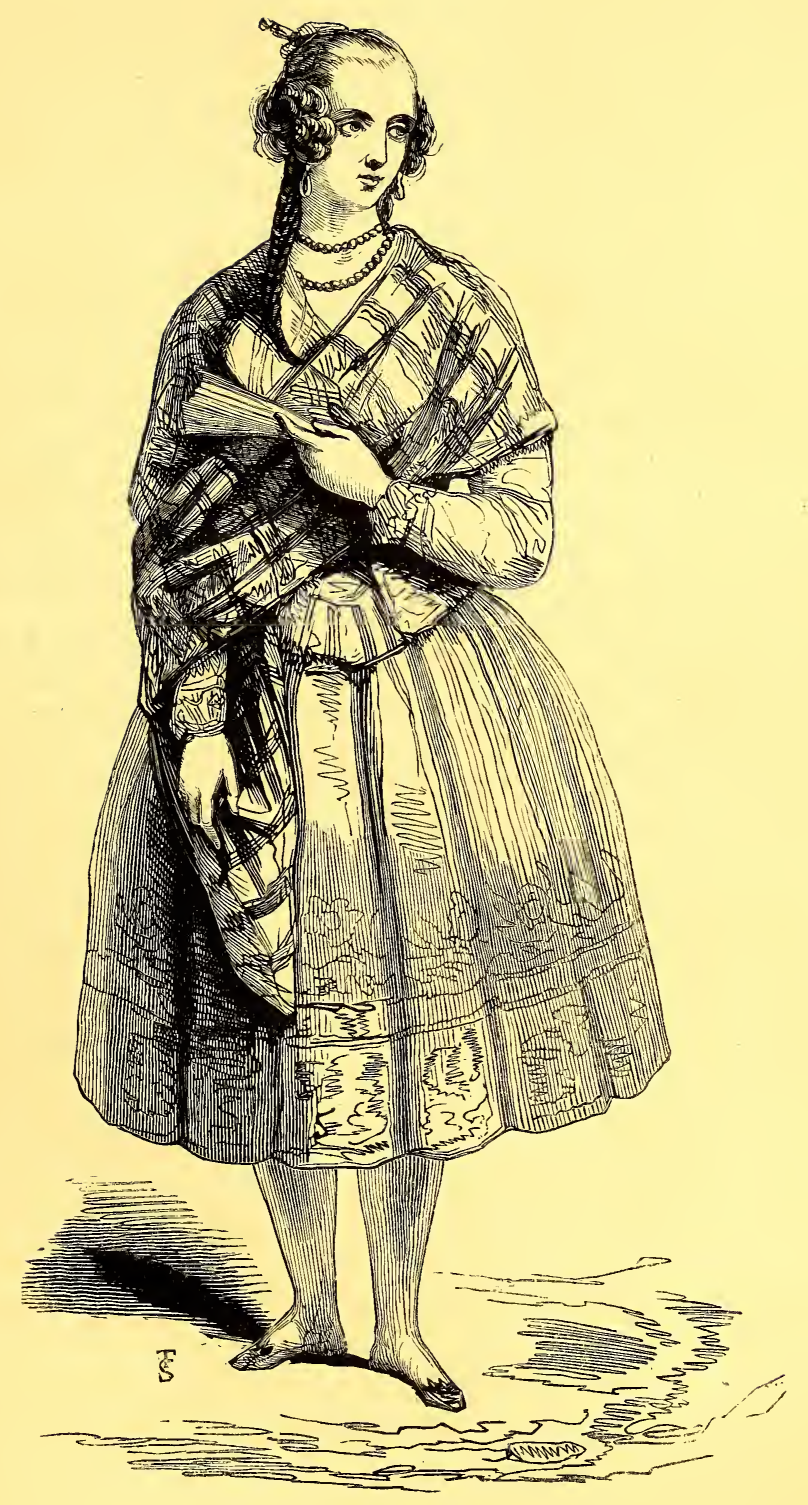

JEUNE FILLE DE L'IIE DE LA CONCEPTION. 



\title{
RÉPUBLIQUE ARGENTINE,
}

\author{
OU DE BUENOS - AYRES.
}

Ce pays confine au sud à l'océan Atlantique et à la Patagonie, à l'ouest à la cordilière des Andes qui le sépare du Chili, au nord à la Bolivie, à l'est au Paraguay et à l'Uruguay.

Découvert en 1515 par Jean Dias de Solis, il dépendit d'abord du Pérou; mais en 1778 il fut érigé en vice-royauté par l'Espagne. A l'époque où toutes les colonies espagnoles se levèrent pour conquérir leur indépendance, celle de Buenos-Ayres fut affranchie l'une des premières. Ce fut en 1810 qu'elle se proclama libre; mais le gouvernement de ce pays n'a pu acquérir cette stabilité salutaire si nécessaire à la prospérité des États. En 1815̆, il parut se constituer définitivement : le Buenos-Ayres prit le titre de Provinces-Unies du Rio de la Plata, puis celui de République Argentine; enfin, il s'est depuis peu organisé en une confédération de quatorze États, dont le nombre et les limites ne sont peut-être encore que provisoires. Pendant ces divers changements, la furme du gouvernement a constamment été mise en question, et si, ce qui n'est pas impossible, le Monte-Video et le Paraguay se réunissaient au Buenos-Ayres, de nouvelles modifications s'introduiraient dans la constitution de celte grande confédération.

La convention préliminaire à un traité de commerce et d'amitié entre Buenos-Ayres et la France, a été signée le 15 mai 1834 par M. Mendeville, consul général français, et par M. le général Guido, commissaire du gouvernement argentin. On altend la ratification de la chambre des députés de la république; aussitôt qu'elle sera oblenue, la convention sera soumise à la ratification du gouvernement français. On assure que la population française et son commerce, en outre de toutes les garanties désirables, ont obtenu, par cette convention préliminaire, les avantages dont jouissaient les nations qui les premières reconnurent officiellement l'indépendance de Buenos-Ayres. Malheureusement, on sait que la présentation de ce traité a excité la plus vive opposition dans le sénat argentin, dont les dispositions sont fort hostiles à la France, dispositions qu'on attribue en France aux intrigues des agents anglais.

Buenos-Ayres, dans la province de ce nom, est la capitale de la république. La population, qu'on pourrait évaluer à 90,000 âmes en y comprenant les étrangers, est partagée en diverses classes. D'abord vient celle des commerçants, qu'on accuse d'ètre, en général, étrangers aux connaissances pratiques indispensables à leur profession, et ne se laissant guider sous ce rapport que par la routine. La seconde classe des habitants de Buenos-Ayres se compose des propriétaires de terres et de maisons, la plupart créoles. La troisième classe comprend les artisans, tels que les maçons, les charpentiers, les tailleurs, qui deviennent rarement riches, quoique travaillant beaucoup et recevant de gros salaires. Les portefaix constituent un corps nombreux; ils se tiennent dans les rues, 
prêts à charger et décharger les charrettes et à porter les fardeaux; mais ils sont si paresseux et si débauchés, qu'on ne peut jamais compter sur eux. Les fonctionnaires publics forment une quatrième classe; les Espagnols européens n'occupent plus les places du gouvernement; depuis l'émancipation toutes les fonctions publiques sont exercées par les indigènes. La cinquième classe est celle des hommes qui composent l'armée. La sixième classe, enfin, se compose des ecclésiastiques, entre lesquels il faut bien distinguer les séculiers d'un reste de moines, dont la crasse ignorance et la grossière superstition ne servent qu'à troubler les esprits faibles et à tourmenter les honnêtes gens.

En général, la société a ses charmes à Buenos-Ayres. Les tertulias, ou soirées dansantes, sont extrêmement agréables, grâce à la gaieté naturelle des portegnas ou jeunes filles, à l'excessive mobilité de leur imagination et à la tournure de leur esprit. En entrant, vous saluez la maîtresse de la maison, et c'est la seule cérémonie à laquelle vous soyez astreint; vous pouvez vous retirer sans aucune formalité, de sorte qu'il ne tient qu'à vous de visiter ainsi une douzaine de tertulias dans le cours d'une soirée. Les manières et la conversation des dames sont très-franches et très-gracieuses. Les attentions délicates qu'elles témoignent aux étrangers les ont fait quelquefois accuser faussement d'un excès de liberté, accusation qui les a déterminées à recevoir moins facilement les étrangers dans leur intimité. Cet abandon sied bien cependant à ces fières et piquantes portegnas, à la taille élégante et noble, qui ne pardonnent plus si facilement à un étranger sa gaucherie et son embarras à prendre le maté brûlant, ou à faire sa partie dans un grave menuet.

Les tailleurs, les marchands de modes, sont tous d'Angleterre ou de France. Les costumes sont surtout français pour l'un et pour l'autre sexe, et toujours dans le dernier goût, à quelques mois près; il faut bien leur donner au moins le lemps de la traversée. Les femmes portent le corsage à la Marie Stuart, robe en satin rose, garnie de fleurs, le collier et l'inséparable éventail... (L'éventail! espèce de sceptre que ne quitte jamais une portegna.) Toutes ont le plus joli pied qui se puisse voir, pressé sous des bas de soie blancs par un soulier de mème étoffe. Un ornement tout spécial distinguera toujours une portegna de toutes les femmes du monde; un ornement auquel elle tient presque autant qu'à la vie. Cet ornement, c'est un peigne immense, dessinant sur sa tête un grand éventail convexe, plus ou moins riche, plus ou moins orné, suivant son rang et sa fortune, mais qui la suit invariablement partout; seulement les accompagnements en diffèrent et varient selon les heures et les circonstances. Les dames de Buenos-Ayres paraissent aimer beaucoup, dans leurs ajustements, l'éclat et la variété des couleurs. Leur teint est ordinairement de la plus éclatante blancheur, et contraste avec l'ébène de leur belle chevelure. Leur nez est aquilin. Leur sourire est plein de douceur, et leurs grands yeux noirs, qui rendent si justement célèbres les dames espagnoles, ont une expression qu'on ne retrouve pas dans les climats septentrionaux. Elles se distinguent, enfin, par la grâce et la majesté de leur port. Les hommes ont aussi leurs avantages et leurs bonnes qualités. Ils sont braves, libéraux et désintéressés.

Les Mendozinos ou habitants de la ville de Mendoza, capitale de la province de ce nom, aiment la danse avec passion. On les accuse d'être fiers, bigots, fantasques; mais, par compensation, on leur reconnaît de la douceur et des sentiments de bienveillance envers leurs inférieurs de toute classe. Simples dans leurs manières, ils sont très-hospitaliers; et, quoique privés d'éducation et de lumières, ils montrent, même dans les classes les plus pauvres, un sens droit, un jugement sain et une franchise qui rendent aux étrangers leur commerce très-agréable.

Les Pampas, depuis 1535 jusqu'en 1794, disputèrent leur terrain aux fondateurs 


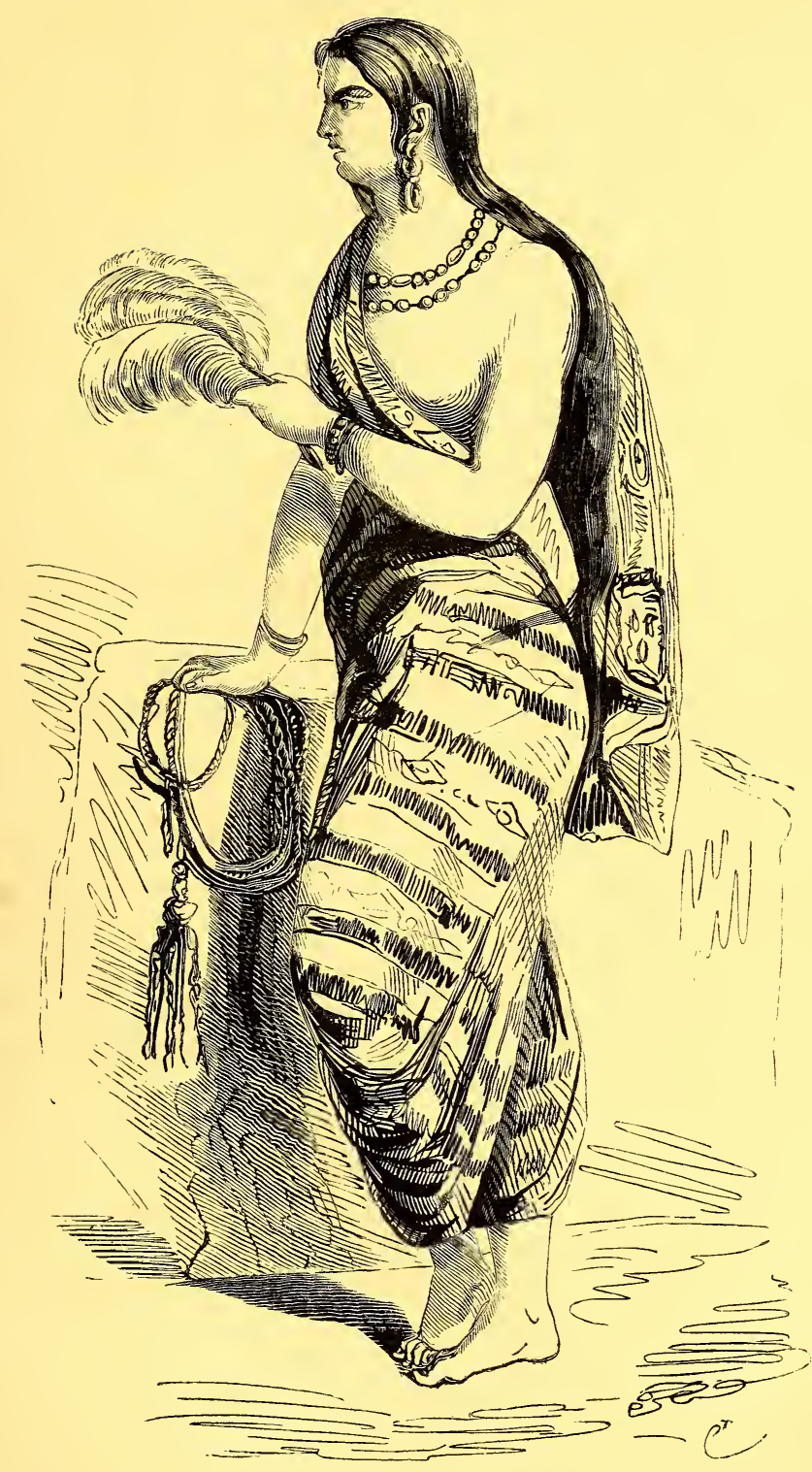

FEMME PAMPAS 




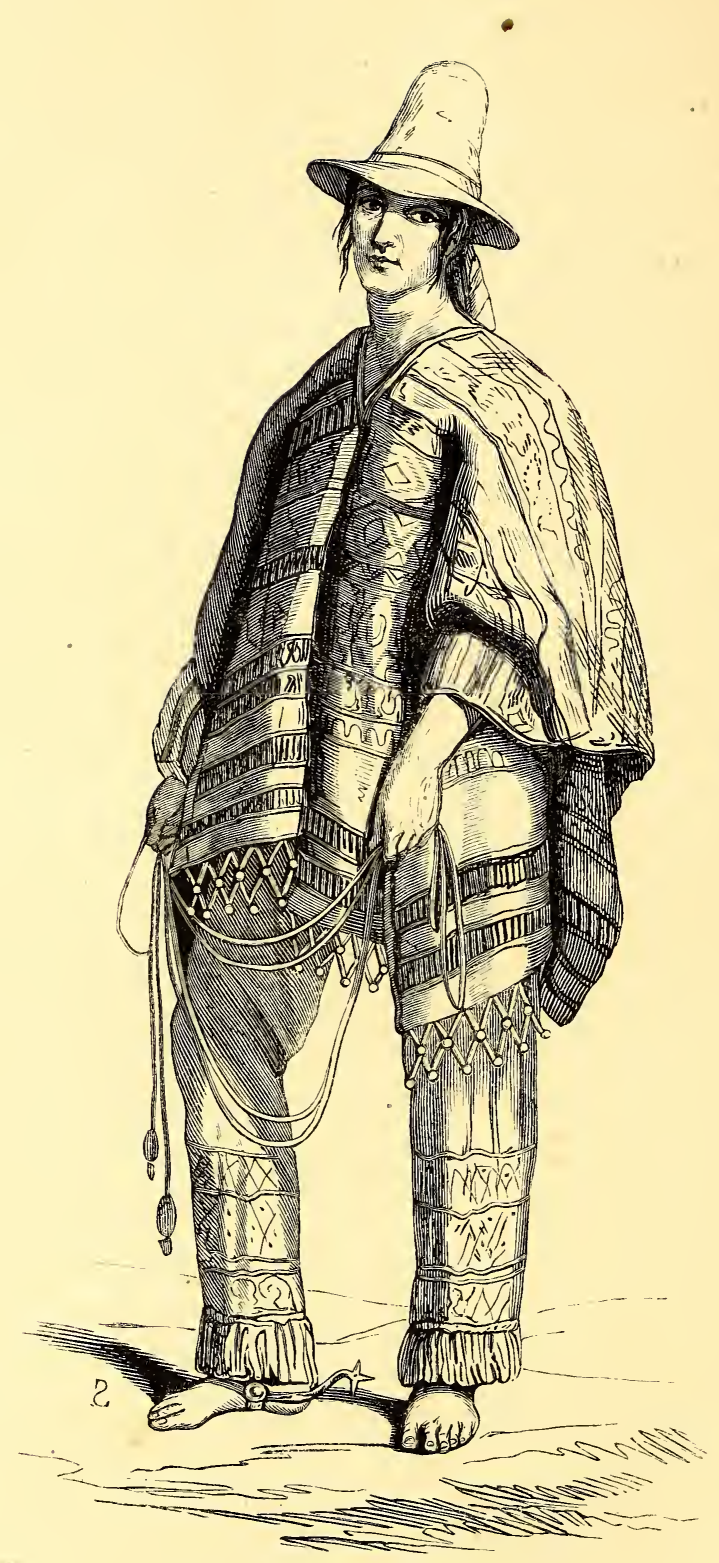

GAUCHO DES ENVIRONS DE BUENOS-AYRES. 
de Buenos-Ayres avec une vigueur, une persévérance et une valeur admirables.

Ils ont tous les caractères physiques des Indiens de l'Amérique; leur commerce avec les Européens ne les a pas autant changés que leurs frères du nord. Les Pampas fabriquent de très-bons ponchos en laine, tissus de manièrè à résister aux plus fortes pluies, et ornés de dessins très-originaux. Ils font aussi, avec beaucoup d'adresse et de succès, toutes sortes d'ouvrages en peaux, comme des corbeilles, des paniers, des fouets et des brides, ces deux derniers objets sont souvent d'une élégance infinie. Ils fabriquent à l'usage des habitants de la campagne, des bottes faites de la peau des jambes de derrière d'un cheval. Ils se teignent comme les autres Indiens, mais seulement le visage. Leurs cheveux sont longs et touffus; tantôt ils sont relevés la pointe par en haut, tantôt soutenus sur le front el autour de la tête au moyen d'un bandeau de couleur tranchante, insuffisant toutefois pour les empêcher de retomber en mèches roides sur le front et sur les épaules, ce qui produit un effet moins agréable que pittoresque. Les femmes les divisent en deux moitiés qu'elles font relomber en queue serrée sur les oreilles et sur les épaules. Elles portent des pendants d'oreilles, des colliers, des bijoux, et affectent ainsi une sorte de coquetterie, sans être beaucoup plus propres que les autres Indiennes, ni beaucoup plus réservées; on les dit même plus faciles encore. Les hommes vont presque nus à la guerre, à la chasse et chez eux, à moins que le temps ne soit froid ou qu'ils ne soient à la ville; alors ils s'enveloppent la partie inférieure du corps d'une espèce de jupon (chilipa) d'étoffe fond blanc, rayé de brun ou chargé d'ornements plus ou moins recherchés et de couleur foncée; ils se couvrent les épaules d'un poncho, qu'ils drapent en écharpe ou disposent en manteau.

Pour la chasse comme pour la guerre, les Pampas ne se servent que de bolas, de couteaux, de sabres sans gaîne et de lances de dix à douze pieds de long, dont la hampe en roseau est ornée, à son extrémité, d'une touffe de plumes d'autruche, et ornée d'un fer qui la fait vaciller sous son poids. Ils sont très-adroits à lancer les bolas, armes formidables entre leurs mains.

Les Puelches, dont M. d'Orbigny vit une famille qui habitait les environs de la Baie-Blanche, sont répandus aussi sur les bords du Rio Negro. Le vêtement d'une jeune Indienne de cette famille se compose de trois pièces d'étoffe bien distinctes, l'une fixée à la ceinture et voilant le devant du corps; une seconde attachée sous les bras descend jusqu'aux pieds, et la troisième, espèce de mante attachée avec une épingle d'argent, couvre les épaules.

C'est dans les plaines appelées pàmpas qu'on se livre à l'élève des bestiaux. Les maîtres bergers sont nommés Capataz; leurs subordonnés ont reçu le nom de Guachos.

Les Capataz, de même que tous ceux à qui leur position le permet, portent une veste, des culottes ou des pantalons blancs; un chapeau, des souliers et un poncho. Quant à leurs serviteurs, ils ne se vètissent guère que du chilipa, dont nous avons parlé plus haut. Bon nombre d'entre eux se passent de chemises. Ils se rasent très-peu souvent, et, pour cet usage, ils se servent d'un couteau. Plus ordinairement ils ont la barbe fort longue. Les femmes vont pieds nus et sont extrêmement malpropres. Leur vêtement habituel est une chemise sans manches, attachée autour de la taille au moyen d'une ceinture; rarement elles en ont une de rechange. Elles ne savent ni coudre ni filer; elles se bornent à balayer la maison, à faire le feu pour rôtir la viande, et bouillir l'eau pour le maté.

Les gens de la campagne n'ayant qu'un seul habillement, le quittent dès qu'il pleut, le placent, pour le tenir sec, sous la peau qui couvre la selle de leur cheval, et le remettent quand la pluie a cessé, par la raison, disent-ils, que leurs habits sèchent difficilement, tandis qu'il n'en est pas de mème de leur peau. 
La province de Corrientes, qui comprend aujourd'hui une partie du célèbre territoire des Missions, s'étend entre le Parana et l'Uruguay. La capitale, appelée aussi Conrientes, ville de 4,000 à 5,000 âmes, est située un peu au-dessous du confluent du Paraguay et du Parana. Sa position, favorable pour le commerce, doit lui donner un jour une plus grande importance. Les anciens villages de Santa-Anna et de Candelaria, bâtis par les jésuites, sont aujourd'hui ruinés.

Cette contrée était le principal siége des fameuses missions des jésuites, dans lesquelles on a prétendu voir le germe d'un empire. L'envie a tour à tour trop embelli et trop noirci le tableau de ces établissements, que regretteront à jamais la religion, l'histoire et la géographie. Ces religieux instruits et habiles ne se bornèrent pas à la persuasion et à la prédication apostolique pour réduire des Indiens; ils surent employer les moyens temporels, mais ils les manièrent avec beaucoup de modération et de prudence. La formation des peuplades de jésuites, le long du Parana et de l'Uruguay, fut aussi due en grande partie à la terreur que la féroce tyrannie des Portugais inspirai aux Indiens. Chaque peuplade était gouvernée par deux jésuites : l'un, appelé curé, uniquement chargé de l'administration du temporel, ne savait souvent pas parler le langage des Indiens; l'autre, que l'on appelait compagnon, ou vice-curé, était subordonné au premier, et remplissait les fonctions spirituelles. L'unique loi était l'Évangile et la volonté des jésuites. Les magistrats choisis parmi les Indiens n'exerçaient aucune espèce de juridiclion, et n'étaient qu'un instrument entre les mains du curé, même pour la partie criminelle. Jamais un accusé ne fut cité devant les tribunaux du roi. Les Indiens de tout âge et de tout sexe étaient obligés de travailler pour la communauté de la peuplade; aucun ne pouvait s'occuper pour son propre compte. Le curé faisait emmagasiner le produit du travail, et se chargeait de nourrir et d'habiller tout le monde. Tous les Indiens étaient égaux et ne pouvaient posséder aucune propriété particulière. Ce régime offrait la seule transition possible de l'état barbare où étaient les Indiens, à une civilisation plus parfaite. Il est vrai que, sous ce régime, nul motif d'émulation ne pouvait porter les Indiens à perfectionner leurs talents, puisque le plus vertueux et le plus actif n'était ni mieux nourri, ni mieux vêtu que les autres, et qu'il n'avait pas d'autres jouissances. Mais cette espèce de gouvernement était la seule convenable au milieu de hordes aussi abruties, aussi féroces; elle faisait le bonheur de ces Indiens, qui, semblables à des enfants, étaient incapables de se gouverner eux-mêmes. C'était un changement bien heureux pour ces sauvages, accoutumés à s'égorger les uns les autres, ou à servir les Espagnols comme esclaves. Les particuliers et les commandants espagnols se permettaient auparavant de réduire en esclavage tous les Indiens qui tombaient dans leurs mains. De là les premiers germes des haines contre les jésuites. "Les plaintes des commandants militaires viennent, comme le père Aguilar le dit dans son mémoire justificatif, de ce qu'ils voudraient que ces Indiens fussent soumis nonseulement à Votre Majesté, mais encore à chaque Espagnol en particulier, et même aux valets et aux esclaves des Espagnols. Dès qu'un Espagnol, un métis, ou même un nègre, voit un Indien qui ne s'humilie pas devant lui, ou qui ne sert pas aveuglément ses caprices, il se déchaîne contre le pauve Indien, il l'appelle un barbare, un rustre, qui pousse l'insolence jusqu'à manquer de respect aux Espagnols. » Les Indiens étaient baptisés et savaient les commandements de Dieu et quelques prières; c'était un commencement d'instruction morale auquel les jésuites bornèrent sagement leurs efforts. Ces peuples n'apprenaient aucune science; mais ils fabriquaient des toiles dont ils s'habillaient : les arts mécaniques leur étaient enseignés par des jésuites envoyés d'Europe à cet effet. Aucun de ces Indiens n'avait de chaussure, et les femmes, sans exception, ne portaient d'autre vêtement qu'une chemise sans manches. Le climat ren- 
dait superflu un vêtement plus compliqué. Il fallait employer les médiocres profits d'une culture naissante à se procurer des instruments, des ustensiles et des armes. Les Indiens néophytes portaient dans les villes espagnoles tout ce qui leur restait de toiles, de tabac, d'herbe du Paraguay, de peaux. Ces effets étaient remis entre les mains du procureur général des missionnaires jésuites, qui les vendait ou les échangeait le plus avantageusement possible. Il rendait ensuite un compte exact du tout, et après avoir pris sur le produit des marchandises le payement du tribut, il employait le restant à l'achat des choses utiles ou nécessaires aux Indiens, sans rien retenir pour lui-même.

Les Indiens des missions étaient des peuples libres qui s'étaient mis sous la protection du roi d'Espagne. Ils étaient convenus de payer un tribut annuel d'une piastre par tête. Ils étaient obligés de joindre les armées espagnoles en cas de guerre, de s'armer à leurs propres frais, et de travailler aux fortificalions. Ils ont rendu de grands services à l'Espagne dans la guerre contre les Portugais. En dépit de conventions aussi sacrées, les despotes libéraux de l'Europe ne se firent aucun scrupule de traiter ces peuples chrétiens comme un troupeau de bestiaux. En 1757, une partie du territoire des Missions fut cédée par l'Espagne à la cour de Portugal, en échange pour Santo-Sacramento. On a prétendu que les jésuites refusèrent de se soumettre à cette cession, ou de se laisser transférer d'un maître à un autre sans leur consentement. Les Indiens prirent effectivement les armes, mais ils furent aisément défaits, et avec un grand carnage, par les troupes européennes envoyées pour les soumettre. La promptitude de cette défaite prouve qu'il n'y avait parmi eux ni union ni chef. En 1767, ces Pères furent chassés de l'Amérique par l'autorité du roi, et leurs malheureux néophytes mis sur le pied des autres habitants indigènes de ce pays. Depuis l'expulsion des jésuites, les moines qui furent chargés du soin de leurs peuplades ne nourrirent ni n'habillèrent les Indiens aussi bien qu'autrefois, et les fatiguèrent de travail. Les marchands et les commandants militaires purent recommencer leurs exactions. Enfin, un rapport ministériel inédit, adressé au roi d'Espagne par un ennemi des jésuites, avoue "que la population des trente villages des Guapanis, établis par ces religieux, s'élevait, en 1774, à 82,066 individus, et que, lors de l'expulsion des jésuites, elle était au moins de 92,000; qu'elle a été réduite, en vingt années, à 42,250 âmes, c'est-à-dire de plus de la moitié; que les Portugais, autrefois contenus, ont envahi sept villages, et que, pour arrêter l'invasion de ces étrangers, il faut rétablir l'excellent règlement militaire des jésuites ${ }^{x}$. "Voilà des faits qui parlent. Si depuis cette époque les Indiens ont continué à se civiliser, s'ils jouissent de quelque aisance, si quelques-uns s'habillent à l'espagnole, et si dans quelques endroits ils acquièrent de petites propriélés, que faut-il voir dans ces faits isolés, sinon les rejetons du magnifique arbre qu'une politique aveugle arracha, mais ne put entièrement déraciner?

Depuis la conquête, les provinces argentines, comme les autres colonies, possèdent une population hétérogène. Elle se compose de créoles, de mulâtres, de métis et de zambos ou zambis. Il serait inutile de s'étendre longuement sur les mœurs et les usages de cette population coloniale : on y retrouve le caractère espagnol, exagéré en certaines localités par l'ardeur du climat, altéré, en d'autres lieux, par la rareté des communications, et partout soumis à l'influence du croisement des races, à celle de la privation de certains objets d'art ou de luxe, à celle enfin d'une existence que la terre et le ciel voudraient rendre indolente et heureuse, mais qui est sans cesse troublée par le voisinage des animaux malfaisants, par les incursions des Indiens, et par la politique de l'Europe.

\footnotetext{
1 Reorganisacion de las Indias, etc.
} 
Les PÉons ou pâtres des plaines forment une classe d'hommes que nous ne devons pas omettre de signaler. Si les Indiens offrent le triste spectacle d'une race sauvage qui n'a pu entrer dans les voies de la civilisation, les Péons présentent celui, non moins déplorable, d'une race jadis civilisée, que le temps et la solitude ont réduite à l'état sauvage.

Descendants des anciens pâtres espagnols, les Péons gardent d'innombrables troupeaux dans les plaines désertes du Tucuman, du Paraguay et de l'Uruguay. Toujours armés du poignard, toujours montés à cheval, ils ne connaissent d'autres lois que celles du besoin. La vie de leurs frères est à leurs yeux du même prix que celle d'un mouton ou d'une vache, et, pour la plus légère offense, ils commettent un meurtre. La passion brutale remplace chez eux le sentiment de l'amour; et quand ils peuvent enlever une femme créole, ils se livrent entre eux des combats acharnés pour s'en disputer la possession. La malheureuse devient la femme du vainqueur, et vit avec lui jusqu'au moment où un nouvel assassinat la livrera à un second époux.

Les Péons dorment sur une peau de bœuf; ils ne se nourrissent que de viande de vache à demi grillée; ils boivent dans un crâne de cheval ou une corne de bœuf. Passionnés pour l'eau-de-vie, ils se disputent à coups de couteau les provisions que les créoles leur en vendent. Excellents cavaliers d'ailleurs et fort habiles à manier le laço, ces pâtres sauvages ont été utiles aux indépendants, à l'époque de la révolution, quand l'espoir du butin a pu les attirer sur le théâtre de la guerre. 


\section{URUGUAY.}

La république de l'Uruguay est bornée au nord par le Brésil, au sud par l'océan Atlantique et le Rio de la Plata, à l'est par le petit territoire compris entre cet océan et la lagune de Mirim, à l'ouest par le cours de l'Uruguay.

Le gouvernement se compose d'un président et de deux chambres : celle des représentants, qui est de vingt-neuf membres, et celle des sénateurs, qui n'en a que neuf.

Les divisions administratives et la population de ce nouvel État sont encore trop imparfaitement connues pour que nous puissions en donner le détail; nous nous bornerons donc à dire qu'il est divisé en neuf départements; que sa superficie est d'environ 1,500 lieues, et que sa population, qui a dû prendre de l'accroissement, n'était en 1826 que d'environ 70,000 habitants. On y compte trois villes, huit villages ou hameaux, et quinze bourgades ou villas.

La capitale de cette république est Montevideo, sur une petite péninsule qui forme un vaste port. Cette ville, bâtie sur une pente douce, a un bel aspect du côté du port : elle a une enceinte bastionnée et une citadelle vers l'extrémité orientale. Les rues sont droites, larges, ont des trottoirs étroits et sont pavées; les maisons, en pierres et en briques, ont rarement plus d'un étage. Sur la grande place s'élève la cathédrale, le plus bel édifice de la ville, et la prison. Montevideo manque de sources; elle tire l'eau d'environ une lieue. Le climat est humide : les orages y sont fréquents en été. Elle possède le meilleur port du Rio de la Plata, exporte du suif et des cuirs pour l'Angleterre, du bœuf salé pour le Brésil, et importe des articles des manufactures européennes, café, sucre, cuivre, thé, etc. Les environs sont fertiles en blé d'une belle qualité et fruits d'Europe. On y élève un nombre considérable de bestiaux et surtout de chevaux. Cette ville est le siége d'un évêché.

Le territoire de l'Uruguay renferme une nation indigène dont nous devons parler : ce sont les Charruas, race presque entièrement détruite aujourd'hui, et dont la férocité était telle qu'on en retrouve le cachet dans leurs usages les plus familiers.

Les femmes même se découpent la peau et les chairs des bras et des jambes en signe de deuil, ou par un inconcevable sentiment de coquetterie. A la mort d'un enfant, sa mère se coupe la première phalange du petit doigt, puis celle du second doigt quand cette perte se renouvelle, et ainsi de suite. Nus et sales, les Charruas ne se lavent jamais, et répandent autour d'eux une odeur nauséabonde. Couchés, le ventre en l'air, sur une peau de bœuf, ces truands de l'Amérique n'aiment que le repos, le soleil et la liberté ; ils ne connaissent ni société, ni musique, ni lois, ni religion. Que leur importent les arts de la vieille Europe? Ne faut-il pas en acheter la jouissance par le travail, et le travail n'est-il pas, pour un Charruas, ce qu'il y a de plus cruel au monde? La faim seule, l'inexorable faim, les force à sortir de cette douce apathie. Alors, le laço en main, ils courent après les chevaux sauvages, les taureaux indomptés et les autruches agiles. 
Leur adresse à manier le lacet est vraiment admirable : à l'aide de cette arme, on les a vus enlever, au milieu des cavaliers espagnols, Diego de Mendoza, le général Paz, et plusieurs autres adversaires non moins distingués. Depuis que les chevaux se sont si prodigieusement multipliés parmi eux, les Charruas sont devenus de très-habiles cavaliers. Nourrissant une haine implacable contre les Européens, ils vivent, depuis trois siècles, en état d'hostilité avec eux, et n'ont jamais voulu souscrire aux conditions de paix qui leur ont été proposées en plusieurs occasions; aussi leur voisinage était-il des plus incommodes pour Montevideo. Enfin, le président de la république orientale de la Plata, don Fructuoso Ribera, les a presque entièrement détruits en 1832. Parmi ceux qui ont échappé au vainqueur, trois hommes et une femme furent conduits en France l'aunée suivante, et amenés à Paris, où ils devinrent l'objet d'une curiosité si fatigante, et en même temps si humiliante, que l'un d'eux, Sénaqué, dit le médecin, en mourut de désespoir. Prêt à rendre le dernier soupir, ce malheureux recueillit ses forces et s'écria, d'un ton si douloureux que tous les assistants en furent émus : Paris! Paris!

Vaïmacà-Pérou, dit le chef, Tacouabé le jeune guerrier, et sa compagne Guyunusa, ont été traînés de ville en ville, et livrés partout à l'insupportable indiscrétion de ces mêmes Européens chez lesquels ils comptaient trouver une franche et noble hospitalité. Un journal de Lyon annonçait, il y a quelques années (juillet 1834), que la jeune Guyunusa et un enfant à la mamelle avaient seuls survécu : ajoutons que ce serait un acte digne de la générosité française que de rendre ces malheureux à la terre qui les a vus naître. 


\section{PARAGUAY.}

Les limites de la république du Paraguay sont au nord et à l'est le Brésil, au sud et à l'ouest la république argentine.

Ce pays est divisé en 8 départements et 28 municipalités; cependant la partie des missions qui lui appartient est partagée en districts administrés d'une manière particulière.

La capitale appelée Assompcion est, des six ou sept villes du Paraguay, la seule quelque peu remarquable. Un évêque et le chef de l'Etat y résident.

L'entrée de ce pays est interdite aux étrangers; tous ceux qui n'ont pas une autorisation spéciale du chef de l'Etat sont retenus prisonniers. De ce nombre fut M. Bonpland, Français, compagnon de M. de Humboldt, qui, après un long séjour forcé, fut relâché en 1829. M. Alcide d'Orbigny, qui eut aussi, mais pour un instant seulement, le même sort, s'exprime ainsi relativement à son arrestation :

a Nous approchions d'Itapua, premier lieu habité que nous devions rencontrer dans le pays, quand nous fùmes brusquement abordés par une douzaine d'hommes en veste bleue, pantalons blancs et chapeaux ronds, armés de sabres, de pistolets, decarabines, et accompagnés de quelques autres, assez mal équipés, en habits bourgeois et portant des lances. Ils nous demandèrent impérativement nos passe-ports, et, sans attendre notre réponse, ils nous entourèrent et nous conduisirent, plus vite que nous n'y aurions été de nous-mêmes, auprès du commandant militaire d'Itapua. G'était un détachement de ces nombreuses guardias ou postes militaires dont le dictateur a couvert les rives du Paraguay, du Parana et de l'Uruguay, pour empêcher de sortir de son empire, qui ressemble assez à l'antre du lion de la fable; car tout y entre et rien n'en sort. Il n'en laisse pas sortir les indigènes, dans la crainte qu'à leur retour, ils n'y rapportent des idées libérales qui pourraient lui nuire; les Espagnols, parce qu'il les regarde comme des olages; les étrangers, pour s'en servir comme d'intermédiaires avec les puissances européennes. Il ne se dissimule pas les inconvénients de l'entrée accordée à ces derniers; mais ces inconvénients sont plus que compensés par l'exactitude de la surveillance qu'il exerce sur eux. Il a établi partout une police des plus inquisitoriales et des plus vexatoires, qu'il fait par tous les hommes en places. Il se charge même souvent, en personne, de l'exécution de ses décrets; mais, dans les villes, les alcades, et les commandants à la campage, en sont particulièrement chargés. Ils ont sous leurs ordres, à cet effet, des espèces d'éclaireurs nommés zeladores qui, de jour comme de nuit, voient et observent tout avec une étonnante sagacité, avec un zèle tout exemplaire. Il dispose, en outre, d'une sorte de police secrète que font volontairement un certain nombre d'amateurs. Pour être plus sûr de son fait, il a supprimé la poste aux lettres, tout en laissant subsister les maîtres de postes, tant pour l'expédition des dépêches officielles que pour la perception du port des lettres particulières, resté le même qu'autrefois. Par là, il se procure de l'argent et se trouve nanti de toutes les lettres qui sortent ou qui entrent. Il les ouvre sans scrupule et les retient ou les renvoie, suivant que le contenu lui convient ou non; aussi ne prend-on plus la peine de les cacheter. 
Enfin on ne peut sortir du pays ni en parcourir l'intéricur sans passe-ports délivrés pour la sortie par le dictateur exclusivement, et pour le voyage, par les commandants.

„C'était en vertu de cette dernière mesure que nous venions d'ètre arrêtés. Au moment où j'entrai chez le commandant, j'eus toutes les peines du monde à m'empêcher d'éclater de rire, en le voyant affublé d'une grande robe de chambre d'indienne, vêtement officiel, espèce d'uniforme que portent, à l'imitation du dictateur, les commandants, les alcades, et, en général, tous les employés, mais sans jamais le quitter, pas même pour monter à cheval. Ce commandant paraissait être un fort brave homme. Il excusa, de son mieux, ses gens de la brusquerie avec laquelle ils avaient rempli leur charge; puis, après avoir pris connaissance de mon passe-port brésilien, il m'apprit que je devais attendre quelques jours à la frontière, le retour d'un messager qu'il allait expédier pour l'Assompcion, à l'effet d'instruire le dictateur de mon arrivée et de lui demander si son bon plaisir était que je traversasse le pays, dans la qualité de voyageur, sous laquelle je m'annonçais. Au reste, ajouta-t-il, je ferai de mon mieux pour que le temps ne vous paraisse pas trop long. Votre qualité de Français n'est point à mes yeux un titre de réprobation, comme auprès de beaucoup de mes compatriotes; au contraire... Moi et deux ou trois autres personnes d'ici, que vous connaîtrez, nous aimons beaucoup les Français.... D

Le lendemain, M. d'Orbigny visita la bourgade en compagnie du commandant.

Les Payaguas ou Payaguayos sont les Indiens qui donnèrent leurnom à la rivière du Paraguay. Leur taille est d'environ cinq pieds quatre pouces; ils sont bien faits. Outre la barbote ou disque dont nous avons parlé, les plumes et autres ornements adoptés par la plupart des Indiens, ils portent une espèce de mante de coton, tissée par leurs femmes. - Celles-ci ont la mamelle artificiellement allongée, à ce point qu'elles allaitent par-dessous leurs bras ou par-dessus leurs épaules, leurs enfants qu'elles portent suspendus à leur cou par derrière. - Les jeunes filles devenues pubères se peignent le corps d'une certaine manière avec plus ou moins de coquetterie. - Après l'accouchement d'une femme, ses amies forment avec leurs habits, de sa demeure à la rivière, une espèce de corridor qu'elle doit parcourir pour aller se jeter à l'eau avec son enfant. Le divorce est rare chez les Payaguas; lorsqu'il a lieu, la femme se retire avec ses enfants dans sa famille, emportant tout le mobilier, car l'homme ne conserve que ses vêtements et ses armes, qui se composent de la mocana, d'arcs de sept pieds et de flèches de quatre et demi. Lorsqu'un individu meurt, on loue un homme pour porter en terre le défunt. - Ils ont grand soin des sépultures; ils les balayent, les couvrent de hultes et de cloches ou pots de terre, ornés de peintures. - Les hommes ne portent point le deuil; quant aux femmes elles pleurent leur père ou leur mari... deux ou trois jours. - Ils ont une fête solennelle, commune à toutes les grandes nations et qu'ils célèbrent au mois de juin dans la ville même de l'Assompcion. Les chefs de famille y figurent seuls; on en exclut les célibataires et les femmes. — La veille de la solennité, ils font une grande toilette, aussi extraordinaire que possible; le lendemain ils s'enivrent, puis, pendant toute la journée, ils se déchiquètent mutuellement les bras, les cuisses et les jambes avec un éclat de bois ou une arête de poisson; ils se percent aussi la langue, ainsi qu'une antre partie plus délicate, et se frottent le visage avec le sang qui découle de la première, tandis qu'ils laissent aller celui de la dernière dans un petit trou qui a été creusé en terre avec le doigt. Durant ces mutilations ils ne sourcillent point, n'exhalent pas une plainte, un soupir. Mais la cérémonie achevée, s'ils ne se sont pas rendus infirmes, ils sont tellement faibles qu'ils ne peuvent reprendre leurs travaux de plusieurs jours. - Il en résulte souvent une privation de nourriture pour leurs familles. 
Les Guanas, divisés en huit hordes, forment une nation répandue sur les deux rives du grand fleuve. Plus sociable que les autres, cette nation se distingue aussi par l'hospitalité qu'elle exerce envers les étrangers, et la manière affable avec laquelle elle les accueille. Les guerriers les conduisent dans leurs huttes, de forme cylindrique, placées chacune au centre d'une place carrée; faites de branches d'arbre, et recouvertes de paille, ces cabanes sont sans voùtes ni fenètres, et n'ont d'autre ouverture que la porte. Ces huttes sont balayées tous les jours avec soin. Quoique flegmatiques, les Guanas sont aimables; leur vue excellente ainsi que leurs autres caractères physiques, les rapprochent des autres nations. Ils ont la coutume de s'arracher les cils, les sourcils et les poils, et portent le barbole. Les jeunes filles à marier sont très-propres, montrent beaucoup d'amabilité et de coquetterie, et ne se piquent pas, une fois mariées, d'une grande fidélité. Dès l'àge de neuf ans, les femmes se marient; mais les hommes attendent jusqu'à vingt, et quelquefois encore plus longtemps. Le cérémonial de leurs mariages est des plus simples. Le jeune homme fait un petit présent à la jeune fille, et la demande à son père; après quoi la future épouse et ses parents font leurs conditions sur la manière dont elle sera traitée, sur ce qu'elle fera ou ne fera pas dans le ménage, si elle aura plusieurs maris, et combien, le nombre de nuits conjugales à accorder à chacun d'eux. Les femmes sont très-portées au divorce, et les hommes fort jaloux. Les parents, d'après leur système d'éducation, n'ont aucune autorité sur leurs enfants; seulement ils leur donnent quelquefois des soufflets, et leur font des remontrances. Dès que les enfants ont atteint l'àge de huit ans, ils partent un malin, à jeûn, en procession, pour la campagne, et le soir ils reviennent chez eux, dans le même ordre et en observant le plus grand silence; de vieilles femmes leur percent alors le bras avec un os pointu, ce qu'ils doivent souffrir sans se plaindre; puis la mère leur donne à manger du maïs et des haricots. Cette pratique bizarre rappelle involontairement la fête sanglante dans laquelle les anciens Spartiates fouettaient leurs enfants autour de l'hồtel de Diane, pour les exercer à la patience.

Indépendamment de quelques fètes de famille, qui sont toutes de caprice, les hommes célèbrent cette fète solennelle dont nous avons parlé en décrivant les Payaguas. Cependant leur plus grand plaisir, ainsi que chez tous les sauvages, est de s'enivrer. Les femmes onl la coutume barbare d'enterrer, dès leur naissance, leurs enfants du sexe féminin, afin, disent-elles, de faire rechercher davantage les femmes, et de les rendre plus heureuses; c'est sans doute la même idée qui porte les Mbayas, leurs voisines, à se faire avorter en recevant des coups de pied dans le ventre, ou même en se laissant fouler aux pieds par de vieilles femmes. La simplicité règne également dans leur politique, qui n'en est pas pour cela plus mauvaise. Un cacique héréditaire gouverne ordinairement chaque horde; cela n'exclut pas absolument le principe électif. A la guerre, ils n'attaquent jamais; en revanche ils se défendent vaillamment, tuent tous les hommes au-dessus de douze ans, et adoptent leurs femmes et leurs enfants, ainsi que le font les Charruas.

De toutes ces nations la plus reculée vers le nord est celle des MBayas; elles'étend sur les deux rives du fleuve, jusqu'au fort Bourbon, et descend vers le sud jusqu'au Rio Pilcomayo. Cette nation guerrière et conquérante fut la terreur des Espagnols dès leur arrivée dans ce pays. De 1661 à 1796 , et même plus tard, pénétrant de tous côtés dans le Paraguay, elle fut mille fois sur le point d'en exterminer les anciens maîtres, ainsi que les nouveaux habitants. Du temps d'Azara, ce peuple, divisé en quatre hordes, présentait alors un effectif de quatre mille guerriers. Cette nation ressemble beaucoup aux autres par quelques coutumes, mais elle s'en distingue par des traits qui rappellent les mœurs homériques, tels que de sacrifier les chevaux d'un chef sur sa tombe. - Les filles 
ne mangent jamais de viande; el certains mets sont défendus aux femmes, qui n'élèvent qu'un fils et une fille, et détruisent leurs autres enfants. Le deuil se marque par l'abstinence de viande, et par le silence, et dure de trois à quatre lunes. Ils se regardent comme la première nation du monde, et méprisent les Européens. Dieu, suivant leur cosmogonie, créa toutes les nations, aussi nombreuses qu'elles le sont aujourd'hui; et ayant ensuite formé un Mbaya et sa femme, il chargea un caracara (pour les indemniser de les avoir oubliés dans le partage de la terre) de leur dire, de sa part, de faire la guerre à toutes les nations, et de tuer tous les mâles adultes, en adoptant leurs femmes et leurs enfants. Les Guanas sont seuls exceplés de celte proscription; ils sont leurs amis, leurs alliés ou leurs esclaves volontaires : les Mbayas les trailent avec douceur. Le plus pauvre Mbaya a toujours deux ou trois esclaves, pour le ménage et pour la culture, tandis que le maître se réserve la chasse, la pêche et la guerre. Leur tactique guerrière est singulière, et rien ne résiste à leur attaque, après une décharge générale, si l'on a l'imprudence d'en faire une contre eux, ainsi que les Espagnols l'ont souvent éprouvé. A nombre égal, ils ne craignent pas les armes à feu; mais ils ne savent point poursuivre un succès, ni consommer une victoire. S'ils sont vainqueurs ils font une espèce de fète, et les femmes célèbrent la valeur de leurs maris, et finissent toujours par se battre entre elles à coups de poing, probablement pour montrer la leur.

Les Tobas, l'une des nations les plus célèbres par leurs luttes contre les Espagnols depuis l'époque de la découverte jusqu'à nos jours, sont encore, quoique moins dangereux, fort redoutés. On frémit involontairement à leur aspect. lls chassent une espèce de rongeur appelé qiya, dont les fourrures cousues ensemble leur font des ponchos. Ces fourrures sont aussi pour eux l'objet d'un grand commerce à Corrientes, où ils vont de temps à autre pour se procurer les articles manufacturés qui leur sont devenus nécessaires, tels que haches el couteaux. Ils ont, ainsi que les autres habitants du Chaco, les yeux inclinés, les pommettes des joues saillantes, et le teint bronzé. D'ailleurs indolents et peu communicatifs, ils ne retrouvent quelque énergie que pour la chasse. Peints comme des hommes terribles, ils sont fort doux, mais intraitables dans l'ivresse. L'arc, les flèches et la massue sont leurs armes les plus ordinaires; ils manient aussi très-adroitement les bolas. Quoique sur le bord des lacs et des fleuves, ils sont étrangers à la navigation. Leur seule industrie consiste en une sorte de poterie, et quelques tissus, surlout pour les ponchos, que fabriquent leurs femmes. Selon d'Orbigny, qui a vu leurs habitations dans leurs villages près de Corrientes, ils possèdent un degré de plus de civilisation que les autres Indiens. Leurs huttes présentent la forme d'un long hangar, et sont construites en roseaux. Dans chaque hutte il y a plusieurs familles.

Les diverses tribus qui habitent les bords du Paraguay ne sont pas loutes également pacifiques; mais l'infériorité de leurs armes les rend peu redoutables; et en les traitant bien, en s'entendant avec leurs caciques, on pourrait recevoir d'eux de grands services, car ils connaissent parfaitement la contrée. Après les Tobas, les tribus les plus remarquables sont : les Ayuilots, les Piticafas, el les Bocobis, dont on évalue le nombre tolal à deux mille guerriers, distribués en quatre hordes principales, tous fiers, belliqueux, vivant des vaches et des brebis qu'ils élèvent, ou qu'ils prennent aux Espagnols du Paraguay, de Corrientes el de Santa-Fé. 


\section{PÉROU, BOLIVIE.}

Le Pérou, en y comprenant la Bolivie ou haut Pérou, est borné au nord par la Colombie, au nord-est et à l'est par le Brésil, au sud-est par la province de GranChaco, au sud par celle de Salta et par la montagne de Morro-Moreno, et au sud-ouest par la mer du Sud.

Le Pérou proprement dit occupe un espace de 45,000 lieues carrées, et renferme une population totale d'environ 1,246,000 habitants; la Bolivie a une surface de 40,000 lieues, et une population de 1,200,000 habitants.

Successivement appliquée à des territoires de diverses grandeurs, la dénomination de Pérou a uné étymologie contestée. Ne pouvant entrer dans les discussions qui ont rapport à l'origine de ce nom, nous nous bornerons à indiquer les différentes divisions politiques que ce pays a subies depuis les premiers temps connus de son histoire jusqu'à nos jours.

Lors de sa destruction, l'ancien empire des incas avait pour capitale Cuzco, et comprenait la province de Quito, dont les souverains du Pérou avaient fait la conquête. Après l'envahissement de cette contrée par les Européens, elle fut constituée en une vice-royauté qui embrassait la totalité des possessions espagnoles au sud de l'isthme de Panama. Par le démembrement qui eut lieu en 1718, les royaumes de Terre-Ferme, de Nouvelle-Grenade et de Quito formèrent une vice-royauté particulière, dont Santa-Fé de Bogota devint le siége. Soixante ans plus tard, les riches districts de la Paz, Potosi, Charcas et Santa-Cruz furent détachés et placés sous l'autorité d'un vice-roi qui eut pour résidence Buenos-Ayres. Quatre gouvernements étaient alors érigés en viceroyautés : le Mexique, le Pérou, la Nouvelle-Grenade et le Rio de la Plata. La dénomination de capitaineries générales fut appliquée aux provinces de Caracas, Cumanas et Chili, ainsi qu'au Guatemala.

Cette division politique et les noms qu'elle comportait ont été changés par la révolution péruvienne. L'empire des incas, à l'exception de Quito, depuis longtemps perdu pour le Pérou, a d'abord été partagé en deux États : le Pérou proprement dit et le haut Pérou ou Bolivie. Bientôt le résultat d'une nouvelle organisation fut une confédération qui comprenait trois États : Pérou du nord, Pérou du sud et Bolivie. Enfin, on en est revenu à la division précédente : le Pérou et la Bolivie.

L'ancienne capitale du Pérou, Luma, est bâtie à l'entrée de la belle et délicieuse vallée de Rimac; elle est encore le siége du gouvernement actuel : le président de la république y fait sa résidence. La construction de cette ville offre la forme d'un croissant; elle est fermée par une muraille en tapia d'environ sept à huit mètres de hauteur et percée de huit portes.

Lima n'offre rien de bien remarquable, si ce n'est le nombre de ses couvents d'hommes et de femmes, sur lesquels on trouvera des renseignements précieux dans nos Cérémonies religieuses de tous les peuples. 
La population de Lima se compose d'un grand nombre de races différentes ou mélangées :

Le CRÉole a beaucoup de ressemblance avec l'Andalou par le caractère : il est vif, généreux, sans prévoyance pour le lendemain, et oublie facilement une injuré. La dissipation, l'amour de la parure sont ses penchants irrésistibles. La vivacité, l'épigramme distinguent sa conversation : celle des femmes est gaie, spirituelle, mais en même temps si franchement légère qu'on les a souvent accusées d'être plus que coquettes.

Le MÉTIs, fils d'un blanc et d'une Indienne, est ordinairement robuste, basané, mais sans barbe. La douceur, l'affabilité, l'obligeance le caractérisent; et il recherche la société des blancs. Pendant leur enfance, les métis ont les yeux bleus, les cheveux blonds et le teint assez blanc; mais ils brunissent à mesure qu'ils avancent en âge.

Le mulatre (né d'un blanc et d'une néğresse) est en général remarquable par la délicatesse de sa constitution, par son amour du faste, son imagination active, son éloquence native, et ses instincts poétiques. Parmi les mulâtres de Lima, beaucoup reçoivent une bonne éducation; des lois absurdes leur défendant l'accès du barreau et de l'élat ecclésiastique, plusieurs se livrent à l'étude de la médecine, et il n'est pas rare de les voir devenir des praticiens d'une grande distinction. On cite des femmes de celle classe pour leur beauté, leur esprit, leur égalité d'humeur et leur fidélité en amour et en amitié. On en voit qui font l'office de duègnes auprès de jeunes dames; celles qui servent dans les maisons riches deviennent souvent les confidentes de leurs maîtresses, et il en est qui parviennent à diriger le ménage.

Le quarteron (issu de race blanche et mulâtre) a généralement les traits réguliers et beaux, le teint clair, les yeux bleus et les cheveux blonds; ces hommes ont l'aspect doux, sociable, mais ils sont moins actifs, moins intelligents que les mulâtres; leur front est étroit comme celui des métis; on doit encore citer comme signes distinctifs chez ces hommes, une petile saillie au milieu du nez; quelques taches noires sur diverses parties du corps, principalement sur les reins; ces dernières ne disparaissent que lentement, et subsistent quelquefois jusqu'à la cinquième génération.

Les zambos (résultat de l'union du nègre et du mulâtre) sont plus robustes que les mulâtres; moroses, entêtés, ils sont plus vicieux que le nègre africain, avec lequel ils ont plus d'un point de ressemblance. Ce sont eux qui fournissent aux tribunaux le plus grand nombre de voleurs et de meurtriers.

Ils ont pourtant, sous ce point de vue, de redoutables concurrents dans les chinos (produit du sang nègre et du sang indien), classe infime de la population péruvienne. La taille de ces derniers est peu élevée; leur menton, presque entièrement privé de barbe, les rapproche des Indiens, et la frisure des cheveux les distingue des autres races. Ils sont d'ailleurs cruels, vindicatifs, stupides, rancuniers et provocateurs.

Le NĖGRE CRÉole se croit bien supérieur au bozolès ou esclave africain, et s'unit rarement à cette race réprouvée. Il a cependant tous les vices, toutes les qualités de sa caste; mais il a aussi des formes plus athlétiques que ses parents d'Afrique.

A l'égard des Indiens répandus dans la capitale, il serait difficile, n'était leur teint cuivré, de les distinguer des créoles, tant ils imitent parfaitement les manières et la mise de ceux-ci. Ils s'adonnent généralement à la passementerie d'or et d'argent; quelques-uns se font tailleurs, porteurs de balles; mais on en voit peu qui embrassent la domesticilé pour laquelle ils témoignent une répugnance qui les honore.

Quant aux restes de la population aborigène qui occupent les environs de Lima, on peut à peine les considérer comme des échantillons de la race indienne.

On trouve dans la sociélé de Lima, qui se rapproche beaucoup de celle de l'Europe, des personnes dignes de remarque, autant par leur instruction que par leurs manières. 


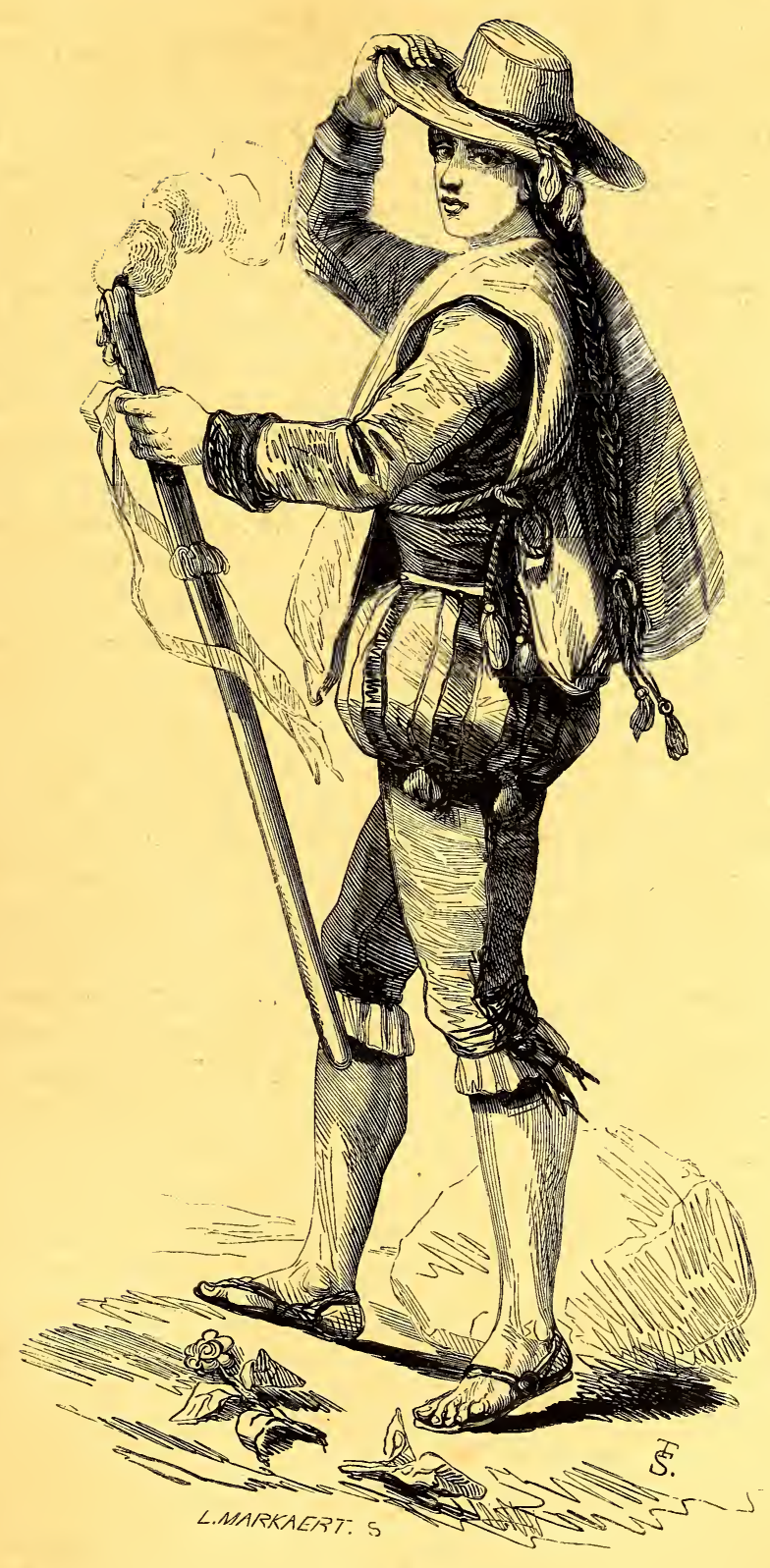

METIS 



Les gens distingués ont adopté les modes françaises, et il règne à Lima beaucoup de luxe, de toilette et de propreté. La plupart des femmes sont petites, gracieuses, spirituelles; leurs traits sont d'une grande finesse; leurs yeux fort beaux; leurs dents belles et blanches; leur chevelure est noire, magnifique, abondante; leur pied petit, bien fait; leur jambe fine par le bas. Quant à leur teint, c'est celui des filles du soleil, d'une nuance blanche, inclinant légèrement sur le jaune, et sans couleurs. On ne saurait exprimer précisément le charme de cette complexion; mais il est très-grand, et, selon un voyageur récent ${ }^{x}$, les femmes de Lima sont incontestablement très-jolies et très-agréables.

L'éducation est moins répandue ici qu'au Chili : à Lima, peu de jeunes personnes parlent une autre langue que l'espagnole, ou sont très-fortes musiciennes; et celles qui s'occupent de lecture et de travaux d'aiguille sont en bien petit nombre. Les femmes àgées n'ayant eu aucune espèce d'éducation, ont l'habitude de fumer ; jeunes, c'élaient des cigarites; plus tard, les cigares ont grandi à mesure qu'elles avançaient en âge : il y a des femmes qui font usage de cigares gros comme des bougies. Cependant elles ne les fument pas en une seule fois ; elles font durer le plaisir plusieurs jours, et même parfois plus d'une semaine.

La toilette de ces dames est élégante et recherchée; elles sont toujours coiffées en cheveux, avec des fleurs naturelles, et ne portent que des bas de soie et des souliers de satin dont elles font une consommation ruineuse, ce qui ne surprendra pas si l'on considère que les bas et les souliers d'une élégante doivent toujours être neufs.

Les dames qui vont à la promenade ou rendre des visites ne sortent qu'en voiture lorsqu'elles ont la toilette dont nous venons de parler; mais lorsqu'elles se risquent à pied, elles ajoutent, par-dessus celui-ci, un autre costume fort original, en usage pour faire les visites du matin : on le nomme saya ou saya manto. Cette toilette consiste en deux pièces principales : la saya, qui est la jupe, prend la taille à la ceinture, et descend jusqu'à la cheville des pieds; elle est en étoffe de soie, de couleur indéterminée, et plissée dans toute sa longueur; les plis, tenus ensemble par des fils qui les maintiennent, n'ôtent rien à l'élasticité de ce vêtement qui est très-étroit, et prend si exactement les formes que les jambes paraissent y être attachées; elles sont tellement serrées qu'il faut forcer la jupe pour avancer le pied et marcher. El manto, la seconde partie du vêtement que nous décrivons, part également de la taille où il est retenu par un cordon sur lequel il est froncé à coulisse; il revient par derrière au-dessus de la lête qu'il enveloppe, ainsi que la partie supérieure du bras; chaque main tient un des bords de cette partie de la mante qui sert de voile et se croise sur la figure. Quelle que soit la couleur de la saya, le manto est toujours en soie noire.

Sous ce costume, les femmes ne peuvent être reconnues, et on peut leur parler sans qu'elles se formalisent. Empaquetées à peu près comme les figurines que l'on trouve dans les tombeaux d'Egypte, elles ne peuvent marcher qu'à très-petits pas, ce qui, lorsqu'elles veulent aller vite, donne à leurs mouvements quelque chose d'excentrique et de fort amusant pour les voyageurs qui voient cet étrange accoutrement pour la première fois.

Cette mode, qui fut généralement adoptée jusqu'à l'émancipation du Pérou, tend chaque jour à se perdre. Les étrangers mariés à Lima ont obtenu de leurs femmes qu'elles l'abandonneraient. Toutefois, il en est qui n'ont fait que de demi-concessions, ainsi que le prouvent les sayas déplissés jusqu'au genou.

Au premier aspect, cette mode semble passablement inconvenante par son manque

1 M. l'amiral du Pelit-Thouars. 
de décence; bientôt on s'y accoutume et on ne remarque plus que la grâce déployée, sous ce vêtement, par quelques femmes.

Les Péruviennes ont une véritable passion pour les fleurs qu'elles se procurent quelquefois à des prix extravagants. On a vu vendre un lis blanc un peu hors de saison, huit dollars ou 40 francs; une hyacinthe 15 francs. On a fait à ce propos la remarque que la plupart des fleurs parliculières aux environs de Lima étaient jaunes, ce qui a donné naissance à ce dicton populaire: Oro en la costa, plata en la sierra ${ }^{\mathrm{x}}$.

On admire le parfum du floripondio, fleur qui a beaucoup d'analogie avec le lis; l'arbre qui la produil est très-louffu, et alleint à une hauteur de dix pieds. Les fleurs ont huit pouces de long; elles sont blanches, faites en forme de cloches et groupées en bouquets. Il ne faut pas plus d'un seul arbre pour parfumer un grand jardin; si ce nombre est dépassé, l'odeur est trop forte, et la tête ne saurait la supporter.

On cite encore le suche ${ }^{2}$ el l'arome comme agréablement aromatiques.

Après Lima, les villes les plus importantes sont: Cuzco, qui se distingue par les proportions grandioses et la magnificence de ses édifices, en tête desquels on doit nommer le temple du Soleil dont la somptuosité frappa d'étonnement les Espagnols, lorsque Pizarre prit possession de celte antique cité.

Le port de Galdao qui mérite une mention particulière, quoique la pelite ville qui porte ce nom ne se compose aujourd'hui que de deux ou trois cents maisons aussi pauvres que l'aspect des habitants est misérable. L'ancienne ville fut entièrement détruite par le tremblement de terre de 1746 ; la mer la couvrit par deux fois, el, des quatre mille habitants dont se composait la population, n'en épargna qu'un seul, probablement pour renseigner sur l'événement les curieux de la capitale. Quoi qu'il en soit, on prétend que par un temps calme on peut apercevoir les ruines de l'ancien Callao, au fond de la mer dans la paríie de la baie qu'on nomme mar braba.

Chuquisaca n'a de remarquable que sa qualité de capitale de la Bolivie. Arequipa se distingue par le piltoresque de ses envirous. Potosi est la ville péruvienne dont le nom est le plus connu en Europe; elle est bâtie au pied de la montagne de CErro, colossal pain de sucre qui s'élève à 17,000 pieds au-dessus de la mer, et dont la base a une circonférence de trois lieues : telle est cetle montagne fameuse dans le monde entier par les métaux précieux qu'elle renferme, et dont les flancs, percés de plus de cinq mille ouvertures, attestent l'importance qu'on attache à ses richesses.

Tout le pays qui environne Polosi est métallifère, et l'on cite la montagne appelée Guayna-Potosi ${ }^{3}$ comme renfermant en abondance de l'argent d'excellente qualité; il est à regrelter qu'elle ne puisse être soumise au travail des mineurs, à cause des sources nombreuses que l'on rencontre à quelques pieds de la surface du sol.

Nous devons placer ici la narration d'un singulier usage signalé par M. Miller, usage auquel l'indulgence des premiers propriétaires des mines a donné naissance ef qui s'est perpétué jusqu'à notre époque :

Entre la nuil du samedi et la matinée du lundi, le Cerro devient la propriété exclusive de toute personne qui veut, dans cel intervalle, travailler pour son propre compte. On comprend ceux qui vont ainsi glaner dans les mines, sous le nom générique de CAXCHAS; ils vendent habituellement à leurs patrons le produit de leurs recherches. On conçoit le préjudice que ces glaneurs causent à l'exploitation générale, en ce

1 Or sur la côte, argent dans les montagnes.

${ }^{2}$ Le suche est un grand arbre à branches étendues, et qui se couvre de grappes de fleurs en forme de cloches; elles sont tantôt blanches, tantôt rouges ou cramoisies.

3 Le nouveau Potosi. 
que, indépendamment du métal ainsi soustrait, ils ne se préoccupent nullement, dans leurs travaux particuliers, d'étayer les terres excavées. D'un autre côté, lorsque, dans le courant de la semaine, les caxchas découvrent une veine plus riche que les autres, ils s'abstiennent de la faire connaître, afin de l'explorer pour leur compte le dimanche suivant. Eı les maîtres n'oseraient, pendant ce jour consacré, surveiller leurs ouvriers, car ils savent que ceux-ci trouveraient moyen de leur faire payer cher cette surveillance. Il y eut un moment où l'on voulut abolir celte coutume, à cause des abus qu'elle comportait; mais tous les efforts restèrent sans fruits. Les caxchas repoussèrent toutes les tentatives les armes à la main, et tuèrent plusieurs soldats en roulant sur eux du haut de la montagne des pierres énormes. Les ouvriers demeurèrent donc en possession de leurs priviléges, à l'endroit desquels ils montrent une telle vigilance, qu'ayant surpris un soir quinze ou vingt lamas chargés d'argent, et qui avaient été mis en route après l'heure fixée pour le commencement de l'exercice du droit de caxcha, ils saisirent les animaux et leurs conducteurs dont on n'entendit plus parler.

Nous ne nommerons plus que Gaxamarca, ville remarquable par les ruines du palais des incas que renferment ses murs, par ses sources d'eau thermale, et par ses forges qui emploient les plus habiles ouvriers du Pérou.

Le territoire de la contrée que nous décrivons était el est encore habité par quatre nations distinctes. La principale et la plus nombreuse est la nation quichua ou inca; la seconde, par rang d'importance, est la nation aymara; les deux autres sont les Alacamas et les Changos.

Les Quichuas étaient autrefois le peuple souverain, dominant, le représentant de la civilisation péruvienne; les trois autres nations leur étaient soumises. Le tableau suivant évalue la population respective actuelle de ces quatre tribus ;

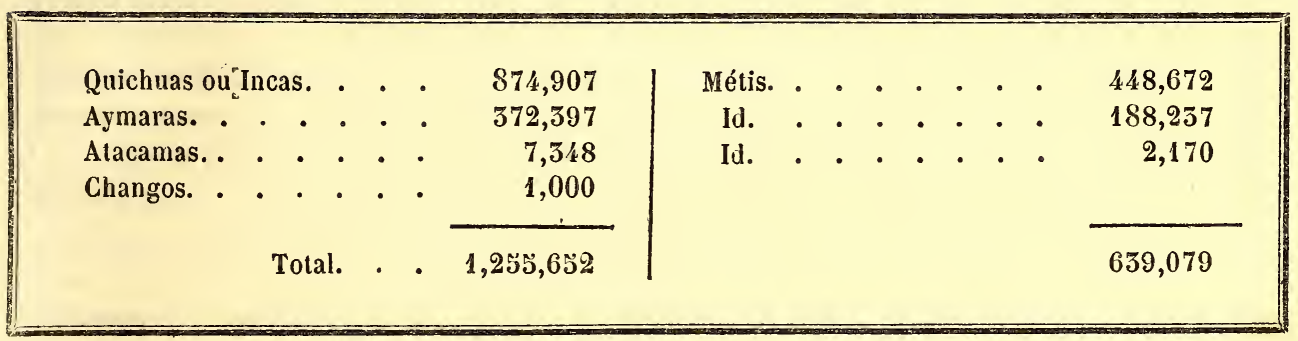

Il faut remarquer que depuis longtemps il n'existe plus au Pérou de peuples à l'élat sauvage proprement dit. Le total de 1,894,731 individus, tant métis que de race pure, que nous venons de présenter, ne comprend donc que des chrétiens.

Les Qurchuas s'étendaient autrefois, vers le nord, sur tout le plateau, et vraisemblablement jusqu'à Quito, puisque, dans le royaume de ce nom, on parle encore aujourd'hui la langue quichua. Il est évident, dit. M. Frédéric Lacroix dans sa description du Pérou, que cette nation a absorbé une foule d'autres tribus qui s'agrégèrent successivement à l'empire des incas. Il paraît même que ce nom de Quichua n'était autrefois que la dénomination d'une de ces tribus; on croit qu'il n'a été généralisé que par les Espagnols. Celui d'inca, qui est devenu synonyme de Quichua, fut d'abord réservé aux membres et aux descendants de la famille royale; il signifiait plus particulièrement roi ou chef.

En ${ }_{\text {¿ }}$ se dirigeant vers le sud, les Quichuas occupaient tout le plateau des Andes du 
Pérou, et une certaine portion du versant oriental jusqu'au $15^{\circ}$ degré sud, où ils confinaient aux Aymaras; au sud de cette dernière nation, ils se répandaient dans les provinces de Cochabamba, de Chuquisaca, de Chayanta, de Potosi; à partir de cette zone, ils ne reparaissent plus sur les plateaux, et vivent sur le versant oriental jusqu'à Tucuman et Santiago del Estero, au $28^{\text {e }}$ degré de latitude. Sur le versant occidental, vers la côte, ils ne vont pas au delà de la ville d'Arequipa, dont les habitants sont des Aymaras, et d'Atacama, habitée jadis par la tribu de ce nom. Sur tout le littoral du sud, les Quichuas avaient sous leur domination des peuples soumis, mais d'une origine différente de la leur. Ils couvraient aussi une longue bande de terrain qui suivait du nord au sud la chaîne des Andes, depuis Quito jusque près du lac de Titicaca; plus loin que les Aymaras, enclavés au milieu d'eux, ils reparaissaient encore sur une lisière du versant oriental, depuis Cochabamba jusqu'à Santiago del Estero; les Andes les bornaient vers l'ouest; vers l'est, les plaines chaudes et boisées formaient les limites de leur territoire. La population quichua est encore assez considérable, comme nous l'avons vu plus haut.

Les Quichuas sont généralement bien constitués, mais petits; la moyenne de leur taille est de 1 mètre 60 centimètres; mais beaucoup d'individus n'atteignent pas ce chiffre, surtout dans les lieux élevés, où la raréfaction de l'air nuit au développement normal du corps. Les femmes sont encore plus petites; elles n'ont guère que 1 mètre 460 millimètres.

En général, ces Indiens ont les formes massives, les épaules très-larges, la poitrine volumineuse, bombée et d'une longueur remarquable, d'où il résulte que le tronc offre une disproportion étrange avec les membres. Il en est de même de la tête, ordinairement très-grosse comparativement au corps.

Il n'est pas vrai que les Quichuas aient, comme on l'a prétendu, le teint rougeâtre; il offre, au contraire, un mélange de brun olivâtre foncé. La physionomie de ces Indiens présente un ensemble qui paraît constituer un type particulier, et rapproché du type mexicain beaucoup plus que de celui des nations voisines. Ils ont la tête oblongue d'avant en arrière, et sensiblement déprimée sur les côtés; le front légèrement bombé quoique fuyant, ce qui n'empêche pas que le crâne soit souvent très-développé, et le cerveau d'un notable volume; la figure large et communément ronde; le nez allongé, saillant, aquilin, recourbé à son extrémité inférieure, déprimé par le haut, garni de narines larges et ouvertes; la bouche grande, proéminente, sans que les lèvres soient trop grosses; les dents blanches et se conservant jusque dans la vieillesse; les joues peu saillantes et seulement chez les personnes avancées en âge; les yeux ordinairement petits, non bridés ni relevés en dehors; les cheveux invariablement noirs, gros, roides, épais, longs et plantés très-bas des deux côtés du front; les sourcils remarquablement arqués, mais étroits, peu fournis; quant à la barbe, c'est à peine si, chez quelques hommes faits, on remarque quelques poils sur la lèvre supérieure et au menton.

Ce qui frappe surtout dans l'expression du visage de ces hommes, c'est un air triste, sérieux, réfléchi, mais en mème temps hypocrite ou tout au moins sournois.

La constitution des femmes est à peu près la même que celle des hommes; elles se distinguent principalement par le volume de la gorge.

Les Quichuas sont doux, pacifiques, sociables; on les a, à tort, accusés de lâcheté: ils ont prouvé, lors de la conquête du Pérou, qu'ils n'étaient dépourvus ni de courage ni d'intrépidité; et s'ils ont mérité l'espèce d'abrutissement qu'on leur a si souvent reproché, c'est aux institutions qui les régissaient qu'il faut l'attribuer. L'ignorance, la superstition leur ont fait envisager comme un sacrilége toule pensée de rébellion contre leurs souverains, et les historiens ont pris pour de la pusillanimilé ce qui 


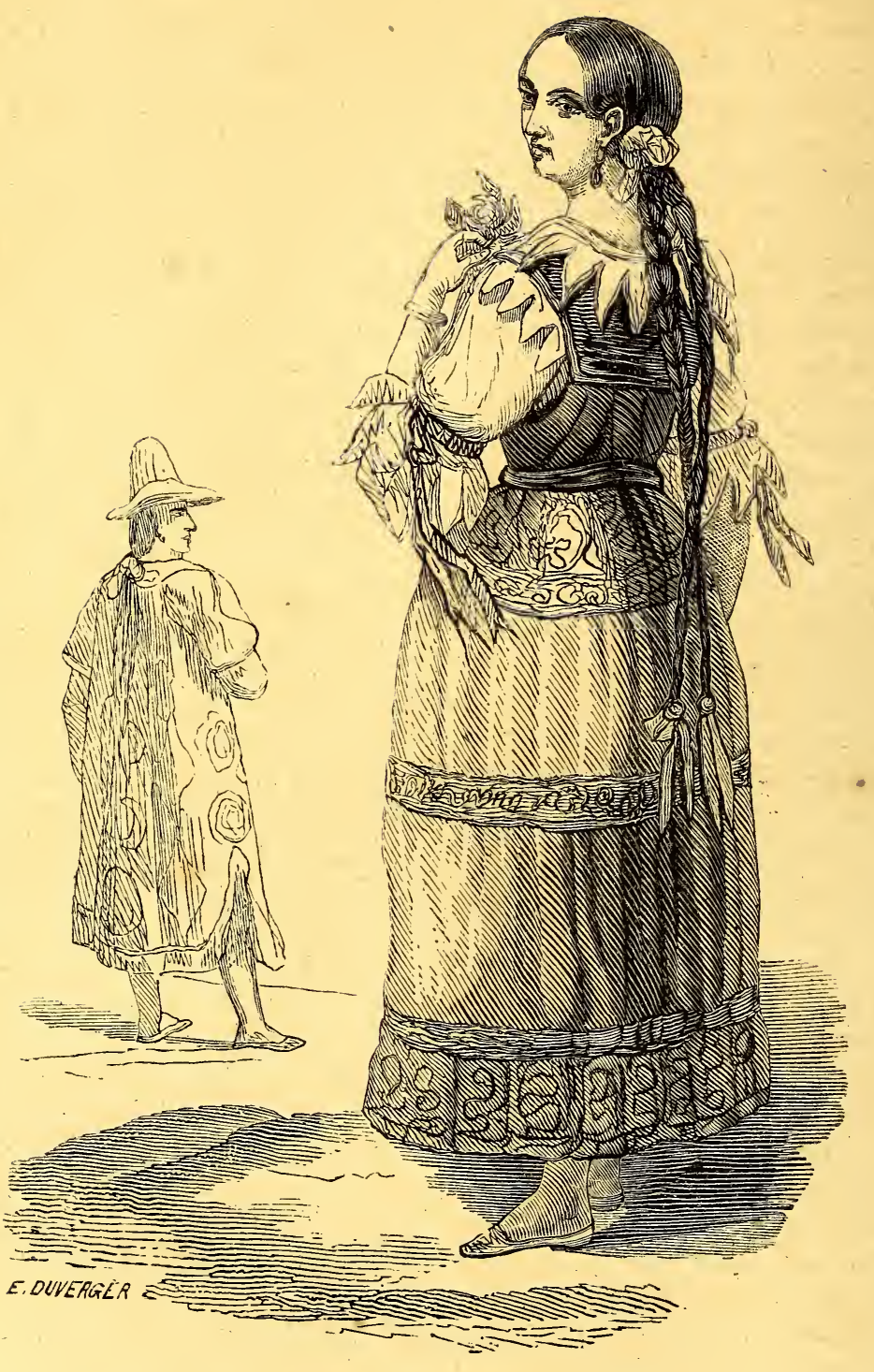

FEMME ET HOMME DE BOLIVIA.

(Amérique du Sud.) 
n'était que l'apathie et l'indolence résultant de coutumes énervantes qui modifient nécessairement les instincts les plus énergiques.

Hospitaliers envers les étrangers, reconnaissants envers les personnes qui leur ont fait du bien, ils sont bons pères de famille, ouvriers adroits et laborieux. Ils conservent le ressentiment d'une offense; mais ils cherchent rarement l'occasion de se venger. La discrétion, la sobriété, la résignation doivent encore être mises au rang de leurs bonnes qualités.

Divers auteurs ont calomnié les Quichuas. Si nous pouvions entrer dans le récit de l'histoire du Pérou, nous trouverions mille témoignages de l'aptitude de ce peuple pour l'industrie, les arts et les sciences qui conduisent à la véritable civilisation : il a élevé des monuments somptueux et grandioses; il a montré une habileté remarquable dans les procédés d'agriculture; il savait fondre et travailler les métaux; il avait compris l'année solaire, était parvenu à déterminer les équinoxes et les solstices, avait inventé toutes les séries de nombres indispensables aux combinaisons de l'arithmétique; enfin il avait déployé dans les voies de communication, et dans un grand nombre d'autres branches d'industrie, une intelligence et des connaissances qui réfutent victorieusement l'opinion de ses détracteurs.

M. d'Orbigny a décrit le costume des Quichuas qu'il a vus à ChuQuisaca. Les hommes portent un casque à houppe rouge, des culottes noires d'où sortent des jambes toujours nues; leurs sandales sont de cuir; et ils ont une espèce de surtout tricolore ou quadricolore, garni de franges rouges et jaunes, sous lequel est une veste.

Les femmes de distinction sont vêtues d'un jupon rond à petits plis, orné, vers le bas, d'une large garniture tranchant sur le fond, et surchargé d'une broderie en or; d'un corsage blanc, à manches larges et serrées au poignet, recouvert d'une sorte de chasuble richement brodée; leurs cheveux, réunis par un grand peigne d'or, sont enlacés de rang de perles, et pendent par derrière en plusieurs tresses.

Les femmes de la classe inférieure ont un costume moins coûteux, mais aussi brillant, aussi lourd, et dont le caractère distinctif est la variété, le bariolage des couleurs les plus tranchantes.

Les Aymaras, sous le rapport physique, semblent ne former qu'une seule et même nation avec les Quichuas. Mais ils méritent une attention particulière, car c'est la nation aymara qui paraît avoir été le berceau de la civilisation péruvienne.

On rapporte comme un fait certain que ce peuple avait jadis la coutume de s'aplatir la tête, et la pression avait lieu d'avant en arrière et encore circulairement; opération dont le but était de refouler en arrière le cerveau, et de donner un grand développement aux parties postérieures de la tête, au détriment des parties antérieures.

L'idiome aymara, de mème que la langue quichua, est d'une grande richesse, et offre toutes les ressources possibles pour l'expression nette et précise des pensées les plus variées. Les sons gutturaux sont encore plus nombreux que chez les Quichuas; mais le caractère général de ce dialecte est poétique, et il a dans ses tournures une grande élégance, quoique la prononciation soit très-dure.

Nous devons encore signaler comme un point essentiel la différence qui existait entre l'architecture des Aymaras et celle des Quichuas. La plupart des monuments de ceux-ci sont dépourvus de toute sculpture, de tous reliefs plats, tandis que toutes les constructions des premiers en sont ornés; ce qui semblerait prouver que les Aymaras ont été les premiers et les plus civilisés des peuples péruviens.

Les Atacamas, dont les ancêtres étaient appelés Olipes ou Llipi, sont aussi semblables aux Quichuas sous les rapports physiques; mais leur langue n'a rien de commun avec celle de leurs voisins. Ils sont pêcheurs et agriculteurs. 
Les Changos forment une population d'environ 1,000 individus. Ils ont la taille un peu plus petite et le teint plus foncé que les Quichuas; leur nez n'est pas aquilin.

Une tente composée de quatre piquets et de peaux de phoques forme l'habitation d'une famille, dont tous les membres couchent pêle-mêle sur des peaux de moutons ou des algues sèches.

Les hommes ont pour unique industrie la pêche, à laquelle ils passent tout le jour. I.eurs barques, sur lesquelles ils s'aventurent en mer, se composent de deux outres de peaux de phoques remplies d'air et liées ensemble. Ces canots, communs aux Aymaras, glissent au milieu des flots au moyen d'une rame à deux bouts, propre à pagayer des deux côtés. A genoux sur le devant de cette embarcation, le pêcheur va chasser le loup marin sur les rochers, et harponner le poisson en pleine mer. Ils sont aussi adroits qu'intrépides, et ils ne rentrent guère chez eux qu'avec un butin convenable.

Lorsqu'ils voyagent à travers les déserts situés entre la côte et l'intérieur du pays, ils font porter à leurs femmes les fardeaux les plus lourds; elles se servent pour cela d'une espèce de hotte qu'elles soutiennent au moyen d'une sangle portant sur le front.

Les Yuracarès ${ }^{1}$ forment une peuplade disséminée au pied des derniers contre-forts des Andes orientales, et principalement dans les forêts qui avoisinent les montagnes. Cette nation, qui ne compte pas 2,000 individus, s'étend sur une surface de vingt à trente lieues de largeur.

La taille de ces hommes est en moyenne ${ }^{2}$ de 1 mètre 66 centimètres. Le corps proportionné à cette stature offre les apparences de la force et de l'agilité. Le fond du caractère des Yuracarès est la vanité, que trahit la fierté de leur démarche. - Les femmes ont également des formes qui annoncent une grande vigueur physique, sans être pour cela dépourvues de grâce et de souplesse.

Ils se rapprochent des Quichuas par les traits du visage; mais leur teint est presque blanc, ce qui paraît résulter de leur séjour au milieu des forêts épaisses et humides à l'ombre desquelles ils vivent; et leur physionomie a une expression de vivacité qui pourrait passer pour de l'enjouement. Une particularité singulière, c'est que le corps et le visage d'un grand nombre sont couverts de larges taches d'une nuance plus claire que le reste de leur peau.

La langue est très-douce, sans accumulation de consonnes ni désinences trop dures.

Selon l'ọpinion de M. d'Orbigny, le caractère de ces sauvages présente une réunion monstrueuse des vices que détermine, chez l'homme superstitieux, une éducation qui n'admet ni les réprimandes ni même de simples conseils. Ils sont assez gais, ont de la pénétration, de la finesse, de l'esprit même; aussi se croient-ils supérieurs aux autres hommes, ce qui les rend insolents, hautains, hardis, entreprenants jusqu’à la témérité.

Endurcis aux souffrances physiques, cruels pour eux-mêmes autant que pour les autres, ils témoignent une insensibilité extrême, qu'il faut attribuer sans doute à l'habitude où ils sont, dans les mille occasions qui naissent de superstitions sans nombre, de se couvrir de blessures et de martyriser leurs femmes et leurs enfants. Les liens de famille ne sont point appréciés par eux; on les voit souvent abandonner leurs parents, et immoler leurs enfants sans autre motif que celui de se soustraire à l'embarras de les élever. Ennemis de toute société, ils ne vivent que par familles, et encore dans celles-ci, on ne connaît ni égards ni subordination; chez les mères elles-mêmes on ne

1 Nom qui signifie hommes blancs.

2 Elle atteint quelquefois 1 mètre 76 centimètres. 
rencontre pas toujours le sentiment maternel; mais ce qui est assez extraordinaire, c'est que, tout en immolant communément la moitié des enfants auxquels elles ont donné le jour, elles sont esclaves de ceux qu'elles ont conservés.

Ces sauvages n'ont aucune espèce de gouvernement, et vivent dans une indépençance que favorise leur dispersion dans les bois.

Une orgie signale le mariage du Yuracarès. Aussitôt la cérémonie terminée, il se rend avec sa femme près d'un ruisseau, au sein de sombres forêts, où, aidé des siens qu'il a invités à se joindre à lui dans cette occasion, il abat des arbres, élève une vaste cabane qu'il recouvre de feuilles de palmier, ensemence un champ, et, en attendant la récolte, a recours, pour vivre, à la chasse et à la pêche. Il séjourne là quelques années, et quitte ensuite la place pour aller s'établir à peu de distance. La femme alors se charge de tout le bagage renfermé dans une espèce de filet, tandis que l'époux ne porte que ses-armes.

Infatigables visiteurs, les Yuracarès préviennent toujours de loin, par des fanfares ou par des sifflements, les voisins chez lesquels ils se rendent. Dans ces entrevues, ils observent entre eux beaucoup de cérémonial, et durant leurs conférences fort longues, ils ne se regardent jamais. Ces réunions se terminent presque toujours par des orgies, des danses monotones, et jamais sans que chacun ait arrosé la terre du sang qui découle des blessures qu'ils se font aux bras et aux jambes; elles se renouvellent à différentes périodes de leur existence : par exemple, à la nubilité d'une jeune fille.

Dès qu'elles ressentent les douleurs de l'enfantement, les femmes se rendent au bord d'un ruisseau, dans les eaux duquel elles se baignent aussitôt après l'accouchement; elles retournent ensuite reprendre leurs travaux sans avoir pris d'autre repos. Souvent elles tuent immédiatement les malheureux qu'elles viennent de mettre au monde, soit parce qu'elles en ont un assez grand nombre, soit parce que les premiers qu'elles ont eus n'ont pas vécu.

Il n'est pas rare de voir les hommes se battre en duel à coup de flèches; ils mettent aussi le suicide en pratique. Ils se regardent comme de très-grands orateurs, et parlent quelquefois des heures entières.

Dans leurs réunions, ils mangent ensemble, et leurs repas, de même que leur chasse et leur pêche, sont assujettis à une multitude de superstitions. Des cérémonies superstitieuses président aussi à la guérison des malades, qui sont communément traités au milieu des bois; quelquefois on emploie des saignées locales.

A la mort de l'un d'eux, tout ce qui appartenait au défunt est anéanti; sa cabane et son champ sont abandonnés; mais on conserve son souvenir longtemps après que la terre a recouvert ses restes.

Des arcs et des flèches, qu'ils confectionnent avec grand soin, composent surtout les armes des Yuracarès, qui s'en servent en guise de harpons lorsqu'ils vont à la pêche sur les rivières; ils sont très-adroits chasseurs. Ils ne couchent point dans des hamacs comme beaucoup de peuples américains.

Ils fabriquent des chemises avec l'écorce de certains arbres, sur laquelle ils impriment des dessins coloriés qui ne sont, à vrai dire, que des lignes droites et courbes, sans signification, même emblématique. Mais ce qui est assez remarquable, c'est que l'impression de ces dessins est faite au moyen de planches en bois sculptées. Toutefois, s'ils ont quelques notions de l'impression que les nations voisines ignorent quoique plus civilisées, ils n'ont en revanche aucune idée de l'art du tisserand.

La culture des terres, le soin de préparer les boissons fermentées et de fabriquer des poteries, sont du domaine des femmes, qui ne se livrent pas à ces diverses occupations sans les accompagner de cérémonies superstitieuses. 
La composition du costume des Yuracarès est assez originale : ils ont pour vêtement principal une tunique sans manches, faite d'écorce de mûrier et ornée de dessins rouges et violets assez élégants quoique bizarres. Les hommes portent les cheveux coupés carrément sur le front, et laissent ceux de derrière tomber en forme de queue sur leurs épaules. Ils se peignent le visage de rouge, soit en partie soit en totalité, mais plus fréquemment le nez et le front; ils ont aussi la coutume de s'épiler les sourcils. A l'occasion des fètes, et au moment de la danse, ils se couvrent la tête de plumes; lorsqu'ils vont en visite chez leurs voisins, ils mêlent à leur chevelure le duvet blanc de l'oiseau appelé grande harpie, et l'on ne voit pas sans surprise leur couteau suspendu à l'extrémité des cheveux. Ils portent aussi comme ornements des sifflets et quelques autres objets.

Quant aux femmes, leur tunique n'est en aucune manière ornée; mais pour danser, elles se parent de bouquets de plumes variées qu'elles placent sur leurs épaules.

Les MocÉtÉnès ${ }^{x}$ ont pour territoire les montagnes que sillonne le Rio Beni, entre $15^{\circ}$ et $16^{\circ}$ de latitude, et $69^{\circ}$ et $71^{\circ}$ de longitude à l'ouest du méridien de Paris. Ce peuple est divisé en petites tribus; et il doit à la position de ses villages, situés au sein des bois les plus sombres, les plus humides, un teint aussi blanc que celui des Yuracarès. Une portion de cette peuplade est encore à l'état sauvage; le reste, converti au christianisme, est organisé en missions, sous les noms de San-Miguel et de Santa-Anna. La population des deux fractions présente un chiffre de 2,500 individus.

Ces Indiens offrent, sous le rapport physique, plusieurs points de ressemblance avec les Quichuas et les Aymaras; mais ils en diffèrent par le nez qu'ils ont court et aplati, et par l'expression de leur physionomie tout à fait efféminée.

Le caractère de ces gens simples et naïfs est éminemment sociable; leur vie paisible s'écoule à la chasse, à la pèche, ou au foyer domestique dans les joies de la famille. Ils sont enclins à la jalousie et défendent à leurs femmes toute course qui pourrait causer une absence prolongée. Il en résulte qu'elles ne quittent guère leurs pénates où l'habitude les retient autant que la volonté de leurs maris.

Ce peuple paraît avoir l'esprit du commerce : il échange contre des haches, des couteaux, et d'autres ustensiles provenant des provinces environnantes, les plumes aux couleurs éclatantes et les rares productions de son pays.

Quoique habitués à la navigation, les Mocéténès ne se servent, dans leurs courses sur les rivières et les torrents, que de troncs d'arbres réunis par des lianes pour former radeaux.

La culture des terres, le tissage et la teinture des étoffes, et la fabrication des armes et des ornements de plumes, telles sont les branches d'industrie de ces Indiens.

Leur costume est semblable à celui des Yuracarès; toutefois ils ne s'épilent point les sourcils comme leurs voisins, et leur tunique est d'un tissu de coton assez fin et garnie d'une bordure rouge sur un fond violet. Ils se bariolent le visage de trois raies bleues : l'une tracée en arc d'une joue à l'autre, en passant par la lèvre supérieure; la seconde traversant l'espace compris entre la lèvre inférieure et le menton; la troisième sur le nez.

Les Tacanas ${ }^{2}$ habitent les profondeurs du versant occidental du Rio Beni. Cette tribu, en y comprenant les Indiens des missions d'Aten, d'Isiamos, de Carinas, de Tumupasa, de San-Jose, et les sauvages Toromonas, ne présentent pas une population de plus de 3,600 individus.

1 Improprement appelés Chunchos par les Espagnols; les Yuracarès les appellent Maniquiés.

2 Les Espagnols les nomment Atenianos; Isiamos et Carinas. 
Ces indigènes tiennent, pour la couleur de la peau, le milieu entre les Quichuas et les Yuracarès. Pleins de vanité, d'ignorance, d'irritabilité, ils se sont pourtant soumis sans répugnance au christianisme, à l'exception d'une certaine portion. Ils sont chasseurs, pêcheurs, agriculteurs, et vivent dans un pays dont les productions suffisent à leurs besoins. Il paraît qu'un homme serait déshonoré s'il ne construisait à lui seul la maison"qu'il doit occuper plus tard avec sa femme et ses enfants.

Les Tacanas sauvages ne portent aucun vêtement, et se bornent, lorsqu'ils se livrent à leurs danses nationales, à orner leur tête de plumes. Ceux des missions vont tête nue; mais ils ont une tunique à manches larges. Les femmes ont pour parure des jarretières en or ou en argent, des bracelets et des colliers de verroterie.

Leur industrie est à peu près la même que celle des Mocéténès.

Les Maropas, réunis en mission, occupent la rive orientale du Rio Beni ; ils comptent au plus 900 individus, et ressemblent beaucoup aux Tacanas, si ce n'est qu'ils sont plus doux et plus pacifiques.

Les Apolistas ont pour territoire le bourg d'Apolobamba, situé sur le Rio d'Apolo, affluent du Rio Beni. Ils sont au nombre d'environ 2,700, et ils ont ceci de particulier qu'ils tiennent à la fois des peuplades répandues sur les plateaux élevés par leur teinte brune, leur petite taille et la vigueur de leurs formes, et des tribus disséminées dans les parties chaudes des montagnes, par leurs traits efféminés, leur nez court, et leur idiome euphonique.

Il y a encore quelques autres tribus dont on sait tout au plus le nom. 



\section{BRÉSIL.}

Les bornes de ce pays ont été et sont encore l'objet de contestations aussi bien sous le point de vue géographique que sous le rapport politique. Nous citerons à ce propos ce passage de la Géographie universelle :

« L'empire portugais en Amérique doit, en quelque sorte, son existence à une erreur de géographie. Lorsque les Portugais eurent fait leur première descente au Brésil, la cour d'Espagne, qui regardait avec raison Vincent Pinson et Améric Vespuce comme les véritables auteurs de la découverte de ce pays, se plaignit vivement de cette invasion d'un continent sur lequel elle prétendait avoir le droit de première découverte. Le pape essaya d'abord de concilier les deux parties en traçant, d'autorité, la fameuse ligne de démarcation à cent lieues à l'ouest des îles du Cap-Vert, ligne qui ne peut atteindre la vraie position du Brésil, quelque échelle qu'on adopte pour l'évaluation des lieues, soit qu'on veuille y voir des lieues castillanes de 26 au degré, soit qu'on en fasse des lieues marines de 20, ou même des lieues portugaises de 17 au degré. Mais le cosmographe don Pedro Nugnez et l'hydrographe Texeira portèrent, dans leurs cartes, le Brésil trop à l'est, l'un de 22 degrés, l'autre de 12 à 13. Moyennant cette erreur énorme, et peutêtre un peu volontaire, les Portugais faisaient entrer dans leur hémisphère une partie quelconque du Brésil. Cependant, mécontents de la décision pontificale, les Portugais profitèrent d'un moment favorable pour arracher à l'Espagne des concessions plus élendues. Le traité de Tordesillas, signé le 7 juin 1594, traça la ligne de démarcation définitive à $\mathbf{3 7 0}$ lieues à l'ouest de l'île la plus occidentale du cap Vert, mais également sans fixer la valeur de la lieue, car les diplomates ont de tout temps été fort habiles à tout embrouiller en géographie. Si l'on entend des lieues castillanes, la ligne n'atteint pas le vrai méridien de Bahia; si l'on veut parler des lieues marines, elle arrive jusqu'à celui de Rio-Janeiro; si enfin, et c'est la supposition la plus favorable, on adopte les lieues portugaises, la ligne correspond à peu près au méridien de Saint-Paul, mais n'atteint pas seulement d'un degré près celui de Para ou l'embouchure de l'Amazone ${ }^{\text {. }}$

\Ainsi les Espagnols accusaient avec raison les Portugais d'avoir, en temps de pleine paix, envahi l'immense territoire de l'Amazone et une grande partie du Paraguay, au inépris des traités solennels. Enfin ces acquisitions illégitimes furent confirmées au Portugal par le traité de 1778; l'Espagne exigea la fixation d'une limite positive, et que désormais elle ne laisserait plus impunément violer. Les Portugais n'ont pas respecté cette limite; ils se sont établis sur le territoire neutre du côté de Mérim; ils ont envahi sept villages des Guaranis, renfermant 12,200 habitants, entre les rivières Uruguay et Iguacu; ils ont passé à travers le territoire des Payaguas, et bâti les forts de

1 Memoria sobre la linea divisoria, etc., manuscrit accompagné d'une carte, et dressé pour le gouvernement d'Espagne, par le ministre M. de Lastarria. 
Nouvelle-Coïmbre et d'Albuquerque sur le territoire des Chiquitos : voilà seulement quelques-unes des plaintes que les autorités locales adressaient au vice-roi de BuenosAyres, et que celui-ci transmettait à la cour de Madrid il y a une quarantaine d'années ${ }^{x}$. Depuis, les troubles de l'Amérique espagnole leur ont fourni une occasion favorable de s'étendre.

\ La comparaison des cartes géographiques anciennes et modernes rend sensible cette constante invasion des Portugais. Sur les anciennes cartes, le nom de Brésil n'a élé donné qu'aux côtes maritimes, depuis Para jusqu'à la grande rivière de San-Pedro. Les contrées situées sur les rivières des Amazones, de Madeira, de Xingu, portaient le nom de Pays des Amazones; elles sont à présent, pour la plus grande partie, comprises dans le gouvernement de Para. La dénomination de Paraguay, dans les carles mêmes de la fin du dernier siècle, s'étend sur la plus grande partie du gouvernement de MatoGrosso, sur la partie occidentale de celui de Saint-Paul : l'usage moderne et une ordonnance du souverain ont enfin consacré le nom d'empire du Brésil pour toutes les possessions portugaises en Amérique. Cette vaste contrée renferme probablement, à peu de chose près, les deux cinquièmes de la surface de l'Amérique méridionale, ou plus de dix fois l'étendue de la France. Mais la population, qui n'est un peu concentrée que sur les côtes et dans les districts des mines, s'élève tout au plus à cinq millions, dont un quart à peine est du sang européen.

Le Brésil renferme $5,340,000$ habitants, parmi lesquels on compte à peu près un cinquième de Portugais.

Le gouvernement est une monarchie constitutionnelle; le chef de l'État, qui prend le titre d'empereur, sanctionne ou rejette les lois, proroge ou dissout les chambres, et commande l'armée. De récentes modifications dans la constitution ont établi que les membres du sénat seront élus pour un temps fixé, et ceux de la chambre des députés pour deux ans par les provinces. Les impôts, le recrutement, le choix de la dynastie en cas d'extinction de la famille régnante, la mise en accusation des ministres, sont du ressort de la chambre élective.

A l'exception des domestiques, des esclaves et des mendiants, tous les Brésiliens jouissent des mêmes droits civils et politiques. La liberté individuelle et religieuse, le libre exercice de l'industrie, la liberté limitée de la presse sont consacrés par la constitution.

En 1822, le vœu général érigea la nation brésilienne en empire indépendant; don Pedro, chef constitutionnel de cet empire, soumit bientôt à l'acceptation de toutes les classes une constitution que, le 25 mars 1824, il fit serment de maintenir. Alors on ne prévoyait pas que, sept années plus tard, des ministres impopulaires compromettraient le trône de ce prince, et que ce dernier, après avoir abdiqué volontairement la couronne de Portugal, se verrait forcé d'abdiquer celle du Brésil, où du moins il avait eu la gloire de calmer les partis avant d'accepler la suprême dignité. Eh bien! aujourd'hui est-il déraisonnable de supposer que le Brésil verra tôt ou tard ses destinées remises en question?... L'esprit des habitants de ce pays ne sera-t-il pas naturellement influencé par l'exemple des trois républiques avec lesquelles il confine au sud, à l'ouest et au nord; et voudront-ils rester exposés à ce que leur jeune prince ait un jour, comme son père, la témérité de repousser le vœu public pour chercher un appui dans la force des baïonnettes ?... Ce sont là des hypothèses que le temps seul peut résoudre, mais que l'état des esprits dans l'Amérique espagnole ne permet pas de traiter d'invraisemblables. De même que les gouveirnements constitutionnels semblent devoir s'établir

1 Les manuscrits précités, et la carte manuscrite du Paraguay y annexée. 
dans toute l'Europe, les institutions républicaines paraissent avoir choisi le nouveau monde pour domaine.

Le Brésil est divisé en dix-huit provinces et vingt-quatre comarcas, subdivisions dans chacune desquelles existe un juge en deuxième instance (ou ouvidor), dont on appelle aux cours souveraines (relacoès).

Celles-ci sont au nombre de deux ; l'une à Bahia à laquelle ressortissent Para, Maranhao, Pernambuco, Goyazes et Bahia; l'autre à Rio-de-Janeiro, dont dépendent Minas-Geraes, Mato-Grosso et San-Paulo. Les gouverneurs de Rio-de-Janeiro et de Bahia sont les présidents de ces cours.

La résidence de l'archevêque primat du Brésil est Bahia; il a sous ses ordres six évêques qui habitent Belem dans le Para; Maranhao, Olinda, dans le Pernambuco; Rio-de-Janeiro, dans la province de San-Paulo; et Mariana, dans Minas-Geraes. En outre, il y a deux diocèses sans chapitres, qui sont appelés prelacias, administrés par des évèques in partibus : ce sont Guyazes et Cayaba. Le nombre des curés est insuffisant ; mais des particuliers entretiennent une foule de succursales.

Rio-De-JanerRo, dans la province de ce nom, est la capitale du Brésil; c'est une ville européenne où l'on trouve toutes les nations, excepté, peut-être, des Américains aborigènes. La douceur des mœurs, la galanterie des femmes, la magnificence des processions font ressembler cette ville à celles de l'Europe méridionale.

Les habitants de la province de Rio Grande peuvent être comparés aux fermiers de la Beauce '; cependant il y a plus de rapports encore avec le Bédouin et le Tatar. Ils sont bien faits et robustes. Ils ne sont heureux que lorsqu'ils se trouvent à cheval, lançant les boules ou le lacet contre une génisse sauvage, car alors il ne leur manque rien; ils emportent une nacelle pour traverser les fleuves, et ce qui leur est nécessaire pour se nourrir et disposer un lit au sein des déserts : s'ils veulent dormir, ils s'étendent sur le cuir écru qui, plié, formait la couverture de leur monture, et la selle étroite et légère, qu'ils appellent lombilho, leur sert d'oreiller; le même cuir, attaché aux quatre coins, se transforme en pirogue; suspendus à la selle, le lacet et les boules sont employés à réduire les bestiaux dont ils se nourrissent; et ils ont pour broche un bâton pointu plus facile encore à transporter que les autres instruments.

Il est peu agréable de voyager dans la province de SAN-PAULO; les issues en sont gardées avec soin par des soldats postés de distance en distance, et chargés de fouiller les voyageurs. Ces mesures sont prises à cause de l'or et des diamants que l'on rencontre dans cette province, mais qui y sont moins abondants qu'autrefois.

Les maisons de la ville de Saint-Paul sont bàties en pisé et peintes à fresques. Le luxe et la mollesse y ont de nombreux sectateurs. Dans tout le Brésil on vante la beauté, l'amabilité, la noblesse des manières des dames de Saint-Paul. Les jésuites du Paraguay avaient répandu sur l'origine ignoble des Paulistes des récits mensongers complétement réfutés aujourd'hui; l'opinon qui altribue la fondation de la ville à une bande d'aventuriers espagnols, portugais, métis et mulâtres, est victorieusement combattue par un membre savant de l'Académie royale des sciences de Lisbonne ${ }^{2}$. Après avoir établi péremptoirement que des Indiens de Piratininga et des jésuites s'y fixèrent les premiers, et que, dès sa fondation, Saint-Paul ne reconnut d'autre souveraineté que celle du Brésil, il nie que les Paulistes aient jamais vécu de brigandages. « L'élévation de leur caractère, dit-il, la délicatesse de leurs sentiments, leur susceptibilité sur le point d'honneur, leur probité, leur industrie, leur esprit public, ne sauraient être un

1 Province de France.

2 Nous voulons parler de Fr. Gaspar da Madre de Deos. 
héritage transmis par des gens de rien et des vagabonds. Citons un fait. Il y a un siècle environ, l'un de leurs gouverneurs, noble de naissance, avait eu une intrigue avec la fille d'un artisan. La ville entière embrassa la cause de la jeune personne, et le gouverneur fut obligé de réparer son honneur en l'épousant.

๑Sans doute, parmi tous les colons du Brésil, les Paulistes se sont signalés autrefois par leur esprit entreprenant, audacieux, infatigable, et par cette ardeur pour les découvertes qui distingua jadis les Portugais parmi les nations de l'Europe. Au lieu de cultiver paisiblement leur beau territoire, ils parcoururent le Brésil dans toutes les directions; ils se frayèrent de nouvelles routes à travers des forêts impénétrables, en portant leurs provisions avec eux; ils ne se laissèrent arrêter ni par les montagnes, ni par les rivières, ni par les déserts, ni par les naturels anthropophages qui partout leur disputaient le terrain. C'est à eux surtout qu'est due la découverte de toutes les mines les plus riches, qu'ils ne se laissèrent enlever qu'à regret, et pas toujours sans opposition, par le gouvernement. Aujourd'hui encore c'est sur leur énergie que repose la sûreté du Brésil occidental, et l'on sait que les troupes portugaises auraient joué un rôle assez triste dans la guerre coloniale de 1770, si elles n'avaient été secondées par les cavaliers paulistes, qui répandirent la terreur de leur nom depuis le Paraguay jusqu'au Pérou. ”

La province d'Espiritu-Santo n'a rien qui puisse nous arrêter. Celle de MinasGeraes est la plus peuplée et la plus importante par ses mines. Elle renferme le Cerro do Frio ou district des diamants; personne ne passe dans cette contrée sans subir un examen rigoureux. On rapporte qu'un muletier, qui se rendait avec des marchandises à Rio-de-Janeiro, fut arrêté par deux cavaliers qui lui demandèrent son fusil qu'il leur remit. Les cavaliers enfoncèrent une vrille dans la crosse, la trouvèrent creuse, en firent sauter la ferrure, et en retirèrent trois cents carats de diamants. L'infortuné muletier eut beau protester de son innocence; il avait élé trahi par un ami. Il fut arrêté, traîné en prison pour y être enfermé le reste de ses jours, ou déporté dans un fort de la côle d'Afrique.

Les autres provinces ne nous offrant rien d'intéressant, nous passerons à la description des peuples indiens qui occupent le Brésil et le littoral environnant cette contrée.

Les Yameos habitent le district de Huarinas, et forment une race paisible, docile el récemment civilisée. Ils sont nonchalants, mous, semblent redouter toute espèce de Iravail, et ne veulent s'adonner à rien qu'à la chasse et à la pêche. Ils sont gloutons si les vivres sont en abondance; mais ils supportent patiemment la disette. Ils ont pour armes une espèce de sarbacane, à l'aide de laquelle ils lancent des flèches empoisonnées; celles-ci sont en bois de palmier, et portent au bout un morceau de colon qui remplit exactement le tube. Ils manquent rarement le but qu'ils visent, même à quarante pas; et l'animal atteint succombe en peu de minutes tant est violent le poison dont ils imprègnent leurs flèches.

La mission de Pebas est habitée par les Yaguas et les Origones. Les premiers sont grands, bien faits, cuivrés, avec une figure belle, pleine d'expression, et la chevelure plus claire que celle des autres Indiens. Ils se parent les bras et les jambes de longues feuilles d'assas. Ils sont autochtones de cette contrée.

Les Origones sont plus noirs, plus petits, plus grêles, et n'ont pas la distinction de taille et de figure qui caractérise les Yaguas. Ils se sont acquis une grande réputation par la manière dont ils préparent un poison qui ne perd rien de sa force au bout de deux ans.

Deux peuplades, entre autres, sont établies aux environs de TABatinga. La première est celle des Maxurunas ou Maxourounas, sur les rives du Rio Yavari. Quelques-uns 


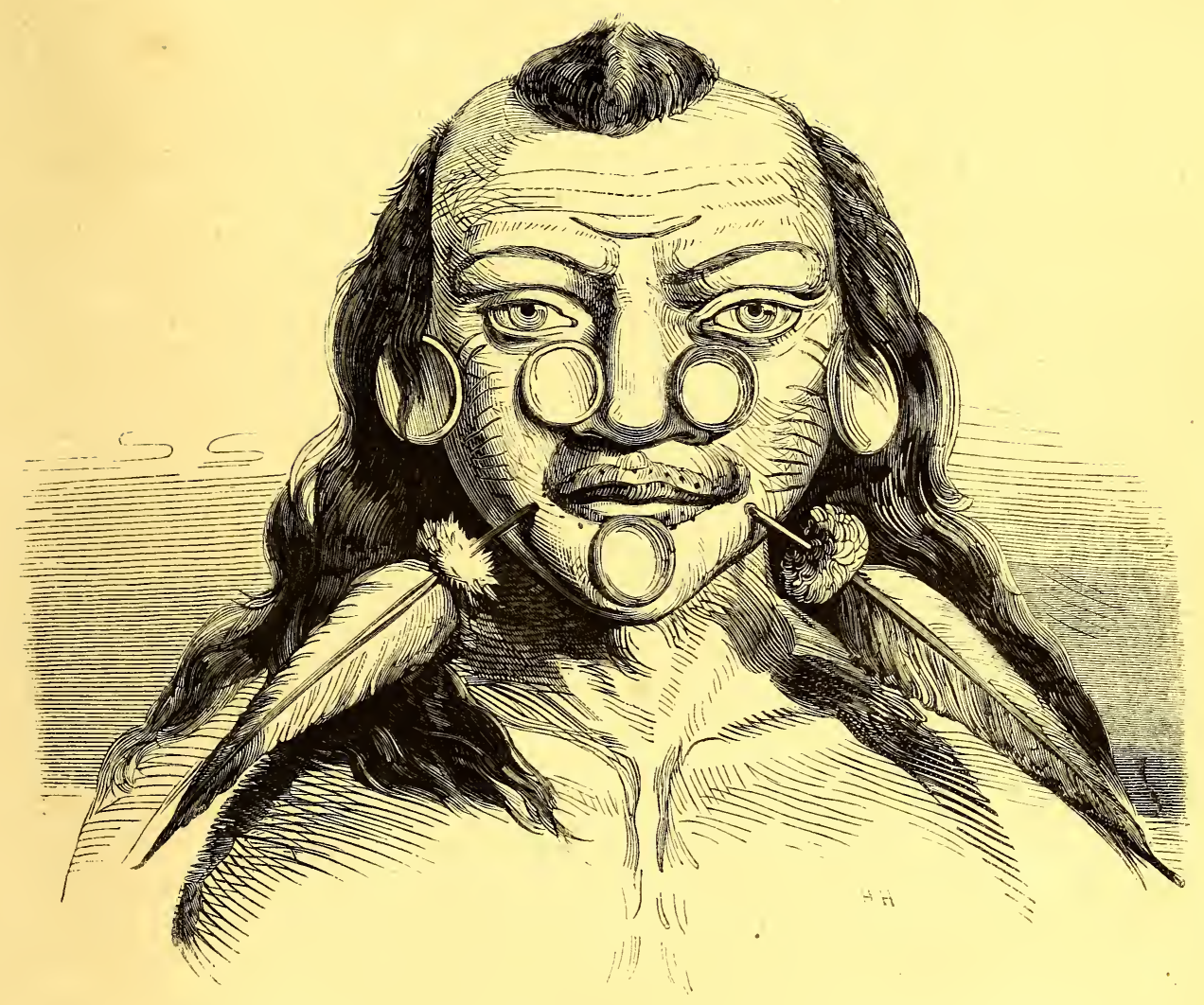

iraxourounes

(Brésii.) 

sont complétement sauvages. Ils ont le nez, les oreilles et les lèvres percés; leur visage est garni de plumes et d'épines d'arbres; leur front rayé de noir et de rouge. Ils portent les cheveux longs et se teignent parfois le corps d'une couleur claire. Des entailles profondes, qu'ils pratiquent comme indices et essais de leurs forces, sillonnent leurs bras. Leurs mœurs n'offrent pas moins de bizarreries que leur physionomie et leur accoutrement. Lorsqu'une femme est en couche, elle ne peut se nourrir que de hoccos; la viande du singe lui est interdite. La naissance d'un enfant n'occasionne aucune cérémonie; mais le percement des joues, des oreilles et des lèvres est un signal de fête pour toute une tribu. Cachés derrière un arbre, sur les bords de l'Ucayali et du Yavari, ces sauvages épient le passage des canots, et, lorsqu'ils sont à portée, ils percent d'abord le pilote d'une flèche, puis se précipitent sur l'équipage, qu'ils massacrent à coups de tamacunos ou massues.

La gravure que nous avons donnée représente un chef de Maxourounas; ses cheveux sont coupés de façon à laisser autour de la tête un cercle de la largeur d'un pouce; les joues et le front sont tatoués par des handes transversales. Des morceaux de coquilles lui traversent les lobes des narines, les oreilles et la lèvre inférieure; plusieurs tiges de plantes sont comme fichées dans ses lèvres; et du coin de sa bouche sort une longue plume d'ara rouge.

La seconde peuplade est celle des Tecunas; ils sont moins farouches que les précédents. Lorsqu'une fête les appelle à Tabatinga, ils y accourent en grand nombre dans leurs pirogues. Ils sont nus, parés de bracelets aux bras et aux genoux, d'épaulettes et de coiffures en plumes, et d'une élégante ceinture faite d'écorces d'arbre. Ces fêtes durent jusqu'à trois jours consacrés à des danses et à de copieuses libations de chicha ${ }^{\mathbf{x}}$. Une pratique atroce a lieu à cette occasion : elle consiste à arracher, en grande pompe, les cheveux d'un enfant qui meurt souvent au milieu d'horribles souffrances.

Dans les environs de San-Paulo de Olivença sont répandus, outre des Técunas, les Campivas, les Culinas et les Araycas.

Les Campivas vont nus et se peignent le corps de différentes manières. Ils ont une pratique curieuse : celle d'étendre les enfants dans un berceau en forme de pirogue, et d'y fixer leurs têtes entre de minces planchettes, pour leur donner, par la pression, à peu près la figure d'une mître. Ils lancent les flèches avec une sarbacane. Ils se montrent d'ailleurs pacifiques et loyaux entre eux, et les voyageurs n'ont qu'à se louer de leur hospitalité bienveillante.

Les Culinas sont semblables aux Campivas. Leurs filles passent pour être, à la course, d'une remarquable agilité. Lorsqu'elles ont atteint l'âge de puberté, on les place dans un hamac, suspendu au sommet de la hutte; elles restent ainsi exposées à une fumée continuelle; elles doivent jeûner alors jusqu'à l'exténuation.

Indépendamment des coutumes communes aux Campivas, les Araycas en ont une qui leur est particulière. Chez eux, le jeune homme qui a une fiancée doit chassêr pour elle et la mériter en nourrissant le père, en le défrayant en toute circonstance; en un mot, en l'entourant des mêmes soins que s'il était le propre auteur de ses jours.

Les Cauxicunas, près de l'embouchure du Tocantin, ne portent point de vêtements. Ils ont le visage barbouillé de rouge et de noir, les bras et les genoux parés de cordons, d'écorces d'arbre et de plumes. Leurs huttes, faites de feuilles de palmier, ont une forme conique et une porte très-basse. Elles forment une pièce unique, basse, sombre, enfumée, où couchent sans distinction la famille et les chiens. Ces naturels mangent

${ }^{1}$ Liqueur tirée de l'aïpori fermentée. 
la chair du crocodille. Ceux de ces Indiens qui habitent le village de Malloca sont grands, bien faits, et ne pratiquent point le tatouage.

Indiens de Marapi. - Ce sont des tribus de Passés, de Yuris, de Coeranas et de Yumanas. Ils ont des arcs en bois rouge, un javelot (marncui), une massue (cuidaraz), dont la forme et les ornements varient suivant les tribus, et un bouclier fait d'une jeau de tapir tannée ou du dos d'un caïman. Les riches ont en outre une lame de couteau.

Spix et Martius, naturalistes allemands, ont visité ces indigènes. Un soir, en pénéIrant dans une de leurs cases, ils reculèrent épouvantés à la vue d'un magnifique serpent aux écailles jaunes et vertes, long de quatre aunes, et se tenant debout au milieu de cette cabane, comme l'eût pu faire un commensal familier et caressant. A la voix d'un vieil Indien, ce singulier hôte fit aux voyageurs des politesses à sa manière, et s'approcha d'eux en sautant, en dansant; puis il se roula, se déroula en longs anneaux, tantôt dans un sens, tantôt dans un autre; et enfin, après ces curieuses démonstrations, se retira dans un angle de la case, sur un tas de foin, d'où il ne bougea plus.

Il ne faut pas croire que chaque habitation ait un serpent. Ce sont les sorciers qui seuls apprivoisent ces reptiles, mème les plus venimeux, en leur arrachant les crocs à poison. Ils s'en servent ensuite pour la cure des morsures, science qui leur permet d'exercer une grande domination sur les autres sauvages, dont la crédulité et la superstition forment le caractère principal.

Les Miraschas forment la tribu la plus puissante de tout le bassin du Yapura. Ce sont les femmes qui remplissent la plupart des fonctions des hommes. Lorsque ceux-ci se mettent en voyage, elles préparent la cassave et le béjur nécessaires à l'approvisionnement des pirogues. Elles cultivent le manioc et soignent des petites plantations de cotonniers, filent au fuseau le duvet de cet arbre, et le teignent avec le suc extrait de diverses plantes. Ensuite, elles broient la graine, et quand elle a été cuite dans l'eau, elles y ajoutent du piment, et en font une espèce de bouillie qui se mange. La volaille qui circule autour des habitations est élevée par les femmes. Les jeunes enfants parcourent les forêts voisines pour y ramasser des racines, des fruits, des larves d'insectes, des fourmis, de petits poissons, du frai de grenouilles; enfin, du tata potaba, espèce d'amadou. Elles font des chemises sans coutures, obtenues de l'écorce du turiri violemment battue à coups de maillet. Avec l'écorce du turiri brun, elles font aussi de petits coffres pour enfermer leurs parures et leurs plumes, et avec le turiri blanc, des ceintures qu'elles peignent en couleur de terre. Malgré cette activité industrielle, les femmes vont entièrement nues.

Non loin de l'embouchure du Yapura se trouv̂e la petite ville d'Égas, où se rencontrent en plus grand nombre les Brancos, classe de métis qui font le commerce des esclaves, et, éludant la loi par laquelle les Indiens furent déclarés libres, poursuivent dans les (emptoirs de l'intérieur, le commerce de chair humaine. Lorsqu'un de ces individus a besoin d'Indiens pour le défrichement de ses terres ou pour les offrir à des planteurs qui en cherchent, il a soin de s'associer trois ou quatre de ses collègues, et demande, en leur nom et au sien, l'entrée des missions indiennes, c'est-à-dire la faculté de remonter le Yapura, sur les bords duquel a lieu le plus grand trafic d'esclaves. Dès que la licence est oblenue, les Brancos arment une petite flottille de pirogues, et s'embarquent sur le fleuve qu'ils suivent jusqu'à l'endroit où ils supposent que les forêts cachent une tribu. Là, ils quittent les pirogues, et vont la nuit surprendre les sauvages dans leurs hamacs. Celte sorte de guerre par guet-apens tient les diverses tribus dans des alarmes perpétuelles.

Les Muras, sur la rive droite du Solimoès, sont hideux à voir avec leurs visages cou- 
verts de rouge et de noir, et défigurés par trois dents de porc qui sortent par des trous pratiqués au-dessous des narines et de la lèvre inférieure. Les paroles qui accompagnent leurs danses ne sont pas moins bizarres que leurs physionomies: "Voici ton diable; qui veut m'épouser? » disent les hommes. "Tu es un joli diable; toutes les femmes veulent t'épouser, " répondent celles-ci, et tout le monde continue à cabrioler.

Les Mandrucus peuplent la mission de Novo-Monte Carmel do Canoma. Ce sont des hommes dont la taille est d'environ cinq pieds six pouces, la poitrine large, les membres musculeux, la teinte de la peau assez claire, les cheveux coupés courts au-dessus du front, les traits du visage communs, fortement accusés, mais débonnaires; enfin le corps bariolé de lignes étroites commençant au cou et ne se terminant qu'à l'extrémité des orteils. L'humeur de ce peuple est des plus belliqueuse, et la guerre est pour lui une habitude et un plaisir. Les huttes sont entourées de pieux garnis de têtes d'ennemis, lesquelles, ainsi qu'une multitude de squelettes de jaguars, de coatis, de pecaris, etc. , donnent à leurs villages l'aspect de véritables charniers. Vainqueur, le Mandrucu n'épargne aucun de ses antagonistes; il le renverse, le saisit par les cheveux et détache la tête du tronc avec une dextérité merveilleuse à l'aide d'un couteau court, fait d'un morceau de roseau. Ce talent de décollation a valu au Mandrucu le surnom de coupe-tête (païquicè). Lorsqu'elles ont été préparées, ces têtes ne quittent plus l'individu qui s'en est fait un trophée; il le porte à la chasse comme à la guerre; il le place auprès de son hamac quand il se retire pour prendre du repos. On évalue les forces de ces peuplades à 40,000 naturels; et ils poursuivent les tribus ennemies avec un tel acharnement que plusieurs d'entre elles ont été anéanties peu à peu.

Les Aponegi-Crus et les Macama-Crus ont une source commune. On les nomme encore Caraonus. Ils sont établis dans les environs de Maranhào. Ce sont de fort beaux hommes, à la taille élevée, aux membres vigoureux, au port hardi, à la démarche sûre, aux traits ouverts et agréables. Leur peau est cuivrée et luisante comme chez la plupart des Indiens. Les gens âgés sont défigurés par des trous dans la lèvre inférieure, et par le prolongement des lobes des oreilles qui ont jusqu'à trois pouces; les trous de la lèvre sont remplis par des cylindres de résine d'un jaune brillant ou d'un blanc d'albâtre, longs de deux à trois pouces et faciles à enlever. Ils ne se tatouent point; mais lorsque le soir, à la lueur des torches, ils se livrent à la danse, ils étendent sur leur visage une couche épaisse de rouge et de noir. Dans ces occasions, leur physionomie a une apparence de frénésie et de férocité. Pour inviter ses compagnons à la danse, l'un d'eux souffle dans un boré, grande trompette faite d'un roseau et qui rend un son bruyant, auquel un autre Indien répond par un hurlement monotone, bientôt répété par tous les assistants. Ces individus vont nus; mais les femmes, lorsqu'elles se montrent dans les postes espagnols, sont vêtues décemment.

Les Tupinambas ou Topinambous s'étendaient autrefois depuis le Rio Muni jusqu'au Rio Para; aujourd'hui, ils sont restreints à quelques hordes éparses dans l'île de Maranhâo, et dans quelques autres localités; on évalue leur nombre à 9,000 individus.

Les Gamellas ou Acobas sont détestés de tous leurs voisins.

De mème que ces derniers, les Tenembas, ainsi que les Cayacas, sont une fraction de la tribu des Bus.

Les Cupinharos sont disséminés dans les solitudes sur la rive droite du Tocantin. Les Chehs (tribus septentrionales) sont chasseurs, pècheurs, et quelque peu agriculteurs. Ils font preuve d'une adresse remarquable lorsqu'ils enlèvent des arbres les nids des abeilles sauvages, et séparent le miel de la cire; la récolte faite, ils viennent la vendre aux colons du voisinage. Chez eur, ils ne portent aucuns vêtements; mais pour la danse et la guerre, ils se parent le corps et ornent leurs armes de plumes omnicolores, de cor- 
dons, de dents d'animaux et des graines luisantes du seleria. Ils se font assez souvent la guerre entre eux. Pendant ces luttes, le plus habile a le commandement; la paix faite, ce chef improvisé dépose son pouvoir, en même temps que sa hache de pierre à manche court, seule marque distinctive de sa qualité durant ses fonctions. Leur arme principale est une massue de bois très-pesante; toutefois l'usage des flèches empoisonnées ne leur est pas étranger. Dans leurs attaques, ils témoignent une certaine entente de la stratégie : ils calculent, préviennent, et mettent en pratique les fausses alertes et les diversions. Quoiqu'ils épargnent rarement leurs prisonniers, ils punissent sévèrenent le meurtre ainsi que le vol; celui qui a dérobé est obligé à une réparation proportionnée à la valeur de l'objet du larcin; le meurtrier est mis à mort par les parents de la victime : c'est la loi du talion pure et simple. Pleins d'effroi vis-à-vis des sorciers, ils paraissent médiocrement occupés de l'idée d'une puissance suprême. Ils calculent le temps par les phases de la lune; lorsque, dans la saison des pluies, elle se couvre de nuages, leur période se prolonge indéfiniment, sans qu'ils cherchent à obvier à cel inconvénient. La succession des nuits et des jours, des saisons sèches et humides, les éclairs, le tonnerre sont, à leurs yeux, des effets mécaniques dont les causes ne les inquiètent pas. Le temps de la récolte, la circonstance du mariage sont le signal de leurs divertissements, qui commencent au coucher du soleil, se continuent à la lueur des étoiles, et durent quelquefois jusqu'au jour. Ces Indiens, très-jaloux de la chasteté de leurs filles, sont d'une indifférence complète à l'égard de leurs femmes.

Les Xerentes ont pour résidence habituelle le territoire entre l'Araguaya et le Tocantin. On les dit anthropophages, et l'on ajoule qu'ils tuent et mangent ceux de leurs parents trop vieux pour subvenir par eux-mêmes à leur subsistance.

Les Capopos vivent sur les bords du Tocantin et de l'Araguaya. Ce sont des Indiens de haute taille et de couleur très-claire. Courageux, robustes, ils n'attaquent leurs ennemis que de jour. Ils ont pour armes l'arc, des flèches longues de six pieds, et une massue de quatre pieds, dont la partie supérieure est aplatie en forme de rame. Afin de s'exercer au maniement de cette arme, ils ont des luttes de divers genres; on en cite, entre autres, une qui consiste à porter un bloc de bois de deux à trois quintaux, masse qu'ils agitent et lancent en courant. Le jeune homme qui ne peut y parvenir n'a pas le droit de se marier. Ces naturels veillent soigneusement à la chasteté des jeunes gens, et assurent ainsi celle des jeunes filles. Cependant ils permettent aux guerriers les plus hardis de s'approcher de leurs fiancées. L'infidélité des femmes encourt la peine de mort.

Voisins de ceux-ci et leurs ennemis mortels, les Chavantes, moins fiers et moins insolents, deviendraient d'excellents ouvriers. Adroits dans les exercices du corps, nageurs intrépides, leurs manières sont empreintes d'un cachet de franchise et de dignité qui contraste avec la timidité incertaine des autres sauvages. La physionomie des femmes a surtout quelque chose d'ouvert et de gracieux.

Dans les forèts qui avoisinent Porto-dos-Angicos habitent les Botocudos ${ }^{\mathrm{x}}$, la plus considérable des tribus qui descendent des Tapuyas. On dit qu'à une époque reculée ils furent contraints de se séparer des hommes de leur race, et s'enfoncèrent dans les montagnes, où ils prirent des mœurs plus féroces qu'aucune des autres peuplades indiennes. Les Botocudos vont complétement nus; ils ont les jambes et les cuisses menues quoique musculeuses; les pieds petits, la poitrine et les épaules larges, le cou

1 Ce nom de Botocudos leur vient de ce que le singulier ornement dont ils chargent leurs oreilles et leurs lèvres offre une grande ressemblance avec le tampon d'une barrigue qui en portugais se nomme botoque. On les appelle encore Aimures ou Ambores. 

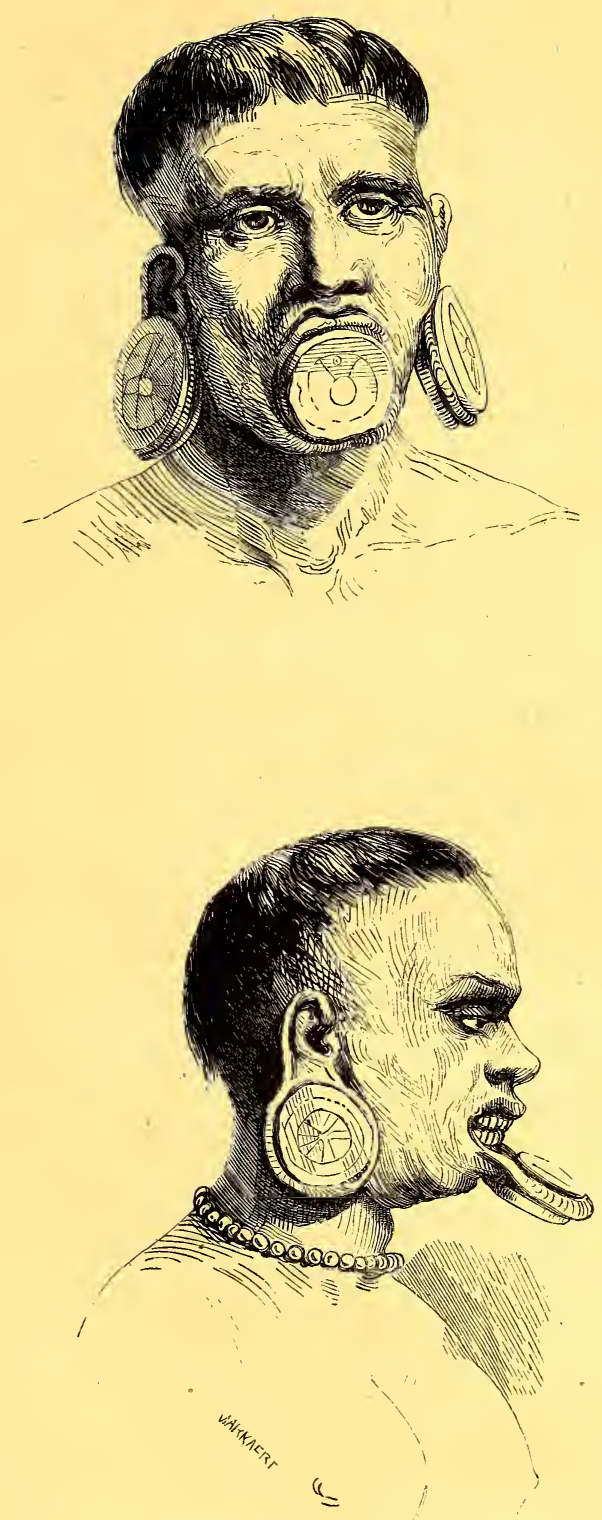

BOTOCUDOS 

court, le nez épaté, l'os des joues élevé et saillant. Ils coupent leurs cheveux au-dessus des tempes de manière à ne laisser qu'une touffe ronde au sommet de la tête, exaclement comme les capucins. Ils ont la physionomie assez ouverte, et le rire fait naître chez cux des rides extrêmement prononcées. On ne peut leur faire une injure plus grave que celle de leur dire qu'ils ont les jambes grosses et les yeux grands; et ils altachent à des jambes menues une telle idée de beauté qu'ils serrent avec des liens celles de leurs enfants.

Ils ont la hideuse coutume, après s'être percé la lèvre inférieure et les lobes des oreilles, d'y introduire d'énormes rouelles ou disques en bois qu'ils agrandissent en avançant en âge. Ainsi agrandie peu à peu, l'oreille peut acquérir jusqu'à trois pouces de diamètre. Tant que celui du disque de bois introduit dans la lèvre ne dépasse pas un pouce, il n'entraîne pas les chairs; mais lorsqu'il est plus fort, il fait pendre toute la lèvre et affecte lui-mème une disposition horizontale. Dans cet état, si l'individu peut relever sa lèvre obliquement, il ne lui est pas possible, en revanche, de l'appliquer contre ses dents, et encore ne la redresserait-il pas si le morceau de bois sur lequel elle s'appuie ne servait à la maintenir. Quoiqu'ils portent ce disque dès l'enfance, ils ne s'y habituent jamais entièrement. Les femmes se défigurent de la même manière; autrement elles seraient jolies et gracieuses.

Les deux sexes se peignent en rouge ou en noir; la première se fait avec le roucou, l'autre avec le fruit du genipayer. Les femmes et les enfants affectent une sorte de symétrie dans le tatouage; les uns ont des mouches; les autres des plaques irrégulières; quelques-uns des bandes qui courent en sens divers; enfin certains individus se peignent de roucou toute la partie supérieure du visage jusqu'au milieu des joues. Les Botocudos sont d'une agilité inconcevable, et vivent presque toujours à l'état nomade, tantôt émigrant par tribus, tantôt marchant par familles. Rien de plus curieux que de les voir portant tout avec eux, se frayant tantôt un chemin à travers les bois, tantôt s'engageant dans les gués d'une rivière. La tâche de l'homme se réduit, dans ces émigrations, à tenir d'une main ses armes, de l'autre le gibier qu'il a abattu, tandis que la femme non-seulement porte dans un large sac tout le mobilier de la famille, mais traîne encore avec elle, soit sur les épaules, soit par la main, tous les enfants en bas âge.

Ils sont excellents chasseurs, découvrent la piste de l'animal ou l'altirent en imitant son cri, et le manquent rarement quand il est arrivé à portée. La pêche se fait à coups de flèches, après que le poisson a été endormi à l'aide de racines vénéneuses.

Ces sauvages sont très-voraces; ils ont un appétit insatiable. Dès que le gibier tué à la chasse a été apporté au camp, on se contente de le flamber pour le dévorer ensuite à demi cru.

Dans leurs pèlerinages à travers les terres, les Botocudos cherchent à trouver un endroit où la nature leur offre des ressources abondantes. Nulle autorité régulière ne semble régner chez eux. Leur nation est divisée en tribus de cinquante à cent guerriers, non compris les femmes et les enfants. Ces tribus, indépendantes l'une de l'autre, ont chacune leur chef, dont la dignité est élective. Ces chefs ont un pouvoir presque absolu. Leur rôle est de diriger les marches, de conduire les hommes à la gruerre, d'apaiser les différends survenant presque toujours à l'occasion des femmes. En campagne, les chefs se distinguent par une manière particulière de se peindre le corps. En toute autre occasion, nul signe ne les fait reconnaître. Chacun de ces chefs a une certaine étendue de forêts où il peut, à l'exclusion de tout autre, chasser et cueillir des fruits. La violation de ce territoire de la part d'une tribu voisine équivaut à une déclaration de guerre. C'est le chef qui fait la part du gibier quand ils ont chassé.

Sitôt qu'une tribu est arrivée dans le lieu où elle veut s'arrêter, les femmes allument du feu à l'aide d'un morceau de bois tendre assez long, et offrant une cavité sur laquelle 
on place perpendiculairement un autre morceau de bois plus dur, qu'on fait ensuite tourner avec rapidité entre les paumes des mains. La construction des cabanes ne coûte pas de grands travaux à ces peuples. Ils se contentent de planter sur le sol, les unes à côté des autres, de grandes tiges feuillées du cocotier, dont les sommités forment une espèce de voûte à deux pieds au-dessus. S'ils doivent faire un long séjour, ils élèvent des cases d'une durée moins précaire, à l'aide de pieux fichés en terre, autour desquels ils entrelacent des feuillages, et qu'ils couronnent par une toiture de grandes feuilles de paltioba. Dans l'intérieur de ces cabanes, on ne retrouve plus le hamac des autres tribus indiennes; mais un lit d'estopa ${ }^{2}$, sur lequel le chef de famille reste constamment élendu, ne s'occupant de rien, hors la chasse et la pêche, et laissant aux femmes toute la fatigue des soins domestiques. A côté du maître du logis se voient ses armes et divers ustensiles, produits de son industrie, de petits pots grossièrement fabriqués, des calebasses pour conserver l'eau, une sorte de gobelet formé d'une tige de roseau fendue, des lignes à pêcher, faites avec les fibres du bromelia ou de l'embira; une hache en néphrite, qu'on enduit de cire et qu'on fixe entre deux morceaux de bois; des flûtes en roseau, un cornet fabriqué de la cuirasse d'un tatou; enfin un grand filet dans lequel la femme transporte en route le mobilier de la famille, et où s'entassent pêle-mêle, outre quelques bagatelles d'Europe, des pointes de flèches, des paquets d'étoupe, du roucou et du genipapo ${ }^{2}$, des carapaces de tortue, de grosses boules de cire, objets d'échange avec les Portugais.

Les Botocudos sont fiers, hardis et courageux, et pardonnent rarement les injures. Ils aiment la guerre, et se la font presque constamment de tribu à tribu. Pour augmenter leurs troupes, les chefs s'enlèvent les uns aux autres des enfants et des femmes.

Ces sauvages ont des armes remarquables par leur forme et leur élégance. Les arcs, de six ou sept pieds, sont en bois de pao d'arco, bignonia d'une cspèce très-haute, à belles fleurs jaunes, et fort commune sur les bord du Rio Belmonte. Les flèches, qui se fabriquent avec des roseaux, sont garnies des plumes du hocco, du jacutinga et du jacupenha. Ces flèches ont ordinairement six pieds; elles sont de deux espèces : les unes employées à la chasse et terminées par un morceau de bambou aigu; les autres, servant à la guerre et terminées par un morceau de bois empoisonné.

Couverts de sueur, ils se jettent dans l'eau la plus froide. Leur vie nomade et l'abus des femmes ne les laissent jamais parvenir à un âge avancé. Quand un Botocudo est malade, ses parents et ses amis entourent sa couche et le pleurent quand il a expiré. Les morts s'enterrent les bras pliés sur la poitrine et les cuisses pliées sur le ventre.

Les jeunes filles se marient avant l'âge de nubilité, mais on ne leur donne pour époux que des enfants impubères. Les fiançailles se font au milieu de danses et de fêtes. En cas de divorce, les enfants restent avec leur mère tant qu'ils sont en bảs âge; mais, devenus grands, ils rejoignent leur père. Les Botocudos connaissent et respectent le lien de famille; mais ils ne sont pas très-scrupuleux sur la fidélité conjugale.

Ils chantent sur un rhythme lent et monotone, quand ils sont violemment émus. Leurs chants sont rauques, sourds, inarticulés; ils ne roulent que sur trois notes. Quand un Botocudo chante, il agite ses bras en sens divers, et les promène sur sa tête.

Dans les grandes occasions, il prononce des harangues guerrières. Les chansons qui ont pu être comprises ne sont qu'une suite de mots sans liaison ou de la plus grande trivialité.

Les Botocudos ne sont pas aussi passionnés pour la danse que les autres Indiens. La

1 Étoupe faite avec l'écorce d'un arbre nommé en portugais pao d'estopa.

2 Nom espagnol du fruit du genipayer. 
seule qu'on leur connaisse consiste en un demi-cercle serré de femmes et d'hommes, dont chacun appuie le bras sur le cou de son voisin. Alors une vieille femme accroupie entonne, d'une voix tremblante, à laquelle la troupe joyeuse répond en dansant et en chantant tout à la fois. Les gambades ont lieu lourdement, presque sans plier les jambes. Les danseurs placés aux deux extrémités du demi-cercle n'ont qu'une jambe par terre; l'autre est passée dans la jambe du voisin, de manière que chacun des deux individus saute sur une jambe.

Les Machaculis habitent les environs de Tocayos, sur les bords du Jiquitinhonha et près de l'île aux Pins. Ils sont chasseurs, et préfèrent ce plaisir aux travaux de l'agriculture. Leurs villages sont très-petits et peu peuplés; ils se composent de dix ou douze maisonnettes construites sans ordre, et semblables à celles des Macunis. Elles sont petites, carrées, couvertes de feuilles de palmier ou de morceaux d'écorces d'arbre. Quelques-unes sont bâties en terre, d'autres de feuilles de palmier passées entre des perches qui forment la charpente. Quoique ces peuples soient à demi civilisés, et qu'ils aient beaucoup de communications avec les Portugais, ils n'ont pas, comme les Macunis, l'habitude d'élever des poules et des cochons. Les Machaculis bornent leur culture à la plantation des patates, qu'ils font cuire aussitôt qu'elles sont extraites de la terre, et qui n'exigent pas les mêmes préparations que le manioc et le maïs. Ils ne les arrachent qu'au fur et à mesure de leurs besoins. Les femmes des Machaculis filent le coton en un cordonnet très-fin, dont elles se servent pour fabriquer des hamacs. En général, ces peuples sont faux, voleurs, perfides et intéressés; cependant ils ont quelques qualités qui compensent ces défauts. Les Machaculis parlent du gosier, et n'ont, dans leur prononciation, aucun des éclats de voix qui caractérisent les Botocudos.

Les femmes des Machaculis portent pour tout vêtement une simple jupe; le chef se couvre d'un caleçon; le reste de la tribu est à peu près nu.

La tribu des Macunis, qui a beaucoup d'affinité avec celle des Machaculis, habite sur l'aldea d'Alto-dos-Boys (hauteur des boufs). L'aldea se compose de cases séparées les unes des autres et dispersées çà et là. Basses, petites, presque carrées et sans fenêtres, ellcs sont couvertes de longues feuilles de palmier qui les rendent impénétrables à la pluie; c'est dans ces maisonnettes que logent les Macunis.

Ces Indiens ne diffèrent point, par leurs traits, des autres hommes de leur race. Comme ceux-ci, ils ont les cheveux noirs et bien fournis, rudes et plats, la tête grosse, les pommettes saillantes, le nez épaté, les épaules et la poitrine larges, les jambes et les cuisses menues, les pieds petits. Leur peau est jaune; seulement elle prend une teinte cuivrée quand ils vont nus. Les femmes, mal faites et sans grâce dans la démarche, ont quelques charmes dans la physionomie. La langue de ce peuple est facile, sauf ses composés qui se compliquent quelquefois de manière que l'intelligence en devient pénible.

Quoique unis par couples et mariés par un prêtre, les Macunis ont un faible respect pour la fidélité conjugale. Pour le moindre présent, les maris laissent partager leurs droits sur leurs femmes; et de leur còté, les femmes cèdent à la première avance. Ces peuples se livrent à un libertinage précoce. Des pères vendent souvent leurs filles, dès l'âge de huit ans, à des hommes faits qui leur donnent le titre d'épouses.

On a enseigné aux Macunis à travailler la terre, et ils la cultivent pour leur compte ou se louent chez les colons du voisinage; quelques-uns servent même comme soldats. Les hommes et les femmes sont fort adroits et industrieux, mais inconstants et paresseux. Ils mangent leur maïs avant qu'il soit mûr, et consomment souvent en un mois les provisions de l'année. Quand ils élèvent des poules, il leur arrive de les tuer toutes 
à la fois; ou bien, s'ils ont des cochons, ils n'attendent pas que la femelle ait mis bas; ils l'éventrent pour manger les petits.

Les Macunis sont d'habiles chasseurs; les enfants s'exercent dès le bas âge à tirer sur Ies rats, et se forment ainsi la main et le coup d'œil. Ils conservent un grand respect pour leurs ancêtres. Les hommes traitent les femmes comme des esclaves, et les punissent à la moindre faute. Ce sont ces dernières qui préparent la nourriture, et vont chercher le bois pour le feu; elles construisent même des huttes quand leurs maris vont dans de grandes chasses. Elles sont aussi chargées de la culture des patates, mais celle du maïs regarde les hommes. Les femmes portent leurs fardeaux sur la lête, à l'aide d'un cordon qui passe sur l'os frontal. Ce sont encore elles qui fabriquent des sacs tissus de coton et d'une espèce de cecropia, et la poterie dont ils se servent dans leur ménage. Un des grands plaisirs des femmes est de suivre leurs maris quand ils font de longues chasses. Les femmes ne font point leurs couches dans l'aldea même, mais dans les bois, où elles se rendent accompagnées des plus vieilles de la tribu. On laisse les enfants nus jusqu'à l'âge de puberté.

Ces Indiens se coupent les cheveux à la façon européenne, quoique quelques-uns d'entre eux, hommes ou femmes, les conservent longs comme autrefois, et partagés au sommet de la tête. Ils se peignent avec un morceau de bois mince et poli, pointu d'un côté, et terminé de l'autre en spatule. Les femmes se percent les oreilles et y font entrer un petit disque de bois. Ces sauvages ne mangent point indistinctement toute espèce de gibier. Ils méprisent plusieurs sortes de quadrupèdes, et entre autres le fourmilier. Le manioc, les patates et le produit de la chasse suffisent à leur nourriture. L'une de leurs passions les plus vives est celle de l'eau-de-vie, la danse l'un de leurs plus grands plaisirs. Elle n'est cependant chez eux qu'un sautillement monotone, accompagné de chants grossiers qui n'ont aucun sens. Quand ces Indiens sont malades, ils n'ont d'autres remèdes que l'ipécacuanha. Les parents entourent le lit du malade, sanglotent, mais ne lui apportent aucun secours.

L'ameublement des cabanes de ces Indiens se compose de pots de terre dispersés ȩà el là, de quelques canapés rustiques, d'arcs, de flèches, de plumes d'aras suspendues au plafond, et enfin d'une férule de bois desîinée à corriger les femmes.

Le costume des Macunis se réduit à bien peu de chose; les hommes ont depuis peu appris à porter un caleçon, quelquefois une chemise; les femmes ont une jupe et une camisole; mais le plus ordinairement elles restent nues jusqu'à la ceinture.

Le territoire occupé par les Malalis a pour chef-lieu Passanha. Ce sont des Indiens de petite taille, à la poitrine el aux épaules larges, aux cuisses et aux jambes menues, au cou peu allongé, à la tête grosse et ronde, aux cheveux noirs, plats et touffus, aux yeux grands, aux joues proéminentes, au nez épaté, à la bouche grande, avec les mâchoires avancées.

La plupart d'entre eux ont reçu le baptême, et sont mariés par le curé de leur cheflieu. Cependant, s'ils remplissent exactement leurs devoirs religieux, c'est plutôt machinalement que par un mouvement de conviction sincère et raisonnée.

Quoique l'un de ces indigènes soit revêtu du titre de capitaine, il n'est que le trèshumble serviteur des Portugais, chefs véritables de celte peuplade. Dans les environs de l'aldea existe une maison du conseil qui appartient à la communauté et que personne n'habite. Les hommes les plus anciens et les plus considérés s'y rassemblent et y délibèrent sur les questions qui intéressent la tribu. C'est un de leurs anciens usages, le seul qui survive. Bien que les Malalis ne parlent pas d'autre langue que la leur, ils savent pourtant le portugais.

Leurs habillements consistent en un calecon de toile blanche, et en une chemise 
qu'ils portent comme une blouse. Les femmes ont une jupe de toile et une simple chemisette sur le sein.

L'agriculture et la chasse forment la principale occupation de ces naturels; ils sont doux, timides et caressants. L'un des mets favoris de ces Indiens est un gros ver blanc ${ }^{x}$ qui se trouve dans l'intérieur des bambous au moment où ils fleurissent. Les Indiens font cuire ces vers, et ils en retirent une espèce de graisse fine et délicate avec laquelle s'apprêtent les aliments. Les bichos dos taquaras, réduits en poudre, forment une espèce de panacée contre les blessures, mais c'est encore un moyen d'obtenir un sommeil extatique qui dure plusieurs jours. M. Auguste Saint-Hilaire raconte que, lorsque l'amour cause des insomnies aux naturels, ils avalent de ces vers que l'on a fait sécher sans en ôter le tube intestinal, et tombent dans un assoupissement profond; à leur réveil, ils racontent des songes merveilleux, parlent des forêts brillantes qu'ils ont vues, des fruits exquis qu'ils ont goûtés. Toulefois, avant de manger le bicho do taquara, les naturels en enlèvent la tête regardée comme un poison dangereux.

Les CARopos, insulaires qui presque tous vont nus, ont pour pays l'aldea de MorroGrande. Un petit nombre seulement font usage de ceinture; il en est qui ont au cou des colliers de rassades ou de graines rouges, et parfois des dents de singe. Les enfants sont tatoués de rouge et de bleu; mais on peut aisément effacer ces peintures qui sont loin d'être indélébiles.

Les femmes ne paraissent pas avoir un attachement bien profond pour leurs époux. Elles suivent de préférence les nègres qui sont pour elles de véritables sigisbées, et ce, tandis que les Indiens n'ont pour les négresses que du mépris, tant ils se croient supérieurs à elles.

Hautes de quinze pieds, larges de trente, les huttes de cette peuplade sont construites sur le sol, au moyen de quatre pieux. Les portes sont en feuilles de palmier. Chaque hutte a plusieurs foyers dont chacun paraît destiné spécialement à une famille, et dont la fumée s'échappe ou par la porte ou par les claires-voies de la toiture. L'ameublement consiste en quelques pots de terre, paniers en feuilles de palmier et remplis de patates, de racines de manioc; on y voit aussi des cujas (vases à boire), des plats peints avec du genipayer, un tronc d'arbre creusé pour piler le maïs. Comme ornements et comme instruments, on remarque les armes des hommes appendues aux murs; la maraca (morceau d'écaille qui, rempli de maïs, rend un son pareil à celui des castagnettes), des touffes, des bandeaux de plumes magnifiques de perroquet, puis des tortues et des singes qui, rôdant autour des cases, semblent en être des commensaux habituels. Un ornement particulier décore la cabane du chef : c'est une corne qui lui sert à faire entendre ses ordres dans la forêt, sonner une fète ou annoncer la présence d'un étranger.

Les Puris et les Coroados, qui paraissent avoir une souche commune avec les Caropos, sont, comme ceux-ci, carrés, trapus, souvent très-charnus. Leur tète est grosse et ronde, leur visage large; les pommettes de leurs joues sont proéminentes; leurs yeux noirs, petits, obliques quelquefois; le nez court et large; les dents fort blanches. Leur peau, plus ou moins cuivrée, selon l'âge, est jaune chez les enfants comme parmi les mulâtres. La maladie donne à leur teint la couleur du safran. Les albinos sont rares chez eux. Un petit nombre de ces sauvages se distinguent par des traits plus prononcés que ceux des autres, par un nez recourbé, et des yeux d'une grande vivacité, agréables chez quelques-uns, sérieux, sombres et caves chez la plupart.

Tous vont dans un état complet de nudité, à l'exception d'une faible partie qui ont

1 Bicho dos taquara. 
pu se procurer quelques lambeaux de toile, ou des culottes courtes dont les Portugais leur ont fait présent. Les uns ont la tête rasée; d'autres les cheveux coupés seulement au-dessus des yeux et de la nuque; un petit nombre ont la barbe et les sourcils ras. Leurs pigments en roucou sont tantôt sur le front et tantôt sur le corps. Ils ornent leur poitrine de colliers indistinctement composés de graines noires et dures, ou de dents canines de singes, de jaguars, de chats et d'autres animaux carnassiers. Les hommes ont quelquefois un morceau de peau du singe mono noué autour du front. Les jeunes filles font aussi parfois usage de bandeaux, et les femmes portent ordinairement un cordon ou un lien d'écorce serré autour des poignets et des jointures, dans le but de rendre ces parties plus minces et de les orner.

Flegmatique et mou, le tempérament de ces sauvages les porte à n'estimer que les jouissances purement physiques. Retirés sous leurs couaris (huttes), étendus dans leur hamac, ils passent inoccupés la plus grande partie du jour. Le chef d'une famille daigne à peine sortir de cette apathique somnolence pour intervenir dans les querelles qui peuvent s'élever entre les autres membres. Il n'y a de préséance ni entre l'aîné el le cadet, ni même entre le père et l'enfant.

Les autres coutumes de ce peuple ne diffèrent guère de celles des autres Indiens, excepté celles qui ont rapport au culte ${ }^{x}$.

Leurs danses sont tout au plus une sorte de promenade qu'ils exécutent en marchant l'un devant l'autre, avec leurs enfants qui les tiennent enlacés et qui s'enlacent ensuite entre eux d'une manière divertissante. Ils décrivent ainsi un cercle presque perpétuel autour d'un vaste foyer allumé.

Les Patachos et les Camacans rappellent par leurs traits, leurs usages ou leur accoutrement les diverses tribus que nous avons déjà décrites.

1 Voyez notre Histoire et Cérémonies religieuses. 


\section{GUYANES.}

Le territoire compris sous la dénomination de Guyanes confine : à l'est, à l'océan Atlantique; au nord et au sud, à deux des plus grands fleuves du monde, l'Orénoque et l'Amazone; on n'a pu encore déterminer sa profondeur à l'ouest.

Cette contrée est partagée entre l'Angleterre, la Hollande et la France. Nous décrirons chacune de ces trois parties.

Guyane anglaise, la plus occidentale et la moins considérable; elle est arrosée par le Pouramoun, l'Esséquédo, le Démérari, sur les bords duquel est une colonie florissante, le Corentyn et le Berbice.

George-Town en est la capitale; elle est située dans le gouvernement d'EsséquéboDémérari. Cette cité populeuse et marchande, bâtie sur une grève plate et stérile, a l'aspect d'une place affairée et active. Sa population est d'environ dix mille âmes. Ce pays offre un pêle-mêle de nations européennes : Hollandais, Anglais, Allemands, Prussiens, Russes, etc. Parmi les édifices publics, il faut citer la maison du gouvernement et une longue file de bâtiments qui servent à la fois de douane, d'entrepôt, de bourse el de tribunal de commerce.

Nulle part on n'accueille l'étranger avec autant de bienveillance et de grandeur. On se dispute presque les nouveaux venus; et, dès qu'ils ont mis le pied dans une maison, ils en sont les commensaux pour un temps illimité.

Les environs du fleuve Démérari sont couverts d'habitations riantes et produclives, presque toutes peuplées de Hollandais, les anciens maîtres du pays. Ces habitations sont jolies, commodes et bien tenues. Les ponts, les portes, les fenêtres, les maisons, etc., tout y est peint en blanc, couleur favorite de cette nation. Les chemins plantés d'arbres rappellent les belles avenues de l'Europe.

Les Warrows sont établis près de l'embouchure du Masarouï; les Caraïbes ${ }^{1}$ occupent les côtes; les Arrowauks campent presque tous auprès des rivières Esséquébo, Démérari et Berbice. Les TAÏras, d'après Stedman, errent entre le Maranham et le Surinam; les Piaunacotaus ne quittent guère les solitudes de l'intérieur; les Macoushis habitent le pays de ce nom.

Quoique plusieurs de ces tribus n'habitent pas le territoire de la Guyane anglaise, nous avons dû les nommer ici, parce qu'à part quelques dissemblances, toutes se rapprochent par le type général.

1 Les anciens Caraïbes se distinguaient des autres Indiens par leur esprit guerrier et leur caractère féroce. La chasse et la guerre étaient leur principale occupation, et ils mangeaient leurs prisonniers. Leurs villages, composés de cabanes de forme circulaire, qui n'étaient couvertes que de feuilles de palmier, ressemblaient à des camps. Ces peuples montraient de l'adresse dans la fabrication de leurs paniers, de leurs nattes, de leurs arcs et de leurs flèches. Quoiqu'ils allassent absolument nus, Christophe Colomb observa qu'ils tissaient une espèce de toile de coton qu'ils savaient teindre en différentes couleurs, surtout en rouge. La polygamie était en usage parmi eux. 
Tous ees Indiens ${ }^{x}$ ont la poitrine élevée et pleine, le cou épais, les épaules carrées, les membres robustes et charnus. Leur visage, quoique souvent ingrat, n'est pas dépourvu d'une certaine régularité. Ils ont le nez aquilin, la bouche et les lèvres moyennes, les dents petites, blanches et bien rangées, le menton arrondi, les angles de la mâchoire inférieure assez marqués. Les deux sexes s'oignent le corps d'huile de caraba, dans le double but de rendre la peau souple et de la garantir contre les piqûres des insectes. Ils se teignent au moyen du roucou et zèbrent de lignes bleues leur corps et leur visage. - « Pourquoi vous barbouillez-vous ainsi? demandait un jour Stedman à un jeune Indien. - Parce que ma peau devient plus douce, et qu'elle est à l'abri des piqûres, répondit-il. Voilà, monsieur. Mais vous, pourquoi vous peignez-vous en blanc? Je ne vois pas pour quelle raison vous perdez ainsi votre farine, et pourquoi vous salissez vos habits. Est-ce pour paraître blanc avant l'âge?... "

Quant au caractère de ces naturels, il est grave, réservé, plein de finesse et de ruse. Plusieurs tribus paraissent avoir la manie de l'empoisonnement. La construction de leurs carbets, hamacs, pirogues, et quelques défrichements bornent leurs occupations.

Leurs habitations ne sont autre chose que des carbets, construits en une heure sur quatre pieux fichés en terre, ouverts de tous côtés, excepté chez les Macoushis, qui les ferment en ne laissant qu'une large ouverture, et chez les Arrowauks, dont les cabanes sont plus spacieuses.

Ils font leur nourriture d'ignames, de plantain, de bananes, de racine de cassave et de manioc, de crabes, de poisson, de tortues de terre et de mer, et même de lézards. Ils mangent aussi la chair du singe qu'ils assaisonnent de poivre de Cayenne, après l'avoir fait bouillir. La liqueur de manioc fermentée est leur boisson ordinaire : on a soupconné d'anthropophagie quelques-unes de leurs tribus. Bancroft rapporte que "dans la dernière insurrection des esclaves de Berbice, les Caraïbes, auxiliaires des Anglais, tuèrent beaucoup de nègres et les mangèrent. "Le mème auteur ajoute que les Caraïbes sont les seuls Indiens de la Guyane qui manifestent cet horrible goût.

Ces naturels pratiquent rarement la polygamie, quoiqu'elle leur soit permise. Ils n'ont pour l'ordinaire qu'une femme, à laquelle ils ne donnent de rivale que lorsqu'elle est trop vieille et trop repoussante. En général, les jeunes filles se marient dès qu'elles sont pubères. Les préliminaires ne sont pas longs; le futur offre à sa fiancée une certaine quantité de poisson et de gibier; si elle accepte, la cérémonie est célébrée par un festin.

L'enfantement n'est jamais accompagné d'accidents graves ni de souffrances laborieuses. La délivrance a lieu sans aucun secours étranger. Aussitôt que la parturition est accomplie, on plonge dans l'eau l'enfant et la mère qui le lendemain reprend son travail. Une coutume singulière qui résulte du témoignage de quelques voyageurs, c'est que, si la femme est valide à la suite de l'accouchement, son mari doit feindre une maladie. Cet usage est de rigueur : il doit se plaindre, et garder le hamac en observant un jeùne sévère, ce qui lui donne une ressemblance grotesque avec une accouchée européenne. Empressés autour de lui, les voisins lui adressent sur son heureuse délivrance des félicitations qu'il reçoit comme s'il avait réellement ressenti les souffrances auxquelles on fait allusion. Après trente jours, on le fait descendre de son hamac pour le fouetter et lui appliquer sur les bras de grosses fourmis. Ceci a lieu dans son intérêt afin de le dégourdir après cette longue et complète inaction. Nous devons ajouter qu'un petit nombre de voyageurs ne font durer que trois jours cette comédie au moins étrange.

1 Il faut remarquer que les Caraïbes et les Arrowauks sont plus blancs que les Indiens des autres peuplades. 
Ces peuples ont pour armes une massue ou casse-tête en bois de fer, l'arc et les flèches, ainsi qu'une espèce de sarbacane ou tube de bambou qui leur sert à lancer des flèches empoisonnées. Ces flèches se taillent dans les éclats de bois provenant de la première couche de l'arbre appelé cokarito; elles ont un pied de long et sont un peu plus grosses qu'une aiguille à tricoter. Bancroft dit que l'une des deux extrémités est imprégnée d'un poison tiré de la racine du woorara; l'autre est entourée d'un petit morceau de coton adapté à la cavité du tuyau. Les Indiens lancent jusqu'à une distance de cent pieds ce projectile dont la blessure est mortelle. Ce poison (wourali) est le plus actif et le plus violent de tous ceux employés par les Indiens. Il est infaillible, et, à peine a-t-il pénétré sous la peau, qu'il tue sans vicier la chair et sans que le sang subisse aucune allération.

Pour tout vêtement, ces hommes n'ont qu'un pagne fait d'écorce d'arbre ou avec les fibres du coco. Les femmes mettent parfois une pièce d'étoffe carrée formée de fils de coton et de rassades. Du reste, le contact européen a déjà modifié ce costume primitif. Les jours de fète, les hommes se coiffent de chapeaux surmonlés de plumes brillantes, qui se dressent autour de leur tète, et sont retenues par un bandeau circulaire, large * de deux pouces. Les femmes ont aux bras, au cou, aux genoux, au-dessus des chevilles des garnitures de rassades.

En cas de maladie, ou s'il est blessé, l'Indien fait appeler le peï (sorcier); celui-ci arrive à l'entrée de la nuit avec les instruments de sortilége, dont le principal est une grande calebasse garnie de cailloux blancs et de graines sèches, et traversée par un bâton qui, d'un côté, forme manche, et, de l'autre, est terminé par de très-belles plumes. Parvenu près du malade, le peii commence ses exorcismes, en imprimant à sa calebasse un mouvement circulaire, et entonnant une supplication à l'yawahou r, et qui dure jusqu'à minuit. Cette heure arrivée, il simule une entrevue avec l'esprit el soutient un monologue dialogué. Au bout de deux séances de ce genre, le peii donne son avis sur l'affection morbide, et fait suivre cette consultation de l'emploi de quelques simples dont les vertus lui ont été révélées par le hasard.

La dignité du peii est fort enviée à cause de l'influence qu'elle donne sur les autres Indiens à celui qui en est revêtu; mais elle n'est due ni à l'audace ni au talent : elle est héréditaire. Elle passe du peii mort à son fils aîné, initié aux mystères de son ordre par une succession de cérémonies superstitieuses qui durent plusieurs semaines ${ }^{2}$.

Guyane hollandaise; placée entre la précédente et la française, sa superficie peut ètre évaluée à 490 milles géométriques carrés.

Paramaribo, dans le gouvernement de Surinam, est le chef-lieu de la Guyane hollandaise.

La population surinamoise se compose généralement de créoles et de nègres créoles, les premiers nés de parents européens, les seconds de parents africains. lls montrent presque tous de la vivacité, de l'intelligence et des dispositions pour les sciences. Mais ils s'adonnent à la mollesse et à l'oisiveté, et ils ont peur de se livrer au moindre travail. Nous pourrions ciler pour exemple un garçon perruquier, esclave lui-même, et qui, au lieu de profiter de l'excédant du salaire qu'il doit rapporter à son maître, aime mieux louer un petit esclave dont il se fait suivre, et qui porle les peignes, la boîte à poudre et le fer à papillotes. On remarque même que ceux qui ont été le plus habitués au travail en Europe, deviennent bientôt aussi mous et aussi indolents que les créoles. La cause de cette disposition est dans la température élevée du climat, et surtout dans

1 Voyez notre Histoire et Cérémonies religieuses de tous les peuples.

2 Ibid. 
la facilité qu'ont les habitants de se procurer tout ce qui est nécessaire aux besoins de la vie.

Les nègres libres et les créoles sont peu friands; ils mangent souvent et ordinairement dans le même plat. Quelquefois ils mangent seuls, couchés ou assis par terre, ayant devant eux une calebasse qui leur sert de plat. Leurs mets favoris sont le poisson salé ou morue, le touton et l'ouilpot.

Les viandes qu'on y mange sont tellement assaisonnées de piment, qu'il est d'abord presque impossible à un Européen de s'en nourrir, mais on finit par s'y habituer et par s'apercevoir que les épices deviennent, dans un climat si chaud, un moyen de conserver la santé.

Les Surinamois n'ignorent pas les délicatesses de la table. Les Européens et les créoles de la bonne société étalent un grand luxe dans leurs repas, qui commencent ordinairement vers cinq à six heures du soir, et durent jnsqu'à minuit et quelquefois jusqu'au matin, au moyen du jeu, de la danse et de la musique. On y trouve tout ce que l'Europe et l'Amérique peuvent produire de plus délicat et de plus recherché.

Dans ces sortes de réunions, on se plaît à étaler les modes nouvellement reçues d'Europe. On est parfaitement bien reçu dans la maison d'un planteur, et surtout avec une franche cordialité tout à fait ennemie de l'étiquette des grandes villes. Vous avez derrière, pour vous servir à table, une troupe de négresses qui vous présentent tout ce que vous désirez, au moindre signal de leur maître.

Ils sont aussi rusés et aussi habiles que les Européens pour le commerce; mais les Européens s'enrichissent plus rapidement, étant plus laborieux. Quoique les blancs et les créoles soient régis par les mêmes lois, on remarque cependant une grande antipathie entre eux. Mais la cause principale de cette désunion tient à ce que les derniers voient avec déplaisir les premiers occuper les emplois les plus importants de la colonie aussitôt qu'ils arrivent d'Europe.

Les habitants de Surinam paraissent généralement être d'un tempérament indolent, mais ils n'en sont pas moins dissolus, et consacrent à leurs plaisirs la plus grande partie de leur fortune. Grand nombre d'entre eux, foulant aux pieds les liens qui les attachent à une seule femme, prennent une ménagère qu'ils entretiennent. Elle porte le nom de missie.

Ces missies, et, en général, les femmes de Surinam, sortent rarement le jour, et vont ordinairement faire leurs visites le malin et le soir. Elles appartiennent principalement à la classe des esclaves affranchies, et même à celle des esclaves proprement dites, ce qui ne les empêche pas de se faire suivre des personnes de leur condition. Il y a dans leur marche beaucoup de nonchalance et d'affectation. Tantôt elles jettent leur châle ou mouchoir sur l'une ou l'autre épaule, tantôt elles relèvent leur pagne ou robe avec prétention. Presque toules ont sur la tête un mouchoir qu'elles savent disposer de mille manières.

Leur teint est basané, leurs yeux sont vifs et noirs, ainsi que leurs cheveux, qu'elles ornent de fleurs et qu'elles portent tantôt crépus, tantôt déroulés de toute leur longueur. Elles ont des dents très-blanches, et, en gẻnéral, les formes du corps bien prises. Leurs épaules et leur poitrine sont à moitié nues; l'usage ne le défend pas. Plusieurs portent des jupes ou des jaquettes ouvertes par devant; mais alors elles ont dessous une pièce d'étoffe ou de toile mélangée de couleurs vives, qu'elles nomment paigsen ou pagne. Ces paigsens font le tour des reins et descendent jusqu'à la moitié des jambes qui sont ornées de bracelets de corail, ainsi que les pieds, les bras et le cou. Il n'y a que les affranchies qui aient le droit de porter des chaussures, les esclaves ont les pieds nus. 
Les missies sont ordinairement assises chez elles sur un canapé, et très-légèrement vètues, mâchant une branche d'orange amère. Quelquefois elles se réunissent deux ou trois dans un jardin donnant sur la rue, et là, dans un langage composé d'anglais, de hollandais et d'africain, elles font la conversation qu'elles appellent takie-takie, ce qui est l'équivalent du mot commérage. Ce caquetage est un besoin pour la classe du bas peuple, et pour les nègres. Elles passent ainsi des heures entières sans changer de position.

Presque toutes les missies ont devant elles des paniers à ouvrages, dont elles font peu d'usage, à la vérité, car elles ne sont pas dans l'habitude de raccommoder leurs habillements, ni même d'en porter qui aient été raccommodés. Un blanc, un créole ou un nègre qui porterait sur lui une partie d'habillement rapiécée, serait montré au doigt, et on l'appellerait poor man aben abie no pikien monie to baay n'joen kloosio, - pauvre homme, qui n'a pas d'argent pour acheter un vètement neuf. - Aussi l'on n'est pas étonné de rencontrer un naturel du pays avec la moitié d'un habit, une partie de culotte, ou même dépouillé de tout vêtement, ayant sur la tête un chapeau de femme.

Les Surinamois prennent fréquemment des bains, et leurs habillements, quoique parfois déguenillés, sont lavés presque tous les jours.

Les femmes du peuple ont des mœurs déréglées, des entretiens et un langage qui révolteraient toute honnète femme en Europe. Leur impudeur est poussée si loin qu'elles paraissent flattées de ce qu'on regarde chez nous comme un odieux outrage; elles voient dans une proposition infâme une sorte de préférence.

Malheur à l'homme qui a donné imprudemment dans le piége que lui ont tendu ces créatures; c'en est fait de sa fortune et même de sa santé; car elles sont insatiables de loilette et d'ornements, et elles aiment à se procurer, à quelque prix que ce soit, les mooi sanies (nouveautés).

Guyane Française. - La partie des Guyanes qui appartient à la France est bornée au sud par la rivière Oyapoch et la baie de Vincent-Pinçon; au sud par la partie hollandaise; ce qui lui donne une étendue de 120 lieues de côtes; quant à sa profondeur, elle est indéterminée. On évalue sa superficie à 2,700 milles géométriques carrés, et sa population à 23,000 habitants, dont 3,700 libres, et 19,300 esclaves '.

Cayenne est la capitale des possessions françaises. C'est une petite ville de 2,000 à $\tilde{5}, 000$ habitants, dont les deux tiers sont des hommes de couleur. Elle renferme deux jardins botaniques de naturalisation, où l'on a importé des plantes utiles tirées des diverses parties du monde ancien.

Les Indiens de la Guyane française semblent descendre des Caraïbes. Ce sont des Galibis, des Arouas, des Palicoubs, des Pirious, des Cariacouyous, des Noragues, des Marawanes, des Oyampis, enfin des Coussanis et des Émerillons. Ils ont le teint qui varie du rouge cuivré au jaune brun, les cheveux gras, lisses, noirs, coupés ras sur le front; la barbe et les poils assez rares. Leurs traits, sans avoir rien de distingué, n'ont pas cette expression stupide qu'on leur a généralement attribuée. Ils aiment à se barbouiller de genipa et de roucou. Demi-nomades, demi-sédentaires, ces Indiens excellent à tirer l'arc, arme à la fois propre à leur pêche et à leur chasse. Toute leur industrie consiste dans la confection de leurs arcs, de leurs flèches et de leurs canots. Ces canots, légèrement construits, semblent doués d'une élasticité qui vaut mieux que la force. Se heurtant à chaque minute contre les roches à fleur d'eau qui barrent le cours des rivières, ils se briseraient cent fois, s'ils ne glissaient comme des poissons sur ces pointes aiguës.

${ }^{1}$ Estimation faite en 1831. 
Tous ces Indiens vont à peu près nus, soit par suite du manque de vêtements, soit par une sorte de préjugé. Toutefois, les hommes ont le calimbé, les femmes la camisa ou tout au moins un couyou, espèce de tablier triangulaire, tissu de grains de rassades. Les hommes ont parfois les joues percées de façon à pouvoir y introduire des plumes et différents ornements. Sans cette monomanie, commune à un grand nombre de tribus indiennes, leur visage offrirait assez de régularité. Sujettes à l'obésité, les femmes on $\iota$ la physionomie douce et engageante, les formes gracieuses et bien proportionnées. Bien qu'elles aillent souvent dans un état complet de nudité, elles ne sont pas pour cela dépourvues de pudeur, et quoique leur corps barbouillé de genipa soit sale en apparence, nulles créatures ne sont plus jalouses d'une propreté continuelle. A peine sortis de leurs hamacs, les deux sexes courent à la rivière, et il est rare qu'ils ne prennent pas un second bain dans la journée.

Les hommes seuls s'occupent de chasse et de pêche. La confection de leúrs canots, leur manœuvre et le gros du travail dans un abatis sont encore dans leurs attributions. Quant à la culture des terres, elle est du ressort des femmes. Quand celles-ci commettent une négligence punissable, le mari inflige sans éclat un châtiment que la coupable subit avec résignation. Autrement une aimable concorde règne dans le ménage. L'adultère est, aux yeux de ces naturels, un crime qu'aucune circonstance ne saurait atténuer.

Le voyageur Lacordaire fut témoin de danses en grand costume. Les acteurs s'y préparèrent plusieurs jours à l'avance à cause de la confection des parures et des instruments de musique. La parure se compose d'une espèce de bonnet à poil, dont la carcasse en écorce d'arouna est ornée de plumes de diverses couleurs, surmontées de trois longues plumes d'oie. Une visière, également en plumes, dérobe une portion de la figure. Dans ces occasions, les Indiens sont barbouillés plus artistement que d'habitude; leur corps est zébré de dessins réguliers noirs et rouges; le calimbé est aussi plus long; les deux bouts touchent le sol.

Les flùtes sont les seuls instruments de musique; elles sont faites avec la tige du bambousier. Chacune de ces flùtes donne une note, et les Indiens se contentent de trois notes pour leurs symphonies. Ils en fabriquent un grand nombre qui, lorsqu'on en joue à la fois, produisent l'effet le plus monotone et le plus discordant. Pour l'accompagnement de ces flùtes, ils ont attaché au-dessus de la cheville, un collier de noyaux d'ahouaye.

Quand la nuit approche, les danseurs arrivent précédés d'une jeune fille qui porte un bâton surmonté d'une sorte d'éventail trifide, composé de trois longues plumes d'oiseau. La danse de ces Indiens ne consiste ni en figures ni en gambades. C'est simplement une promenade, où les danseurs, marchant à la file l'un de l'autre, ont chacun la main gauche posée sur l'épaule de celui qui précède; la main droite soutient la flùte. Quant aux danseuses, elles enlacent le danseur avec leur bras droit. Les flûtes commencent, les grelots d'ahouaye marquent la mesure. Alors les danseurs s'ébranlent, se retournant à chaque pas comme s'ils saluaient. Ces danses doivent avoir une physionomie fantastique, exécutées à la lueur des torches. 


\section{COLOMBIE.}

Il est impossible d'indiquer exactement les limites de cette contrée qui comprend la confédération des républiques de Venezuela, de la Nouvelle-Grenade et de l'Équateur. Toutefois, ainsi composée des trois territoires que nous venons de nommer, on peut donner pour bornes à la Colombie : au nord la mer des Antilles; au nord-est le Guatemala; à l'est les Guyanes; à l'ouest l'océan Pacifique; au sud le Pérou. M. de Humboldt évalue la superficie de ce vaste pays à 91,952 lieues carrées. On porte la population à $3,232,100$ habitants.

Toujours en proie aux guerres intestines, la Colombie a subi tant de bouleversements politiques que sa description topographique ne peut offrir qu'une grande incertitude. Ainsi l'organisation de 1819 n'a pu tenir contre la versatilité des partis et les efforts de quelques chefs ambitieux. Les services de Bolivar méconnus, son désintéressement mal récompensé, peut-être même calomnié, annonçaient, dès 1827 , le retour de l'anarchie. En 1829, deux partis se forment sur les débris de la constitution renversée : les unitaires qui demandent l'indivisibilité de la république colombienne, les fédéralistes qui réclament sa séparation en trois États indépendants. Ce dernier parti l'emporte au sein du congrès assemblé à Santa-Fé de Bogota, et Bolivar, qui venait à la suite de quelques revers militaires de déposer au sein de l'assemblée les pouvoirs qu'elle lui avait confiés, Bolivar, que les nouvelles plaies de la patrie affectaient profondément, succombe à ses chagrins le 17 décembre 1830, après avoir vu proclamer l'indépendance des trois nouveaux États de Venezuela, de la Nouvelle-Grenade et de l'Équateur.

Aujourd'hui donc la Colombie est divisée en trois États ou républiques, douze départements, trente-huit provinces et trois cent vingt-six districts. Elle renferme quatrevingt-seize villes, cent cinquante-quatre bourgs, treize cent quarante villages, et huit cent quarante-six hameaux.

Suivant la constitution colombienne, le pouvoir exécutif est confié à un président, et le pouvoir législatif à un congrès composé d'un sénat et d'une chambre des représentants. Les membres de ce congrès sont élus par des électeurs de cantons nommés par des électeurs de paroisses. Les titres nécessaires à cette dernière qualité consistent à être âgé de vingt-cinq ans, à posséder un peu de lecture et d'écriture, ainsi qu'un capital de 100 piastres.

Les Colombiens peuvent être divisés en deux classes; ceux des régions chaudes et ceux des régions froides. Les premiers sont maigres, petits de taille, et ont le teint jaune; ils sont indolents et restent souvent couchés dans un hamac où ils se balancent en fumant un cigare. Ils doivent cette nonchalance à la haute température qui règne chez eux, et qui invite au repos et nuit aux applications de l'esprit; aussi laissent-ils languir les sciences et les arts. 
Lorsqu'on s'élève vers les régions froides, la couleur des blancs devient moins jaune; pâle encore jusqu'à 600 toises, dit M. Mollien, elle se colore à 1,000 toises, et brille d'un éclat charmant à la hauteur où se trouve Santa-Fé de Bogota. Il en résulte que les habitants des Andes jouissent de la douce influence d'un climat tempéré, et, livrés aux charmes d'une mélancolie pensive, apprécient les sciences, les arts et la litlérature.

Le Colombien est hospitalier; mais, plein d'ostentation, il exagère dans ses prévenances et ses démonstrations d'amitié. Il nourrit une admiration aveugle pour sa patrie et ses compatriotes, et les vices dominants de son caractère paraissent être l'ingratitude, la jalousie et la vengeance.

L'agriculture est dans un état déplorable. Les manufactures y sont dans l'enfance. L'esclavage a été aboli depuis le triomphe de l'indépendance, mais seulement pour ceux qui ont porté les armes, ou qui peuvent payer 200 dollars (1,000 francs environ).

De bonne heure les Colombiens commencent à se plaindre de douleurs rhumatismales; mais leurs véritables fléaux sont la fièvre jaune, la dyssenterie, le vomissement noir, et surtout la lèpre, qui passe, en ce pays, pour une maladie incurable; aussi, à peine un individu en est-il atteint, qu'on l'arrache à sa famille, quelque riche ou considérable qu'elle soit, pour le jeter dans un hospice spécial, et là, privé de toute communication avec l'extérieur, à la merci d'un impatient mercenaire, le malheureux se voit perdu; le désespoir s'empare de lui, et il succombe victime des préjugés et de l'ignorance de son pays.

Les individus de l'un et de l'autre sexe, dans un grand nombre de localités de la Colombie, sont sujets à la difformité connue sous le nom de goître.

«On fera des affaires avec l'Américain dı nord, dit M. Mollien, mais on vivra avec l'Américain espagnol, parce que s'il a des formes moins franches, elles sont au moins plus douces. Les travers et les vices des Colombiens appartiennent à toutes les nations qui ne sont pas parvenues au degré de civilisation que nous avons atteint. Si on en excepte les forfaits politiques qu'ils ont commis par représailles, on n'en a pas encore ¿ leur reprocher. »

Après avoir tracé le caractère général de l'habitant de la Colombie, nous essayerons le décrire les différentes nations qui forment la population de cette contrée; et, pour y parvenir, il nous faut de toute nécessité suivre une marche topographique.

Des trois États qui forment aujourd'hui le territoire de la Colombie, le plus oriental est celui de la république de l'ÉQuateur, qui en comprend la partie la plus méridionale, autrefois nommée royaume ou présidence de Quito, et qui constituait une partie de la vice-royauté de la Nouvelle-Grenade.

Quiso est la capitale dı département de l'Équateur et de la république du même nom. Elle est bâtie sur le penchant du Pichincha, cratère éteint, mais fumant encore. Les rues sont d'un niveau trop inégal pour qu'on puisse s'y servir de voitures; la plupart sont tortueuses et obscures; les quatre plus larges seulement sont pavées. Il y a une quantité prodigieuse de couvents, presque tous beaux et riches. Le plus important est celui de San-Francisco, monument immense et d'une ordonnance assez belle. $\Lambda$ près le couvent de San-Francisco vient celui des jésuites, qui renferme aujourd'hui l'université de la ville, la bibliothèque et l'imprimerie.

Les habitations sont en terre, ou en briques sèches crépies à blanc; un petit nombre est en pierres. Des tuiles creuses pour les maisons, des briques vertes ou bleues pour les églises, voilà pour les toitures. L'intérieur de ces logements est assez simple. On n'y décore guère que le salon qui sert à recevoir les visites, et la plus grande décoration consiste en assez mauvaises peintures. Des lampes altachées aux plafonds, des tapis 


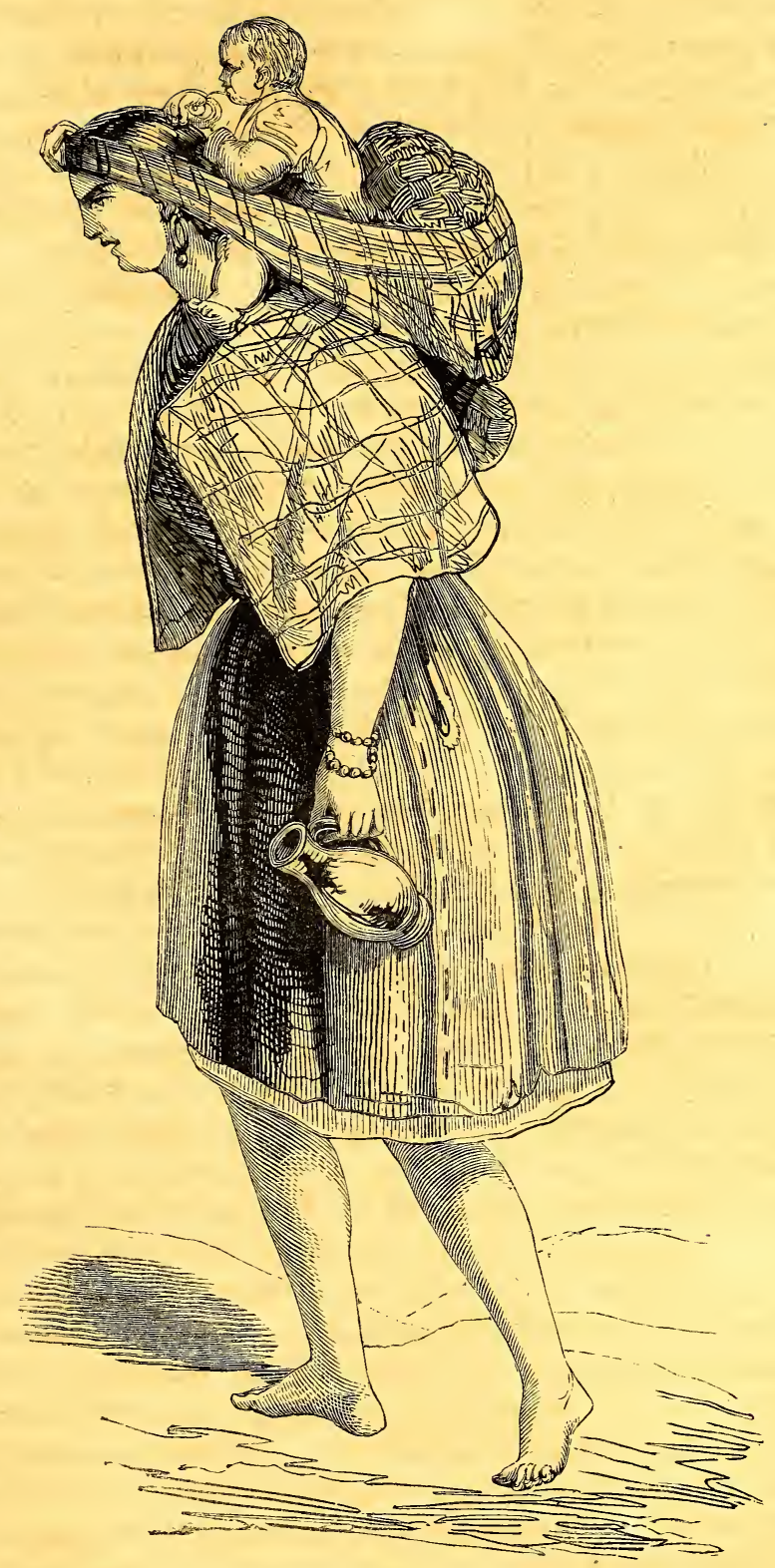

INDIENNE DF OUITO. 

indigènes sur le plancher, des tables pour écrire, des canapés en étofle de soie et de coton, un lit doré et tendu de damas dans une alcôve richement sculptée, complèten l'ameublement des bonnes maisons de Quito. Parmi les pièces, on compte le vestibule, fort sale, et servant, au besoin, de magasin à fourrage; la cuisine, les dortoirs des domestiques, et l'obrador, chambre de travail, boudoir émaillé de fleurs, où se retirent les femmes. La vie est assez chère à Quito; le bœuf y est rare, le mouton peu choisi. En revanche, les confitures et le chocolat y sont parfaits, et les pommes de terre excellentes. Le peuple boit de la rápsadura, espèce de chicha que fournissent les moulins à sucre d'Ibarra. Les autres fruits ou légumes sont les poires, les pommes, diverses espèces de pêches, les fraises, les tunas, les aguapates, les guabas, les melons el les papayes.

Les habitants excellent dans la plupart des arts et métiers. Ils fabriquent surtout des draps et des cotons, qu'ils teignent en bleu; ils en fournissent tout le Pérou. Le commerce de la ville est aussi très-actif; elle est le siége d'un tribunal suprème et d'un évèché.

Les Indiens de Quito sont les plus habiles industriels du pays. La mollesse des créoles les éloignant de tout travail manuel, les mulâtres et les nègres esclaves forment avec les Indiens toute la classe ouvrière. C'est à eux que l'on doit des draps, des cotonnades grossières, des tapis, des ponchos, et surtout cette étoffe imperméable en gomme élastique qui s'est popularisée en Europe. Elle se fabrique dans le district de Pasto. Outre les Indiens de Quito, qui ont une foule d'analogies avec ceux de Bogota, on en voit d'autres accourir dans cette ville, comme les Indiens de Maynas, des vallées de l'Amazone, etc.

Leur costume, extrêmement pittoresque, consiste, pour les deux sexes, en une espèce de tunique faite d'une étoffe à carreaux qui couvre le corps depuis le cou jusqu'aux genoux, et laisse à découvert les bras et les jambes. La tète est nue; les cheveux sont quelquefois ras, le plus souvent longs et lisses. Un petit nombre de ces Indiens porte une zagaie; mais l'arme la plus ordinaire pour eux est une sarbacane de six ou sept pieds de long, avec laquelle ils lancent à une soixantaine de pas de petites flèches en bois dur, dont la pointe est empoisonnée. Ces naturels viennent échanger, sur les marchés de Quito, les productions les plus précieuses de leurs vallées contre les objets d'industrie américaine ou européenne. Quant aux créoles aisés qui habitent la ville, leur costume ne diffère que très-peu de ceux que nous décrirons à Bogota.

Quito a acquis, en France, quelque célébrité par le séjour 'qu'y ont fait, en 1756, les académiciens envoyés par l'Académie des science de Paris, pour mesurer un degré du méridien. Ces intrépides géomètres élevèrent sur l'une des cimes du Pichincha la croix qui devait leur servir de signal.

En allant du sud au nord, le second État est celui de la Nouvelle-Grenade, qui a pour ville principale Bogota, laquelle est aussi la capitale de la Colombie. Siége du gouvernement, d'un archevêché et d'une université, elle renferme environ 40,000 habitants, des églises, des maisons magnifiques, ainsi que cinq ponts superbes. Fondée en 1538; elle est située près la rive gauche du Bogota, dans une des plus belles et des plus fertiles vallées de l'Amérique méridionale.

Le climat de Bogota demande qu'on se précautionne contre de brusques variations atmosphèriques. Des vêtements chauds suffisent à peine, l'hiver, pour s'y garantir des atteintes du froid. L'année est ainsi partagée pour les saisons : six mois pendant lesquels le ciel est nuageux et la température pluvieuse; trois mois de jours incertains et variables; trois mois seulement de journées sèches et belles. Cependant, malgré son humidité, le climat n'est point malsain, et les Européens n'éprouvent à Bogota d'autre 
maladie qu'une fièvre de quelques jours, résultat de la raréfaction de l'atmosphère, ou d'un long voyage dans les plaines. Il est plus difficile de s'accoutumer à la cuisine qui a pour base la chair de porc assaisonnée d'ail.

Bogota possède un théâtre qu'elle doit à la munificence d'un particulier passionné pour les représentations scéniques. Le parterre est vaste, dégarni de bancs et disposé en talus. On s'y tient debout. L'art dramatique est encore dans l'enfance; aussi les sujets patriotiques sont-ils toujours les mieux accueillis du public. Mais par une curieuse singularité, la manière d'exprimer la satisfaction est, au théâtre de Bogota, celle qui nous sert à témoigner le mécontentement : on accueille par des sifflets les pièces qui plaisent.

Pour bien saisir les diverses nuances de la population de Bogota, il faut se rendre aux environs de la bourse : d'un còté ce sont les portefaix de la douane, transportant les colis à l'aide de courroies, soit sur le front, soit sur les épaules; plus loin, ce sont les dames en toilette de visite ou se rendant à la messe. L'habit d'étiquette consiste dans la sayá, jupon de satin noir un peu court, terminé souvent par des franges d'un pied et demi de long, et dans la mantilla, pièce de drap fin, bleu de ciel ou bleu de lapis, taillée en demi-cercle, et qui se dispose de manière à tomber de la tête sur les épaules, comme un long béguin de nonne. Assez souvent ces dames portent, en outre, des chapeaux de feutre et des souliers de satin ou de peau. La chaussure est ce qui distingue les femmes des hautes classes. Les filles du peuple vont nu-pieds. Quand leur beauté ou un caprice de la fortune les élève à la classe qui a le droit de porter chaussure, elles sont obligées d'user de certains ménagements, et de se faire beatas, c'est-à-dire de prendre un costume en tout pareil à celui des religieuses, noir ou marron, costume qui leur permet de se chausser. A côté de ces femmes, bourgeoises, beatas, ou simples servantes, on voit des prêtres en manteau noir, coiffés d'un chapeau à la Basile; enfin des mendiants, race qui pullule à Bogota. Rien de hideux comme ces hommes qui, pour la plupart, étalent des plaies dégoùtantes, et font parade de la lèpre et de l'éléphantiasis. Parmi les nombreuses variétés de mendiants, on remarque celle des frères quêteurs, qui s'en vont ployant sous le poids de leurs besaces; puis celle des hommes qui, vêtus de noir et munis d'une sonnette, parcourent les rues en criant : Priez Dieu pour les trépassés.

L'usage de fumer est général, mème parmi les femmes qui ne quittent presque jamais le cigare. Cependant la guerre de l'indépendance a été l'occasion d'une réforme à cet égard. A l'arrivée des volontaires, plusieurs liaisons se formèrent, et les blonds officiers disaient à leurs amies : "Nos Anglaises ne fument pas; voilà pourquoi nous les aimons." Dès lors, le cigare fut mis à l'index par les jeunes femmes. Vives, belles, passionnées, clles ne se piquent ni d'un esprit sérieux, ni d'une grande austérité de mœurs; et leur vie s'écoule entre les plaisirs et les pratiques d'une dévotion sans doute peu profonde.

A Bogota, comme dans les autres villes de la Colombie, les hommes ont conservé le costume espagnol, c'est-à-dire l'habit européen, couvert du manteau castillan, sur lequel la fantaisie place souvent de riches broderies.

Le Cundinamarca, dont Bogota est la ville principale, fournit les plus riches lavages d'or de la Colombie. Les eaux qui descendent de la cordilière roulent souvent des paillettes d'or, des pyrites ferrugineuses et des émeraudes. Quelques esclaves, dressés à ce travail, lavent ces sables pour en extraire les matières précieuses. On a remarqué que les nègres excellent particulièrement dans ce genre d'industrie.

A Mariquita, dans la même province, on voit des mines d'or et d'argent exploitées par une compagnie de capitalistes anglais. Ces insulaires ont le monopole de l'exploitation des mines de la Colombie; mais, jusqu'à présent, ils ont enfoui, sans résultat 


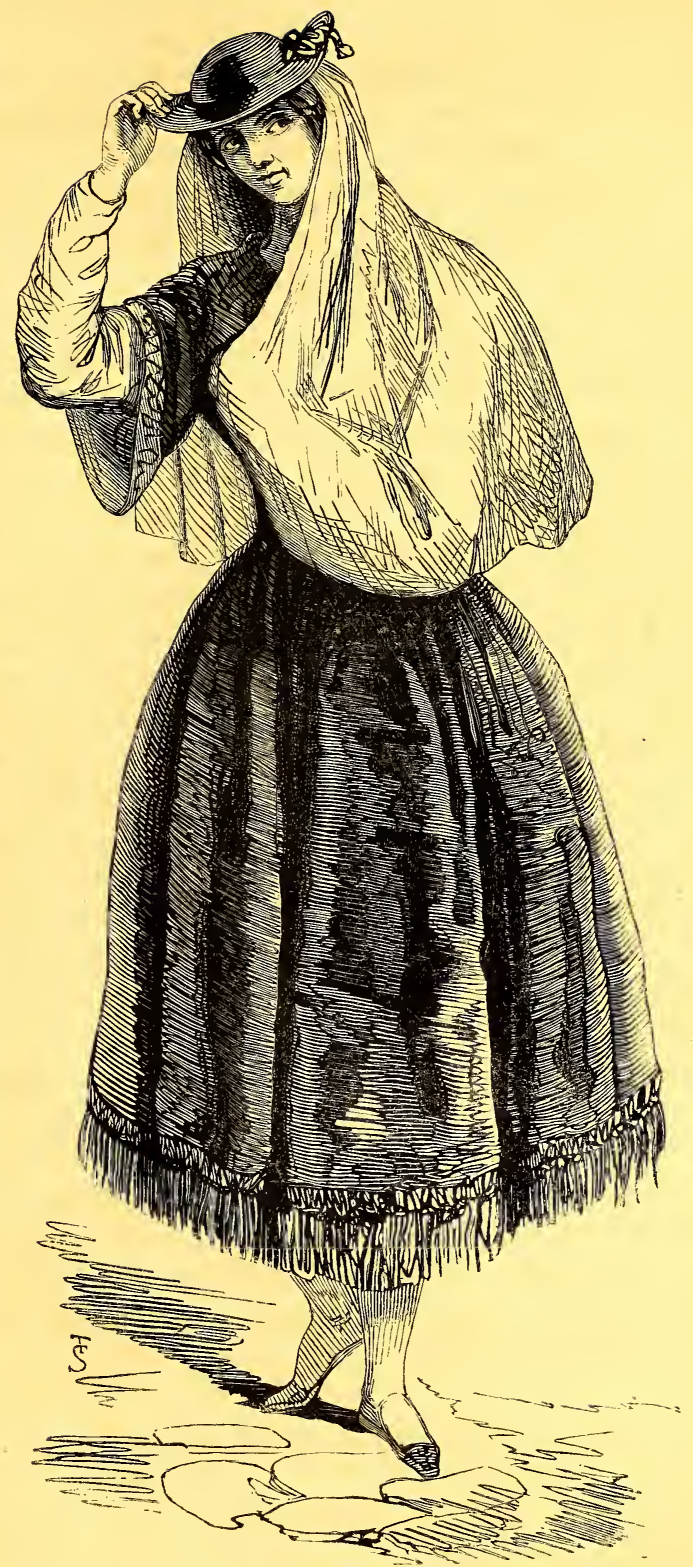

JEUNE FILLE DE BOGOTA 

satisfaisants, leurs capitaux dans ces opérations, et leurs relations commerciales avec ces nouvelles républiques n'ont pas eu plus de succès.

C'est également dans le Cundinamarca qu'existe la coutume étrange, pour ne pas dire barbare, de voyager à dos d'homme, comme en d'autres localités on voyage à dos de mulet. Les malheureux cargueros qui servent de monture à des voyageurs peu philanthropes, sont, pour la plupart, Indiens ou métis. Vètus légèrement, et armés d'un long bàton, ils voyagent pendant plusieurs jours consécutifs, exposés à l'inclémence de la température, à travers un pays rocailleux et bouleversé, portant sur leurs épaules un fardeau qui s'élève à huit arrobes (environ 100 kilogrammes). Deux courroies qui leur ceignent les épaules supportent une chaise sur laquelle le voyageur s'assied, armé d'un large parasol; et quand il trouve que sa monture va trop lentement, ou n'a pas le pied assez sûr, ni le trot assez doux, il ne craint pas de lui cingler un coup de cravache, ou de lui promener ses éperons sur le flanc !!!... Il est d'autant plus difficile de justifier cet usage que la province fournit d'excellents mulets, animaux intelligents dont le pied est tellement sûr que, dans les passages périlleıx, le voyageur n'a rien de mieux à faire que de s'en rapporter à sa monture dont il ne doit jamais contrarier la volonté. Entre Honda et Bogota, les mauvais pas mettent à tout moment la patience des cavaliers et l'adresse des mulets à de rudes épreuves. Là, ces courageux animaux gravissent ou descendent des escaliers roides taillés dans le roc; ici, ils avancent avec précaution sur le talus d'un rocher qui surplombe un effrayant précipice : ils y ramassent prudemment leurs quatre pieds, et s'élancent sur le bord opposé, à la vive satisfaction du voyageur encore pâle d'effroi.

Avant de quilter la province de Bogota, nous devons dire un mot des paysans du plateau : ces Indiens, à demi civilisés, n'ont, pour la plupart, d'autre vêtement qu'une sorte de manteau de drap qui leur couvre la tète, se serre autour du cou et descend jusqu'à l'orteil. Les deux sexes posent sur ce vêtement un petit chapeau de paille ou de feutre. Les hommes ont le menton garni d'une touffe de barbe assez semblable à celle des boucs; leurs yeux, petits et bridés comme ceux des Chinois, leur donnent un air de ressemblance avec ce dernier peuple. Ils sont assez bons cultivateurs, el moins indolents que leurs compatriotes des contrées inférieures.

La troisième république de la Colombie, celle de Venezuela r, a pour capitale Caracas qui jouit d'un printemps presque perpétuel. Cependant, en décembre et janvier, les montagnes sur lesquelles cette ville s'appuie, claires durant la matinée, se chargent le soir de traìnées de vapeurs qui s'y condensent en couches superposées, et qui, détachées ensuite par la brise, se morcellent par flocons, et quittent les sommets arrondis ou dentelés de la Cilla ou du Cerro de Avila, pour se résoudre en pluie dans la vallée.

Caracas n'a rien de bien remarquable si ce n'est qu'elle occupe un immense espace, parce que ses maisons ont toutes un jardin; chacune a aussi son filet d'eau courante.

S'il quitte les bords humides de l'Orénoque et les vallées de Caracas, le voyageur reste frappé d'étonnement en pénétrant dans ces déserts arides, dépourvus de végétation et connus sous le nom de llanos ${ }^{2}$. M. de Humboldt a donné de ces lieux une description qui se distingue autant par la vérité des assertions que par l'élégance du style. L'illustre savant s'exprime ainsi :

"Pas une colline, pas un rocher ne s'élève au milieu de ce vide immense. Le sol brûlant, sur une surface de 2,000 lieues carrées, n'offre que quelques pouces de différence

1 Petite Venise.

2 Il faut prononcer Lianos ou $\boldsymbol{Y}$ anos. 
de niveau. Le sable, semblable à une vaste mer, offre de curieux phénomènes de réfraction et de soulèvement ou mirage. Les voyageurs s'y dirigent par le cours des astres, ou par quelques troncs épars du palmier mauritia et d'embothrium, que l'on découvre à de grandes distances. La terre présente seulement çà et là des couches horizontales fracturées, qui couvrent souvent un espace de 200 milles carrés, et sont sensiblement plus élevées que tout ce qui les entoure. Deux fois chaque année l'aspect de ces plaines change totalement; tantôt elles sont nues comme la mer de sable de Lybie, tantôt couvertes d'un tapis de verdure, comme les steppes élevées de l'Asie moyenne. A l'arrivée des premiers colons, on les trouva presque inhabitées. Pour faciliter les relations entre la côte et la Guyane, on a formé quelques établissements sur le bord des rivières, et on a commencé à élever des bestiaux dans les parties encore plus reculées de cet espace immense. Ils s'y sont prodigieusement multipliés, malgré les nombreux dangers auxquels ils sont exposés dans la saison de la sécheresse et dans celle des pluies qui est suivie de l'inondation. Au sud, la plaine est entourée par une solitude sauvage et effrayante. Des forêts d'une épaisseur impénétrable remplissent la contrée humide située entre l'Orénoque et le fleuve des Amazones; des masses immenses de granit rétrécissent le lit des fleuves; les montagnes et les forêts retentissent sans cesse du fracas des cataractes, du rugissement des bêtes féroces et des hurlements sourds du singe barbu qui annoncent la pluie. Le crocodile, étendu sur un banc de sable, el le boa, cachant dans la vase ses énormes replis, attendent leur proie ou se reposent du carnage.

\ Dans les forêts, dans les plaines, vivent des peuples de races et de civilisations diverses. Quelques-uns, séparés par des langages dont la dissemblance est étonnante, sont nomades, entièrement étrangers à l'agriculture, se nourrissent de fourmis, de gomme et de terre, et sont le rebut de l'espèce humaine; tels sont les Otomąues ${ }^{2}$ et les JARuRES ${ }^{2}$. La terre que les Otomaques mangent est une glaise grasse et onctueuse, une véritable argile de potier, d'une teinte jaune grisâtre, colorée par un peu d'oxyde de fer. Ils la choisissent avec beaucoup de soin, et la recueillent dans des bancs particuliers, sur les rives de l'Orénoque et du Meta. Ils distinguent au goût une espèce de terre d'une autre; car toutes les espèces de glaises n'ont pas le même agrément pour leur palais. Ils pétrissent cette terre en boulettes de quatre à six pouces de diamètre, et la font cuire à un petit feu, jusqu'à ce que la surface antérieure devienne rougeâtre. Lorsqu'on veut manger cette boulette, on l'humecte de nouveau. Ces hommes, féroces el sauvages, se nourrissent de poissons, de lézards ou de racines de fougère, lorsqu'ils peuvent s'en procurer; mais ils sont si friands de terre glaise, qu'ils en mangent tous les jours un peu après le repas pour se régaler, dans la saison où ils ont d'autres aliments à leur disposition.

Les Otomaques et les Amarizanos ont encore une passion funeste et bizarre, celle de la poudre de niopo, produit d'une espèce de munose, mise en morceaux, humectée et fermentée. Lorsque les graines commencent à noircir, on les pétrit comme une pâte, on y mêle de la farine de manioc et de la chaux tirée d'une coquille; et ensuite on expose ce mélange à un feu vif, où la pâte prend la forme de petits gâteaux. Cette substance se prise avec délices, à toute heure, en tous lieux. Dès qu'un étranger met le pied dans une case d'indigènes, on lui présente le niopo comme un gage de prévenance hospitalière.

1 M. d'Orbigny les appelle Otomacos.

2 Il faut nommer aussi les Amarizanos qui sont également géophages ou mangeurs de terre. $\Lambda$ Uruana, M. d'Orbigny vit une tribu d'Amarizanos, réunie à une peuplade d'otomaques. 
Le naturel qui prend le niopo s'étend à terre, prend un plat de cinq à six pouces de large sur lequel est placé le niopo réduit en poudre, et, de la main qui lui reste libre, il s'applique à la narine un os fourchu de gallinazo, à travers lequel il aspire cette espèce de tabac qui procure une ivresse voluptueuse. Cependant le niopo n'agit pas continuellement comme spasmodique et soporatif ; l'excitation qu'il fait naître chez les Indiens est parfois telle que leur ivresse dure plusieurs jours.

Lés cabanes de ces indigènes ont un aspect misérable. Elles sont couvertes de feuilles de palmier, mais ouvertes de toutes parts. Le meuble principal est le hamac suspendu au toit. On n'y voit d'autres ornements que des flèches empoisonnées accrochées à un poteau.

Au delà de la Boca et de la Tortuga, on remarque à droite l'embouchure de l'Arauca, large cours d'eau qui fut le théâtre de divers épisodes de la guerre de l'indépendance; et, plus loin, sur la rive opposée, le village d'Uruana, distant des bouches de l'Orénoque de deux cents lieues. A celte hauteur, l'aspect du fleuve change, il ne coule plus entre deux terres unies et plates; de hautes montagnes l'eneaissent, et présentent un aspect très-pittoresque. Le plus remarquable des défilés qu'il baigne est celui de Baraguan : il aboutit à la plage de Pararuma, lieu renommé pour la récolte abondante des œufs de tortue, et peuplé de tribus indiennes, appartenant toutes aux races de la zone moyennc et de la zone supérieure de l'Orénoque. On y remarque encore des Macos, des Salivas, des Maquiritares, des Carancuganas, el des Parecas, peuples donx et faciles à civiliser, tandis que leurs voisins, les Guambos et les CHiricoss, sont toujours intraitables et insoumis. On peut les diviser en Indiens des plaines, et en Indiens des forèts, monteros et planeros. Pour les deux types indigènes, une sorte de terrain neutre commence à Pararuma : c'est là le seul endroit où ils se rencontrent et se tolèrent. Ces Indiens ont, en général, de vilaines formes et la figure désagréable; leur corps est couvert de terre et de graisse. Ils se tiennent accroupis près du feu, ou assis sur de grandes carapaces de tortue, ayant, durant des heures entières, les yeux fixés sur le sol, immobiles, et dans un état de crétinisme.

Le seul vêtement des naturels est le pignent. La richesse chez ces sauvages se reconnaît par la vivacité et la grandeur des peintures qu'ils ont sur la peau. Pour signifier la misère de quelques-uns d'entre eux, ils disent : Il n'a pas de quoi se peindre le corps. Les pigments les plus beaux sont faits avec une bignone qui produit une couleur d'un rouge très-éclatant.

Les Caraïbes et les Otomacos s'en peignent seulement la tête; mais les Salivas, le peuple le plus industrieux du pays, s'en couvrent tout le corps.

Après la bignone nommée chica, vient l'onoto ou roucou, employé si fréquemment dans la Guyane. Les peintures ne sont ni uniformes ni régulières, et prennent les configurations les plus bizarres. Elles représentent tantôt la forme d'un habit européen, un habit bleu avec des boutons jaunes ou noirs, tantôt ce sont de larges stries rouges transversales, sur lesquelles on applique des paillettes de mica argenté, ce qui, de loin, fait l'effet d'habits brodés de galons.

La mission de San-Balthasar est l'un des hameaux les mieux bâtis que l'on remarque après Caracas. Les cases en sont régulières et propres, et les plantations belles et bien tenues. C'est au-dessus de ce village que l'on entre dans le Rio Temi. Avant d'arriver à son confluent, on voit la Piedra de la Madre, butte granitique à laquelle se rattache un épisode trop caractéristique pour être omis.

Lors des battues faites contre les Indiens, pour renforcer la population des villages, des créoles entrèrent dans la cabane d'un guahiba, et y trouvèrent la mère et trois enfants dont deux n'étaient point adultes. Le père étant allé à la pêche, toute résis- 
tance fut impossible. La fuite était leur seule et unique ressource. On courut après cette femme, on la garrotta avec ses deux enfants, et on les transporta tous les trois à San-Fernando. Séparée de son mari et de ses deux fils aînés qui avaient suivi leur père, celte femme n'eut désormais d'autre pensée que la fuite. Quoique entièrement dépaysée, ulle n'en renonça pas pour cela, malgré la distance, à la chance de retrouver sa cabane. Plusieurs fois, elle s'enfuit avec ses deux enfants; mais, toujours rattrapée, elle fut cruellement battue. On la sépara alors de sa famille, pour la conduire vers les missions du Rio Négro. On la lia sur une pirogue; cependant, ayant rompu ses liens, elle se jeta à la nage, et gagna la rive gauche de l'Atabapo. Elle s'enfonça alors dans les bois; mais, vers le soir, ses gardiens la rattrapèrent, et la lièrent sur la butte granitique, qui fut, pour cette raison, nommée la Piedra de la Madre, et, avec des lanières de cuir de lamentin, lui déchirèrent la peau. On la reconduisit ensuite dans une barque vers la mission de Javita. On la jeta alors dans un de ces caravansérais nommés pompeusement casa del Rey. Pendant la nuit elle brise ses liens, et s'enfuit avec l'intention d'aller reprendre ses enfants captifs à San-Fernando de Atabapo, pour les reconduire vers leur père, sur les bords du Guaviare. C'étail un voyage d'environ cinquante lieues, à travers des forêts inondées et presque impraticables. Ce que l'Indien le plus robuste n'eût pas entrepris, cette femme l'accomplit en grande partie. Malgré les lianes, elle Iraversa les bois, et, moitié nageant, moitié marchant, franchit tous les cours d'eau; vécut de fourmis noires aux nids résineux, et arriva jusqu'aux environs de la mission où étaient retenus ses enfants. Mais la fatalité poursuivit la malheureuse Guahiba; on s'empara d'elle de nouveau, et au lieu de récompenser un tel dévouement, on l'envoya mourir loin de ses fils, dans une des missions du haut Orénoque. Elle s'y laissa mourir de faim!

Nous devons dire un mol du poste de l'Esméralda. C'est là que se fabrique le meilleur curare, l'un des poisons les plus actifs que l'on connaisse. Il y a une espèce de mystère dans la confection de cette substance, et on le célèbre comme une fète appelée la fiesta de las juvias. Les juvias sont les fruits du bertholletia, liane qui fournit le curare. Une orgie complète précède la fabrication.

Quand les fumées des spiritueux sont passées, on dispose de grandes chaudières pour la cuisson de ce poison, qui ne se trouve ni dans les fruits, ni dans les feuilles de l'arbre, mais dans l'aubier. On racle la liane, qui est le bejuco de mavacure, et l'écorce enlevée est réduite en filaments très-minces sur une pierre à broyer. Quand le suc devient jaune, toute la masse filandreuse prend la même couleur. Une infusion à froid, puis une concentration par évaporation, suffisent pour obtenir ce poison, dont on ne connaît pas jusqu'à présent l'antidote.

Le curare terminé, le premier acte de la fête des juvias commence. La scène se passe dans de vastes cabanes, autour desquelles on range de grands singes, des marimondes et des capucins rôtis et noircis par la fumée. La chair de ces singes est très-estimée par les naturels, qui en réservent toujours un grand nombre pour le repas de la fête. Ces anthropomorphes, ainsi grillés et alignés, offrent assez l'apparence d'enfants brûlés dans un incendie, ou de momies rangées dans un caveau. Ce spectacle dégoûtant pour l'Européen ravit les Indiens qui avaient, à ce qu'il paraît, à une époque mème récente, des habitudes d'anthropophagie qu'on n'a pu déraciner sans de grandes difficultés.

Le second acte se compose de danses dont les hommes seuls ont le privilége, ce qui en auginente la monotonie. Tous, jeunes ou vieux, tournent en rond, tantôt à droite, tantôt à gauche, avec une gravité silencieuse. Les danseurs, presque toujours euxmêmes musiciens, soufflent dans une espèce de syringe à tuyaux inégaux, et marquent la mesure en ployant les genoux en cadence, mais constamment sur un mode triste et lent. 
Pendant ces divertissements, les femmes demeurent à l'écart; on les admet tout au plus à servir aux danseurs du singe rôti, des boissons fermentées, du chou-palmiste, et de la farine de poisson séchée au soleil.

Idolâtres pour la plupart, ces Indiens sont polygames. Les femmes sont fort peu considérées, et néanmoins elles ont établi entre elles une espèce de hiérarchie domestique.

Les Guaraunos, la tribu la plus nombreuse parmi celles qui occupent les terrains inondés, habitent aux environs d'Angostura. Ils ont des carbets bâtis sur pilotis comme ceux des Indiens de la Guyane. Ces carbets, adossés au palmier moriche, ont une espèce de plate-forme fabriquée avec les jeunes rejetons de cacaotiers, et sur laquelle les naturels suspendent leurs hamacs. La richesse de ces tribus consiste dans le grand nombre de palmiers moriches qui croissent sur leurs îles et sur leurs terrains submergés, et qui leur fournissent à la fois la boisson et la nourriture. Ainsi l'existence de ces Guaraunos, qui sont au nombre d'environ dix mille, paraît liée à celle de la famille des palmistes, comme celle de certains oiseaux ou insectes tient à certaines fleurs ou à certains arbres. Grands, vigoureux et bien faits, les Guaraunos sont moins indolents que les autres sauvages de l'Amérique méridionale. Ils aiment la danse avec passion, sont fort adroits pêcheurs, et dressent à cet exercice une espèce de chien qui ressemble aux chiens de nos bergers. Ces chiens sont les compagnons des Guaraunos. Bons, sociables, hospitaliers, et d'un caractère gai, quand tous les Indiens des environs sont tristes, les Guaraunos ont une langue douce, harmonieuse et riche. Leur commerce consiste en poissons, filets et paniers.

Les Guahiros habitent le littoral des Cienegas ${ }^{x}$ et toute la partie du territoire entre Santa-Marta et la Hacha. Leur population peut être évaluée à 4,000 âmes environ. Bien armés, bien disciplinés, maniant également bien le mousquet et la flèche vénéneuse, ces Indiens ont établi un grand commerce interlope avec les négociants anglais de la Jamaïque. Ils échangent des mulets, des moutons, des perles, des bois de teinlure, des peaux, contre du rhum, de l'eảu-de-vie, des munitions et des colifichets. Ils trafiquent encore avec la ville de la Hacha. Leurs chefs ou caciques se distinguent par un habit de guerre qui consiste en une peau de tigre, ornée sur les bords de plumes de toucan; les dents de cet animal servent à composer un diadème à ces petits souverains.

Les Chaymas forment une tribu assez remarquable. Ils sont d'une petite taille, et atteignent rarement cinq pieds. Trapus et ramassés, ils ont les épaules larges, les membres charnus, la poitrine aplatie, la peau bronzée, le front petit et déprimé, les yeux noirs, les pommettes fortes, les cheveux plats, la barbe rare, le nez proéminent, la bouche grande avec les lèvres larges, le menton court et rond. L'ensemble de leur physionomie est triste, grave, mélancolique. Leurs dents seraient belles, s'ils ne les noircissaient.

Ils aiment mieux marcher nus que vêtus, malgré les remontrances des prêtres. Si pour sortir ils se couvrent d'une tunique de coton, qui ne descend qu'au genou, rentrés dans leurs cases, ils rejettent loin d'eux cette enveloppe gênante. Les femmes, souvent nues aussi, sont rarement belles, quoiqu'elles aient dans le regard quelque chose de louchant et de doux. Leurs cheveux sont réunis en deux longues tresses. Elles ne se tatouent pas la peau, et leurs seuls ornements consistent en colliers et en bracelets formés de graines, d'os d'oiseaux et de coquilies.

\footnotetext{
1 Espèce de lagune située sur les bords de la mer, et dans laquelle le Rio Magdalena se décharge par quatre bouches.
} 
Leurs cases, propres et bien tenues, contiennent leurs hamacs, leurs estoras (nattes de jonc), leurs pots pleins de maïs fermenté, leurs arcs et leurs flèches. Autour de ces cases se trouvent les conucos ou champs, qu'ils cultivent avec quelque soin. Quand le couple revient des champs le soir, l'homme ne porte que son machete, qui lui sert a frayer les chemins à travers les broussailles, tandis que la femme succombe sous la. charge des bananes et des autres fruits. Souvent même elle est obligée de porter deux ou trois enfants, tant sur ses bras que sur ses épaules. Ces Indiens sont, en général, peu intelligents; leur vie est régulière et tranquille.

Avant de quitter la Colombie, nous devons dire un mot des ventas ou auberges de celte contrée. A peine peut-on s'y procurer quelques provisions; on n'y trouve guère que la chicha, bière de maïs, et du guarapo. Quelquefois pourtant, on cède aux voyageurs de la carne seca, viande séchée au soleil, de la graisse, des saucissons, el quelques légumes, tels que la racine baracacha, du manioc doux, et des aciamas ou citrouilles. Ces auberges se composent d'une case assez petite, pourvue d'une toiture en chaume qui déborde de manière à former une espèce de galerie extérieure. A l'intérieur se trouve un comptoir flanqué de la grande jarre de chicha ou de guarapo, qui sert à la consommation des muletiers qui passent. Pour la plus grande commodité du service, on y a pratiqué un guichet à travers lequel on donne à boire pendant la nuit. Sur le comptoir figure aussi habituellement un plat rempli de piment et d'ail pilé et mêlé dans du vinaigre. On y trempe la galette de maïs, que l'on mange en buvant. Ces ventas sont tenues par des naturels ou par des métis, qui vivent sans beaucoup de peine des profits de l'auberge. Presque toujours inoccupés, ils passent le temps, soit à fumer, soit à tourmenter une mauvaise guitare en calebasse, très-commune dans les ventas. Les attenances de la maison consistent presque toujours en un petit clos planté de bananiers et de papayers. Les maîtres des ventas y récoltent quelques fruits et quelques légumes. Ce sont, du reste, d'assez pauvres logis, où, ne trouvant presque rien pour se coucher, on se sert des hamacs que l'on porle avec soi dans un grand sac de cuir. 


\title{
GUATEMALA
}

$0 \mathrm{C}$

\author{
RÉPUBLIQ̣UE DE L'AMERIQ̣UE CENTRALE。
}

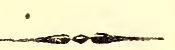

La position géographique de cette république est très-avantageuse, et doit singulièrement favoriser le développement de sa richesse et de sa puissance. Elle est située au centre du Nouveau-Monde, entre l'Amérique du Nord et celle du Sud, ayant d'un côté pour limite la république de Colombie, et de l'autre celle du Mexique. L'Atlantique et l'océan Pacifique, qui baignent également ses côtes, lui donneront de grandes facilités pour entretenir les relations qu'elle doit établir un jour avec tous les peuples de l'univers. Guatemala présente une surface de 26,152 lieues carrées, qui varient beatcoup quant à l'exposition, la qualité du sol, la hauteur, la température et la fertilité. () noit que cette superficie forme un État plus étendu que n'est l'Espagne en Eırope, oı la république du Chili dans le Nouveau-Monde. Du sommet des montagnes qui Iraversent le territoire de Guatemala descendent de nombreuses rivières qui fertilisent le sol qu'elles arrosent, rafraîchissent l'atmosphère, et vont se perdre dans les deux océans. Quelques-unes de ces rivières sont en partie navigables, telles que la Motagua, l'Ulna, l'Aguan; beaucoup d'autres pourraient aisément le devenir, et nul doute que le gouvernement ne s'occupe avec zèle de cette amélioration importante, lorsque les ressources de celte nation commenceront à se développer. Le grand lac de Nicaragua, dont la circonférence est de 150 lieues, baigne le territoire de cette république, et sera une des causes principales de sa prospérité, si le projet d'ouvrir, à travers ce lac el la rivière San-Juan de Nicaragua, une communication entre l'Atlantique et l'océan Pacifique, reçoit jamais son exécution. Plusieurs maisons de commerce de Londres et de l'Amérique du Nord désirent vivement aujourd'hui réaliser celle entreprise. Un grand nombre de ports facilitent l'accès du territoire de l'Amérique centrale. Vers le nord, siont ceux d'Omon, Truxillo, San-Juan et Matina; au sud ceux de Ricoia, Acalejo, Conrhagua, Acajutla, Iztapa, etc. Les productions du sol sont innombrables; la nature ne se lasse pas d'y prodiguer ses trésors; et dans tout le cours de l'année il y a une succession non interrompue de fruits et d'autres produits végétaux de toute espèce.

Les deux productions les plus estimées sont l'indigo et la cochenille. C'est dans la province de Soconusco qu'on recueillait autrefois le cacao pour l'usage particulier de lit cour de Madrid. Les provinces renferment plusieurs mines d'argent.

D'après les calculs de M. de Humboldt, en 1822, la population de l'ancien royaume de Guatemala n'excédait pas 1,600,000 âmes.

Le Guatemala a été dévasté dans les $x v^{-e}$ et $x v i^{e}$ siècles par des corsaires anglais el hollandais, et il a eu à se défendre pendant longtemps des invasions des Mosufuitos et 
des Poyais. Ces naturels, qui se montraient les ennemis les plus acharnés des Espa gnols, se comportaient cependant amicalement envers toute autre nation; car ils permirent aux Anglais de former des établissements sur leurs côtes, et ceux-ci les occupèrent jusqu'en 1812 : l'aventurier Mac-Gregor parvint aussi à établir une colonie au milieu des Poyais. Le Guatemala a pris peu de part aux révolutions qui ont agité dans ces derniers temps les autres colonies espagnoles de l'Amérique; il a été le dernier à se séparer de la mère patrie, car ce ne fut qu'à la fin de 1821 qu'il proclama son indépendance. Il avait d'abord été incorporé aux États mexicains ; mais, à la chute d'Iturbide, il se déclara État indépendant. En 1823, il s'est constitué en république fédérative sous le nom de republica federal de Centro America. Sa constitution, décrétée par une assemblée nationale, le 22 novembre 1824, est modelée sur celles des États-Unis et de la Colombie.

Il y a quelques années qu'un Américain aussi recommandable qu'éclairé, M. Rocafuerte, a démontré, dans un livre intitulé : El Systema Colombiano, la nécessité d'adopter le système républicain; et c'est en partant de ce principe que l'assemblée constituante de Guatemala a choisi, pour forme de gouvernement, le système d'une république représentative et fédérale, et a investi de la puissance législative un congrès et un sénat. Le congrès se renouvelle par moitié tous les ans. Chaque État fournit un représentant par trente mille habitants. Le sénat se compose de membres élus par le peuple, sur le pied de deux par État. Ce corps a le droit de sanctionner toutes les résolutions passées dans le congrès, et se renouvelle tous les ans par tiers, les membres sortants restant éligibles et pouvant être réélus. L'exercice du pouvoir exécutif est confié à un président nommé par les habitants des différents États de la fédération. Le vice-président est nommé de la même manière, et, comme le président, pour quatre ans; mais ceux qui remplissent ces fonctions peuvent être réélus une fois sans qu'il y ait interruption dans l'exercice de la puissance souveraine. La constitution abolit l'esclavage, établit la liberté individuelle, et garantit celle de la presse. La république est maintenant divisée en six États, dont chacun est libre et indépendant quant à son gouvernement et à son administration intérieure.

Voici en quels termes M. Barrandia, un des plus zélés patriotes et des plus éloquents orateurs de la république, et président de la commission qui a préparé le projet de constitution, plaide la cause de la forme du gouveruement fédératif adoptée par le Guatemala : «Nous avons reproduit, autant que possible, dit-il dans la rédaction de ce projet, le modèle que nous offraient les États-Unis, modèle digne d'être imité par tous les peuples qui viennent d'acquérir leur indépendance. Nous n'avons pas jugé à propos d'y faire aucune altération importante, mais plus tard nous pourrons y ajouter tout ce qui sera compatible avec notre propre situation, ou en rapport avec les grands principes, qui, depuis que cetle nation s'est constituée, ont contribué si puissamment aux progrès de la science législative. Nos regards se sont aussi portés sur les constitutions d'Espagne et de Portugal, sur la constitution fédérative et centrale de la Colombie, et sur toutes les opérations législatives de la France constitutionnelle, de cette grande nation qui, dotée de tant d'écrivains célèbres, de philosophes et de publicistes, a fait des essais dans toutes les formes de gouvernement, excepté dans le gouvernement fédératif; et qui, du fond de l'abîme où les malheurs de sa révolution l'avaient plongée, donnait encore des leçons au monde; qui s'est régénérée par un effort admirable, el à qui nous devons, sans aucun doute, les idées les plus propres à améliorer les institutions sociales des différentes nations de l'univers. "

Le 20 février 1825, l'assemblée constituante fut dissoute, et remplacée par le congrès fédéral qui, le 10 avril de la même année, jura le maintien de la constitution. 
M. del Valle, qui, jusqu'à cetle époque, avait été président du pouvoir exécutif, avant de quitter ses fonctions, prononça un discours éloquent à l'ouverture du congrès. On ne saurait donner assez d'éloges à ce citoyen estimable pour tout le bien qu'il a fait à son pays.

Au temps où la métropole espagnole administrait encore cette province, elle ressortissait à l'audience royale de Guatemala, résidence du gouverneur ou capitaine général. Les affaires spirituelles relevaient de l'archevèque de Guatemala et de ses trois suffragants. La division ecclésiastique comprenait quatre évêchés : celui de Guatemala avec cent huit cures, quatre cent vingt-quatre églises paroissiales et 539,765 habitants; celui de Leon avec trente-neuf cures, quatre-vingt-huit églises paroissiales et 131,932 habitants; celui de Ciudad-Real avec trente-huil cures, cent deux paroisses et 69,525 habitants; enfin celui de Comayagua avec trente-cinq cures, cent quarante-cin églises paroissiales et 88,143 habitants.

Aujourd'hui les divisions politiques ont absorbé les divisions ecclésiastiques, el la capitainerie de Guatemala, devenue la confédération de l'Amérique centrale, est partagée en six districts ou Ĺtats principaux : le district fédéral, l'Élat de GuATEMala, l'État de San-Salvador, l'État d'Honduras, l'État de Nigaragua el l'État de Costa Rica.

C'est dans l'Élat de Guatemala qu'est comprise aujourd'hui l'ancienne province de Vera-Paz où la société belge de colonisation a récemment fondé un établissement.

Les habitants de Guatemala sont, en général, doux, humains, libéraux, affables, dévots, hospitaliers; mais en revanche mous et indolents. Les ouvriers y sont intelligents et habiles, surtout dans la sculpture, dans l'orfévrerie et dans la lutherie. On a vu des ouvrages de sculpteurs distingués s'exporter non-seulement pour Mexico, mais encore pour l'Europe, où ils obliennent les suffrages des artistes. La classe des tisserands est fort nombreuse, et de leurs métiers sortent des gazes, des mousselines charmantes el des tissus plus ordinaires pour l'usage des classes inférieures. Les femmes sont ou brodeuses, ou fleuristes, ou fabricantes de cigares. Quant aux mœurs et aux usages, ils diffèrent peu de ceux des autres colonies espagnoles.

Avant la conquête, les Indiens étaient idolâtres, et avaient leurs prêtres qui, dans beaucoup de circonstances, faisaient l'office de devins. Plus tard, en 1524, lorsque don Pedro Alvarado eut soumis, pour l'Espagne, les différents royaumes entre lesquels celte vaste portion de l'Amérique était partagée, le zèle des missionnaires espagnols, qui se succédèrent dans celte contrée, fit embrasser à ses diverses populations la religion catholique, et ce n'est pas sans braver d'affreux périls et des difficultés sans nombre, que ces ardents instituteurs parvinrent à propager les lumières de l'Évangile. Sans parler des dangers des chemins, de la soif, de la faim, et des maladies fréquentes sous des climats meurtriers, il leur fallait souvent affronter la mort, que leur montraient, sous la forme la plus terrible et la plus effrayante, les tortures inventées par la barbarie et la férocité de leurs indociles néophytes. Toutefois ces saints personnages ne se laissèrent rebuter par aucun obstacle; ils essayèrent sur les Indiens la séduction des présents; ils leur prodiguèrent les caresses : habiles à profiter des conversions déjà opérées pour en étendre le cercle, ils revêtaient de formes poétiques quelques-uns des mystères de la religion, et, en faisant chanter ces poésies, ils excitaient la curiosité des Indiens. C'est ainsi que l'Amérique fut initiée aux mystères du nouveau culte.

Ceux des Indiens qui n'habitaient pas les grandes villes et les forteresses, vivaient dans des villages ou bourgs, dont quelques-uns existent encore aujourd'hui, sous le nom de pajuynco : les maisons de ces pajuyncos sont si éloignées les unes des autres, qu'il n'est pas rare de voir un bourg de cinq cents familles occuper l'espace d'une lieue. Les missionnaires, pour trouver plus de facilité à baptiser et à instruire, onı 
rassemblé leurs catéchumènes dans des villages bâtis sur le modèle de ceux d'Espagne, c'est-à-dire que l'église s'élève au centre, ayant en face le presbytère, la prison et d'autres bâtiments publics, tandis que les maisons sont placées en carré dans les rues lirées au cordeau. Si le missionnaire espagnol avait dédaigné l'emploi des baïonnettes, el n'eût altendu ses succès que de la seule persuasion; s'il s'était abstenu de remplir de superstitions absurdes et d'un amas de ridicules miracles les esprits qu'il cherchait à convertir, la prédication de l'Évangile, dans le Nouveau-Monde, eût été un des plus grands services rendus à l'humanité.

Cependant, malgré le zèle des missionnaires, beaucoup d'Indiens, un siècle après la conquète, n'étaient pas convertis au christianisme; et d'autres, vers l'an 1725, abjurèrent cette croyance et mirent à mort trois missionnaires, qui se trouvaient au milieu d'eux, en accusant la religion et les moines espagnols d'avoir été les instruments de leur esclavage. A présent la plus grande partie de ces Indiens professent la religion catholique; mais elle n'est comprise que du petit nombre. Ils sont crédules et superstitieux. L'État d'Honduras, sur les bords de la rivière Uloa, nourrit une tribu de quinze à vingt mille Indiens, appelés Sicaynes, d'un caractère doux et hospitalier. Ils fontà tous les étrangers l'accueil le plus affectueux, et, lorsque quelqu'un manifeste le désir de se fixer parmi eux, ils lui donnent une cabane, el lui fournissent des instruments araloires; si, après un stage d'une année, cet étranger s'est bien conduit, ils l'incorporent à leur tribu, et lui offrent une de leurs filles en mariage.

L'étranger, objet de ces marques d'hospitalité et de faveur, doit éviter, avec un soin scrupuleux, de leur parler des missionnaires qu'ils détestent, attendu qu'ils ont toujours été les principaux agents de leur oppression.

D'autres Indiens habitent encore l'État d'Honduras. Ce sont les Indiens MosQurTos; iis sont d'un aspect sauvage, malpropres et presque nus. Les Espagnols ont trouvé dans cette tribu un ennemi implacable, qu'ils n'ont jamais pu dompter. Ils ne sont pas hospitaliers, et font un commerce de peu d'importance seulement avec les Anglais, qui leur achètent le peu d'or et d'argent qu'ils recueillent dans les rivières et dans les mines. Dans les rues d'un établissement anglais nommé Wallis, on en voit quelques-uns qui ressemblent à nios bohémiens, et qui vivent séparés des autres habitants, se nourrissant d'ordures et des restes qu'ils peuvent ramasser dans les rues. Quelques auteurs prélendent qu'ils sont cannibales. Ce qu'il y a de certain, c'est qu'ils sont idolâtres.

A voir le désordre, la mesquinerie et l'incommodité absolue que présentent les maisons des aborigènes, et l'état de misère où ils se trouvent maintenant, il paraît incroyable qu'avant la conquête, les Indiens aient possédé ces palais magnifiques, ces villes si bien bâties, ces forteresses et ces châteaux défendus avec tant d'art, et tous ces édifices de pure ostentation et de parade, qui font l'admiration de plusieurs historiens, et dont on trouve encore quelques traces. Le plus riche Indien vit aujourd'hui dans une maison misérable, qui le plus souvent n'a qu'une seule chambre. Quoique leurs habitations contiennent quelquefois plusieurs appartements, leur distribution n'offre aucun ordre suivi, el ils sont séparés les uns des autres; de sorte qu'il n'y a pas d'exemple qu'un Indien possède une maison, entourée de murs réguliers, et offrant quelque trace de goût, quoiqu'ils aient incessamment sous les yeux les demeures des Espagnols.

Les Indiens du voisinage de Guatemala sont encore dans l'état de nature. lls parlent la langue indigène, et s'habillent comme des sauvages, si l'on peut donner le nom d'habillement à un morceau de drap dont ils se couvrent le milieu du corps, laissant tout le reste entiêrement nu. Les femmes ne se couvrent pas davantage; mais leur peau de bronze et leurs traits grossiers diminuent le danger qu'offre un si léger costume. Les 



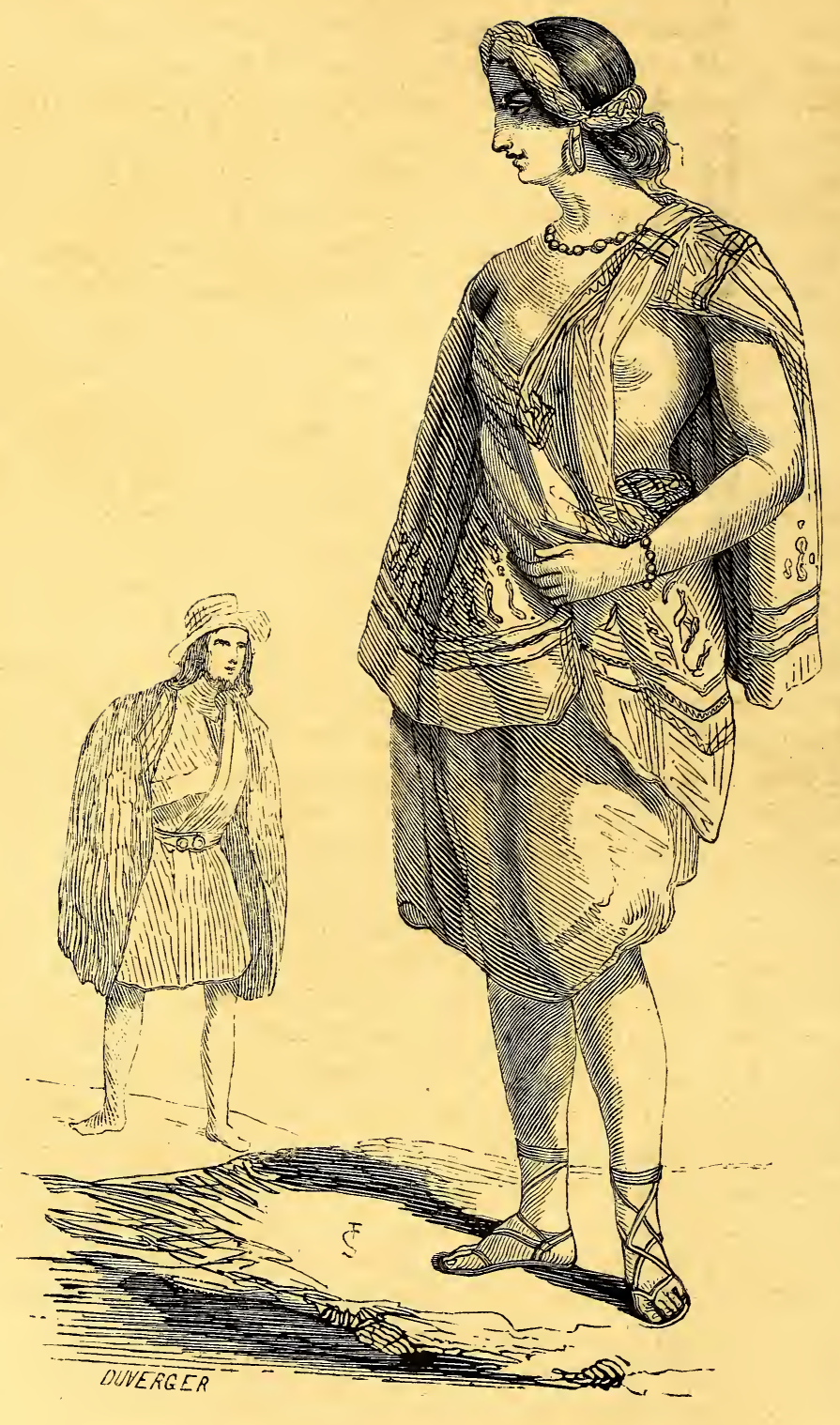

FEVME ET HOMME DE GUATEMALA 
Indiens des autres provinces sont plus civilisés, s'labillent à l'européenne el parlent espagnol.

Plusieurs écrivains s'accordent à dire que les Indiens sont naturellement lâches et timides; à mesure qu'ils avancent dans la carrière de la civilisation, ils acquièrent du courage et de la valeur, et plusieurs d'entre eux se sont distingués dans la dernière guerre. Leur arme principale est le sabre, et on en voit beaucoup qui savent aussi se servir du fusil. Plusieurs tribus sont armées de lances, et sont habiles à lancer les flèches.

Par la constitution actuelle, les Indiens ont acquis le droit de cité, el jouissent des mèmes avantages politiques que les descendants des Espagnols. Aussi, ils ont en général beaucoup d'attachement pour le nouveau système, et dans plusieurs de leurs villes, la totalité des habitants est ouvertement prononcée en faveur du gouvernement républicain.

Sous la domination espagnole, ces peuples vivaient dans l'oppression. Le gouvernement paraissait les protéger; mais les lois n'avaient, en effet, d'autre but que de les tenir dans l'ignorance et dans l'esclavage. C'est ainsi qu'une fiction de la loi espagnole considérait les Indiens comme des mineurs pendant loule leur vie, et les soumettait à une tutelle perpétuelle. Pour fermer à l'instruction tout accès dans leurs esprits, l'entrée des villages indiens n'était pas permise aux Espagnols. La danse, dans leurs propres maisons, leur était défendue, el la crainte de leurs progrès dans les exercices de la guerre leur avait fait interdire l'équitation, quoique le pays qu'ils habitent produise beaucoup de chevaux. Enfin, sous la verge espagnole, les propriétaires de mines pouvaient forcer les Indiens à travailler dans ces cavernes souterraines, à deux réaux par jour. Ces peuples ont donc sujet de bénir la constitution actuelle qui les a tirés de l'état de dégradation où ils gémissaient, et leur émancipation opposerait toujours une diggue puissante aux prétentions et aux entreprises de l'Espagne, quand mème cetle puissance serail dans un état assez florissant pour lui permettre d'aspirer à reconquérir ses colonies.

Selon l'historien Torquemada, les Indiens, du temps de leurs rois, avaient des collíges et des séminaires pour les enfants et les adultes, sous la direction de personnes rapables et prudentes. Quoiqu'il ne reste aujourd'hui aucune trace de ces colléges, les Indiens donnent beaucoup de soins à l'éducation de leurs enfants; la mère nourrit son 'nfant jusqu'à l'àge de trois ans, et il n'y a pas d'exemple qu'elie l'ait livré à un sein ćtranger. Elles les portent suspendus à leurs épaules, enveloppés dans un morceau de drap qu'elles nouent devant elles. Ce fardeau ne les empêche pas de laver, de moudre, et le mouvement de la mère sert à bercer doucement l'enfant. Elles ne les garantissent pas des rigueurs du vent, de la pluie, du soleil ou du froid, et ils n'ont d'autre berceau que la terre, ou tout au plus une pièce de drap. Aussitòt que l'enfant peut marcher, on lui fait porter des fardeaux proportionnés à sa force, et, dès l'àge dé cinq ou six ans, on le conduit aux champs pour faire de l'herbe ou ramasser du bois. Plus tard, le père apprend à ses fils le labourage, l'usage de l'arc, de la fièche et du fusil, la danse, el les autres exercices. La mère instruit ses filles à moudre, à filer le colon et le pita, et à tresser plusieurs sortes d'étoffes. Elles les habituent à se baigner souvent, jusqu'à deux ou trois fois par jour. Elles sont jalouses de l'honneur de leurs filles, et ne les laissent pas s'éloigner un seul instant de leur vue.

Les Indiens mènent une vie très-pénible, couchant sur la dure, la tête enveloppée d'une couverture de laine, et les pieds découverts. Ils n'ont d'autres tables que la terre, ne se servent ni de nappes ni de serviettes, et leur principale nourriture est le maïs, ou blé des Indes; car, quoique la chair du bœuf, celle du gibier et d'autres animaux 
des montagnes leur şoient connues, ils n'en mangent que de petiles quantités, et toujours avec leur tortilla, ou gâteau de maïs, qui est un gâteau mince, cuil sur un plat de terre et sans autre assaisonnement qu'un peu de sel. Ils boivent de l'eau ou du chicka, breuvage extrait du maìs, du son ou de différents fruits. Le chicka est une boisson douce; cependant il y en a aussi de fort. La liqueur que les Indiens préfèrent est l'eau-de-vie qu'ils achètent en bouteilles, ou qu'ils font eux-mêmes dans leurs maisons avec du son ou du pencla, espèce de sucre d'une qualité très-inférieure. Dans certains villages, une bouteille d'eau-de-vie se vend deux réaux, et dans d'autres quatre. Le gouvernement a toujours mis une taxe sur cette liqueur.

Quand ils font des visites, ils débitent de longues harangues pleines de répétitions; leurs fils, lorsqu'ils les accompagnent dans ces occasions, observent le plus profond silence. Les Indiens sont de la plus grande fidélité pour garder un secret, et souffriraient la mort plutôt que de le trahir. Quand on leur adresse quelques questions, ils ne répondent jamais positivement, mais toujours sous la forme dubitative, et avec un quizas si, qui veut dire peut-être. L'occupation la plus générale des Indiens est l'agriculture. Plusieurs d'entre eux travaillent aux mines; d'autres à leurs manufactures, encore bien grossières. Le gouvernement a, dans ces dernières années, ordonné qu'il fùt accordé en propre à chaque village une lieue de tour de terrain, pour familiariser la populalion avec les travaux des champs, et mettre chaque homme en état de labourer pour ses propres besoins.

Parmi les Indiens de la province de Guatemala et ceux de Quesaltenago, plusieurs possèdent de nombreux troupeaux de moutons. Ils font avec leur laine des étoffes de diverses espèces. La plus commune de ces étoffes est celle appelée serga, qui est un tissu de laine noire et blanche, avec lequel ils s'habillent. Ils préparent une autre étoffe plus ordinaire, digne à peine du nom de drap, et qui sert à plusieurs usages. Le plus bas prix de ces étoffes est un réal la vara, laquelle vaut à peu près une aune anglaise. Les Indiens fabriquent aussi un tissu de coton plus cher que les étoffes dont nous venons de parler, et qui sert de vêtement aux femmes indiennes, comme aux classes les moins riches du peuple des grandes villes. 


\title{
ARCHIPEL COLOMBIEN,
}

\author{
$0 \mathbf{U}$ \\ GRANDES ET PETITES ANTILLES.
}

Entre les deux continents de l'Amérique s'étend en arc de cercle une chaîne d'îles à laquelle on a donné le nom insignifiant d'Antilles, et le nom inexact d'Indes occidentales. La raison et la reconnaissance doivent faire justice de ces dénominations, el imposer le nom générique de Colombien à cet archipel, dont l'extrémité méridionale se rattache au cap Paria dans l'Amérique du Sud, tandis que son extrémité septentrionale se lie à la Floride par les îles Bahama, et que la pointe occidentale de Cuba correspond en quelque sorte à la partie la plus avancée de l'Yucatan.

Toutes ces îles sont divisées en grandes et petites Antilles. Les grandes Antilles sont:

\section{GUBA.}

La plus considérable et la plus occidentale des Antilles, Guba est située entre $19^{\circ} 48^{\prime}$ et $23^{\circ} 12^{\prime}$ de latitude nord, et $76^{\circ} 30^{\prime}$ et $87^{\circ} 18^{\prime}$ de longitude ouest. Longue de 263 lieues sur une largeur de 10 à 40 , elle approche en étendue de la Grande-Bretagne. La vérilable division de Cuba, qui en a plusieurs, la seule que puisse accepter la géographic moderne, c'est celle établie récemment par le gouverneur général Vivès, et qui scinde l'île en trois districts; occidental, central, oriental, subdivisés en partidos (sections). La capitainerie générale a son siége à la Havane, chef-lieu du district occidental. Un brigadier général commande les deux autres districts.

La Havane est la plus importante de toutes les villes de Cuba. Vue du large, elle étonne et plaît. Sa ceinture de forts, son bassin bordé de villages, les aiguilles de ses clochers, les toits rouges de ses maisons, les palmiers panachés de ses jardins, tout semble promettre des splendeurs grandioses, inconnues; mais cette impression s'affaiblit quand on pénètre dans l'intérieur. Au reste, ce pays grandit et se civilise de jour en jour.

M. d'Orbigny raconte ainsi son arrivée à la Havane :

"Le Jefferson "était à peine amarré le long du quai, que son canot nous porta à terre avec nos malles. Le môle, couvert de têtes noires, offrait alors un mouvement et une confusion étranges. Vingt nègres sautèrent dans le canot dès qu'il toucha au débarcadère. On nous enlevait d'assaut; on se disputait l'honneur de nous servir. Sans un

1 Brick sur lequel le voyageur s'était embarqué à Bordeaux. 
soldat qui fit jouer sa canne sur cette foule officieuse, nous n'aurions jamais pu défendre nos bagages. On parvint pourtant à les charger sur une charrelle qui se dirigea vers la ville.

จ Vingl pas plus loin, autre ennui, autre retard. C'était un douanier qui voulait savoir, au nom du roi de toutes les Espagnes, combien nous avions de chemises et d'habits à notre usage. Il les compta gravement et nous laissa passer. Sortis de la douane, nous traversâmes la $P l a \approx a$ de armas pour arriver, à travers des rues boueuses, jusqu'à la Fonda de Madrid, l'une des plus belles hôtelleries de la Havane, mesquine auberge qui donnait une bien pauvre idée des autres. J'y pris une chambre, ou, pour mieux dire, un petit cabinet nu, triste, dégarni, avec un lit de sangle pour tout meuble, un lit sans matelas : le matelas est de luxe à la Havane.

"L'aspect de cette hôtellerie, la morgue du maître, la perspective d'un mauvais gîle et d'une mauvaise chère, me firent songer à quitler la Fonda de Madrid; mais où aller? Presque tous les Européens ont leurs amis, leurs correspondants à la Havane. C'est là qu'ils descendent. Les auberges ne logent que des aventuriers. Trois chevaliers d'industrie et deux actrices émérites faisaient alors les délices de la Fonda de Madrid. La place n'était plus tenable. Je me décidai à solliciter à mon tour l'hospitalité créole. Je nommai à mon hôtelier la veuve de mon oncle, ma tante la mulâtresse. Cet homme la connaissait; il m'apprit qu'elle était en ville, et me donna un nègre pour me conduire vers sa maison, j'allais dire son palais; c'était un vrai palais auprès de la triste auberge. Introduit, je me nommai, et l'on m'accueillit avec des larmes de joie. Ma tante était une femme de quarante ans, belle encore, quoiqu'un peu replète, douce, instruite et spirituelle. Trois grandes filles se tenaient à ses côlés, sveltes et gracieuses cousines, liont l'âge roulait entre quinze et vingt ans, charmantes créalures, bonnes autant que jolies. L'accueil que je trouvai au milieu de cette famille tiendra toujours une place dans mes souvenirs. Je n'élais pas un hôte pour ces femmes, mais un chef; pas seulement un parent, mais presque un maître. Dans leurs affectueuses prévenances, dans leurs soins minutieux, dans leurs attentions raffinées, perçait toujours quelque peu de 'e respect que la population de couleur porte à la population blanche. On eût dit qu'en me logeant, qu'en me défrayant, elles élaient mes obligées. On m'avait arrangé dans ret intérieur une sorte de vie orientale qui ne me laissait pas un souhail à faire, pas un service à réclamer. J'étais devancé en tout. Au lieu du cabinet sombre et nauséabond de la Fonda de Madrid, j'avais une vaste chambre de trente pieds de haut, aérée, commode, garnie de meubles, somptuosité assez rare à la Havane; j’avais un lit surmonté l'un dais d'où pendait une longue cousinière; j'avais des domestiques, des esclaves, des 'hevaux, des volantes à mes ordres. C'était un faste de prince.

"Belle, vaste et carrée, la maison de ma tante avait une cour intérieure entourće d'arcades, et au premier étage des galeries fermées de persiennes."

Nous devons faire remarquer que l'ordonnance de cette construction forme une exception. Les maisons ordinaires'n'ont qu'un étage, et leurs toits sont aplanis en terrasses. Les fenêtres, dont l'appui se trouve à un pied du niveau du sol, montent fréquemment jusqu'à une hauteur de trente pieds, el sont fermées dans toute la baie par des grilles de fer ou de bois. La transparence de cette clòture laisse voir au passant les Espagnoles assises sur leur sofa, l'éventail à la main, les cheveux garnis de fleurs, les bras et le haut du buste nus. Cetle toilette d'intérieur est sans contredit bien gracieuse, mais accuse des charmes avec une coquelterie qui pourrait être quelque peu jlus voilée.

Les étrangers parcourent le pays au moyen d'une sorte de véhicule appelé volante, el qui a l'aspect d'une chaise de poste, montée sur des ressorts, et flanquée de roues 
très-hautes : un rideau de drap, préservatif contre le soleil et la poussière, s'abaisse i volonté et ferme ce char comme une boîte. Au brancard est attelé un mulet ou un cheval que monte le calesero, nègre habillé comme le groom, avec le chapeau à galou d'or, la veste rouge, le pantalon blanc, les boltes à l'écuyère, et le machete ou sabre droit. La volante et le calesero sont deux choses inséparables, deux meubles essentiels d'une bonne maison havanaise.

Le Paseo est une sorte de promenade publique située à la porte de la ville. Cette AllécVerte de la Havane consiste en une large allée de 1,500 mètres de longueur, avec deux latérales pour les piétons; de beaux arbres jalonnent toute cette étendue.

La Havane est pourvue de spectacles, de bals et de concerts; elle en use pour les siens, elle en fait les honneurs à l'étranger qui la visite. Le théàtre peut contenir dix-huit cents spectateurs. Après les plaisirs du spectacle viennent ceux du bal. Les salles de bals ct de jeux se trouvent à un quart de lieue de la ville. Le bal est le prétexte, le jeu, le vrai motif de ces fètes. Là se coudoyent et circulent le moine espagnol et le capitaine hollandais, l'un avec son rosaire dans les mains, l'autre avec son cigare à la bouche. Le magistrat, l'hidalgo, le négociant, le militaire, le subrécargue, toutes les notabilités de la ville, et tous les étrangers qu'elle renferme, accourent à ces réunions les pochei pleines d'or. Le bal est triste et froid; les créoles, parées comme des madones, mal à l'aise dans des souliers étroits, marchent et ne dansent pas.

La ville est pauvre en monuments, mal lenue, bourbeuse, encombrée par sa population de 112,000 âmes. L'usage local veut que toutes les volantes rencontrées par lo Saint Sacrement soient mises à la disposition des officiants qui le portent. La ville est presque impraticable dans l'été à la suite des longues pluies. A dix heures du soir, les voleurs et les assassins s'en rendent maîtres; la ville leur appartient : ils y règnent par le droit des ténèbres. La vie d'un homme peut ètre mise à prix. Les nègres assassinent à raison d'une once par tête, 84 francs environ.

Le palais du gouverneur est situé sur la Plaza de armas, et fait face à celui de l'inlendant. L'architecture de ces deux édifices a quelque chose d'indécis et de bâtard, quoique son aspect général ne manque ni de grandeur ni de noblesse. Des arcades, des fenètres, des soldats aux portes, tout cela n'offre pas un mauvais coup d'œil. Vis-à-vis du palais du gouverneur est une chapelle bâtie, dit-on, sur le lieu mème où se célébra la première messe à l'époque de la découverte par Colomb.

La Regla, petit bourg situé à un quart de lieue de la ville, repaire des forbans qui croisent dans le golfe du Mexique, est peuplée d'une race amphibie qui a deux éléments et deux existences. A terre, elle vit suivant les lois, se montre obéissante, jalouse de ses devoirs religieux, hantant les églises, loyale et coulante en affaires; à bord, ellc oublie son pacte avec la société, attaque, égorge, pille, incendie, extermine, défie la justice humaine, assise sur l'or de son butin. Ce commerce de boucaniers enrichit la Regla. Aussi ne faut-il pas s'étonner de voir vingt, trente, quarante tables de jeu en permanence sur la place du bourg. Ces lables sont entourées de monteros (paysans), qui risquent jusqu'à deux ou trois onces d'or à la fois (168 à 242 francs). Ces monteros son! maigres, élancés, avec des physionomies expressives et régulières; ils portent un chapeau de paille, une chemise et un pantalon de toile rayée; le cigare à la bouche, et le machete au côté.

Ils ont la manie des combats de coqs, et elle n'est pas limilée aux classes populaires; les hidalgos, les grands et les gouverneurs eux-mêmes en font parfois une affaire fort sérieuse. Parmi ces derniers, on pourrait citer le général Vivès, qui a toujours été plus occupé de la santé et de l'éducation de ses coqss, que du bonheur de la colonie. 


\section{Le district de San-Maro a de nombreuses cafesales (caféiries) et des ingenios} (sucreries).

Les caféiries forment, en général, des espèces de quinconces plus ou moins étendus, et dont les plants, presque tous étêtés, n'ont guère que quatre pieds de hauteur. Il existe ordinairement entre chaque plant de caféiers un intervalle de quinze à vingt pieds qu'occupent des orangers, les uns en fleurs, les autres chargés d'oranges qui se nuancent dans tous les tons, depuis le vert foncé jusqu'au jaune le plus vif. Quand le café est mûr, on l'écosse et on le fait sécher pour le mettre ensuite en futaille.

La fabrication du sucre est plus longue et plus compliquée. Entre le premier jus de la canne el la cassonnade pilée qui nous arrive en Europe, se pratiquent une foule d'autres préparations qui occupent plusieurs milliers de bras. C'est la nuit principalement qu'a lieu le travail des sucreries. Il s'accomplit à la lueur de vastes feux, au chant monotone et discordant d'une foule de nègres. On dirait une scène de sabbat qui se déroule confusément au milieu de la vapeur et de la fumée. Ici les noirs se passent de main en main les cannes qu'ils emploient; là ils les glissent par un bout sur d'énormes cylindres qui les absorbent et les broient. Ailleurs on excite les bœufs qui tournent au manége; plus loin on surveille la cuve où bouillonne le sirop, on écume la clairée, on cherche à deviner l'instant précis de la cuisson. Partout du feu, du bruit, de la vapeur, des chants, des figures noires et huileuses, des bras en activité, des hommes, des femmes, des enfants empressés autour d'immenses chaudières en ébullition; et, au milieu de cette foule, l'intendant, despote de l'atelier, contre-maître blanc qui a sur ces travailleurs le droit du fouet et de la prison.

Au milieu d'une végétation aussi riche, ces campagnes riantes ont aussi, à côté de tant d'avantages naturels, leurs inconvénients et leurs petits fléaux. On ne devrait y rencontrer que les oiseaux particuliers aux latitudes équatoriales, oiseaux dont le plumage est si vivement coloré qu'on le dirait peint, les perroquets, les perruches, les tangaras et les colibris. Mais des animaux malfaisants ou hideux pullulent dans ces plaines. Ce n'est pas assez que les moustiques et les maringouins vous y dévorent; on y voit encore par milliers de monstrueuses araignées velues, des scorpions énormes, et une bète noire nommée mancaperro, parce qu'elle fait boîter les chiens qu'elle touche. Un autre ennemi de l'homme est une sorte de crabe qui pullule sur les bords de la mer. Cet animal s'y retranche et y creuse des caves profondes qui s'éboulent et enterrent les passants. Il y a aussi une espèce de puce presque imperceptible. Souvent elle s'introduit sous la peau, s'y loge, s'y enfonce et s'y développe à la grosseur d'un pois.

Dans l'île de Cuba, le règne végétal a aussi ses dangers. On y trouve sur les sommets élevés le mystérieux guao, sorte d'arbre vénéneux, doué, dit-on, d'une énergie plus grande que celle du mancenillier lui-même. Le mancenillier tue, comme l'opium, par l'engourdissement et le sommeil; le guao cause des douleurs égales à celles d'une mort par l'arsenic.

Les nègres marrons sont un autre fléau des campagnes cubanaises. Ils campent dans las Tomas, ou montagnes de San-Salvador et de Cusco. Descendus par bandes dans les caféiries isolées, ils brûlent et ravagent tout. Aussi leur donne-t-on la chasse comme à des bêtes fauves.

On peut diviser la population en quatre classes : les blancs, les mulâtres libres, les nègres libres, et les nègres esclaves. Les blancs européens, ou créoles, ont conservé les habitudes et les costumes espagnols. Les riches parures, les vêtements de soie, les dentelles, les blondes, les éventails de luxe, les peignes d'écaille, les ombrelles de prix, les diamants, les perles, les rubis, les émeraudes, rien n'est ignoré des dames, qui prodiguent les onces d'or aux capricieuses fantaisies de leur toiletle. Les mulàtresses et 



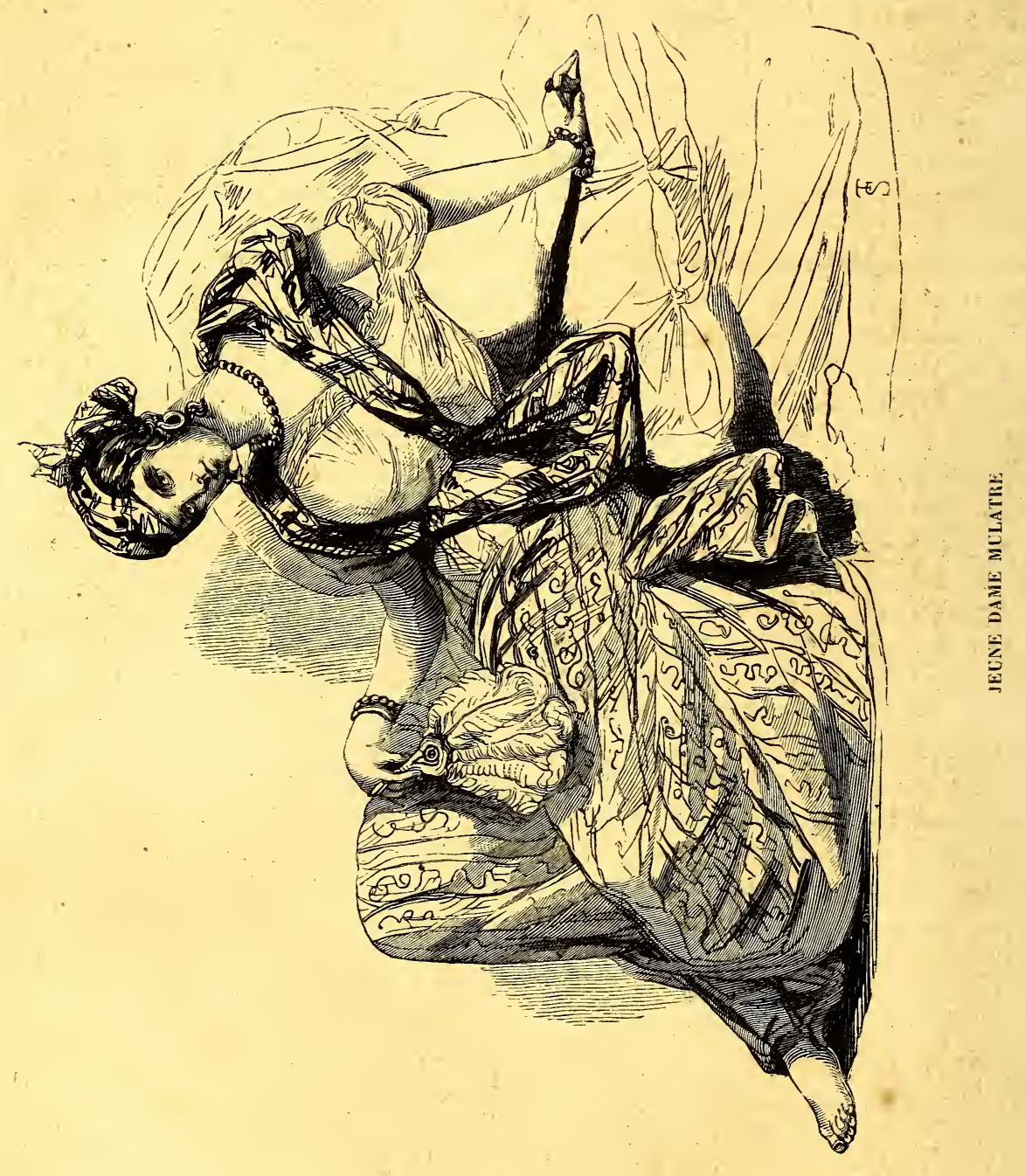


les négresses libres portent, en général, des robes faites avec l'écorce du dagilla, ou arbre à dentelle, découpée en tranches minces dans la longueur de la branche. Ces robes de dagilla sont ornées parfois d'insectes phosphorescents, placés dans la ceinture et dans les plis, artistement et de telle sorte qu'ils ne puissent bouger de place. Dans les lénèbres, le soir, ces robes sont vraiment rayonnantes.

C'est le calesero qui remplit les fonctions de cuisinier; la cuisine des Européens est lout espagnole. Le calesero est le factotum d'une maison havanaise, son maître Jacques, son homme de confiance. Au besoin, il cumule les emplois utiles et les talents d'agrément; il soigne les chevaux et fait danser les dames au son de sa guitare, tient la place de chef d'office, et courtise les négresses.

Le dessert est le service le plus varié et le plus appétissant d'une table havanaise; environ trente sortes de fruits y figurent, la banane, l'ananas, la sapotille, l'orange, le mango au goût de térébenthine, la noix de coco, l'avocat, etc.

Parmi les classes distinguées, il existe un usage assez singulier; c'est de s'envoyer l'un à l'autre, à table, de petits morceaux choisis et friands embrochés sur une fourchette. Un parreil envoi est une faveur très-grande. Une autre faveur non moins digne d'envie est celle que fait une dame en buvant dans le verre d'un cavalier, avant qu'il ne le porte à ses lèvres.

Une chose assez difficile à supporter pour un Européen, c'est la taciturnité qui règne dans les réunions du soir. L'introduction terminée, chacun est tenu de s'asseoir dans une espèce de chaise à dossier élevé, assez ressemblante à nos demi-baignoires; et, placés à distance l'un de l'autre, au milieu de salons très-vastes, dont quelques meubles épars font cucore ressortir la nudité, les invités, mollement accoudés, imitent le maître du logis : ils dorment; puis ils s'éveillent pour accepter un verre d'eau et partir. A part les bals et les concerts, c'est ainsi que se passe la vie du soir, parmi des gens pour qui parler seulement serait une fatigue.

Un fléau terrible, le vomito negro ou fièvre jaune, celle endémie des Antilles, frappe souvent non la population indigène de Cuba, mais les étrangers qui l'habitent ou y séjournent. Les phases de cette maladie sont foudroyantes; quelques heures suffisent pour occasionner la mort. Comme le choléra, comme la peste, comme la petite vérole, lc vomito negro est un mystère, même pour ceux qui l'ont cent fois éludié et suivi. Des empiriques ont vainement entrepris de le combattre; quant aux hommes de l'art, ceux du moins qui sont de bonne foi, déclinent leur impuissance. Ainsi, devant cet agent de destruction, la science humaine doit s'avouer vaincue : lorsque le mal cède, e'est généralement aux ressources de la nature qu'on le doit; et les soins des négresses sont plus efficaces que ceux des médecins les plus habiles.

\section{HAÏTI :}

Celte île est située entre $17^{\circ} 45^{\prime}$ et $19^{\circ} 58^{\prime}$ de latitude nord, et $70^{\circ} 45^{\prime}$ et $76^{\circ} 55^{\prime}$ de longitude ouest. Elle a pour capitale le Port-Républicain (autrefois Port-au-Prince), ville qui doit son importance à son commerce actif et considérable, et où les principales autorités ont leur résidence.

1 La république d'Haïti portait, avant son émancipation, le nom de Saint-Domingue; en espagnol Santo-Domingo ou IIspaniola. 
Haïti mérite une mention historique toute particulière, puisque, la première, elle a rompu ses chaînes et forcé l'orgueil européen à reconnaître que, malgré la couleur de leur peau, les nègres el les mulâtres ne sont pas moins dignes que les blancs qui les méprisent, de jouir des bienfaits de la civilisation.

Hispaniola fut une conquète importante pour les Espagnols par l'abondance de l'or que l'on trouvait dans ses terrains d'alluvion; ils obligeaient les indigènes à leur fournir tout ce qu'ils potivaient recueillir de ce métal. L'établissement que les vainqueurs fondèrent sous le nom de Santo-Domingo, dans la partie méridionale de l'ile, fut l'origine du nom de Saint-Domingue qu'elle reçut dans la suite. Nous ne rappellcrons pas les barbares traitements infligés aux Caraïbes par leurs vainqueurs, ni conment les vaincus, forcés à se révolter contre les Espagnols, furent entièrement détruits par ceux-ci. Restés paisibles possesseurs d'une île déserle, les Espagnols, au commencement $d u x{ }^{e}$ siècle, la repeuplèrent d'esclaves arrachés au sol africain. Il était réservé à ceux-ci de venger un jour ceux qui les avaient précédés sur cette terre devenue un séjour de misère et de larmes depuis l'arrivée des Européens. La vengeance fut terrible; mais les Français, qui, dans le courant du xvir ${ }^{\mathrm{e}}$ siècle, avaient fondé une colonie à Saint-Domingue, en furent les victimes aussi bien que les Espagnols. Les premières scènes de révolte commencèrent en 1791; quelques années plus tard, un nègre, Toussaint-Louverture, établit un nouveau gouvernement dont il fut nommé président à vie; en 1801, les noirs affranchis rendirent à cette île son ancien nom d'Haïti. En vain Napoléon chercha-t-il à soumeltre tout le pays qui avait formé une des plus importaules colonies de la France; la valeur française céda devant des citoyens combattant pour la liberlé. Enfin, en 1820, l’indépendance d'Haïti fut reconnue par la France, moyennant une indemnité de 150 millions au profit de ses anciens colons. La population de celte île franchit tous les degrés de l'anarchie pour arriver au gouvernement républicain. Ce gouvernement est formé d'un sénat, d'une chambre de représentants, et d'un prísident élu par le sénat. Les membres de ce dernier corps doivent être âgés de trente ans; les députés de vingt-trois. Les principales bases du système législatif de l'État d'Haïti sont : un code calqué sur le code français, la liberté de la presse et l'institution du jury. Les fonctions de président de la république sont à vie.

La population du Port de la République se compose d'un pelit nombre de négociants étrangers, et de citoyens de la république haïtienne, nés sur les lieux ou naturalisés, et qui se divisent en trois classes :

Les blancs, en fort petit nombre;

Les mulâtres dans toutes les nuances;

Les nègres.

Mais si ces trois catégories ont le titre commun de citoyens, ils ne jouissent pas tout à fait des mêmes droits civiques : les mulâtres et les nègres se sont réservé quelques priviléges que les blancs ne partagent pas. L'article 34 de la constitution établit que a tout Indien, Africain, tout homme de sang nègre ou mêlé, est, après un séjour de douze mois, citoyen d'Haïti, avec la faculté d'y devenir maître, propriétaire, député, ministre, membre du gouvernement. " - Le blanc, au contraire, n'obtient que difficilement des lettres de naturalisation; et quand il les a obtenues, il se trouve en face d'un article de la même constitution ainsi conçu : a Aucun blanc, quelle que soit sa nation, ne pourra mettre le pied sur ce territoire à titre de maître ou de propriétaire. » Il est juste de reconnaître que cette injurieuse exclusion avait été désapprouvée par Christophe, et que Vasti, dans ses Réflexions politiques, émettait la proposition de remplacer "aucun blanc "par a aucun Français."

Toutefois, malgré l'exclusion stipulée par la loi constitutionnelle, les habitudes 
sociales ne s'en ressentent pas le moins du monde. On ne voit régner nulle part une égalité plus caractérisée, plus complète. En dehors de la hiérarchie du pouvoir, il n'existe aucune distinction de classe : les emplois et l'argent, ce dernier surtout, sont les seuls agents qui puissent constituer une facon d'aristocratie, quoique, au reste, les puissants et les riches ne croient point déroger en frayant avec le peuple.

Une langueur qui n'est pas le repos, un air singulier d'apathie sont communs à tous les rangs, et caractérisent la population haïtienne. Courir est un mot qu'il faudrait rayer du dictionnaire des Haïtiens. Nous citerons un exemple de cette indolence :

Sur la route de Léogane, la ville et le fort Bizotton renferment des garnisons de troupes régulières, astreintes à un service constant. Les avenues en sont surveillées par divers corps de garde, et des sentinelles placées de distance en distance semblent chargées de faire respecter une consigne rigoureuse. Eh bien! ces postes sont, en général, pourvus de chaises pour les factionnaires, et de hamacs pour les autres soldats. La sentinelle est assise nonchalamment, tenant son arme entre les genoux, et fumant insoucieusement un cigare. S'il arrive qu'un cavalier passe au galop, ce qu'il lui est défendu de faire devant un poste, le soldat se lève et lui crie d'aller au pas; puis, ce sacrifice aux exigences de la consigne accompli, il reprend sa première attitude. Une activité générale ne règne dans les postes que lorsqu'il s'agit de se rendre sur les marchés publics, pour y confisquer les bananes, les ignames et autres fruits dont on voulait tenter la vente clandestine à des jours défendus. Dans ce cas, la patrouille, voulant venger l'insulte faite à la majesté de la loi rurale, saisit bravement le corps du délit dont elle fait un supplément au frugal ordinaire accordé par la république.

Dans les bals donnés par les indigènes, les hommes sont vêtus d'une manière plus ou moins bizarre; les uns en veste, les autres en habit. Les femmes déploient un luxe prodigieux de robes de soie, de parures de corail et de perles, de blondes et de dentelles bien choisies. Mais, comme il ne serait pas facile de donner une tournure convenable à des cheveux crépus, la majeure partie des danseuses portent des madras noués avec coquetterie sur leur tête.

I.es danses se composent de quadrilles, entremêlés d'une espèce de cotillon qu'on appelle la carabinière. C'est la ronde du pays, importation française probablement, et qui se conserve parmi les mœurs indigènes, avec un grand nombre d'autres coutumes. En général, les femmes dansent en mesure et non sans grâce; les hommes se tirent passablement d'affaire, mais ils sont plus empruntés et plus gauches. La seule chose vraiment détestable dans ces fètes, c'est l'orchestre qui se compose de trois clarinettes fèlées et de cornets à bouquin. Les rafraîchissements, un peu bourgeois il est vrai, sont servis avec une prodigalité que limite seulement le nombre des verres. Indépendamment dı rhum, du sirop, de l'orgeat et de la limonade offerts aux deux sexes, il y a, pour les hommes, un buffet chargé de bouteilles de vin et de viandes salées.

Les bals champêtres sont tout primitifs, tout africains. On y danse le congo et la chega des esclaves. Ils ont lieu dans des cabanes dont les branches d'un arbre forment le toit. Vètu d'une façon fantastique, le musicien s'accroupit dans un coin devant un énorme tambour qu'il frappe d'abord lentement, puis avec une vitesse qui va croissante, progression suivie par les danseurs dans les pas et dans les figures.

Nous ne quitterons pas Haïti sans parler de ces aventuriers connus sous le nom de boucaniers et de flibustiers, noms qui, à notre époque même, ne sont pas encore oubliés.

Vers 1625, les Français et les Anglais avaient occupé en commun l'une des Antilles du vent, l'île Saint-Christophe, conquise sur les Caraïbes. L'Espagne trouva ce voisinage trop dangereux, et, en 1730 , sur sa route vers le Brésil, Frédéric de Tolède attaqua cette 
colonie, détruisit l'établissement, et dispersa les habitants. Ce qui échappa au fer espagnol se répandit dans toutes les directions. Montés sur de grandes chaloupes, quelques colons peu nombreux allèrent atterrir et se fixer sur la côte nord de SaintDomingue et sur l'île de la Tortue.

Animés d'intentions pacifiques, ces aventuriers vécurent d'abord du bétail qu'ils trouvaient sur ces îles, où ils voulaient fonder une colonie agricole et commerciale, cxploiter le sol et organiser des échanges avec les Hollandais. Mais les Espagnols ne voulurent pas laisser aux nouveaux occupants le droit de jouissance paisible; ils les altaquèrent, opérèrent plusieurs descentes sur leurs territoires, anéantirent les plantations, s'emparèrent des femmes, des enfants, et tuèrent sans miséricorde tous les hommes qui tombaient en leur pouvoir.

A cette guerre d'extermination, les aventuriers répliquèrent par une guerre de pirates. Ils avaient reçu le nom de boucaniers parce qu'ils boucanaient leurs viandes à la manière des sauvages; on y joiguit alors le nom de flibustiers qui devint le synonyme d'écumeurs de mer.

L'anarchie dans laquelle vivaient ces malheureux avait une organisation. Il existait parmi eux une sorte de code à l'usage de la troupe. Ils formaient une espèce de grande famille, avec des biens communs, dépouillaient les étrangers, mais ne se volaient point cntre eux. Leur habillement se composait d'une chemise teinte du sang des animaux tués, d'un caleçon, d'une ceinture à laquelle on suspendait un sabre court, et d'un chapeau à larges bords. Hardis, intrépides, ils armèrent de petites barques, et infestèrent les côtes. Leur caractère farouche, altéré de sang, était le résultat de l'instinct chez quelques-uns; mais le plus grand nombre n'était cruel que parce qu'ils avaient à exercer de terribles représailles, à venger la mort d'un ami, d'un frère, d'un fils, d'une mère.

Peu à peu, tous les Français et les Anglais qui se trouvaient à l'établissement de Saint-Christophe émigrèrent et vinrent grossir le noyau des aventuriers. Les Anglais, en plus grand nombre que les autres, imposèrent à la communauté un chef de leur nation nommé Willis; mais le gouverneur général des Antilles, M. de Poincy, envoya à temps l'officier le Vasseur, qui chassa Willis et ses compagnons. Ainsi la Tortue et la côte qui y fait face devinrent françaises. L'Espagne envoya vainement une escadre contre les flibustiers; toutes les descentes demeurèrent sans résultats.

Dès lors ce fut le beau temps des courses et des déprédations maritimes. Réunis par groupe de cinquante hommes, les flibustiers prenaient le large sur de petits brigantins qu'une seule bordée eût suffi pour couler. Sitôt qu'ils apercevaient un navire, gुros ou petit, armé ou non, ils s'efforçaient de l'atteindre et sautaient à l'abordage : à cet instant, ce n'étaient plus des hommes, mais des démons exaltés par le désir du butin, fanatisés par un courage fébrile, ayant soif du sang espagnol, et n'espérant jamais de guartier.... Aussi, rarement un vaisseau leur échappait....

Quelques mois de courses suffirent pour asseoir solidement leur réputation, à ce point que tout bâtiment sur lequel ils avaient jeté leurs grappins ne résistait plus et criait. merci! De retour à la Tortue avec leurs prises, ils procédaient au partage. Chaque homme jurait n'avoir rien détourné à son profit personnel, et la mort attendait le parjure. Cette déclaration faite, on réglait les parts; et le produit s'en allait en débauches, en orgies, en véritables bacchanales.

On peut le dire, la vie de ces aventuriers fut le roman de la marine française, roman vì se mêlent les sanglantes horreurs et l'héroïsme le plus merveilleux. D'un côté, une existence souillée par le meurtre et le pillage; de l'autre, une vie ennoblie par de beaux, d'éclatants, d'incroyables faits d'armes. Rentrés plus tard sous la loi commune, 
ces hommes expièrent leurs forfaits antérieurs par des services exemplaires, et les forbans de la Tortue devinrent pour la France une pépinière d'excellents marins. C'est à eux aussi que l'on doit la possession tant contestée d'une partie de Saint-Domingue. Pour qu'une poignée d'hommes résistât ainsi à la première puissance du monde, pour qu'elle se jouât de ses vaisseaux et bravât ses escadres, il fallait certes bien des ressources d'intrépidité, bien des combinaisons audacieuses, surnaturelles! Aussi que de traits prodigieux dans celte histoire; que de choses réalisées qui paraisșaient impossibles! Ici, c'est Pierre le Grand, un Dieppois, qui, avec quatre canons et vingt-huil hommes, accoste le vice-amiral des galions, monte à bord après avoir coulé sa propre barque, surprend le capitaine dans sa chambre, lui fait amener pavillon et ramène sa prise en France. Là, c'est Michel le Basque, qui, sous le canon de Porto-Bello, s'empare de la Margarita, chargée d'un million de piastres; puis, Jonqué et Laurent le Graff, qui capturent des vaisseaux de guerre devant Carthagène; ou Brouage allant surprendre les autorités espagnoles jusque dans leur palais, et les traînant à bord, malgré leurs gardes, pour les échanger contre d'énormes rançons. Ailleurs, nous voyons le fameux Monbart, Monbart l'exterminateur, véritable type du héros de mélotrame, né avec des passions furieuses, préférant le sang au butin, et le versant à tout propos. Et l'Olonais! qui, de simple flibustier, devint l'un de leurs chefs célèbres, l'Olonais, qui prit et pilla tour à tour Venezuela et Maracaybo! Enfin Morgan le Gallois, vainqueur de Porto-Bello et de Panama, traître aux flibustiers après en avoir été l'un des plus braves chefs, et nommé, après sa défection, lieutenant-gouverneur de la Jamaïque!

Les flibustiers continuèrent leur vie de pillage et de meurtre jusque vers 1666 , époque à laquelle un gentilhomme angevin, Bertrand d'Oger'on, entreprit d'utiliser ces courages farouches pour la colonisation de Saint-Domingue. La tâche était difficile. II s'agissait de donner des goûts sédentaires à des esprits actifs et aventureux, d'assujeltir aux lois des pirates habitués à n'en écouter aucune, d'élever dans le respect du monopole de la compagnie des Indes occidentales un peuple d'écumeurs de mer brouillé lepuis longtemps avec toutes les idées de propriété. Le sage administrateur réussit en partie; il fit venir des femmes, et créa pour ces forbans le lien de la famille; il attira des cultivateurs et les attacha au sol par les résultats de la culture; il distribua des primes d'argent, affecta des priviléges au travail, évita de blesser des caractères irritables, de contrarier trop brusquement des habitudes prises. Ces mesures ne furent pas trompées par les résultats : à la mort d'Ogeron, la colonisation était avancée.

\section{PORTO-RICO.}

Cette île est située à l'est de la précédente, et présente la continuation de la grande chaîne des Antilles. Elle est extrêmement fertile : elle produit la plupart des denrées coloniales, principalement du sucre, toutes sortes de fruits et du coton. On y élève de nombreux troupeaux de bestiaux, et beaucoup de volaille; les bois sont peuplés d'une infinité d'oiseaux d'espèces très-variées. Les côtes sont très-poissonneuses. On trouve de l'or dans les sables de quelques rivières. Porto-Rico exporte du sucre, du gingembre, les fruits confits, du coton, de la casse, du mastic, etc. On évalue la population à 400,000 individus; les dépenses, qui s'élèvent à 300,000 francs, sont dépassées de 100,000 francs par les revenus. 
La capitale est Saint-Jean de Porto-Rico, dont les fortifications sont considérables et bien entretenues.

\section{ILES BAHAMA OU LUCAYES.}

Avant de décrire les petites Antilles, nous devons dire un mot des îles Bahama ou Lucayes qui s'étendent au sud-est de la Floride, dont elles sont séparées par un courant de mer large et rapide, appelé golfe de Floride ou nouveau canal de Bahama. Elles sont au nombre de 500 ; quelques-unes sont des rochers; mais il y en a 12 grandes et fertiles dont le sol est le même que celui de la Caroline. La population est d'environ 10,000 à 12,000 individus.

Les loyalistes des États-Unis s'y sont établis en grand nombre. Les nègres y sont bien traités par les maîtres qui les surveillent eux-mêmes : il n'y a point d'inspecteurs; et, par une conséquence naturelle, on n'y entend pas si souvent claquer le fouet ensangrlanté. On assigne aux nègres une tâche proportionnée à leurs forces, et leur bonne conduite les montre dignes de ces procédés humains.

Les îles Turques et les îles Cä̈Ques, occupées par les Anglais, dépendent des Lucayes.

Parmi les petites Antilles nous citerons :

\section{LA MARTINIQUE.}

Cette île, une des petites Antilles, est située entre $14^{\circ} 23^{\prime}$ et $14^{\circ} 52^{\prime}$ de latitude nord, et entre $63^{\circ} 10^{\prime}$ et $63^{\circ} 39^{\prime}$ de longitude ouest, et baignée à l'ouest par la mer des Antilles, et à l'est par l'Atlantique.

La Martinique est divisée en quatre arrondissements : le Fort-Royal, le Marin, Saint-Pierre et la Trinité, qui sont subdivisés en vingt-sept paroisses, et renferment deux villes, quatre bourgs et vingt villages. Le Fort-Royal, qui en est le chef-lieu, est en même temps le siége principal de la station française aux Antilles.

Les Hollandais, commandés par Ruyter, attaquèrent vainement cette île en 1674. Les Anglais s'en emparèrent le 15 février 1762, et durent la restituer seize mois après. A l'époque de la révolution française, ils la reprirent, et la gardèrent jusqu'en 1802; elle retomba, en 1809 , en leur pouvoir, et ils ne la rendirent à la France que le 9 décembre 1814.

Il n'est point de rade plus belle et plus sûre que celle de Saint-Pierre. Dans son bassin encaissé par de mornes massifs, glissent ou louvoient d'élégantes escadres de navires, de bricks européens aux larges huniers carrés, des schooners avec leur gracieuse voilure latine, des bateaux pontonnés qui effleurent la còle, et de magnifiques vaisseaux de guerre noblement endormis sous les batteries du fort.

On ne peut se défendre d'un sentiment pénible quand on voit une vente publique de nègres, faite aux enchères par l'office d'un priseur juré : * Trois cents piastres le nègre! » dit le crieur. Et le sujet posé devant les chalands subit l'examen le plus scrupuleux. Un cheval amené au marché par des maquignons n'aurait pas été l'objet de plus de defiance. Celui-ci lui ouvre la bouche pour compter les dents; celui-là se baisse 
pour inspecter les pieds, les jambes, les cuisses et le buste, cherchant à s'assurer qu'on ne lui dissimule rien, ni varices ni hernies. Les femmes elles-mêmes se mêlent de cette inspection.

Ces nègres une fois répartis dans les habitations, y mènent une vie douce et tranquille. Si l'humanité manquait aux planteurs, l'intérèt seul leur conseillerait de soigner une chose qui est devenue leur propriété. Il est donc rare que la misère atteigne les esclaves. Dans leurs heures libres, ils cultivent quelques petits morceaux de terrain pour leur propre compte, et se font une épargne qui leur appartient. Des hommes laborieux ont ainsi gagné leur rançon en fort peu d'années. Sur les habitations, chaque ménage nègre a sa case plus ou moins ornée, suivant que l'esclave est plus ou moins riche, plus ou moins industrieux. Ces réduits valent nos chaumières d'Europe. Des poules, des cochons vaguent devant la porte, et de petits enclos, plantés de légumes, leur servent d'attenances. Une pareille aisance échoit rarement à de simples travailleurs; elle est le lot des nègres qui exercent un métier, des charpentiers, des maçons, des serruriers, des tonneliers; puis encore de ceux que leur figure ou leur intelligence destine à des services d'intérieur, et qui sont dans la maison du maître à titre de valets de chambre, de cuisiniers, de cochers, de sommeliers.

Dès six heures du matin, le gros des nègres est appelé au travail par la cloche de l'habitation. Chaque travailleur prend alors sa longue pioche et se dirige vers le champ en culture, sous la conduite de deux intendants européens ou créoles. Arrivés sur le terrain, les noirs s'alignent en longues files, et frappent leur coup presque à l'unisson, en chantant un de ces refrains du Congo si mélancoliques et si doux. Les intendants les surveillent, appuyés sur le manche d'un long fouet dont ils se servent de temps à autre pour les exciter au travail. A onze heures, la cloche sonne le dîner, qui se compose de manioc et de bananes, quelquefois de poisson et de porc salé. Ce repas dure une heure, puis le travail recommence jusquà six heures du soir.

Le défaut le plus commun et le plus fatal à cette race est son goût immodéré pour les boissons spiritueuses. Ils sont bons, doux et patients, mais vindicatifs, dissimulés et enclins à la paresse. Tous de race africaine, ils se divisent cependant en noirs nouvellement arrivés de la côte de Guinée. Ces derniers sont bien moins estimés que les autres, et, mème entre noirs, on leur donne le surnom de nègres d'eau salée. Arrivés sur les habitations, ils contractent entre eux des mariages volontaires, et gardent presque toujours la foi promise.

La Martinique compte plus de 80,000 esclaves. La population libre, qui va a 29,000 âmes, se compose de deux autres races, les blancs et les hommes de couleur, presque égaux devant la loi, mais séparés par de profondes nuances sociales. Les blancs eux-mêmes se subdivisent en Européens et créoles; les premiers, accourus de loin pour faire fortune, actifs, remuants, intéressés; les autres, presque tous nés dans l'aisance, indolents, légers, prodigues. Le créole de la Martinique et des Antilles en général, a tous les défauts et toutes les qualités des races nées sous les zones ardentes. Passionné pour le bien comme pour le mal, vif, présomptueux, hospitalier, inconstant, débauché, doué de poésie et d’intelligence, il abuse sans jouir; il se blase de bonne heure, gaspillant tout, croyances et illusions. Quoique pâle et brun, son visage est généralement beau, expressif, d'un caractère hardi; sa taille est gracieuse, son air élégant et noble. Les femmes sont à l'unisson des hommes. Pâles et incolores, elles rachètent cela par un laisser aller parfait, par des traits spirituels et doux, par une taille ravissante de souplesse. Chez elles, le premier abord est froid; mais elles montrent ensuite de l'abandon et du naturel. Rien ne saurait rendre la mollesse onduleuse de leur pose, quand, couchées sur un sofa et entourées d'esclaves attentives, elles semblent éviter la 
fatigue d'un mot ou d'un geste, et ne ramasseraient pas un mouchoir tombé à leurs pieds. Délicieuses créatures, qu'on dirait toutes nées pour être reines! Le soir pourtant, quand la bougie étincelle, quand l'orchestre marque le temps pressé d'une valse, il faut les voir s'élancer fortes et légères, saṇs jamais demander à leurs danseurs ni repos ni merci.

\section{LA GUADELOUPE.}

Cette possession française est divisée en deux parties; la Grande-Terre, nom génẻrique donné à toute portion d'île située au vent, et lá Basse-Terre, nom qui s'applique à la portion située sous le vent. Cette dénomination est vicieuse, car la Grande-Terre est la plus petite des deux; et la Basse-Terre est la plus haute. Mais l'usage a consacré le mot.

La Guadeloupe a deux villes principales : la BASSE-TERrE, résidence du gouverneur colonial, de la cour royale et du tribunal de première instance. Sa mauvaise rade foraine a empêché de tout temps son commerce de s'accroître et sa population de grandir. Elle n'a que 9,000 âmes. La Pointe-a-Pitre en a 16,000. Située à l'embouchure du canal qui sépare les deux moitiés d'île, la Pointe-à-Pitre est un port florissant et riche; elle rivalise avec Saint-Pierre, métropole commerciale de la Martinique.

Nous regrettons que l'espace nous manque pour donner quelques détails sur le malheureux événement récemment arrivé à la Pointe-à-Pitre; mais tous nos lecteurs auront lu dans les journaux le récit de cet épouvantable fléau qui a frappé la population de ceite terre.

\section{ILE DE TABAGO.}

Cette île est longue de onze lieues et large de quatre et demie. Elle est surtout remarquable par le beau sexe qu'on y rencontre. Nulle part, dans les Antilles, on ne trouve de femmes plus attrayantes; celles qui sont d'origine française se distinguent par la finesse et l'harmonie de leurs formes, leurs traits sont pleins de délicat esse, et leurs regards respirent la volupté; elles sont grandes et frêles, mais elles ont la taille trèscourte; leur pied ressemble à celui d'un enfant; on leur reproche leur nonchalance, leur paresse. Les douceurs du far niente, les plaisirs de l'amour, voilà leur vie; mais ces défauts sont ceux du climat, et surtout de l'éducation qu'elles reçoivent au sein de la population de nègres qui les entoure; ce qui le prouve, c'est qu'après un séjour de quelques années dans la mère patrie, ces jeunes femmes reviennent dans leur pays actives et réservées, et ne gardent plus qu'une faible teinte des défauts qu'on leur reproche. Enfin leur intelligence est facile, et se plie avec une promptitude admirable aux études qui exigent le plus d'attention.

Nous n'en dirons pas davantage sur les Antilles; outre que la plupart du grand nombre d'îles, que nous ne pouvons même nommer, ne méritent aucune description, celles qui pourraient nous arrêter nous entraîneraient à des répétitions fatigantes pour le lecteur. 


\section{AMÉRIOUE SEPTENTRIONALE.}

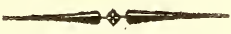

On ne connaît pas encore avec certitude les limites de l'Amérique septentrionale, vers le pôle. Néanmoins, les découvertes de Hearne et de Mackenzie, constatées et rectifiées par Franklin et par la navigation du capitaine Parry, qui donnent un air de vraisemblance aux relations de Maldonado et de Bernarda, longtemps considérées comme fabuleuses, ont fait conjecturer que l'Amérique est bornée au nord par la mer polaire (celle-ci communique, à l'ouest, avec le grand Océan boréal par le détroit de Behring, et peut-être par l'entrée de Norton ou de Ferer); au sud-est avec la mer de Baffin et celle d'Hudson; et qu'elle renferme un grand nombre d'iles, parmi lesquelles on remarque celles de Cumberland et de Southampton, de Banks, de Melville, etc. De ces découvertes, il résulte que le Groënland est entièrement détaché du continent de l'Amérique; et que, dans le nord, cette partie du monde est, comme dans le sud, bornée par une mer entrecoupée d'îles et de canaux, avec cette différence toutefois, que le continent étant très-étroit vers le sud, ces îles n'occupent pas une grande étendue de l'est à l'ouest, tandis que, dans le nord, elles se prolongent sur une ligne qui comprend plus de 100 degrés de longitude entre les $68^{\mathrm{e}}$ et $70^{\mathrm{e}}$ degrés parallèles.

La partie occidentale de l'Amérique du nord est couverte par les ramifications d'une grande chaîne de montagnes, formée par plusieurs lignes parallèles qui suivent la direction des côtes, et s'étend sans interruption du nord au sud-sud-est ou de l'embouchure du fleuve Mackenzie, vers le $68^{\circ}$ degré de latitude nord jusqu'à l'isth me de Darien, où elle se joint à la cordilière des Andes. Depuis sa naissance jusque vers le $45^{\mathrm{e}}$ degré de lati tude nord, elle porte le nom de monts Rocailleux; vers le $60^{\circ}$, elle envoie à l'ouest des rameaux qui se prolongent jusqu'à l'extrémité de la pointe d'Alaska; probablement il s'en détache aussi qui vont vers le détroit de Behring. Ces deux portions de cette chaîne sont couvertes, en beaucoup d'endroits, de neiges perpétuelles, notamment le long du grand Océan. La ligne la plus occidentale qui longe la côte du nord au sud vient en s'abaissant se terminer à l'extrémité méridionale de la Californie. L'on y a observé des volcans. Les divers groupes de la ligne orientale, au sud du $45^{e}$ degré parallèle, se nomment Sierra Verde, Sierra de los Mimbres, et Sierra de la Madre; plus au sud se présente le haut plateau du Mexique, dans lequel plusieurs volcans sont en activité; la chaîne se rétrécit en tournant au sud-est et contient de nombreux volcans; enfin elle diminue de hauteur dans l'isthme de Darien. La chaîne des monts Rocailleux s'abaisse vers l'est en plateaux, que séparent de vastes prairies, et qui au sud-est, par $\mathbf{3 5}{ }^{\circ}$ de latilude nord, se rattachent aux monts Alleghany; ceux-ci s'étendent en ligne oblique parallèlement à la côte de l'Atlantique jusqu'au 47e degré de latitude nord. Le reste du continent, à l'est des monts Rocailleux et au nord des Alleghany, n'offre pas de chaînes d'une grande hauteur, du moins dans la partie qui est connue. 
Ces montagnes donnent naissance à des fleuves considérables qui versent leurs eaux dans les deux Océans. Du versant occidental des monts Rocailleux descendent le Tacoutché-Tessé, la Colombia, le Rio Grande, et plusieurs autres fleuves qui se rendent dans le grand Océan. Le Rio Colorado vient aussi du même versant, et débouche au fond du golfe de Californie. L'espace qui sépare les monts Alleghany de l'Océan est trop étroit pour permettre aux rivières qui sortent du versant oriental de ces monts, de se joindre et de former des fleuves considérables; presque toutes se jettent séparément dans l'océan Atlantique. Les plus remarquables sont le Hudson, la Delaware, le Potoınac, et la Savannah. L'immense vallée qui s'étend entre les monts Alleghany et les monts Rocailleux est arrosée par un grand nombre de rivières qui viennent de l'une ou de l'autre de ces chaînes, et presque toutes grossissent le Missouri el le Mississipi, dont les eaux coulent dans le golfe du Mexique, après un cours de près de 1,000 lieues. Parmi les autres fleuves qui se déchargent dans le golfe du Mexique, on distingue encore le Rio del Norte, qui vient de la Sierra Verde; l'Alabama et l'Apalachicola, qui sortent des monts Alleghany. Les lacs Supérieur, Michigan, Huron, Érie et Ontario, qui séparent les États-Unis des possessions anglaises, et ne reçoivent aucune rivière considérable; mais qui forment le magnifique fleuve Saint-Laurent, par lequel leurs eaux descendent dans l'Atlantique. La mer d'Hudson reçoit les eaux de l'Albany, qui vient de l'ouest, et celles du Nelson, qui arrivent du lac Ouinipeg, où se rendent des rivières sortant de petits lacs situés tout près de ceux où le Mississipi prend sa source, et d'autres sortant des monts Rocailleux. Le nord de l'Amérique septentrionale renferme encore un grand nombre de lacs : l'Athapasca, dans lequel affluent des rivières venant, les unes de l'ouest, des monts Rocailleux, et d'autres du sud et de l'est, envoie ses eaux au lac de l'Esclave, qui donne naissance au fleuve Mackenzie, dont l'embouchure est dans la mer Polaire. Beaucoup d'autres lacs sont épars sur cette vaste surface, et communiquent presque tous les uns avec les autres; ils envoient de divers côtés des rivières qui sillonnent la surface du pays. Ces eaux sont gelées pendant neuf mois de l'année. Le lac Point est traversé par le fleuve Copper-Mine, qui tombe dans la mer Polaire. Toutes ces eaux ne sont séparées les unes des autres que par des chaînons rocailleux qui forment les sommets d'un plateau élevé, dont la pente se dirige à l'est et au nord, dont l'étendue au nord-est et au nord-ouest est inconnue, et qui, en général, n'est décrit que d'une manière très-imparfaite.

On a prétendu que l'Amérique septentrionale est moins riche en métaux précieux que l'Amérique méridionale. Cependant $M$. de Humboldt a prouvé que les produits du Mexique l'emportent sur ceux de tous les autres pays espagnols de l'Amérique méridionale. L'or du Mexique provient, en grande partie, d'alluvions; on le trouve dans les montagnes primitives. Ses mines d'argent sont, pour ainsi dire, inépuisables. Le fer abonde dans l'Amérique russe, dans le Canada, et dans les États-Unis. Il y a des mines de cuivre, et l'on a trouvé ce métal natif près de la rive méridionale du lac Supérieur; et au milieu des régions boréales, dans les montagnes et près du fleuve qui en ont pris leur nom. Le feldspath du Labrador est célèbre. Les mines de houille de la vallée de l'Ohio sont très-productives. Il y a de l'étain au Mexique, et des mines de plomb très-abondantes dans la háute Louisiane. Le sel est commun dans toute l'Amérique septentrionale; on le trouve à la surface du sol, dans des mines et dans des sources. On tire de divers endroits du soufre, et toutes sortes de marbres.

Les immenses forêts de l'Amérique septentrionale sont peuplées, dans la zone tempérée, de pins et de sapins d'une hauteur extraordinaire, de chênes de plusieurs espèces, de noyers, châtaigniers, hêtres, bouleaux, érables, genévriers, cyprès, thuya, mélèses, frênes, ifs, peupliers, platanes, tilleuls, aunes, saules, coudriers, micocou- 
liers : tous ces arbres diffèrent spécifiquement de ceux de l'Ancien-Monde qui portent le même nom. On y remarque aussi, parmi ceux qui sont particuliers au NouveauContinent, les magnifiques magnolias, le tulipier, les acacias, le gordonia, et beaucoup d'arbrisseaux qui portent de très-jolies fleurs; enfin le sassafras, le mûrier rouge, le myrte à cire, etc. Dans les forêts de la zone torride s'élèvent des palmiers de plusieurs espèces, l'hématoxyle, le cacaoyer, le sidéroxyle, l'acajou, le cotonnier et le cocotier. Les hommes ont tiré parti de plusieurs de ces végétaux, et les Européens ont apporté l'oranger, le citronnier, le caféier, la canne à sucre, l'indigotier. On cultive aussi dans cette zone l'agave, le piment, le bananier, l'igname, la patate, le cactus, sur lequel vit la cochenille. On recueille dans les forêts la gousse odorante de la vanille. Tous les arbres fruitiers, les légumes, les plantes utiles et les céréales de l'AncienMonde, ont été naturalisés dans la zone tempérée, et cultivés avec succès; de sorte que l'Amérique septentrionale envoie en Europe de la farine de froment et des pommes. Le maïs et le tabac sont indigènes de l'Amérique. La région boréale est dénuée de grands végétaux. Les bords des fleuves offrent de belles prairies et d'immenses savanes peuplées de troupeaux de bisons, élans, cerfs, chevreuils, antilopes, etc. Les autres animaux remarquables sont : les castors, les hermines, les martres, les loutres, les ratons, les écureuils, et beaucoup d'autres animaux à fourrure. L'Amérique a aussi le porc¿pic. Le bœuf musqué n'habite, comme le renne, que les régions boréales. Les animaux carnassiers, tels que l'ours, le loup, les renards, le carcajou, le lynx et d'autres, sont très-nombreux dans les contrées peu fréquentées. Le cheval, le bœuf, le mouton, la chèvre, le cochon et le chat ont été importés dans le Nouveau-Continent. Tous ces animaux s'y sont multipliés sans dégénérer, et quelques-uns à un tel point, qu'ils sont devenus sauvages. L'abeille est commune dans les forèts. L'Amérique septentrionale est infestée, dans toutes ses parties, de reptiles dangereux : il suffit de citer le serpent à sonnettes, dont le nom seul inspire l'effroi. Les cousins et les mosquitos sont aussi incommodes sur les bords de la mer Polaire que sur les rives de l'océan Allantique. Un oiseau particulier à l'Amérique septentrionale est le dindon, qui s'y trouve encore sauvage, depuis les grands lacs du Canada jusqu'au sud du Mexique; il fut envoyé pour la première fois en Europe en 1523 : quelques peuplades indigènes l'avaient apprivoisé. Le colibri remonte, dans le nord, à une latitude très-haute. Parmi les oiseaux remarquables par leur chant, on cite le moqueur, espèce de grive; d'autres, tels que le cardinal et différentes espèces de tangaras, ont un plumage varié des plus belles couleurs. Les oiseaux-mouches ne se trouvent que dans des contrées de la zone torride. Les pigeons se montrent quelquefois par volées dont le nombre est incalculable. Les volailles de l'Ancien-Monde ont été naturalisées dans le Nouveau. Les oiseaux que l'on y voit, tels que les aigles, les hiboux, les corneilles, les cygnes, les oies, les canards, les goëlans, rt une infinité d'autres, offrent quelquefois des différences qui les distinguent de ceux de nos climats. Les lacs septentrionaux et les rivières abondent en brochets, esturgeons, truites, anguilles, et surtout en saumons. Le grand banc de Terre-Neuve el les côtes voisines sont depuis longtemps célèbres par la pêche abondante des morues qui s'y fait, et qui attire des flotles entières de navires marchands. 



\section{MEXIQUE.}

Le Mexique (ou États-Unis mexicains) s'étend entre $16^{\circ}$ et $42^{\circ}$ de latitude nord, et entre $88^{\circ} 75^{\prime}$ et $126^{\circ} 30^{\prime}$ de longitude ouest. Il a pour limites : au nord et au nord-est, les États-Unis; à l'est, le golfe du Mexique; au sud-est, la mer des Antilles et le Guatemala; au sud et à l'ouest, le grand Océan. On évalue sa superficie à 210,000 lieues carrées, et sa population à $7,000,000$ à $8,000,000$ environ d'individus. "

On trouvera dans le tableau suivant les provinces, ainsi que les principales villes de la confédération mexicaine.

\section{TABLEAU STATISTIQUE}

DE LA RÉPUBLIQUE FÉdérative DU MEXIQUE.

RÉGION MÉRIDIONALE.

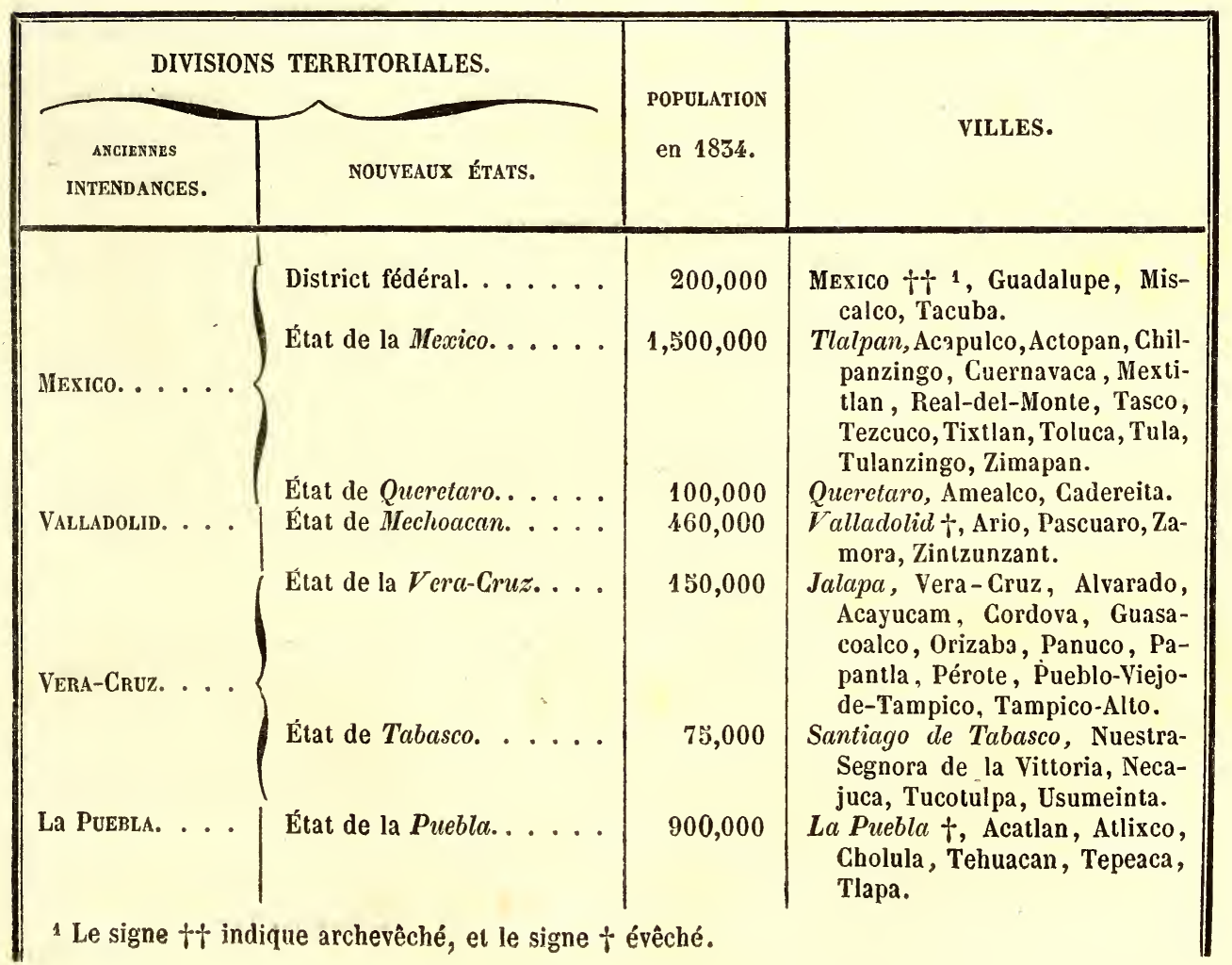




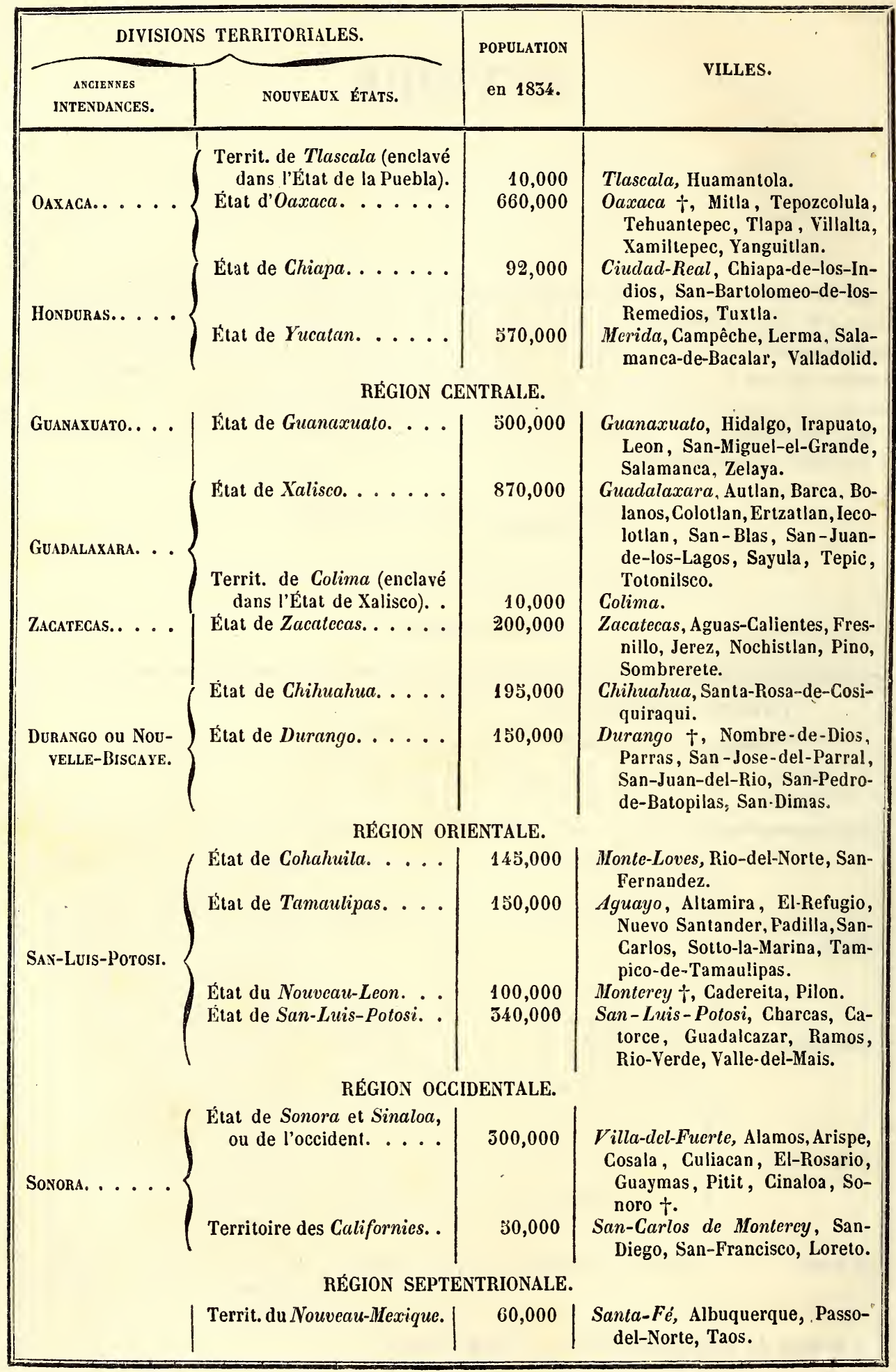


Un certain nombre d'antiquités, principalement les ruines de Palanqué, vers la frontière du Guatemala, attestent que les habitants primitifs avaient atteint, longtemps avant l'arrivée des Européens, un certain degré de perfection dans les arts. En 1519, Fernand Cortez découvrit cette belle contrée qui, deux ans plus tard, fut soumise à l'Espagne, par suite de la prise de Mexico.

Charles-Quint chercha à protéger les malheureux Mexicains contre les vexations de leurs féroces vainqueurs : il accorda aux colonies un code de lois, d'après lequel nulle distinction ne devait être faite entre les conquérants, les colons et les naturels; jusqu'au commencement de ce siècle, l'introduction de la littéralure et des arts de l'Europe fut défendue, et le commerce de ce pays était sacrifié à la cupidité de quelques marchands de Cadix, auxquels le gouvernement en abandonna le monopole. Pour assurer le débit des vins, des eaux-de-vie, des huiles et des soies d'Espagne, on empèchait les créoles de cultiver la vigne, l'olivier et le mûrier, sous des peines atroces. Tel était depuis près de trois siècles le sort des habitants du Mexique, lorsque la France envahit la péninsule espagnole en 1808. Deux ans après, le moine Hidalgo leva l'étendard de la révolte, et fut vaincu et mis à mort l'année suivante. Don Jose-Maria Morelos prit sa place, mais l'autorité royale fut bientôt rétablie. Xavier Mina suscita une nouvelle insurrection en 1815 . Vers le milieu de 1820, la nouvelle de la révolution de l'île de Leon arriva au Mexique. Auguslin Iturbide publia le 24 février 1821, un manifeste par lequel le Mexique était déclaré empire constitutionnel indépendant de l'Espagne. Il fut élu empereur par le congrès, et, au moment où il se faisait couronner, les insurgés proclamèrent la république. Après une lutte sanglante, l'empereur consentit à abdiquer en 1823, et partit pour l'Europe. Vers la fin de 1824, Iturbide tenta de reconquérir son trône, mais il fut presque aussitôt arrêté et fusillé. Depuis, de nombreuses commotions politiques ont encore agité intérieurement la république mexicaine. Une insurrection éclata dans la capitale le 30 novembre 1828 , et le général Guerrero, qui en était le principal chef, fut investi de la présidence; son prédécesseur, Pedraza, s'embarqua pour les États-Unis, et le congrès décréta l'expulsion de tous les Espagnols. Nous verrons à l'article Texas comment ce territoire fut détaché du Mexique.

Le Mexique paraît avoir été habité, dès les temps les plus reculés, par un grand nombre de tribus de races différentes. On cite parmi les plus anciennes (celles qui se regardaient comme autochtones) les OLmèQues ou Hulmèques, dont les migrations atteignaient jusqu'au golfe de Nicoya et à Leon de Nicaragua; les Xicalangues, les Cores, les Tepanèques, les Tarasques, les Miztèques, les Tzapotèques, et les AtoMistes ou Atonies. Les Olmèques et les Xicalangues habitaient le plateau de Tlascala. Toutes ces nations étaient établies avant la grande migration toltèque.

Les Aztè ques fixent l'arrivée des ToltèQues sur le plateau mexicain au vir ${ }^{\mathrm{e}}$ siècle de l'ère chrétienne; ils sortaient de Huehuetlapallan ou Tlapallan, c'est-à-dire contrées situées au nord de Rio Gila. Ces Toltèques venaient chercher un climat plus doux que le leur et des terres plus fertiles. Ils s'étendirent en peu de temps sur la plus grande partie de l'Anahuac, fondèrent Tula à l'extrémité de la vallée de Mexico; ils en firent Jeur capitale, la ville de leur roi. Leur monarchie fleurit pendant quatre siècles, de 667 à 1031. Cette période fut l'àge mythique du pays, l'àge des choses merveilleuses. Ils possédaient des connaissances astronomiques; ils savaient cultiver le maïs et le coton, construire des villes, tailler les pierres, travailler les métaux, exprimer la pensée en caractères hiéroglyphiques, et leur état social et leur forme de gouvernement étaient loin d'annoncer un peuple nouvellement sorti de la barbarie.

Les Toltèques étaient à la merci des saisons, comme tous les peuples placés à de grandes 
hauteurs, dans un pays sans eau. Il arriva que leurs récoltes manquèrent complétement, et la famine et les maladies les décimèrent. Alors quelques-uns d'entre eux allèrent habiter les contrées du sud; d'autres, avec les fils du dernier roi, restèrent sur le plateau, où ils virent bientôt arriver de nombreuses tribus du nord, qui parlaient leur langue; la fusion s'opéra rapidement entre les nouvelles populations, issucs probablement de la même souche. Vers la fin du xir ${ }^{\mathrm{e}}$ siècle, les ChichimèQues furent suivis des Acolinues; ceux-ci, en peu d'années, se placèrent au premier rang dans la nouvelle division politique de l'Anahuac, et leur capitale Texcuco, assise sur les bords du lac de ce nom, levint le foyer de la civilisation du pays, partagé à cette époque en une multitude de petits États, sous l'influence d'une aristocratie militaire assez semblable à celle dé l'Europe au moyen âge.

Vers cette période, une autre peuplade barbare, dont le nord était aussi la patrie prinitive, vint encore chercher une place sur le plateau mexicain. C'était la belliqueuse tribu des Aztèques, pauvre, nombreuse, et de mœurs féroces. Ils s'arrêtent quelques années sur les bords du Gila. Nous les voyons ensuite dans les environs de Tula, siége de l'ancienne civilisation toltèque; puis sur les bords du lac de Texcuco, où quelques chefs riverains leur cherchent querelle, et les forcent à s'établir sur un groupe de petites îles à l'extrémité méridionale de ce lac; ils y séjournent un demi-siècle dans le plus pitoyable état, vivant de racines, d'insectes, de poisson, et n'ayant, pour couvrir leur nudité, que la feuille du palma palustri. Fatigués de cette vie, ils se hasardent à mettre le pied sur la terre ferme; là, de plus grands malheurs les attendent, ils sont attaqués par les Colhuas et réduits en esclavage. Dans cette triste condition, leur race et leur nom auraient disparu, si leurs maîtres, attaqués par un voisin puissant, n'eussent été obligés de les employer comme soldats pour la défense commune. Les Colhuas durent la victoire aux Aztèques, et à ceux-ci elle valut la liberté, prix de leurs services.

Une fois libres, ils abandonnèrent la terre ferme pour aller reprendre une position retranchée au milieu des eaux. Ce n'est plus sur les îles d'Acocolco, trop petites pour leur famille augmentée, qu'ils vont s'établir, mais sur un autre groupe plus à l'ouest, là où est aujourd'hui la capitale du Mexique.

Les progrès de la puissance aztèque furent rapides : en moins d'un siècle, les descendants de ces pauvres pêcheurs, esclaves des Colhuas, soumirent tous les petits États riverains des lacs de la vallée de Tenochtitlan : ces conquêtes ne satisfont pas l'ambition de Montezuma ${ }^{\mathrm{er}}$; il franchit les barrières alpines qui enferment cette vallée célèbre, il porte la guerre au sud, à deux cents milles de Mexico, et à l'ouest sur les bords de l'océan Pacilique.

Le roi guerrier se fait homme politique et législateur. Il achève de cimenter dans un intérêt commun l'union de l'autel et du tròne. Il accorde aux prêtres des honneurs et des richesses en échange d'une portion de pouvoir spirituel qu'ils lui abandonnent. Il publie de nouvelles lois en faveur de la propriété; il rend des lois sévères contre l'ivrognerie. A son règne heureux se rattache la prépondérance de Mexico sur tout l'Anahuac. Cinquante ans plus tard, cette puissance était aux mains du second Montezuma, un de ces hommes que la Providence met sur le trône quand elle a prononcé la chute d'un empire. Grand prêtre et roi, sa fortune l'aveugle.

Le gouvernement aztèque avait une diplomatie organisée; l'administration intérieure paraissait porter l'empreinte d'une civilisation déjà perfectionnée. Leur organisation judiciaire n'avait rien de sauvage. La sévérité des lois pénales était excessive. Le divorce était permis; il était défendu au mari de tuer sa femme lors même qu'il la surprenait en adultère : le juge s'en chargeait pour lui. Les menteurs avaient les oreilles 
et les lèvres coupées; à soixante et dix ans seulement on pouvait s'enivrer impunément : avant cet âge, on pendait les ivrognes.

Si l'on jugeait les Aztèques d'après leur culte, il faudrait les reléguer au dernier rang des barbares. Aucune nation, à aucune époque, n'a plus multiplié les sacrifices humains.

Les Aztèques, comme tous les autres Américains, n'avaient pas d'alphabet. Ils transmettaient les faits par des peintures hiéroglyphiques, système commun à tous les peuples du plateau d'Anahuac, à ceux même, dont la langue différait de l'aztèque; ce qui établit l'antériorité de cette espèce d'écriture à l'établissement de toutes les contrées mexicaines.

Vivant sous un climat tempéré ou dans des contrées fort chaudes, les Aztèques ne connaissaient aucun de ces vêtements qui nous sont indispensables; ils étaient à moitié nus. Un morceau d'éloffe de coton, ou un tissu de fil d'aloès, ou de poil de lapin, jeté sur leurs épaules comme un manteau, et rattaché sur la poitrine; une ceinture de même étoffe, dont les nœuds retombaient de manière à cacher ce que la pudeur de presque tous les peuples cherche à dérober aux yeux; tel était leur costume ordinaire. l.es femmes laissaient descendre une des extrénités de celte ceinture jusque sur les talons, et portaient un vêtement assez semblable à une blouse sans manches. La chaussure n'était autre chose que des feuilles d'aloès taillées en semelles, et fixées sous le pied par une courroie. Pour les riches seuls étaient les tissus de coton garnis et ornés de plumes; pour eux aussi les colliers et les bracelets, joyaux communs aux deux sexes.

La capitale du Mexique est Mexico, dont l'aspect est agréable et régulier. En promenant ses regards du haut des terrasses qui dominent les habitations, on ne voit pas sans plaisir la symétrie des rues, l'ordonnance élégante et simple des maisons bourgुeoises que dominent de loin en loin les dômes des grandes églises ou les clochetons des pelites paroisses. L'elfet des cimes neigeuses qui se dessinent à l'horizon, et la ceinture de montagnes vertes qui forment le plan secondaire, ne contribuent pas peu à l'attrait du tableau.

Plus on voit Mexico, plus on s'y habitue et plus il séduit. Les rues larges, belles, unies, ont jusqu'à deux milles de longueur. Les maisons, d'une hauteur égale et généralement à deux étages, sont ornées de balcous de fer travaillé, quelquefois de bronze peint ou doré. On entre au rez-de-chaussée par de doubles portes ornées en bronze, qui conduisent dans une cour plantée d'arbres et embaumée de fleurs. Les maîtres se logent au premier étage, les serviteurs occupent le rez-de-chaussée. Dans les pièces très-hautes et très-aérées, on a ménagé toutes les jouissances d'un climat chaud à côté de quelques précautions contre les froids subits. La façade des maisons, peinte à la détrempe, en blanc, en rouge ou en vert, a une apparence riante et aisée. Sur quelquesunes on lit des passages de l'Écriture; d'autres fois, le revêtement est en carreaux de porcelaine qui forment des arabesques ou d'autres dessins du plus gracieux effet, quelquefois même des tableaux entiers empruntés à la Bible. Les parois de Mexico sont un musée qui luit au soleil. On dirait une des villes méridionales de la France tapissée de tentures pour une fète solennelle. Les murs des escaliers intérieurs sont souvent couverts de la mème matière, avec une profusion de dorure qui tranche sur le bleu et le blanc de la porcelaine. Ce système d'ornement, quoique peu usité en Espagne, a dû être inspiré aux conquérants espagnols par le souvenir des magnificences analogues qui recouvraient les palais moresques et les mosquées de Cordoue et de Séville. A une époque où les mines d'or et d'argent du Nouveau-Monde jetaient parmi les colons des richesses immenses, ils durent chercher à se faire honneur de leur fortune par un 
grand étalage extérieur. Ce fut alors qu'on fit venir à grands frais des Pays-Bas ces carreaux de porcelaine, matière inconnue jusqu'alors au Mexique. On en revêtit les maisons et on en couvrit les églises.

Les toits, pavés de briques et couverts en grande partie d'arbres à fleurs, sont une suite de terrasses qui offrent le soir la plus ravissante promenade.

A l'intérieur, les maisons semblent donner un démenti à leur apparence extérieure.

Les plaies des révolutions récentes ne sont pas encore toutes cicatrisées. Autrefois, dans ces mêmes pièces, se montraient de magnifiques tables, des chandeliers, des vases, des cadres de glaces en argent ou même en or massif; aujourd'hui ce luxe n'est plus permis au Mexique.

Outre l'Alameda, il y a encore une autre promenade appelée Mexico el parco; elle est plantée de deux allées d'arbres et longue de deux milles, et se termine tout à coup auprès d'un pont et d'une grande porte sous laquelle passe le canal de Chalco. C'est vers cet endroit que se dirigent surtout les voitures et les cavalcades. Rien de plus gracieux que son aspect les dimanches et les jours de fète. Dans toutes les directions se croisent des canaux couverts d'une barge et remplis d'Indiens proprement vêtus et la tète couronnée de fleurs. A la proue de chaque canot est un musicien qui joue de la guitare, tandis que le reste de la troupe se livre au chant et à la danse.

On voit un grand nombre d'iles artificielles sur le canal de Chalco, connues dans le pays sous le nom de chinampas, et que les Européens appellent jardins flottants. Dans le nombre, il en est en effet qui sont mobiles, mais d'autres tiennent au rivage, séparés les uns des autres par des fossés de quelques verges de large.

L'invention ingénieuse de ces chinampas paraît remonter au xive siècle, et sans doute elle naquit du besoin de pourvoir à la subsistance d'une grande ville jetée sur un lac peu poissonneux. La nature a dù donner aux Aztèques l'idée de ces jardins sur les rives marécageuses du lac de Chalco. Les plus anciens chinampas n'étaient que des mottes de gazon réunies, consolidées ensuite, puis enfin devenues cultivables. Plus tard l'industrie s'en mêla. Les peuples aztèques formèrent des champs entiers à l'aide de radeaux de roseaux, de joncs, de racines et de branches de broussailles. Ils recollvrirent ces matières légères et enlacées les unes dans les autres, d'un terreau noir, nạturellement imprégné de muriate de sonde. Quand ces chinampas étaient mobiles, rien de plus curieux que de les voir s'en aller au gré du vent, avec leur verdure, quelquefois mème avec la cabane de l'Indien qui cultivait le terrain. Aujourd'hui les chinampas tendent toutes à se fixer. C'est sur les chinampas que se cultivent les fèves, les petits pois, le piment, les pommes de terre, les choux-fleurs qui défrayent les marchés de la capitale. Les bords sont généralement garnis de fleurs.

Dans ces environs et auprès des chinampas s'élèvent de pittoresques villages d'Indiens bàtis au milieu des fleurs et de la verdure. Cià et là se montrent aussi des champs de maguey de pulque, sorte d'agave qui sert à la fabrication du pulque, boisson des Mexicains.

A Mexico les costumes subissent une grande variété d'une classe à l'autre. Les Espagnols et les blancs natifs portent des habits confectionnés à l'européenne, au dehors des fracs et des redingotes, dans leurs maisons des surtouts on des vestes de calicot imprimé. Les dames et les enfants marchent dans les rues toujours vêtus de noir. Les femmes ont la tête découverte : quelquefois elles jettent un léger voile par-dessus leurs beaux cheveux. Elles sont fort recherchées dans leur chaussure. Les dimanches, elles revêtent des habillements plus gais.

Les visites mexicaines ne sont pas seulement toujours trop longues, elles ont en outre l'impardonnable défaut d'ètre, pour la plupart, parfaitement ennuyeuses. 
Madame Calderon ${ }^{1}$ se plaint à diverses reprises des absurdités de l'étiquette espagnole et de la monotonie des compliments; d'abord il lui fallait embrasser toutes les femmes qu'elle recevait, puis les faire asseoir à sa droite et répéter ensuite mot à mot le dialogue suivant, qui est de rigueur :

«Comment vous portez-vous? votre santé est-elle bonne? - Votre servante; et vous, comment allez-vous? - Rien de nouveau (sin novedad, sans nouveauté). Votre servante. -J'en suis bien aise, et comment vous trouvez-vous, segnora? - Votre servante, et vous? - Votre servante, et le segnor? - Votre serviteur, sin novedad. "

La conversation dure quelquefois deux ou trois heures sur ce ton, seulement elle change de sujet. Après la santé vient le temps, après le temps la chaleur, etc., etc. Tous les sujets usuels épuisés, la visiteuse embrasse une seconde fois la maîtresse de la maison, qui la reconduit en personne jusque sur le palier de l'escalier. Là de nouveaux compliments s'échangent. "Madame, vous savez que ma maison est à votre disposition.-Mille remerciments, madame; la mienne vous appartient. - Adieu; je vous souhaite une bonne nuit. - Dormez bien, madame, etc., etc. $\$$

Au Mexique, toutes les personnes de la même classe, hommes et femmes, s'appellent par leur nom de baptème, comme si elles se connaissaient intimement depuis l'enfance. Grand fut l'étonnement de madame Calderon d'entendre des jeunes gens dire sans façon à des femmes marièes plus âgées qu'eux, et qu'ils voyaient pour la seconde ou pour la troisième fois, Maria, Anita, Antonia, au lieu de segnora. Souvent même on se permit à son égard cette irrévérente familiarité.

Toute vertu poussée à l'excès devient un défaut; il est bon d'être poli, mais on ne doit pas abuser de la révérence et des compliments. On se rend ridicule et on met dans l'embarras les personnes auxquelles on s'imagine faire un vif plaisir. Les Mexicains ne se doutent pas de cette double vérité. Madame Calderon avait un médecin qui était la créature la plus polie de toute la création. Chaque jour il venait lui tâter le pouls et il lui ordonnait de boire une potion; mais chaque jour aussi, en prenant conge d'elle il lui tenait ce langage :

a Madane (au chevet du lit), je suis votre serviteur. - Mille remercîments, monsieur, répondait madame Calderon. - Madame (au pied du lit), regardez-moi comme le plus humble de vos servileurs. - Bonjour, monsieur, bonjour. A demain. - Madame (derrière une table), j'embrasse vos pieds. - Monsieur, je vous baise les mains. - Madame (près de la porte), tout ce que je possède est à votre disposition. - Mille remercîments, monsieur.-Adieu, madame (la porte ouverte), votre serviteur.-Adieu, monsieur, adieu. $₫$

a Je m'en croyais débarrassée, ajoute madame Calderon; mais il imitait le Basilio du Barbiere di Siviglia, et dès que la porte s'était refermée sur lui, il la rouvrait brusquement, et me présentant sa figure souriante, il me disait une dernière fois de sa voix la plus douce : - Bonjour, madame.

Le gentilhomme de campagne ou paisano a un costume très-brillant et très-coûteux. Il se compose $1^{\circ}$ de culottes brodées, généralement de peau de couleur, ouvertes sur les genoux et ornées d'un grand nombre de boutons ronds en argent, et de larges galons de même métal; $2^{\circ}$ d'une chemise brodée avec un col très-haut, et une veste courte en calicot imprimé, sur laquelle est jetée une manta, soit de drap fin, soit de bclle étoffe de coton fabriquée dans le pays, souvent même couverte de galons d'or. Le paisano porte des souliers de cuir très-mince, ou des bottines qui forment vers le haut

1 Madame Calderon est une Américaine, mariée à M. Calderon, Espagnol représentant sa patrie au Mexicque. 
une espèce de guêtre retenve par une jarretière ornée. Cette partie du costume est fort dispendieuse, les bandes de peau étant travaillées en relief. Ces sortes de bottines se vendent jusqu'à quarante et cinquante piastres la paire. Les étriers et les éperons sont à l'unisson de ce luxe, aussi bien pour le travail que pour la richesse de la matière. Les chapeaux, dont les couleurs varient, ont les bords très-larges et la forme basse; ils sont bordés d'une ganse ronde, et ont une boucle et une frange d'or. On ne saurait se former une idée de l'élégance de ces chapeaux.

Le cheval a un équipement qui n'est pas moins resplendissant ni moins coûteux. D'abord la grande selle espagnole avec ses larges oreillettes est richement brodée de soie, d'or et d'argent. L'arçon de devant est fort élevé; les étriers eux-mêmes sont en argent ou en bois couvert d'étoffe brodée; la bride étroite soutient un mors très-fort et très-large, à l'aide duquel les cavaliers peuvent arrêter leurs chevaux en plein galop.

Les femmes ont moins de luxe dans leur costume. Elles portent, en général, une chemise brodée, une espèce de spencer qui s'ouvre sur le devant, enfin une jupe de drap écarlate ou rose, couverte de broderies et de paillettes.

Le costume des classes pauvres, Espagnols, métis ou Indiens, varie suivant les provinces. Quelques-uns n'ont presque pour vêtement qu'une couverture de laine roulée autour du corps. D'autres ont un chapeau de paille avec un justaucorps à manches, et des culottes courtes, ouvertes sur les genoux, en peau de chevreau ou de pécari avec le poil tourné en dehors. Par-dessus ce vêtement sont des caleçons de calicot qui descendent jusqu'à mi-jambe. La chaussure consiste en sandales de cuir assez semblables à celles des Romains. Les femmes ont un petit jupon et une veste courte; elles portent leurs cheveux tressés de chaque côté de la tête avec des lacets rouges. En général, leur vètement est propre, leur maintien modeste et décent. Parmi les Indiens qui fréquentent leś marchés de Mexico, les plus curieux sont ceux de Mitchoacan, descendants des

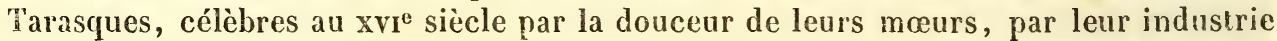
dans les arts mécaniques, et par l'harmonie de leur langue. Les huttes de ces Indiens liont pas toutes la mème forme. Dans les cantons les plus chauds ce sont des cages faites avec des cannes ou de petits bâtons et couvertes de feuilles. Dans les montagnes neigeuses, ce sont des chaumières à peu près semblables à celles de la Norwége ou de la Suisse. Une natte étendue à terre ou un filet suspendu, quelques vaisseaux de terre et quelques calebasses, une pierre pour faire cuire les tortillas ou pains de maïs, tels sont les meubles d'utilité.

Ce sont les Indiens mitchoacans qu'on emploie, de préférence à tous les autres, dans le petit nombre de manufactures qu'on exploite à Mexico. On y fabrique d'excellents chapeaux de castor et des chapeaux de laine appropriés à l'usage des campagnards. On y confectionne en outre les mantas ou manteaux de paisanos et des cuirs tannés fort bien Iravaillés.

Vera-Cruz, siége du riche commerce que fait le Mexique avec l'Europe, ne doit rien aux faveurs de la nature. Les rochers de madrépores, dont elle est construite, ont été lirés du fond de la mer. La seule eau potable est recueillie dans des citernes; le climat est chaud et malsain; des sables arides entourent la ville au nord, tandis qu'on voit s'étendre, au sud, des marais mal desséchés. Le port, peu sûr et d'un accès difficile, est protégé par le fort de San-Juan-d'Ulloa. La population, souvent renouvelée par les fièvres jaunes, peut être estimée à 16,000 habił̧ants.

Riche et populeuse lorsque le Mexique était soumis à l'Espagne, elle n'offre plus aujourd'hui que l'aspect d'une cité déchue. Ses rues, presque dépeuplées, sont larges, ses maisons sont basses, rarement à plus d'un étage, et sont surmontées de terrasses. 




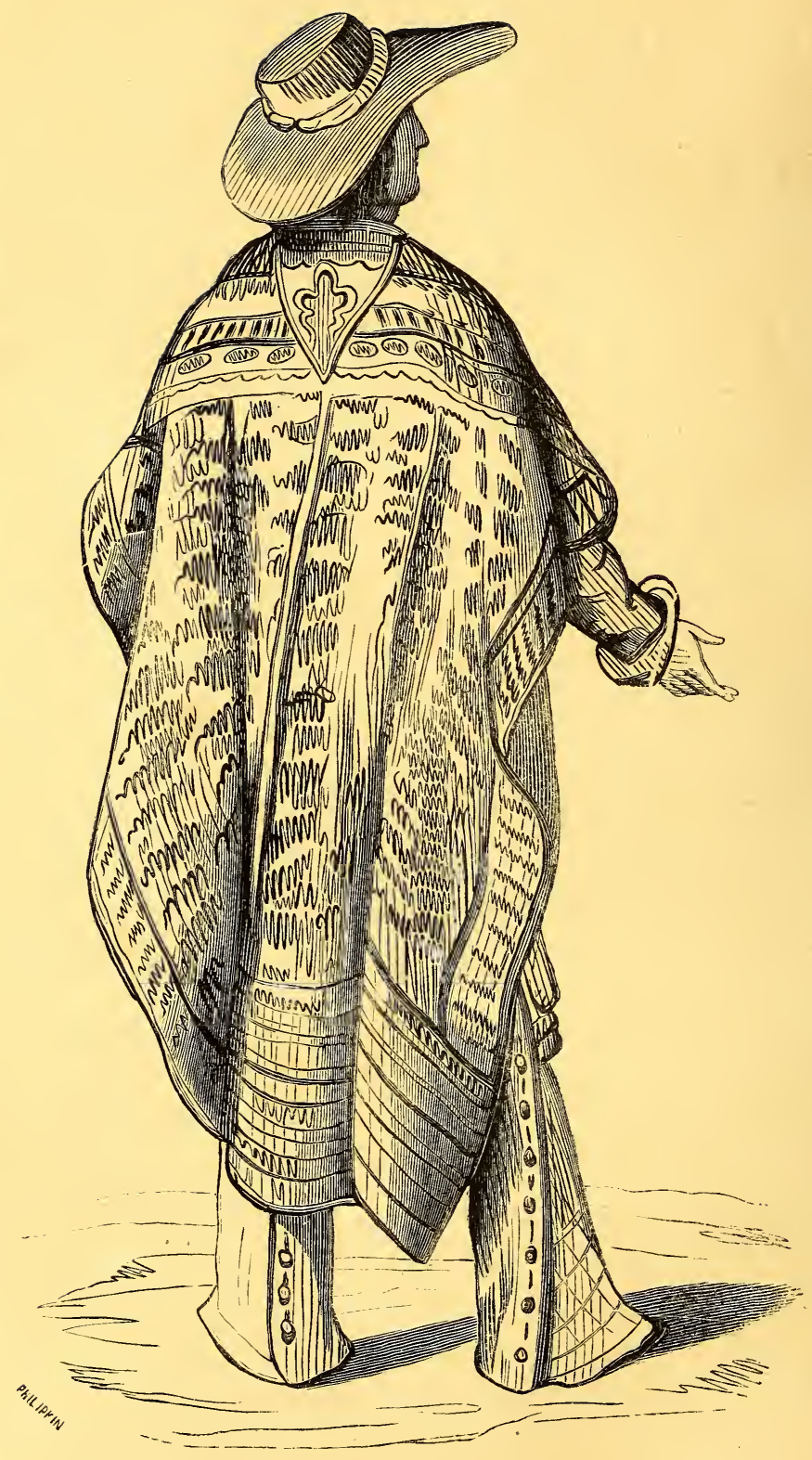

HOMME DE PUEBLA. 



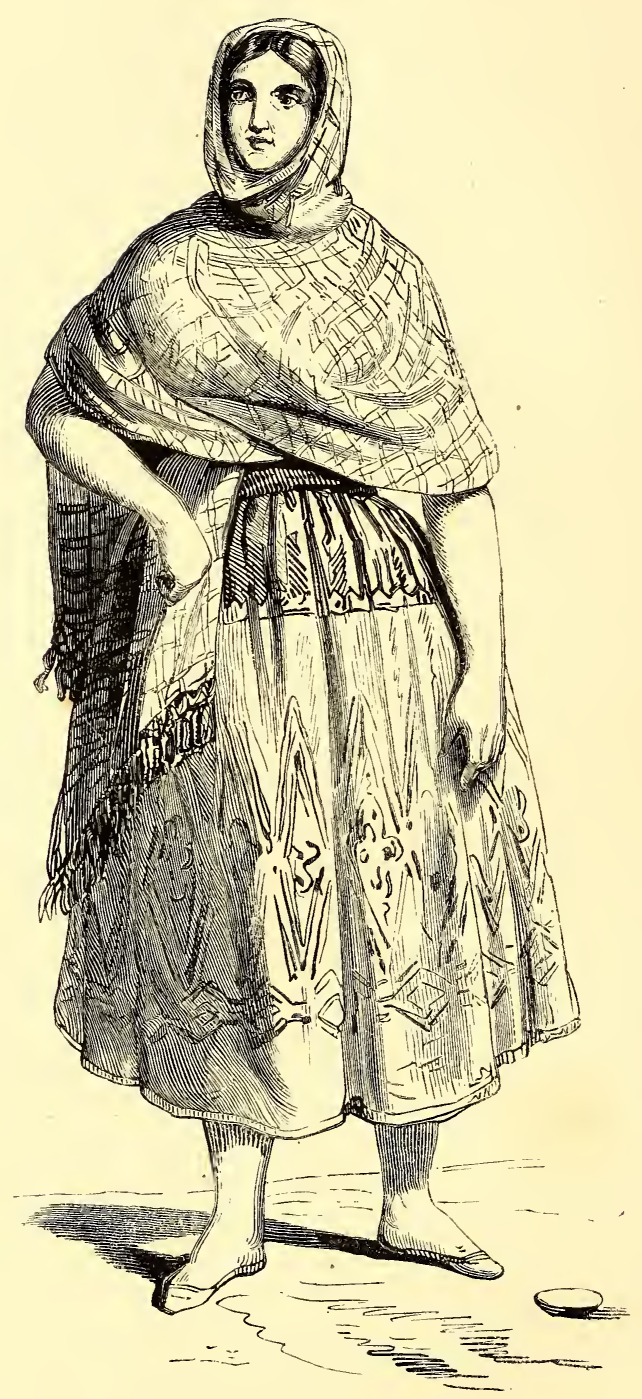

FEMME DE JALAPA . 



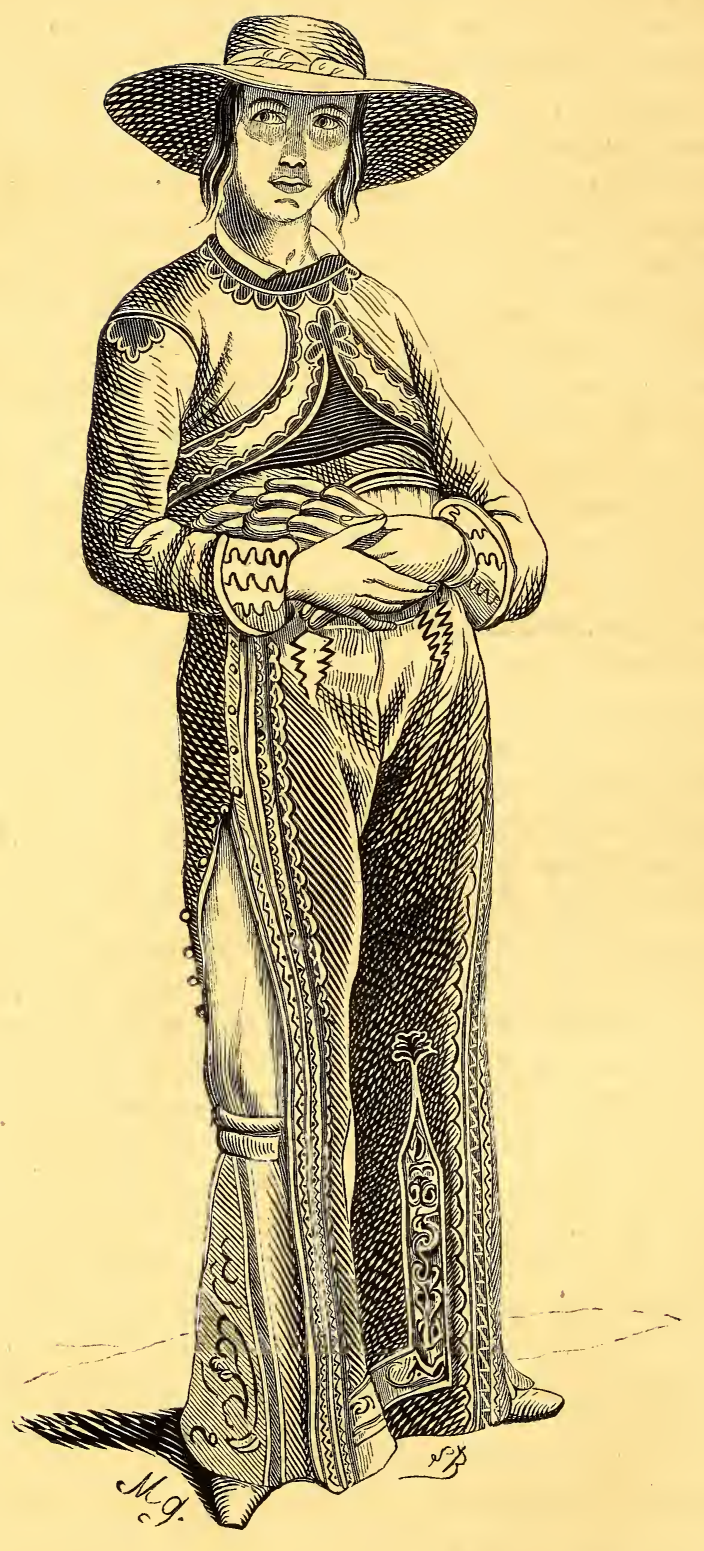

HABITANT DES ENVIRONS DE VERA-CRUZ.

(Mexique.) 
Sous ce climat dangereux, la police de salubrité aurait besoin d'être active et prévoyante; elle est, au contraire, tellement négligée qu'elle semble seulement être confiée à des bandes d'oiseaux du geure vautour. On en rencontre à chaque pas : quelques-uns sont gros comme des dindons; ils dévorent les chiens et les chats morts, les lambeaux de viande qui tombent des boucheries, et une parlie des immondices qu'on jette dans les rues.

L'Alameda est fort convenable; les promeneurs y trouvent des siéges pour se reposer. Quant à la société qu'on y rencontre, elle varie suivant les heures et les jours, le Nouveau-Monde ayant, comme le nôtre, son code de fashion et d'étiquelte.

Les officiers de l'armée mexicaine sont revêtus d'uniformes brillants et chamarrés d'or; mais le costume des troupes répond mal au luxe des chefs.

Les marchés de Vera-Cruz ont un aspect plus satisfaisant que les promenades. Ils sont encombrés de naturels et d'Indiens dont les divers accoutrements offrent un spectacle curieux par leur originalité.

Les environs de Vera-Cruz, dévastés et déserts, sont peu susceptibles de culture; le sol est beaucoup trop sablonneux. Il en résulte que les objets de première nécessité, apportés de fort loin, sont à Vera-Cruz d'une cherté excessive.

C'est à Puentes del Rex (Pont du Roi) que l'on peut surlout observer ce que l'on nomme l'Indien de la Tierra caliente, homme simple à qui peu suffit et qui se nourrit de fruils venus presque sans culture. L'usage de la viande est peu commun parmi ces peuples. Leurs vêtements, quand ils en ont, proviennent de la vente de leurs œufs dans une ville voisine. Un machete, une selle et un cheval, voilà les objets de plus grand luxe parmi eux; mais les riches seuls les possèdent.

Xalapa n'est plus aujourd'hui que la maison de plaisance de Vera-Cruz; elle a perdu son ancienne importance commerciale. Les maisons y sont bâties à l'ancienne manière espagnole, élevées de deux étages : elles entourent une cour carrée, au milieu de laquelle coule une fontaine, d'où s'élance un jet d'eau. Quelques-uns de ces bâtiments ont des fenêtres vitrées, mais le plus grand nombre n'a que des jalousies, suffisantes dans cette atmosphère tempérée. Xalapa compte huit églises, proprement tenues et décorées de riches sculptures; le maître-autel de la cathédrale est en argent.

La bourgeoisie et le peuple ont un air d'aisance et de luxe. Les femmes y sont uniformément vêtues de noir, et plusieurs d'entre elles portent de fort beaux voiles de dentelle; elles ont la réputation d'être gaies, affables, même un peu galantes. Les femmes, comme dans les autres colonies espagnoles, font usage du cigare, et, dans leurs réunions, elles se renvoient entre elles des bouffées de fumée.

La Puebla, fondée par les Espagnols en 1533, est une des plus riches et des plus belles cités du Mexique. Elle se déploie sur le plateau d'Anahuac, au milieu d'un territoire bien cultivé, avec ses maisons régulières et propres, et ses églises qui, pour le luxe intérieur et pour les formes architecturales, ne le cèdent pas mème à celles de Mexico. Elle conserve encore, soit dans sa forme, soit dans les habitudes de ses citadins, on ne saurait dire quel parfum des jours de la conquête. Les décorations gothiques, sous ce climat conservateur, sont restées fraîches comme au premier jour; les dorures, les statues coloriées, lout a gardé son premier éclat.

Les rues de la ville sont droites, larges, se croisant à angles réguliers, pavées de larges dalles et pourvues de trottoirs; les maisons, assez vastes, de deux à trois étages, ont des toits plats, dont quelques-uns sont couverts en tuiles vernies, arrangées en mosaïque, et formant des peintures qui représentent presque toujours des sujets tirés de l'Écriture sainte. Quelquefois on peint les maisons à fresque comme dans les villes italiennes. A l'intérieur, elles ont, comme celles de Vera-Cruz, une grande cour carrée 
dont les galeries sont ornées de vases de porcelaine garnis de fleurs. Les pièces sont nues et sans tapisserie, avec un mobilier assez mesquin.

La Puebla est le siége d'un évêché dont la richesse balance presque celle de l'évêché de Mexico. Elle est administrée par quatre alcades qui ont au-dessous d'eux seize inagistrats subalternes. Sur les places, on trouve des voitures publiques traînées par des mules. Les marchés sont fournis par des Indiens. Leur cuisine est toujours fortement assaisonnée avec le chili, ingrédient favori des Mexicains.

Cette ville n'est pas favorisée sous le rapport de la population. Elle manque surtout de femmes qui en animent et en égayent la physionomie extérieure. Ce n'est guère que dans les églises, aux jours de grandes fètes, ou dans les rues quand une procession les traverse, qu'on peut voir la société élégante et riche de la deuxième ville du Mexique.

Nous ne terminerons pas la topographie du Mexique sans dire un mol des mines de celle contrée. Les principales sont celles de Guanaxuato (vingt mines), de San Luis Potosi (trente mines), Mexico (quarante mines), Guadalaxaca (trente-sept mines), Sonora (cinquante-huil mines), Valladolid (vingt-huit mines), OAXaca (seize mines), Puebla (dix mines), Vera-Cruz (quatre mines), ancienne Californie (une mine).

Tout le minerai tiré des divers points de Guanaxuato provient de ce que l'on appelle la veine mère (veta madre) qui serpente dans le groupe porphyritique désigné sous le nom de Sierra de Santa Rosa, dont la pente méridionale est traversée par le filon de Guanaxuato.

De même que ceux du Pérou, les indigènes du Mexique connaissaient, bien avant l'arrivée des Européens dans leur patrie, l'usage des métaux que renfermaient les entrailles de leur terre natale. Ils ne se bornaient pas, comme on l'a cru, à ramasser ceux qui, à l'état natif, se trouvent à la surface du sol et dans le lit des torrents; ils se livraient à des travaux souterrains pour l'exploitation des filons, perçaient des galeries et creusaient des puits. Nous savons par Cortez qu'au grand marché de Tuoctitland on vendait de l'or, de l'argent, du cuivre et de l'étain. Les habitants de Trapoteca séparaient l'or au moyen du lavage des terrains d'alluvion, et payaient leurs tributs suit en grains d'or natif, soit en barres d'or fondu. Dans les villes principales de l'Anahuac, on fabriquait des vases d'or et d'argent, quoique ce dernier métal fủt médiocrement eslimé. Cortez fait l'éloge des orfévres mexicains; dans une lettre adressée à Charles-Quint, il donne le détail des objets qui lui furent offerts par Montezuma, lorsque celui-ci força la noblesse aztèque à prêter hommagge au roi d'Espagne. "Outre une grande quantité d'or el d'argent, dit Corlez, on me présenta des objets d'orfévrerie et de bijouterie si précieux que, ne voulant pas les laisser fondre, j'en séparai pour plus de cent mille ducats, afin de les offrir à Votre Altesse Impériale. Ces objets étaient de la plus grande beauté, et je doute qu'aucun prince de la terre en ait jamais possédé de semblables. Afin que Votre Altesse ne puisse croire que j'avance des choses fabuleuses, j'ajoute que tout ce que produisent la terre et l'eau et dont le roi Montezuma pouvait avoir connaissance, il l'avait fait imiter en or et en argent, en pierres fines et en plumes d'oiseaux, et le tout dans une perfection si grande que l'on croyait voir les oljets mêmes. Quoiqu'il m'en eût donné une grande partie pour Votre Altesse, je fis exécuter par les naturels plusieurs autres ouvrages d'orfévrerie en or d'après les dessins que je leur fis remettre, tels qu'images de saints, crucifix, médailles et colliers. Comme le quint ou le droit sur l'argent payé à Votre Altesse se monta à plus de cent marcs, j'ordonnai que les orfévres indigents les convertissent en plats de diverses grandeurs, en cuillers, en tasses et autres vases à boire. Tous ces ouvrages furent imités avec la plus grande exactitude. " 
Le métier de mineur est un métier libre dans tout le Mexique; aucun métis, aucun Indien ne peut ètre contraint à cette exploitation. Le mineur mexicain est le plus libre, et aussi le mieux rétribué. Il gagne de vingt-cinq à trente francs par semaine, tandis que les cultivateurs du plateau ont peine à avoir, dans les temps prospères de la contrée, neuf à dix francs pour le mème temps. Les tenateros et faeneros, qui sont destinés à transporter les minerais aux places d'assemblage, gagnent jusqu'à six francs par journée de six heures. A côté de ce bénéfice licite, il en est d'autres qui le sont moins. Le mineur mexicain est aussi sujet au vol que le diamantaire brésilien, et on est obligé d'exercer à son égard une surveillance non moins grande. Comme on fouille les ouvriers, bien qu'ils soient à demi nus, ils cherchent à cacher des morceaux d'argent natif et d'argent sulfuré rouge dans leurs cheveux, sous leurs aisselles et dans leur bouche; ils cherchent aussi à loger partout où ils peuvent des cylindres d'argile (longanos) qui contieunent le métal. Plus d'une fois on prend les voleurs sur le fait et ou tient registre des quantités qui ont été retrouvées.

On contrôle dans l'intérieur de la mine avec le plus grand soin la gangue qui s'en extrait. A la place d'assemblage des grands puits sont assises, devant une table, deux personnes (despachadores) qui out un livre sur lequel est inscrit le nom de tous les mineurs employés au transport. Chaque tenatero se présente chargé de son minerai, et les deux experts parfois le pèsent, parfois l'estiment au gré de l'ouvrier, puis inscrivent le poids qui doit servir de règle pour son payement. Pour une charge de neuf arrobes on lui paye un réal, et pour une charge de treize arrobes et demi, un réal et demi.

Avant de livrer le minerai à ces portefaix, on fait dans l'intérieur de la mine un triage auquel on emploie principalement les femmes. Ensuite le minerai passe sous les bocards, puis sous les tahonas ou arastres. Ces arastres sont des machines dans lesquelles la gangue est triturée sous des pierres très-dures, auxquelles on imprime un mouvement giratoire et qui pèsent sept à huit quintaux. Les bocards (mazos) sont des espèces de meules volantes ou de moulins dont le travail diffère selon que le minerai est lestiné à la fonte ou à l'amalgamation. De ces deux procédés, l'amalgamation à l'aide du mercure et la fonte, le premier est sans contredit le plus usité et le plus productif.

L'espèce humaine présente, dans le Mexique, quatre grandes divisions, qui forment huit castes, savoir :

$1^{\circ}$ Indiens aborigènes cuivrés.

$2^{\circ}$ Espagnols... $\left\{\begin{array}{l}\text { Originaires, nés en Europe; } \\ \text { créoles, nés en Amérique. }\end{array}\right.$

$3^{\circ}$ Nègres. .... A Africains, esclaves;

$\{$ descendants de nègres.

$4^{\circ}$ Castes mixtes. $\left\{\begin{array}{l}\text { Métis, issus d'un mélange de blancs et d'Indiens; } \\ \text { mulâtres, issus de blancs et de nègres; } \\ \text { zambos, issus d'Indiens et de nègres. }\end{array}\right.$

Quelques Malais et Chinois, qui sont venus des Philippines se fixer au Mexique, ne peuvent entrer en considération. Le nombre des Indiens cuivrés de race pure, principalement concentrés dans la partie méridionale du plateau d'Anahuac, excède deux millions et demi, ce qui forme environ les deux cinquièmes de la population du Mexique, population que l'on ne peut guère évaluer au delà de 8,000,000 d'âmes.

Les indigènes du Mexique à une grande force musculaire, joignent l'avantage de n'ètre sujets à presque aucune infirmité; ils ont la couleur basanée, les cheveux plats et lisses, peu de barbe, le corps trapu, l'œil allongé et un peu bridé, les pommettes saillantes, les lèvres larges. Parmi ces indigènes, ceux qui se sont résignés au joug 
espagnol et qui se vouent aux travaux du sol dans les plaines du plateau mexicain, arrivent d'ordinaire à un âge fort avancé. Ils n'ont pas à essuyer les fatigues de la vie errante qui épuise les peuples chasseurs et guerriers du Mississipi et des savanes du Rio Gila.

Dans les pays dont les habitants souffrent du goître, cette affection de la glande thyroïde ne s'observe jamais chez les Indiens, rarement chez les métis. Les Indiens de la Nouvelle-Espagne, et surtout les femmes, atteignent généralement un âge assez avancé. Leur tête ne grisonne jamais, et ils conservent toutes leurs forces jusqu'à la mort. Les couples centenaires, homme et femme, se rencontrent assez fréquemment dans la zone tempérée, située à mi-côte de la cordilière. Parmi ces Indiens, on en trouve peu de louches, de boiteux, de manchots et de bossus. Un fait singulier, c'est que dans les pays où les Européens et les créoles sont sujets aux goîtres, les Indiens ne connaissent pas cette infirmité.

Pour ce qui concerne leurs mours et leurs habitudes sociales, il est difficile de les apprécier avec justesse. L'esclavage, qui altère si profondément les types, agit encore plus profondément sur les coutumes et les mours. Ensuite, il faut dire que les femmes de la classe distinguée, parmi les anciens Mexicains, aimèrent mieux toutes contracter des mariages avec les vainqueurs que de subir le mépris que ceux-ci témoignaient pour les Indiens. De là il est résulté que les indigènes actuels sont les descendants de la race la plus pauvre et la plus misérable de l'ancien Mexique, des portefaix, des mendiants, des colporteurs qui, dès ce temps, pullulaient dans la capitale.

L'Indien est aujourd'hui grave, mélancolique, taciturne, aussi longtemps que les liqueurs enivrantes n'ont pas agi sur lui : cette gravité est surtout remarquable dans les enfants qui, à l'âge de quatre ou cinq ans, montrent beaucoup plus d'intelligence et de développement que les enfants des blancs. L'Indien aime à mettre du mystérieux dans ses actions les plus indifférentes; aucune passion ne se peint dans ses traits. Toujours sombre, il présente quelque chose d'effrayant lorsqu'il passe tout à coup du repos absolu à une agitation violente et effrénée. L'énergie de son caractère, qui ne connaît aucune douceur, dégénère habituellement en dureté. Elle se déploie surtout chez les habitants de Tlascala : au milieu de leur avilissement, les descendants de ces républicains se distinguent encore par une certaine fierté que leur inspire le souvenir de leur ancienne grandeur. Les indigènes du Mexique, comme tous les peuples qui ont gémi longtemps sous le despotisme civil et religieux, tiennent avec une opiniâtreté extrême à leurs habitudes, à leurs mœurs, à leurs opinions : l'introduction du christianisme n'a presque pas produit d'autre effet sur eux que de substituer des cérémonies nouvelles, symboles d'une religion douce et humaine, aux cérémonies d'un culte sanguinaire. De tout temps, les peuples à demi barbares recevaient des mains du vainqueur de nouvelles lois, de nouvelles divinités; les dieux indigènes et vaincus cèdent aux dieux étrangers.

Point de gaielé, point de laisser aller même dans la danse et dans la musique. Les chants sont mélancoliques et lugubres. Quant à la danse, les hommes seuls s'y livrent pendant que les femmes présentent à la ronde des liqueurs fermentées. Les Mexicains ont conservé un goût particulier pour la peinture et la sculpture sur pierre et sur bois. Ils ont conservé le même goût pour les fleurs que Cortez leur trouvait de son temps.

Les Indiens mexicains, considérés en masse, présentent le tableau d'une grande misère. Indolents par caractère, et plus encore par suite de leur situation politique, ils ne vivent qu'au jour le jour. Au lieu d'une aisance générale, on trouve quelques familles dont la fortune paraît d'autant plus colossale qu'on s'y attend moins. Cependant les lois actuelles, généralement douces et humaines, leur assurent le fruit de leurs 
fatigues et pleine liberté pour la vente de leurs productions. Ils sont exempts de tout impôt indirect, et uniquement sujets à un tribut de capitation que payent les Indiens mâles depuis l'âge de dix ans jusqu'à celui de cinquante, et dont le fardeau a été beaucoup allégé dans les derniers temps. Mais si la législation paraît favoriser les indigènes sous le rapport des impôts, d'un autre côté elle les a privés des droits les plus importants dont jouissent les autres citoyens. Dans un siècle où l'on discuta formellement si les Indiens étaient des êtres raisonnables, on crut leur accorder un bienfait en les traitant comme des mineurs, en les mettant à perpétuité sous la tutelle des blancs, en déclarant nul tout acte signé par un natif de la race cuivrée et toute obligation qu'il contractait au-dessus de la valeur de 15 francs. Ces lois, maintenues dans leur pleine vigueur, élèvent des barrières insurmontables entre les Indiens et les autres castes, dont le mélange est aussi prohibé, et dont la désunion, ainsi que celle des familles et des autorités constituées, a été considérée de tout temps par la politique espagnole, comme le plus sûr moyen de conserver les colonies dans la dépendance de la capitale. La loi défend non-seulement le mélange des castes, elle défend même aux blancs de se fixer dans les villages indiens; elle empêche que les natifs ne s'établissent au milieu des Espaguols. Les Indiens se gouvernent par eux-mèmes; mais leurs magistrats, généralement les seuls habitants du village, qui parlent l'espagnol, ont intérêt à maintenir leurs concitoyens dans l'ignorance la plus profonde. Restreints dans un espace étroit de 500 mètres de rayon, qu'une loi ancienne assigne aux villages indiens, les natifs sont en quelque sorte sans propriété individuelle : ils sont tenus de cultiver les biens communaux, sans espoir de recueillir le fruit de leur travail. Le dernier règlement des intendances portait que les natifs ne peuvent plus recevoir de secours de la caisse de la communauté, sans une permission spéciale du collége des finances du Mexique. Les biens communaux furent mis en ferme par les intendants; le produiten était versé dans les caisses royales, où les employés du gouvernement tenaient compte, sous des rubriques particulières, de ce qu'on appelle la propriété de chaque village. Mais il est devenu si long et si difficile d'obtenir, pour les natifs, quelques secours de ces fonds, qu'ils renoncent à en demander. Par une singulière fatalité, ou par un vice inhérent à l'organisation sociale, les priviléges accordés aux Indiens, loin de leur procurer des avantages, ont produit des effets constamment défavorables à cette caste.

C'est entre les mains des Espagnols que se trouvent presque toutes les propriétés et leś richesses. On les divise en blancs nés en Europe, et en descendants d'Européens, nés dans les colonies espagnoles de l'Amérique et dans les îles asiatiques. Les premiers portent le nom de chapeloms, ou de gachupinos; les seconds celui de griollos (créoles). Les natifs des îles Canaries, que l'on désigne sous la dénomination d'Islénos, et qui sont la plupart gérants des plantations, se considèrent comme Européens.

Par un raffinement de vanité, les habitants des colonies ont enrichi leur langue en désignant les nuances les plus fines des couleurs qui naissent de la régénération de la couleur primilive. Le fils d'un blanc, né d'un Européen ou d'un créole, et d'une indigène au teint cuivré, est appelé métis ou mesti 0 . Sa couleur est presque d'un blanc parfait ; sa peau est d'une transparence particulière; le peu de barbe, la petitesse des mains et des pieds, une certaine obliquité des yeux, indiquent (mieux que ne le pourrait faire la nature des cheveux) le mélange du sang indien. Si une métis s'allie à un blanc, la seconde génération qui en résulte ne diffère presque plus de la race européenne. Les métis composent vraisemblablement les sept huitièmes de la totalité des castes. Ils sont réputés d'un caraclère plus doux que les mulâtres ou mulatas, fils de blancs et de négresses, qui se distinguent par la vigueur et l'énergie de leur couleur, par la violence de leurs passions, et par une singulière volubilité de langne. Les descendants de nègres et d'In- 
diennes portent, à Mexico, à Lima et mème à la Havane, le nom bizarre de chino, Chinois. Sur la côte de Caracas et dans la Nouvelle-Espagne, on les appelle aussi zambos. Aujourd'hui cette dernière dénomination est principalement restreinte aux descendants d'un nègre et d'une mulâtresse, ou d'un nègre et d'une china. On distingue de ces zambos communs les «ambos-prietos, qui naissent d'un nègre et d'une zamba. Les castes du sang indien ou africain conservent l'odeur qui est propre à la transpiration cutanée de ces deux races primitives. Du mélange d'un blanc avec une mulâtresse provient la caste des quarterons. Lorsqu'une quarteronne épouse un Européen ou un créole, ses enfants portent le nom de quinterons. Une nouvelle alliance avec la race blanche fait tellement perdre le reste de couleur, que l'enfant d'un blanc et d'une quinteronne est aussi blanc que l'Européen natif.

La peau plus ou moins claire, et le plus ou moins de sang européen, décident de la considération dont l'homme doit jouir dans la société, et de l'opinion qu'il a de luimême. La couleur établit même une certaine égalité entre des hommes qui, comme parlout où la civilisation est peu avancée ou dans un mouvement rétrograde, se plaisent à raffiner sur les prérogatives de race et d'origine. Parmi les métis et les mulâtres, il y a béaucoup d'individus qui, par leur couleur, leur physionomie et leur intelligence, pourraient se confondre avec les Espagnols; mais les préjugés les tiennent dans le mépris et l'avilissement. D'un caractère énergique et ardent, ces hommes de couleur vivent dans un état constant d'irritation contre les blancs, et le ressentiment les porte fréquemment à la vengeance. Il arrive souvent que des familles qui sont soupçonnées d'être de sang mêlé demandent à la haute cour de justice qu'on les déclare appartenir aux blancs. On voit ainsi des mulâtres très-basanés qui ont eu l'adresse de se faire blanchir, selon l'expression populaire.

Les étrangers constituent une classe à part qui a une grande influence dans le pays, parce que les riches Mexicains, paresseux par nature, faisant la sieste une partie du jour et consacrant le reste au jeu et à d'autres vices, négligent l'administration de leurs biens et laissent la gestion de leurs affaires aux étrangers.

Les Mecos, les Apaches, les Lipanis, Indiens chasseurs, que les Espagnols embrassent sous la dénomination d'Indios bravos, et dont les hordes, dans leurs courses souvent nocturnes, infestent les frontières de la Nouvelle-Biscaye, de la Sonora et du Nouveau-Mexique, annoncent plus de mobilité d'esprit, plus de force de caractère que les Indiens cultivateurs : quelques peuplades ont même des langues dont le mécanisme paraît prouver une ancienne civilisation. Ils ont beaucoup de difficulté à apprendre nos idiomes européens, tandis qu'ils s'expriment dans le leur avec une grande facilité. Ces mêmes chefs indiens, dont la morne taciturnité étonne l'observateur, tiennent des discours de plusieurs heures, lorsqu'un grand intérêt les excite à rompre leur silence habituel.

Les indigènes sont ou descendants d'anciens plébéiens, ou le reste de quelques grandes familles qui, dédaignant de s'allier aux conquérants espagnols, ont préféré labourer de leurs mains les champs que jadis ils faisaient cultiver par leurs vassaux. Ils se divisent donc en Indiens tributaires et en Indiens caciques, qui, d'après les lois espagnoles, doivent participer aux priviléges de la noblesse de Castille; mais il est difficile de distinguer par leur extérieur, leur habillement ou leurs manières, les nobles des roturiers; ils vont généralement pieds nus, couverts de la tunique mexicaine, d'un tissu grossier et d'un brun noirâtre; ils sont vêtus comme le bas peuple, qui néanmoins leur témoigne beaucoup de respect. Cependant les hommes qui jouissent des droits héréditaires du caciquat, loin de protéger leurs compatriotes, pèsent fortement sur les tributaires. Exerçant la magistrature dans les villages indiens, ce sont eux qui lèvent la 


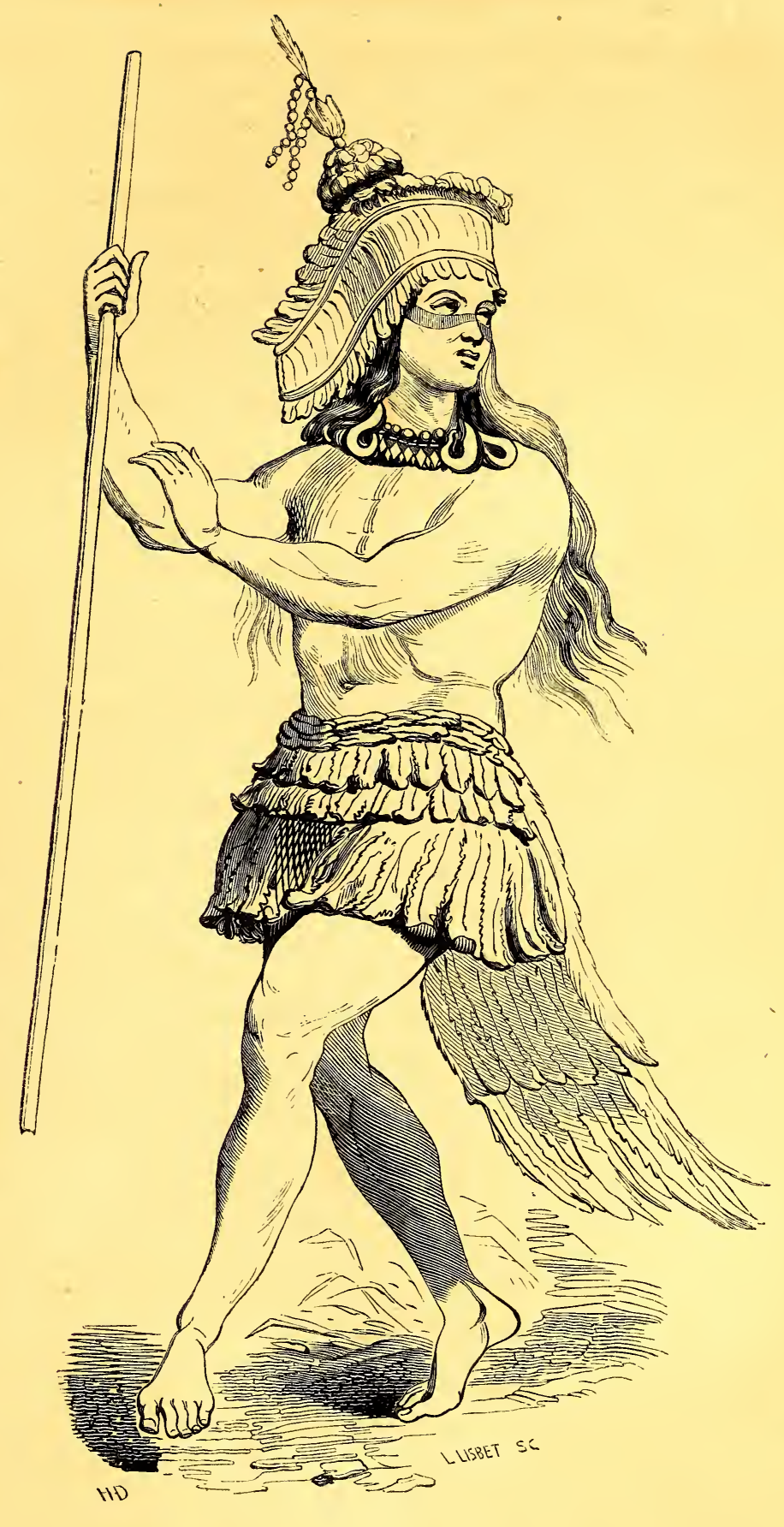

Indien dansant.

(Californie.) 

capitation : non-seulement ils se plaisent à devenir les instruments des vexations des blancs, mais ils se servent aussi de leur pouvoir et de leur autorité pour extorquer de petites sommes à leur profit. La noblesse aztèque offre d'ailleurs la mème grossièreté de mœurs, le mème manque de civilisation, la mème ignorance que le peuple indien. Isolé, abruti, on a vu rarement un de ses membres suivre la carrière de la robe ou de l'épée. On trouve plus d'Indiens qui ont embrassé l'état ecclésiastique, surtout celui de curé.

Les créoles et la plus grande partie des races mixtes n'ont pas adopté ici, comme dans le Pérou, un dialecte indigène, mais se servent de la langue espagnole, tant dans la conversation que dans les écrits. Parmi les dialectes indigènes, la langue aztèque ou mexicaine est la plus répandue; mais les domaines de plusieurs autres langues sont comme enclavés dans le sien. 



\section{TEXAS.}

L'extrémité orientale du Mexique, voisine des États de l’Union américaine, est désignée sous les noms de Fredonia et Texas; ce dernier a toutefois fini par prévaloir. Ce territoire, qui, au temps des vice-rois espagnols, faisait partie de l'intendance de San Luis de Potosi, fut, lors de l'organisation des États-Unis mexicains, annexé au Cohahuila pour former l'État de Cohahuila et T'exas. Depuis 1835, il constitue une république dont nous retracerons plus loin l'origine.

La superficie du Texas est évaluée à 4,900 myriamètres, ou 24,806 lieues géographiques. La population, en 1840 , était de 480,000 habitants.

Le Texas est partagé en trente-deux comtés, qui sont : Jefferson, Jasper, Sabine, San Augustino, Shelby, Harrison, Red River, Fannin, Nacogdoches, Houston, Liberty, Galveston, Harrisbourg, Montgomery, Robertson, Milam, Brazoria, Austin, Fort Bend, Washington, Matagorda, Colorado, Fayette, Bastrop, Travis, Jackson, Victoria, Gonzales, Refugio, Goliad, Béjar ou Bexar, San Patricio.

Deux tentatives de révolution eurent lieu au Texas en 1812 et en 1819 ; elles furent sans succès. Depuis l'érection de la république mexicaine, cette contrée a subi plusieurs changements : en 1824, la colonie de Fredonia y fut établie; on offrait à chaque colon un lot de 640 acres de terre el un lieu d'habitation sur le golfe du Mexique. Cette colonie s'érigea en république fédérative, et la constitution fut copiée sur celle des États-Unis, excepté en ce qui concerne la religion. Un traité d'union et de confédération avait été signé le 21 décembre 1826 entre la nouvelle république et trente-trois tribus indiennes; mais le congrès mexicain déclara le Texas partie inlégrante du Mexique, et le réunit à l'État de Cohahuila. - Il est impossible d'énumérer toutes les vexations que la république fit éprouver aux Texiens; mais le contact d'une soldatesque oisive avec la population des travailleurs devait amener des collisions fréquentes. Il n'était pas jusqu'aux officiers qui ne se livrassent aux actes d'arbitraire et d'insolence dont ne se fait jamais faute la force brutale lorsqu'elle est sûre de l'impunité. Au commencement de 1832, ils allèrent jusqu'à jeter dans les prisons d'Anahuac des commissaires chargés de réclamer contre tant de violences. En recevant la nouvelle de cette arrestation illégale, les Texiens du Rio-Trinidad, transportés de rage, abandonnent leurs sillons, courent aux armes, altaquent la citadelle que veut en vain secourir le colonel Piedras : rien ne saurait résister à la bouillante valeur des colons qui, quoique indisciplinés et inférieurs en nombre, culbutent les Mexicains, entrenı vainqueurs dans Anahuac et délivrent leurs commissaires.

Le fort de Velasco fut pris pendant cette courte expédition, dont la portée fut immense; elle inspira aux colons la confiance dans leur force et dans leurs droits, et les enhardit à réclamer du gouvernement l'autorisation de former dans la confédération mexicaine un État distinct. Fn conséquence, une constitution fut rédigée en assem- 
blée générale, vers la fin de 1832, et Stephen Austin fut chargé de la présenter à l'acceptation du gouvernement central.

Parti de San Felipe, sur le Brazos, où l'assemblée avait eu lieu, le fondateur de la colonie arriva à Mexico vers le milieu de $\mathbf{1 8 3 3}$, et, après de longues conférences que rendait inutiles l'anarchie à laquelle le Mexique était en proie, il reconnut que le gouvernement n'accorderait rien, tant que les Texiens n'appuyeraient pas leurs prétentions par des faits. Il adressa donc à l'ayuntamiento (municipalité) de San Antonio de Bexar une lettre dans laquelle il conseillait à ses conciloyens d'organiser, sans retard, un gouvernement de fait. Mais une partie des membres de la municipalité de Bexar, ancienne ville espagnole, était opposée aux vues d'Austin, et sa lettre fut secrètement envoyée au gouvernement. Il en résulta que, tandis que las de ces luttes, Stephen revenait au milieu des siens, il fut arrêté à plus de 200 lieues de Mexico, et jeté dans les cachols sous la prévention de crime de haute trahison.

Cependant le trésor de l'État de Cohahuila et Texas était épuisé, et le gouvernement, afin de faire face aux dépenses, proposa la vente d'une immense étendue de terres dars le Texas. Les acquéreurs se présentèrent en grand nombre; mais tous étaient Texiens, et le gouvernement refusa de ratifier le traité. Quoique ce refus eût évidemment pour but de mécontenter les Texiens, la législature de Cohahuila, poussée par la pénurie où elle se trouvait, insista et voulut terminer avec les colons du Texas. Aussitôt, SantaAnna, président de la république, donna ordre au général Cos, commandant supérieur des provinces orientales du Mexique, de marcher sur la capitale de l'Étal el d'expulser la législature rebelle : plusieurs membres, et le gouverneur lui-même, furent incarcérés.

L'instant était venu pour les Texiens de conquérir leur indépendance : le 16 aoùt 1835, ils volent aux armes, pendant que Cos passe le Rio Norte, et vient s'enfermer dans la ville de Bexar.

Mais Stephen Austin, après une captivité de dix-huit mois, reparut au milieu de ses compatriotes qu'il remplit de confiance par sa présence et sa résolution calme. Une assemblée générale eut lieu à San Felipe, et, en onze jours, elle régla tout ce qui était indispensable à la défense du pays; on publia une déclaration solennelle qui exposait, en termes fermes et mesurés, les molifs qui engageaient les Texiens à recourir aux armes. Austin fut député aux États-Unis pour solliciter leur appui, et Samuel Houston prit le commandement de l'armée.

Cos était assiégé dans Bexar; mais les Texiens n'étaient point munis du matériel de guerre nécessaire pour prendre une ville d'assaut. Le siége allaiı donc être levé, lorsqu'un de ces hommes énergiques dont les obstacles grandissent le courage, sortit des rangs des patriotes, et promit d'enlever la place si trois cents de ses concitoyens voulaient se dévouer avec lui. L'intrépide Milam tint parole; aux nombreux actes de bravoure qui avaient popularisé son nom, il en ajoutait un qui effaça tous les autres: la ville fut prise; la citadelle même dut capituler, et le général Cos, à la tète de 1,500 Mexicains, défila devant les faibles restes de la petite troupe de Milam, qui avait trouvé la mort au sein mème du triomphe, et qui reçut de ses compagnons le surnom de Léonidas. G'est ainsi que se termina la campagne de 1835 : il ne resta pas un soldat mexicain sur le territoire texien.

L'affront qui venait d'ètre fait aux armes mexicaines fut vivement ressenti par le président Santa-Anna, qui résolut d'en tirer une éclatante vengeance, et se hâta de faire des préparatifs formidables, tandis que, de leur côté, les Texiens se disposaient à une résistance désespérée.

Le 21 février, Santa-Anna entrait en campagne avec trois corps d'armée, et le 1 er du 
mois suivant, une nouvelle assemblée texienne, tenue à Washington sur le Rio Brazos, votait par acclamation l'indépendance du pays.

Soit par excès de confiance, soit insuffisance de moyens, les Texiens n'avaient pas assez garni de troupes la conquête de Milam. Santa-Anna, avec 3,000 hommes, se présenta devant Bexar, dont la garnison, réduite à 240 hommes, se retira dans le fort d'Alamo. Treize jours durant, cette poignée de preux repoussa tous les efforts des Mexicains, et au troisième assaut seulement, après une perte de 1,500 soldats, Santa-Anna put pénétrer dans le fort qui offrait un tableau digne d'admiration et de pitié : tous ses défenseurs avaient cessé de vivre; une femme restait seule pour raconter avec enthousiasme qu'elle avait vu le dernier Texien faire feu sur les assaillants, et tomber criblé de balles, après avoir refusé de se rendre à une armée!!

Cependant, le deuxième corps de troupes mexicaines avait marché sur la ville de Goliad. Les Texiens, commandés par le colonel Famin, étaient en trop petit nombre pour pouvoir résister, et ils se disposaient à la retraite lorsqu'ils furent cernés et forcés d'accepter le combat. Famin, avec 500 hommes, soutint pendant une journée le feu de 1,900 Mexicains; mais, après l'épuisement de leurs munitions, les Texiens déposèrent les armes. Néanmoins, sur l'ordre de Santa-Anna, les 400 Texiens qui avaient capitulé furent enveloppés, égorgés sans défense, et le brave Famin fut passé par les armes.

Tout l'odieux de cette horrible trahison pèse sur Santa-Anna, qui manqua d'ailleurs son but, car au lieu de les frapper de terreur, il remplit les esprits d'une juste indignation, el fit naître dans tous les cœurs une soif de vengeance qui doubla le courage des insurgés.

La campagne s'ouvrait, comme on le voit, sous les plus tristes auspices pour le Texas. Rien ne semblait prêt pour une résistance efficace. L'organisation de l'armée régulière élait fort peu avancée. Le commandant en chef, Houston, n'arriva lui-mème au quarlier général, sur le Guadalupe, que deux ou trois jours avant la chute de l'Alamo, et n'y trouva que trois cents hommes. Aussi, en apprenant ce désastre, ordonna-t-il sagement de se replier sur le Colorado, afin d'y rallier les renforts qui se préparaient sur ses derrières. Le général mexicain Sezma ayant atteint le Colorado le 22 mars, Houston poursuivit son mouvement de retraite jusqu'au Brazos, et continua ainsi jusqu'au milieu d'avril à reculer dans la direction de l'est. Les habitants de San Felipe, que cette relraite laissait à découvert, évacuèrent la ville après y avoir mis le feu. C'est à tort que l'on a reproché au général Houston de n'avoir pas plus tôt tenu tète à l'ennemi. Sur le Colorado et même sur le Brazos, il n'avait pas encore une seule pièce de canon. $\Lambda$ mesure qu'il se repliait en arrière, il concentrait davantage toutes ses forces disponibles, tandis que Santa-Anna laissait toujours en chemin un peu des siennes; et on a lieu de croire qu'en se rapprochant de la frontière des États-Unis, il comptait sur quelques secours, au moins indirects, du général Gaines, qui s'était avancé de son côté jusqu'à Nacogdoches, sur le territoire texien, par ordre du général Jackson, président de la république des États-Unis.

Enfin, le 21 avril, fut livrée, sur les bords du San-Jacinto, la bataille qui décida du sort du Texas. L'armée de Santa-Anna s'élevait à quinze cents hommes effectifs, celle d'Houston à sept cent quatre-vingt-trois, dont soixante-un seulement de cavalerie. La veille, Houston avait fait rompre tous les ponts par lesquels l'ennemi aurait pu se retirer vers le Brazos. Son instinct ne l'avait pas trompé. L'engagement ne fut pas long; les Texiens marchèrent en avant au cri de : Souvenez-vous de l'Alamo! et bientôt Travis et ses braves furent vengés. On tua aux Mexicains six cent trente hommes, dont un officier général et quatre colenels; deux cent quatre-vingts furent blessés, et sept cent trente faits prisonniers. La destruction de ce corps d'armée était donc complète. Celle victoire ne coùta aux Texiens que deux hommes tués et vingt-trois blessés, dont 
six mortellement. Le colonel M. B. Lamar, aujourd'hui président de la république, commandait la cavalerie, et justifia par sa bravoure la confiance des soldats qui l'avaient choisi pour chef.

Santa-Anna ne fut pris que le lendemain par un détachement envoyé à la poursuite du peu de Mexicains qui avaient échappé. On le trouva caché dans de hautes herbes et fort effrayé. Il baisa la main du premier soldat texien qui se présenta, et offrit à ceux qui l'entouraient une fort belle montre, des bijoux et de l'argent; mais ce fut en vain qu'il tenta de les corrompre. Alors il se prit à pleurer. On le rassura et on le conduisit auprès d'Houston, qui dormait au pied d'un arbre, la tète appuyée sur sa selle. Ce fut seulement alors que Santa-Anna se fit connaître. Il lui dit en espagnol : " Je suis Antonio Lopez de Santa-Anna, président de la république mexicaine et général en chef de l'armée d'opérations. " Puis il demanda de l'opium, dont il prit une grande quanlité, et, paraissant se remettre de son trouble, il dit encore au général Houston : "Vous n'êtes pas né pour les choses ordinaires; vous avez vaincu le Napoléon de l'Ouest. „ Après cette bouffée d'orgueil, au moins ridicule dans un tel moment, il demanda quel sort lui était réservé. Houston lui reprocha sa cruauté envers les Texiens, cruauté dont SantaAnna se défendit en invoquant les droits de la guerre. - "Soit quant à l'affaire de l'Alamo, repril Houston; mais le massacre de Fannin et de ses gens? - Il n'y avait pas de capitulation, répliqua le prisonnier; et d'ailleurs je n'ai fait qu'exécuter les ordres da gouvernement mexicain. - Mais c'est vous qui êtes ce gouvernement, lui dit llouston. „Il était difficile de répondre à cela.

Quoi qu'il en fût, Houston le protégea contre l'exaspération des Texiens, et ne voulut pas souiller sa victoire par un meurtre inutile.

Le 24, le général Cos fut pris par un détachement qui poursuivait quelques fuyards.

L'issue de celle guerre assura l'indépendance du Texas. Élu président de la république en septembre 1836, Houston, se conformant au vœu du pays, dépècha au cabinet de Washington un ministre, avec la double mission de réclamer la reconnaissance de l'indépendance du nouvel État, et de proposer son adjonction aux États-Unis de l'Amérique du nord. Le congrès fit droit à la première demande; mais il n'accéda pas à la seconde. Le Texas fut donc érigé en république indépendante.

La France a donné à l'Europe un noble exemple, en même temps qu'elle a fait acte đe bonne politique, en signant, le 25 septembre 1839 , un traité de commerce avec cette république, qui paraît ètre appelée à de hautes destinées. Vers la fin de 1840, l'Angrleterre, la Hollande et la Belgique ont imité la France, et tout fait présumer que le Mexique lui-même sentira bientòt qu'il est de son intérèt de faire oublier ses torts envers le Texas, en s'en faisant un allié, et en y cherchant un débouché pour son commerce.

En travaillant à leur indépendance, les Texiens songeaient si bien à s'incorporer aux Etats-Unis, que leur organisation est entièrement calquée sur celle des diverses parties de l'Union américaine. C'est de là que résulte la division du T'exas en comtés.

Le gouvernement est divisé en trois pouvoirs : le législatif, l'exécutif et le judiciaire. Le premier est exercé par une chambre des représentants et un sénat; le pouvoir exécutif est confié à un magistrat qui prend le titre de président, est élu pour trois ans et n'est point rééligible au terme de sa magistrature; le pouvoir judiciaire repose sur une cour supérieure et des tribunaux secondaires. Les juges, nommés pour quatre ans, peuvent être réélus.

On doit remarquer que la population, qui a décuplé en cinq ans, ne comprend qu'un petit nombre de femmes et d'enfants, Composée de colons hardis el vigoureux, elle peut fournir, au besoin, un effectif de 60,000 combattants.

Les produits des impôts suivront inévitablement la même progression que la popu- 
lation. On doil s'altendre à d'immenses progrès dans un pays qui offre tous les éléments possibles de prospérité. Ainsi, en 1838 , les douanes ont versé au trésor environ $1,400,000$ francs, et en $1840,2,930,000$ francs.

En 1838, on publiait déjà cinq journaux, qui s'imprimaient dans les villes de Brazoria, Houston, Matagorda, Macogdoches, et Velasco.

On évaluait, en 1836, l'effectif de l'armée à 2,500 hommes. La marine du Texas se composait alors d'une corvette, de deux bricks, de deux goëlettes, et de deux bâtiments à vapeur armés.

Les Texiens se livrent à l'élève des chevaux, des moutons, etc. Ils cultivent l'indigo, la cochenille, le tabac et la canne à sucre; celle-ci donne deux récoltes. Enfin, le cotonnier paraît devoir être une source de richesses pour le pays : on a calculé que le territoire du Texas pourrait fournir annuellement $\check{5}, 000,000$ de balles de coton, qui, à 40 dollars la balle ${ }^{\mathrm{x}}$, produirait plus de 1,000,000,000 de francs.

Les sauvages, qui ont été pendant plus d'un siècle la terreur des colons espagnols du Texas, ne sont plus très-nombreux. Ils peuvent encore détruire çà et là quelques fermes, assassiner quelques voyageurs; mais leurs faibles restes ne sauraient inquiéter sérieusement les colons, et se replient sans cesse devant la population blanche, qui envahit leurs derniers domaines. Plusieurs tribus n'existent plus que de nom, et les peaux rouges du Texas, qu'il ne faut pas confondre avec les indigènes du Mexique, disparaissent aussi vite que celles des États-Unis. On voit souvent dans les rues d'Houston de misérables Indiens de la tribu autrefois puissante des Cushattes, qui s'étendait jusqu'à la Louisiane. Ils sont petits, et plutòt bronzés que rougeâtres. L'eau-devie, qu'ils se procurent en échange des produits de leur chasse, les dévore et les abrutit.

Les Lappans ou Lipans sont d'une taille plus élevée que les Cushattes, ils ont la peau plus rouge, le maintien plus noble, la physionomie plus fière. Ils vinrent un jour en députation auprès des Texiens, qui les reçurent avec beaucoup d'égards; ils dìnèrent avec les officiers du gouvernement, qui leur firent un discours contre les Mexicains, lequel les pénétra si bien que plusieurs Indiens qui savaient un peu l'espagnol s'écrièrent avec leurs hôtes : Muerte a los Mejicanos!(mort aux Mexicains). Du reste, on leur offrit en vain du rhum du whiskey et de l'eau-de-vie; ils suivirent presque tous l'exemple du chef Castro, qui ne but que de l'eau et du café; aucun d'eux ne s'enivra.

Les Comancues ont la taille élevée, la peau rouge foncé, les cheveux d'un noir de jais. Quelques-uns, et surtout les chefs, portent la chevelure très-longue et pendante jusqu'au milieu du dos, sous la forme d'une tresse, à laquelle sont attachées, de distance en distance, de belles plaques d'argent de deux à trois pouces de large, et placées les unes au-dessus des autres. Ces tresses sont au nombre de cinq chez les chefs. Presque tous ces naturels ont, au-dessus du coude, un large anneau de cuivre, auquel sont attachées les chevelures des ennemis qu'ils ont tués, et dont quelques-unes offrent les traces d'un sang noir et desséché. Ghez quelques-uns cet anneau est en or grossièrement travaillé. - Leur vètement consiste en une couverture de laine rouge ou de couleur lie de vin; d'autres portent une peau de buffle avec le poil tourné en dedans.

Les femmes sont vêtues d'une espèce de pantalon collant en peau de daim taunée, et d'une veste ronde, également en peau de daim et souvent sans manches. Quelquesunes ont aux doigts des anneaux d'or d'un travail très-grossier, et presque toutes des colliers de verroterie. Il est aisé de voir, dit M.F. Leclerc, que les grains de verre allongés, blancs ou rouges, charment surtout les belles Comanches.

Quant aux enfants, ils vont généralement nus.

${ }^{1}$ Le poids de la balie de coton peut être évalué à 500 livres anglaises environ. 
Pendant le séjour que fit M. Leclerc à San Felipe de Austin, on y annonça l'arrivée d'une centaine d'Indiens comanches, qui allaient aussi faire leur traité de paix à Houston. Ils montaient de petits chevaux sauvages qu'on appelle mustangs, et formaient avec leurs femmes et leurs enfants une grande caravane. C'était un officier texien qui leur servait de guide. La tribu des Comanches est restée puissante; on la redoute encore au Texas, où les traditions espagnoles lui ont fait une trop juste réputation de courage et de férocité. Ces Indiens s'arrêtèrent à la droite et un peu au-dessous de la ville, sur le bord du fleuve. Chacun d'eux rendit la liberté à sa monture et la lança dans la prairie : pour toute précaution, un long lacet de cuir pendant avait été attaché au cou des plus indomptables de ces animaux. Les hommes prirent leur pipe et se mirent à fumer gravement, sans presque jeter un coup d'œil sur la ville, et en observant ce rigoureux silence qui est le trait caractéristique de l'Indien. A peine descendues de cheval, les femmes coururent au bord du fleuve, couper des branches d'arbres qui, plantées en terre, entrelacées et recouvertes de peaux de buffalo (bison), servirent de tentes. Celle du vieux chef fut établie la première à une certaine distance des autres; elle était la plus spacieuse et la mieux construite; deux femmes qui paraissaient appartenir au vieux chef avaient été chargées du soin d'élever cette hutte.

De tous ces Indiens, celui dont l'accoutrement était le plus étrange, c'était certainement le vieux chef. Il avait pour vêtement une étroite ceinture rouge au milieu du corps, un habit bleu à collet rouge, des débris d'épauletles et des boutons de métal, habit analogue à ceux des gardes nationaux ou des soldats d'infanterie française, et un chapeau recouvert de toile cirée, comme ceux de nos postillons. Ce chapeau était celui d'un Mexicain qu'il avait tué peu de temps auparavant, dans une excursion sur les lurds du Rio Grande. Les mœurs des Comanches nous sont peu connues. On sait qu'ils ne sont point cultivateurs, et que, semblables à certains Indiens de l'Amérique du Sud, ils ont appris à dompter le cheval.

"Au premier abord, dit M. Leclerc, on eut beaucoup de peine à s'entendre avec ces sauvages; le jeune officier texien comprenait seul quelques mots de leur langue. Heureusement il se trouva parmi eux un pauvre enfant mexicain d'une douzaine d'années environ, qui put servir d'interprète. Cet enfant avait été enlevé par les Comanches après le massacre de sa famille, et fait esclave; il parlait très-bien leur langue et n'avait pas encore oublié la sienne. J'ai cru remarquer que la langue comanche ne manquait pas de douceur; les mots en sont singulièrement complexes et les sons gutturaux.

》Le vieux chef connaissait le pouvoir de l'eau de feu, car, un jour qu'on lui en offrait, je le vis faire un geste qui indiquait qu'après avoir bu de ce dangereux breuvage, la lète s'appesantissait, et l'on tombait dans un profond sommeil. Les Comanches passèrent quatre jours à San Felipe sans qu'on eût à se plaindre de leur conduite. Le jeune officier texien, leur guide, avait été pris de la fièvre intermittente; mais, grâce au vieux chef, il recouvra promptement la santé. Quelques instances que je fisse, je ne pus obtenir du vieillard yu'il me communiquât son secret. En quoi consistait donc ce traitement héroïque? Le quinquina était-il connu de l'Indien? Cet arbre précieux n'a jamais été rencontré à la Nouvelle-Espagne, et, des régions habitées par les Comanches aux montagnes du Pérou, la distance est trop grande pour qu'on puisse un instant supposer les moindres relations. Peut-être ce vieux chef devait-il ses connaissances médicales à quelques Européens; je serais tenté de le croire, si j'en jugeais par le fait suivant : il fit un jour venir plusieurs enfants indiens et me montra leurs bras, qui portaient des cicatrices vaccinales parfaitement légitimes. Quelle que fùt l'origine d'un pareil bienfait, il est certain que ces sauvages avaient compris et adoplé ce moyen d'échapper au fléau le plus terrible qu'aient à redouter les Indiens. 
- Dix jours plus tard, les Comanches étaient de retour à San Felipe, et les cris sauvages dont ils faisaient retentir la forêt de l'autre côté du Brazos, nous averlissaient de leur approche. Ils attendaient que le batelier leur prêtât le secours de son bac pour traverser le fleuve; mais depuis quelques jours la seconde crue du printemps avait commencé, et les eaux s'étaient élevées très-vite à plus de quarante pieds au-dessus de leur niveau moyen. Le fleuve était couvert de débris et de gros troncs d'arbres, dont quelques-uns portaient encore leurs racines, leurs branches et leur feuillage. Au centre seulement il élait plus libre, le courant entraînant vers le bord celte masse énorme de végétaux. Il y avait donc pour le batelier péril imminent à traverser; mais quelques Indieus, ennuyés d'attendre, se jetèrent dans l'eau et alteignirent l'autre rive sans accident. Sur le soir on put enfin aller chercher tous les autres : notre vieux chef était du nombre; il portait à la main une longue tige de bamousacée, au sommet de laquelle était attaché un drapeau texien ${ }^{x}$.

Le voyageur que nous venons de citer ajoute que les Comanches retournèrent à leurs tentes. La silencieuse gravité du chef avail fait place à une vive expansion. Il ne cessait de s'écrier : Houston! Houston! puis se frappait la poitrine, et montrait les présents qu'il avait reçus du président. Vingt fois il renouvela ce manége, et se fit apporter un grand sac rempli de verroteries, de couvertures el de pièces d'étoffes rouges. Il étail dans un état d'exaltation incroyable et témoignait la joie d'un enfant, en proclamant que Houston et lui étaient deux grands chefs, deux amis.

Cependant, lorsque les sentiments tumultueux, que la vue de tant de richesses avait fait naître, furent apaisés, le caractère de l'Indien reparut. 11 invitait les Texiens à entrer dans sa tente, el leur montrait des balles de plomb, en s'écriant: Polvora! polvora! (de la poudre! de la poudre!) et, avec un geste significatif, il étalait aux yeux des visiteurs de belles peaux de daim et de buffalo parfaitement préparées.

Le drapeau que portait le vieux chef indiquait suffisamment que le traité de paix avait pleinement réussi; mais il ne devait pas être observé longtemps de la part des Comanches. Cette troupe, qu'on venait d'accueillir à San Felipe, volail, quelques jours après, tous les chevaux qu'elle rencontrait dans les environs de Béjar. Trois Texiens, entraînés par la passion des aventures, ou par le désir de gagner de l'argent et d'ouvrir de nouvelles voies au commerce, avaient suivi les Indiens dans leurs sauvages retraites. Ces infortunés ne devaient jamais revoir leur patrie; l'un d'eux avait été assassiné longtemps avant que les sauvages eussent atteint leurs wigwams; quant aux deux autres, on n'en entendit plus parler.

Quelques autres tribus d'Indiens habitent les terres situées entre le San-Antonio et la rivière de la Vaca : ce sont les TAnkoways ou Tarankowais, qui peuvent à peine mettre sous les armes une centaine de guerriers.

On voit aussi quelques peuplades de CHérokis, dont le territoire se trouve aux environs des sources du Natchèz.

1 Frédéric Leclerc, Le Texas et sa révolution. 



\section{ÉTATS-UNIS.}

Le territoire de la république fédérale des États-Unis, depuis que la Louisiane et les Florides y ont été annexées, égale en étendue les plus vastes empires du monde. Séparée du Nouveau-Brunswick et du bas Canada par une ligne conventionnelle, l'AmériqueUnie se voit ensuite bornée, au nord, par une limite naturelle qui suit le fleuve SaintLaurent, à partir d'une ligne tracée au nord du lac Champlain jusqu'au fleuve, et qui, en traversant les grands lacs Ontario, Érie, Huron et le lac Supérieur, la sépare des possessions britanniques du haut Canada.

La limite passe, à l'ouest de ce dernier lac, par les lacs Seiganah et Bois-Blanc (Whitewood), le lac de la Pluie (Rain-Lake), et la partie occidentale du lac des Bois, et de là se dirige directement, à l'ouest, jusqu'à la rivière de Columbia. De là elle descend en ligne droite jusqu'au $42^{\mathrm{e}}$ degré de latitude, retourne ensuite, à l'ouest, jusqu'au $110^{\mathrm{e}}$ méridien, redescend jusqu'au $38^{\mathrm{e}}$ parallèle, se prolonge, à l'ouest, jusqu'au $103^{e}$ degré de longitude, redescend encore jusqu'à la rivière Rouge (Red river), dont elle suit le cours jusqu'au lieu appelé Pecan-point, d'où elle redescend perpendiculairement jusqu'à la rivière de la Sabine, longue d'une centaine de lieues, dont elle suit les sinuosités jusqu'à la mer.

Son territoire présente, de l'est à l'ouest, une longueur de 1,250 lieues au nord et de 270 au sud, et une largeur de 485 lieues sous le 94 e méridien. Sa superficie est évaluée ả 313,000 lieues carrées, dont un quinzième est couvert d'eau. Ses côtes ont un développement de plus de 1,200 lieues, dont 800 sur l'Atlantique et 400 sur le golfe du Mexique.

Cette vaste contrée est partagée en deux parties à peu près égales par le Mississipi ; mais, dans celle à l'est du fleuve, on compte deux millions d'hectares d'eau. En observant encore qu'il n'y a guère d'établissement européen au nord-ouest de la rivière des lllinois, on réduit à moins de 20 millions d'hectares l'espace dans lequel s'agite la civilisation américaine.

La population civilisée, qui surpasse le nombre de 12 millions, se trouve presque lout entière à l'est du Mississipi, et un cinquième de cette population est concentré dans les provinces qui formaient la Nouvelle-Angleterre. C'est de ce foyer primitif, ainsi que des autres Élats situés sur l'océan Atlantique, que les colons se sont répandus vers les contrées de l'intérieur et de l'ouest. Les États-Unis, qui surpassent en étendue le double de la Chine propre, sont plus de onze fois moins peuplés.

Le district du MarNe, le plus septentrional de tous, forme, depuis 1820, un État divisé en dix comtés, renfermant une population de 400,000 habitants. La capitale est Portland, jolie ville de 12,000 à 13,000 âmes, où l'on remarque un observatoire d'où la vue s'étend au loin sur les innombrables îles qui bordent la côte.

Les Indiens Penobscott qui habitent ce pays, vivent paisiblement dans le giron de 
l'Église catholique. ⿷匚⿳丨コ丨 d'autres tribus s'éteignent, leur population va tous les jours en augmentant.

Les habitants de l'État de New-Hampshire sont fameux par la construction des navires. Le principal port est Portsmouti, où l'on construisit l'America, vaisseau de 64 canons, lancé au mois de décembre 1782 , et dont le congrès fit présent au roi Louis XVI.

Le Vermont, qui abonde en pâturages, a des bœufs et des moutons renommés. La population, évaluée à 300,000 âmes, fait un commerce assez considérable avec le Canada; dans la guerre contre les Anglais, en 1814, elle n'a pas démenti la réputation d'intrépidité qu'elle avait méritée dans les guerres de l'indépendance. Cet État a pour chef-lieu la ville de Montpellier.

Le Massachusets peut être placé au nombre des États de second rang; il renferme 600,000 habitants, et, d'après un voyageur récent, plus de 65,000 personnes sont occupées à l'agriculture, 36,000 dans les diverses manufactures de coton, de laine, de toiles, de verreries, de papiers, de savon, dans les fonderies, etc., et 14,000 dans le commerce; le surplus de la population est employé dans les administrations, dans l'instruction publique, ou comme artisans, et il y a bien peu d'oisifs. Aussi l'Européen qui visite cette contrée est-il frappé de l'aisance qui règne dans les familles, résultat de l'activité industrielle.

- Le dimanche, dit M. A. Levasseur, il est impossible de distinguer à la mise, et l'on pourrait même dire aux manières, un artisan de ce que l'on appelle dans la société un gentleman. La multiplicité des écoles et le droit qu'a tout homme de s'occuper des affaires publiques répandent jusque sur les artisans une instruction et une rectitude de jugement qu'on chercherait vainement dans les classes moyennes de France. Boston est la capitale de cet État, et s'honore d'avoir donné le jour au célèbre Franklin. Au. cune cité n'approche de cette ville pour l'élégance et la propreté de ses rues.

Le Massachusets a une milice régulière qui forme une armée de 50,000 fantassins, 2,000 cavaliers et 1,500 artilleurs avec 60 pièces de canon. Parmi les sectes religieuses, celle des congrégationalistes domine; elle adopte les dogmes de Calvin; mais d'après son régime ecclésiastique, chaque congrégation des saints forme une société indépendante, gouvernée par ses propres chefs, et non par des synodes, comme chez les presbytériens.

Fondé par un ministre chassé comme hérétique par les congrégationalistes du Massachusets, l’État de Rnode-IsLand fut peuplé par des baptistes, secte qui adopte les dogmes de Calvin, et dont le régime ecclésiastique est celui des indépendants. Cette république tire son nom de Rhode-Island (l'ile de Rhode), que le sol, le climat et la situation avaient fait regarder comme l'Eden de l'Amérique; mais que la guerre de l'indépendance a assez appauvrie pour que les effets s'en fassent encore ressentir aujourd'hui. La jolie ville de Providence, située sur le continent et qui a souvent 150 bâtiments marchands en mer, est un des deux chefs-lieux de l'État de Rhode-Island.

Ces quatre Élats forment, avec celui de Connecticut, le territoire de la NouvelleAngleterre. Le Conneclicut est, relativement à la superficie, la plus peuplée de ces divisions; il renferme 30,000 habitants, presque tous congrégationalistes. Observateurs très-rigides des devoirs prescrits par leur religion, ils ne permettent pas que les dimanches on joue à aucun jeu chez soi, ni mème que l'on monte à cheval ni en voiture dans l'intérieur des villes. Mais celte espèce de fanatisme est largement compensé par l'institution de leurs écoles et leur hospitalité qui sont dignes d'éloges. Dès 1811, le fonds des écoles s'élevait à 1,201,165 dollars. - Le fermier de ce pays, libre, heureux, s'habille de bons draps fabriqués chez lui. L'état de la culture et celui des routes annoncent partout une civilisation dejjà avancée. 
Le conseil législatif du Connecticut siége alternativement à HArtford el à NewHaven. Nous devons citer aussi Cornwal, célèbre par son école des missions étrangères, dont le but est d'instruire et de convertir à la religion chrétienne les indigènes de l'Amérique et de l'Océanie.

Le mouvement industriel et intellectuel qu'on remarque dans toutes les contrées de la Nouvelle-Angleterre est le résultat d'un fait d'une haute importance qui a présidé à la fondation de ses premières colonies. M. Alexis de Tocqueville s'exprime ainsi à cet égard :

- Les émigrants qui vinrent s'établir sur les rivages de la Nouvelle-Angleterre appartenaient tous aux classes aisées de la mère patrie. Leur réunion sur le sol américain présenta dès l'origine le singulier phénomène d'une société où il ne se trouvait ni grands seigneurs ni peuple, et pour ainsi dire, ni pauvres ni riches. Il y avait, proportion gardée, une plus grande masse de lumières répandues parmi ces hommes que dans le sein d'aucune nation européenne de nos jours. Tous, sans en excepter un seul, avaient reçu une éducation assez avancée, et plusieurs d'entre eux s'étaient fait connaître en Europe par leur talents et leur science. Les autres colonies avaient été fondées par des aventuriers sans famille; les émigrants de la Nouvelle-Angleterre apportaient avec eux d'admirables éléments d'ordre et de moralité; ils se rendaient au désert accompagnés de leurs femmes et de leurs enfants. Mais ce qui les distinguait surtout de tous les autres, était le but même de leur entreprise. Ce n'était point la nécessité qui les foreait d'abandonner leur pays; ils y laissaient une position sociale regreltable et des moyens de vivre assurés. Ils ne passaient point non plus dans le Nouveau-Monde afin d'y améliorer leur situation ou d'y accroître leurs richesses; ils s'arrachaient aux douceurs de la patrie pour obéir à un besoin purement intellectuel; en s'exposant aux nisères inévitables de l'exil, ils voulaient faire triompher une idée.»

Le grand État de New-Yonk ${ }^{x}$ est arrosé par la belle rivière d'Hudson, et la plus grande masse de son territoire se prolonge derrière la Pensylvanie jusques aux lacs Ontario et Érié. En s'avançant au sud, ce pays jouit d'un climat plus modéré que la Nouvelle-Angleterre; mais c'est là que commence le domaine de la fièvre jaune. En 1731, cet État renfermait 50,291 habitants; en 1840 on y en a reconnu $\boldsymbol{\varkappa}, 400,000$.

Le gouvernement fait sa résidence à Albany, qui s'agrandit rapidement, mais qui ne saurait effacer New-York, la plus commerçante et une des plus peuplées des villes de l'Amérique. New-York est située dans l'île de Manhattan; elle est le centre du commerce et de la librairie de l'Únion. On y trouve plusieurs sociétés savantes. Si les anciens quartiers ont des rues étroites et tortueuses, les nouveaux sont composés de rues belles ct larges. Parmi ces dernières on cite Broadway (rue Large), qui traverse la ville sur une longueur de plus d'une lieue, et qui a 80 pieds de large.

Le voyageur qui arrive à New-York doit, en descendant à l'hôtel, faire inscrire son nom sur un livre à ce destiné. Mais, en revanche, on ne connaît pas en Amérique cel esprit tracassier qui, dans toute l'Europe, met sur une mème ligne l'homme qui voyage pour la science et le marchand. Il suffit, pour que vos malles ne soient point ouvertes, que vous déclariez, sur l'honneur, que vous n'avez rien de prohibé.

Les Anglais qui, sur le continent, montrent tant d'arrogance envers les étrangers, ne paraissent pas aimer à entrer en explication personnelle avec les Américains; et si quelque chose les blesse, ils n'osent même pas témoigner hautement leur mauvaise humeur.

Il n'y a qu'un seul hôtel à New-York, le Globe, qui soit établi à l'européenne et oủ

1 Nonvelle-York. 
l'on dine séparément à la carte. L'arrangement si commode, en Europe, de loger à l'hôtel et de manger où bon vous semble, n'existe point en Amérique. On est obligé ici de payer ensemble logement et nourriture à tant par jour; si l'on veut être confortablement, il faut payer deux dollars et demi ${ }^{x}$ par jour. Il est juste de dire qu'on fait jusqu'à quatre repas.

Tout en Amérique se fait méthodiquement et par tout le monde à la fois : dans les auberges, le signal de se réunir est donné par un gong chinois. A cet appel, les hommes se rendent dans la grande salle à manger, tandis que les dames et les personnes dont elles sont accompagnées gagnent une salle particulière. Le déjeuner se compose de thé, de café, de beurre et d'œufs. A trois heures ordinairement, et à deux heures le dimanche, le gong retentit de nouveau, et les voyageurs se précipitent dans la salle à manger. Heureux ceux qui peuvent trouver une place, car il arrive souvent que la salle peut à peine contenir la moitié des convives. Les deux dernières collations ont lieu à sept et à dix heures du soir. Les vins se payent à part et sont à un prix très-élevé.

Vouloir jouir du chez soi dans l'hôtel, en se faisant servir dans son appartement, est une disposition coûteuse ${ }^{2}$ et qui n'a pas de résultats satisfaisants. On se trouve, en effet, dans son propre salon à la merci des domestiques de la maison qui sont tous négligents et sans complaisance, bien qu'ils soient préférables à ceux dont on se sert en ville. On sonnera dix fois pour le même objet, et dix personnes différentes se présenteront à chaque coup de sonnette sans jamais vous apporter ce que vous avez demandé. Cela provient sans doute de ce que ces domestiques n'ont aucune gratification à espérer du voyageur. Ces individus sont presque tous étrangers. Il est extrêmement rare de voir un Américain entrer en service; sa fierté y répugne. Quant aux maîtres, ils ne savent pas traiter leurs domestiques, et cela se comprend assez : servis hier encore par des esclaves, ils le sont aujourd'hui par des hommes qui se croient leurs égaux.

On rencontre à New-York beaucoup de nègres qui, pour l'ordinaire, sont cochers, bateliers, commissionnaires. Ils sont libres, mais également avilis par la loi et par l'opinion publique. Il leur est défendu de contracter mariage avec les blancs, et l'on voit même rarement ces derniers causer avec eux. Ils sont paresseux et mauvais domestiques, mais excellents comme stewards ou garçons de table. Il en est un petit nombre de riches, et ils ont une église à part. Ils mettent une grande pompe dans leurs cérémonies, surtout lors des funérailles.

Le New-Jersey forme une espèce de péninsule qui commence, au nord, par des montagnes abondantes en minerais de fer et de zinc. Il renferme un grand nombre de rivières qui font mouvoir une multitude de moulins et d'usines; on n'y rencontre point de grandes villes; et la population de Trenton, la capitale, n'est que de 5,000 âmes. Parmi les habitants de cetle province, qui se distinguèrent dans les guerres pour la liberté, quelques-uns descendent de ces Hollandais qui avaient compris le Jersey oriental avec le New-York sous la dénomination de Novum-Belgium. Il y a encore des descendants des Suédois qui, établis sur la Delaware, avaient tenté de fonder une Nouvelle-Suède. - Ces deux faibles colonies ont été absorbées dans le grand nombre d'Anglais, principalement quakers qui vinrent chercher la liberté religieuse dans cette contrée.

La Pensylyanie ou Pennsylvanie forme la transition entre les zones chaude et froide

1 Le dollar vaut 5 fr. 50 c.

2 Celui qui veut joindre un parlour (salon) à sa chambre à coucher, doit payer pour cette location 3 dollars. 
des États-Unis, et des constitutions robustes peuvent seules résister aux brusques changements qui naissent de cette position. Les Pensylvaniens se distinguent par leur activité, leur courage et leurs bonnes mœurs. Plus éclairés que ceux du New-York, plus tolérants que ceux de la Nouvelle-Angleterre, les habitants de la Pensylvanie ne sont pas corrompus par l'esprit exclusif du commerce, et dédaignent les préjugés qui, dans les États du sud, accompagnent une classe d'esclaves. La constitution démocratique repose sur de bonnes institutions municipales; la tolérance religieuse n'a de bornes que celles de la morale universelle, et cette conscience de l'homme qui se refuse à l'athéisme. La population est, pour un tiers, composée de quakers et d'Anglais épiscopaux, qui habitent Philadelphie et les comtés de Chester, de Bucks et de Montgomery. - Les Irlandais, en général presbytériens, occupent les contrées de l'ouest et du nord; on les nomme quelquefois Ecossais-Irlandais, parce qu'ils sont pour le plus grand nombre originaires du nord de l'Irlande. - Les Allemands sont au nombre d'environ 150,000 à 200,000 individus, répandus dans les comtés de Lancastre, d'York, de Dauphin et de Northampton, ou sur les premières rampes des montagnes Bleues; ils descendent des Allemands qui vinrent de la Souabe et du Palatinat.

La milice de cet État ne dépasse pas 116,000 hommes, ce qu'il faut attribuer à la doctrine religieuse des quakers, laquelle leur défend de prendre les armes.

La ville principale de cet Élat est Philadelphie, grande place de commerce qui a 200,000 habitants, y compris ceux des faubourgs. Elle fut construite sur les plans de William Penn, fondateur de la province; ses rues principales ont cent pieds de largeur, et cette ville est la première des États-Unis pour la variété, la richesse et la supériorité de ses manufactures.

Parmi les nombreuses institutions publiques de cette ville, nous devons mentionner le Penitentiary, établissement qui a donné lieu à tant de controverses, mais dont le mérite est certain, puisque le détenu en sort corrigé ; il n'y a pas d'exemple que celui qui en est une fois sorti, y ait été ramené pour un crime nouveau.

Cet établissement a pour principe le solitary confinement (reclusion solitaire). Chaque prisonnier, séparé des autres, est seul dans sa cellule, qu'il ne peut quilter que le jour de l'expiration de sa peine, laquelle peut avoir une variation de une à douze années de détention. Jusqu'à cet instant, toute communication lui est interdite, non-seulement avec ses compagnons d'infortune, mais encore avec les étrangers qui visitent cette importante institution, à moins que ces derniers ne soient munis d'une permission spéciale du directeur, ce qui est très-difficile à oblenir. Le prisonnier est donc tout à fait solitaire, et n'a d'autre distraction que celle que lui fournit son travail, et qui seule peut lui faire supporter ce terrible isolement. Il devient lảborieux, forcé par la nécessité, par le désespoir, pour combattre l'ennui, les tourments de sa reclusion. Il résulte de cette nécessité, l'habitude, le besoin du travail, qui devient tel, que, pour infraction à la discipline, il n'est pas d'autre punition que d'en priver les prisonniers, pour un ou plusieurs jours, selon la gravité du fait.

Nous pensons que, pour donner une idée plus précise de ce système, il est bon de donner quelques détails succincts sur la construction et l'organisation intérieure de la prison. G'est ce que nous allons essayer de faire.

Au milieu d'une vaste cour, ceinte d'une très-haute muraille, se trouve le bâtiment, composé d'une rotonde, d'où sept corridors très-longs partent du centre comme autant de rayons. Trois de ces corridors ont un étage supérieur, et les uns et les autres contiennent les cellules des prisonniers, qui y sont rangées symétriquement chacune avec sa porte en fer s'ouvrant du dehors; de sorte qu'un gardien placé au milieu de la salle suffit pour veiller sur tous les corridors du rez-de-chaussée, qu'il parcourt de l'œil en 
quelques secondes. Chaque cellule occupe un espace de huit pieds de large sur douze d'élévation; elle ne regoit le jour que par le haut, au moyen d'une fenêtre très-étroite. La chaleur y est amenée en hiver au moyen de cuyaux en métal, chauffés avec de l'eau chaude; d'autres tuyaux sont tenus propres par de l'eau qu'on y fait passer tous les jours. Un enclos deux fois aussi long que la cellule et entouré d'une haute muraille se trouve joint à chacune des cellules du rez-de-chaussée, afin que le prisonnier puisse y prendre l'air pendant une heure chaque jour. Il sort et rentre à cet effet de sa cellule par une petite trappe placée vis-à-vis de la porte, et qui s'élève et redescend à l'aide d'un mécanisme extérieur. Le prisonnier ne peut pas plus être vu dans cet enclos que dans sa cellule mème, excepté par le gardien placé au sommet de la rotonde pour surveiller les prisonniers, qui doivent tous, à la même heure, passer dans l'enclos où chacun d'eux reste isolé. Les femmes, qui occupent l'étage supérieur, ne pouvant avoir l'avanlage de ce petit enclos, ont par compensation chacune deux cellules.

On introduit la nourriture des prisonniers dans les cellules par une ouverture pratiøuuée dans la porte et fermant à clef. Elle se distribue trois fois par jour : en hiver, à sept heures du matin, à midi et à cinq heures du soir; en été, à six heures, à midi et à sept heures du soir. Le déjeuner se compose d'une boisson faite avec du cacao, appelé coco, et du pain. A midi, ils ont du bouillon, trois quarts de livre de viande et des pommes de terre. Le soir, une bouillie de maïs et de mélasse.

Le nombre des cellules est de cinq cent quatre-vingt-dix, pouvant contenir un nombre égal de prisonniers, qui ne sont surveillés que par douze gardiens sans armes.

Le travail des prisonniers consiste en tisseranderie ou en cordonnerie, et ils y sont instruits, dans les commencements, par les gardiens, qui, du reste, ont la consigne d'éviter, autant que possible, toute conversation avec eux. On fabrique chaque semaine, dans la prison, jusqu'à cinq cents paires de bottes et de souliers. Le revenu que l'on en tire est destiné à couvrir les frais de l'établissement, et les prisonniers n'en recoivent absolument rien, même lors de leur sortie.

Les dimanches et les jours de fète, on ouvre les portes des cellules pendant le service divin, qui se dit avant et après midi. Le prisonnier reste derrière sa porte entr'ouverte, de sorte qu'il peut entendre le prédicateur placé au bout du corridor; mais il ne peut pas plus le voir qu'il n'en est vu. Tout est arrangé de manière à ce que le détenu ne puisse être connu de personne. Aussitôt que la sentence qui le condamne a élé prononcée, on le conduit au Penitentiary dans une voiture fermée de tous côtés. Avant de le faire descendre, on lui couvre la tête d'un mouchoir noir, et deux hommes, le tenant sous les bras, le mènent jusqu'à sa cellule, de sorte qu'on ne peut le reconnaître, tandis qu'il n'a lui-même aucune idée du local où il se trouve. Après avoir subi sa peine, il est reconduit de la même manière, et il quitte la prison sûr de n'avoir été vu que par le gardien, et que personne, excepté lé directeur, ne sait son nom; car il ne connaît pas lui-même ceux des autres prisonniers.

Malgré l'excellence de ce système de reclusion, toutes ces précautions rappelleraient un peu, par leurs formes, celles de l'inquisition, si l'on ne songeait au résultat que l'on s'est proposé et que par ce moyen l'on obtient mieux que par tous ceux employés jusqu'à ce jour.

Selon M. Isidore de Lowenstern, il n'est point, dans l'Union, de ville d'un esprit aussi social que Philadelphie. "S'il n'y a que peu de voyageurs, dit-il, qui aient fait celte remarque, c'est qu'ils avaient négligé de se munir des recommandations nécessaires pour être admis dans la bonne société, et que la facilité avec laquelle les connaissances se font généralement aux États-Unis, leur avait fait regarder cette précaution comme inutile. Mais c'est cet abus même qui a rendu l'admission aux cercles de ce 
que je nommerai l'aristocratie de Philadelphie si difficile; nouvelle preuve de la maxime que les extrêmes se touchent.

On n'est pas dans l'habitude d'inviter au dîner, qui se fait dans la journée; les réunions ont lieu le soir, soit pour prendre le thé, soit pour assister à des soirées qui se terminent par des soupers. Cet usage paraît résulter de ce que la société dont nous parlons se compose d'avocats, d'employés de l'État, de négociants, etc., en un mot, des personnes occupées dans le jour. Il ne reste donc que la soirée, le dimanche étant, ainsi que dans toutes les contrées où domine le rite anglican, consacré aux exercices pieux.

Deux motifs nous engagent à nous arrêter aux mœurs de Philadelphie : l'un, c'est qu'elles donnent l'idée la plus juste de la classe supérieure des États-Unis; le second, c'est que, ainsi que le dit l'écrivain cité plus haut, ces coutumes paraissent être sur leur déclin et qu'on n'en parlera bientôt plus que, comme chez nous, des manières du bon vieux temps. On voit en toutes choses percer le désir d'imiter les façons et le luxe européens. Les distinctions de rang ont, en Amérique, leurs partisans aussi zélés que dans l'ancien monde; seulement cette tendance ne peut être ostensible. Déjà les négociants et les gens d'affaires ont soin de séparer leurs demeures de leurs bureaux : les comptoirs, les magasins ont leur place assignée près de la rivière; leur habitation en est éloignée autant que possible.

L'idée que la fortune et la position sociale ne leur constituent aucune prérogative, est insupportable aux femmes, qui émettent leurs opinions antirépublicaines avec une franchise au moins égale à la dissimulation de leurs maris. Les dames déploient donc toute leur adresse, toute leur sollicitude pour établir entre elles et les classes inférieures une ligne de démarcation; el tandis que le mari, quelque dignité qu'il occupe, surtout s'il est dans la magistrature, devra distribuer des poignées de mains à tout savetier, la femme évitera soigneusement toute personne dont la condition ne lui paraîtra pas égaler la sienne.

Comme conséquence de cette distinction, on remarque dans les soirées de Philadelphie une société composée en grande partie de personnes bien élevées, et la différence de leurs manières avec les nôtres ne saurait ètre altribuée à un défaut de sentiment des convenances; elle résulte plutôt de causes locales, de la diversité des mœurs et coutumes de chaque pays.

L'étranger est frappé tout d'abord du respect, de la déférence dont on entoure les femmes, de la place qu'elles occupent dans la société américaine. Afin de masquer son insouciance pour le charme de leur présence, l'Anglais prodigue aux dames une sorte de considération; mais il n'en est pas de même chez les Américains : leurs témoignages de soumission illimitée sont réels; et si les femmes n'ont pas, au Nouveau-Monde, des adorateurs chevaleresques, elles ont assurément des serviteurs très-humbles.

Nous empruntons le passage suivant à M. Isidore de Lowenst'ern :

"Ladies..., à ce mot magique qui annonce leur approche, comme celle de souverains, tout homme se lève, soit à table, soit au spectacle, avec les signes du plus profond respect. En tout lieu on doit leur céder les premières et les meilleures places, devoir désolant, mais impérieux pour ce pauvre Américain, si heureux quand il a une fois réussi à placer son corps et ses jambes dans le repos le plus complet. All for Ladies (lout pour les dames)! s'écriait un vieil Américain, ivre et en lambeaux, faisant le Ganymède d'une vieille sorcière à laquelle il offrait un verre de gin. »

On retrouve les prérogatives des femmes aussi bien dans les transactions civiles que dans les rapports sociaux; en revanche, ces dames sont assujelties à une contrainte qui nulle part n'est poussée aussi loin : chaque personne se constituant gardienne de 
la vertu de l'autre, toutes doivent veiller sur leur conduite, au moins en apparence, avec un soin rigoureux.

La beauté des dames est remarquable; rarement en d'autres endroits on voit autant de belles figures réunies. Aux charmes d'un joli visage, elles joignent encore l'esprit et l'amabilité. Malheureusement tous ces avantages sont perdus pour la société; car la contrainte qui leur est imposée les oblige à paraître froides et guindées, à dérober, sous le voile d'une indifférence glaciale, le plus admirable attrait de leur sexe, les grâces. L'enjouement en société exposerait, sous un régime puritain, à la perte de la réputation, et les Américains pensent que l'aristocralisme est incompatible avec des manières vives et pleines d'aisance : aux prétentions des classes inférieures, ils ne savent opposer d'autre barrière qu'une roideur qui, pour être ici de bon goût, serail fort ridicule chez nous.

- Je m'entretenais un soir dans un cercle avec une dame, dit M. de Lowenstern : sa conversation était libre, aisée, engageante sans pruderie ni affectation, et elle y mettait l'abandon, mais la réserve de la bonne compagnie du continent de l'Europe, où elle avait passé plusieurs années. - Quelle femme aimable! dis-je en m'adressant à mon voisin après l'avoir quillée !- Oui, fut sa réponse; mais..., enfin..., l'on dit..., l'on croit..., il paraît... - Qui donc, après cela, voudrait être aimable dans un tel pays? La coutume usitée en Angleterre, mais observée ici avec encore plus de rigueur, de nc pouvoir adresser en sociélé la parole à aucune dame ou demoiselle qu'on ne lui ait été présenté dans toutes les formes, est des plus gênantes. Et mème, après avoir été présenté en règle, l'étranger n'ose encore, cette première fois, s'entretenir avec la dame que peu de moments; il est toujours observé, et une conversation soutenue entraînerait de suite des chuchotements. Plus une dame est belle et aimable, et plus elle est en butte aux observations, ce qui ôte tout le charme de leur société et les rend froides, ou plutôt embarrassées.

"En Europe, si l'on est présenté à une dame ou placé près d'elle, dans toute réunion où le ton de la maison est une garantie que l'on n'y rencontrera que des personnes convenables, c'est elle qui fera les frais de la conversation, qui mettra l'étranger à son aise. Combien de questions générales la dame ne peut-elle pas lui adresser, sur sou arrivée, le séjour qu'il vent faire, et tant d'autres qui sont également sans conséquences; tandis que l'étranger ne peut se borner qu'à des réponses, de crainte d’imiter ce jeune imbécile qui, sur la recommandation de son père de demander à tout le monde des nouvelles de leurs enfants, fit cette question à certain abbé! Mais ce n'est pas ici qu'un étranger pourra trouver cette facilité; la dame restera roide, et, quelques moyens qu'elle possède, muette comme une statue, attendant que l'étranger entre en matière, peut-être même qu'il lui adresse un compliment à l'américaine: malheur à lui s'il ne sait en trouver! Enfin la conversation reste languissante, et souvent c'est au moment où elle commence à s'animer, qu'il faut l'interrompre. »

Les dames sont toujours mises avec le plus grand luxe, mème pour rester chez elles; elles se servent pour leur toilette de la soie et des étoffes les plus coûteuses, même quand leur fortune n'est que médiocre. Celles qui sont riches se font un point d'honneur de suivre les modes parisiennes. Elles étalent une profusion de fleurs; mais elles ne portent pas ordinairement de joyaux.

Dans toute réunion, la simplicité républicaine règne parmi les hommes. Avant d'entrer dans un salon, ils déposent leurs chapeaux, ce qui leur donne une contenance raisonnablement embarrassée. Au reste, ils sont préférables avec leur roideur naturelle, que lorsqu'ils veulent singer le fashionable; car alors ils sont d'un ridicule achevé; et mieux vaut encore les voir faire le télégraphe avec les bras qu'avec le chapeau. 
Un fait digne de remarque dans les mœurs des États-Unis, c'est le libre arbitre laissé aux jeunes perșonnes, lorsqu'il s'agit du choix d'un mari. La coutume ne permet pas aux parents d'intervenir dans cette importante affaire. Il suffit que le prétendant soit accepté par la demoiselle : elle lui apportera sa dot, quelque considérable qu'elle puisse ètre. Cette indépendance a parfois de tristes conséquences. Ainsi, l'on a vu des demoiselles appartenant aux premières familles de l'Union, s'attacher à des aventuriers sans nom, qui souvent même étaient mariés dans leur pays. Dépouillées de leur apport en mariage, et aussitôt abandonnées, ces infortunées n'ont plus qu'à déplorer l'irréparable malheur dans lequel les a jetées leur aveuglement propre et celui de leurs père et mère, ou plutôt la misérable vanité de tous; car ces unions n'ont pour motifs qu'une ridicule ambition qui pousse les Américains à rechercher pour leurs enfants un rang et des titres qui ne se trouvent que parmi les étrangers.

Ceci nous conduit à rapporter une petite aventure arrivée à $M$. de Lowenstern, dans une des villes des États-Unis. Nous laisserons parler le voyageur :

« J'étais, dit-il, en visite chez madame G...., lorsqu'une dame entre daus l'appartement avec beaucoup de pétulance, et, les how do you do, my dear, à peine échangés, elle se met à me toiser de la tête aux pieds et à demander de suite: The gentleman is a stranger? (Monsieur est étranger?) Madame G.... se hâte de présenter M. L......, ami du comte de.... « Donc un Français! s s'écrie la dame (et un comte, pense-t-elle, mais en se gardant bien de le dire tout haut). "Non, un Allemand.-Comment, un Allemand? mais j'en suis charmée! Quelle excellente rencontre! Ma fille étudie l'allemand; elle a eu pour maître le docteur X., de Berlin. Quelle bonne occasion de vous faire parler ensemble! Pouvez-vous venir aujourd'hui? Pouvez-vous venir demain?»

- Madame G...., qui sentait l'inconvenance des manières de son amie, se chargea de répondre pour moi, en disant que j'aurais cet avantage probablement le lendemain. La dame de la prendre au mot, et, s'adressant à moi : "Pouvez-vous venir nous voir demain à midi? voici mon adresse. Où est ma carle? Je ne trouve pas ma carte; mais c'est vraiment désolant! (Elle fouille dans son ridicule....) Ah ! la voici. Mistress Quiss..., ıwenly fifth street. Venez à midi, à midi précis; vous demanderez Mistress Quiss... N'oubliez pas; vous avez mon adresse, Mistress Quiss...., twenty fifth streel. "Puis, s'adressant à madame G...., "Quel plaisir! un Allemand; je suis folle de cette nation et de leur langue. Gothe est mon auteur favori.... A propos, comment le prononcez-vous, monsieur? Ah bien! très-bien! vous prononcez tout autrement que le docteur X., etc., etc. »

» Je pris congé de cette dame, assez décontenancé, et je m'en allai avec la précieuse adresse. Le lendemain je fus exact; à midi précis je me rendis à son invitation. On m'attendait, et je fus introduit au premier. Mistress Quiss... me recut avec beaucoup de gràce. "Charmée de vous voir, M. L.... Puis, me présentant à sa fille, qui était assez jolie : Miss Quiss...., voici M. L...., le German genlleman. "Mais la jeune miss n'était pas encore disposée à nous accorder la faveur de sa compagnie; il fallait bien se faire désirer, attendre un peu. Elle continua donc à jaser pendant toute une demiheure avec une dame qui était sur le point de partir, et qui déjà mème tenait la porte pour s'en aller.

„Cependant la maman, tout en jetant sur sa fille des regards courroucés, s'entretenait avec moi, et faisait rouler la conversation sur les distances qui séparent les diverses classes de la société, et sur la nécessité de maintenir ces distinctions. Je ne pus cacher ma surprise d'entendre la bouche d'une républicaine exprimer de pareils sentiments : "Où donc avez-vous jamais rencontré une femme républicaine? " s'empressa-t-elle de me répondre avec un orgueil tout féodal; et elle continua, pour me convaincre entièrement de la pureté de ses sentiments aristocratiques, à se lamenter 
sur les désagréments auxquels une dame de condition (papa élait peut-ètre le petit-fils d'un tailleur) se trouvait exposée en Amérique par la hardiesse du mob, c'est-à-dire de la canaille, affirmant qu'on ne pouvait se préserver de ce contact impur qu'en évitant avec cette classe toute espèce de relation, en se barricadant chez soi pour jouir de son intérieur. Or, par ce mol intérieur, il ne faut pas entendre que madame s'occupe des soins du ménage. En Amérique, c'est le mari qui conduit la maison, qui va le matin au marché faire les emplettes, tandis que madame étudie Schiller ou Gœthe, ou discute la facon ou le prix d'une robe avec un des descendants de ses aïeux resté fidèle au métier.

- Mademoiselle trouva enfin qu'il était temps de ne pas seulement me faire admirer la beauté du revers de sa taille, el, sans laisser à sa mère le temps de continuer son discours, chose au reste qui n'étail pas facile, elle commença à me parler allemand, secondée dans la conversation par une de ses amies qui venait d'arriver, et avec laquelle elle entama une discussion germanique, après avoir croisé avec beaucoup de grâce ses jambes l'une sur l'autre. Nous avions donc tout le temps, maman el moi, de continuer notre discours sur la distinction des classes; mais, voyant qu'elle n'avançail pas vers le but principal qu'elle se proposait dans cette conversation, et qui était d'apprendre si dans mon pays j’appartenais au mob ou à la classe des gens de condition, elle laissa tomber ce lieu commun, et recommença sur le chapitre des langues.

\Mistress Quiss.... \& Je suis toujours heureuse quand j'entends parler allemand (sourire modeste de ma part), et je me flatte d'être une grande amie de votre nation. J'adore les Prussiens. - (Je crois devoir sourire une seconde fois.) Je suis né Autrichien, madame. - Vraiment! Mais c'est égal, vous parlez tous la même langue. — Oui, madame, mais on ne loue pas trop l'idiome de l'Autriche. - Oh! faites-le-nous entendre. Mais parlez donc, miss Quiss.... (Or la langue de la jeune miss n'était pas encore restée une seconde en repos.) - Mais, chère maman, vous voyez bien que nous ne parlons qu'allemand, c'est si drôle; cela nous divertit beaucoup. Madame, s'adressant à moi : - Ma fille parle aussi français. Parlez donc français avec M. L.... Nous parlâmes franģais, puis italien. Je fis compliments sur compliments. Madame Quiss.... devenait de plus en plus charmante. "Mais, monsieur L...., vous parlez donc toutes les langues? " Obéissant à une sotle vanité, je réponds d'un air modeste : « Ah! seulement quelquesunes. - Eh bien, lesquelles? - Telle langue, telle autre, puis celle-ci.... - Mais c'est prodigieux ! Et laquelle de ces langues préférez-vous? - Moi (avec beaucoup de satisfaction), le turc. La demoiselle : "Ah le ture! je voudrais bien entendre parler turc; de grâce, dites-nous-en quelques paroles. „Je pince ma bouche très-gracieusement, puis je commence : "Her dil hassederim ghusell kess aghessi ". Madame s'écrie : "Mais c'est charmant. Qu'est-ce que cela veut dire? Je traduis. La mère et la fille sourient de la manière la plus aimable. Mistress Quiss.... : a C'est très-amusant, et j’espère bien que vous nous ferez le plaisir de venir nous parler ture quelquefois. ¿ La jeune miss ne bouge plus sur sa chaise, el devient attentive. - Mistress Quiss.... \& Comment avez-vous donc fait pour apprendre cette langue? - Madame, j'ai parcouru l'Orient, et c'est dans ce voyage que j'ai appris le turc et quelques mots d'arabe. - Ah! mon Dieu! que de choses intéressantes vous avez dù voir! Je m'aperçois avec satisfaction que j'inspire un intérêt toujours croissant, et je commence à prendre grand plaisir à la conversation. "Que c'est beau d'avoir vu tant de choses, d'en pouvoir entretenir ses amis'! Mais, en vérité, je crois que cela doit vous suffire maintenant. Ne trouveriez-vous donc aucun charme dans les jouissances de la vie domestique? - Il est vrai, madame,

1 J'aime tonte langue parlée par une jolie demoiselle. 
chaque chose a son temps. "Madame Quiss...., continuant sur ce chapitre qui semble l'intéresser vivement : « N'avez-vous donc point de parents, point d'am is dans votre patrie? - J'en ai, madame, mais ils ne me gênent nullement; ma famille a dû se faire à mes nombreuses absences. "Madame Quiss...., avec la curiosité la plus marquée : "Avezvous des parents bien proches? „Puis elle ajoute, comme en badinant: a Mais vous n'êtes point marié? " Et moi, tombant de mon haut, tout déconcerté : "Pardon, madame, je le suis. "Mistress Quiss...., avec un sourire amer : "Vous êtes marié !" (Avec mépris) : « $\mathrm{Ah}$ ! (Avec force) : \& Et où aviez-vous laissé votre femme pendant votre voyage en Turquie? 刃 Je réponds, tout bouleversé : a Mais, madame, elle m'accompagnait. - Vraiment, et.... " (Changeant de ton, avec une amabilité forcée, et les lèvres pincées) : “Vous allez souvent au spectacle? - Quelquefois, mais.... - Votre littérature est excellente..." (Puis, se tournant vers sa fille) : "Que faites-vous donc, mademoiselle? Vous oubliez que vous avez donné rendez-vous à votre modiste. - Il est vrai, chère maman. "Miss Quiss.... et son amie se lèvent, et recommencent à s'entretenir, mais cette fois en bon anglais. Je m'aperçois avec effroi que je suis le sujet d'une conversation satirique; je regarde tour à tour la mère et la fille; enfin, ne comprenant plus rien à ce changement subit, à ce froid glacial pour l'intéressant Allemand, je prends le parti de me lever. Madame Quiss...., sans bouger de son sofa, et d'un signe de tête fait avec toute la grandez̃a americana, c'est-à-dire à la manière d'une pagode chinoise, s'empresse de me congédier. Je me tourne vers mademoiselle, elle me présente de nouveau le revers de la taille.

\Tant de grâces me rendent enfin à moi-mème. Je prends la liberté de regarder fixement madame Quiss...., je souris, et mes yeux semblent lui dire, en parodiant Hamlet :

Oui, mon crime est horrible, abominable, affreux;

Mais est-il donc plus grand que la bonté des dieux?

Mais voilà que je tombe moi-même dans le goût des Amẻricains, qui ne peuvent rien écrire, fût-ce même une dissertation sur l'art de Carême, sans y mêler de la poésie.

"Cependant le signe de tête se répète d'une manière plus impérative, et madame Quiss.... clôt l'entrevue en me disant d'une voix sépulcrale : I hope to see you again '" ce que l'on pourrait traduire, en bon français, par : Va-t'en au diable.... imbécile. 》

Le petit Élat de Delaware, qui a pour capitale Dover ou Douvres, est florissant par son agriculture.

L'État de Maryland est surtout riche en tabacs. Sépàré en deux par la baie de Chesapeake, il a pour capitale la petite ville d'Annapolis, siége du gouvernement.

Le district Fédéral ou de Columbia forme un territoire qui appartient à toute l'Union; c'est la plus petite des divisions politiques des États-Unis : elle ne dépasse pas en superficie 147 kilomètres. Au milieu s'élève la Cité-Fédérale, à laquelle on a donné le nom illustre de WASHington, ville qui depuis 1801 est la résidence du gouvernement central.

Le Capitoie s'élève sur une éminence des plus belles, d'où l'œil découvre toutes les parties de la ville et la vaste étendue des campagnes environnantes. C'est un grand et bel édifice surmonté de trois dômes, et bâti en pierre de taille à gros grains, dont la teinte légèrement jaune n'a rien de désagréable à l'œil. Il renferme deux salles spacieuses destinées aux séances de la chambre des représentants et du sénat, une autre pour les assemblées de la cour suprême des États-Unis, et une troisième pour

S'espère vous revoir, monsieur. 
la bibliothèque nationale. Il fut incendié en 1814 par les Anglais, qui se conduisirent comme des Vandales lorsqu'ils prirent Washington; mais aujourd'hui, il est sorti de ses cendres, plus vaste et plus riche qu'à cette époque. "La chambre des représentants est une magnifique salle de forme circulaire, de quatre-vingt-seize pieds de diamètre et de quarante-huit de hauteur. Quatorze colonnes de marbre soutiennent le dôme, et sont réunies sous la corniche par des festons de damas rouge. La galerie pour le public, élevée de vingt pieds au-dessus du sol de la chambre, règne dans toute l'étendue derrière les colonnes. Au centre est assis le président, du fauteuil duquel sept passages vont rayonner à la circonférence; les membres sont placés sur des siéges disposés en rangées concentriques, faisant face au président. Chaque membre a un fauleuil bien rembourré, et un pupitre muni de tout ce qui est nécessaire pour écrire, au-dessous duquel est un tiroir fermant à clef. " La salle où se réunit le sénat est plus petite, mais de la même forme que celle des représentants : le diamètre de l'hémicycle n'est que de soixante-quinze pieds.

Le territoire compris sous le nom de Virginie s'étend depuis la baie de Chesapeake jusqu'aux rives de l'OHro. Ce pays est partagé en deux parties par les montagnes Bleues, ou les Alleghanys. Celle de l'ouest a de magnifiques points de vue et ressemble à un parc immense; l'autre enrichit les cultivateurs par l'excellent tabac, le froment et le riz qu'elle produit. La première est presque exclusivement habitée par des blancs; la population de la seconde est en grande partie formée d'esclaves noirs; et tandis que le culte presbytérien domine dans les montagnes de l'ouest, le rite anglican règne dans la portion orientale. On rencontre le long des montagnes Bleues une race d'habitants très-forts et très-grands; on voit rarement parmi eux un homme qui ait moins de six pieds de haut.

Il existe entre les riches et les pauvres une distinction touchante qui rend le gouvernement plus aristocratique que celui des autres États; mais le petit nombre d'hommes riches, éclairés et intelligents, qui forment l'oligarchie virginienne, a montré, dans les affaires générales de la confédération, l'esprit le plus opposé à la monarchie; c'est dans ce sens qu'on a désigné la Virginie comme le siége de l'esprit démocratique. Dans cette patrie de Washington et de Jefferson, on néglige les sciences et les lettres. Les gens du bas peuple s'enivrent et se battent avec toute la fureur des sauvages; dans leurs combats, un œil poussé hors de l'orbite, une oreille arrachée à coups de dents, ne comptent pour rien. Les Virginiens riches aiment les courses à cheval, ce qui les a engagés à élever des chevaux excellents. Livrés à des plaisirs champêtres, ils fuient le séjour des villes. Il en résulte que la capitale, Richnond, ne contient pas plus de seize mille âmes.

La population de la Virginie s'accroît lenteinent; les finances paraissent être dans un état satisfaisant; on connaît ici une taxe sur les propriétés, pour le principe de laquelle les autres Anglo-Américains témoignent une telle répugnance qu'on n’a jamais pu l'établir parmi eux.

La Caroline du nord ne possède qu'un bon port de commerce, appelé New-Berin. La plus grande partie du territoire est une forêt à goudron, lequel forme la principale branche d'exploitation; on élève aussi des bêtes à cornes et des porcs dont la viande est exportée aux Antilles. Près de la petite ville de Charlotte, dans la partie méridionale, on exploite des mines d'or importantes et des dépôts d'alluvions aurifères très-riches; cette exploitation occupe 20,000 individus, et produit, année commune, une valeur de 4 à 5 millions de dollars.

En parcourant cet État, on s'aperçoit partout que l'on approche des régions tropicales; la douccur du climat, la couleur des naturels, le nombre de nègres employés 
aux travaux pénibles, enfin la culture du riz, du tabac el du coton, en fournissent des preuves à chaque pas.

Pourvus de talents naturels, mais n'ayant aucune instruction, les Caroliniens du nord vivent dans l'indolence, au sein d'une contrée fertile. On ne leur connaît aucune espèce de religion, et ils sont trop adonnés aux plaisirs sensuels; mais ils sont hospitaliers. Dans les montagnes, les nouveaux colons, d'origine irlandaise ou écossaise, conservent un rigide presbytérianisme; ils ont des mœurs sévères et un grand amour du travail.

La Garoline du sud a pour capitale Columbia, qui est le siége du gouvernement. Le haut pays jouit d'un climat tempéré, tandis que les côtes éprouvent de très-grandes chaleurs.

Ce pays exporte du riz, de l'indigo, du tabac, des peaux, du coton, du bœuf, du porc, de la poix, du goudron, de la térébenthine, de la cire végétale, des bois de construction, des cuirs et des plantes médicinales.

Durant la mauvaise saison, Charleston, ville de 55,000 habitants, est le rendez-vous des riches planteurs; la politesse et l'urbanité de ses habitants en rendent le séjour agréable. Les Charlestonnais, hors de leur commerce, n'ont que de bien médiocres connaissances; en revanche, ils ont une santé excellente; leurs amusements consistent à tirer au blanc, à jouer à la paume à la manière basque, et à voir des courses de chevaux; les dames sont renommées pour la vivacité de leur danse.

La GÉorgie, qui, pour le sol et le climat, ressemble à la Caroline du sud, a des mines d'or qui produisent annuellement plus d'un million de revenu. Le coton, abondant ici, passe pour être d'une qualité supérieure. Miluedgevilue, chef-lieu de cet État, n'a que 2,500 habitants; mais sa fondation ne date que de 1807.

La FlORIDE ne formait qu'un district; mais, au commencement de 1840, elle s'est constituée en État, et a adopté une constitution. Ce pays offre le même climat que le précédent, avec un plus grand nombre de lacs, de marais, de plaines sablonneuses, et de savanes privées d'arbres.

Sous les rapports historique et physique, cette contrée est inséparable des États-Unis.

Fondé en 1818, l'État d'Illinors, tire son nom du peuple ainsi appelé. Ses villes sont peu considérables; et Vandalia, son chef-lieu, n'avait, en 1830 , que 500 habilants; M. d'Orbigny lui en donne 1,500.

Les Sawanees, les Illinois et les Potowatonies, peuplades indigènes de l'Illinois et de l'Indiana, ne sauraient se déterminer à une vie sédentaire et agricole. Dans ces derniers temps, un prophète, qui prétendait avoir vu apparaître la Divinité, a essayé de les réunir en une confédération militaire. Quelques rapports lui donnent le nom de Skenadaryo, et lui attribuent la doctrine politique et morale la plus élevée; les sages de l'antiquité avoueraient ses pures et nobles maximes; mais, selon d'autres relations, où il est nommé Maygouis, ses idées et ses discours ne paraissent être que ceux d'un fanatique allié du gouvernement du Canada, d'un ennemi implacable des États-Unis, qui veut en même temps empêcher ses compatriotes de vendre leurs terres aux Américains, et de les mettre en culture pour leur propre compte. Ce prophète, après avoir livré aux généraux américains des combats opiniâtres, a fini par succomber et est tombé an pouvoir de ses ennemis.

Quoique ces Indiens mènent une vie misérable, leurs idées morales ont pris un certain essor. Une femme sawanee ayant rencontré seul, dans les forêts, un voyageur américain qui cherchait à lui inspirer des sentiments tendres, lui répondit avec dignité : Oulamav, mon époux, est toujours devant mes yeux, et m'empêche d'apercevoir aucun autre homme. 
État démembré de la Virginie, le Kentucky a reçu son nom de la principale rivière qui se jette dans l'Ohio; il est situé en face de ce dernier État, sur la rive gauche dı fleuve. Il a une superficie de 40,000 milles carrés. La capitale est FrancForT, ville de 25,000 habitants.

Ge pays, plus montueux que celui de la rive opposée, serait très-fertile s'il était bien cultivé, le sol en étant partout mélangé de chaux. Les arbres y sont d'une grosseur extraordinaire; les plus communs sont le hêtre, le sycomore et l'érable à sucre.

Dès qu'on a mis le pied dans cetle contrée, la funeste influence de l'esclavage se fait sentir. Au lieu des riants vergers, des vertes prairies, des champs d'orge et de froment cultivés avec intelligence et soigneusement enclos, qui attiraient vos regards sur la rive droite du fleuve, on n'y voil que quelques rares plantations de tabac. Les élégantes maisons de l'Ohio sont remplacées par de grandes chaumières qui ressemblent à celles de la dernière classe du peuple dans le nord de la Pensylvanie. Et derrière ces habilations on aperçoit les misérables huttes des nègres, autour desquelles rampent une foule d'enfants destinés à l'esclavage.

Son climat tempéré, moins exposé que les États voisins aux maladies endémiques, est peu sujet aux variations de l'atmosphère.

La fertilité de celte contrée serait une source inépuisable de richesse pour ses habitants s'ils savaient en tirer parti : le tabac, bien cultivé, y deviendrait un article de commerce important; le blé et l'orge donnent d'abondantes récoltes; les fruits sont délicieux; le coton réussit très-bien dans le midi; mais toutes ces cultures, excepté celle du chanvre, qui fournit le principal article d'exportation à la Nouvelle-Orléans, y sont négligées. L'aspect de ce pays, entrecoupé de vallées et de coteaux, la plupart couverts de forêts natives, est extrèmement pittoresque. Le sol est presque partout mêlé de chaux.

L'État de Kentucky n'a fait, sous aucun rapport, les progrès qu'auraient dû lui assurer la fertilité de son territoire et les avantages de sa situation. La mauvaise réputation de ses habitants en éloigne les paisibles émigrants qui songeraient à s'y établir. La majeure parlie de la population est composée des descendants des anciens colons, que l'on a nommés bachwood, parce qu'ils furent les premiers qui pénétrèrent dans les forêts de l'intérieur du pays. Les Indiens, avec lesquels ils ont été longtemps en guerre, leur ont communiqué la férocité de leur caractère implacable. Un Kentuckois reste, pendant des mois entiers, en embuscade dans les bois pour y attendre l'instant qui doit assurer sa vengeance: le pardon est un sentiment inconnu chez ces hommes féroces, et le sang de leur ennemi peut seul éteindre leur haine.

La population du Kentucky est de 57,000 habitants, y compris 150,000 esclaves : les planteurs y tiennent le premier rang; les négociants, les hommes de loi et les manufacturiers viennent après eux; le clergé et les médecins viennent un degré plus bas; enfin la dernière classe se compose des artisans, des cultivateurs qui n'ont point d'esclaves en propre, et ils ne sont pas mieux traités par leurs compatriotes que ne le sont les nègres.

Le pouvoir de la religion est nul sur l'esprit rebelle des Kentuckois, el toute espèce de culte est l'objet de leurs railleries. Les institutions littéraires et les académies pour l'instruction de la jeunesse n'ont, jusqu'à présent, exercé qu'une influence bien faible sur leurs mœurs.

L'État d'Indrana commence à quelques milles de la ville de Cincinnati. Il est arrosé par le grand Wabash, qui le sépare des Illinois, et par le grand Miami, qui coule à l'ouest. Le lac Michigan le borne au nord, et l'Ohio au midi. Cet État s'étend du 470 degré $50^{\prime}$ au $47^{\mathrm{e}} 10^{\prime}$ de latitude nord, et du $7^{\mathrm{e}} 40^{\kappa}$ au $10^{\mathrm{e}} 47^{\prime}$ de longitude ouest. Il est compris, ainsi que l'Élat de l'Ohio, dans la grande vallée dı Mississipi. Sa situation est moins 
élevée que celle de ce dernier État, et ses points culminants sont les Knoles, on montagnes d'Argent, qui courent au-dessous de Louisville, dans une direction nord-est.

Le climat de l'Indiana est plus chaud que celui de l'Ohio. Le coton et le tabac y sont cultivés pour la consommation du pays. Les vallées sont semées de bouquets de sycomores et de hêtres; près des cataracles on trouve beaucoup d'érables, de noyers et de cotonniers. Les montagnes sont couvertes de sassafras et de bois de campèche. A cause de l'absence de communication, la fertilité de l'Indiana est presque nulle pour le pays. Les rivières qui l'arrosent ne sont navigables sur aucun point, à l'exception toutefois de l'Ohio, qui baigne ses limites méridionales, et cet État ne peut remédier, comme ses voisins, à ce grave inconvénient par des canaux, la rarelé du numéraire s'y faisant sentir plus que dans toutes les autres parties de l'Union.

La population de cet Élat est, en général, moins estimable que celle de l'Ohio. Le sud est le séjour ordinaire des Kentuckois, que leurs dettes ou quelque autre cause du mène genre ont forcés de quitter leur pays; et le nord-ouest est habité par les Franeais émigrants du Canada. Cet État devient ainsi le refuge de vagabonds et d'avenluriers de toute sorte. Ce pays se ressent de leur fàcheuse influence; la plupart des villes, quoique fondées à une époque antérieure à celle de l'Ohio, leur sont inférieures à tous égards. Le caractère léger des habitants se refuse à tout ce qui a un caractère stable et solide. Les habitants de l'Indiana n'ont point de vertus sociales et ne se rendent jamais entre eux aucuns des services les plus ordinaires d'un bon voisinage. Les Américains de l'est, dont les établissements offrent un aspect plus satisfaisant, habitent l'intérieur de l'Élat et les bords du Wabash. Leurs mœurs sont fort douces, et ils vivent dans une union qui fait ressortir les mauvais exemples de leurs voisins. Un grand nombre d'Irlandais et d'Allemands se sont répandus dans les villes, et y exercent les professions de cabaretiers, d'aubergistes, de boulangers et d'épiciers.

La population de l'Indiana s'élève à 215,000 àmes; son admission comme Élat indépendant, dans l'Union, date de 1815 , et sa constitution diffère en beaucoup de points de celle de l'Ohio.

Le chef-lieu de cet Etat est Indianapolis, qui renferme environ 2,000 habitants.

Le costume des habitants du district de Harmony, dans l'Élat d'Indiana, n'a rien de bien caractéristique; c'est un mélange et une mauvaise imitation de toutes les modes del'Angleterre; des bonnets, des chapeaux de paille ou de feutre, des redingotes, des fracs, des manteaux écossais, etc. Les femmes aussi cherchent à imiter les modes des villes; elles portent de grands chapeaux, avec des voiles volant au caprice de la brise, et des manleaux écossais, ce qui forme un contraste fort bizarre au milieu des bois solitaires qu'elles habitent. Le costume d'hiver des hom mes est assez bien imaginé, mais il paraît cependant extraordinaire aux yeux d'un étranger. Ils portent des surtouts faits d'une couverture de laine comme on en met aux chevaux, blanche ou verte, avec quelques raies de couleur dont on profite pour faire le collet, les parements et les basques; quelquefois ces surtouts sont rayés comme la fourrure du zèbre. Par ce moyen, ils se procurent des habits épais de laine avec des ornements bleu foncé, jaunes, verts ou noirs.

Ce district produit principalement du maïs, qui parvient à la hau teur de douze à quinze pieds, et dont les épis sont très-grands et très-lourds. On se sert pour cultiver la terre d'une charrue assez différente de celles que l'on emploie en Europe, et les bœufs y sont attelés à l'aide d'un joug d'une forme toute particulière. Il se compose d'un morceau de bois long, épais, recourbé, qui se passe sur le cou des deux bœufs, et duquel partent deux arcs en bois qui s'attachent autour du cou de l'animal, lequel, par conséquent, ne tire point avec la tète, mais avec le cou et la poitrine. Au lieu de battre le blé, on se sert communément de chevaux que l'on altache deux à deux cl que l'on fait courir dans 
une aire ronde construite au milieu des champs, sur le terrain mème où le froment a été récolté.

Avant 1809, il existait encore dans les forêts du Harmony une race d'indigènes, grands, forts, vêtus d'une espèce de tablier appelé breechcloth, armés de l'arc et de flèches; quelques-uns d'entre eux possédaient de vieux fusils, et ils étaient, en général, excellents archers. Leurs cabanes, construites à l'embouchure du Wabash, étaient faites de gros paquets de roseaux et garnies en dedans de peaux de cerf. Ces indigènes se rasaient la tête, à l'exception d'une mèche de cheveux par derrière, comme les Indiens du bas Missouri et du Mississipi. Ils se peignaient le visage en rouge, et se montraient fort disposés pour les blancs, qu'ils visitaient dans leurs habitations, surtout quand le temps était mauvais. Mais aujourd'hui tous ces Indiens ont disparu de l'État, sans y laisser de traces de leur présence.

Les premiers navigateurs étendirent à loute la contrée au midi des monts Alleghanys le nom de Floridas ou Pâques-Fleuries, donné d'abord au cap sud-est et à la péninsule, que les indigènes appelaient Tegesta. Ce promontoire fut découvert en $\mathbf{1 5 1 2 ,}$ par Ponce de Léon, navigateur espagnol, allant à la recherche d'une miraculeuse fontaine de Jouvence dont l'existence se fondait sur une tradition conservée parmi les Caraïbes des Antilles. Quelques Français s'étant fixés dans ce pays négligé par les autres puissances, qui alors ne cherchaient que des mines d'or, Philippe II, roi d'Espagne, jaloux de la possession exclusive de toute l'Amérique, y envoya une flotte chargée de détruire ce nouvel établissement. Par une barbarie digne de ce temps, les colons qui avaient échappé au massacre furent pendus à des arbres portant cet écriteau : Non pas comme Français, mais comme hérétiques. Dominique de Gourgues, marin gascon, indigné du meurtre de ses compatriotes, vendit ses terres, construisit quelques vaisseaux, s'associa une élite d'aventuriers chevaleresques, cingla vers la Floride, surprit, battit, écrasa les coupables, fit sauter leur fort, et pendit à son tour les prisonniers, a vec cet écriteau : Non pas comme Espagnols, mais comme assassins. Après avoir ainsí vengé l'afrront national, il s'en retourna en Europe, et, réclamé par l'Espagne, il fut heureux que son nom restât dans l'oubli.

La F LOpIDE est naturellement divisée en deux parties : la Floride orientale, qui comprend une péninsule baignée, à l'est, par l'océan Atlantique, et, à l'ouest, par le golfe du Mexique; la Floride occidentale, qui, au nord, longe une partie de ce golfe.

Tallahassee, dont la population était, en 1830, de 2,600 individus, est la capitale de la Floride.

Les CHerokis, grâce aux missionnaires baptistes et moraves, semblent avoir eu la faculté rare de se ployer à la civilisation au lieu de se laisser absorber. Ils ont aujourd'hui des maisons commodes, des fermes, des villages, élèvent de nombreux bestiaux qu'ils vont vendre aux habitants des villes voisines. Plusieurs ont étudié les arts mécaniques, et sont aujourd'hui charpentiers ou forgerons; et, s'il faut en croire les relations des missionnaires moraves, la plupart savent lire, écrire et calculer. Les femmes tissent les étoffes, et fabriquent le beurre et le fromage.

En 1836, le 4 juillet, l'ancien territoire de Mrchigan fut constitué en État, et admis, à ce titre, dans l'Union. Il a pour chef-lieu DÉrnort, petite ville dont les maisons sont en bois. On rencontre dans ce pays des Cimppaways et des OtTawas, peuples que nous décrirons plus loin.

L'État de l'Ono est borné, au nord, par le lac Érie, à l'ouest'par l'État d'Indiana, au sud par le fleuve qui lui donne son nom, et à l'est par la Pensylvanie; il a une ćtendue de 4,000 milles carrés, et se divise en soixante et onze comtés : la population s'élève à 72,000 âmes. Cet Étal forme l'extrémité orientale de la grande vallée du 
Mississipi, qui a les monts Alleghanys à l'est, et les montagnes Rocheuses à l'ouest; cette vallée s'abaisse graduellement en s'approchant du Mississipi, et s'étend à plus de 1,000 milles vers le sud. L'État de l'Ohio tient le milieu entre la montueuse Pensylvanie et le marécageux État de Mississipi. Son climat est tempéré et peu sujet aux variations; le sol en est inépuisable, et quoique beaucoup de parties aient élé cultivées depuis plus de trente ans, sans recevoir d'engrais, il est toujours d'une fertilité élonnante.

En traversant l'État de l'Ohio, il est facile de s'apercevoir que les richesśes n'y sont pas accumulées sur un seul point, et qu'elles se répandent avec égalité dans toutes les parties. Les villes et les villages y sont construits a vec beaucoup plus d'élégance et de goût que dans la Pensylvanie, ou que dans les autres États du nord; les maisons de campagne, les fermes toujours bâties en briques, quelquefois en bois, sont jolies et trèscommodes.

Les routes y sont très-bonnes, et il est rare que les voyageurs trouvent l'occasion de faire entendre leurs plaintes ordinaires sur leur mauvais état, et sur le peu de confortable des auberges. Enfin, tout dans cet État annonce une heureuse médiocrité, fort éloignée de la grande richesse, mais qui repose sur des bases bien plus solides; l'industrie persévérante des cultivateurs et la fertilité du sol.

Les crimes, dans l'État de l'Ohio, sont bien plus rares que dans ceux du nord, dont la population est généralement moins bien composée. Le peuple de cet État est aussi éloigné de la grossièreté et de l'ignorance des Américains de l'est, que de la finesse et de la duplicité des Yankees, ou Américains du nord.

La capitale de cette province est Cincinnati.

Les diverses nuances de la société ne sont pas encore aussi bien prononcées ici que dans les autres parties de l'Union. Cependant elles tendent chaque jour à se faire sentir davantage, et elles se développent tout autant que peut le permettre le combat perpétuel entre la richesse et le luxe, l'ambition et les sciences d'une part, et, de l'autre, l'ignorance et la pauvreté.

Les États de Tennesee et d'Alabaha n'ont rien qui mérite notre attention. On voit dans ce dernier pays beaucoup de Cherokis.

Le Mississipr, érigé en État en 1817, s'étend depuis la rive gauche du Mississipi jusque près de l'Alabama. La ville principale est Natchez.

L'État de la Louisiane comprend aujourd'hui : $1^{\circ}$ le Delta du Mississipi; $2^{\circ}$ les parties de la terre ferme occidentale située entre la rivière des Adayes, nommée Sabina on Mexicana, à l'ouest; le golfe du Mexique au sud, le Mississipi à l'est, et le 33e degré de latitude au nord; $3^{\circ}$ la partie de la Floride occidentale, appelée Féliciana, et occupée par les Américains.

La Louisiane a une étendue d'environ 500 lieues de longueur sur 300 de largeur. Elle est productive en coton, sucre et riz. La population actuelle doit dépasser 300,000 âmes. La capitale est la Nouvelde-Orbéans, qui paraît destinée à devenir l'Alexandrie de cette autre Égypte; celte ville, qui renferme déjà 60,000 habitants, voit chaque jour en accroître le nombre, aussi bien que l'étendue de son commerce, la splendeur et l'élégance de ses nouvelles habitations.

La Nouvelle-Orléans est divisée en deux parties par une rue très-large, nomméc Canal-street, dont l'une forme l'ancienne ville habilée par les Français et les Espagnols, tandis que les Américains se sont établis dans l'autre.

On trouve des noms français, tels que rue des Chartres, rue Saint-Louis, rue Royale, etc., dans la première, et des noms anglais, comme Camp-street, etc., dans l'autre. L'extérieur des maisons présente cette différence : celles du quartier français 
sont construites dans le style de ce pays, et crépies avec de la chaux, tandis que dans les maisons bâties à l'anglaise, les briques restent à découvert. Quant au plan des maisons, les Américains ont suivi la mode française en les construisant grandes, longues et très-hautes, de sorte qu'elles servent d'habitations à plusieurs familles, et que Je rez-de-chaussée est occupé par des magasins et des boutiques; tandis que les petites maisonneltes, dans le nord, ne sont occupées que par une seule famille, selon la coulurne de l'Angleterre.

Cetle dernière disposition est des plus agréables, puisque, tout en jouissant ainsi d'un parfait chez soi et du confortable, on économise pour l'ameublement; car chaque étage ne se composant que de deux chambres, on ne fait que peu de frais pour l'ameublement des étages supérieurs. Tout le luxe et la splendeur se trouvent réunis au rez-de-chaussée cl au premier, comprenant chacun deux pièces, dont l'une sert de salon, et l'autre de salle à manger; le second, où mille objets se trouvent entassés, est réservé pour servir de chambre à coucher et de toilette aux maîtres; les enfants et les domestiques occupent le troisième et les mansardes; la cuisine est reléguée sous terre avec les caves.

La partie de la ville la plus peuplée et la plus belle est celle qui longe le fleuve, les autres quartiers étant presque déserts ou habités par la populace et les hommes de couleur : usage contraire à celui des autres villes des États-Unis, où l'on ne trouve, près des quais, que les bureaux, les magasins des négociants et les habitations des ouvriers, tandis que le monde élégant, ou plutôt l'aristocratie naissante, fuit l'odeur du goudron et les bords de l'eau.

Cette circonstance doit être attribuée à ce que la Nouvelle-Orléans n'est habitée, en grande partie, que par des négociants qui n'y séjournent que pendant l'hiver, les ćtrangers retournant au nord, et les créoles passant l'été à leur campagne ou à leurs plantations.

Tout le monde est commerçant à la Nouvelle-Orléans, de sorte qu'il n'existe point le ville qui, par rapport à sa population, possède un nombre aussi limité d'ouvriers, ce qui a pour conséquence de rendre le prix du travail des plus exorbitants. Les avocats y sont nombreux comme partout en Amérique; les médecins et les apothicaires n'y manquent pas non plus, et ces derniers, pour l'ordinaire, cumulent les deux professions, en y ajoutant encore le commerce de la parfumerie.

L'Américain des États du midi a, de lui-même, l'opinion qu'il est plus civilisé que ses voisins du nord. Cependant, s'il n'en a pas les mœurs cyniques, il ne possède pas non plus ses bonnes qualités. Toute sa supériorité se borne à une éducation superfirielle qu'il acquiert par la lecture; car il n'emploie pas, ainsi que le font ses compatriotes du septentrion, le temps à des travaux manuels; il regarde ceux-ci comme des paysans, tandis que lui-mème joue le ròle de seigneur féodal, et traite comme des serfs les infortunés esclaves qu'il occupe.

Les méridionaux sont plus hospitaliers, surtout lorsqu'ils se trouvent sur les planlaiions; car, outre que c'est là surtout qu'il peut satisfaire sa vanité à peu de frais, l'ennui le pousse naturellement à rechercher la société. L'amour du travail qui caractérise l'Américain du nord, est remplacé, chez celui du midi, par le désir unique de salisfaire ses passions. Ainsi, l'étranger ne trouve que le dégoût, là où il espérait rencontrer les plaisirs innocents, dont il avait senti l'absence parmi les populations puritaines.

Ici, l'on use avec excès des boissons fortes, et non-seulement les gens du peuple, mais des négociants riches et considérés prennent, avant le dîner, jusqu’à douze verres le grog ou de wisky punch.

Tout hôtel américain est pourvu d'une antichambre où l'on sert à boire toutes sortes 
de vins et de liqueurs, et devant lequel ces messieurs passent rarement sans y entrer prendre, debout et à la hâte, leur verre de gin ou de bitters, ainsi que le font chez nous les cochers de fiacre dans les cabarets.

Le bar (comptoir) est, aux États-Unis, le commerce le plus avantageux, le plus productif; aussi l'on en trouve jusque sur les bateaux à vapeur. Mais c'est principalement à la Nouvelle-Orléans que l'entrepreneur peut réaliser de beaux bénéfices; car il a soin d'établir deux fois par jour, de une heure à deux, et de huit à onze heures du soir, un buffet dont les provisions sont offertes gratis aux boarders de la maison. En revanche, les étrangers qui y prennent leur luncheon (second déjeuner) sont traités de manière à compenser largement la prodigalité faite en faveur des habitués.

Quant au peuple, il s'abreuve d'une liqueur plus à sa portée, et nommée tom; elle est composée d'œufs, de sucre, d'eau-de-vie et d'eau chaude. En y mettant assez de ce dernier liquide, cette préparation n'aurait rien de désagréable ; mais on imagine aisément que la dose en est toujours assez minime.

La gloutonnerie est commune aux habitants des deux régions; mais ceux dı sud ont en outre une propension pour la boisson, vice qu'ils ont emprunté aux Anglais dont ils ont encore adopté le vocabulaire de jurements si prohibés par les puritains. L'amour des femmes, du jeu, des récréations bruyantes et sans goùt, telles sont leurs principales passions.

Peut-ètre faut-il attribuer cet esprit violent du midi, ce laisser aller aux passions, dont celles que nous venons de citer plus haut sont encore les plus innocentes, ce déréglement complet de mœurs, cette véhémence dans les actions, à l'esclavage qui. règne dans celle partie des États-Unis, et qui donne à tout un aspect mélancolique et sombre.

Par la grande habitude qu'il a d'assouvir ses passions sur des êtres envers lesquels il exerce le droit du plus fort, l'Américain méridional a pris l'habitude de ce ton impérieux, tracassier, qui ne se plaît que dans des querelles presque toujours sanglantes, et qui repousse toute raison.

Avant l'achèvement de la nouvelle bourse, la vente des esclaves se faisait au café de la Bourse; l'ameublement de ce café n'étant pas très-somptueux, les crieurs publics montaient, à l'heure de la vente, sur des tables, et l'esclave se plaçait au-dessous de lui, debout sur une chaise adossée à la table; les chalands, les connaisseurs el les curieux se plaçaient ensuite en avant en demi-cercle, et la vente commençait.

Il y a une grande variation dans le prix des esclaves, selon le plus ou le moins de vivacilé dans le marché de coton. Ils vont quelquefois de 600 à 1,000 dollars, et mème les bons ouvriers coûtent le double de ce dernier prix.

Le jour de la vente des esclaves est le mercredi ; ceux qui doivent être compris dans une vente particulière sont exposés dans la rue, vis-à-vis du café de la Bourse, de midi à une heure. On voit alors, d'un côté, sept ou huit négresses et mulâtresses, assises sur des bancs, et autant de garçons de l'autre còté. Les femmes sont habillées avec soin, et presque élégamment; elles mettent beaucoup de coquetterie à nouer le foulard qu'elles portent sur la tête. Les hommes sont aussi proprement vêtus. Il s'entend que tout ce luxe n'appartient pas aux pauvres esclaves, et ne passe pås plus à l'acquéreur que le riche harnais avec lequel le maquignon pare son cheval pour le faire valoir, ne devient la propriété de celui qui achète cet animal.

Ce qu'il y a de plus triste dans l'esclavage, à la Nouvelle-Orléans, c'est que cette dégradation continue de génération en génération, et l'individu né d'une mère esclase reste esclave lui-même, quels que soient l'état et la couleur de son père, le fils du planteur blanc étant aussi bien esclave que celui du nègre le plus foncé. Dans les Antilles, le 
descendant de blanc, jusqu'à un certain degré, devenait libre, quand même la mère ne l'était pas; chez les Américains, cet état dure jusqu'à la centième génération.

La liberté nẻ sert pas beaucoup, dans l'Amérique, à ceux qui ont seulement une goutte de sang nègre dans les veines. L'affranchi, ainsi que ses descendants les plus éloignés, sont assujettis à un égal avilissement. Ils sont exclus de lous les droits de citoyen; il leur est interdit de s'allier avec les blancs, et même un contrat passé devant l'église deviendrait nul par la loi. lls n'osent exercer aucun emploi, ni jamais se mêler aux blancs dans aucun lieu public; ainsi, par exemple, ils ont leurs places assignées aux spectacles, et ils ne se hasarderont jamais à en occuper d'autres.

La race connue, à la Nouvelle-Orléans, sous le nom de quarteroons, est celle qui souffre le plus de l'esclavage ou de ces restrictions. Issus, pour l'ordinaire, de planteurs blancs et de griffs, filles de blancs et de mulâtresses, ou de quarteroons même, ils ressemblent, par la blancheur de leur peau, à leurs pères, de sorte qu'un œil exercé peut seul reconnaître leur origine africaine à leurs yeux noirs et vifs, ainsi qu'à la nalure et à l'épaisseur de leurs cheveux.

Malgré la loi qui interdit toute instruction pour les esclaves, il y a des cas où ces filles sont élevées avec soin; quelques-unes mème sont envoyées par leurs pères en Lurope pour y recevoir une éducation brillante, don le plus funeste pour leur triste existence; car il peut se faire que le père, jaloux de ces doubles droits, n'affranchisse pas son enfant, ou ajourne cel acte d'un jour à l'autre, jusqu'à ce que la mort vienne le surprendre, et alors la pauvre victime se trouvera exposée à des humiliations et à des tourments d'autant plus durs qu'elle aura été élevée dans des idées d'indépendance et de liberté.

Il y a quelques femmes quarteroons qui, étant libres comme filles de mères affranchies, ou affranchies elles-mêmes par leurs pères, deviennent héritières de leur fortune. Ce sont ces quarteroons libres qui forment une caste à part. Il y en a qui possèdent des richesses immenses, et bien plus d'éducation que les créoles qui les méprisent. Alors, toute leur fortune et tous leurs avantages ne servent qu'à leur faire sentir plus fortement leur dégradation. Elles emploient tous les moyens imaginables pour se mêler aux blancs, et préfèrent au bonheur de s'allier avec ceux de leur caste, vivre avec ces premiers comme maîtresses.

Avant que la question de l'abolition n'eût été agitée entre le nord et le midi, et n'eût amené ceux-ci au plus haut degré d'irritation, on admettait les quarteroons aux bals de certaines dames blanches; mais depuis, cette faveur, même si minime, leur a été retirée, et les bals se divisent aujourd'hui en bals blancs et bals de couleur. Dans ces derniers bals ne se trouvent que des femmes de couleur et leurs adorateurs blancs, et les Africains en sont rigoureusement exclus par les dames patronesses. Toutes ces dames mettent autant de soin à cacher la couleur provenant du sang maternel qu'à faire ressortir la ressemblance qu'elles tiennent de leur père, et, pour cela, elles s'appliquent sur le visage et la gorge une bonne dose de poudre blanche, qui fait un effet singulier, quand elles sont échauffées par la danse dont elles s'acquittent fort bien et avec beaucoup de grâce.

Il y a encore d'autres bals, outre ceux dont nous venous de faire mention; mais ils sont composés d'une société trop mêlée, quoique de sang blanc, pour que nous en parlions ici avec plus de détails. Les femmes qui fréquentent ces bals viennent la plupart du nord, pour des spéculations qui ne sont pas des moins lucratives dans cette ville où l'on est fort peu difficile sur le choix des divertissements.

Quelque peu distingués que soient ces bals, l'entrée n'en est pas moindre de deux dollars ( 11 francs) par personne. On y exécule des contredanses, des cotillons el des 
valses avec la musique de Strauss. Mais les Américains ont la coutume de valser si lentement, qu'on croirait les voir danser un menuet, et que l'on a tout le temps d'admirer la roideur de leurs mouvements.

A l'entrée de ces bals, on est visité de la tête aux pieds, sur tout le corps et dans toutes les poches, comme par des douaniers, pour s'assurer qu'on ne porte point d'armes cachées, précaution qui peint mieux que des pages entières le caractère violent des habitants de la ville que nous décrivons.

La moindre querelle, le moindre mot, entraîne des disputes sanglantes, souvent même la mort, et c'est ce qui a amené le funeste usage de porter des armes sur soi. On n'est pas seulement exposé, à la Nouvelle-Orléans, aux querelles résultant de la violence des passions, mais à la rencontre d'aventuriers qui font le métier d'assassins.

Il faut attribuer la multiplicité des crimes dans ce pays à l'impunité. La loi n'est sévère que contre l'esclave, ou plutôt elle n'existe pas pour lui. Son maître peut le tuer, et il en sera quitte pour une amende, à laquelle il échappe le plus souvent, puisqu'il faut, pour le convaincre, des témoins blancs; car, sur un fait de cette nature, le témoignage de l'homme de couleur n'est pas reçu. Le criminel n'a pas plus à craindre, à la Nouvelle-Orléans, la désapprobation publique que la poursuite des lois. La police est cependant assez nombreuse; mais elle n'est établie que par rapport aux noirs, pour les surveiller, les punir et les reprendre quand ils s'enfuient. Le principal soin de la police est de s'emparer de tout homme de couleur que l'on trouve dans les rues après le coup de canon qui donne le signal de la retraite, et qui se tire, en été, à neuf heures, et, en hiver, à huit heures du soir. Tout nègre pris ainsi, et qui ne peut légilimer sa sortie ou par un billet de son maître, ou par des papiers qui prouvent qu'il est libre, est de suite conduit au calabozo (nom espagnol donné à la prison), où il est gardé jusqu'à ce que son maître vienne le réclamer, ou qu'il puisse prouver qu'il est libre; dans le cas contraire, il est mis en vente après un certain temps, pour couvrir les frais de détention. Cet usage n'existe pas seulement à la Nouvelle-Orléans, mais dans tous les États où il y a des esclaves.

Au nombre des amusements, il faui encore citer trois théâtres, dont deux sont anglais (Saint-Charles et the American theatre), et le troisième, un théâtre français. Le premier donne des opéras et des divertissements, des ballets, des tragédies, des drames. Les chanteurs en sont assez bons, mais le public ne les goûte point. C'est ce qui arrive généralement en Amérique pour tout ce qui n'est pas entièrement mauvais; le bon goût des Américains est tel qu'il n'y a que les choses détestables qui soient applaudies par eux.

Ledernier de ces théàtres possède un public juge plus compétent quant au goût, mais qui manque d'impartialité. Comme partout ailleurs, les petits-maitres y donnent le ton, ce dont ils s'acquittent avec une pétulance trop lourde pour être gracieuse. Le second, l'American theatre, est pour les farces et d'autres pièces qui attirent la populace. Les pièces qu'on y joue sont aussi exagérées qu'il le faut pour un pareil public.

Quelque facilité qu'aient les dames de la Nouvelle-Orléans de se procurer les modes de Paris, on recomnaît néanmoins dans leur toilette un peu du goût espagnol, surtout dans la coiffure.

Les créoles sont aimables; mais tout respire en elles une sorte de tiédeur, une nonchalance qu'elles n'apportent cependant ni dans l'amour, ni dans la haine. S'il faut en croire certaines personnes qui ont longtemps séjourné à la Nouvelle-Orléans, quelquesunes d'entre elles se livrent par jalousie à des cruautés inouïes envers leurs esclaves.

Les incendies sont fréquents à la Nouvelle-Orléans, et résultent autant de la négligence avec laquelle on garde les cheminées, que de l'insouciance américaine. Le plus 
souvent ils sont dus à la manie des feux d'artifice que tous les habitants, quels que soient leur âge et leur sexe, partagent, et qui forment le principal amusement du dimanche, el se tirent au milieu des rues.

Lorsque le feu a une fois pris, on peut avoir l'assurance qu'il ne sera pas éteint de sitôt. Outre que la cathédrale tarde beaucoup à donner l'alarme, on n'entend ni tambour, ni aucun signal qui puisse rassembler le monde, ce qui au reste devient inutile, puisque les personnes employées aux pompes peuvent seules agir.

En Amérique, les pompes à feu sont très-petites, et traînées par des hommes. Fort belles et d'une élégance finie, elles ne sont ni assez grandes, ni assez fortes pour lancer l'eau en quantité nécessaire et à la hauteur voulue. Elles sont desservies par des compagnies particulières, formées d'hommes de tous les rangs, et qui sont exempts du service militaire et libres d'impositions. Ils se distinguent par des manteaux et des chapeaux de toile cirée rouge ou verte, sur lesquels sont inscrits les nom et numéro de la compagnie à laquelle ils appartiennent. C'est sur ces hommes que repose le soin d'éteindre l'incendie; ils s'attachent à leurs pompes, puis courent de toutes leurs forces, en jetant des cris étourdissants, vers le théâtre du désastre, où ils arrivent si haletants et tellement essoufflés qu'il leur faut de suite du brandy pour se ranimer.

Dans ces occasions, ce qui frappe surtout, c'est le courage et l'audace qu'ils déploient, la témérité avec laquelle ils s'exposent dans des bâtiments déjà croulants; et, d'autre part, l'indifférence, le stoïcisme témoignés par les incendiés qui supportent leur perte sans la moindre émotion. La fermeté du caractère américain entre pour beaucoup dans cctte insensibilité; mais elle résulte plus encore de ce que, presque toujours, les maisons et leur mobilier sont assurés au delà du prix réel.

Nous emprunterons encore quelques lignes à M. J. de Lowenstern, qui fut témoin d'un incendie :

«Au moment où le feu avait le plus d'intensité, dit-il, je rencontrai une de mes con》) naissances qui fumait tranquillement. son cigare : A qui appartient celte maison qui - s'écroule, lui demandai-je?-A moi.-Comment? et vous me le dites avec un tel ") sang-froid? - Elle est assurée. Bonsoir, à demain. „

L'État d'Arkansas n'a rien qui puisse nous arrèter.

La province de Missouri, au nord de la précédente, a pour capitale Jefrerson. L'une de ses villes, SaInT-Louis, doit son importance à sa position sur l'un des plus grands fleuves du monde et à sa faible distance de deux de ses principaux affluents : l'lllinois et le Missouri.

Les Indiens qui habitent les environs de cette ville sont forts, bien faits, d'unc taille au-dessus de la moyenne, musculeux et charnus. Leur physionomie est expressive; ils ont les traits fortement marqués, les pommettes saillantes, les côtés de la mâchoire inféricure larges et anguleux, les yeux noirs, vifs, pleins de feu, et l'angle intérieur un peu rabaissé, surtout dans leur jeunesse, bien moins pourtant que chez les Brésiliens.

Les Sacs et les Renards sont les principaux habitants de ce district. Ils portent les cheveux rasés sur la tête comme ceux de Harmony, ne laissant qu'une petite mèche qu'ils coupent courte comme une brosse, et qui aboutit à une étroite queue tressée, à laquelle ils attachent la coiffure appelée queue de cerf, et qui se compose effectivement d'une touffe de poils de la queue du cerf de Virginie; ces poils sont blancs, mêlés de quelques noirs, mais la partie blanche est teinte en rouge avec du cinabre. Les naturels ont donné à cette singulière coiffure le nom de katenikunn. C'est à l'aide de ficelles et de quelques chevilles de bois que cet ornement s'attache d'une manière ingénieuse à la touffe de cheveux du derrière de la tête, tandis qu'au milieu, et caché parmi les cheveux, on place un petit bâton en bois ou en os taillé, au bout duquel est adapté un 


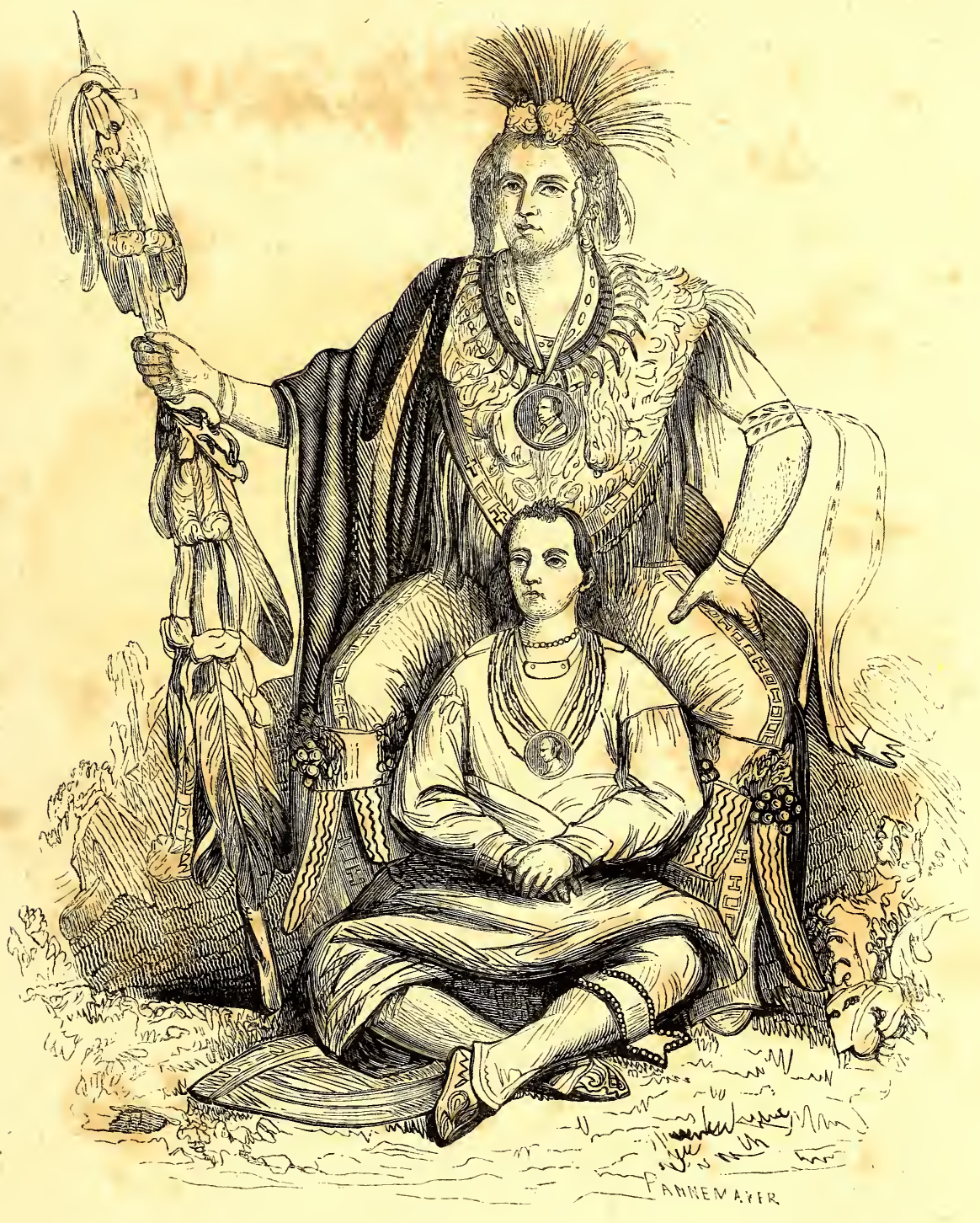

CHEF DES RENARDS

(Aniérique.) 


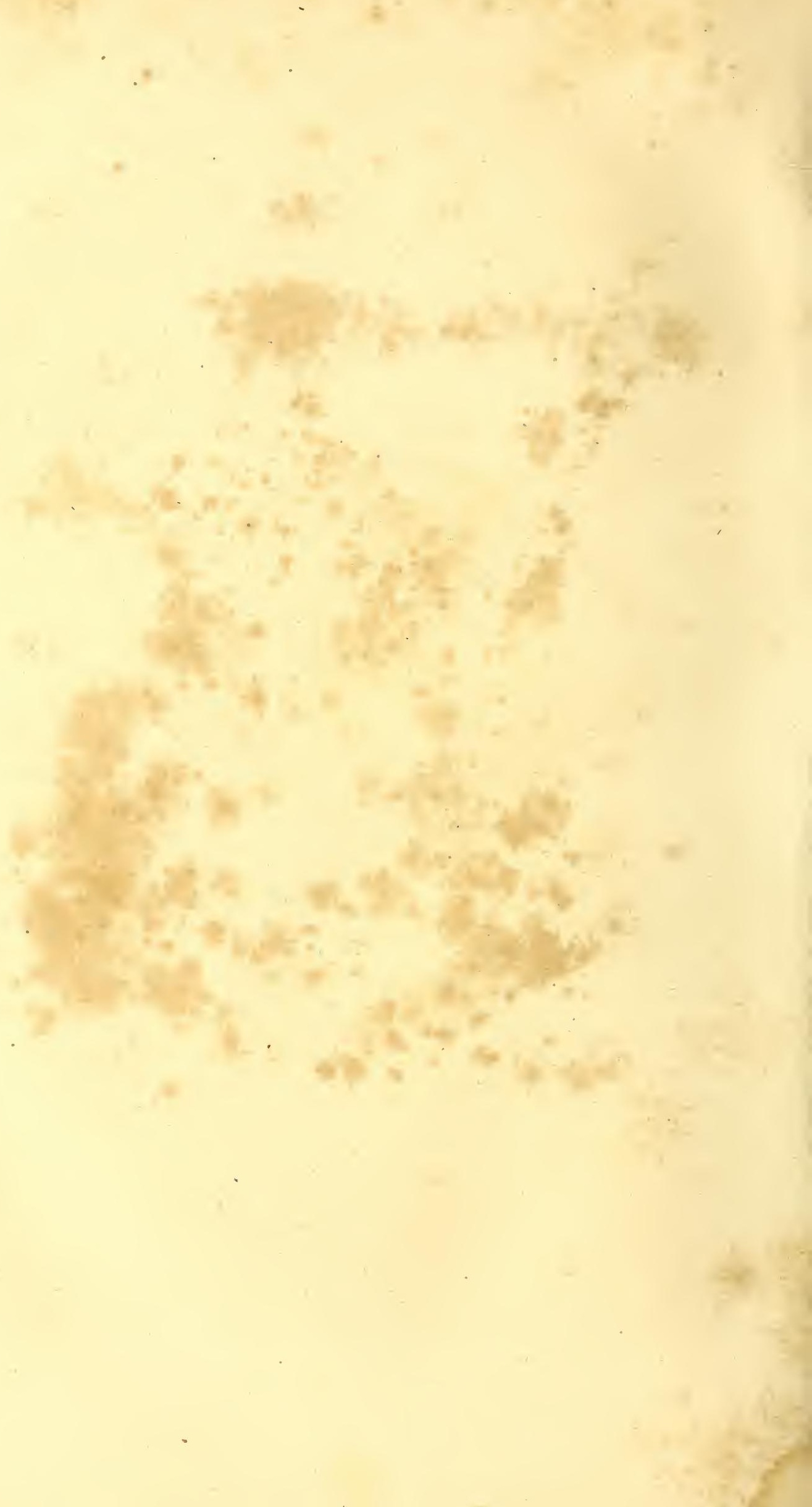


petit étui en os, dans lequel est fixée une grande plume d'aigle qui s'avance horizontalement par derrière. Cette plume est aussi souvent teinte en rouge avec le cinabre; elle est la marque distinctive d'un vaillant guerrier; celui qui se distingue en outre comme grand voleur de chevaux, acte fort hérö̈que aux yeux des naturels, ajoute encore au bout de cette plume une sonnette de serpent. La queue du cerf tout entière, quand on ne la porte pas, se roule, au moyen de lanières de cuir, dans la forme d'un gros navet, et reste ainsi renfermée, afin que les poils se conservent lisses et dans leur position naturelle. Ces Américains du nord s'arrachent avec soin les sourcils, la barbe et les poils de toutes les autres parties du corps; ils se servent pour cette opération d'un fil de fer terminé en spirale, entre les tours duquel on saisit les poils. Ils ont aussi une manière fort originale de parer leurs oreilles. Au bord extérieur et postérieur, ils percent trois grands trous, l'un au-dessus de l'autre, et ils y suspendent des cordons, de petits cylindres, en forme de glands blancs et bleus, taillés de la coquille nommée venus mercenaria, et auxquels ils donnent le nom de wampum. Quelques hommes se découpent tout le bord postérieur de l'oreille, en sorte qu'il ne tient plus que par le haut et par le bas, et l'ornent du cordon de wampum et d'anneaux de métal. Ils portent aussi autour du cou des cordons de ces morceaux de coquillage blancs et bleus.

Les femmes sont petites et trapues; elles ont, en général, la tête ronde et grosse, le visage large, plat et arrondi. Elles partagent au milieu de la tête leurs cheveux qu'elles laissent croître naturellement, et les nouent par derrière en une espèce de queue grosse et courte, qu'elles entourent d'étoffe ou de rubans verts et rouges. Quelques vieillards portent les cheveux non rasés, mais ils sont en très-petit nombre. Les deux sexes ont le visage plus ou moins peint en rouge; chez les Sacs, les figures qu'ils s'y peignent sont rouges, chez les Renards, rouge et jaune, ou bien blanc, rouge et noir. Du reste, la manière de disposer des couleurs dépend de la volonté ou du caprice de l'individu. La plupart d'entre eux ont le tour des yeux et des oreilles rouge, et des raies de la mème couleur descendent le long des joues, tandis que les autres parties du visage conservent leur couleur naturelle; ils se servent pour se teindre ainsi du cinabre. Chez les Indiens renards, la tête tout entière est rouge sans exception, avec une bande jaune ou blanche sur le front; la bouche et le menton sont peints avec la forme d'une main jaune, ou bien tout à fait noirs. Plusieurs de ces Indiens portent des chemises de calicot de couleur, et presque tous se couvrent de culottes de peaux indiennes appelées leggings par les Anglais. Ces culottes, séparées pour chaque jambe, retombent jusqu'aux souliers, et sont ornées de franges de cuir par le bas; chacune des deux s'attache au haut de la ceinture avec une courroie. L'espace qui reste libre par devant et par derrière, entre les deux culottes, est couvert par une étoffe de laine qui est ordinairement rayée de bleu et de blanc, el que l'on passe entre les jambes, puis par devant el par derrière sous la ceinture, par-dessus laquelle une partie vient encore retomber. La ceinture et les genouillères sont ornées élégamment de perles de verre, et, dans la première, on voit, dans un fourreau orné de la même façon, un couteau long, large et fort tranchant, dont ils se servent principalement pour scalper leurs ennemis et pour dépecer le gibier. Leurs souliers ou mocassins sont de peau de daim préparée et adoucie, et rabattus avec leur rebord au-dessus de la cheville; beaucoup de ces Indiens les portent unis et sans aucun ornement. Quelques-uns se parent encore les?genoux de peaux de cygne avec le duvet, et plus souvent encore de peaux de putois fortement marquées de blanc, et dont la queue poilue retombe jusqu'à terre ou au moins jusqu'à la cheville. D'autres portent des colliers et des bracelets de cuivre. Les hommes ne se montrent jamais sans armes; ils portent des haches d'armes fabriquées par les blancs, qui contiennent par derrière le godet de la pipe, et dont le manche creusé sert de 
tuyau à cette même pipe; ils donnent à cette arme, qui est en même temps un ustensile domestique, le nom de tomahawk; d'autres se servent de la massue ordinaire des Indiens; c'est un morceau de bois étroit, un peu aplati, dont la partie supérieure est recourbée en arrière, et dans l'angle saillant duquel est adaptèe une plaque d'acier à deux tranchants et pointue par devant; ils ont encore des lances formées d'une longue lame d'épée attachée à une perche recouverte de drap rouge et ornée d'une grande quantité de plumes noires de corbeau ou d'aigle, suspendues par touffes ou par longues rangées. L'arc est aussi compté au nombre de lenrs armes offensives. L'Indien ne se sépare jamais de son atlirail de guerre; il le porte continuellement avec lui. Les femmes, comme les Brésiliennes, portent leurs paquets sur le dos suspendus à des courroies passées autour du front. Elles portent aussi avec elles leurs enfants couchés dans des berceaux fort commodes.

La langue de ces peuples n'a rien de barbare; elle renferme quelques sons gutturaux et nasaux; du reste, les sons se prononcent souvent d'une manière indistincte, ce qui les rend fort difficiles à transcrire. En général, toutes les langues de l'Amérique septentrionale sont plus difficiles à prononcer pour les Français et les Anglais que pour les Allemands, les sons gutturaux y étant très-communs. Quand on s'approche d'eux avec franchise et qu'on leur adresse la parole, les uns répondent d'une manière agréable et amicale; les autres, au contraire, restent froids et paraissent même animés d'intentions hostiles. Ils répètent avec plaisir les mots de leur langue quand ils y sont invilés par les voyageurs, et ne font aucune difficulté de laisser faire leur portrail; seulement ils exigent chaque fois un présent.

Les Sioux, nation puissante, sont la terreur des peuplades sauvages, depuis le pays des Indiens Serpents et la rivière du Corbeau, au nord, jusqu'au confluent du Missouri et du Mississipi.

Ils sont divisés en plusieurs tribus :

Les Mrnoa-Kantongs s'étendent de la prairie du Chien à la prairie des Français, et sont subdivisés en quatre tribus qui obéissent à différents chefs. Ils passent pour les plus braves de tous les Sioux, et sont beaucoup plus civilisés que les autres; eux seuls font usage de canots. Ils construisent des cabanes de troncs d'arbres, et s'adonnent à la culture de la terre; mais quoiqu'ils récoltent un peu de maïs et de fèves, l'avoine sauvage, que la nature fournit à presque tout le nord-ouest de ce continent, leur sert principalement en guise de pain. Cetle bande est généralement pourvue d'armes à feu.

La bande des Waspetongs, ou " gens de feuilles, „erre dans le pays compris entre la prairie des Français et la rivière Saint-Pierre.

Les Sassitongs, divisés en deux tribus, chassent sur le Mississipi depuis la rivière Saint-Pierre jusqu'à celle du Corbeau.

La bande vagabonde des Yanetongs du nord et du sud maintient son indépenlance dans les vastes. solitudes qui s'étendent entre la rivière Rouge et le Missouri; elle s'y confond en quelque sorte avec celle des Trtons, également divisée en branche du nord et du sud, et dispersée sur les deux rives du Missouri, depuis la rivière du Chien jusqu'au pays des Mahas et des Meunitarris. Le bison fournit à ces deux bandes la nourriture, le.vètement et l'habitation, ainsi que les selles et les brides de leurs chevaux, dont elles possèdent des troupeaux innombrables.

Les Waschpecontes forment la plus petite bande et font la chasse vers les sources de la rivière des Moines. Elle fournit aux Yanetongs du nord el aux Titons le peu de fer dont ils ont besoin; du reste, ils paraissent être les plus indolents et les plus stupides de la nation.

La guerre est la passion dominante des Sioux, qui sont les plus belliqueux et les plus 



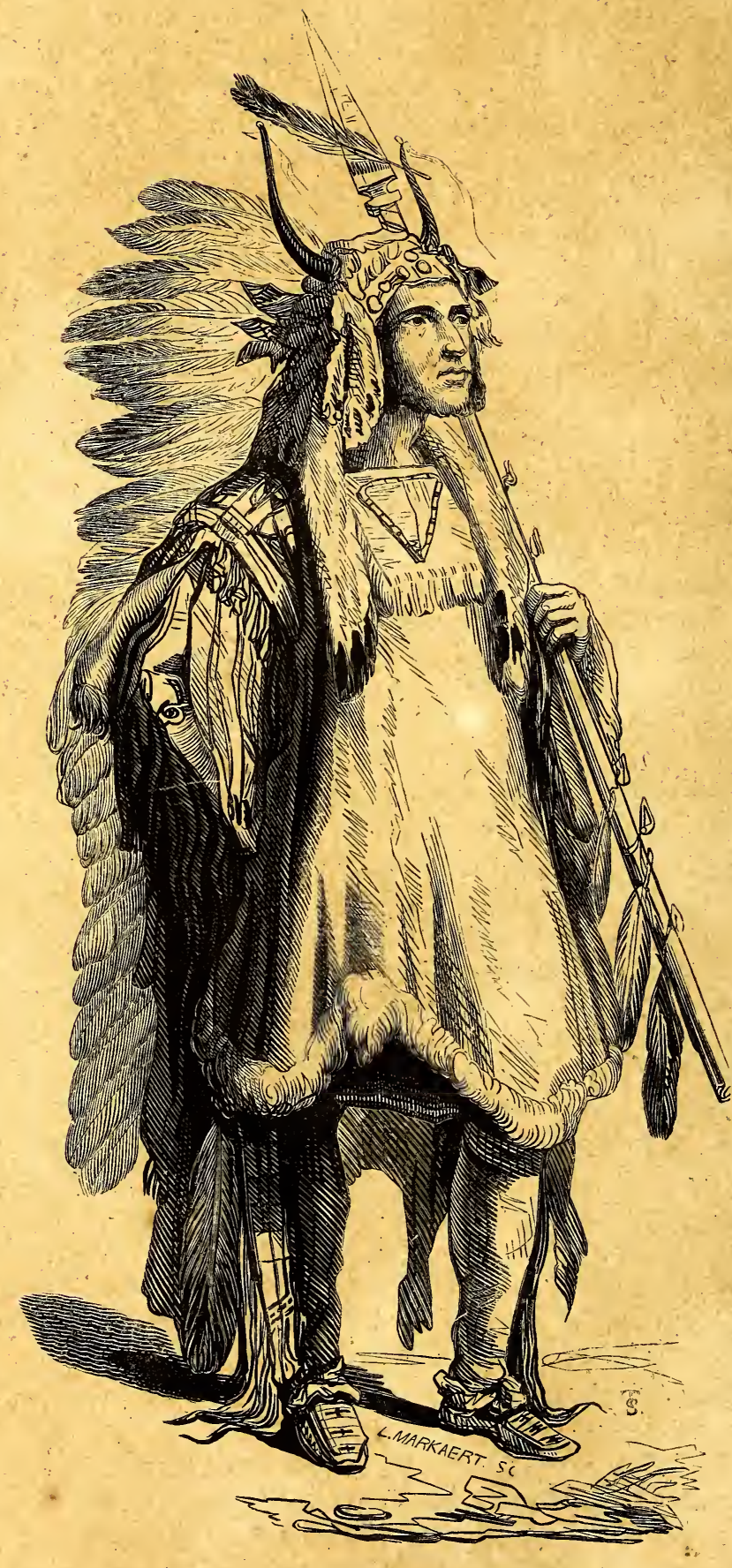

$\therefore$ CHEF MANDAN.

(Amérique.) 
indépendants des Indiens établis sur le territoire de l'Union. Lorsqu'ils craignent une attaque subite de l'ennemi, ils font des retranchements en terre, derrière lesquels leurs femmes et leurs enfants se garantissent contre les balles et les flèches. Quoi qu'il en soit, les marchands peuvent voyager en sûreté parmi eux, en se gardant toutefois de blesser le point d'honneur chez ces hommes.

Leurs pommelles saillantes et l'ensemble de leurs traits; leurs mœurs et leurs traditions, confirmées par le témoignage des nations voisines; leur prononciation gutturale; lout enfin fait supposer qu'ils ont émigré de la partie nord-ouest de l'Amérique. De même que les Indiens du Mexique, ils écrivent en hiéroglyphes.

Pendant deux siècles les Sioux furent en guerre avec les Chippaways dont nous avons parlé plus haut. Ce fut M. Pike qui, en 1805 , les réconcilia.

Lors d'une conférence qu'eurent avec eux les voyageurs Lewis et Clarke, le grand chef des Indiens sioux prononça le discours suivant:

"Je vois devant moi les deux fils de mon grand-père (c'est ainsi qu'ils nomment le président); vous me voyez avec le reste de nos chefs el guerriers. Nous sommes bien pauvres; nous n'avons ni poudre, ni balles, ni couteaux, et nos femmes el nos enfants n'ont pas de vètements. Je souhaile que mes frères, puisqu'ils m’ont donné un drapeau el une médaille, donnent aussi quelque chose d'utile à ce pauvre peuple. Je réunirai les chefs des Pawnas et des Mahas, el je ferai la paix entre eux; il vaut mieux que ce soit moi qui la fasse que les fils de mon grand-père, car ils m'écouteront plus facilement. Je suis allé auparavant chez les Anglais, el ils m'ont donné une médaille et quelques habits. ๖

Les Ayonas, moins dépravés, mais aussi moins civilisés que les Sacs et les Renards, avec lesquels ils sont liés, cultivent un peu de maïs et poussent leur chasse jusqu'à l'ouest du Missouri.

Les MÉnomènes ont charmé tous les voyageurs par la beauté de leurs traits. Leur teint est plus clair que celui des autres indigènes; ils ont les yeux grands el pleins d'expression, les dents belles, la stature moyeune et bien proportionnée; la taille convenablement prise. Leur physionomie respire la douceur et une noble indépendance; ils ont l'intelligence vive et des mœurs patriarcales. Comme les Illinois, ils ont pour habitations des, hutles spacieuses, construites avec des natles de jonc.

Les Mandans ou Mandanes formaient autrefois un peuple assez considérable, qui habilait treize villages et même un plus grand nombre. Le nom qu'ils se donnent à cux-mèmes est Nunnanykake (hommes); et quand ils veulent faire connaître plus exactement leur origine, ils nomment le village d'où ils sont sortis, car chacun des villages porte un nom particulier. Ce peuple porte aussi le nom général de Mahna-Herré.

L'ancienne histoire des Mandans est enveloppée dans l'obscurité. Ils prétendent descendre de nations plus orientales et qui vivaient sur le bord de la mer. lls demeuraient antrefois dans les environs de Natka-Passahé (rivière du Cœur).

Les Mandans sont une race d'hommes vigoureux, bien faits, et de taille moyenne, ou un peu au-dessus; il y en a peu chez eux que l'on puisse appeler petils. En général, pourtant, ils ne sont pas aussi grands que les Meunitarnis. Ces Indiens sont forts, robustes, charnus et ont les épaules larges; les traits de leur visage sont les mêmes que ceux des autres Indiens du Missouri; mais ils ont le nez moins aquilin et les os des joues moins saillants que les Dacotas. Les Mandans et les Meunitarris n'ont pas les ailes du nez larges; ce trait est souvent chez eux recourbé ou légèrement arrondi, souvent aussi tout droil. Leurs yeux sont étroits et longs, d'un brun foncé, parfois un peu rabaissés et serrés à l'angle intérieur, surtout chez les enfants, mais moins souvent chez les adulles. Ils ont la bouche large, grande, un pen proéminente, el les côtés de la 
màchoire inférieure larges et anguleux. La forme de leur crâne offre de grandes variétés; pourtant il en est bien peu qui aient le front plus évasé que les Européens. Ces Indiens ont les cheveux longs et forts, plus ou moins lisses, noirs, mais moins foncés que ceux des Brésiliens. Beaucoup d'enfants ne les ont que d'un brun foncé, surtout à l'extrémité. Il se trouve chez eux, comme chez les Pieds-Noirs, des familles entières où les cheveux sont gris ou noirs mêlés de blancs, de sorte que toute la tête pourrait être grise; tels sont, par exemple, les familles de Sih-Chide et de Mato-Chihé; cette dernière était surtout remarquable sous ce rapport ; lorsque le prince de Newied la visita, elle avait les cheveux, par touffes, brunâtres, noirs, gris d'argent, mais surtout gris blanc, et des cils tout à fait blancs, ce qui faisait un très-singulier effet dans les hommes, d'ailleurs vigoureux et bien taillés de l'àge de vingt à trente ans. Ils laissent croîtrc leurs cheveux et les allongent mème artificiellement autant qu'ils peuvent. Ils ont les dents remarquablement belles, fermes, forles, blanches comme l'ivoire et parfaitement rangées; on y observe rarement des défauts ou du vide, mème chez les personnes âgées. Les dents des vieillards s'usent et sont quelquefois très-courtes, ce qui vient de l'usage de manger de la viande dure et desséchée.

Les femmes des Mandans sont assez fortes; quelques-unes sont grandes, mais la plupart petites et trapues; on en voit peu que l'on puisse appeler belles, même à la manière indienne; il y a cependant parmi elles des visages passables.

Les femmes mandanes possèdent une certaine conformation naturelle du genre de celle des femmes hottentotes; mais chez les Mandans, il paraît que la nature y a moins de part que l'art. Les enfants présentent souvent des membres grèles et de gros ventres, comme ceux des Brésiliens. On rencontre rarement parmi ces Indiens des individus naturellement difformes ou contrefaits. En revanche on en voit beaucoup de borgnes ou avec une tache dans l'œil. Il y a quelques sourds-muets, un petit nombre de goîtreux ou plutôt de gros cous, particulièrement chez les femmes, ce qui vient de l'habitude de perter des fardeaux sur la tête. Beaucoup d'entre eux manquent de quelques phalanges aux doigts, mais ceci provient de mutilations volontaires.

La couleur de ces Indiens est d'un beau brun, tantôt rougeâtre, tantòt plus ou moins foncé, ce que l'on pourrait aussi parfois désigner par le terme dé cuivré. Che\% les uns, il tire sur le gris, chez d'autres il est plus jaune. Quand ils se lavent avec soin, on en trouve chez eux dont la peau se rapproche beaucoup du blanc et qui ont mème une nuance rose sur les joues. Ils ne se font pas d'entailles sur le corps; seulement ils se percent le bord postérieur des oreilles, auxquelles ils suspendent des rangs de perles en verre, des anneaux de fer ou de cuivre, des coquillages enfilés, yu'ils recoivent en échange d'autres tribus indiennes.

Les Mandans sont vains; ils aiment à se parer, et les jeunes gens portent habituellement de petits miroirs suspendus au poignet par un ruban rouge ou un cordon de cuir. Quelques-uns altachent ce miroir à la surface inférieure de leur aile d'aigle, dans laquelle ils l'insèrent avec art. Le petit-maître indien se regarde souvent dans ce miroir; et quand il a traversé le pays par un vent violent, il ne manque point de s'en servir pour rajuster avec le plus grand soin le désordre de sa toilette. La vanilé des hommes indiens est bien plus grande que celle des femmes, el celles-ci leur cèdent en tout point pour l'élégance de la mise. Du reste, celle des Mandans est assez simple. De toutes les parties du corps, c'est.la tête dont ils s'occupent le plus; ils portent les cheveux partagés en travers au milieu; ceux du devant sont lisses et parlagés en trois tresses plates, dont deux retombent de chaque côté des tempes ou derrière les yeux, et sont, en général, entrelacés. Ils portent à cette queue un ornement qui se compose de deux morceaux de cuir ou de drap, garnis de grains de verre 
bleu clair ou blanc, et noués au milieu avec du fil de laiton; on attache cet ornement à la tresse, et on le fait monter jusqu'au-dessus de la tempe; mais à son extrémité il est allongé par un long cordon qui pend jusqu'au milieu du corps, et qui se compose de franges de perles bleues et de coquilles blanches placées alternativement et accouplées de dentalium. Entre ces deux tresses de cheveux pend au milieu du front et jusque sous le nez, une autre bande de cheveux plate et coupée en travers par le bas; celle-ci n'a point d'ornement, et en petite tenue elle est simplement nouée par un ruban rouge. Les cheveux du derrière de la tête retombent, partagés en plusieurs queues, jusqu'au bas des reins; ils sont pétris gà et là avec de l'argile brune, rouge clair ou blanche, de sorte qu'ils forment de longs cordons tout à fait plats, d'un pouce et demi à deux pouces de large. Quand les cheveux ne sont pas naturellement longs, on les allonge en y ajoutant des cheveux étrangers, entre autres, avec ceux des ennemis que l'on a tués ct que l'on y attache avec de la résine. Sur le derrière de la tète, on porte le paokatkappe, ornement long, roide et plat, large de trois à quatre doigts, et fait de petits morceaux de fil de métal ou de bois entortillés; il s'attache par le haut aux cheveux, et retombe par-dessus les épaules. Il est recouvert de beaux piquants de porc-épic, peints de diverses couleurs et disposés dans les dessins les plus gracieux. Sur le sommet de cet ornement est placée horizontalement une plume d'aigle dont le tuyau est couvert de drap rouge, et l'extrémité ornée d'une touffe de crin peint en jaune. Lorsque ces Indiens vont à la chasse ou en voyage, et qu'ils ne sont pas, par conséquent, en graud costume, ils nouent leurs longs cheveux en une épaisse touffe. Quand, au contraire, ils sont en grande tenue, ils fichent dans leurs cheveux des plumes de différentes espèces; parlois c'est un demi-cercle de plumes d'oiseaux de proie, s'écartant comme des rayons, ou bien une touffe de plumes de corbeau placées de même; tantôt une épaisse touffe de plumes de hibou, tantôt de petites rosettes de larges plumes de corbeau coupées court, et du milieu desquelles s'élève la queue d'un oiseau de proie disposée en éventail. Ces Indiens portent aussi le grand bonnet de plumes cornu, dont nous avons donné la description pour une des autres tribus du Missouri. Un guerrier qui veut se parer a besoin d'un temps très-long pour sa toilette. Ces naturels délayent dans de la graisse la couleur dont ils se peignent le corps. Quand ils sont en deuil, ils se blanchissent la figure et les cheveux. Les femmes et les enfants ne font que sc peindre la figure en rouge; leurs cheveux conservent la couleur naturelle.

Les Mandans et les Meunitarris portent aulour du cou un beau collier de griffes d'ours, qu'ils appellent mato-unknappinindé. Ces griffes sont longues au printemps; alors elles ont Irois pouces et sont blanches à la pointe, particularité fort estimée. On'n'emploie àcet usage que les griffes des pieds de devant; elles s'attachent à un cordon de peau de loutre yii retombe doublée de drap rouge. Ces griffes sont séparées les unes des autres, vers leur milieu, par une rangée de grains de verre bleus, et leur surface latérale est peinte en jaune ou en rouge; de sorte que le tout ensemble forme un deṃi-cercle, d'une épaule à l'autre, au-dessus de la poitrine. Les Mandans portent encore plusieurs autres ornements autour du cou, comme des rangs de grains de verre de différentes couleurs, de racines odoriférantes ou d'éponges, de dents d'elk, qu'ils achètent au prix d'un cheval pour cent ou cent cinquante dents, etc. Ces Indiens ont communément le haut du corps nu; on leur voit rarement la chemise de cuir des Assiniboins, des Dacotas, des Corbeaux, des Pieds-Noirs et des autres nations qui habitent plus loin vers le nord et le nordouest; quelques-uns d'entre eux possèdent de ces chemises dont on leur a fait présent ou qu'ils ont achetées, et ils les appellent wapenpi-imachoté. Les Mandans ne portent sur leur corps nu qu'une robe de bison, mème pendant les hivers les plus rigoureux. Ils 
se peignent la peau en rouge'brun, et, dans certaines occasions, ils l'enduisent d'argile blanche; souvent ils se font aussi des dessins rouges ou noirs sur les bras. Ordinairement le visage se peint tout entier en rouge avec du cinabre, parfois aussi en jaune; mais alors le tour des yeux et le menton, jusqu'à la bouche, sont toujours rouges; il n'y a pourtant pas de règle fixe pour cetle peinture; elle dépend du goût du petit-maître, cependant il y règne une certaine régularité. Dans les bandes et leurs danses, après les combats, el quand ils ont fail des exploits, il est d'usage de suivre la règle établie. Dans les fètes et les danses ordinaires, quand les jeunes gens veulent paraître très-beaux, ils se peignent chacun d'une façon différente, el s'efforcent à l'envi d'inventer quelque chose de nouveau. Quand un d'entre eux en trouve un autre qui s'est peint de la même manière que lui, il s'éloigne sur-le-champ pour aller changer son dessin, ce qui arrive quelquefois. Quand ils ont fait un coup, ils se peignent tout le visage en noir. Quelquefois ils portent au poignel el au haut du bras des bracelets d'acier poli qu'ils reçoivent en échange des marchands. Ils portent aux doigts des anneaux de cuivre. La principale partie de leur costume est la grande robe de bison, appelée mahitou ou mih-ihé, dans la décoration de laquelle ils déploient un grand luxe. Quand le temps est sec, ils portent ces peaux de bison avec le poil en dedans, et quand il pleut, avec le poil ẹn dehors; elles sont tannées du côté de la chair, ornées en travers d'un cordon de grains de verre bleus ou blancs, auquel se rattachent ordinairement trois rosettes rondes, tantôt petites, tantôt très-grandes, placées à distances égales et de la même manière, formant du reste des dessins divers el élégants. Le centre est souvent rouge et le tour bleu de ciel, avec des figures blauches, ou bien ces mêmes couleurs différemment disposées. Ce cordon transversal est fréquemment aussi brodé avec des piquants de porc-épic, teints de différentes couleurs, et alors il est plus étroit; mais c'est là la manière dont. ils les portaient dans l'origine, avant que les blancs leur eussent fait connaître les grains de verre. Parmi ces robes il y en a aussi qui, du côté de la chair, présentent des figures noires sur un fond rouge brun; ces figures sont surtout celles d'animaux; d'autres encore représentent, en noir ou en couleurs brillantes, sur un fond blanc, les coups et les exploits des propriétaires de la robe, ses blessures, le sang qu'il a perdu, les hommes qu'il a tués ou fait prisonniers, les armes qu'il a prises, les chevaux qu'il a volés, dont le nombre est indiqué par celui des fers; tout cela est dessiné à la manière grossière de leur peinture, encore dans l'enfance, en noir, rouge, vert ou jaune. Ils ont encore une autre manière de peindre ces robes, par laquelle ils indiquent le nombre exact des objets de valeur qu'ils ont donnés en présents. Par ces présents, qui sont souvent d'un grand prix, ils se font un nom el acquièrent de la considération parmi leurs compatriotes. Sur ces robes on remarque alors des fig̣ures rouges, avec un cercle noir à l'extrémité, placées à côté l'une de l'autre en rangées transversales; elles signifient des fouets ou des chevaux donnés, parce que, quand on fait présent à quelqu'un d'un cheval, on y ajoute toujours le fouet. Des figures transversales rouges ou d'un bleu noirâtre indiquent du drap ou des couvertures de laine; des raies parallèles représentent des fusils, qui sont assez exactement dessinés. Souvent la robe est découpée par le bas en plusieurs bandes retombantes, et ornée sur les côiés de touffes de cheveux, de crins teints en jaune ou en vert, el de grains de verre. Autrefois les Indiens peignaient ces robes avec plus de soin, et on les obtenait pour cinq balles de fusil et autant de charges de poudre; aujourd'hui, au contraire, elles sont mal faites, ce qui n'empêche pas qu'elles coûtent huil à dix dollars pièce.

Leurs leggings ou culottes s'attachent avec des courroies à la ceinture de cuir, et consistent, comme chez tous les Américains du Nord, en deux parties séparées, une pour 
chaque jambe. Au còté extérieur, éest-à-dire à la couture, elles sont brodées d'une longue raie de piquants de porc-épic de couleurs vives et variées, et souvent aussi de grains de verre bleus et blancs, et garnies de longues franges de cuir, formant à la cheville une épaisse touffe qui traîne un peu par terre. Le cuir de la culotte même est généralement d'un brun rouge ou d'un jaune rougeâtre, peint avec de l'argile; souvent aussi il est blanc et marqué de raies noires transversales au-dessous du genou. Le vètement que les Anglais appellent breechcloth (nokké) est d'usage parmi eux, comme chez loutes les nations de l'Amérique septentrionale. Il se compose, en général, de morceaux d'étoffe de laine, étroite et rayée de blanc et de noir, qu'ils font passer entre les jambes et puis sous la ceinture par devant et par derrière, où elle retombe dans toule sa largeur. Leurs souliers (humpé), de peau de cerf ou de bison, sont généralement simples et peu ornés; toutefois, quand ils veulent se parer, ils en portent de plus élégants, qui alors sont brodés avec des roseltes ou de longues raies de piquants de porc-épic de différentes couleurs, ou avec des grains de verre. Les hommes qui ont fait un coup portent autour de la cheville une queue de loup qui traîne par terre derrière cux, ou bien des lanières de peau de loutre garnies de drap rouge du côté de la chair, ct formant aussi une longue queue par terre. Dans l'été, quand les hommes sont chez cux et qu'ils se promènent en grande toilette, ils portent à la main l'éventail de plumes d'aigle.

Généralement les enfants mâles vont nus, et ne se couvrent d'une robe qu'en hiver. Les filles sont vêtues de cuir, même en été. Les femmes portent un long vètement de cuir, à manches ouvertes, et une ceinture autour du corps. Le bas de cette robe est souvent découpé et frangé de différentes manières. Elles s'ornent le poignet de bracelets de fer, et le cou de colliers de grains de verre; elles portent aussi des pendants d'oreilles. Les souliers de ces femmes sont sans ornements et unis.

Chez ces peuples le tatouage est très-commun; mais tous ne portent pas, àbeaucoup près, les mènes figures sur le corps. Ordinairement il n'y a que le côté droit de la poitrine t' la moitié du bras correspondant qui soient marqués de lignes noires parallèles et d'un petil nombre d'autres figures; quelquefois aussi l'avant-bras é quelques doigts. Les hommes ne se tatouent pas le visage. On teint les ongles en bleu foncé.

Les villages de ces Indiens sont des agglomérations de cabanes en terre, rangées sans aucun ordre el sans régularité. Entre chaque cabane, il y a un grand nombre d'échafaudages de pieux, à plusieurs étages, sur lesquels on sèche le maïs. Cés cabanes sont rondes, légèrement voûtées par le haut, avec une entrée défendue par une espèce de porche. Quand les habitants sont absents, cetle entrée est bouchée par des branchages et des ronces. Pour fermer l'ouverture elle-mème, on suspend au devant une peau séchée et fortement tendue sur des bâtons, que l'on pousse de côté quand on cntre. Au milieu du toit de la cabane, il y a une ouverture pour donner passage à la fumée, et qui est défendue contre la pluie et le vent par une espèce de cage arrondie, faite de bâtons et de rameaux et qu'on recouvre de peaux en cas de besoin. L'intérieur le la cabane est vaste, propre et assez clair. Quatre gros pieux, placés au centre, supportent le toil avec des poutres de traverse. Le pourtour intérieur de l'édifice est formé par douze à quinze gros pieux de quatre à cinq pieds de haut, entre lesquels on en a placé d'autres plus petits et plus rapprochés. Sur le plus élevé reposent de longues poutres hiaisant vers le milieu, et qui, placées fort près les unes des autres, soutiennent le toit. On les recouvre extérieurement avec une espèce de nattes, faites de rameaux de saule liés ensemble avec de l'écorce. Telle est la charpente de la cabane sur laquelle on étend ensuite, d'abord du foin, puis de la terre. Les hommes et les femmes, aidés des parents el des amis, s'occupent en commun de sa construction. Le soin des cabanes, la fabri- 
cation des armes, la guerre et la chasse, sont l'ouvrage des hommes, qui prennent aussi part à la moisson; toutes les autres occupations sont le partage des femmes, qui, quoique généralement bien traitées, sont néanmoins chargées des travaux les plus pénibles. Ce sont elles qui vont chercher de lourdes charges de bois pour le chauffage, qui portent l'eau, qui cassent la glace en hiver et la transportent dans les cabanes, qui font la cuisine, qui tannent les peaux, qui cousent les vêtements, qui font les plantations, et qui récoltent les fruits de la terre. Au milieu de la case, il y a un trou rond dans lequel on allume le feu, et au-dessus duquel on suspend la marmite. Ce foyer est garni tout entier de pierres placées perpendiculairement. Le bois est posé en bûches modérément grosses, sur le bord extérieur du foyer, en se réunissant et se croisant au centre. C'est là qu'on l'allume, et on le pousse en avant à mesure qu'il brùle. Les Indiens n'aiment pas à faire de grands feux. La famille s'assied autour du foyer, sur des siéges bas, faits d'osier pelé el recouverts de peaux de bison ou d'ours. Autour des parois sont suspendus divers effets, les meubles, les ustensiles, etc., dans des sacs de cuir; les sacs de nuit en parchemin peint, les harnais des chevaux; tandis que sur des cadres particuliers sont étalés des armes, des patins, des souliers à neige, et des tas de viande et de maïs. Les lits ou couchettes sont rangés autour des murs de la cabane. Ils se composent d'une grande caisse carrée de parchemin ou de peau, avec une entrée carrée; ils sont assez grands pour contenir plusieurs personnes qui s'y couchent très-commodément et très-chaudement, sur des couvertures de laine ou des peaux.

Les cabanes d'été sont très-fraîches et exemptes de toute mauvaise odeur; devant la porte de celles d'hiver, on construil une cloison de branches de saule, que l'on couvre de peaux, et qui sert à défendre du vent extérieur, et surtout protége le foyer contre les courants d'air. Quand les Mandans et les Meunitarris sont dans leurs cabanes, ils s'asseyent autour du feu el s'occupent de toutes sortes de travaux de ménage. L'homme est ordinairement nu, et s'amuse à fumer du tabac. Les femmes ne sont jamais oisives. En hiver, ces Indiens se rendent, avec la plus grande partie de ce qu'ils possèdent, dans les forêts du voisinage, où ils ont construit leur village d'hiver, qui se compose de cabanes en tout semblables aux autres; seulement elles sont un peu plus petites. Dans l'intérieur de ces cabanes, il y a une séparation où l'on fait entrer les chevaux le soir, el où on leur donne du maïs; pendant le jour, ils restent dans les prairies et se nourrissent dans les bois d'écorce de peuplier. Dès qu'ils quittent leurs cabanes pour un temps un peu long, les Mandans et les Meunitarris mettent leurs bagages sur de petits traineaux composés de deux planches minces et étroites, et altachées ensemble par des courroies, auxquelles sont adaptées des lanières de cuir qui servent à altacher les chiens.

Les Mandans et les Meunitarris, comme tous les Indiens de ces contrées, pratiquent parfois, dans les environs de leurs villages, ce que l'on appelle des caches. Ce sont des Irous creusés dans la terre, et si artistement, qu'il est fort difficile de les trouver. On voit souvent les Indiens se rendre de leurs villages d'hiver à ceux d'été pour y chercher divers objets dont ils ont besoin, car ils y laissent toujours une partie de leurs effets.

Les Mandans sont très-hospitaliers; ils invitent souvent leurs amis à venir les voir; alors on mange et on fume. Leurs pipes sont faites de pierre rouge ou d'argile noire, souvent aussi l'argile n'est que peinte en noir; ils ont aussi des godets de pipe en bois Joublé de pierre. Le tuyau est simple, long, rond ou plat, et de même forme que chez les Dacotas. Le tabac des blancs est trop fort pour eux, par l'habitude qu'ils ont de faire entrer la fumée dans les poumons. Les Mandans servent leurs mets dans des plats de bois; ils font usage de grandes cuillers jaunâtres et ventrues, faites de corne de bigorne; celles (quifent ont pas de ventre sont faites de corne de bison. Leurs aliments varient beaucoup. 
Les Indiens qui habitent des villages stables ont sur les nomades l'avantage qu'ils ne lirent pas exclusivement leur nourriture de la chasse, mais encore des terres qu'ils cullivent, ce qui leur offre toujours une ressource certaine en cas de besoin. Les plantes qu'ils cultivent sont le maïs, les fèves, la citrouille et le tabac. Le labourage des champs de maïs, dont chaque famille cultive quatre à cinq acres, se fait au mois de mai, et c'est au mois d'octobre que se fait la moisson, à laquelle hommes, femmes et enfants travaillent en commun. Les Mandans mangent à peu près de toute espèce d'animaux, excepté le cheval et l'hermine. Le breuvage des Mandans est l'eau, car ils ne savent pas faire des boissons fermentées, comme les nations de l'Amérique méridionale. Ils aiment beaucoup le sucre, et ils salent leurs mets. Ils aiment aussi beaucoup le café et le thé bien sucrés.

Deux et parfois trois familles habitent en commun une cabane indienne. La polygamie est d'un usage universel. Les femmes sont fort adroites pour tous les travaux du ménage. Une grande partie de leur temps est employée au tannage des peaux. Les trois nations savent aussi fabriquer des vases de terre de différentes formes et grandeurs. L'argile dont ils se servent est d'une couleur d'ardoise foncée, et devient, par l'action du feu, d'un jaune rougeâtre. On mêle cette argile avec du granit réduit en poussière par le feu; uné pierre grosse et ronde à la main, l'ouvrière forme le creux du vase en y enfonçant cette pierre, tandis qu'elle l'empèche de se fendre extérieurement, et le polit au moyen d'un morceau d'écorce de peuplier. Quand le vase est achevé, on le remplit de copeaux secs; on en entoure aussi le dehors, après quoi on le brûle; on peut alors s'en servir pour faire cuire les aliments. Quant à leurs bateaux, les Américains du nord se montrent beaucoup plus adroits que les Brésiliens, les Patagons et les autres nations de l'Amérique méridionale. On en voit, chez les Mandans, qui sont faits de peau de bison, et si légers qu'un seul homme peut les porter sur ses épaules; ils sont parfaitement ronds, et tendus sur plusieurs morceaux de bois recourbés el se croisant.

Quand un jeune Indien a le désir de se marier; et qu'il s'est assuré du consentement de sa maîtresse, il s'efforce d'obtenir celui du père. Lorsqu'il lui a été accordé, il amène plusieurs chevaux, qu'il altache à la cabane de sa fiancée, qui les remet à son père; celui-ci prend alors d'autres chevaux (s'il n'en a pas un assez grand nombre ses amis lui en donnent), et il les attache à son tour à la cabane de son futur gendre. La quantité de chevaux donnés doit toujours ètre égale. Après cette espèce d'échange, la fiancée fait cuire du maïs, et en apporte chaque jour un plat à son futur. Au bout de quelque temps, le jeune homme se rend à la cabane de sa maîtresse, cohabile avec elle, et le mariage est conclu. Le jeune couple s'établit dans la cabane du beau-père, si mieux il n'aime en construire une nouvelle; quelquefois même il arrive que les deux époux se séparent de nouveau. Le beau-père, par la suite, joue le premier rôle dans la cabane; tout se fait pour lui, tout dépend de lui.

Les couches des femmes sont d'une facilité remarquable; elles ont coutume, aussitôt qu'elles sont délivrées, d'aller se baigner dans la rivière, fùt-elle couverte de glaçons. Au bout de dix jours on regarde l'enfant comme sauvé. Les Indiennes ont pour leurs enfants des berceaux qui sont faits d'un sac de cuir que l'on suspend, par une courroie, à l'une des poutres de traverse de la cabane.

Les enfants sont libres d'agir comme ils le veulent; on s'efforce par tous les moyens possibles d'exciter chez eux le sentiment de la volonté et de l'indépendance. Si, par hasard, une mère fait une observation à son fils, il lui répondra par un soufflet, et parfois même il en fait autant à son père, qui baisse la tête et dit : "Celui-là sera un jour un brave guerrier. "Les hommes traitent leurs femmes si brutalement, que bien souvent ces malheureuses sortent de leurs cabanes pour aller se pendre 
à un arbre. Elles obliennent peu de dédommagement pour leurs rudes travaux ; elles n'ont même pas la jouissance de posséder pour elle les plus beaux habits; ce sont les hommes qui jouissent du privilége de la toilette. Les Indiennes qui ont épousé un blanc ne veulent plus travailler. Les sœurs ont de grands priviléges chez les Indiens; tous les chevaux volés par les jeunes gens leur appartiennent. Quand un Indien revient à cheval d'une expédition, s'il rencontre sa sœur, il met pied à terre sur-le-champ, et lui donne sa bète. En revanche, s'il désire posséder quelque objet qui appartienne à sa sœur, il va sans cérémonie le lui demander, et il l'obtient aussitôt.

La pruderie n'est pas le défaut des femmes indiennes; elles ont souvent deux ou trois amants, et même davantage, et l'infidélité est rarement punie. Quand un Indien enlève une femme mariée, le mari se venge en s'emparant de ce que le séducteur possède de plus précieux, et celui-ci est obligé de le laisser faire. On ne reprend jamais la femme qui s'est laissé enlever. Quand on épouse une fille aînée, on a des droits sur toutes ses sœurs. Une des principales occupations des jeunes gens est de tenter leur fortune auprès des jeunes filles et des femmes; celte recherche et le soin de se parer remplissent presque tous leurs instants. Ils ne trouvent pas beaucoup de beautés cruelles. Ils ont une manie toute particulière de publier leurs exploits dans les champs de l'amour, surtout quand ils se rendent, daus leurs plus beaux habits, auprès de leur maîtresse. Ils croient ne pouvoir mieux lui plaire qu'en lui faisant connaître le nombre de leurs victoires, et ils marquent celles des belles dont ils ont triomphé par des paquets de rameaux de saule dépouillés de leur écorce et dont l'extrémilé est peinte en rouge. Ces bâtons sont de deux espèces; la plupart ont deux ou trois pieds de long; d'autres cinq ou six. Ces derniers, se portant seuls, sont peints en bandes circulaires alternativement blanches et rouges, dont le nombre indique celui des victoires. L'autre espèce le bâtons, qui sont plus courts, ne sont peints en rouge qu'à la pointe, el alors c'est chaque petite vergette qui fait connaître les triomphes, qui, réunis après cela en un seul paquet, forment un faisceau assez volumineux. Les petits-maîtres indiens portent avec eux plusieurs de ces faisceaux quand ils partent pour une expédition amoureuse. Chez les Mandans, ces bâlons, qu'ils appellent mih hirouché-kehkarouche, sont généralement unis; mais chez les Meunitarris, il y a d'ordinaire au milieu du faisceau un bâton plus long que les autres et dont l'extrémité est ornée d'une louffe de plumes noires. Ces plumes représentent la favorite, et le galant ne manque pas de dire, à chaque femme, que c'est pour elle qu'il a déployé cet étendard.

Il n'est pas permis à une belle-mère d'adresser la parole à son gendre jusqu'au moment où il est revenu à la maison, lui rapportant le scalp d'un ennemi et son fusil; après cela, elle peut lui pårler. Cette coutume, dit le prince de Wied-Neuwied, existe aussi chez les Meunitarris, qui l'ont sans doute empruntée des Mandans.

On voit chez les Mandans et les Meunitarris, comme chez toutes les nations indiennes de l'Amérique du nord, des hommes-femmes, que les Canadiens nomment bardàches, et connus chez les Mandans sous le nom de mih-decké. Ces hommes, qui s'habillent en lemmes, se livrent à toules les occupations de celles-ci. Les jeunes gens les traitent absolument comme des femmes, et entretiennent avec eux certaines relations contre nature. Ces hommes-femmes prétendent qu'une inspiration d'en haut leur a ordonné d'embrasser cet état comme leur médecine ou leur salut, et rien ne peut les dissuader de leur projet.

Les Mandans montrent un grand désir de s'instruire, et des dispositions à saisir les choses d'un ordre élevé. S'ils étaient moins attachés aux préjugés qu'ils ont hérités de leurs ancêtres, il serait très-facile de les éclairer. Les mauvais exemples qu'ils reçoivent trop souvent des blancs qui habitent leur pays, el qui n'ont d'autre but que de 
gagner de l'argent, ne sont pas faits pour attirer de leur part un grand respect ou pour les rendre meilleurs; et si on ne les a pas trouvés favorablement disposés pour la religion chrétienne, c'est en grande partie la faute des Européens. La vie inactive qu'ils mènent, et qui est enracinée chez eux, devient un grand obstacle à leur faire adopter une autre manière d'ètre ; mais leurs dispositions pour le dessin, pour la musique, elc., sont frappantes. Ils aiment le langage figuré, et disent souvent à leurs oppresseurs de dures vérités. On trouve souvent chę ces hommes une énergie de caractère portée au plus haut degré. Plusieurs se sont lués par amour ou par un sentiment d'honneur blessé. Ils ont une mémoire extraordinaire; il y en a qui peuvent raconter toute l'histoire de leur nation sans commettre la plus légère erreur.

Les Mandans et les Meunitarris sont très-fiers et ont beaucoup d'ambition. Ils mettent à tout ce qu'ils possèdent une valeur imaginaire, bien supérieure à celle que ces objets ont en réalité. Ainsi, une petite peau d'hermine se paye seize florins d'Allemagne.

En général, les hommes sont fort paresseux, sauf toutefois quand ils peuvent se livrer à leurs exercices favoris: la chasse et la guerre. Du reste, à tout prendre, ces peuples ne sont pas dangereux, et quoiqu'il y ail parmi eux beaucoup d'hommes grossiers et sauvages, ils sont assez bien disposés pour les blancs, et, chez les Mandans surtout, on trouve un grand nombre d'excellents hommes. Il ne manque pas de voleurs, principalement parmi les femmes et les enfants. Les querelles sont fort rares chez eux; mais il n'en est pas de mème des duels qui sont fréquents.

Ces Indiens sont fort propres et se baignent presque tous les jours, en hiver comme en été; cependant ils ont souvent les mains très-sales, couvertes de couleur et de graisse, comme parfois tout le corps. Les femmes ont moins de propreté que les hommes, surtout pour leurs mains, ce qui provient des pénibles travaux auxquels elles se livrent. Les Indiens prétendent que les blanes sentent mauvais, parce qu'ils se lavent trop rarement le corps. Généralement ils portent les ongles fort longs, et sont fort tolérants pour la vermine, ce dont leur épaisse chevelure et même leurs robes de bison n'offrent que trop de preuves. Il paraît, du reste, que ces insectes ne sont pas fort dangereux pour les blancs. Ils se cherchent mutuellement ces petits hôtes, et les mangent; les femmes en font souvent présent aux hommes.

Les sauvages habitants des prairies sont extrêmement adroits et endurcis au mal. Ils aiment à se baigner, au cœur de l'hiver, dans de l'eau glacée, et vont dans cette saison nus jusqu'à la ceinture, c'est-à-dire sans autre vètement que leur robe de bison. La natation est un de leurs principaux exercices, et ils s'y livrent dès leur tendre jeunesse. Ils montent souvent à cheval à nu, et courent les uns sur les autres. Ils sont aussi excellents archers. Chez eux, tous les sens sont perçants et fort exercés.

Comme chez la plupart des nations de l'Amérique du nord, il existe chez les Mandans et les Meunitarris des bandes ou associations qui se distinguent par des marques extérieures et des lois particulières. Ils ont trois espèces de sifflets de guerre (ihkocheka), qu'ils attachent autour du cou, et qui font partie des marques distinctives des bandes qui partagent les hommes en six classes.

La première bande est celle des meniss-ochkta-ochaté, c'est-à-dire les chiens fous ou les chiens dont on ne connaît pas le nom. Elle se compose de jeunes gens de dix à quinze ans, qui portent pour ihkocheka un aileron d'oie sauvage, dont l'os est fort petit. Quand ils dansent, trois d'entre eux ont un long morceau de drap rouge qui leur pend du cou jusqu'à terre; de même que toutes les autres classes, ils ont un chant particulier pour accompagner leur danse. Quand de jeunes garçons veulent entrer dans la première bande, pour devenir des hommes, ils s'adressent aux membres de cette bande, en leur donnant le titre de père, et cherchent à apprendre la danse et le chant et à 
acquérir le grade et le sifflet de guerre pour certains objets de prix, tels que des coslumes de laine, du drap, des chevaux, de la poudre, du plomb, elc.; et c'est leur père qui paye pour eux. S'ils trouvent quelqu'un qui consente à leur vendre le grade, ils ont droil sur-le-champ à toutes les distinctions de la bande, et le vendeur renonce à toutes ses prétentions; mais alors il cherche à acheter, à son tour, l'entrée dans une bande supérieure. Les danses des diverses classes sont les mêmes quant au fond; mais à chacune s'altache un chant différent el quelquefois des pas particuliers.

La seconde classe ou bande est celle des héhderoucha-ochaté, c'est-à-dire la bande du corbeau, et se compose de jeunes gens de vingt à vingt-cinq ans. Il arrive souvent que des jeunes gens restent pendant six mois ou plus longtemps sans faire partie d'aucune bande; ils vont alors à celle du corbeau, et disent : a Père, je suis pauvre, mais je voudrais bien acheter de toi. "Si le propriétaire y consent, ils recoivent la plume du corbeau, que cette bande porte sur la tête, un double ihkocheka, composé de deux ailerons d'oie attachés l'un à l'autre. Chacune de ces bandes a un chef, qui décide de ia vente des droits et des attributs; c'est à lui qu'on s'adresse dans les difficultés qui surviennent. On dispose ensuite une fète qui se prolonge pendant quarante nuits; on y danse, on y mange et l'on y fume. Les frais sont pour le compte des acheteurs, qui cèdent, en outre, pendant tout ce temps, leurs femmes aux vendeurs, jusqu'à ce que les pères soient satisfaits et remettent aux acheteurs leur propriété, ce qui termine la fète.

La troisième classe ou bande est celle des charak-ochaté, ou des kana-karakachka; ce sont les soldats, ou les guerriers les plus distingués. Quand ils dansent, ils se peignent le haut du visage en rouge et le bas en noir; leur sifflet de guerre est grand et fait de l'aileron d'une grue. Leurs insignes sont deux longs bâtons droits, entourés de peau de loutre, qu'ils appellent manna (le bois), et auxquels ils suspendent des plumes de hibou. Quand ils vont à la guerre, ils plantent ces bâtons en terre devant l'ennemi, et il ne leur est pas permis de ies abandonner, non plus qu'aux Européens leurs drapeaux. Ils ont un chant et une danse, et doivent acheter des places dans les classes supérieures. Leur chichikoué, ou crécelle, est fait de fer-blanc; il est de la forme d'un petil chaudron, avec un manche; ils possèdent aussi deux pipes dont ils se servent pour fumer dans certaines occasions particulières : deux hommes sont chargés de garder et de porter ces pipes. Toutes les classes supérieures peuvent en mème temps faire partie de la bande des kana-karakachka, parce qu'elle est destinée à maintenir la police; mais il va sans dire que tous les membres doivent s'ètre entendus pour l'achat. Si un seul homme vote contre la vente, l'affaire ne peut se conclure. Il y en a quelquefois qui ne donnent pas leur consentement sur-le-champ, afin de faire monter plus haut le prix de l'achat, ct revendre ensuite d'autant plus cher. Ces soldats formen't un comité qui dirige toutes les principales affaires, surtout quand il s'agit d'entreprises générales, comme changements de demeure, chasses au bison, clôtures de villes, etc. Si les troupeaux de bisons sont dans le voisinage, ils les surveillent et ne permetlent pas qu'ils soient rroublés par des individus isolés, jusqu'à ce qu'une chasse générale puisse être organisée.

Pendant ce temps, si quelqu'un tire un loup ou quelque autre animal, les soldats lui enlèvent son fusil et lui donnent parfois des coups, ce qu'il est obligé de souffrir; on n'épargne pas, en pareil cas, les chefs. Les blancs qui demeurent dans le voisinage, et qu'ils appellent ouachi, sont soumis aux mèmes lois, et il est arrivé souvent que les soldats ont enlevé aux fendeurs de bois du fort leurs haches, ou leur ont défendu de joursuivre leurs travaux, de peur qu'ils ne troublassent par leur bruit les troupeaux de bisons. 
Les membres de la quatrième classe ou bande, qui est celle des meniss-ochaté, ou des chiens, portent, en dansant, un grand bonnet de drap bigarré, auquel est attachée une grande quantilé de plumes de corbeau, de pie et de hibou, et qui est orné de crins de diverses couleurs et de bandes d'hermine; ils ont aussi un grand sifflet de guerre, fait de l'aile d'un cygne. Trois d'entre eux ont alors, pendante sur le dos, la mème lanière de drap rouge dont nous avons parlé à l'occasion de la première bande. Leur tète est généralement ornée d'une épaisse touffe de plumes de hibou, de corbeau ou de pie, qui relombe par derrière, et souvent aussi ces trois espèces de plumes sont mèlées ensemble. A ces trois hommes, décorés de longues lanières de drap rouge, et qui sont les chiens proprement dits, on a le droit de jeter un morceau de viande par terre ou dans la cendre du foyer, en leur disant : "Tiens, chien, mange! „ et ils sont obligés de se jeter dessus et de le dévorer tout cru comme des chiens et des animaux de proie. Le chichikoué de celle bande est formé d'un bàton d'un pied ou de dix-huit pouces de long, auquel sont altachés un grand nombre de sabots d'animaux.

La cinquième bande se compose de berach-ochaté, les bisons ou les loups; ils portent, en dansant, la peau de la tète d'un bison, avec sa longue crinière et sa corne; mais les deux plus vaillants d'entre eux, choisis parmi tous, et à qui, après cela, il n'est permis, dans aucun cas, de fuir devant l'ennemi, portent sur la tête une imitation complète d'une lête de bison tout entière avec les cornes, et regardent à travers les yeux artificiels, entourés d'un cercle de fer ou de fer-blanc. Celte bande est la seule qui porte un ihkocheka de bois; el, dans la société, il y a une femme qui, lorsqu'ils dansent, leur présente un bassin avec de l'eau pour se rafraîchir; mais elle ne peut présenter celte eau qu'aux plus braves qui portent la tête entière de bison. Dans cette occasion, elle est vètue d'un beau costume neuf en cuir de bigorne, et se peint le visage de cinabre. Les hommes s'altachent par derrière un morceau de drap rouge, avec une figure qui représente une queue de bison, et ils portent les armes à la main. Les hommes à la tète de bison se tiennent toujours, pendant la danse, en dehors du groupe, imitant les mouvements et le beuglement de cet animal quand il court de côté et d'autre, inquiet et limide, regarde autour de lui, elc.

La sixième bande est celle des champsi-ochaté, ou les chevreuils à queue noire. Elle se compose d'hommes âgés de plus de cinquante ans, mais qui dansent pourtant encore. Deux femmes appartiennent à celte bande; elles la servent pendant la danse, font cuire des mets, distribuent de l'eau fraîche et rendent d'autres offices de ce genre. Les hommes de celte bande portent tous autour de la tèle une couronne de griffes d'ours, et autour du corps toutes les marques distinctives de leurs exploits, telles que plumes, touffes de cheveux aux bras et aux jambes, scalps, peintures, elc.

Ces bandes, ainsi que toutes les autres danses, s'achètent et se vendent; et dans ces occasions, ainsi qu'il a été dit, il faut que l'acheteur abandonne sa femme au vendeur pour lout le temps que dure la fète. Si c'est un jeune homme qui n'est pas encore marié, il fail souvent un long voyage, pour aller dans un autre village demander à un de ses amis de lui prèter sa femme; celui-ci l'accompagne alors, et remet sa femme tous les soirs après la danse. Il arrive souvent que cet ami amène avec lui, à la danse, trois ou quatre femmes, ou mème davantage, et les remet à son soi-disant père, c'està-dire aussitôt que la danse, Ie repas, la fumerie el le calcul des coups ou exploits sont terminés. Dans ces occasions, une femme se présente après l'autre; elle passe la main par-dessous le bras de l'homme qu'elle veut favoriser, et va se placer à l'entrée de la cabane, où elle attend qu'il la suive. Souvent celui qu'elle a invité demeure assis et baisse la tête; alors la femme retourne chez elle, et revient avec des objets de prix, tels que des fusils, des robes, des couvertures de laine et autres objets semblables, qu'elle 
dépose successivement devant lui, jusqu'à ce qu'il soit satisfait, qu'il se lève et qu'il la suive dans le bois.

Il y a encore d'autres danses qui se vendent et s'achètent, comme, par exemple, une seconde des kana-karakachka, et la danse de la tête à demi tondue ichoché-kakochochaté, que la plus basse classe peut acheter.

Il y a aussi la danse du meniss-chéh-ochaté, old dog dance, la danse des vieux chiens. La bande des chiens peut l'acheter de celle des bœufs, avant de devenir bœufs euxmêmes, ou de pouvoir entrer par achat dans la bande des berock-ochaté. A la danse des vieux chiens, on se peint en blanc et les mains en rouge et en noir; on porte des plumes qui pendent en arrière de la tête, et autour du corps une lanière de peau d'ours.

A Rouhptare et chez les Meunitarris, qui l'ont achetée des Ariccaras, a lieu la danse dite chaude (wadaddéch-ochaté). Les petits chiens dont on ne connaît pas le nom la conduisent. Pour la danser on allume un grand feu et l'on éparpille par terre une quantité de charbons ardents, au milieu desquels les jeunes gens dóivent danser les pieds nus, ainsi que le reste dı corps; leurs mains avec l'avant-bras, et les pieds jusqu'au-dessus de la cheville, sont peints en rouge; sur le feu il y a une marmite dans laquelle cuit de la viande coupée par morceaux; et quand elle est cuite, ils sont obligés de tremper la main dans l'eau bouillante, au risque de se brûler, pour y prendre la viande et la manger. Ceux qui viennent les derniers sont le plus mal partagés, parce qu'ils sont forcés de rester plus longtemps dans l'eau. Pendant la danse, ils portent à la main le chichikoué et leurs armes.

Chez les Mandans, les femmes sont divisées de la mème manière que les hommes, en quatre classes, d'après l'âge. La classe la plus jeune s'appelle eruhpa-mih-ochaté (la bande du fusil); elles portent derrière la tête une couple de plumes d'aigle, se peignent la figure et ont leur danse.

La classe suivante, dans laquelle elles s'achètent, est la bande de la rivière, passanmih-ochaté. Quand les femmes de cette bande dansent, elles portent, attachée sur le devant de la tête par un bandeau blanc, une plume d'aigle qui penche à gauche et dont le tuyau est enveloppé d'herbe.

Les femmes du foin, chan-mih-ochaté, composent la troisième classe; elles mettent leurs plus beaux habits quand elles dansent, et ne chantent que la chanson du scalp.

Enfin, la quatrième classe est celle de la vache blanche, plihou-tack-ochaté. Les femmes se peignent un des yeux de la couleur qui leur plait, mais généralement en bleu de ciel. Ces femmes, qui sont pour la plupart âgées, sont tatouées de lignes noires, depuis la bouche jusqu'au bas du menton; elles sont coiffées d'un large morceau de peau de bison blanc, ressemblant à un bonnet de hussard, et qui est orné d'un plumet.

Ces sociétés ou bandes donnent lieu à beaucoup de fètes, de chants, de musique et de danses. Leurs amusements musicaux sont d'un genre fort simple. Le chant des diverses nations indiennes de l'Amérique septentrionale est, à peu de chose près, le même. Il se compose de cris poussés de temps à autre et souvent interrompus par de grands éclats de joie; il est accompagné de grands coups frappés sur le tambour pour marquer la mesure, pendant que d'autres hommes agitent le chichikoné. Indépendamment de ces instruments, les Mandans ont encore de longs sifflets de bois, à l'extrémité inférieure desquels voltige d'ordinaire une plume d'aigle attachée à un cordon. D'autres sifflets, appelés ihwochka, sont plus gros, d'une longueur de vingt pouces, et ont des trous sur lesquels on pose les doigts; c'est en cela qu'ils diffèrent de l'ihkocheka; ils sont parfois ornés de peaux et d'autres objets. Ce sont là tous les instruments de musique de ces Indiens. Ils ont encore plusieurs autres jeux pour se divertir. Celui que les Canadiens français appellent billard, skohpe dans la langue du pays, se joue par 
deux jeunes gens armés de longs bâtons, souvent entourés de cuir, et auxquels sont suspendus une foule d'objets différents. Sur une longue lanière droite et unie, ou sur une route bien aplanie, dans le village ou dehors, on fait rouler un petit cerceau rond, recouvert de cuir; on court après et on lui jette le bâton. Le jeu dépend de la convention faite d'avance, d'après laquelle le bâton doit demeurer dans le cerceau ou à côté. Les Meunitarris appellent ce jeu mah-kache.

Les femmes sont fort adroites au jeu de la grosse balle de cuir, qu'elles font tomber alternativement sur le pied et sur le genou, la renvoyant ef la rattrapant toujours, et la tenant ainsi pendant fort longtemps en mouvement sans que jamais elle touche la terre. Ce jeu donne lieu à des primes qui sont souvent très-élevées. La balle est ordinairement fort jolie et artistement recouverte de piquants de porc-épic coloriés.

Quand le temps est beau, vers la mi-mars, les garçons et tous les jeunes gens jouent avec un cerceau, autour duquel sont placées plusieurs bandes de cuir qui se croisent en divers sens. Le diamètre du cerceau est d'environ un pied. On le roule ou on le lance; après quoi l'on jette et l'on enfonce de côté, un bâton pointu, dans le tissu, et celui qui approche le plus du centre a gagné.

Aussitòt que la débâcle a eu lieu, au printemps, les jeunes gens courent le long de la rivière et lancent ce cerceau dans l'eau. On appelle ce jeu wah-gachi-ü̈hlka. En été, les Mandans et les Meunitarris se divertissent souvent à courir dans la prairie, les environs des villages leur offrant les localités les plus favorables à ce jeu. Vingt jeunes gens et plus courent souvent les uns contre les autres; ils sont nus, et il y a parmi eux des coureurs très-vigoureux et très-prompts, et l'on fait à cette occasion de fort gros paris.

Ils sont extrêmement superstitieux, et, dans les affaires un peu imporiantes, les Mandans et les Meunitarris se laissent guider par des motifs de crédulité. Ils ont les idées les plus fantastiques sur la nature dont ils sont environnés; ils croient à l'existence d'une foule d'ètres différents dans les corps célestes; ils leur offrent des sacrifices, implorent leur secours dans toutes les occasions, pleurent, gémissent, jeùnent, s’imposent de cruelles pénitences pour se rendre les génies favorables, et ajoulent surtout une grande foi aux songes. Quelques-unes de leurs traditions ont du rapport avec les révélations de la Bible, comme, par exemple, l'arche de Noé et le déluge universel, l'histoire de Samson, elc.; mais il reste à savoir si ces récits ne leur ont pas été communiqués par les chrétiens aves lesquels ils ont eu des relations, ce qui est fort viraisemblable. Bien qu'ils n'aient pas embrassé les doctrines chrétiennes, il paraît qu'ils en ont adopté quelques parties qui leur ont paru frappantes et intéressantes.

Ces Indiens sont tellement absorbés par leurs préjugés ế leurs superstitions, qu'ils expliquent tous les phénomènes de la nature d'après les folles idées que leur fournit leur imagination.

Chez toutes les nations de l'Amérique septentrionale, il y a une classe de personnes qui se livrent particulièrement à tout ce qui a rapport aux conjurations et à la médecine. Chez les Mandans, elles prennent le nom de numank-choppenih (hommes de médecine).

Les occupations principales des Indiens, après le soin de décorer leurs belles parures, de se regarder dans la glace, de fumer, de manger et de dormir, sont la chasse et la guerre : ce sont elles qui remplissent la plus grande partie de leur temps. Leur principal gibier est le bison. Les hommes vont ordinairement à la chasse en corps et à cheval, afin d'ètre plus en sûreté, dans le cas où ils rencontreraient des ennemis en plus grand nombre qu'eux. Leurs harnais ressemblent à celui des Pieds-Noirs, et la selle est à la hongroise. Ils achètent quelquefois des brides des blancs; clles sont doublées de drap rouge et bleu et très-ornées. Quand ils sont à cheval, ils ont loujours le fouet à la main; le manche en est ordinairement fait de bois; ils ne portent 
jamais d'éperons. En été, les troupeaux de bisons sont épars au loin dans la prairie, et leur poursuite exige alors plus de temps et d'efforts; mais en hiver, lorsqu'ils se rapprochent du Missouri et cherchent un asile dans la lisière des forèts, on en tue souvent un grand nombre en fort peu de temps. Les Indiens restent parfois huit à dix jours hors de chez eux, dans leurs expéditions de chasse. Ils reviennent ordinairement à pied, parce que tous leurs chevaux sont chargés de viande. Les bisons sont généralement lués à coups de flèche et à la distance de dix à douze pas. Quand il fait très-froid, si les bisons restent, malgré cela, au loin dans la prairie, les Indiens chassent peu, préférant souffrir de la faim et ne vivre que de maïs et de fèves; et puis, lorsque, à l'entrée du printemps, on voit beaucoup de bisons noyés descendre la rivière sur des glaçons détachés, ils savent adroitement nager entre ces glaçons, sauter par-dessus et ramener les animaux sur la rive, où ils mangent cette chair demi-pourrie, qui ne leur inspire aucun dégoût. Il est remarquable, dit M. le prince de Wied-Neuwied, à quel point leurs chiens affamés connaissent et utilisent les expéditions de chasse de leurs maîtres. Quand les chevaux reviennent chargés de viande, les enfants du village ont coutume de faire entendre un cri de joie que les chiens comprennent fort bien. Ils se mettent aussitôt à hurler, et courent dans la prairie du côté où la chasse a eu lieu, pour se réunir à leurs parents les loups, et dévorer les restes abandonnés par les chasseurs.

Lorsque les Indiens ont tué un animal, ils commencent par manger tout le foie, l'estomac, la moelle des gros os et les rognons. Les entrailles et la peau appartiennent à celui qui a tué le gibier. S'il arrive un homme de distinction qui ait fait un coup au moment où un animal vient d'être tué, et qu'il en désire la langue ou quelque autre bon morceau, on ne peut le lui refuser. Les Mandans et les Meunitarris ne se servent point de chiens pour la chasse. Ils ont des cerfs et des elks dans les bois, des cabris et des grosses-cornes dans les prairies ou dans les montagnes Noires et autres montagnes des environs. Pour prendre les cabris, qu'ils appellent koké, ils élablissent des parcs, mais non pour les bisons; ils poussent les cabris dans l'eau et les y tuent avec leurs casse-tête; mais cela ne peut se faire que dans quelques cas particuliers. Les Meunitarris font des parcs à cabris plus fréquemment que les Mandans. On cherche, à cet effet, une vallée en pente douce, située entre des collines et ayant à son extrémité une descente escarpée. Sur le sommet des collines, on établit deux lignes convergentes, d'un ou deux milles de long, formées de branches isolées. Au bas de la còte on construit, avec des pieux et des branches, une espèce de clôture ou de claie, de quinze à vingt pieds de long, remplie et couverte de branches de pin. Un certain nombre de cavaliers poussent les cabris entre les extrémités écartées des deux lignes de branches, et les suivent après cela d'un pas rapide. Les animaùx effrayés s'élancent en avant, suivent l'enfoncement et finissent par se précipiter dans la clòture, où on les prend en vie, ou bien on les tue à coups de fouet.

Les ours sont rares dans ces environs, et les Indiens n'aiment pas beaucoup cetle espèce de chasse, parce qu'elle est souvent périlleuse sans que le profit en compense le danger.

Les renards et les loups sont quelquefois lués à coups de fusil, de même qu'en hiver les lièvres blancs; les deux premiers animaux se prennent aussi dans des piéges. Ceux qu'ils ḍressent contre les loups sont très-forts et formés par un tronc d'arbre qui retombe. Le loup des prairies n'est pas facile à prendre étant fort prudent. On prend les renards dans de petits piéges que l'on couvre de branchages et de têtes de bison, pour en cacher l'entrée. On rencontre partout dans la prairie des piéges de ce genre, qui sont entourés de petits bâtons, pour empêcher que l'animal n'y entre par le côté. Les castors se traquent au moyen de piéges en fer, que les Indiens achètent des mar- 
chands. Les animaux plus petits, tels que l'hermine, se prennent avec des piéges en crin que l'on dresse devant leurs terriers. On dit que la chasse aux oiseaux de proie est fort remarquable. L'oiseleur s'étend dans un trou creusé exprès, et assez long pour contenir toute sa personne. On le couvre de branchages et de foin; sur la surface on place des morceaux de viande, et l'on y attache une corneille ou quelque autre oiseau de ce genre. L'oiseau de proie s'abat sur la viande, et le chasseur le saisit alors par les serres. On prend de celte manière l'aigle à queue noire et blanche, le quilion ou oiseau de médecine des Canadiens. Les Indiens y allachent un grand prix.

Après la chasse, la guerre est une des occupations des Indiens; et la gloire des armes est la plus haute à laquelle ils aspirent. On sait que la valeur des Indiens est très-différente de celle des blancs : s'exposer à découvert au feu de l'ennemi ne serait pas, à leurs yeux, de la bravoure, mais de la folie. C'est la ruse qui leur donne la supériorité. C'est dans l'espionnage, dans l'art de cacher leurs mouvements et dans les attaques au point du jour qu'ils meltent leurs forces. Celui qui tue beaucoup d'ennemis, sans éprouver lui-même aucune perte, est regardé comme le meilleur gucrrier; faire un coup est pour eux l'affaire la plus importante. Quand un jeune homme veut se faire une réputation sous ce rapport, il commence par jeûner pendant quatre ou sept jours, aussi longtemps que ses forces le lui permettent; il se plaint, il pousse des cris au seigneur de la vie, il invoque le secours des puissances célestes, et ne relourne dans sa case que le soir pour coucher. Si le seigneur de la vie le fait rèver d'un animal ou d'un morceau de bois de cerisier, c'est bon signe. S’il fait bientôt un coup, sa renommée est consolidée. Mais quel que soit le nombre de coups par lesquels il se distingue, s'il ne fait pas des présents d'objets de valeur, il n'est point considéré, et on dit de lui qu'il a fait, à la vérité, beaucoup de coups, mais qu'il est aussi à plaindre que ceux qu'il a tués. Du reste, quelque nombreux que soient les coups qu'un homme a faits, il ne lui est pas permis de placer de petites touffes de cheveux à ses habits, s'il ne porte pas un sifflet el s'il n'a pas été partisan, c'est-à-dire chef d'un détachement de guerre. Quand un jeure homme, qui n'a point encore fait ses preuves, se trouve ètre dans une expédition, au premier de ses coups qui tue un ennemi, il se peint sur le bras une raie en spirale, de la couleur qui lui plaît, et il a le droit de porter une queue deloup tout en tière autour de la cheville. Si le pre. mier il a touché l'ennemi, et s'il le tue, il peint une ligne qui tourne en biaisant autour du bras, et puis une seconde qui la croise en sens opposé, avec trois raies transversales. Au second ennemi, il se peint la jambe gauche en rouge brun. S'il tue également ce second ennemi, avant qu'aucun de ses camarades ail été lué, il peut meltre deux queues de loup entières autour de ses pieds. Au troisième coup, il se peint deux raies longitudinales sur le bras, toujours avec trois raies transversales accouplées. C'est là le coup qui fait le plus grand honneur. Après le troisième exploit, on ne le marque plus. S'il tue un ennemi après que d'autres personnes du détachement en ont déjà tué, il s'attache à la cheville une queue de loup dont le bout a été coupé. Dans tout gros détachement de guerre, il y a toujours quatre partisans, quelquefois sept; mais il n'y en a jamais que quatre véritables; les autres s'appellent de mauvais partisans. Pour devenir chef, il faut commencer par avoir été partisan, puis tuer un ennemi dans une expédition où l'on n'est pas partisan. Quand on suit, pour la seconde fois, un autre partisan, il faut ĉtre le premier à décou vrir la peuplade ennemie, tuer un homme de cette tribu et avoir possédé la peau entière d'un bison blanc femelle : sans cela on ne saurait prétendre au titre de noumakchi (chef). Tous les guerriers portent autour du cou de petits sifflets de guerre (ihkocheka), qui sont souvent très-élégants et décorés de piquants de porc-épic. Aussitôt que l'on se jette sur l'ennemi, chacun siflle et pousse en même temps le cri de guerre. Ce cri est aigu, et on le fait trembloler en frappant, à plusieurs reprises et avec 
vitesse, de la main sur la bouche. Ceux qui jeûnent et qui rêvent pour faire un bon coup, ont le droit de porter une peau de loup. Autant on a fait de coups, autant on peut porter de plumes d'aigle dans les cheveux.

Tous les Indiens, dans leurs expéditions de guerre, se construisent, le soir, une espèce de fort; ils s'y trouvent, en quelque façon, en sûreté contre une surprise. Ils posent toujours des sentinelles la nuit, dans leurs expéditions, aussitôt qu'ils approchent de l'ennemi, et envoient souvent des éclaireurs fort loin en avant. Dans ces occasions, les Indiens sont très-vigilants et dans une activité perpétuelle. Après les combats, on n'enterre point les morts; si on n'a pas le temps de les emporter, on les laisse sur le terrain. Les Mandans, les Meunitarris et les Corbeaux ne martyrisent jamais leurs prisonniers, comme les nations d'Orient et les Pahnis. Aussitôt qu'un prisonnier est entré dans un village et y a mangé du maïs, on le regarde comme faisant partie de la nation mème, et personne ne l'insulte. Mais il est arrivé souvent que les femmes sont allées au-devant d'un prisonnier, et l'ont tué avant qu'il entrât au village, surtout lorsque leurs maris ou leurs fils avaient péri dans le combat. 11 est rare que les Indiens fassent des prisonniers du sexe masculin dans leurs combats. En génèral on les tue,

Lorsqu'un jeune homme veut devenir partisan, il consacre une pipe de médecine, toute simple et sans ornement. Il a eu soin auparavant de se concilier la bienveillance des jeunes gens par des présents, et celle de toute l'armée céleste par un jeûne et ses gémissements de quatre jours, qui servent aussi à la consécration de sa pipe. Il s'adresse ensuite aux jeunes gens el les prie de le soutenir dans son projet. Quand il a trouvé un assez grand nombre de personnes disposées à entreprendre une expédition, et lorsqqu'elle a été décidée, ils dansent, mangent et s'amusent pendant plusicurs nuits, et se mellent aussi ordinairement en marche pendant la nuit. Les femmes ne font jamais partie de ces expéditions. En partant, les guerriers sont mal vêtus et ne sont pas peints. Ils ne partent pas tous ensemble, mais isolément ou du moins par petits détachements. Parvenus à une certaine distance du village, ils font halte sur quelque colline isolée; on s'assied en cercle, on ouvre les sacs de médecine; le partisan tire sa pipe de médecine et la fume.

Lorsque les guerriers reviennent de leur expédition après avoir fait des coups, ils se peignent le visage et souvent tout le corps en noir, et portent les scalps suspendus à des perches. Les femmes et les enfants vont au-devant d'eux, et ils rentrent dans le village en dansant la danse du scalp. On répète ensuite cetle danse pendant quatre nuits. Si la campagne a eu lieu au printemps, et si après cela il n'y a plus aucun membre de la nation de tué, on continue à danser jusqu'à la chute des feuilles; si, au conIraire, c'est en automne que l'expédition est sortie, on danse jusqu'au printemps. Si, dans l'intervalle, quelqu'un de la nation est tué, toutes les réjouissances cessent immédiatement. Pour se livrer à la danse du scalp, les Indiens se peignent de différentes manières; ils se placent en demi-cercle, marchent en avant el en arrière, chantant, battant du tambour et jouant du ehichikoué. Les femmes dont les maris ont conquis les scalps, les portent attachés à de longues verges.

Les hauts faits exécutés par un délachement de guerre sont tous complés au parlisan. C'est à lui qu'appartiennent les scaljs, ainsi que les chevaux enlevés. L'homme qui ${ }_{*}^{*}$ a tué un ennemi est un brave el compte un coup; mais la principale gloire en revient au partisan, quand même il u'aurail vu lui-même aucun des ennemis tués. Quand il revient chez lui, les vieillards et les vieilles femmes lui chantent le chant du scalp, honneur qui l'oblige de faire à tous des présents de prix. Il donne tous les chevaux qu'il a enlevés, ainsi que tous les objets qui ont quelque valeur. Après une de ces expé- 
ditions, il est pauvre, mais il a acquis une grande réputation. Les partisans heureux deviennent chefs et acquièrent une haute considération dans leur nation. Les jeunes Indiens vont à la guerre dès l'âge de quatorze ou quinze ans.

Les Mandans et les Meunitarris s'étendent jusqu'aux montagnes Rocheuses; dans leurs guerres contre les Pieds-Noirs, contre les Ojibouais, ils vont jusqu'à Pembina. Leurs autres ennemis sont les Dacotas, les Ariccaras, les Assiniboins, les Chayennes. Ils sont en paix avec les Corbeaux.

Ils ont pour armes : d'abord l'arc et la flèche. Le premier se fait de bois d'orme ou de frêne; car on n'a pas dans ces contrées de bois de bonne qualité, et il est souvent couvert d'ornements. Dans ce cas, on attache à chaque extrémité un morceau de drap rouge de quatre à cinq pouces de long, dont on entoure l'arc, qui est orné de grains de verre blancs, ou de rangées de piquants de porc-épic teints, ou bien encore de petites bandes d'hermine. A l'extrémité supérieure de l'arc on adapte ordinairement une touffe de crin peint en jaune. Le carquois, au haut duquel est altachée la gaîne de cuir de l'arc, est fait de peau de panthère ou de bison; dans le premier, le poil est en dehors, la longue peau est pendante, et elle est garnie du côté de la chair, de même que chez les Pieds-Noirs, de drap rouge orné de grains de verre blancs disposés en diverses figures. De fort beaux carquois de ce genre se font en peau de loutre; on y attache un grand prix. Aux deux bouts du carquois on laisse retomber, comme ornement, d'étroites lanières de peau.

Les flèches des Mandans et des Meunitarris sont travaillées avec goût. Quoiqu'au premier aspect toutes ces flèches se ressemblent parfaitement, il y a cependant une grande différence dans la manière dont elles sont fabriquées. On assure que, de toutes les nations du Missouri, ce sont les Mandans qui fabriquent les flèches les plus belles et les plus solides. Les pointes de fer en sont épaisses et fortes, les plumes entièrement collées, et l'entourage autour de la pointe et à l'extrémité des plumes est de nerfs d'animaux très-fins et très-égaux. Sur toute la longueur est tracée une ligne rouge en spirale qui doit représenter la foudre. Les pointes de fer failes par les Meunitarris sont plus minces et moins bonnes; ce peuple ne colle pas aussi bien les plumes, et se contente de lés altacher par les deux extrémités, comme font les Brésiliens. La pointe en est triangulaire, longuette, plate et bien pointue; ils les fabriquent euxmêmes avec du vieux fer. Elle s'attache légèrement au hois de la flèche, et elle reste ordinairement dans le corps qui a été blessé. On n'empoisonne jamais les flèches. Autrefois toutes les pointes se faisaient avec des pierres aiguës.

Presque tous les Mandans el les Meunitarris ont des fusils; les Mandans les ornent de petits morceaux de drap rouge, qu'ils allachent aux anneaux de cuivre, dans lesquels on passe la baguette. Indépendamment de la baguelte qui appartient au fusil, tous les Indiens en portent à la main une autre très-longue, dontils se servent habitutlement. La giberne est en cuir ou en toile, souvent ornée de grains de verre ou de piquants de porc-épic, et leur pend sur le dos à une courroie ou à une large et forte bande de drap.

Leurs haches et massues de guerre sont de différentes espèces. "Il y en a qui portent à l'extrémité d'un bâton une grosse pierre ovale, quelquefois recouverte de cuir. D'autres ont de petites haches de fer. Le grand casse-tête, avec la large pointe de fer sur le côté, s'appelle manna-okatanhé; et une simple massue noneuse en bois est nommée mannapauiché. Plusieurs Mandans portent en outre des lances. On voit aussi chez ces Indiens des boucliers, mais qui ne diffèrent en rien de ceux des autres nations. Tous portent par derrière, à leur ceinture, leur grand coutelas, qui leur est indispensable, tant à a chasse qu’à la guerre. 
Les Mandans et les Meunitarris se battent bien à leur manière, et l'on cite même d'eux quelques traits de bravoure.

Les plaies guérissent chez les Indiens avec une élonnante rapidité. Dans les blessures faites par des flèches, on a coutume de leur faire traverser toutes les chairs, pour que le fer h'y reste point. Il arrive souvent que dans les combats, des hommes et des femmes sont scalpés, qui reprennent ensuite connaissance et guérissent.

Les maladies sont communes chez les Indiens. Les Mandans et les Meunitarris sont sujets à des ophthalmies; il y en a beaucoup de borgnes ou qui ont une taie sur un des yeux. Dans les inflammations des yeux, leur traitement consiste à se gratter le globe de l'œil avec une espèce d'herbe tranchante comme une scie, jusqu'à ce que le sang coule, et c'est peut-être à cela qu'il faut attribuer la perte de cet organe. Ils souf. frent beaucoup de rhumatismes, de la toux et d'autres maux semblables, ce dont il ne faut pas s'étonner, puisqu'ils vont à demi nus dans les plus grands froids, et se baignent dans de l'eau glacée. Les bains de vapeur qu'ils prennent dans une cabane hermétiquement fermée, où l'on jette de l'eau sur des pierres échauffées, ont souvent des résultats très-favorables. En sortant de ces bains, ils vont se rouler dans la neige ou se jeter dans la rivière au milieu des glaçons; mais ils ne rentrent pas après cela dans la chaleur, comme on le fait dans les bains russes. Il y en a qui souffrent de la goutte et dont les membres se déjettent, mais tous ceux qụi ont pu supporter ces remèdes violents sont ensuite beaucoup plus forts et plus endurcis. Parfois aussi ils se font piétiner le corps, principalement sur le ventre; usage qui se retrouve chez les Brésiliens. On marche alors sur eux avec tant de force qu'il en résulte souvent des squirres aux entrailles ou des tumeurs au foie. Le bain de vapeur. s'emploie contre toules les maladies.

Lorsqu'un Mandan ou un Meunitarri vient à mourir, on ne laisse pas le corps longtemps dans le village; on le transporte à deux cents pas environ, sur un échafaudage étroit, de six pieds de long, el reposant sur quatre pieux d'une dizaine de pieds de haut, qu'ils appellent un macholté; mais auparavant on enveloppe le corps dans des robes de bison ou dans une couverture de laine. Le visage, qui a été peint en rouge, est tourné vers l'orient. Un grand nombre de ces échafaudages entourent leurs villages; et quoiqu'ils avouent que cet usage est nuisible à la santé des habitants, ils n'y renoncent pourtant pas. On y voit aussi de petits cercueils qui renferment des corps d'enfants attachés avec une toile ou une peau. Les corbeaux se perchent d'ordinaire sur ces échafaudages, et les Indiens n'aiment pas ces oiseaux, parce qu'ils mangent la chair de leurs parents. Quand on demande à un Mandan pourquoi il n'enterre point ses morts, il répond: "Le seigneur de la vie nous a dit, à la vérité, que nous venions de la terre et que nous y retournerions; mais nous avons pourtant commencé depuis peu à placer les corps des délunts sur des échafaudages, parce que nous les aimons el que nous voulons pleurer en les regardant. "Ils croient que chaque homme a quatre âmes, une noire, une brune, el une d'une couleur claire; que celle dernière retourne seule vers le seigneur de la vie. Ils disent qu'après la mort on va habiler plusieurs villages situés vers le midi, el qui sont souvent visités par des dieux. Les hommes vaillants et distingués vont au village des bons, et les méchants vont dans un autre. Ils y vivent comme ils vivaient auparavant; ils y ont des aliments et des femmes; ils chassent et font la guerre. Ceux qui ont bon cœur et font beaucoup de présents aux autres, retrouvent là de tout en abondance; leur existence est conforme à la conduite qu'ils ont tenue su. la terre.

Ils portent pendant une année le deuil de leurs morts; dans ces occasions ils se coupent les cheveux, s'enduicent le corps d'argile blanche ou grise, et se font fréquemment des 
entailles aux bras ou aux jambes avec un couleau ou une pierre à fusil tranchante, de sorte qu'ils paraissent tout couverts de sang. Dans les premiers jours qui suivent le décès, on n'entend que des pleurs et des gémissements. Un parent, ou quelque autre personne, vient souvent pour faire ce qu'ils appellent couvrir le mort. Il apporte avec lui une ou deux couvertures de laine ou de toile rouge, bleue, blanche et verte, et, aussitôt que le corps est posé sur l'échafaudage, il y monte et le recouvre avec ce qu'il a apporté. Cet ami reçoit alors en présent un cheval de la famille affligée. Quand on apprend d'avance que quelqu'un va se présenter dans cette intention, on attache immédiatement un cheval à l'échafaudage, et celui qui est venu couvrir le mort, après avoir accompli ce devoir pieux, détache sans façon le cheval et l'emmène. Lorsqu'un Mandan ou un Meunitarri est tué à la guerre et que la famille en reçoit la nouvelle, sans que l'on ait pu rapporter le corps, on roule une peau de bison et on la porte hors du village. Tous ceux qui veulent pleurer le mort se rassemblent et jettent sur le cénotaphe une foule d'objets de valeur, dont ils font présent aux assistants, pendant que la famille se coupe les cheveux, pleure et gémit. Les Mandans ne se coupent pas les phalanges des doigts en signe de deuil, comme les Pieds-Noirs; quand ils le font, c'est comme pénitence ou sacrifice au seigneur de la vie.

Pour un Français ou pour un Anglais la langue des Mandans est difficile à prononcer, mais elle l'est beaucoup moins pour un Allemand ou un Hollandais, parce qu'ils ont une foule de syllabes gutturales. Il n'y a qu'un petit nombre de syllabes nasales; mais, en revanche, ils parlent souvent en entr'ouvrant à peine la bouche, et d'une manière fort indistincte, et en adoucissant beaucoup les voyelles.

Les Chochonis mènent une vie errante. Depuis le milieu de mai jusqu'aux premiers jours de septembre, ils restent sur les eaux de la Colombia, vivant de saumon que ce fleuve nourrit en abondance; puis, l'automne venu, ils descendent vers les plaines du Missouri, y forment des alliances avec les Tètes-Plates, pour se garantir des attaques des Pakis, et ils se livrent ensuite à la chasse du bison. Francs et communicatifs avec les étrangers, les Chochonis leur donnent volontiers le peu de vivres qu'ils ont.

Ils sont de taille médiocre; ils ont les pieds gros et plats, les chevilles grosses. Leur teint ressemble à celui des Sioux; il est plus foncé que celui des Meunitarris, des Mandans et des Panis. Les hommes et les femmes laissent flotter leurs cheveux épars sur les épaules. Quelques hommes les partagent pourtant, avec des courroies de cuir ou de peau de loutre, en deux queues égales pendant par-dessus les oreilles sur le devant du corps. Les Chochonis se coupent les cheveux à la hauteur du cou, quand la peuplade est affligée d'un grand deuil, comme celui de la perte de plusieurs guerriers distingués.

D'un caractère sociable, doux et gai, ils aimeni la parure. On ne saurait dire quel est au juste leur gouvernement. Chaque individu relève de lui-mème, et le chef n'a pour lui que l'action du conseil. Ce chef est ordinairement le guerrier le plus brave; c'est un rang qui n'est ni conféré par des cérémonies, ni caraclérisé par des insignes. Dans sa famille, l'homme est maître et despote : il peut vendre ses femmes et ses filles.

La polygamie est en vigueur chez les Chochonis; mais on n'y peut, comme chez les Mandans et les Meunitarris, épouser sa propre sœur. Les filles sont fiancées en bas âge, cl échangées par le père contre des chevaux et des mulets. A l'âge de puberté, c'est-àdire à quatorze ou quinze ans, on remet la jeune fille à son mari, et le père fait un cadeau égal à celui qu'il a reçu lors des fiançailles. Loin d'être jaloux, les Chochonis trafiquent des faveurs de leurs femmes.

Chez les Chochonis, la femme est chargée des plus rudes travaux de la maison; l'homme ne se réserve que les périls du combat et le soin de son cheval. Ils regardent 
comme une humiliation d'aller à pied à une certaine distance. Du reste, les chevaux sont assez nombreux pour que tout le monde en ait, femmes et hommes. Leurs chevaux sont beaux el pleins de vigueur; chaque guerrier en a toujours un ou deux attachés à un pieu près de sa cabane. La guerre étant le premier besoin des Chochonis, nul ne peut espérer de marquer dans sa tribu, s'il n'a fait ses preuves de courage. Tuer un ennemi n'est rien, si l'on ne rapporte pas sa chevelure du champ de bataille. Qu'un guerrier melte à mort beaucoup d'adversaires dans un combat, il n'en aura pas les houneurs si d'autres que lui ramassent les chevelures des morts. Les armes ordinaires du guerrier chochoni sont l'arc et les flèches, le poggamogou, une lance, et un bouclier.

L'habillement des hommes consiste en une robe, une collerette, une chemise, de longues chausses ou bas, et des mocassons ou chaussons. La robe est ordinairement de peaux de grosse-corne ou de cerf rouge, de peaux de castors, de marmottes, d'élans, de jeunes loups, quoique la peau du bison soit prélérée à lout cela. On passe ces peaux en y laissant le poil ; les robes descendent jusqu'au milieu de la jambe. Mais la pièce la plus élégante de l'habillement des Indiens est la collerette, dont le collet est une bande de quatre à cing pouces, coupée le long du dos d'une peau de loutre. Le museau et les yeux en forment une extrémité, et la queue une autre. A cette bande on laisse les poils; puis on attache sur l'un des bords, d'un bout à l'autre, cent ou deux cents petits rouleaux de peaux d'hermines. On fixe des glands faits de franges de la même peau au bout de la queue pour en mieux faire ressortir la couleur noire. Le milieu du collet est, en outre, orné de coquilles perlières. Ces collerettes sont très-estimées; on ne les donne yue dans les occasions importantes. La chemise est de peau d'élan; elle descend jusqu'à mi-cuisse: ses bords sont quelquefois unis, d'autres fois terminés par la queue de l'animal. Les coutures pratiquées sur les còtés sont garnies de franges et de piquants de porc-épic. La partie inférieure de la chemise garde la forme naturelle des jambes de devant et du cou de l'animal, décorés d'une légère frange. Les chausses sont aussi faites de peau d'élan; le mocasson ou chausson est en peau de cerf, d'élan ou de bison, passée et sans poil. Il est orné de figures faites de piquants de porc-épic.

L'habillement des femmes diffère peu de celui des hommes. Quoique plus courte, la robe est portée de la mème manière; la chemise, les mocassons diffèrent. Le principal ornement de la chemise des femmes est sur la poitrine, où l'on voit des figures bizarres faites avec des piquants de porc-épic. Les femmes ont, comme les hommes, une ceinture autour du corps. Les enfants seuls, portent des colliers de verroterie. Les adultes les suspendent aux oreilles en petites pendeloques, et les entremèlent de morceaux d'huîtres perlières. Quelques hommes en pareni leurs cheveux en y ajoutant des ailes et des queues d'oiseaux, notamment des plumes du grand aigle, qu'ils recherchent beaucoup. Les colliers sont faits, soil de coquilles marines, soit d'écorces aromatiques, qu'ils tressent el tordent de la grosseur du doigt. Les hommes ont quelquefois un collier d'os ronds semblables à des vertèbres de poissons; mais le collier préféré, le collier le plus honorable, est fait des griffes de l'ours brun. Ces griffes sont alors suspendues à une lanière de cuir; on les décore de grains de verroterie; et les guerriers sont tout fiers de les porter au cou; car tuer un de ces animaux est un exploit équivalent à celui de tuer un ennemi.

Échanger son nom avec son ami est une marque de politesse chez ce peuple, de mème que la cérémonie d'ôter les mocassons est un gage de sincérité el d'hospitalité. Quand un Chochoni fait ce dernier acte, il semble dire : "Puissé-je marcher pieds nus, si je vous trompe; "ce qui, dans un pays semé de plantes épineuses, est la plus terrible des imprécations. Les noms des Chochonis varient dans le cours de leur vie. 
A chaque nouvel exploit, un adilte ou un homme fail a le droit d'en changer. Sous le nom générique de Têtes-Plates, on comprend les Killamoks, les Clastops, les Tcunnouks, les Catcamahs; ces peuples ont entre eux de grandes ressemblances lant physiques que morales. Ils sont en général de petite taille, mal faits et d'un extérieur repoussant. La couleur de ces Indiens est le brun cuivré; ils ont la bouche grande, les lèvres épaisses, le nez de moyenne grandeur, charnu, élargi aux extrémités, avec de grandes narines. Les yeux sont presque toujours noirs.

Le nom de Têtes-Plates est venu à ces tribus de l'usage où ils sont d'aplatir la lète aux nouveau-nés. Pour obtenir cet aplatissement, la mère place son enfant dans une machine qui lui comprime la tête, et l'y laisse dix à douze mois; les garçons plus longtemps que les filles.

Ces peuples ont le caractère doux et affectueux. Ils sont questiouneurs el grands parleurs; ils ont de l'intelligence, de la finesse et une excellente mémoire. Tout ce qu'ils voient excite leur curiosité; ils répondent sensément à toutes les questions, et apprennent facilement les langues étrangères. Chez eux, la femme n'est pas dans l'état d'infériorité que l'on remarque parmi les autres peuplades. 11 leur est permis de parler librement devant les hommes; on les consulte, on les écoute, on suit même leurs avis. La conduite des pirogues, qui ailleurs repose sur les femmes, est ici commune aux đleux sexes. Les travaux du ménage sont partagés. Les hommes ramassent du bois, font le feu, aident à vider le poisson, à bàtir les maisons, à construire les pirogues, à fabriquer les ustensiles. Les femmes recueillent les racines, fabriquent divers objets avec le jonc, l'acorus, l'écorce de cèdre et le bear-grass.

Ils ont le vice des jeux de hasard, dont ils connaissent un grand nombre, assez perfectionnés pour la plupart. Dans le commerce, ces Indiens montrent de l'intelligence, de la finesse, mème de la subtilité. Naturellement soupconneux, ils refusent constamment la première offre, quelque élevée qu'elle soit. Ces habiludes de calcul, étrangères à toutes les autres tribus indiennes, leur sont venues de leurs rapports fréquents avec les brocanteurs de la Colombia. Le lieu du grand marché est à la chute mème du fleuve. Toutes les nations voisines s'y rassemblent à des époques fixes; celle des plateaux de l'est, et celle du littoral de l'ouest, chacune avec les produits de son sol, de son industrie ou de sa chasse.

Leur costume diffère beaucoup de celui des Chochonis. Les hommes portent une petite robe qui ne va qu'à mi-cuisse; quelquefois aussi des couvertures tissues de la laine de leurs moutons. La robe des femmes ne commence qu’à la ceinture. Les plus estimées sont en bandes de peaux de loutre de mer, que l'on tord el que l'on entrelace avec des liens d'herbe ou d'écorce de cèdre.

Au rebours des indigènes de la montagne, ces sauvages ne portent ni bas ni mocassons; vivant sous un climat chaud et sur une plage unie, ils n'ont pas besoin de chaussurc. Ils se coiffent avec un chapeau fait de bear-grass et d'écorce de cèdre entrelacée; ce chapeau est conique avec un bouton de mème forme au sommel. Quelquefois ces sauvages se tatouent ou se laissent talouer. La plus grande passion des hoinmes el des femmes est celle de la verroterie blanche et bleue.

Les Kansas ou Konzas habitent les bords de la rivière de leur nom. Moins nombreux ¿que les Osages, ils sont plus redoutables par leur courage. Leur gouvernement est une espèce d'oligarchie républicaine, présidée par des chefs, la plupart héréditaires, mais qui souvent sont éclipsés par des guerriers illustres. Toute affaire importante est soumise à l'assemblée des guerriers, qui décident à la majorité des voix. Le peuple est divisé en trois classes. Le gros de la nation se compose de guerriers ou chasseurs; les jongleurs et les cuisiniers forment les deux autres classes. Les jongleurs, qui sont en 
mème temps prètres et magiciens, ont une grande influence sur les affaires publiques par leurs divinations, leurs sortiléges, et par l'interprétation des rêves. Quoi qu'il en soit, ils se montrent assez bons jongleurs; ils s'enfoncent de larges couteaux dans la gorge en répandant le sang à gros bouillons; ils insèrent des bâtons aigus dans leur nez, ou ils rejettent par les narines des os qu'ils ont avalés auparavant; d'autres percent leurr langue d'un bâton, et se la font couper pour rejoindre ensuite les morceaux, sans qu'il restc aucune trace de l'opération. Les cuisiniers sont au service du public, ou attachés à quelque personnage marquant : ce sont quelquefois d'anciens guerriers qui, se trouvant affaiblis par l'âge ou accablés d'infirmités, et ayant perdu toute leur famille, se voient obligés d'embrasser cette profession; chargés en même temps des fonctions de crieurs publics, ils convoquent les chefs aux conseils ou aux festins.

Les Osages proprement dits sont disséminés en trois villages qui, un jour, pourraient bien former trois peuplades particulières : les grands Osages, les petits Osages, et les Osages de l'Arkansas : le nombre de ces derniers s'accroît journellement.

Ces peuples sont redoutés comme une nation brave et belliqueuse par les peuplades au sud et à l'ouest de leur territoire; mais ils ne șauraient lutter avec les guerriers des nations septentrionales, munis de bons fusils rayés, et envers lesquels ils jouent sagement les rôles de quakers du désert, en continuant de faire une guerre implacable aux sauvages de l'occident, nus et sans défense, ou seulement armés de flèches et de lances. Il faut croire cependant que, par la suite, ils sauront mieux résister à leurs voisins du nord, s'il est vrai qu'ils possèdent aujourd'hui quatre pierriers provenant d'un fort espagnol, et deux canons de bronze donnés par le gouvernement des ÉtatsUnis, qui paraît vouloir les amener promptement à une civilisation européenne.

Les Osages ont pour mets ordinaires des épis verts de maïs préparés avec de la graisse de poisson, des citrouilles bouillies et des viandes. Ils sont hospitaliers par ostentation. Lorsqu'un Américain des États-Unis entre dans un village, l'usage veut qu'il se présente d'abord à la cabane du chef, qui lui sert un repas où son hôte mange le premier, à la manière des anciens patriarches. Ensuite, tous les personnages les plus importants du village invitent l'étranger, el ce serait leur faire une grande insulte que de ne point obéir à l'appel; en sorte que dans une même après-dînée, on peut recevoir douze à quinze invitations; c'est le cuisinier qui les fait, en criant : \& Venez et mangez, un tel donne un festin; venez et jouissez de sa libéralité. »

Dans les villages, les cabanes sont dressées sans ordre, et quelquefois si rapprochées, qu'elles obstruent le passage. Pour surcroît d'embarras, les chevaux parquent la nuit au milieu des rues, lorsqu'on a lieu de craindre que l'ennemi ne rôde dans le voisinage. Du reste, leurs habitations sont fraîches et très-propres.

Les Panis ou Pawnees, que les Espagnols appellent Padoucas, forment une nation nombreuse, disséminée sur les bords des rivières Plates et Kansas, et divisée en trois branches principales : les grands Panis, les Panis républicains, et les Panis loups, qui quelquefois se font la guerre. Ils ont la stature haute et élancée, les os des joues fort proéminents et la prononciation gutturale. Leur gouvernement a la forme d'une aristocratie héréditaire.

Ils se livrent à la chasse du bison, qui abonde dans leur territoire, ce qui ne les empêche pas de s'appliquer à la culture des champs, ni de penser à l'avenir, en faisant des provisions pour l'hiver. Ils coupent les citrouilles en tranches fort minces, qu'ils font sécher au soleil, afin d'avoir de quoi donner à leur soupe quelque consistance pendant loute l'année. Ils ont des troupeaux d'excellents chevaux, dont ils prennent le plus grand soin; cependant ils font la guerre à pied, en cherchant des positions où ils puissent se servir avec avantage de leurs armes à feu. 
Les habitations sont de forme ronde avec une saillie vers la porte; chaque membre de la famille a sa chambre particulière. Ils aiment les jeux d'exercice, auxquels ils se livrent dans des places publiques de 700 à 800 pieds de long, préparées exprès de chaque côté du village.

Les Omaнas, que quelques voyageurs appellent, à tort, Mahas, formaient autrefois une tribu nombreuse; mais les guerres cruelles qu'ils eurent à soutenir contre leurs voisins, et la petite vérole, les ont beaucoup réduits; ils n'ont plus maintenant que bien peu de jeunes gens vigoureux. Ces indigènes ne diffèrent pas beaucoup des autres Indiens; seulement ils ne sont pas aussi bien faits que les Sacs.

Comme nous l'avons dit, la petite vérole leur a causé de grands dommages; aussi en sont-ils presque tous marqués; plusieurs même en sont devenus aveugles, d'autres borgnes, et d'autres enfin ont des taies sur les yeux. Leur visage est marqué de raies rouges; chez les uns, le front et le menton sont peints en rouge; d'autres n'ont de raies que sur les joues. Peu d'entre eux ont le nez aquilin; leurs yeux sont rarement rabaissés aux coins; en général, ils les ont petits, quoique quelques-uns, par exception, les aient assez grands. Ils portent leurs cheveux retombant sans ordre sur le cou; aucun n'a la tête rasée, et tous sont fort sales et misérables. La physionomie des femmes est laide; cependant leur.visage n'est pas tout à fait aussi large et aussi plat que chez les Sacs et les Renards. Leur costume ne diffère pas beaucoup de celui des autres tribus; et, comme celles-ci, elles portent des rangs de wampum dans les trous de leurs oreilles.

Le costume des hommes se compose des culottes que nous avons décrites pour les Sacs et les Renards, et leurs épaules sont couvertes d'une peau de bison. Ils sont armés d'arcs et de flèches renfermées dans des carquois de peau, et jetés en travers sur leur dos.

Le prince de Wied-Neuwied fut témoin d'une danse d'Omahas. II raconte que le coryphée, homme fort et de haute taille, portait sur la tête un panache colossal, semblable à ceux de quelques tribus brésiliennes, mais travaillé moins artistement; il se composait de longues plumes provenant de la queue et des ailes de hibou el d'oiseaux de proie. Le danseur, qui tenait à la main un arc et des flèches, avait le haut du corps nu, sauf une peau blanchâtre qui lui couvrait l'épaule droite et la poitrine. Ses bras, son visage et toutes les parties nues de son corps étaient peints de raies et de taches blanches; sa culotle, rayée en travers d'une couleur foncée, était garnie par le bas d'un grand nombre de franges; il portait en outre un tablier. Sa taille athlétique ajoutait encore à son air naturellement martial et sauvage. - Un autre homme, plus jeune que celui-ci, mais également d'une taille herculéenne, tenait à la main une massue de guerre, blanche et ornée à la poignée d'une peau de putois. Nu jusqu'à la ceinture, il avait sur la tête un bonnet de plumes. Ces deux hommes, ainsi que plusieurs jeunes gens, formaient une ligne et avaient en face d'eux d'autres Indiens, aussi placés en ligne, mais assis Au milieu de la réunion, le tambour résonnait dans une mesure accélérée, tandis que plusieurs individus secouaient en cadence leurs massues pourvues de sonnettes, et que toute la compagnie, dont la majorité des membres étaient peints en blanc, chantait: haï! haï! ou bien : hi! hi! etc., en s'interrompant, de temps à autre, pour pousser une vive acclamation. La manière de danser consiste à pencher le corps en avant et à sauter en l'air des deux pieds à la fois, sans néanmoins s'éloigner beaucoup de terre; puis à secouer les armes et à les élever à des instants déterminés; le tout au bruit du tambour, qui continue à battre vivement. - Quand ils se sont livrés à ce violent exercice pendant une heure environ, on jette à terre, devant eux, un tas de tiges de tabac, présent accoutumé dans ces occasions, et qui est le signal de la clôture de ces jeux. 
Les Poncars ou Pons des Français sont une tribu d'Omahas, dont ils parlent aussi à peu près la langue. Mais ils en sont depuis longtemps séparés et habitent les deux rives de l'Eau qui Court et les bords du Punctsa-Creck, que Clarke et Lewis appellent Poncara. Autrefois ils vivaient, comme les Omahas, dans des huttes de terre, à l'embouchure de la rivière; mais leurs puissants ennemis, les Dacotas et les Pawnees, détruisirent leurs villages, et depuis ce temps ils ont adopté la manière de vivre des premiers, c'est-à-dire qu'ils demeurent dans des tentes de cuir, et qu'ils ne s'arrêtent pas longtemps dans le même lieu. Quant aux formes extérieures el au costume, ils diffèrent peu des Omahas. C'étaient de braves guerriers; mais, comme leurs vainqueurs, la petite vérole et la guerre leur ont été nuisibles.

Les Poncars ont les traits fortement marqués, les os des joues proéminents, le nez aquilin, et les yeux noirs et expressifs. Ils laissent croître leurs cheveux qui pendent jusque sur leurs épaules et mème plus bas; les chefs seuls les portent un peu plus courts, et les rassemblent par derrière en une tresse. Ces Indiens vont nus jusqu'à la ceinture, et portent autour du cou un ruban orné. Leurs oreilles sont percées de grands trous, auxquels pend un ornement de coquillages. Les chefs laissent encore croître leur barbe sous le menton, laquelle, du reste, ne se compose que de quelques poils longs et épars. Ils portent au poignet un étroit bracelet de métal; leurs culottes sont fort simples, et une grande peau de bison complète leur toilette. Cette peau est remplacée chez les chefs par une couverture de laine blanche.

Les Dacotas, ou Sioux des Français, forment encore aujourd'hui une des nations indiennes les plus nombreuses de l'Amérique du nord. Le pays qu'ils parcourent s'étend depuis le Big-Sioux-Riou, entre le Missouri et le Mississipi, le long de ce dernier jusqu'au Root-River, et au nord jusqu'à l'Elk-River, puis se dirigeant en ligne droite vers l'ouest, ce qui comprend les sources de Saint-Peter's-River, joint le Missouri au-dessous des villages des Mandans. Les Dacotas se subdivisent en diverses branches qui, à quelques différences près, parlent toutes la même langue.

Les traits de ces Indiens sont moins réguliers que ceux de beaucoup d'autres nations du Missouri; mais il n'y a pas une grande différence dans leurs physionomies. Les Dacotas ont, en général, les os de la face très-forts et ceux des joues proéminents, levisage allongé, les yeux longs et peu ouverts, le nez tantôt aquilin, tantôt long et un peu recourbé, le teint d'un brun foncé. Ils portent les cheveux longs et pendants, souvent tressés par derrière en queue; les hommes âgés les laissent tomber naturellement; mais ils les coupent derrière le cou et les écartent sur le front. Chez les jeunes gens, ils sont souvent partagés, et une large boucle plate retombe sur le nez. Tous ces Indiens sont chasseurs; ils poursuivent les animaux que l'on peut prendre, et dans leurs voyages, ils couchent sous des tentes de cuir faciles à transporter. Les Dacotas possèdent des chevaux et des chiens; ils mangent ces derniers. Autrefois les Dacotas du Missouri étaient dangereux pour les blancs; mais aujourd'hui, à l'exception de la branche des Ianhtoans ou Yangtons, ils jouissent d'une assez bonne réputation et vivent en paix aves les Européens. Ceux d'entre ces Indiens qui demeurent dans le voisinage des blancs s'allient souvent a vec eux par des mariages, et se fient à leur protection. Ils deviennent alors des chasseurs paresseux, nonchalants, et par conséquent fort pauvres.

Les hommes sont nus jusqu'à la ceinture, et couverts seulement d'une grande peau de bison blanche ou peinte. Ils portent dans les oreilles de longs cordons de coquilles de wampum, blanches et bleues, et quelques jeunes gens se parent la tête de deux ou I rois plumes dépouillées de leurs barbes, excep téà la pointe. Ils portent sur le dos un carquois de cuir qui contient leurs flèches et auquel est attaché le fourreau de l'arc; ils tiennent celte dernière à la main. M. Bodmer, qui accompagnait le prince de Neuwied, fit au 
crayon le portrait d'un de ces' naturels. Cet homme se présenta en grande toilette, le visage peint en rouge avec du cinabre, et de courtes raies noires parallèles sur les joues. Sur la tête, il portait des plumes d'oiseaux de proie, placées sans ordre; c'étaient des trophées de ses exploits, une indication des ennemis qu'il avait tués. Elles étaient attachées horizontalement par des bandes de drap rouge. Les oreilles étaient parées de longs cordons de grains de verre-bleu, et sur la poitrine pendait, à un cordon passé autour du cou, la grande médaille d'argent des États-Unis. Sa culotte, ou ses leggings de cuir, peinte avec des croix et des raies de couleur sombre, était ornée extérieurement avec beaucoup de goût d'une large bande brodée avec des piquants de porc-épic en figures rouges, bleues et jaunes. Ses souliers étaient également ornés et de la même manière. Sa robe de bison était blanche par le bas, et à la main il tenait son tomahawk ou hache d'armes. Il paraissait très-flatté de servir de modèle, et il garda pendant toute la séance la position qui lui avait été ordonnée, ce qui est, en général, fort difficile pour les Indiens.

Les femmes dacotas ressemblent assez à celles des autres Indiens dont nous avons déjà parlé; seulement leurs traits sont moins larges et moins plats que chez les femmes des Sacs et des Renards, et il y en a quelques-unes dans le nombre qui sont assez jolies.

Les tentes des Dacotas ont la forme de grands pains de sucre; elles sont pointues par le haut, faites de gros pieux et recouvertes de peaux de bison cousues ensemble. Ces peaux sont ratissées des deux côtés, au point qu'elles deviennent transparentes comme du parchemin, et laissent pénétrer le jour dans l'intérieur des tentes. Au sommet, à l'endroit où les pieux se réunissent, se trouve l'ouverture par laquelle s'échappe la fumée et que l'on cherche à mettre à l'abri du vent au moyen de soupapes ou d'ailes formées avec la peau de la tente. Une longue perche, uniquement destinée à cet usage, et qui s'attache à l'extrémité supérieure du bord de la couverture de la tente, est placée de manière qu'une de ces ailes, posée perpendiculairement, se tourne toujours du côté d'où vient le vent. Au lieu de porte, il y a une fente sur le devant de la hutte, et elle se bouche ordinairement avec un morceau de peau tendu sur un cadre. Au centre de la hutte on entretient seulement un petit feu. A côté de ces tentes de cuir on plante en terre des pieux, auxquels on suspend divers ustensiles, des cadres pour étendre les peaux nouvellement préparées, pour attacher des sacs et des poches de parchemin, peints de diverses couleurs, ou bien pour garder les armes, telles que les arcs, les flèches, les carquois, les lances, les massues de combat et les boucliers de cuir.

Une des plus importantes occupations des Dacotas est le vol des chevaux; cette action, quand elle a lieu au détriment d'autres nations, est regardée comme un exploit, et honorée autant et même plus que la mort d'un ennemi.

Les chiens sont précieux à ces Indiens; ils en ont de deux espèces : l'une sert à tirer les fardeaux, et l'autre à chasser. Les premiers ressemblent beaucoup aux loups; ils en ont la taille et la force; leur couleur est souvent la même; d'autres fois, noire, blanche ou blanche tachetée de noir; et ils ne se distinguent des loups que par la queue qui est un peu plus retroussée. La voix de ces animaux n'est pas un véritable aboiement, mais plutôt une sorte de hurlement; et il est facile de voir qu'ils sont alliés au loup, lequel, même pendant le jour, s'approche des huttes indiennes, et qui, par conséquent, s'accouple souvent avec les chiennes. Les seconds descendent tous de chiens européens, dont ils ont l'aboiement.

Les Dacotas ont une singulière manière de traiter leurs morts. Ils les enveloppent de couvertures et de peaux, et les placent, tout habillés et peints, avec leurs armes et autres ustensiles, sur un échafaud soutenu par quatre piliers, où ils restent jusqu'à ce 
qu'ils soient corrompus; après quoi on les enterre. Ceux qui sont tués en combattant sont enterrés sur le champ de bataille. Même en temps de paix, ils déposent leurs morts dans la terre, et les protégent contre les loups par des bois et des épines. D'autres fois, ils déposent leurs morts dans les branches des arbres, sur le tronc desquels on pratique un petit berceau, qui sert de retraite aux parents lorsqu'ils viennent pleurer et gémir, cérémonie qu'ils répètent souvent plusieurs jours de suite. Les parents du défunt se coupent les cheveux en signe de deuil, se frottent d'argile blanche, et distribuent tous les objets de prix qu'ils possèdent et leurs plus beaux habits aux personnes présentes.

Les Indiens dacotas qui habitent les environs du Fort-Pierre sur le Teton-River, font, en général, partie de la tribu de Tetons ou Tentons, mais il existe parmi eux quelques Yangtons. Ils sont, en général, fort musculeux, de moyenne taille, et ressemblent en tout aux Dacotas des autres tribus. Ils se peignent les joues en rouge, quelques-uns le tour des yeux en blanc; ils se marquent quelques points noirs sur le front, ou bien un cercle blanc avec des points noirs sur chaque joue. Plusieurs de ces indigènes portent dans les oreilles des cordons de wampum; mais la plupart préfèrent des rangs te grains de verre bleu ou blanc. Ils se tatouent la poitrine de raies noires ou bien de petites figures. Ces Indiens laissent croître leurs cheveux aussi longs que possible, et les tressent par derrière en une longue queue qu'ils ornent de plaques rondes ou de rosettes de cuivre. On voit de ces Dacotas qui ont trois de ces queues, une par derrière, et une de chaque côté.

Leurs femmes portent les cheveux retombant naturellement, séparés au milieu de la lète; la ligne de séparation est peinte en rouge. Leurs robes sont en cuir, peintes en rouge ct noir. Leurs souliers sont ornés avec goût et garnis de piquants de porc-épic, coloriés (t disposés en toutes sortes de figures.

Les Dacolas, en général, attachent un grand prix à la vaillance; c'est pourquoi ils étalent toujours, d'une manière visible, les marques distinctives de leurs exploits. Du nombre de ces marques sont surtout les touffes de cheveux aux bras et aux jambes, ainsi que les plumes sur la lête. Celui qui, en présence du parti opposé, touche un ennemi mort ou vivant, a le droit de placer une plume horizontale dans ses cheveux. Celui qui tue un ennemi de sa propre main, place une plume perpendiculaire. Si l'ennemi est tué d'un coup de fusil, on place dans les cheveux un petit morceau de bois représentant la baguette. Quand un guerrier s'est distingué par différents exploits, il acquiert la faculté de porter un grand bonnet à plumes avec des cornes de bœuf; le bonnet, de plumes d'aigle attachées à un bandeau de toile rouge retombant par derrière le long du dos, est fort estimé de tous les peuples du Missouri, et on ne l'échange jamais que contre un bon cheval. Il est permis à celui qui le premier découvre l'ennemi de porter une petite plume à laquelle on a enlevé les barbes, excepté à l'extrémité. Enfin, celui qui a fait un prisonnier, porte un bracelet d'une forme particulière.

Les Dacotas ne savent pas guérir les malades, mais ils sont habiles à panser les blessures. Avant leur mort, ils ont coutume de fixer la manière dont ils veulent être ensevelis : sur un échafaudage, dans un arbre ou dans la terre.

Les Dacotas se livrent souvent au sangkodeska-kutepi, ou jeu du cerceau. Il consiste à lancer au travers du cerceau des bâtons marqués de cuir.

La vie de ces hommes, si l'on en excepte la chasse et la guerre, se passe à manger, à fumer, à dormir et à fabriquer des armes.

Les Conbeaux ou Crows des Anglo-Américains, sont aussi appelés, par les Mandans, Maiderouka; et le nom qu'ils se donnent eux-mêmes est Apsarouké. Le territoire qu'ils habitent est borné, au nord, par le Yellow-Stone-River (rivière de la Roche-Jaune), et 


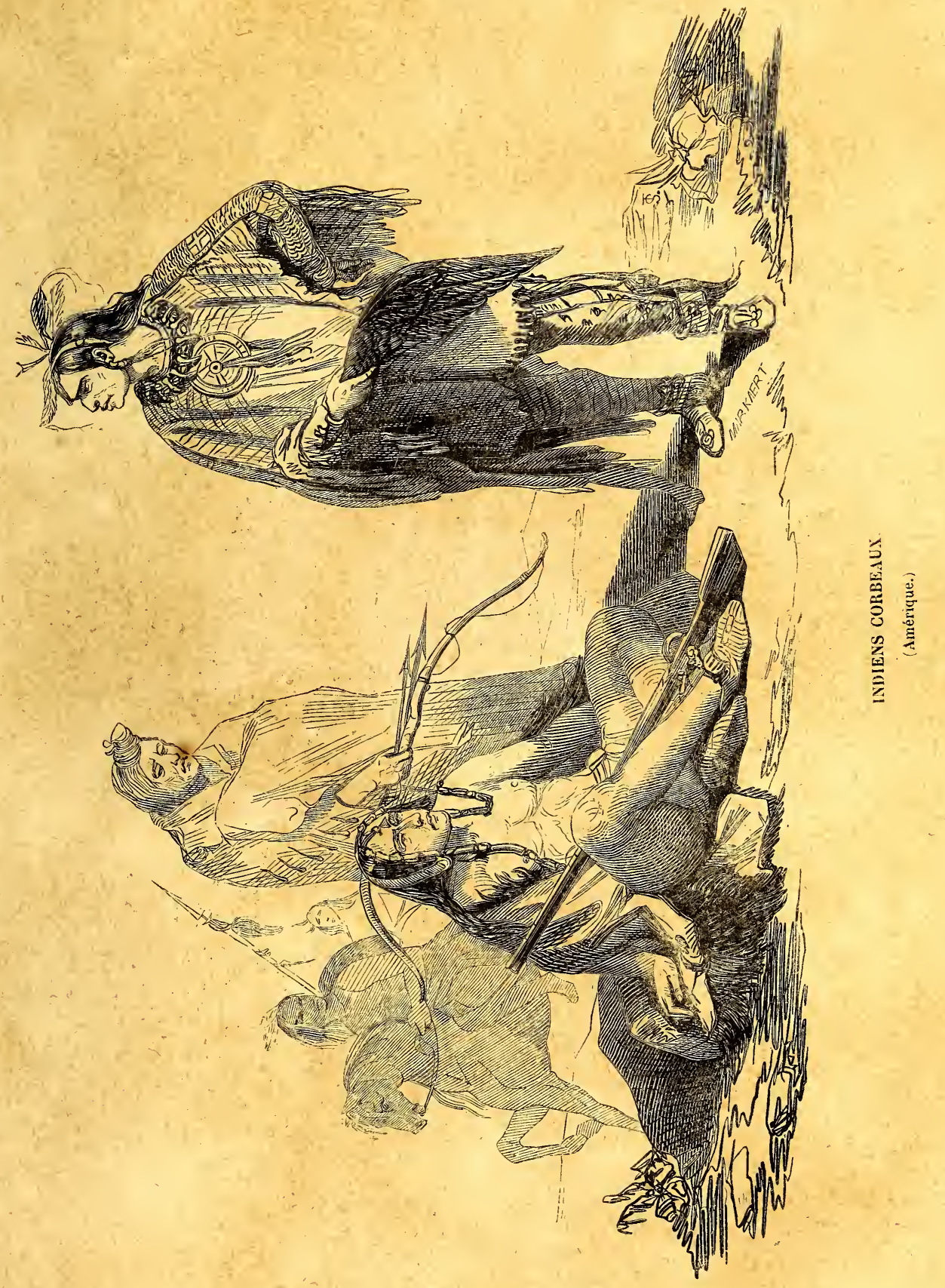



s'étend, autour du Bighorn-River, jusque vers les sources de la Chayenne et les montagnes Rocheuses.

Ces Indiens sont un peuple nomade et chasseur, qui ne demeure point dans des villages stables, comme les Ariccaras, les Meunitarris et les Mandans; ils ne se livrent à aucune culture, si on en excepte une très-petite quantité de tabac, qu'ils ont coulume de semer. Ils voyagent avec leurs tentes de cuir, chassent le bison et toutes sortes de gibier, élèvent beaucoup de chevaux et de chiens; mais ils ne se nourrissent point de la chair de ces derniers. De même que chez tous les Indiens du Missouri, il existe parmi les Corbeaux diverses associations. Ces associations ont chacune une danse qui leur est particulière; le droit d'y prendre part s'achète, comme chez les autres tribus indiennes.

Les Corbeaux sont les plus fiers d'entre les Indiens. Ils méprisent souverainement les blancs, qu'ils ne tuent point, mais qu'ils pillent souvent. Pour ce qui regarde le physique de ces Indiens, et leur manière de s'habiller, ils ressemblent aux Meunitarris, les deux peuples n'en ayant formé, dans l'origine, qu'un seul, ainsi qu'il est aisé de le reconnaître au rapport de leur langage. Les femmes des Corbeaux sont très-habiles aux travaux manuels; leurs costumes de cuir de bigorne, brodés et peints, et leurs chemises brodées en piquants de porc-épic coloriés, sont d'une beauté extraordinaire, ainsi que leurs robes de bison, aussi peintes et brodées. Les hommes fabriquent leurs armes, qu'ils parent avec beaucoup d'élégance, surtout leurs grands arcs, incrustés de corne de bigorne ou d'elk, et souvent aussi recouverts de la peau d'un serpent à sonnettes.

Ces sauvages sont très-superstitieux; par exemple, ils ne veulent jamais fumer leur pipe quand il y a une paire de souliers suspendus dans leur cabane. Ils éprouvent encore une espèce de crainte à la vue d'un bison femelle. Quand un Corbeau rencontre un de ces animaux, il se tourne vers le soleil et lui adresse ces mots : "Je veux te la donner. "Il s'efforce alors de tuer l'animal, et quand il a réussi, il le laisse à terre, et dit encore au soleil : "Prends-la, elle t'appartient. "Du reste, ils ne font pas de la peau de ces bisons femelles le même usage que les Mandans. Les objets les plus sacréz pour ces peuples sont le soleil, la lune et..... le tabac; aussi tous les enfants portent-ils une petite portion de ce végétal autour du cou, bien enveloppée comme une amuletle.

Les Corbeaux vendent quelquefois leurs femmes, qui du reste sont les plus dissolues de toutes les nations du Missouri. Ils n'enterrent pas leurs morts; mais, de même que les Mandans, ils les placent au milieu de la prairie, sur des échafaudages isolés. Une femme de la nation des Corbeaux, étant sur le point de mourir, témoignait une grande inquiétude, dans la crainte qu'après sa mort on ne la déposât dans la terre à la manière des blancs. Dès qu'on l'eut tranquillisée à ce sujet, elle rendit le dernier soupir avec la plus grande tranquillité d'âme.

Ils se frottent de castoreum, dont ils trouvent le parfum agréable; ils le délayent avec une couleur rouge; mais cet usage n'est pas exclusif à cetle nation.

Par l'apparence extérieure, les Assiniborns diffèrent peu des Dacotas, dont ils sont une tribu anciennement détachée; ils ne sont cependant pas aussi grands et aussi efflanqués que ceux-ci. Leur visage est large, avec les pommettes proéminentes et de larges bajoues. Ils ne portent pas les cheveux aussi longs que les Dacotas, et chez plusieurs, ils ne descendent guère plus bas que les épaules; quelques-uns pourtant les portent fort longs, partagés en deux ou trois queues, et retombant quelquefois autour de la tête et sur le visage comme la crinière d'un lion. Ils se coiffent de bonnets de cuir ronds el blancs, d'étroites bandelettes de peau nouées en travers de la tête, ou portent simplement des plumes dans les cheveux. Leur coiffure la plus remarquable est 
celle qui représente deux cornes; eette coiffure est faite de bandes blanches d'hermine, ayant par derrière une large bande de drap rouge retombant jusqu'au mollet, et sur laquelle est attachée une crête droite de plumes d'aigle, blançhes et noires, qui commence à la tête et se prolonge jusqu'au bout en rang serré. Le tout est orné de deux cornes de bœuf. Il n'y a que les guerriers distingués qui aient le droit de porter ce bonnet.

Les Assiniboins vivent, comme les Dacotas, en simples chasseurs, dans leurs tentes de cuir qu'ils emportent avec eux, et ne se livrent à aucune espèce d'agriculture. Leur nourriture principale leur est fournie par les troupeaux de bisons qu'ils poursuivent, en été, dans les prairies, loin des rivières, et, en hiver, dans les forêts qui bordent ces rivières, où, dans cette saison, ces troupeaux vienuent chercher de la pâture et un abri. C'est avec la chair de ces animaux desséchée, pulvérisée et mêlée de suif, que les femmes préparent le pemmican, qui forme le principal aliment des sauvages dans leurs courses. Souvent, quand les chasses leur ont été défavorables, ces Indiens sont en proie à la famine. Alors des familles entières meurent de faim; ils sont obligés de manger toutes sortes d'animaux, et la chair des chiens morts est pour eux un mets très-délicat; ils se nourrissent beaucoup de chevaux pour obvier au manque de vivres dans les temps de disette. En comparaison des autres nations, ces indigènes ne possèdent pas beaucoup de ces derniers animaux; ils les sellent et les brident de la même manière que les Meunitarris. La corde de poil de bison, attachée à la mâchoire inférieure du cheval en guise de rênes, est toujours longue, et l'animal la traîne après lui sur le pavé, quand il n'est pas attaché. Beaucoup se servent de grands étriers de parchemin, en forme de souliers, et tous tiennent à la main un petit fouet court, fait de bois d'elk et orné de différentes manières. Les chiens allégent les travaux des femmes. Ce sont eux qui traînent les fardeaux.

Les Assiniboins partagent les coutumes et les superstitions des Dacotas. Ils sont braves dans les combats; ils se glissent dans les villages des Mandans et des Meunitarris, tuent les habitants à coups de fusil, et enlèvent les chevaux au milieu des habitations. Les hommes qui, pendant leur vie, ont montré de la bravoure, ne doivent point être placés, après leur mort, sur des arbres; leurs corps doivent être exposés par terre, attendu qu'ils sauront bien se tirer d'affaire eux-mêmes; ce qui n'empêche pas les loups de les dévorer, bien qu'on les couvre de pierres et de bois. Les autres corps sont exposés comme ceux des Dacotas, et souvent on en met trois ou quatre sur un même arbre.

Les Assiniboins sont vêtus de robes de bison et se parent de la manière la plus variée et la plus fantastique. La plupart se peignent la figure avec du cinabre, d'autres sont tout à fait noirs; ils portent des plumes d'aigle et d'autres oiseaux de proie dans leurs cheveux; quelques-uns fabriquent des bonnets de peau de loup qu'ils colorent en rouge; d'autres attachent des feuilles vertes autour de leur tête, et traînent par terre après eux de longues queues de loup, marque d'honneur indiquant les ennemis tués.

Les Indiens PIEDs-Norrs forment une nation nombreuse qui se subdivise en trois tribus parlant la même langue. A l'extérieur ils ne diffèrent pas beaucoup des autres habitants du haut Missouri. Ils sont vigoureux, bien faits, souvent beaux; quelques-unes de leurs femmes et de leurs filles sont fort jolies. Ces Indiens ont les bras et les jambes plus minces que les blancs; leurs mains et leurs pieds sont ordinairement petits, d'un brun noirâtre, avec les veines très-marquées. Chez la plupart des Pieds-Noirs, le nez est aquilin, les yeux brun noir. Leurs cheveux sont noir de jais, assez roides, mais moins brillants que ceux des Brésiliens. Ils ont la barbe et le poil peu épais, et ils l'arrachent avec soin au moyen d'un fil tordu ou d'un morceau de fer-blanc recourbé. Chez les vieillards, les 
cheveux sont gris. La couleur ordinaire de ces Indiens est d'un beau brun rouge vif, quelquefois cuivré. Cette teinte se voit déjà chez les petits enfants; les nouveau-nés sont seuls un peu plus clairs. De même que les enfants brésiliens, les jeunes Pieds-Noirs ont le ventre gros et proéminent, et les membres minces.

Les Pieds-Noirs ne déforment pas leur corps. Aucune des nations du Missouri ne se perce le nez ni les lèvres, à l'exception de la seule tribu des Chopouniche ou Pierced-NoseIndians, qui habite les montagnes Rocheuses, et qui se perce la cloison du nez. Ce n'est qu'aux oreilles seulement que les Pieds-Noirs pratiquent un ou deux petits trous, dans lesquels ils portent des rangs de grains de verre alternant avec des cylindres blancs de dentalium, qu'ils reçoivent en échange des nations de l'ouest des montagnes Rocheuses, et même beaucoup d'entre eux n'en portent-ils pas, et leurs longs cheveux touffus cachent ces parties. Ils ne pratiquent pas le tatouage, mais plusieurs portent au bras des entailles parallèles, et beaucoup manquent d'une ou de deux phalanges des doigts. Ils se fardent avec du rouge de vermillon, que les marchands leur procurent et qu'ils rendent luisant en y mêlant de la graisse. Les Pieds-Noirs ne se peignent pas le corps. Il y en a qui ne se peignent en rouge que le tour des paupières, ou qui se font quelques raies sur les joues; d'autres, enfin, se peignent le visage tout entier en noir, les paupières et quelques raies seulement en rouge. Chez les femmes et les enfants, on ne remarque que la couleur uniformément rouge de cette partie. Les cheveux de ces Indiens pendent en désordre sur les yeux et autour de la tête; mais les jeunes gens qui tiennent à l'élégance, les séparent régulièrement, les peignent et les lissent. Souvent on voit des deux côtés, près des tempes, un petit coquillage attaché à une mèche de cheveux; d'autres portent sur le côté gauche du front une mèche de cheveux entourée d'un fil d'archai ou de fer, et parfois ils portent cette même mèche des deux côtés.

Les Pieds-Noirs habitent sous des tentes de cuir dont la distribution intérieure est la même que chez les Dacotas, les Assiniboins et les autres hordes errantes et chasseresses du haut Missouri. Ces tentes de bison tanné ne durent guère plus d'un an; au commencement, elles sont blanches et propres; plus tard, elles deviennent brunes et même noires autour de l'ouverture par où s'échappe la fumée; plus tard encore, elles se montrent transparentes comme du parchemin et fort claires à l'intérieur. On voit rarement des tentes peintes ou ornées de figures dessinées; il n'y a que quelques chefs qui en possèdent. Quand ces cabanes sont démolies, elles laissent après elles un cercle de mottes de gazon. Elles sont souvent entourées de quinze à vingt chiens, que l'on ne mange point, mais dont on se sert pour tirer ou pour porter des fardeaux; la manière dont ils les chargent, ainsi que les chevaux, est celle des autres nations dont nous avons parlé plus haut. A côté des tentes, les Indiens placent leurs travails, qu'ils appellent manesté, et qu'ils empilent en forme de còne, ce qui les fait ressembler aux tentes, si ce n'est qu'ils ne sont pas recouverts de cuir. C'est là que l'on suspend les boucliers ou pare-flèches, les sacs d'emballage, les selles et les brides; et très-haut, sur des cordes, à l'abri des dents des chiens, la viande, les peaux et autres objets semblables, coupés par bandes et sur des couches étroites. Souvent aussi on suspend et l'on attache à une perche séparée, ou bien au-dessus de l'entrée de la tente, le sac ou le paquet de médecine, c'est-à-dire l'appareil magique. Le mobilier de la case consiste en robes de bison, en convertures de laine pour coucher dessus, et plusieurs sacs de parchemin peint, parfois en forme de croissant, garnis de cordons de cuir et de franges; en plats de bois, en grandes cuillers faites de la corne de bigorne, qui est très-large et très-creuse; en vases à boire faits de corne, en chaudrons, quelquefois aussi en batterie de cuisine de f:r-blauc qu'ils achètent des marchands, et en différents autres petits objets. Au milieu de la tente brûle le petit feu, dans un cercle formé de pierres, au-dessus duquel on suspend 
le chaudron. On peut aussi compter comme faisant partie du mobilier les harnais des chevaux. En général, on attache seulement à la mâchoire inférieure du cheval un long cordon de poil de bison tors, ce qui sert à le fixer à la prairie. La selle ressemble beaucoup à celle dont on se sert en Hongrie; elle se compose dé deux planches plates et larges, formant entre elles un angle, et qui reposent le long des côtés du dos de l'animal; par devant et par derrière, elle a un appendice qui s'élève tout droit à une assez grande hauteur, et d'où pendent des franges de cuir. Cette selle se couvre d'une peau et une autre est placée dessus. Ces deux peaux servent la nuit de lit au cavalier. Les Pieds-Noirs aiment, comme objet de luxe, de belles housses faites de peaux de panthère qu'ils tirent principalement des montagnes Rocheuses. La peau de cette panthère est placée en travers, de façon que la longue queue retombe d'un côté; elle est doublée de drap écarlate qui forme une large bordure tout à l'entour.

Au nombre des meubles indispensables aux hommes, il faut encore compter la pipe. Celles qu'ils fabriquent sont moins belles que celles des Dacotas, qu'ils estiment beaucoup et qu'ils cherchent à se procurer par des échanges. Les véritables pipes des PiedsNoirs sont faites de talc vert, ou bien d'une pierre noirâtre que l'on trouve dans les montagnes Rocheuses. Elles sont souvent en forme de globe ou de poire, et reposent sur un pied cubique. Le tuyau est en. bois, large, plat ou rond, quelquefois entaillé comme un șerpent. Les plus belles sont les pipes de médecine, auxquelles nous avons donné le nom de calumet. Elles sont ornées de têtes ou de becs de pic rouge, et d'un grand éventail de plumes. On les retrouve, plus ou moins ornées, mais toujours dans le même modèle, à toutes les fêtes, à tous les traités des peuplades de l'Amérique du nord. Quand les Pieds-Noirs fument, ils placent à terre un morceau de bouse de bison desséchée, sur lequel ils posent le godet de la pipe, ou bien une espèce de gâteau rond fait avếc les barbes et les cônes de certaines plantes aquatiques. Le tabac qu'ils fument se compose de petites feuilles rondes du sakakomi (arbutus uva ursi), qu'ils appellent kocksinn. Quand on visite un de ces Indiens dans sa tente, la première chose qu'il fait est de prendre sa pipe, qui, selon l'usage, circule dans la société, de droite à gauche. Souvent le maître de la maison envoie quelques bouffées au soleil et à la terre; puis on aspire deux ou trois fois, et l'on passe la pipe plus loin. On fait entrer la fumée dans le poumon, après quoi on la renvoie. Le dernier fumeur ne fait jamais circuler la pipe en arrière, mais il la donne à celui qui est assis en face de lui, et elle continue à passer de droite à gauche.

Les Pieds-Noirs, de même que la plupart des tribus du Missouri, sèment ȩà et là les graines du tabac, après avoir brûlé la place qu'ils destinent à cette culture, et la plante qui y croît ne se fume que dans les occasions solennelles.

Les Pieds-Noirs, comme tous les Américains, sont superstitieux, et il est rare de voir un homme qui ne déploie pas quelque habitude ou quelque particularité qu'il a adoptée comme un talisman, et dont il s'imagine que dépend la réussite de ses plans et de ses entreprises. Il y en a qui secouent des sonnettes avant de fumer leur pipe; d'autres crachent de divers côtés avant de boire; d'autres encore marmottent quelques paroles ou une sorte de prière avant d'entreprendre quelque travail. La plupart de ces Indiens ont adopté quelques singuliers usages de ce genre; mais, par malheur, ils n'aiment pas à communiquer leurs pensées à ce sujet, de sorte qu'il est fort difficile d'en découvrir l'usage.

Les hommes de médecine, ou docteurs des Pieds-Noirs, sont très-maladroits; ils crac hent sur les plaies des blessés, de l'eau qu'ils prennent dans la bouche, et quelquefois aussi de la salive. Du reste, ils ne lavent jamais ces plaies, et le second jour le sang caillé y est encore. Ces médecins possèdent quelques remèdes actifs tirés du règne 
végétal, qui sont d'un effet très-efficace contre la morsure des serpents. Ils ont, du reste, toujours recours au tambour dont le fracas insupportable inspire la plus grande confiance. Les Pieds-Noirs confectionnent leur aouanaï (chichikoué), espèce de tambour, avec du cuir, du bois et de la peau de vessie. Ils mettent aussi beaucoup de confiance dans la médecine des blancs, dont ils recherchent souvent les secours; mais il y en a parmi eux qui sont tellement affectés de maladies syphilitiques, qu'il est impossible de penser à les guérir. Quand les Indiens sont guéris par leurs médecins, ce qui a quelquefois lieu au moyen de bains de vapeur, ils leur font de grands prèsents, ou bien l'homme de médecine fait monter fort haut son mémoire.

Quand un Pied-Noir vient à mourir, on ne l'enterre point, s'il est possible. On le couvre de ses plus beaux habits, qu'on lui attache sur le corps; on lui peint le visage en rouge, puis on l'enveloppe, sans ses armes, dans une robe de bison, et on le dépose dans quelque lieu inaccessible, dans une forèt, une caverne, un rocher, sur une rive escarpée, et l'on couvre son corps de pierres et de bois, afin d'empècher les loups de s'emparer du cadavre. Quand il est impossible de trouver un emplacement solitaire, on laisse le mort dans une espèce de cabane, et souvent on est obligé à la fin de l'enterrer, ou d'en faire aux blancs un présent précieux, ce qu'il n'est pas permis de refuser. Les parents se coupent leurs longs cheveux, les couvrent, ainsi que le visage et les vêtements, d'une argile gris blanchâtre; et tant que dure le deuil, ils s'habillent le plus mal quils peuvent. Il leur arrive aussi souvent de se couper une phalange d'un doigt, pour témoigner leur douleur. La croyance de ces Indiens, quant à la deśtinée des morts, c'est qu'ils sont dans un autre pays, où il ne leur manque rien, et où on les a souvent entendus s'appeler les uns les autres, pour fumer ensemble et se réunir. Aux funérailles des riches Indiens, on a coutume de tuer plusieurs chevaux sur leurs tombeaux. A la mort d'un de leurs parents, les Pieds-Noirs s'assemblent chez le décédé, et les hommes même pleurent et se lamentent. Le corps est enseveli d'ordinaire dans la journée, et si le défunt est mort dans la nuit, l'ensevelissement a lieu dès le lendemain matin.

La langue des Pieds-Noirs ne manque pas d'harmonie, et, comme tous les idiomes du nord de l'Amérique, elle n'est pas difficile à prononcer pour les Allemands.

Ce peuple tire sa nourriture et ses vêternents principalement des troupeaux de bisons qu'il poursuit, et contre lesquels il dispose souvent, en hiver, de grands parcs fermés. Les cabris et surtout les grosses-cornes leur fournissent le cuir dont ils ont besoin pour la confection de leurs habits les plus fins. Ils mangent pour ainsi dire de tous les animaux, excepté toutefois de l'ours. Ils ont aussi une grande aversion pour les amphibies. Le règne végétal leur fournit encore plusieurs espèces de racines. Les femmes et les enfants déterrent ces racines avec un outil de bois fait exprès, et les vendent aux blancs, enfilées à des cordons. Il y a surtout une racine qui est amère, et qu'on fait cuire avec du jus de viande; alors elle est très-nutritive, et une fois qu'on s'est accoutumé à sa saveur, on ne la trouve plus désagréable. La racine de tabac des Canadiens est une espèce de navet que l'on enfonce dans la terre avec des pierres échauffées; el aussitôt qu'elle est mangeable, elle devient noire comme le tabac. Ces racines, mêlées à la queue de castor, forment un morceau des plus friands des Indiens. Les Pieds-Noirs obligent leurs enfants à mâcher de la viande dès que leurs premières dents paraissent, et, en revanche, on voit des enfants déjà grands teter encore leur mère. L'eau-de-vie est pour ces Indiens l'objet de la plus grande prédilection ; pour en obtenir, ils donnent tout ce qu'ils possèdent, jusqu'à leurs vètements. Dans l'ivresse, ils sont moins dangereux que d'autres peuples, et on assure même qu'ils ont le vin tendre. Il n'est pas rare de voir un Indien échanger sa femme contre une boutcille d'eau-de-vie. 
L'habit des Pieds-Noirs est fait de cuir tanné, et leurs plus belles chemises de cuir sont fabriquées de peau de grosse-corne qui, lorsqu'elle est neuve, est d'un blanc jaunâtre et fait un effet fort agréable. Tout autour de ces chemises se trouve, èn général, une bordure à laquelle on a laissé le poil. Elles ont des demi-manches, et les coutures en sont garnies de touffes de cheveux d'homme ou de crins de cheval teints de différentes couleurs, et dont la racine est entourée de piquants de porc-épic. Autour de l'ouverture par laquelle passe le cou, elles sont garnies d'un rabat doublé de drap rouge et orné de franges ou de rangs de piquants de porc-épic, jaunes et bigarrés, ou bien de grains de verre bleu. Quelques-uns font tous ces nombreux cordons qui retombent, d'étroites bandes d'hermine, ornement devenu fort coûteux par la rareté de ces petits animaux de proie. Aussitôt que la chemise commence à devenir sale, on la peint en rouge brun, mais neuve elle est beaucoup plus belle. Leurs leggings ou culottes sont faites comme celles des autres Indiens, et ornées, comme elles, de touffes de cheveux ou de cordons bigarrés de piquants de porc-épic; leurs souliers, qui sont faits avec le cuir de bison ou d'elk, sont aussi brodés de piquants de porc-épic, mais avec celte différence que la couleur des ornements change dans chacun; ainsi, si les ornements de l'un sont jaunes, ceux de l'autre sont blancs, mode qui n'existe pas dans le bas Missouri, où les deux souliers sont d'une couleur uniforme.

La peau de bison, qui forme la principale pièce de leur costume, est toujours teinte du côté tanné. On y remarque des lignes noires parallèles, avec un petit nombre de figures variées, telles que des pointes de flèches ou autres mauvaises arabesques; il y en a qui représentent les exploits de guerre, en noir, en rouge, en vert et en jaune. Ces figures peignent la prise des prisonniers, des morts, des blessés, des armes et des chevaux enlevés, du sang qui coule, des balles traversant les airs et autres objets semblables. Ces robes sont brodées des plus vives couleurs et ornées d'une bande transversale de piquants de porc-épic, partagée en deux parties égales par une roselte semblable. Le fond de la peau est presque toujours rouge brun avec les figures noires. Pendant l'élé, on porte ces robes avec la fourrure en dehors; l'hiver, on met le poil en dedans; l'épaule et le hras droits restent ordinairement libres. Les Pieds-Noirs portent à la main une aile d'aigle ou de cygne, ou une queue d'oiseau de proie, en guise d'éventail ; la poignée en est garnie de cuir ou de drap de couleur. Chaque individu tient à la main son fouet, ainsi que son arme, son fusil, et porte sur le dos, en bandoulière, son carquois ou sac de peau contenant ses flèches, et auquel s'attache un étui your l'arc, de même genre, mais plus étroit. Il place à une courroie passée sur l'épaule, sa giberne et son cornet à poudre, tandis qu'un grand couteau de chasse est fixé par derrière, dans sa gaîne, à un ceinturon de cuir.

Le costume des femmes est semblable à celui des autres Indiennes du Missouri; il consiste en une longue chemise de cuir qui descend jusqu'aux pieds et qui est nouée au-dessus des hanches avec une ceinture, souvent ornée de plusieurs rangées de dents d'elk, de boutons de métal et de grains de verre que l'on y a cousus. Sur la poitrine, ce vètement se ferme en travers, un peu largement; il a les manches courtes et larges, garnies de beaucoup de franges, qui retombent comme dans le costume national polonais, mais seulement à la hauteur, à peu près, du coude. L'avant-bras demeure nu. Lebas le la chemise est égalemeut garni de franges, et découpé en festons. Les femmes ornent leur costume de cérémonie de piquants de porc-épic peints, et d'étroits cordons de cuir, ou bien de rangs diversement disposés de grains de verre bleus et blancs sur le bord supérieur et aulour du haut du bras. Les Indiens n'aiment pas à voir sur la peau des grains de verre d'autres couleurs, de rouge, par exemple; quant au contraste des nuances, leur goût est juste; c'est ainsi qu'ils portent dans leurs cheveux noirs, du 
rouge, et sur la peau, qui est brune, du blanc, du bleu de ciel ou du jaune. Les femmes sont fort adroites à travailler les habits et à tanner le cuir; les hommes ne confectionnent que l'appareil à fumer et les armes. Comme dans les autres tribus, ce sont les femmes qui sont chargées de tous les travaux pénibles. Elles savent fort bien teindre, et se servent, pour la couleur jaune, d'une espèce de mousse jaune citron, qui croît sur les arbres des montagnes Rocheuses. Une racine donne la belle couleur rouge, et ils tirent plusieurs autres couleurs très-vives des matières que leur fournissent les blancs. Les petites filles des Pieds-Noirs sont vêtues de la même manière que les femmes, et souvent leur costume est garni, autour des bords, de dents d'elk, que les Indiens achètent fort cher.

Les mariages chez les Pieds-Noirs ne sont accompagnés d'aucune cérémonie particulière; on pare la femme et on l'emmène. On fait savoir le prix d'achat au père, par un ami ou par quelque autre homme; s'il accepte, on remet la jeune fille et le mariage est conclu. Si l'homme en est fatigué, ou si la femme ne se conduit pas bien, il la renvoie sans façon; cela ne cause aucune querelle. Elle prend ce qui lui appartient el se retire; les enfants restent la propriété du mari. Cependant, quelquefois, ils punissent avec une grande sévérité l'infidélité de leurs femmes, auxquelles ils coupent le nez. Ils leur coupent aussi les cheveux comme punition, et ces malheureuses ont honte, après cela, de montrer leur tête qu'elles s'efforcent de couvrir. Celle qui a eu le nez coupé, est répudiée sur-le-champ par son mari; personne ne l'épouse plus, et ces femmes sont obligées de travailler moyennant un certain salaire, ou de soigner les enfants pour vivre. On a vu des maris qui ont tué leurs femmes dès qu'elles avaient eu des relations avec un autre homme; souvent même, ils se vengent sur l'amant, à qui ils enlèvent ses chevaux et d'autres objets de valeur, tandis que celui-ci est obligé de les laisser faire. On voit de ces Indiens qui ont jusqu'à six ou huit épouses, dont, par un singulier contraste avec ce que nous avons dit plus haut, ils se montrent fort généreux envers les blancs, auxquels ils offrent aussi de petiles filles toutes jeunes. Les Pieds-Noirs ont souvent beaucoup d'enfants, qui courent tout nus, jouent et nagent dans la rivière comme des canards. Les garçons vont nus jusqu'à treize ou quatorze ans; mais les filles reçoivent plus tôt leur petit vêtement de cuir. Les Pieds-Noirs sont tranquilles dans leur intérieur, mais ils ont plus de colère que les autres nations. Des duels ont quelquefois lieu, et la vengeance du sang s'exerce dans la plupart des cas. Quand un Indien est tué, ses parents se vengent, s'ils le peuvent, sur le meurtrier; et s'ils n'en trouvent pas l'occasion, ils s'en prennent au premier membre de sa famille qu'ils rencontrent; mais aussi la vengeance du sang se rachète par des objets de valeur.

On trouve chez les Pieds-Noirs les associations dont nous avons déjà parlé pour les Assiniboins. Tous les nouveaux admis dans ces associations sont obligés de payer un droit d'entrée, qui est plus considérable pour les hommes de médecine et pour les riches. Si une femme, dont le mari fait partie d'une association, a eu des relations avec un autre homme, toute la bande s'assemble dans une tente; on y fume, et, la nuit, quand tout est plongé dans le sommeil, après être entré de force dans la tente de cette femme, chacun agit comme il lui plaît avec elle; puis on la renvoie, non sans lui avoir coupé le nez. Le mari n'a pas le pouvoir d'empêcher cette exécution; il est obligé de répudier une telle femme. On lui dit alors le motif pour lequel on a agi de la sorte, et il a son recours contre le séducleur.

Dans leurs combats, les Pieds-Noirs vont quelquefois à demi nus; d'autres fois, ils montent à cheval dans leur plus beau costume; quelques-uns se distinguent par des boucliers richement ornés, et par de magnifiques bonnets de plumes. Les guerriers distingués ont une touffe de plumes de hiboux ou d'oiseaux de proie, qui pend sur le 
derrière de la tête, et parfois des peaux d'hermine ornées de sonnettes, de bandes de drap ou de boutons brillants. Leur manière de combattre ne diffère en aucune façon de celle des autres Américains du nord. De petits détachements se glissent autour de l'ennemi et essayent de le vaincre par les embuscades, la ruse ou les attaques imprévues; ces attaques ont toujours lieu au point du jour. Ils forment de longues lignes de tirailleurs, et tirent de fort loin et très-mal. Les femmes et les enfants soignent les blessés; ils poussent de grands cris et des lamentations. L'ennemi tue sans distinction, les hommes, les femmes et les enfants, à coups de fusil, de flèche, de lance et de couteau; il scalpe aussi les femmes, que souvent encore on fait prisonnières et que l'on emmène en esclavage; dans ce cas, elles ne sont pas maltraitées. Quant aux tourments que les nations de l'Amérique du nord faisaient subir autrefois à leurs prisonniers, on n'en trouve plus aucune trace chez les Pieds-Noirs.

Lorsque les guerriers se rapprochent du camp, après un combat, ils se mettent à chanter, et l'un d'eux court en avant, à pied ou à cheval, s'avançant vers les tentes, en serpentant. On lève en même temps les scalps en l'air, on les secoue et on les montre de loin. Si quelqu'un s'est emparé d'une arme, il la lève également en l'air, se nomme et crie que c'est lui qui l'a prise. Après un combat heureux, les hommes entonnent le chant qu'ils appellent Anénaï, ce qui vent dire : "Ils sont peints en noir. "Ils se rassemblent alors à còté des tentes, s'asseyent en plein air, le visage peint en noir, leurs leggings et robes tachetées de noir, et se mettent à chanter sans accompagnement de musique. Ce chant n'a point de paroles. Les armes des Pieds-Noirs ne diffèrent pas beaucoup de celles des autres Indiens; mais elles ne sont pas aussi belles, ni aussi bien travaillées que chez les Corbeaux. Leur pays ne produisant pas de bois propre à faire des arcs, ils échangent un cheval pour se procurer le bois nécessaire à ces armes, el le carquois de peau de panthère. Au bout de ce carquois, ils laissent pendre la queue de l'animal; elle est garnie de drap rouge du côté de la chair, brodée en grains de verre et ornée des deux còtés de bandelettes de peau en forme de glands. Ils se servent encore de boucliers ou pare-flèches; ces boucliers sont ronds, faits de cuir épais, ordinairement peints en vert ou en rouge, et ornés de plumes et de toutes sortes de signes superstitieux. Quand ils se disposent à combattre, ils roulent autour de leur tête, comme un turban, la gaîne de leur fusil, qui est en cuir; des peaux de loup leur sont alors fort utiles, surtout quand ils veulent observer l'ennemi. Ils les portent en sautoir sur l'épaule, s'en enveloppent la tête quand ils veulent approcher de l'ennemi sans en être vus, et se couchent par terre, derrière une hauteur, de telle façon qu'on les prendrait pour des loups blancs.

Les Pieds-Noirs sont de terribles mendiants; ils ne cessent de vous harasser de leurs supplications. Le vol des chevaux est devenu chez eux un art vérilable; le plus adroit voleur de chevaux est un personnage distingué.

Ces Indiens ont imaginé plusieurs espèces de jeux pour se divertir. Dans l'un, ils se placent en demi-cercle et forment plusieurs petites piles de grains de verre ou d'autres objets qui font les enjeux. L'un d'eux prend en main de petits cailloux, et les remue, de côté et d'autre, en chantant et avec des mouvements mesurés, pendant qu'un autre doit deviner le nombre de ces cailloux. Des sommes considérables sont souvent gagnées et perdues à ce jeu. Les Pieds-Noirs ont aussi des danses de divers genres. Nous n'en décrirons que deux, qui sont les principales. La première, qui s'appelle danse de la médecine, et qui est exécutée par les femmes, n'a pas lieu tous les ans. On construit une grande cabane de bois; les femmes revêtent leur plus beau costume, et toutes portent unggrand bonnet en plumes sur la tête. Les femmes qui ne figurent pas dans cette danse, et les hommes, forment les spectateurs. Quelques-uns de ces derniers battent le 
tambour et secouent l'aouanaï ou chichikotié. Pendant plusieurs jours de suite, la danse continue sans aucune variation; mais le dernier jour, en terminant, on figure des parcs de bisons. Les honimes, les enfants et les femmes qui ne dansent pas, forment deux lignes divergentes qui partent de la loge de médecine, dont les femmes sortent en se traînant sur les mains et les pieds, en imitant la manière des bisons femelles. Plusieurs hommes jouent le rôle des bisons mâles, qui sont d'abord repoussés par les femmes; mais alors, ainsi qu'il est d'usage dans cette espèce de chasse, on allume des feux au vent de la loge, dans laquelle les femmes se retirent dès qu'elles commencent à sentir la fumée, ce qui termine la fète.

La danse de la chevelure a lieu quand on a tué des ennemis. Les femmes s'habillent. alors comme les hommes, et prennent aussi leurs armes. Si les femmes ont assisté à l'expédition dans laquelle ces ennemis ont élé tués, elles se peignent la figure en noir. Une femme porte la chevelure du vaincu, et quelquefois plusieurs, selon le nombre que l'on en a; d'autres fois, elle est portée par une vieille femme, qui se tient alors à part et danse seule, tandis que toutes les autres forment un rond, et que les hommes accompagnent la danse sur le tambour. Il y a aussi pour les hommes la danse des braves ou guerriers. Ceux-ci forment un cercle, et plusieurs d'entre eux dansent au milieu, imitant tous les gestes d'un combat et déchargeant leurs fusils. Dans cette circonstance, ils sont peints comme pour aller combattre.

Les OJibuais, que les Anglais appellent Chipewais, et les Français Sauteurs, habitent le vaste pays qui s'ẻtend entre le lac Supérieur, le Red-River, l'Asșiniboin-River, et plus loin, vers le nord, près du Lake-Winipick. Ils forment une nation nombreuse et brave, mais divisée en plusieurs petites compagnies.

Les Indiens ojibuais n'ont rien de bien remarquable; ils sont de moyenne taille, mais avec les membres forts; ils portent les cheveux retombant naturellement sur les épaules; du reste, ils diffèrent fort peu des Crihs, dont ils ont les mœurs et les usages.

Les Ojibuais parlent la langue algonquine, qui est en même temps celle des PolowaLamis, des Ottawais, des Crihs, des Muscotins et d'autres tribus. Les Français avaient donné, dans l'origine, à toutes ces petites bandes d'une seule et mème nation, des noms différents, ce qui a jeté une grande confusion dans l'histoire de ces peuples. Quelques voyageurs prétendent qu'ils sont anthropophages.

Les Corneilles forment une des tribus les plus guerrières, les plus rusées et les plus pillardes des montagnes. Ces Indiens sont surtout grands voleurs de chevaux. Ils ont l'air belliqueux, et sont d'un caractère inquiet, porté au brigandage; ils ont quinze cents hommes d'armes; mais leurs hostilités perpétuelles avec les Pieds-Noirs et leurs mœurs vagabondes les minent insensiblement.

Leur pays renferme plusieurs curiosités naturelles, entre autres une abondante source jaillissante de naphte; on y trouve aussi deux solfatares, dont l'une s'appelle la Montagne-Brûlante, et qui contient beaucoup de houille anthracite; on fait la descriplion la plus terrible de ses feux cachés, de ses vapeurs pestilentielles.

La conduite des Nez-Percés est empreinte de dévotion, leur probité est sans tache, leurs intentions sont pures et l'observance des rites de la religion qu'ils professent est uniforme et très-remarquable. " $O$ n croirait voir, dit le capitaine Bonneville daus son ouvrage intitulé : Aventures et expéditions dans l'intérieur de l'Amérique septentrionale, une nation de saints plutôt qu'une horde de sauvages. \

Il y a des Haut-Nez-Percés et des Bas-Nez-Percés; ils ont le caractère aimable. En voici deux exemples rapportés par le capitaine Bonneville :

Ce voyageur fut accueilli, chez les Bas-Nez-Percés, avec les plus grandes prévenances et logé dans la maison du vieux chef. Au moment du départ, le bon vieillard prit le capitaine 
à part pour lui exprimer combien il l'aimait, el pour lui dire qu'il désirait lui offrir un beau cheval comme une marque de son estime. En achevant ces mots, il fit un signe à un de ses gens qui amena en effet un jeune cheval bai superbe. Le capitaine fut touché de cette marque d'affection; mais il connaissait trop bien les Indiens pour ne pas savoir qu'un présent en appelle un autre; en conséquence, il présenta au vieux chef un beau fusil. Après avoir ainsi amplement acquitté la dette de la reconnaissance, et tandis qu'il se disposait à transporter sa selle sur le cheval qui venait de lui être donné, le vénérable patriarche le tira par la manche, et lui présenta une vieille Indienne ridée, vraie momie, et qui s'approcha de lui en pleurant.

a Voici ma femme, dit le chef; c'est une bonne femme; je l'aime beaucoup; elle aime le cheval, elle l'aime infiniment; elle pleurera longtemps sa perte; je ne sais comment faire pour la consoler; elle m'afflige le cœur. "Il fallait bien que le capitaine essayât de calmer la douleur de la tendre vieille. Quoiqu'elle eût passé l'âge de la coquetterie, il lui offrit une paire de boucles d'oreilles de verre. Elle s'empressa de s'en parer, et, à compter de ce moment, elle cessa de regretter le coursier. Le capitaine se crul, après cela, maître de partir ; mais, comme il allait mettre le pied dans l'étrier, le vénérable chef s'ávança une seconde fois, tenant par la main un jeune Nez-Percé qui paraissait bouder. "Vous voyez mon fils, dit-il; il est très-bon, excellent cavalier; c'est lui qui a toujours pris soin de ce très-beau cheval; il l'a élevé, il en a fait ce qu'il est; il l'aime comme un frère; il aura le cœur bien gros quand ce beau cheval quittera le camp. "Que pouvait faire le capitaine? Il lui restait une hache qu'il présenta au jeune homme. Aussitôt sa figure s'épanouit, et il se retira aussi satisfait que sa mère l'avait été de ses boucles d'oreilles. Cette fois, le capitaine se flattait que rien ne le retarderait plus; mais le vieux chef lui adressa la parole une troisième fois, en posant une de ses mains sur la crinière du cheval, et en soulevant le fusil de l'autre. \& Ce fusil, dit-il, sera ma grande médecine. Je le presserai contre mon cœur; je l'aimerai toujours à cause du bon ami qui me l'a donné. Mais un fusil, par lui-même, est muet; je ne saurais le faire parler. Si j'avais un peu de poudre et quelques balles, je le prendrais avec moi, el j'irais, de temps en temps, tirer un cerf; et puis, quand je rentrerais chez moi, je dirais, en posant le gibier devant ma famille affamée : Voilà ce que j’ai tué avec le fusil de mon bon ami le chef blanc, celui à qui j'ai donné ce très-beau cheval. Il n'y avait pas moyen de résister à une páreille invocation. Le capitaine donna de la poudre et des balles, mais se hâta de mettre le beau cheval au galop pour éviter de nouveaux témoignages d'amitié de la part du vieux Nez-Percé.

Le capitaine trouva parmi eux le véritable propriétaire d'un cheval qu'il avait acheté quelque temps auparavant à un sauvage d'une autre tribu. L'Indien, après avoir prouvé jusqu'à l'évidence l'identité de l'animal, ajouta : "N'importe, vous l'avez acheté de bonne foi : vous avez plus besoin de chevaux que moi; gardez-le; c'est un bon cheval; traitez-le bien.

Les Shoshokons, malgré leur pauvreté et leur indolence, ne sont pas absolument dépourvus d'industrie; ils fabriquent d'assez bonnes cordes et même du fil assez fin, qu'ils tirent d'une espèce de graminée; ils font aussi des vases avec de petits morceaux de bois entrelacés, qu'ils mettent en élat de contenir de l'eau au moyen d'un peu de cire. Ces sauvages donneraient tout ce qu'ils possèdent pour le plus petit morceau de miroir cassé, afin de pouvoir contempler leurs figures pâles et décharnées. Ils sont, en général, très-pauvres, privés de presque tous les agréments de la vie, et extrêmement indolents. Ils ont une assez singulière manière de chasser l'antilope. Quand la neige a disparu, et lorsque la terre s'est ramollie, les femmes cueillent de l'absinthe dans les champs où elle croît la plus touffue; puis elles en construisent une haie d'environ trois 
pieds de haut, dont elles entourent un espace de terrain d'une centaine d'arpents, ne laissant qu'une seule ouverture pour que le gibier y puisse entrer. Cela fait, les femmes se cachent derrière l'absinthe, ferment l'entrée et attendent patiemment qu'il se présente des antilopes, qui entrent souvent en grand nombre dans cette enceinte. Dès qu'elles y ont pénétré, les femmes donnent le signal, et les hommes accourent. Un seul entre dans l'enclos, et se met à pourchasser ces animaux, courant jusqu'à ce qu'il soit fatigué; après quoi il est remplacé par un de ses camarades. A la fin, les pauvres antilopes sont si harassées, que quand les hommes entrent tous à la fois, il ne leur reste plus qu'à les abattre à coups de pioche. Ce qu'il y a de plus remarquable dans cette chasse, c'est qu'un animal agile et prompt comme l'antilope continue à faire le tour de ce fatal enclos sans jamais essayer de franchir la barrière peu élevée qui l'entoure.

Les Indiens surnommés Dignes-DE-Pití́ sont extrêmement misérables, ne possèdent point de chevaux, et sont privés de tous les objets qu'ils auraient pu se procurer par des relations avec les blancs. Ils ont pour armes des arcs et des flèches à pointes de caillou, avec lesquels ils chassent le cerf, l'élan et le mouton des montagnes. Ils sont répandus dans les pays des Shoshokors, des Tètes-Plates, des Corneilles et des Pieds-Noirs; mais ils habitent toujours les cavernes et les lieux les plus isolés. Les traqueurs remarquent souvent les traces de leurs pas dans les montagnes; ils voient de loin se dérouler la fumée de leurs feux; mais il est fort rare qu'ils les rencontrent, et bien plus rare encore qu'ils parviennent à leur parler, tant leur timidité est grande, tant ils ont peur des étrangers. Ces êtres infortunés, qui semblent former le dernier chaînon qui lie l'homme à la brute, sont des êtres dignes de mépris pour les traqueurs créoles.

Les TRAQUEURS INDÉPENDANTS, quoique d'origine européenne, se sont façonnés à loutes les coutumes des indigènes. Parmi les chasseurs qui s'engagent au service des 'ompagnies de pelleteries, les uns ont des traitements fixes et reçoivent des armes, des chevaux, des piéges, etc. Ceux-ci sont sous les ordres des commandants, dont ils loivent suivre les instructions. On les appelle traqueurs à gages. Les traqueurs indépendants vont et viennent, au contraire, où il leur plaît; ils ont leurs propres chevaux, leurs armes et leurs équipements, ils traquent et trafiquent pour leur propre compte, et disposent de leurs peaux et de leurs pelleteries en faveur de ceux qui leur en donnent le plus haut prix. Parfois, quand ils se trouvent dans les parages dangereux, ils s'attachent au camp de quelque trafiquant; alors ils sont obligés de se soumettre aux règles ordinaires du traquage, et de prendre leur part de service établi pour le mainlien du bon ordre et de la sûreté du camp. En retour de la protection qu'ils reçoivent, ils sont tenus de vendre au commandant du camp tous les castors qu'ils prennent pour un prix stipulé d'avance, et s'ils préfèrent en disposer ailleurs, ils lui payent une somme de trente ou quarante dollars, comme droit de rachat.

On ne saurait faire un compliment plus flatteur à un traqueur indépendant que de l'assurer qu'on l'a pris pour un Indien; à dire vrai, l'imitation est parfaite. Ses cheveux, qu'il laisse croître, sont peignés avec soin : tantôt ils retombent négligemment sur ses épaules, tantôt ils sont tressés et noués avec des peaux de loutre ou des rubans de diverses couleurs. Une chemise de chasse de calicot, de couleurs brillantes, ou de cuir verni, lui tombe jusqu'aux genoux; puis des jambards de forme singulière, ornés de cordons, de franges et d'une foule de grelots, rejoignent sur les pieds une paire de riches mocassins des meilleures fabriques indiennes, élégamment brodés en grains de verre. Une couverture écarlate ou quelque autre couleur éclatante, pend sur leurs épaules et est nouée autour de la ceinture par une écharpe rouge, dans laquelle ils placent leurs pistolet's, leur couteau et-le tuyau de leur pipe. Le fusil est couvert d'ornements de cuivre et renfermé dans une gaîne de peau de daim frangée et ornée de 
plumes. Le cheval du traqueur est encore plus richement et plus bizarrement harnaché. La bride et la croupière sont couvertes d'une profusion de grains de verre et de cocardes; la tête, la crinière et la queue sont entremêlées de plumes d'aigle qui flottent áu vent. Pour compléter ce grotesque équipement, le fier animal est fardé de vermillon ou d'argile blanche, nuances qui forment le plus singulier contraste avec la couleur naturelle de la robe.

Lorsqu'il reste célibataire, le traqueur indépendant n'a pas d'objet plus cher que son cheval; mais du moment où il prend femme, et son choix se fixe toujours sur une Indienue, il s'aperçoit bientôt qu'une créature plus capricieuse va devenir désormais l'objet de ses soins et de ses attentions. La beauté qu'il lionore de sa main sent ses idées s'élargir avec sa nouvelle dignilé; elle dispose de la bourse de son mari et même de son crédit pour paraître avec l'éclat convenable. L'épouse d'un traqueur indépendant ne doit pas ressembler à une squaw ordinaire. En premier lieu, il faut qu'elle ait un cheval pour son usage particulier, et ce cheval ne doit pas être une vieille rosse telle que les Indiens en donuent à leurs squaw pour les porter, elles et leurs enfants, mais le plus bel animal qu'elle a pu trouver. Il faut qu'il soit caparaçonné avec une richesse extraordinaire. De chaque côté de la selle pend un esquimoul, espèce de poche dans laquelle clle dépose les ornements et les bijoux qu'elle n'a pu placer sur son cheval ou sur sa personne. Par-dessus elle étend avec soin un drap et des couvertures de coton imprimées. Elle est, comme de raison, plus prodigue encore d'ornements quand il s'agit de sa personne. Ses longs cheveux, artistement nattés, retombent, avec une apparente négligence, des deux côtés sur sa poitrine; son chapeau est orné de plumes bigarrées, sa robe, qui pour la forme ressemble à celles des femmes blanches, est d'une étoffe rouge, verte et quelquefois grise, mais toujours la plus fine possible. Ses jambards sont du travail le plus recherché, et ses mocassins lui serrent exactement le pied et la cheville, que les Indiennes ont en général fort jolis; ses bijoux, ses bagues, ses pendants d'oreilles, ses colliers sont en aussi grand nombre et aussi riches que le permet la fortune de son mari. Pour achever sa toilette, elle jette sur ses épaules une couverture d'une couleur très-éclatante, et s'élançant sur la selle de son coursier caracolant, elle suit partout son mari avec amour et fidélité, jusqu'au dernier soupir.

Quand il y a plusieurs femmes de traqueurs indépendants dans le même camp, la concurrence la plus vive s'établit entre elles pour ce qui regarde la toilette, au grand détriment de la bourse de leurs maris. Elles ne songent qu'à s'éclipser l'une l'autre, et ne le cèdent en rien à cet égard aux directrices de la mode de nos contrées civilisées.

L'équipement d'un traqueur se compose d'un fusil, d'une livre de poudre, de quatre livres de plomb, d'un moule à balle, de sept piéges, d'une hache, d'une cognée, d'un couteau, d'une alène, d'un poêlon, de deux couvertures de laine; et quand les provisions sont abondantes, il emporte sept livres de farine. Il a en général deux ou trois chevaux pour lui, son bagage et ses pelleteries. Deux traqueurs vont ordinairement ensemble afin de se prèter un mutuel appui. S'ils étaient plus nombreux, ils échapperaient difficilement aux poursuites des Indiens.

Leur service est périlleux, et bien plus aujourd'hui qu'il ne l'était autrefois, car depuis que les Indiens ont pris l'habitude de trafiquer sur les pelleteries avec les blancs, ils ont appris à connaître le prix du castor; aussi regardent-ils les traqueurs comme des braconniers qui viennent leur enlever les trésors de leurs eaux; aussi n'hésitent-ils pas à assassiner tous ceux qu'ils rencontrent isolés; ils se délivrent à la fois d'un compétiteur, et s'enrichissent de ses dépouilles. Il faut malheureusement convenir qu'ils sont souvent poussés à ces actes d'hostilité par des trafiquants qui cherchent à nuire à leurs rivaux. 
Lorsque deux traqueurs entreprennent une grande rivière, ils commencent par cacher leurs chevaux dans un endroit solitaire où ils puissent paître sans être aperçus. Ils conștruisent ensuite une petite cabane et un canot avec un tronc d'arbre. Dans cette frêle embarcation, ils suivent la rivière en silence, et le soir ils dressent leurs piéges. Ils y retournent dans le même silence au point du jour, et quand ils ont pris un castor, ils le rapportent à la cabane, l'écorchent, étendent la peau sur des piquets pour la faire sécher, et en mangent la chair. Le corps, suspendu devant le feu, tourne par son propre poids et se rôtit ainsi parfaitement ; la queue est le morceau de roi ; ils la coupent et la font griller devant le feu au bout d'un bâton; elle passe pour un mets plus délicat encore que la langue ou la moelle d'un buffle. 



\section{CANADA,}

\section{AVEC TERRE-NEUVE, LA NOUVELLE-ÉCOSSE, ETC.}

Cette vaste contrée de la Nouvelle-Bretagne est située entre $42^{\circ} 12^{\prime}$ et $52^{\circ} 16^{\prime}$ de latitude nord, et entre $66^{\circ} 30^{\prime}$ et $97^{\circ}$ de longitude ouest; sa superficie est de plus de 55,000 lieues carrées; mais en n'y comprenant que les terres, elle est de $\mathbf{3 9 , 4 0 0 ~ l i e u e s ; ~}$ et la population est portée à 900,000 individus environ.

La lempérature du haut et du bas Canada est beaucoup plus rigoureuse que ne pourrait le faire supposer son élévation modérée en latitude. Il y règne l'hiver des froids beaucoup plus rigoureux qu'en d'autres pays situés sous la même zone, et cette différence provient, soit de la grande quantité de forêts et de terres en friche, soit des lacs immenses et nombreux qui se succèdent sur ce territoire. Bien que froid, ce climat est salubre : en été les chaleurs y sont plus fortes qu'en Europe. On attribue la découverte du Canada à Jean et Sébastien Cabot; elle eut lieu en 1497. Depuis cette époque, un grand nombre de voyageurs parcoururent cette contrée, et la firent connaitre aux Européens.

Le Cánada est, en général, très-fertile, et produit toutes sortes de grains, du lin, du chanvre, du tabac, el des plantes potagères. Les forèts sont nombreuses et peuplées d'excellents bois de construction, de charpente, etc.; elles servent de retraite à des ours, des cerfs, des élans, des renards, des martes, des chats sauvages, desfurets, des belettes, des écureuils d'une grosse espèce et de couleur grise, des lièvres et des lapins. Elles renferment aussi des serpents à sonnettes de quatre à six pieds de long; des serpents noirs de six à huit pieds, qui ne sont pas venimeux, et une grande variété d'autres plus petits. On remarque parmi les oiseaux de ce pays l'aigle, le vautour, le hibou, le pélican, le cygne, le cormoran, la grue, le faisan, la perdrix, l'outarde, et un nombre infini de petits oiseaux d'un agréable ramage; les volailles n'y sont pas rares. Les lacs, les étangs et les rivières fourmillent de bons poissons ainsi que de loutres, de castors blancs et noir's très-estimés, et de tortues.

Le Canada a été divisé en deux parties ou provinces, par un acte du parlement brilannique de 1791, sous les noms de haut et bas Canada. Ces deux provinces ne sont pas moins distinctes par les lois que par les mœurs. Dans l'une et dans l'autre, il existe un conseil législatif et une chambre des représentants. Ces deux assemblées ont la faculté de proposer des lois à l'acceptation du gouvernement anglais. Le conseil législatif est composé de vingt-deux membres dans le haut Canada, et de vingt-huit dans la province basse.

L'administration supérieure des deux Canadas se compose du conseil législatif, de la chambre des députés, et d'un gouverneur, aidé d'un conseil exécutif.

Il est à remarquer que dans le bas Canada, qui a conservé les anciennes lois fran. 
çaises, les terres qui ont le titre de seigneurie sont encore soumises au régime féodal, et que dans le haut Canada, où les lois anglaises sont seules en vigueur, les propriétés coloniales, appelées townships, et qui consistent en terres qui ont été distribuées à des militaires de tous grades, sont au contraire régies par les lois communes.

Les dépenses d'administration sont évaluées à 620,000 francs; l'Angleterre en paye la moitié. Le seul profit que la Grande-Bretagne tire du Canada provient de son commerce avec cette colonie, qui occupe environ 7,000 tonneaux. Le Canada est, en temps de paix, le débouché de plusieurs produits des manufactures anglaises qui entrent aux États-Unis, soit légalemenl, soit en fraude. Les produits du sol même du Canada, et ceux que le commerce anglais tire par cette voie de l'intérieur de l'Amérique septentrionale, fournissent les objets d'un échange el d'une navigation considérables.

Le has Canada a environ 300 lieues de longueur sur 140 dans sa plus grande largeur; sa superficie en terre est de 27,000 lieues. Il est divisé en seigneuries ou francs-fiefs, concédés par la couronne de France aux premiers colons. Ces seigneuries subsislent toujours, malgré la nouvelle division administrative adoptée par le gouvernement. Ces seigneuries sont au nombre de 210. Mais depuis 1810 , le pays est divisé en cinq districts qui se subdivisent en quarante comtés. Ils s'étendent le long du fleuve Saint-Laurent. Le reste du territoire est habité par les indigènes.

L'accroissement de la population du bas Canada, de ses revenus, de son commerce, a été très-rapide sous la domination anglaise.

QuéBec, capitale du bas Canada, a un aspect imposant et vraiment magnifique, et se développe majestueusement en forme d'amphithéâtre. Les habitants, au nombre de 25,000, ou 30,000, selon quelques auteurs, se dédommagent des froids longs et rigoureux de l'hiver par des parties de traìneaux et par des réunions où l'on danse. La garnison soutient un mauvais théâtre anglais, et des courses de chevaux, récemment introduites, contribuent à l'amélioration de la race. Québec est la résidence du gouverneur général de l'Amérique anglaise.

Montréal, la seconde ville du bas Canada, renferme plus de 30,000 âmes. Son commerce consiste en fourrures qui arrivent des environs du lac Ouinipeg ou Bourbon, pour le compte de la compagnie anglaise. Sa population est toute française au fond, quoique de nombreux émigrants anglais y soient arrivés dans le cours de ces quinze dernières années. Le caractère des habitants est, en général, bienveillant et hospitalier; la société y est agréable, douce, communicative et spirituelle. C'est un mélange heureux des éléments qui constituent le caractère anglais et français et qui unit à la sûreté des rapports l'élégance des manières. Les hommes de la classe inférieure que l'on rencontre dans les rues ont un air de vigueur, de satisfaction et de gaieté qui plaît à voir. Jusqu'ici Montréal est restée étrangère à cette lèpre du paupérisme qui infeste presque toutes les grandes villes et les grands États de l'Europe.

Le haut Canada a environ $\mathbf{3 5 0}$ lieues de longueur et 130 dans sa plus grande largeur; sa superficie, en n'y comprenant que les terres, est de 12,400 lieues carrées. Sa frontière, commençant au lac Français, longe ensuite la rivière d'Ottawa. Il a été divisé en quatre districts et vingt-cinq comtés.

YoRK, siége des autorités et du gouvernement et capitale du haut Canada, est une ville assez régulière dont les rues sont coupées à angle droit. Elle renferme à peu près $\bar{\jmath}, 000$ habitants et cinq cents maisons, dont la plupart sont bâties en bois. On y trouve cependant quelques jolies habitations en briques ou en pierres.

Kingston est la ville la plus importante et la plus populeuse du haut Canada; sa population est évaluée à 5,500 âmes. Elle pourrait passer pour jolie, si ses rues, qui sont droites et garnies de maisons en pierres, étaient pavées. 
Au commencement de 1855 , la colonie anglaise du haut Canada a pris un développement prodigieux qu'elle doit au commerce, à la civilisation, à des capitaux considérables, à un sol fertile et à un esprit entreprenant. Les établissements de Brockville, Sainte-Catherine, Hamilton, Kobourg, Queenston, et plusieurs autres qui naguère étaient considérés comme de simples villages, peuvent prendre rang parmi les villes.

Le voyageur qui traverse les parties défrichées et cultivées du haut Canada, admire la fertilité du sol, et la beauté de la culture, les simples habitations de troncs d'arbres à peine équarris, mais commodes et abondamment pourvues de tout ce qui sert aux nécessités de la vie. Frappé de ce tableau charmant, qui ne respire que le calme et le bonheur, il ignore sans doute que ces biens, cette prospérité, cette aisance, sont le fruit de plusieurs années des privations les plus dures, des travaux les plus pénibles, qui ne peuvent être supportés et vaincus que par un courage et une persévérance indomptables. Rien n'est plus rude que les premières années de la vie des pionniers. Qu'on se représente deux personnes, ayant le plus souvent de jeunes enfants, perdues au milieu des forêts, éloignées des villes, dans une contrée qu'aucune route ne traverse, se procurant avec beaucoup de peine les provisions les plus grossières, manquant souvent dans l'hiver, durant des semaines entières, du plus strict nécessaire et mème de pain : tel était, il y a peu d'années, le sort de tous les pionniers au début de leur carrière aventureuse; c'est encore aujourd'hui celui des familles pauvres ou fort éloignées des habitations. Aussi n'est-il pas surprenant que, trompés par les brillants tableaux des voyageurs, plusieurs émigrants se laissent bientôt rebuter par les difficultés qu'ils rencontrent, et préfèrent même une indigence moins laborieuse dans la mère patrie.

L'émigrant, en prenant possession de la partie de la forêt qu'il a acquise, commence par se construire une chétive cabane. Une coutume fraternelle, qu'une nécessité commune a consacrée à ces extrêmes limites de la civilisation et du désert, lui procure assistance dans ce premier travail. Sur son appel, ses voisins les moins éloignés accourent l'aider à élever les murs du shanty, misérable hutte où il cherche un premier abri, et qui est au log-house ce que la cabane est à la maison, car il ne faut pas songer d'abord à une demeure commode et spacieuse; des nécessités plus pressantes font négliger les agréments de la vie. Le shanty n'est guère qu'un hangar formé de troncs d'arbres bruts dont on remplit les intervalles avec de la mousse et de la boue. Le toit est fait de troncs fendus avec la hache et grossièrement juxtaposés. Le plus souvent le shanty ne reçoit la lumière que par l'ouverture qui sert de porte et de passage à la fumée de l'âtre, formé de quelques pierres plates rangées en cercle. C'est dans ces misérables cabanes que les pionniers, même les plus aisés, passent les premiers temps de leur établissement, et souvent plusieurs années. C'est dans ces huttes, pêlemêle avec les bestiaux et la volaille qui servent à leur subsistance, que se confinent souvent des familles qui ont joui de toutes les délicatesses de la civilisation la plus àvancée. L'espérance et les joies pures de la vie domestique sont leur seul sontien. Au milieu des misères et des souffrances de cette première existence, on voit les femmes anglaises déployer la force d'âme qu'elles ont puisée dans leur première éducation et dans les graves enseignements d'une sévère religion.

Les Indiens vagabonds qui rôdent dans le haut Canada ont perdu plus qu'ils n'ont gagné à leur contact avec les Européens. Ils ont vu disparaître tout ce qui pouvait leur rester de vertus sauvages, et ils ont acquis des vices qu'ils eussent toujours ignorés au fond de leurs déserts. L'ivrognerie leur a enlevé cette finesse de sens, si remarquable parmi les indigènes de l'Amérique du nord.

Le gouvernement anglais a un soin tout paternel de ces peuplades; un certain nombre de personnes forment ce que l'on appelle le département des Indiens, veillent 
à leurs intérèts et gèrent leurs affaires. Deux fois l'année, un médecin visite leurs villages, donne des avis et distribue des médicaments parmi les habitants. Annuellement aussi une distribution de présents a lieu sur les bords de l'Ouse et à l'extrémité occidentale du lac Érie. Chaque Indien reçoit quelque bagatelle qui peut lui être utile; chaque Indienne un objet de parure. Il est vrai que ces distributions manquent leur but, et qu'aussitôt qu'elles sont faites, les Indiens cherchent à revendre à tout prix les objets qu'ils ont reçus, pour acheter en échange des liqueurs fortes. Cequ'en fait le gouvernement anglais tend plutôt à obtenir, de la part de ces sauvages, une attitude pacifique et la neutralité en cas de guerre. Les Indiens sont des alliés faibles et inutiles, mais des ennemis dangereux. Quand les Anglais les ont eus pour auxiliaires, ils n'ont jamais pu les plier à la discipline. Ils prenaient la fuite au commencement de l'action, et revenaient seulement pour dépouiller les morts. Cependant la connaissance qu'ils ont des localités et leur adresse au tir les rendent redoutables dans une guerre d'escarmouches. Ils possèdent des secrets qu'ils ne veulent révéler à personne; ils teignent les piquants du porcépic et autres substances de couleurs brillantes et durables, et connaissent les propriétés de plusieurs plantes douées de vertus médicales très-énergiques. Ils savent aussi tendre des appâts qui ne manquent jamais d'attirer certains animaux au piége.

C'est dans cette partie favorisée du Canada que l'on rencontre parfois des serpents qui, plus que d'autres, ont de grandes propriétés de fascination sur le regard et sur l'odorat. Voici, à ce sujet, un fait que raconte un voyageur anglais. "Un fermier me dit qu'un jour d'été qu'il faisait très-chaud, sa fille était allée étendre du linge sur des buissons voisins de la maison, pour le faire sécher. La mère trouvant qu'elle ne venait pas assez tôt, et la voyant debout sans rien faire, à une certaine distance, l'appela plusieurs fois; elle ne répondit pas. A la fin, la mère s'approcha : la fille était pâle, immobile et comme fixée à sa place; la sueur lui découlait du front; ses mains étaient fermées par un mouvement convulsif. Uún gros serpent à sonnettes étendu sur une poutre, vis-à-vis de la jeune fille, tournait sa tête de côté et d'autre, et tenait ses yeux constamment attachés sur elle. La mère lui donna un coup de baguette; il décampa. La fille, revenue à elle, fondit en larmes; elle était si faible et si agitée, qu'elle n'avait pas la force de marcher. s

Il existe encore un contraste frappant entre les fermiers du haut et du bas Canada, comme on peut s'en assurer à la Chine, village situé sur le Saint-Laurent; c'est autoụr de ce village que commencent à se développer de belles et fertiles plantations, exploitées par des fermiers canadiens, établis de père en fils. Ces paysans ont le teint brun et les traits caractérisés; ils sont, en général, maigres, quoique d'une structure athlétique; ils ont les yeux petits, brillants et vifs; ils sont, en général, d'une politesse affectueuse et familière envers les étrangers. Adroits, spirituels, prévenants, ils convient les voyageurs à venir boire un verre de cidre avec eux, leur pressent la main avec une sorte d'effusion, et se montrent fort empressés autour d'eux.

Les Canadiens vont peu à pied; tout fermier est à peu près en état d'avoir un cheval et une calèche. Les chevaux canadiens, bons au fond, sont en apparence les plus misérables que l'on puisse imaginer. Ils sont longs, lourds et d'un poil rude; mais ils s'animent sous le fouet du conducteur. On ne peut se faire une idée de la fierté du paysan canadien, qui conduit son cheval chétif et sa voiture mal assurée; c'est l'être le plus vif, le plus gai, le plus pétulant que l'on puisse voir. La calèche et le cheval, tels sont les premiers meubles d'un Canadien, ce qu'il nomme son établissement. Dans ces hommes qui arpentent la grande route, on rencontre la même politesse, la même prévenance que daus les fermiers sédentaires. Jamais ils ne passeront devant un étranger sans lui ôter leur chapeau, et les enfants, pour peu que le voyageur soit con- 
venablement vêtu, ne manqueront pas de le saluer profondément. Sïdeux postillons sont à portée de s'entendre, ils se diront mutuellement un bonjour cordial, en se traitant de monsieur.

Dans son excursion au Canada, M. d'Orbigny fit la rencontre de deux pirogues d'Indiens; les femmes étaient assises; les hommes debout maniaient leurs pagaies avec une rapidité remarquable. Ces Indiens ont la tête ornée d'un cercle d'acier et de plumes; le reste de leur vêtement se compose de peaux de bêtes fauves et de longs manteaux écarlates couverts d'ornements en oripeaux. Leur langage est dur, heurté, guttural, bizarre; ils semblent imprimer à tous leurs entretiens un caractère de querelle et de dispute.

“ Ayant pris terre presque en même temps que nous, dit M. d'Orbigny, ces Indiens ne parurent pas intimidés par notre présence. Sans s'inquiéter autrement de nous, les femmes se mirent aussitôt à couper du bois pour le feu, et les hommes ayant rassemblé des perches et de l'écorce de bouleau, commencèrent à construire un wighwam. Quand nous fùmes tous installés, eux de leur côté, nous du nôtre, chaque caravane commença son repas, et celui des Indiens eût été fort maigre, si nous n'y avions ajouté un peu de nos provisions, accompagnées d'une bouteille de rhum. »

Ce dernier présent fut une véritable fête pour ces sauvages. Ils remercièrent les voyageurs par des cris bruyants, et se passèrent l'un à l'autre, à la ronde, la boisson spiritueuse jusqu'à ce qu'il n'en restât plus une seule goutte. Bientôt les Indiens, entassés dans leur wighwam, autour du feu où rôtissait leur gibier, se ressentirent du rhum qu'ils avaient bu, et prirent les poses les plus comiques, les allures les plus singulières. Ceux-ci affectaient un regard belliqueux et féroce; ils frottaient leurs tomahawks avec une sorte de rage, et poussaient par intervalle des cris de guerre comme s'ils eussent voulu défier un ennemi lointain; les femmes se livraient à un bavardage intarissable, et les enfants jouaient de la guimbarde. Enfin, peu à peu, toutes ces manifestations bruyantes cessèrent, et ils tombèrent dans un profond sommeil.

La population française est resserrée principalement sur la rive septentrionale du fleuve Saint-Laurent, depuis Montréal jusqu’à Quebec. Les premiers colons français paraissaient être venus de la Normandie. Contents de peu, attachés à leur religion, à leurs usages, soumis au gouvernement qui respecte leur liberté, ils possèdent, à côté de beaucoup d'indolence, un fonds naturel de talents et de courage qui n'aurait besoin que d'être cultivé par l'instruction : ils se livrent avec ardeur aux travaux les plus rudes. Ils fabriquent eux-mêmes les étoffes de laine et de lin dont ils s'habillent à la campagne; ils tissent ou tricotent eux-mêmes leurs bonnets et leurs bas, tressent leurs chapeaux de paille, et tannent les peaux destinées à leur fournir les mocassins ou grosses bottes; enfin leur savon, leurs chandelles, leurs charrues, elc.

Ils ont le visage long et mince; leur teint brunâtre et hâlé devient quelquefois, sans doute par l'effet du mélange avec la race indigène, aussi foncé que celui des Indiens; leurs yeux, petits et noirs, ont beaucoup de vivacité; leur nez avancé tend à la forme aquiline; les lèvres sont peu épaisses, les joues maigres et les pommettes saillantes. Une politesse noble et aisée règne dans leur conversation; ils se présentent avec un air qui les ferait prendre pour les habitants d'une grande ville, plutôt que pour ceux d'une contrée demi-sauvage. La plus parfaite harmonie existe entre eux : souvent les enfants de la troisième génération demeurent dans la maison paternelle.

Quoique le climat, en rendant nécessaire l'usage des poils et fourrures, donne aux Canadiens l'apparence des Russes, la gaieté française y conserve son empire. Les plaisirs y ont le caractère simple et un peu grossier qu'ils avaient en France avant le raffinement introduit sous Louis XIV : les parents et les amis s'assemblent tous les jours 
autour d'une table chargée de mets solides; à côté d'un énorme quarlier de bœuf ou de mouton, on voit de vastes terrines remplies de soupes ou de lait caillé. Immédiatement après un dîner qu'anime une gaielé franche et bruyante, les violons se font entendre; tout le monde se livre à la danse, les menuets et les gigues se succèdent sans interruption.

Les femmes du Canada sont remarquables par leurs grâces et leur brillante santé. Par l'éclat de leur teint, la régularité de leurs traits et la beauté de leur taille, elles ressemblent aux Cauchoises; leurs grands yeux noirs tranchent agréablement avec l'incarnat de leurs joues fraîches et vermeilles. Bonnes épouses, mères tendres, ménagères soigneuses, elles font la félicité de leurs familles. Les Canadiens suivent avec une scrupuleuse exactitude les modes dont ils reçoivent les modèles de Paris.

Dans l'éducation des jeunes personnes de bonne famille, les arts d'agrément ne sont point négligés; le dessin forme une partie importante de l'instruction qu'elles reçoivent; la musique compte des élèves jusque dans les fermes et les villages. Enfin, dans la classe inférieure, une jeunesse joyeuse répète en chœur d'anciennes chansons normandes.

La sobriété n'est pas la verlu des Canadiens; l'habitude de l'ivresse y produit des accidents tragiques.

Quoiqu'une longue paix ait répandu de l'aisance el quelques germes d'industrie parmi les classes supérieures, el quoique le cultivateur du Canada jouisse d'un bonheur sans égal, le goût des études a besoin d'être encouragé.

Les deux Canadas ont faịt dans l'industrie des progrès récents et assez rapides depuis quelques années. Considéré comme position militaire, le Canada forme le principal anneau de cette chaîne de possessions britanniques du nord, qui, depuis l'Acadie et Terre-Neuve, vient se perdre aux environs du lac Ouinipeg, chaîne qui enveloppe les Elats-Unis par le nord-est et le nord.

Nous ne nous étendrons pas sur les mœurs des tribus sauvages qui habitent dans les limiles du Canada. Les Hurons, qui s'étendent au nord et à l'est du lac qui porte leur nom, jouirent autrefois d'une certaine célébrité; mais ce peuple ne se compose plus aujourd'hui que de quelques familles. Quelques restes des tribus appelées les Six-Nations, et principalement des Monarons, ont quelques villages sur la rivière d'Ure. Les MissiSAGues, tribu alliée des Algonquins, habitent encore dans la péninsule du Canada, aux sources de la rivière de Crédit; on porte leur nombre ả 16,000. La branche principale des Iroquors occupe les bords de l'Ottawa; c'est un faible reste de celte nation généreuse et redoutable.

Les Agniers habitent le misérable village de Cachenonaga, non loin de Montréal; c'est une tribu d'Iroquois qui a adoplé la religion chrétienne. Celte peuplade a une dévotion particulière à la sainte Vierge.

Les Tumiskamings ou Timmiscameins habitent au nord des sources de l'Oltawa. Ils passent pour être les plus nombreux'des indigènes du haut Canada, el parlent la langue algonquine ou knistenane. Les Algonquins s'étendent vers la rivière Saint-Maurice. Les Pikouaganis, aux environs du lac Saint-Jean; les Mistissinnys, sur le lac du mème nom, et les Papinachors, au nord de la rivière Saguenay, mènent aujourd'hui une vie paisible et commencent à se livrer à quelques essais de culture.

Le Gaspé ou la GaSPÉsıe, qui renferme environ 4,000 habitants, est la patrie ancienne l'une tribu indienne, remarquable par ses mœurs policées et par le culte qu'elle rendait au soleil. Les Gaspésiens distinguaient les aires du vent, connaissaient quelques étoiles et traçaient des cartes assez justes de leur pays. Une partie de cette tribu adorait la Croix avant l'arrivée des missionnaires, el conservait une tradition curieuse sur un homme 
vénérable qui, en leur apportant ce signe sacré, les avait délivrés du fléau d'une épidémie.

Le Nouveau-Brunswick s'étend, d'un côté, sur le golfe Saint-Laurent; de l'autre, sur la baie de Fundy. Le climat de ce pays est plus froid que ne l'indique sa latitude entre le $45^{\mathrm{e}}$ et le $48^{\mathrm{e}}$ parallèle.

La tribu indigène des MaréchItes est réduile à 140 gुuerriers. Les Européens y dépassent le nombre de 80,000 .

Frédérictown, autrefois Sainte-Anne, est la capilale du Nouveau-Brunswick, la résidence du gouverneur et des principales autorités.

La Nouvelte-Écosse est une presqu'île qui partage avec toute cette partie du globe un climat fort rigoureux en hiver. Sa population est d'environ 140,000 âmes.

HaLIFax, capitale de la Nouvelle-Écosse et l'une des plus importantes échelles marilimes du Canada, est une ville charmante et régulièrement bâtie. Elle est peuplée de 16,000 à 20,000 habitants.

L'île du Cap-Breton est séparée de la Nouvelle-Écosse par le détroit de Causo; elle est importante par ses vastes et excellentes baies, par les pêcheries et par le commerce considérable auquel elles donnent lieu. On cite Sinner, petite ville de cinq cents àmes, aux environs de laquelle sont des houillères; Louisbourg, jadis la ville principale du Cap-Breton.

L'île du Prince-Édound, quoique voisine de celle du cap Breton, lui est bien supérieure par la fertilité de son sol. On y trouve Charlotte-Town, petite ville avec un heau port et 5,400 habitants; Belfast, colonie agricole d'Écossais ; Charlotte-Town et Murray-Harbeur, importants par leurs ports.

Terre-Neuve. - Cette île, appelée par les Anglais New-Foundland, ferme, au nord, l'entrée du golfe Saint-Laurent. Elle passe généralement pour stérile, les bords des rivières exceptés. Cependant elle produit diverses sortes de bois employés soit à l'établissement des nombreux échafaudages dressés tout le long de la côte pour la préparation de la morue, soit à la construction navale.

Parmi les animaux, on distingue une race particulière de chiens remarquables par leur grande taille, leur long poil soyeux, et surlout par la grande dimension de la peau entre les doigts de pied, ce qui les rend propres à nager. Il paraît que cetle race descend d'un dogue anglais et d'une louve indigène.

Longtemps considérée comme un pays inhospitalier, comme une simple station de pêcheurs, Terre-Neuve a, depuis quelques années, vu doubler son industrie et sa population.

Cette population se compose de colons, de pècheurs el d'Indiens sauvages qui vivent dans? l’h'intérieur des terres. Les colons se divisent en sédentaires et en pècheurs, car un grand nombre d'entre eux suivent l'exemple de ces marins intrépides, qui, pour un bénéfice quelquefois fort modique, vont risquer leur vie au milieu des écueils du littoral. On conçoit qu'il est assez difficile d'évaluer avec exactitude une telle population.

La"condition intellectuelle des habitants n'est pas, on peut bien le penser, des plus satisfaisantes, et l'état social de celte réunion d'hommes laborieux, mais grossiers, n'est guère propre à faire envie à leurs voisins de Saint-Pierre et Miquelon. La canse de celte situation n'est pas difficile à deviner : pendant longtemps Terre-Neuve n'a, ainsi que nous l'avons déjà dit, été qu'un établissement de pêche, et les pêcheries appartenaient exclusivement à des négociants résidant en Angleterre qui les faisaient exploiter. Ceux-ci estimaient que le nombre, alors fort petit, des planteurs fixés dans la colonie même, n'avait aucun droit d'intervenir dans la discussion des intérêts de l'ìle; en conséquence, ils s'opposaient toujours aux mesures qui auraient pu a méliorer 
la position d'une population qu'ils traitent comme un troupeau de vassaux ou d'esclaves. Mais l'augmentation continuelle du nombre des habitants sédentaires, les progrès de l'agriculture et du commerce parmi les résidants, autorisent ces derniers à se meltre au-dessus des caprices des armateurs, et le parlement impérial avisera sans doute à les doter d'institutions en harmonie avec leurs besoins actuels.

Les indigènes y forment deux ou trois tribus de 100 à 300 individus chacune. Les Inders Rouges s'étendent au sud, dans l'intérieur, jusqu'au grand lac.

Les Micmacs habitent les environs de la baie de Saint-George, de celle du Désespoir, et les bords de la rivière Great-God-Bey. Ces peuplades font avec les Anglais le commerce de fourrures, et sont loin de vivre en bonne intelligence.

Les îles Saint-Pierre, Mrquelon et Langlade ou Petite-Miquelon, sont des colonies françaises voisines de Terre-Neuve. 


\section{RÉGION DU NORD-OUEST,}

0 U

POSSESSIONS RUSSES。

Appelée aussi Amérique russe, la région nord-ouest de l'Amérique s'étend le long du détroit de Behring et se prolonge par la presqu'île d'Alaska et une longue chaine d'iles, jusqu'aux terres asiatiques, c'est-à-dire les îles de Cuivre et de Behring et la péninsule du Kamtchatka, en formant le bassin maritime appelé la mer de Behring.

Les îles Aléoutes ou Aléoutiennes proprement dites sont au nombre de trois : Attou, Agattou et Semitch. A l'est de celle-ci, se présente le groupe des Andréanoff, composé de plusieurs îlots peu importants et de vingt îles longues en général de quinze à vingì lieues : ce sont Boulduire, Kiska, Kriseï ou l'île du Rat, Tanaga, Bobrowoï, Gorolö̈, Semisopotnoï ou l'île des Sept-Cratères, Adahk, Sitkhine, Tagilak, Goulduir, Kekoup, Segoulla, Amtchàtka, Krouelö̈, Illak, Ounialea, Kouiouliok, Kanaga et Tchougoulla.

A l'est de ces îles se trouvent celles des Renards (Ostrova Lisii), dont les principales sont Oumnak, Ounalachka, Akoutan, Akoun, Ounimak, Spirkine, Cacalga, Sannakh, Choumaghine et Kadiak.

En réunissant la population de toutes ces îles, on aura un total d'environ 400 mâles, dont près de la moitié sont employés par les chasseurs russes. Ces naturels étaient autrefois beaucoup plus nombreux; ils avaient des chefs, un gouvernement particulier et une religion nationale; mais les Russes ont anéanti leur population avec leurs mœurs, leurs coutumes et leur liberté. Envoyés comme esclaves à la chasse et à la pêche, les insulaires périssent en grand nombre sur la mer ou dans des hôpitaux mal tenus.

OunalachKa renferme le plus grand nombre d'habitants. Ces insulaires sont d'une taille médiocre, leur teint est brun. Ils ont le visage rond, le nez petit, les yeux noirs. Leurs cheveux, également noirs, sont rudes et très-forts. Ils ont peu de barbe au menton, mais beaucoup sur la lèvre supérieure. En général, ils se percent la lèvre inférieure, ainsi que le cartilage qui sépare les narines, et y portent, comme ornements, des petits os façonnés ou de la verroterie. Les femmes ont des formes arrondies sans être belles; elles se tatouent le menton, les bras, les joues; douces et industrieuses, elles fabriquen: avec beaucoup d'art des natles et des corbeilles. De leurs nattes, elles font des rideaux, des siéges, des lits. Leurs robes de peau d'ours ont le poil en dehors. Les baidares ou pirogues d'Ounalachka sont travaillées avec art; leurs formes sont pittoresques; ì Iravers la peau transparente dont elles sont convertes, on aperçoit les rameurs et tous leurs mouvements. Ces insulaires sont voués à des superstitions qui paraissent se rapprocher du chamanisme. Ils n'ont point de cérémonie de mariage. Quand ils veulent une femme, ils l'achètent du père et de la mère, et ils en prennent autant qu'ils en peuvent nourrir. S'ils se repentent de leur acquisition, ils rendent la femmeà ses parents, 
qui alors sont obligés de restituer une partie du prix. Les peuples de cet archipel ne paraissent pas entièrement exempts d'un amour contre nature. Ils rendent des honneurs aux morts et embaument leurs corps. Une mère garde ainsi souvent son enfant privé de vie avant de le confier à la terre. Les restes mortels des chefs et des hommes riches ne sont pas du tout enterrés; suspendus dans des hamacs, l'air les consume lentement. La langue des Aléoutiens, différente de celle du Kamlchatka, paraît avoir quelque analogie avec les idiomes de Yeso et des îles Kouriles. Dans l'île d'Oumnak, la plus voisine du continent, les Russes ont un évêque, un monastère, une petite garnison et un chantier de construction.

La partie nord-ouest du continent américain, depuis le canal de Portland, sur la côte du grand océan Boréal, jusqu'au cap des Glaces, dans l'océan Arctique, et depuis la mer de Behring jusque sous le $41^{\mathrm{e}}$ degré de longitude, forme ce qu'on peut appeler la Russie américaine. Il faut y comprendre aussi les archipels du Prince-de-Galles, du Ducd'York et de George-Trois, l'île de l'Amirauté, la longue chaîne des îles Aléoutiennes, qui, s'avançant jusque près des côtes de l'Asie, forme le prolongement de la péninsule d'Alaska, et sur la côte de la Nouvelle-Californie le comptoir de Bodega, à l'embouchure de la Slavinska-Ross.

Les archipels du Prince-de-Galles, de George-Trors et du Duc-d'York sont, ainsi que la grande île de l'Amrrauté, des terres garnies de forêts de pins, et habitées par des Iribus indigènes qui échangent des fourrures avec les Européens contre des armes à feu.

Les habitants de la baie de Tchinkitané, appelée par les Anglais baie de Norfolk, dans l'archipel du Roi-George, ressemblent, pour la taille et la figure, aux habitants de Noutka; mais leurs cheveux rudes les rapprochent des tribus plus septentrionales et de la race des Esquimaux. Les jeunes gens s'arrachent la barbe, les vieux la laissent croître. Les femmes portent un ornement bizarre qui leur donne l'air d'avoir deux bouches, et qui consiste dans un petit morceau de bois qu'elles font entrer de force dans les chairs, au-dessous de la lèvre inférieure. Ces peuplades montrent beaucoup d'adresse dans leur manière de faire le commerce, et beaucoup de courage dans leur pêche de la baleine; leur tannerie, leur sculpture, leur peinture et leurs autres arts les présentent comme un peuple intelligent et industrieux. lls conservent la tête des morts dans des espèces de sarcophages qui sont ornés de pierres polies.

La péninsule d'Alaska, au sud de la mer de Behring, est couverte de montagnes dont deux sont remarquables par leur hauteur et surtout parce que ce sont deux volcans qui ont été vus en éruption en 1786. Elle n'a pas moins de 200 lieues de longueur sur une largeur de 10 à 12. Les Russes y ont un petit établissement.

Les habitants de la côte du détroit de Behring paraissent être de la mème race que les Tchouktchis, sur la côte opposée d'Asie, quoiqu'ils leur fassent, dit-on, la guerre. Leurs hameaux, plus nombreux qu'on ne le supposerait dans un semblable climat, sont situés le long des rivages de la mer jusqu'au golfe Kamtchatkien, auquel le capitaine Cook avait donné le nom de baie de Bristol, parce qu'en effet il ressemble à cette baie d'Angleterre.

Toute la parlie qui borde la mer et le détroit de Behring est peuplée de Tchouktchis; ils se divisent en deux tribus : les stationnaires, et les errants ou Rennes. Les premiers occupent les bords de la mer et toutes les localités où l'on peut pêcher commodément; ils font, pour l'hiver, des provisions de morceaux de rennes, de phoques, de morses, dans des magasins creusés en terre, où ils conservent aussi de l'huile de poisson dans des outres de peaux. Les Tchouktchis errants sont fiers, et regardent avec mépris les hommes des nations voisines. Les rennes sont leurs seules richesses.

La partie orientale de la péninsule d'Alaska, presque séparée dı continent par le 
lac Chelckoff, est habitée par les Koniagurs. Ils paraissent de la mème race que les Aléoutiens, ainsi que les Kenaïts, leurs voisins à l'orient. Ceux-ci ont donné leur nom au golfe Kenaïtzien, appelé par les Russes Kenaïs-Kaïa-Gouba, auparavant désigné sous le nom de rivière de Cook; malgré les apparences, on n'a pas trouvé ici de grand fleuve. Plus à l'est demeurent les Tchougatches, peuplade d'une taille avantageuse, et qui parle un idiome rapproché de celui des Tchouktchis.' La baie remplie d'îles et appelée Entrée de Norton par le capitaine Cook, porte, sur les cartes russes, le nom de golfe Tchougatchiẻn. Une rivière sépare la tribu des Tchougatches de celle des OUGaLAK HMIOUTrs, voisins du célèbre mont Saint-Élie, pic volcanique, et dont on estime l'élévation à 2,829 toises. Ce fut aux environs de cette montagne que Behring aborda dans la baie qui porle son nom, ou, dans l'idiome des indigènes, celui d'Iakatak. Les Russes y ont élevé un petit fort; mais leur dernier établissement, nommé Sitka ou Nouvelle-Arkhanged, est situé deux degrés plus au sud dans l'une des îles que Vancouver avait nommées l'archipel du Roi-George. Un climat moins rigoureux y laisse croître avec vigueur le pin, le cèdre américain et plusieurs autres arbres. On y cueille des baies d'un excellent goût; le poisson y est abondant et délicieux. Le seigle et l'orge y ont réussi.

La Nouvelle-Arkhangel est le centre des opérations de la compagnie russe; c'est la principale station de la Russie américaine. Elle se compose d'une centaine de maisons renfermant un millier d'habitants, d'un port abrité de tous les vents, d'un chantier de construction pour les navires, d'un hôpital, d'un hôtel destiné au gouverneur et d'une église. On y fait un commerce considérable de fourrures. La forteresse, garnie de 40 pièces de canon, donne au palais du gouvernement une sorte d'élégance qui contraste de la manière la plus pittoresque avec l'aspect sauvage des sites qui l'entourent. La maison réservée aux officiers, les magasins et les casernes, sont tenus avec la plus grande régularité; l'hòpital, fondé par la compagnie commerciale, se fait remarquer par la propreté qui y règne. Le palais du gouvernement renferme une riche bibliothèque composée des meilleurs ouvrages russes et étrangers; une collection d'objets rares; enfin, tout ce qui peut contribuer à rendre la vie supportable dans un établissement aussi éloigné du monde civilisé.

Les divers comptoirs fondés par la compagnie russe-américaine font annuellement pour 800,000 francs d'exportations en fourrures pour la Russie.

Les Russes tirent de ces contrées des pelleteries qui proviennent principalement des loups marins et des autres animaux du genre des phoques, ainsi que des loutres de mer. Ces derniers, vivement poursuivis, commencent à devenir rares. Les Indiens, employés comme chasseurs, apportent de l'intérieur du continent des peaux de renards bleus, noirs et gris. Déjà les partis de chasseurs russes franchissent les montagnes Rocheuses, et se croisent probablement avec les chasseurs canadiens et américains. La compagnie russe d'Amérique possède un fonds de six millions et demi. Les principaux intéressés sont des négociants de la ville d'Irkoutsk en Sibérie. Les factoreries semées sur les côtes du continent et dans les îles sont des amas de cabanes, entourés d'une palissade en bois. Elles sont protégées par deux frégates et deux corvettes continuellement en station dans ces parages.

Les peuplades de la côte nord-ouest, dit un voyageur russe ${ }^{\mathrm{x}}$, se divisent en une foule de races qui se distinguent par les noms de certains animaux : ainsi, il y a une race de I'Aigle, du Loup, du Corbeau, de l'Ours; et lorsqu'on entre dans un village, on sait bientôt à quelle race il appartient, car la cabane du chef est couronnée d'un symbole qui représente cét animal peint avec plusieurs couleurs. Ce symbole les accompagne

${ }^{1}$ Achille Schabelski. - Voyage aux Colonies russes, etc. 
aussi à la guerre. Le chef jouit d'une puissance illimitée; cependant elle a beaucoup diminué depuis que le contact avec les nations civilisées a naturalisé le luxe chez ces peuples. Le pouvoir des chefs est héréditaire; mais il ne se transmet point à leurs enfants, il passe à leurs neveux fils de leurs sœurs. Les chamans ou prêtres occupent le second rang chez ces peuplades; toute leur science se borne à la divination, à l'art de guérir les malades, et à quelques vieilles chansons que le peuple comprend à peine. Quoique leur influence ait beaucoup diminué depuis la fondation de NouvelleArkhangel, elle est encore trop grande sur quelques esprits faibles. M. Schabelski raconte à ce sujet l'anecdote suivante :

"Dans le village le plus voisin de la colonie russe, un chaman fit une déclaration d'amour à une jeune fille, et n'en fut point écouté. Résolu de se venger, il attendait une occasion favorable qui ne tarda pas à se présenter. Le chef du village tombe malade, et le chaman, appelé près de lui, déclare la maladie incurable parce qu'elle est causée par une jeune fille possédée du démon, et il désigne celle qui l'avait repoussé. A peine le frère de cette malheureuse jeune fille a-t-il entendu prononcer son nom, qu'il s'élance hors de la cabane et porte à sa sœur plusieurs coups de lance; aux cris de l'infortunée, quelques Russes accourent, la sauvent des mains de ce forcené et la transportent à l'hôpital. Les secours de l'art rétablirent cette jeune victime du fanatisme; le frère apprit les détails de cette aventure, déplora sa conduite, et le chaman fut contraint de s'absenter pendant quelque temps du village. ”

Les belliqueux et féroces Kolioujis, Kolioujes ou Kalougrens habitent cette côte; munis de quelques armes à feu, ils font encore aux Russes une guerre opiniâtre. Ce fut dans, le territoire des Kalougiens que l'infortuné la Peyrouse découvrit le Port des Français, immortalisé par le noble et malheureux dévouement des frères Laborde. Les voyageurs français rendent le compte le plus avantageux de l'esprit actif et industrieux des indigènes; forger le fer et le cuivre, fabriquer à l'aiguille une sorte de tapisserie, natter avec beaucoup d'art et de goût des chapeaux et des corbeilles de roseaux, tailler, sculpter et polir la pierre serpentine, telles sont les prémices de la civilisation naissante de cette tribu. Mais la fureur du vol, l'indifférence entre parents et époux, la malpropreté des cabanes, et la coutume dégoûtante de porter dans la lèvre fendue un morceau de bois, les rapprochent de leurs sauvages voisins et des Russes sibériens, qui viennent aggraver ici la barbarie primitive de tous les maux d'une barbarie vieillie.

Ces peuplades sont dans un état continuel d'hostilité les unes à l'égard des autres. La vanité des chefs et le pillage des subsistances sont les deux principales causes de guerre. Ils la font avec acharnement; pendant la nuit ils surprennent le village ennemi et en égorgent tous les habitants : ceux qui échappent au carnage sont condamnés à la plus rigoureuse captivité. Lorsqu'une peuplade déclare la guerre à une autre, les guerriers se peignent le corps en noir, afin d'inspirer plus de terreur, et se couvrent la tête avec des crânes ornés du symbole de leur race. Rarement ils se battent en rase campagne : la guerre, chez eux, est une suite de ruses réciproques à l'aide desquelles chaque parti espère surprendre le parti ennemi. Ils sont grands amateurs de cérémonies. En temps de paix, ils s'envoient réciproquement des ambassadeurs; la mort d'un chef est le sujet de pompes et de fètes religieuses dont la magnificence s'estime par le nombre d'esclaves immolés sur son bûcher. Chez les peuples de Sitka et de ses environs, il r'ègne sur leur origine une tradition qui porte que : lorsque Dieu parcourut le monde, la terre était couverte d'eau dans laquelle nageait une femme qui donna naissance à l'espèce humaine. Cette tradition, et beaucoup d'autres plus ou moins ridicules, s'adaptent très-bien aux idées des naturels, qui passent la plus grande partie de leur vie sur les flots ou sur les côtes de l'Océan. 
Les peuplades qui occupent la Nouvelle-Géorgie diffèrent en taille, mœurs et manière de vivre; mais, pour les traits principaux, toutes se rapprochent des habitants du Noutka dont nous parlerons plus loin.

La dépopulation apparente des environs du port de la Découverte contrasta singulièrement avec le grand nombre de crânes et autres ossements humains qu'on y trouva ramassés, comme si toutes les tribus voisines y eussent établi leur communcimetière. Lewis el Clarke ont observé les habitants de l'intérieur. En descendant des montagnes Rocheuses, ils virent plusieurs tribus qui ont l'habitude d'aplatir la tête de leurs enfants encore très-jeunes. Les Solkouks ont le crâne tellement aplati, que le sommet de la tête se trouve sur une ligne perpendiculaire à celle du nez. Les idiomes des tribus diffèrent autant que leur physionomie. La langue des Enouchours, comprise par toutes les tribus qui habitent sur la Columbia, au-dessus de la grande chute, est inconnue plus près de la côte, et on se sert de l'idiome des EchiLlouts, qui en diffère absolument. Le langage des Killamouks est très-répandu parmi les tribus qui demeurent au sud, entre la côte et le fleuve Multnomah. Ces Killamouks sont au nombre d'environ 10,000. Les Koukouses, voisins de ces derniers, mais plus reculés dans l'intérieur, sont d'une autre race; ils sont plus blancs et n'ont pas la tête aplatie. En général, le teint de toutes ces tribus, soit à tête ronde, soit à tête plate, est d'un brun cuivré, plus clair que celui des peuplades du Missouri et de la Louisiane. Vivant de pêche, ils accordent aux femmes plus de considération qu'elles n'en ont chez les peuples chasseurs. L'air maritime gâte leurs yeux et leurs dents. Les tribus aux environs de la grande chute de la Columbia construisent des maisons en bois, industrie qui ne se montre pas dans l'immense intervalle depuis cette chute jusqu'à Saint-Louis.

L'île de NoutKa ${ }^{x}$ est située devant la Nouvelle-Géorgie. Les Anglais ont un établissement dans la baie de Noutka ou Nootka.

Les indigènes s'appellent eux-mêmes WaKas ou Wakash. Leur taille est au-dessus de la taille ordinaire, mais ils ont le corps musculeux; leur visage offre des os de joue proéminents; il est souvent très-comprimé au-dessus des joues, et il semble s'abaisser brusquement entre les tempes; leur nez, aplati à la base, présente de larges narines et une pointe arrondie; ils ont le front bas, les yeux petits et noirs, les lèvres larges, épaisses et arrondies. En général ils manquent absolument de barbe, ou ils n'en ont qu'une petite touffe peu fournie sur la pointe du menton. Cependant, ce défaut a peut-être une cause factice, puisque quelques-uns d'entre eux, et particulièrement les vieillards, portent une barbe épaisse, et même des moustaches. Leurs sourcils sont peu lournis ef toujours droits; mais ils ont une quantité considérable de cheveux très-durs, très-forts, et, sans aucune exception, noirs, lisses et flottants sur les épaules. De grossiers vêtements de lin, des couvertures de peaux d'ours ou de loutres marins, les couleurs rouges, noires et blanches dont ils enduisent leur corps, tout leur costume ordinaire retrace l'image de la misère et de l'ignorance. Leur équipage de guerre est bizarre. Ils s'affublent la tête de morceaux de bois sculptés qui représentent des têtes d'aigles, de loups, de marsouins. Plusieurs familles demeurent ensemble dans une même cabane; des demi-cloisons en bois donnent à ces huttes l'air d'une écurie. Quelques-unes de leurs étoffes de laine, quoique fabriquées sans le secours d'un métier, sont très-bonnes et ornées de figures d'un coloris éclatant. Ils sculptent en bois des statues grossières. Leurs pirogues légères, plates et larges, voguent sur les flots d'une manière assurée, sans l'aide d'un balancier; distinction essentielle entre les canots des peuplades améri, caines et celles des parties méridionales des Grandes-Indes et des îles de l'Océanie. Leur

${ }^{1}$ Appelée aussi Quadra et Vancouver. 
attirail de pèche et de chasse est ingénieux et d'une exécution heureuse : on remarque surtout une espèce de rame garnie de dents, avec laquelle ils accrochent les poissons. Cet instrument, ainsi que les javelots avec lesquels ils frappent la baleine, annoncent un esprit fort inventif. Le javelot est composé d'une pièce d'os qui présente deux barbes, dans laquelle est fixé le tranchant ovale d'une large coquille de moule qui forme la pointe; il porte deux ou trois brasses de corde; pour le jeter ils emploient un bâton de douze à quinze pieds de long, la ligne étant attachée à une extrémité, le javelot a l'autre, de manière à se détacher du bâton, comme une bouée, quand l'animal s'enfuit.

Plusieurs tribus du Nouvel-Hanovre, observées par Mackenzie, se rapprochent par divers traits des insulaires de Taïti et de Tonga-Tabou. On les regarde néaumoins comme des Wakas.

Les habitants de la rivière du Saumon, ou, comme ils la nomment, l'Annahyou-Tessé, vivent sous un gouvernement despotique; ils ont deux fêtes religieuses, l'une au printemps, l'autre en automne; dans leurs réceptions solennelles, ils étendent des nattes devant leurs hôtes; le peuple s'assied par devant en demi-cercle; ils marquent leur amitié pour un individu en le revêtant de leurs propres habits; ils y joignent quelquefois l'offre de leur place au lit conjugal. Mais ces traits se retrouvent chez beaucoup d'autres peuplades de l'Amérique et de l'Asie. Ces peuples sont assez généralement d'une taille moyenne, forts et charnus; ils ont le visage rond, les os des joues proéminents, l'œil petit et d'une couleur grise mêlée de rouge, le teint à la fois olivâtre et cuivré. Leur tête prend la forme conique par la suite des pressions continuelles exercées sur elle depuis l'enfance. Leurs cheveux sont d'un brun foncé. Ils font leurs habits d'une espèce d'étoffe tirée de l'écorce de cèdre, et quelquefois enlacée avec des peaux de loutre. Ils font preuve d'habileté dans l'art du sculpteur. Leurs temples sont soutenus par des piliers de bois en forme de cariatides; parmi ces figures, il en est qui sont courbées et comme accablées sous un fardeau, tandis que les autres sont debout et dans l'attitude de vainqueurs.

Les Stoud-Couss ont la physionomie agréable et paraissent très-propres. Ils ne maltraitent point leurs femrnes, et conservent les ossements de leurs parents enfermés dans des caisses ou suspendus à des poteaux. Ils dérobent tout ce qu'ils aperçoivent dans les mains des étrangers; et, chose étrange! ils sont dépositair es fidèles des objets qui leur sont confiés par les voyageurs.

Les Indiens Nanscoud ou de la Cascade, les Nagaïls ou Nagaillers, et les Atnahs parlent divers idiomes dont quelques-uns ont de la ressemblance avec les langues des nations du Canada.

Les Carriers ou Tacullies, vivent de la chasse et de la pêche, habitent des huttes, et sont vêtus de peaux d'animaux ou de draps grossiers qu'ils obtiennent des facteurs de la compagnie anglaise en échange de leurs fourrures. En hiver, ils se servent de traîneaux auxquels ils attellent de gros chiens. La polygamie est en usage chez eux. Leurs femmes ont soin du ménage et font les habits de toute la famille.

Vancouver a vu, sur la côte, des villages qui étaient placés sur une espèce de terrasse artificielle, et dont la représentation, gravée dans l'atlas de ce voyageur, rappelle un peu les peuples de la Nouvelle-Zélande.

Les Anwikmutes, les Maginutes, les Kyltschanes et les Inkalischluates sont de haute taille; leur chevelure est noire et hérissée. Ils se fendent la lèvre inférieure et placent dans cette ouverture de petites pierres et des perles de verre. Les femmes, qui se bornent à se faire deux raies bleues au menton, divisent leurs cheveux en deux tresses qui tombent de chaque côté de la tête et sont ornées de verroteries. 
Les hommes s'habillent de peaux de castor; lorsqu'il pleut, ils s'enveloppent presque entièrement dans un manteau de peau de poisson.

Les femmes sont vêtues de peaux de martre ou de lièvre.

En été, ces Indiens se disséminent sur les rivières et les, lacs voisins, où ils se livrent à la pêche. L'hiver, ils voyagent à la manière des Esquimaux.

Ces peuples ne font qu'un repas par jour. On allume un grand feu dans le Kiashim $^{\mathrm{x}}$; les hommes en profitent pour prendre un bain de vapeur général et se laver avec de l'urine, occupation pendant laquelle ils pleurent les morts et chantent leurs louanges. On éteint ensuite le feu, et les femmes leur apportent leur repas; mais avant de le prendre, ils avalent une grande quantité d'eau froide pour apaiser la soif causée par la chaleur. Les femmes des hommes mariés et les sœurs ou les mères des célibataires s'asseyent à terre et altendent avec patience qu'ils aient fini de manger ; après quoi elles emportent dans leurs cabanes particulières les restes du repas destinés à elles el à leurs enfants.

Les différentes tribus ont une telle défiance les unes des autres, qu'un indigène n'ose se hasarder à visiter un village un peu éloigné, de peur d'être trailé en ennemi.

1 Maison commune destinée aux assemblées. 



\section{RÉGION DU NORD ET DU NORD-EST.}

Sous la dénomination de région 'du nord et du nord-est, nous comprenons le pays sur le fleuve Mackenzie, les terres arctiques, le pays de la baie d'Hudson, le Labrador, le Groenland, l'Islande, et le Spitzberg.

\section{PAYS SUR LE FLEUVE MACKENZIE,}

\section{TERRES ARGTIQUES ET PAYS DE LA BAIE D'HUDSON.}

Les trois premières contrées, c'est-à-dire le pays sur le fleuve Mackenzie, les terres arctiques et le pays de la baie d'Hudson, sont habitées par trois nations indigènes.

Les Esqumaux ${ }^{1}$ habitent depuis le golfe Welcome jusqu'au fleuve Mackenzie, et probablement jusqu'au détroit de Behring; ils s'étendent, au sud, jusqu'au lac de l'Esclave; au nord, ils s'arrêtent sur les bords de la mer Polaire ou prolongent leurs courses dans un désert glacé. Petits, trapus et faibles, mais bien proportionnés, ces hommes polaires ont le teint moins cuivré que d'un jaune rougeâtre et sale. Ils ont les épaules larges, les mains et les pieds d'une petitesse remarquable, le visage plus long et en même temps plus large que celui des Européens; leur nez est petit; leurs yeux, noirs et petits, sont enfoncés et cachés en partie par des paupières épaisses; leur bouche est grande, leurs lèvres sont épaisses, leurs oreilles larges et mobiles, leurs cheveux noirs, longs et rudes. Ces hommes ont naturellement peu de barbe, et encore ont-ils le soin de l'épiler. Leurs huttes, de forme circulaire, sont couvertes de peaux de daim dans l'intérieur des terres, et de phoque sur les bords de la mer; on n'y entre qu'en rampant sur le ventre. Les canots, formés de peaux de veau marin cousues sur tne carcasse en bois ou en os de baleine, naviguent avec vitesse. Il y en a de deux sortes : ceux qu'ils nomment kadjacs ont quinze à dix-sept pieds de longueur sur deux de largeur. Leur forme est celle d'une navelte de tisserand; au milieu de la peau qui les couvre se trouve un trou dans lequel se place l'Esquimau qui le dirige avec une rame longue de cinq à six pieds, étroite au milieu, large et plate aux deux extrémités. S'il

1 La famille des Esquimaux comprend cinq nations principales, dont une vit en Asie; on en remarque, en Amérique, trois branches principales, savoir : les Kalalits ou Karalits, qui sont les Groenlandais; les Esquimaux proprement dits, qui vivent sur la côte nord-est du Labrador, et sont les plus méridionaux et les moins civilisés; les Esquimaux occidentaux, qui errent près des embouchures du Mackenzie et de la rivière aux Mines-de-Cuivre (Copper-Mine), dans les environs du cap Dobb, de la baie Repulse, sur la presqu'lle Melville, sur les côtes des lles Winter, Igloulik, Southampton, et autres qui forment l'archipel de Baffin-Parry. 
rencontre un champ de glace, il met son kadjac sur ses épaules, traverse l'obstacle et se remet à naviguer. Les autres canots, appelés cumiacs, sont construits de la même manière, mais plus grands et de la même forme que nos batelets : ils peuvent contenir jusqu'à vingt personnes. Ces sauvages travaillent patiemment une pierre grise et poreuse dont ils forment des espèces de cruches et de chaudières; les bords de ces vases reçoivent des ornements élégants. Les Esquimaux conservent leurs provisions de viande dans des outres remplies d'huile de baleine. Ceux qui demeurent vers l'embouchure du fleuve Mackenzie se rasent la tête, coutume particulière, mais qui ne suffit pas pour démontrer une origine asiatique.

Les Esquimaux portent des vêtements de peaux d'animaux et principalement de phoques dont le poil est en dehors : ils consistent, pour les hommes, en une tunique ronde que les femmes portent aussi, mais fendue sur le côté, en un pantalon et en bottines communes aux deux sexes : les bottines des femmes montent jusqu'à la hanche; elles sont soutenues par des baleines, et elles leur servent à placer leurs enfants lorsqu'elles sont fatiguées de les porter dans leurs bras. Elles tressent leurs cheveux en nattes auxquelles elles suspendent des dents et des griffes d'ours blanc, ornement qui constitue leur principale parure. Elles ornent leur figure d'une sorte de tatouage, de mème que le reste du corps.

Pour éviter l'action de la trop grande lumière sur la glace et la neige, les Esquimaux portent une espèce de garde-vue composée d'une petite planche très-mince, percée de deux fentes étroites, à travers lesquelles ils peuvent distinguer les objets.

Ils se nourrissent de chair de phoque, de baleine, de poissons et de différents gibiers qu'ils fument ou font cuire à demi. Ils mangent volontiers de la chair crue, et sont très-friands de suif et de savon; ils boivent avec délices de l'huile de poisson.

La cérémonie du mariage est chez eux très-simple : l'homme choisit une femme, quelquefois même il jette ses vues sur une jeune fille à la mamelle, et déclare qu'il la prend pour épouse. Lorsque celle-ci est en âge d'être mariée, ses parents la conduisent chez le mari, qui a eu soin de préparer un repas, après lequel les deux époux exécutent une danse de cérémonie; lorsque celle-ci est terminée, chacun des convives se retire en adressant à la mariée une exhortation pour lui rappeler ses devoirs d'épouse et de mère, et le mariage est conclu.

Le seul animal domestique qu'on trouve chez les Esquimaux est le chien, que l'on attelle, comme en Sibérie, à un petit traîneau qui peut contenir une ou deux personnes. II ressemble à nos chiens de bergers: quelquefois son poil est tacheté, d'autres fois noir et plus souvent blanc. Il a les oreilles droites et courtes comme celles du renard. Il n'aboie point; son cri est une sorte de grognement. Son ennemi naturel est le loup, animal très-féroce et très-hardi dans les régions hyperboréennes.

Les Chippeways ont été observés entre le lac de l'Esclave et le lac Atapeskow; ils paraissent s'étendre jusqu'aux montagnes Rocheuses à l'ouest, et jusqu'aux sources du Missouri au sud-ouest. Le major Pike porte leur nombre à 11,000. Ceux qui habitent les environs du fort Chippeway se donnent le nom de Aa-issa-Rinnis (hommes du soleil levant). Les Indiens serpents, les Cattanachowes et d'autres tribus en semblent des démembrements. Une branche des Chippeways est répandue dans le territoire des Élats-Unis. Quoiqu'un peu moins cuivrés et un peu moins barbus que les peuples voisins, les Chippeways n'ont pas le teint des Mongols. Leurs cheveux, lisses comme ceux des autres Américains, ne sont pas toujours de couleur noire. Ils se font, en peau de daim, un vêtement très-chaud et très-solide.

Ces Indiens, quoique très-pacifiques entre eux, sont continuellement en guerre avec les Esquimaux, sur lesquels la supériorité du nombre leur donne un avantage considé- 


$$
11
$$





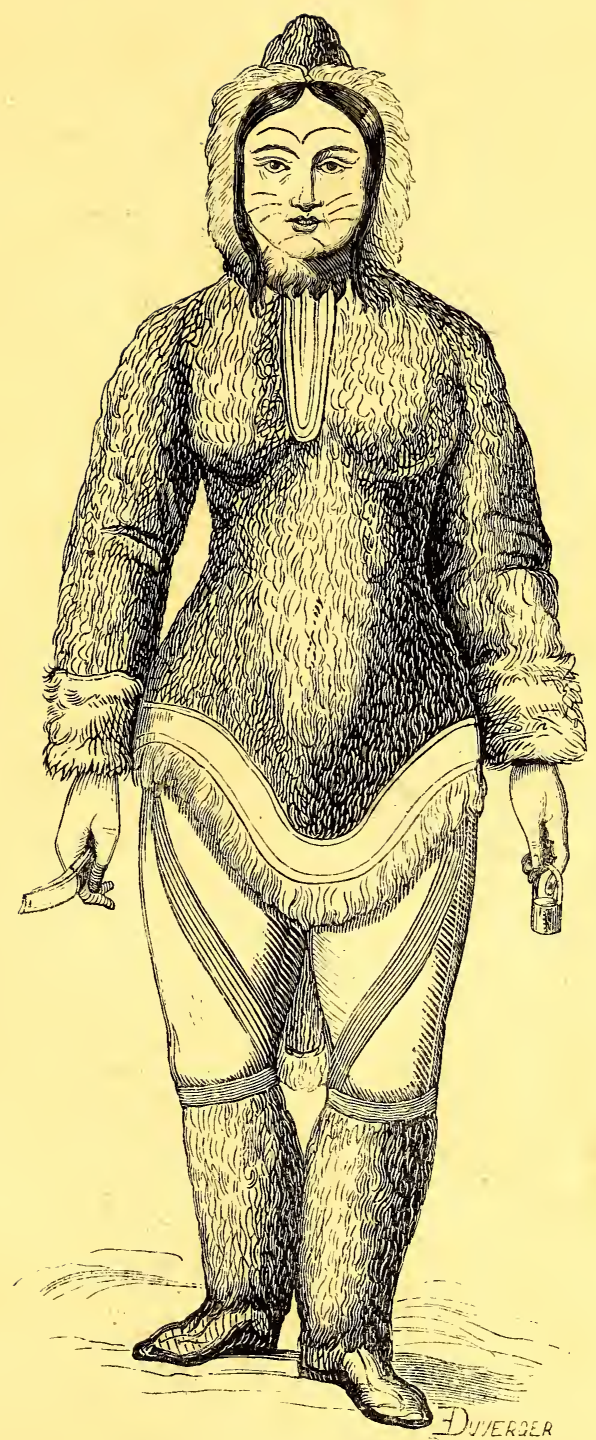

FIMME ESQU⿴囗十ЫIDE. 

rable. Ils égorgent tous ceux qui tombent entre leurs mains, car la crainte leur a donné le principe de ne jamais faire de prisonniers. Ils se soumettent aux Knistenaux, qui sont bien moins nombreux.

La contrée qu'ils appellent leur pays n'a que très-peu de terre végétale; aussi ne produit-elle presque pas de bois ni d'herbe. Ce qu'on y trouve en quantité, c'est de la mousse que paissent les daims. Une autre espèce de mousse croît sur les rochers et sert d'aliment aux hommes. On la fait bouillir dans de l'eau, et en se dissolvant elle forme une substance glutineuse assez nourrissante. Le poisson abonde dans les lacs des Chippeways, et des troupeaux de daims couvrent leurs collines. Mais, quoiqu'ils soient les plus clairvoyants et les plus économes des sauvages de l'Amérique septentrionale, ils ont beaucoup à souffrir de la disette en certaines années.

Ils se prétendent les descendants d'un chien; aussi regardent-ils cet animal comme sacré. Ils se figurent le créateur dı monde sous la figure d'un oiseau dont les yeux lancent des éclairs et dont la voix produit le tonnerre. Les idées d'un déluge et de la longue vie des premiers hommes leur sont héréditaires.

Les Chippeways, qui habitent le territoire du Missouri, sont plus doux, plus dociles que les Sioux. Avec plus de sang-froid et de résolution que ceux-ci dans les combats, ils y apportent plus de prudence et d'adresse. Ils ont d'ailleurs l'avantage de posséder des armes à feu. La calligraphie est remplacée chez eux par des hiéroglyphes sculplés en bois de cèdre ou de pin.

Les tribus désignées par Hearne sous le nom d'INDIENs Du NORD, et qui demeurent entre la rivière de Churchill, peuvent être considérés comme une branche des Chippeways. Ces Indiens du nord sont, en général, d'une taille moyenne, bien proportionnés ct forts; mais ils manquent de cette activité, de cette souplesse si naturelles aux Indiens dont les tribus habitent les côtes méridionales et occidentales de la baie d'Hudson. La couleur de leur peau approche de celle du cuivre foncé. Leurs cheveux sont noirs, épais et lisses comme ceux des autres Indiens. A l'instar des Chippeways, ils prétendent devoir leur origine aux amours de la première femme avec un chien qui, la nuit, se transformait en un beau jeune homme.

La femme n'est chez eux qu'une espèce de bête de somme. Qu'on demande à un Indien lu nord en quoi consiste la beauté, il répondra qu'une figure large et plate, de petits yeux, des joues creuses dont chacune offre trois ou quatre traits noirs, un front bas, un menton allongé, un nez gros et recourbé, un teint basané et une gorge pendante la constituent véritablement. Ces agréments augmentent beaucoup de prix lorsque celles qui les possèdent sont capables de préparer toutes sortes de peaux, d'en former des habits, de porter un poids de 100 à 140 livres en été, et d'en tirer un plus lourd en hiver. L'usage de la polygamie leur procure un plus grand nombre de ces servantes soumises, fidèles et mème affectionnées. Lorsqu'ils ont reçu un affront quelconque, ils provoquent leur ennemi à une lutte; le meurtre est très-rare parmi eux. L'homme qui a versé le sang de son compatriote est abandonné par ses parents et ses amis; il est réduit à une vie errante, et dès qu'il sort de sa retraite, chacun s'écrie : Voilà le meurtrier qui paraît!

Les CriHS " se rapprochent beaucoup des Assiniboins. Ils sont de haute taille, trèsvigoureux. Leurs mœurs sont, à peu de chose près, les mèmes que celles de ce dernier peuple, et leur costume en diffère bien peu. Ils portent les cheveux retombant droits sur les épaules, mais avec une touffe large et plate qui vient recouvrir les yeux, et qui, chez quelques-uns, descend jusqu'à la bouche; chez d'autres, les cheveux sont partagés

${ }^{1}$ Cristinaux ou Knistenaux. 
en plusieurs queues tressées. Ils se coiffent de bonnets de peau ornés de plumes; quelquefois ils y attachent la queue entière d'une poule des prairies. Beaucoup d'entre eux portent les gaînes en cuir de leur fusil roulées sur la tête en forme de turban. Ils se peignent le visage en rouge avec des raies noires. Les hommes sont souvent tatoués, et se couvrent, dans certaines circonstances, le corps d'une peau de loup dont la tête pend sur la poitrine et la queue traîne à lerre. Parmi les femmes, il y en a de fort bien faites, et elles se teignent le corps d'une belle couleur rouge, avec la racine du galium tinctorium, et en noir avec l'écorce d'aune.

La terre de LABRAdor est une vaste péninsule découverte, en 1496, par les Portugais, qui la nommèrent Terra Labrador ${ }^{\mathrm{I}}$. Cette contrée, de forme triangulaire, a d'un côté les côtes orientales de la baie d'Hudson qui en font partie, projette une de ses faces sur le détroit de Davis, et s'appuie avec la troisième sur le Canada et le golfe SaintLaurent.

Les Esquimaux ont peuplé toutes les côtes septentrionales et orientales de cette contrée; ils vivent de la pêche. C'est parmi eux que les frères moraves ont fondé les trois colonies de Nain, d'OKkak et de Hoffenthal ou Hopedale. Lorsqu'ils y abordèrent, les Esquimaux avaient la coutume de tuer les orphelins et les veuves, pour ne pas les exposer à mourir de faim. Les missionnaires, après leur avoir enseigné diverses pratiques utiles pour la pêche, bâtirent un magasin où chacun pût conserver son superflu; ils les engagèrent à mettre de côté la dixième partie de leurs récoltes pour les veuves et les orphelins. Voilà comment on convertit véritablement les peuples!

Ils ont le visage plat, le nez court, les cheveux noirs et rudes, les mains et les pieds très-petits, et diffèrent des indigènes de l'intérieur par la barbe, qui manque à ceux-ci. Leur nourriture consiste principalement en chair de phoque et de renne, et en poissons qu'ils mangent quelquefois crus et même dans un état de putréfaction.

Les vêtements des Esquimaux du Labrador consistent en une camisole à capuchon, des pantalons, des bas et des bottes en peau de phoque dont le poil est en dedans, du moins en hiver. Les femmes ont le même costume que les hommes, à l'exception de leurs bottes qui sont plus amples et de leur habit de dessus qui a une queue; elles ornent leur tête de petits objets en verroterie, ou d'un cercle en laiton brillant.

Les Esquimaux vivent, en été, dans des tentes de forme circulaire, construites avec des perches, couvertes de peaux cousues ensemble, et qu'ils transportent continuellement d'un lieu à un autre. Ils ont un grand nombre de chiens qui servent à tirer leurs traîneaux, et dont la peau est quelquefois employée comme vêtement et la chair comme nourriture.

Ils sont adonnés à la polygamie; mais leur famille est, en général, peu nombreuse. Leurs armes sont la javeline, l'arc et la flèche. Ils n'ont ni gouvernement ni lois. Un homme n'est regardé comme supérieur à un autre que lorsqu'il se fait remarquer par son courage, sa force, ou le nombre des membres de sa famille.

Nain, le principal établissement des frères missionnaires moraves, est situé sur la côte orientale, vis-à-vis des îles Hillsborough; il possède un port assez bien abrité.

Une tribu particulière habite les montagnes méridionales; malheureusement le mélange avec les Canadiens français en a effacé les traits avant qu'ils aient pu ètre examinés avec soin. Cette peuplade, qui a adopté le rit catholique, se nourrit de rennes et de gibier. On ne les appelle que les Montagnards. Une autre tribu, nommée les Escopics, habite la partie occidentale.

${ }^{1}$ Terre dutlaboureur. 


\section{GROENLAND.}

Le Groenland ", contrée de l'Amérique septentrionale, dont on ne peut déterminer exactement les limites, paraît, d'après les explorations des navigateurs Parry, Ross et Graah dans la mer Polaire, être entièrement séparé du continent par cette mer, par celle de Baffin, par le détroit de Lancastre et par celui de Davis. L'Atlantique le baigne au sud-ouest et au sud-est, et l'océan Glacial arctique à l'est. Au nord et au nord-ouest ses bornes sont tout à fait inconnues; on présume cependant que sa longueur du nord au sud est d'environ 600 lieues, et que sa largeur vers le $78^{\circ}$ degré est de 300 lieues de l'est à l'ouest. Les habitants du Groenland, qui ont pris la place des anciens Islandais, paraissent être au nombre d'environ vingt et un mille, dont sept ou huit mille chrétiens. Ils appartiennent à la grande famille des Esquimaux.

Le Groenland n'est véritablement qu'un amas de rochers entremêlés d'immenses blocs de glaces, l'image réunie du chaos de l'hiver.

L'histoire d'un pays tel que le Groenland, à part les incidents de la découverte et de la colonisation, doit être à peu près nulle. Elle se borne à l'énumération de quelques faits douloureux, tels que l'introduction de la petite vérole, qui fit parmi ces pauvres gens des ravages épouvantables; des famines affreuses qui, à plusieurs reprises, décimèrent cette population infortunée, et quelques accidents météorologiques qui ont augmenté le nombre des pages lugubres de leurs annales.

Les GroenLandaIs sont attachés si forlement aux croyances et aux usages de leurs pères, qu'ils répugnent infiniment à ouvrir les yeux à la lumière. Cependant aujourd'hui l'administration danoise régularisée suit un plan de colonisation propre à établir l'ordre et le bonheur; mais les anciens défauts et les nouveaux vices des Groenlandais y opposent de grands obstacles. Presque dépourvus de loute idée de religion et de lois, ils ne voient dans le culte qu'une cérémonie sans but, et dans les punitions que l'abus de la force. Le malfaiteur lui paraîl assez puni lorsque, dans une assemblée publique, il a été accablé de reproches. Les missionnaires ont avoué que la conversion des Groenlandais avançait lentement et n'influait que peu sur leurs idées morales. Depuis plusieurs années, les prédications des indigènes, élevés comme missionnaires, ont produit un heureux changement. Les frères moraves réussissent aussi singulièrement à frapper l'imagination de ces hommes simples, mais doués d'un esprit vif. L'administration commerciale, en introduisant le numéraire et même le papier-monnaie, leur a donné des notions nouvelles sur la propriété. Dans la partie méridionale, on leur a enseigné la tonnellerie et la construction des bateaux. Déjà ils oublient le nom de leur antique divinité, Torngarsouk, à laquelle ils n'ont jamais offert de culte, ainsi que la déesse malfaisante, sans nom, qui était censée habiter un palais sous les flots, gardé par des chiens marins redoutables. Une sorte de philosophie s'est mème glissée parmi eux, et il existe diverses opinions nouvelles sur la vie à venir et sur la transmigration des âmes. Les esprits forts groenlandais nient le paradis, où l'âme, dans une heureuse indolence, se nourrissait de têtes de chiens marins. Les sorciers-prêtres, nommés anghekok, et les enchanteurs malfaisants, nommées iliseets, perdent continuellement de leur influence. L'époque n'est peut-être pas très-éloignée où le sublime dévouement du vertueux Égède aura porté des fruits, et où une peuplade chrétienne et civilisée habitera cette mémo-

${ }^{1}$ Ce mot danois signifie terre verte. 
rable colonie, la plus boréale que les Européens aient fondée. Une gloire douce et pure récompensera alors le Danemark des sacrifices pécuniaires que lui a couttés cette lutte contre les éléments, dans laquelle un zèle pieux et des souvenirs historiques l'ont entrainé.

Les Groenlandais sont petits, mais généralement bien faits. Ils ont la figure plate et large, les joues rondes et charnues; les yeux petits, noirs et sans feu; la bouche étroite et ronde; la lèvre inférieure épaisse; les cheveux noirs, épais, longs et rudes; ¡resque pas de barbe, soit qu'elle ne croisse pas, soit qu'ils s'épilent avec soin; les membres très-musculeux; la poitrine haute, les épaules larges, la main petite et potelée, de mème que le pied. Les femmes ont la taille remarquablement carrée, et les épaules aussi larges que les hommes. La couleur de ces indigènes est jaune verdâtre; leur épiderme est d'un brun approchant du rouge clair; mais ce qui prouve que le brun n'est pas leur couleur naturelle, c'est que leurs enfants naissent blancs comme la plupart des Européens; ils acquièrent cette teinte d'abord par l'usage de la graisse et de l'huile dont ils se frottent continuellement le corps et le visage, ensuite par l'action de l'épaisse fumée que l'huile de leurs lampes répand dans leurs demeures.

Les Groenlandais exhalent par tous les pores une odeur repoussante. Comme ils ne se nourrissent guère que de chair de phoque, d'huile et de viande de baleine, et qu'ils manient continuellement les restes, souvent putréfiés, de ces animaux, leurs mains, leur bouche, leur halcine, et jusqu'à leur sueur, sont d'une puanteur affreuse. Le dimanche, lorsque plusieurs centaines de ces sales créatures sont entassées dans une église, c'est à peine si les missionnaires danois peuvent résister à l'action de l'atmosphère empestée qui les environne. La respiration est gênée par les miasmes qui s'élèvent de celte multitude dégoûtante; et les exhalaisons de l'huile et de la graisse dont la lampe est garnie ajoutent singulièrement à ce supplice.

Les Esquimaux du Groenland sont intrépides, courageux et persévérants. Tel d'entre cux qui n'aura rien mangé depuis deux jours, ou qui n'aura pris pour toute nourriture qu'un peu de mousse de mer, ramera avec assurance dans son batelet, et le conduira sans crainte à travers les flots courroucés de l'Océan. Les femmes portent de pesants fardeaux, soit qu'elles aient pris leur nourriture habiluelle, soit que la faim les dévore.

Nalurellement tristes el silencieux, ces sauvages semblent presque constamment plongés dans une espèce de stupeur. Ils sont doux, paisibles, et d'un caractère sociable. Quoiqu'ils vivent dans un état de misère presque continuel, ils ne se trouvent pas malheureux; l'indépendance et une sécurilé absolıe pour leurs familles leur semblent une compensation suffisante. Ils ne sont ni querelleurs, ni rancuniers; quand ils voient des Européens se disputer, et quelquefois même se baltre, ils s'étonnent de ces violences, ct les attribuent à l'usage des liqueurs forles : "Ils ont perdu l'esprit, disent-ils; la mauvaise eau les a rendus fous. On dit qu'on ne les surprend jamais en flagrant délit de mensonge; toutefois, si l'on accuse un Groenlandais d'une mauvaise action, il ne l'avouera pas, de crainte de perdre, par un aveu sincère, l'estime de ses connaissances, dont il est éminemment jaloux.

Le caractère de ce peuple est difficileà définir. Il offre des contrastes étranges, des contradictions qu'on ne peut guère expliquer. S'il est doux et humain, d'un autrecôté, il pousse quelquefois l'indifférence jusqu'à la cruauté. Par exemple, lorsque ces hommes voient un bateau près de faire naufrage, ils ne portent pas secours au pècheur en danger, s'ilne fait pas frartie de leir compagnie. Toutefois, s'ils entendaient dans la barque des cris de femme on d'enfants, ils ne balanceraient pas à se jeter à la mer pour les sauver. Il en est tout autrement lorsqu'ils partent plusieurs pour la pèche; alors tout est commun entre eux, 
Iravail, péril, fatigue, misère et faim même ; ils ne se refusent jamais alors aucun service mutuel.

D'autres contradictions méritent d'être signalées pour bien faire connaître le naturel des Esquimaux du Groenland. Quoiqu'ils soient généralement honnêtes, ils convoitent souvent les biens de leurs compatriotes, et se les approprient par les moyens les plus odieux. S'ils sont jaloux de la richesse de quelque voisin ou de son activité à se procurer les nécessités de la vie matérielle, ils ne prendront pas le parti de le voler; ils iront l'attaquer en mer; ils renverseront son canot, ou lui lanceront un harpon par derrière, et l'abandonneront ainsi à la fureur des vagues. Enfin, quoiqu'ils soient pacifiques et peu querelleurs, comme nous l'avons dit, ils n'en sont pas moins très-vindicatifs dans certaines circonstances. Ainsi, lorsqu'un homme a été assassiné, ses parents dissimulent leur ressentiment jusq̣u'à ce qu'ils trouvent l'occasion de venger le défunt; cette occasion ne dủt-elle se présenter que vingt ans après le crime, ils ne témoignent jusque-là au meurtrier ni haine ni colère. Si, un beau jour, ils rencontrent l'assassin dans l'intérieur du pays, ils le saisissent, lui reprochent son forfait, et le font mourir sous un tas de pierres, ou le précipitent du haut d'un rocher. Quelquefois la fureur les porte à couper le malheureux par morceaux, et à manger son cœur, pour ôter, disent-ils, à ses parents le courage de venger sa mort. Ajoutons que la vengeance est héréditaire cliez ce peuple, et se lègue comme un patriotisme, de génération en génération; elle passe même, à ce qu'il paraît, aux voisins, excepté cependant lorsque-le premier meurtrier a été un vagabond et un scélérat, méprisé de sa propre famille; dans ce cas, personne ne cherche à le venger.

Les mœurs et usages des Groenlandais se ressentent et de leur caractère généralement pacifique, et du climat dont ce peuple subit l'influence. Nous n'entrerons pas dans tous les détails que donnent à ce sujet les voyageurs et les chroniqueurs; nous nous bornerons à signaler les faits et les coutumes caractéristiques.

Le mariage est une affaire très-importante pour ces pauvres gens. C'est pour la plupart des femmes une question de vie ou de mort; car si l'homme auquel s'unit une jeune fille est incapable de la nourrir, ou s'il meurt, la malheurcuse ne tarde pas à périr de faim et de froid, quand elle ne trouve pas une âme assez charitable pour la recueillir. Aussi voit-on souvent des filles nubiles qui craignent le mariage au point de s'enfuir dans les montagnes quand il est question de leur donner un époux, et qui déclarent se vouer pour toujours au célibat, ce qu'elles expriment en se coupant les cheveux. II paraît que les duègnes qui font, dans ces circonstances, l'office d'entremetteuses, se permettent quelquefois envers la jeune fille des violences qui ne sont pas désapprouvées par les parents. Les coups et les tortures sont les arguments ordinaires de ces furies, qui ont fort à cœur de gagner la récompense promise par le prétendu.

Point de cérémonie pour le mariage. Dès que tout est convenu, les parents unissent lout simplement et sans aucune solennité les deux jeunes gens, et les installent dans leur hutle.

La polygamie est tolérée, mais uniquement dans un but de reproduction. Comme le plus grand déshonneur pour un Esquimau est de n'avoir pas d'enfants, celui qui est assez riche pour nourrir plusieurs femmes a le droit d'avoir des concubines, mais seulement comme moyen de laisser une nombreuse postérité; sa conduite serait sévèrement blàmée si elle avait pour mobile le liberlinage.

Au sujet de la polygamie et de ses conséquences morales, Égède fait une observation dont il importe de prendre note : "Avant l'arrivée des missionnaires, les femmes ne connaissaient pas la jalousie; mais depuis qu'elles savent que le christianisme prohibe la polygamie, elles ne supportent pas aussi facilement les infidélités de leurs maris. » 
Hâtons-nous d'ajouter toutefois que la meilleure harmonie règne dans la plupart des ménages groenlandais. Le divorce est en usage, et consiste dans l'expulsion pure et simple de la femme, qui, en pareil cas, ne se sépare jamais de ses enfants.

Quand un Groenlandais perd sa femme, il cherche aussitòt à la remplacer. Quelques jours après l'avoir enterrée, il étale ses richesses à la vue de ses voisins; il affecte de se montrer lui-même plus qu'à l'ordinaire; il fait parade de ses enfants; sa maison est ouverte à tout le monde; il expose sa provision de poisson, son équipage de pêche et de chasse, en un mot tout ce qu'il possède. Cependant il ne convole en secondes noces qu'après un an de veuvage, à moins qu'il n'ait des enfants dont ses parents ne veulent pas prendre soin. Lorsqu'il a plus d'une femme, la seconde, par ordre de date, prenil la place de la défunte. Ce qu'il y a de particulier, c'est que cette promotion par ordre d'ancienneté se fait avec les marques de la plus profonde tristesse de la part de la seconde femme, malgré la joie qu'elle ressent au fond du cœur de cet événement.

Les Esquimaux aiment tendrement leurs enfants. Les mères ne les sèvrent qu'à trois on quatre ans et les portent constamment sur leur dos, dans quelque lieu qu'elles aillent et à quelque travail qu'elles se livrent.

Les seules occupations des hommes sont la pèche et la chasse. Ils sont d'une habileté merveilleuse dans le premier de ces exercices. Pour frapper la baleine, ils se servent d'un javelot muni d'une vessie de chien marin gonflée de vent; cette arme surnage toujours et empêche l'animal, une fois blessé, de rester longtemps sous l'eau. On retrouve cet instrument de pêche parmi les habitants sauvages de toute l'Amérique russe. Quant aux canots dans lesquels les Groenlandais s'aventurent sur la mer, leur construction révèle chez ce peuple une intelligence remarquable : ces canots ou kajaks sont des espèces de caisses failes de branches légères. Ils n'ont que cinquante centimètres de largeur, sur une longueur de quatre mètres, et on leur donne la forme d'une navette. Ils sont exactement couverts de peau dans la partie supérieure, ordinairement creuse. Au centre est pratiquée une ouverture circulaire; au cerceau de bois qui la forme, esl attachée une peau qui, au moyen d'une courroie, se resserre comme une bourse. C'est dans ce trou que se place le pêcheur; il est muni d'un simple aviron trèsmince, long d'un mètre et demi, et s'élargissant à ses extrémités. En ramant à droite el à gauche alternativement, le Groenlandais, porté par cet appareil rempli d'air atmosphérique, s'élance hardiment au milieu des vagues les plus effrayantes, sans courir plus de danger que n'en courent les cachalots et les phoques, dont il est en quelque sorte devenu le rival, en se faisant homme-poisson. Il est surprenant que cette ingénieuse invention, commune, du reste, à toules les tribus sauvages de l'Amérique septentrionale, n'ait pas été imitée en Europe pour le service des côtes et l'usage de la pèche. Elle n'a été mise à profiı que par quelques pilotes norwégiens et danois.

Aux femmes groenlandaises sont dévolus, non-seulement tous les soins du ménage, mais encore l'entretien des vètements de leurs maris, el des corvées très-fatigantes, telles que le transport des animaux pêchés ou tués à la chasse par les hommes. Leur condition est généralement fort douloureuse, surtout quand elles viennent à perdre leurs époux.

Les Groenlandais se visitent pendant. l'hiver, et viennent les uns chez les autres quelquefois de très-loin. Les visileurs sont toujours accueillis avec empressement et régalés à la manière du pays. Malgré les cérémonies qu'ils font, pour ne point paraître affamés, ils se laissent bourrer d'aliments grossiers avec une complaisance exemplaire. Le hareng salé, la chair de phoque séchée; le mitriack, qui n’est autre chose que du chien marin à moitié pourri; les queues de baleine, mets réputé très-succulent; la viande de renne; les mûres sauvages trempées dams le sang de cet animal ou dans l'huile 
de cachalot, tels sont les aliments ordinaires que les Esquimaux servent sur leur table. Cependant on n'aurait pas une idée complète des usages culinaires de ce peuple, si nous n'entrions pas à cet égard dans quelques détails indispensables.

Le premier soin des pêcheurs, dès qu'ils ont pris un phoque, est de sucer la plaie qu'ils lui ont faite, pour étancher le sang qui en sort; on verse ensuite ce sang dans des pots et on le conserve précieusement pour en apprêter diverses viandes; c'est le seul coulis en usage. La tête et les pieds de l'animal se conservent sous l'herbe pendant la belle saison; le corps reste sous la neige durant l'hiver; les côtes sont séchées à l'air et mangées telles quelles. Peu importe à ces appétits gloutons que la viande qu'ils exhument au fur et à mesure de leurs besoins soit gelée ou putréfiée; ils ne la mangent pas avec moins de plaisir et d'avidité. Du sang de chien marin ou de l'huile mêlée avec de l'eau de mer pour tout assaisonnement, telle est la sauce en usage. Le Groenlandais ne dédaigne pas non plus le ventre des jeunes animaux; la seule préparation qu'il fasse subir à ces débris infects, est de presser fortement les intestins entre ses doigts pour en faire sortir la fiente. Celle que contiennent les boyaux de renne est pour eux un régal. Ils en font des présents à leurs meilleurs amis. Ils n'estiment pas moins la fiente de perdrix et l'huile fraîche de baleine. Mais les deux mets les plus recherchés par ces barbares sont les deux suivants : le premier consiste en une pâte composée d'œufs, de graines de genièvre et de racine d'angélique battus avec de l'huile de poisson dans une vessie de phoque; le second, qu'on ne trouve que chez les habitants les plus riches et les plus gourmets, est un mélange de graisse d'ailerons d'oies sauvages et de chien de mer. On a dit que les Groenlandais mangeaient de la viande crue; cela n'est vrai qu'exceptionnellement : par exemple, quand ils ont tué un renne, ils enlèvent un morceau de sa chair et le dévorent encore tout palpitant, en l'arrosant de sang chaud; mais on croit que c'est là un acte purement religieux.

Les Groenlandais prennent leurs repas de la manière la plus dégoûtante. Rarement les femmes se donnent la peine de laver les plats et les marmites; les chiens sont chargés de ce soin, et on n'y regarde pas après eux. Les plats consistent en petites planches de bois sans rebords; ils y déposent leur viande et leur poisson, après avoir avalé la sauce dans laquelle ces aliments ont été cuits. Pour manger le poisson de moyenne grosseur, tel que le hareng, ils en enfoncent un tout entier dans leur gosier, et coupent ce qui passe hors de la bouche. Tout ce qui a pu entrer est englouti dans leur insatiable estomac. Quant à la viande, ils la dépècent à belles dents, en la tenant à pleines mains. Leur couteau ne leur sert guère que de serviette; ils en nettoient leurs dents, ils en raclent leurs mains, ils en frottent même leurs lèvres huileuses. Lorsqu'ils veulent traiter un Européen, ils lèchent très-soigneusement le morceau qu'ils lui destinent, afin de le débarrasser de la graisse et de la sauce qui y restent attachées en sortant du chaudron; ils le présentent ensuite à l'étranger, qui ne saurait le refuser sans faire à ses hôtes un véritable affront.

Les hommes mangent en particulier; mais les femmes n'y perdent rien; elles ont un appétit tout aussi vorace, et empiètent souvent sur la portion du mari. Leur plus grand plaisir est de voir leurs enfants se remplir de nourriture au point d'en être suffoqués. Quand ils ne peuvent plus avaler, elles les roulent à terre, et leur pressent le ventre, dans le but d'y faire place à de nouveaux aliments.

La gloutonnerie des Groenlandais est telle, qu'ils consomment fréquemment loute leur provision d'hiver dans les premiers mois de la mauvaise saisou. Aussi, quand le temps ou un accident quelconque les empêche d'aller à la chasse et à la pêche, sont-ils réduits aux plus cruelles extrémités. Quelquefois ils sont obligés, pour ne pas mourir de faim, eux et leur famille, de dévorer le cuir de leurs chaussures, les peanx qui 
couvrent leurs tentes d'été, et de tuer, pour les manger, les chiens qu'ils attellent à leurs traîneaux. Rien de comparable à la misère de ces pauvres gens dans ces périodes de disetle; il en est qui meurent d'inanition, quand la charité de leurs voisins ne vient pas à leur aide.

Quelques détails sur les habitations et le costume des Groenlandais compléteront cette esquisse d'un peuple encore peu connu en Europe.

Les Esquimaux habitent, pendant l'été, des tentes couvertes de peaux de phoques; en hiver, des huttes dans lesquelles ils bravent le froid et les tempêtes. Ces huttes sont construites en pierres superposées les unes au-dessus des autres, en terre, en mousse, en pièces de bois et en ossements de baleine. Un corridor assez spacieux, ménagé à l'entrée, forme une espèce de voûte dans laquelle l'air extérieur pénètre, et renouvelle celui de la hutte sans y apporter ni le vent ni le froid. Ce passage ou couloir est si bas, qu'on ne peut le parcourir qu'en se traînant sur les genoux et sur les mains, et c'est ainsi qu'on parvient à la retraite ou plutôt à la tanière de la famille groenlandaise. Des peaux tendues contre les parois de la cabane préservent de l'humidité; d'autres suspendues à des traverses divisent la demeure en compartiments, dont chacun est habité par un ménage ; quelquefois dix familles sont réunies sous le même toit. De simples bancs servent de lits; les hommes s'y tiennent, pendant le jour, les jambes pendantes, et les femmes assises à la manière des Orientaux. Point de fenêtres, ni de cheminées. La partie antérieure de la hutte est seule éclairée par une ouverture à laquelle est adaptée une membrane transparente provenant d'un intestin de poisson. L'absence de cheminée se comprendra aisément quand on saura que la flamme d'une lampe est, pour chaque famille, le seul mode de chauffage. Cette lampe dont la mèche est d'une mousse très-fine éclaire tout l'appartement. Elle produit en même temps une chaleur telle, qu'elle fait bouillir un chaudron immense contenant tout le repas de la famille, et qu'elle maintient la température à un degré aussi élevé que celui qu'on pourrait obtenir du meilleur poêle d'Allemagne. On peut se faire une idée de la puanteur insupportable que répandent dans ces sales habitations la cuisson des aliments, la fonte de la graisse et de l'huile, l'haleine d'une dizaine d'individus, les peaux mal écorchées qui tapissent les murs, la fumée des lampes, les déjections des enfants, et l'urine que les grandes personnes ne se font pas faute de répandre dans tous les coins de l'appartement.

Le phoque, si utile à l'Esquimau pour la nourriture qu'il lui procure, l'huile qu'il produit, et les ustensiles que fournissent ses ossements et ses dents, offre encore à ce peuple un vêtement chaud et imperméable. Plusieurs peaux de ces animaux, jointes à la dépouille du renne, sont cousues en manière de robes, et forment un surtout merveilleusement propre à amortir les atteintes d'un froid glacial; ce surtout est muni d'un capuchon destiné à protéger la tête et le visage. La culotte, les bas et les souliers, ou plutôt les sandales, sont aussi faits de peaux de chiens marins. La chemise est de drap ou de toile de coton; quelquefois elle consiste en un assemblage de peaux d'oiseaux de mer, dont le plumage, tourné en dedans, entretient sur le corps une chaleur constante.

L'habit de mer se compose d'un manteau de peaux artistement unies, du gilet et du pantalon ordinaire; il est complété par une chemise imperméable faite avec des membranes provenant d'intestins de phoque.

L'habit de pêche consiste en un seul vêtement formé de la veste, de la culotte, des bas et des souliers, le tout fait d'une pièce, s'adaptant parfaitement au corps, et si bien cousu, que l'eau ne saurait parvenir à traverser cette solide enveloppe. Une petite ouverture est ménagée à la hauteur de la poitrine, et sert, dit-on, à introduire la quantité d'air nécessaire pour soutenir l'Esquimau dans l'eau de mer et l'empêcher de se 
noyer. Après l'introduction de l'air, le trou est fermé au moyen d'une cheville de bois. Ainsi entouré d'une espèce de vessie gonflée qui le fait surnager, le pècheur groenlandais peut poursuivre le phoque en s'élançant après lui dans les flots, où il ne craint pas de trouver la mort.

Le costume des femmes est à peu près semblable à celui des hommes. Elles portent aussi calegon et culotte. Les jeunes filles, pour attirer les maris, se tracent sur le visage des lignes de couleur qui forment l'ornement le plus estimé de leurs adorateurs. Elles portent les cheveux longs et relevés sur la tête, tandis que les hommes les tiennent courts.

Un mot seulement sur la langue de ce peuple. Les voyageurs et le missionnaire Égède, qui a écrit un dictionnaire et une grammaire groenlandaise, disent que cette langue est remarquable par la richesse de ses formes grammaticales. Malte-Brun, qui a étudié ces deux documents philologiques, a remarqué que les particules et les inflexions étaient aussi nombreuses dans cet idiome que dans le grec; mais comme il est de règle d'intercaler toutes les parties du discours dans le verbe, il en résulte des mots d'une longueur extraordinaire. Les consonnes $r, k$ et $t$ dominent et produisent, par leur accumulation, des sons désagréables par leur rudesse. Ce fait est assez singulier, vu l'aptitude des Esquimaux pour la musique et la justesse d'oreille qui les distingue. Les femmes, comme chez les Caraïbes, ont des mots et des inflexions de voix dont elles seules peuvent se servir.

\section{ISLA NDE.}

L'Islande ou Iceland ' n'est, à proprement parler, qu'une chaîne de rochers immenses dont le sommet est toujours couvert de neige. Elle a 120 lieues de longueur, 50 de largeur, et 5,000 lieues carrées de superficie.

L'Islande était divisée en quatre quartiers, nommés d'après les quatre points cardinaux. Ceux du sud, de l'est et de l'ouest formaient le diocèse de Skalholt. Le diocèse de Holum comprenait le quartier du nord. Mais depuis 1801 les deux évêchés ont été réunis. Aujourd'hui l'île est divisée en trois districts, celui du sud, celui de l'ouest el celui du nord et de l'est, et en dix-neuf cantons.

Tout concourt à faire de l'Islande une terre de désolation, et de ses habitants un peuple de martyrs; le monopole commercial achève d'épuiser les ressources des infortunés insulaires déjà si largement restreintes par les hivers rigoureux, les étés sans soleil, et les nombreuses éruptions volcaniques ${ }^{2}$. Durant près de deux siècles, tout le commerce de l'Islande fut soumis à des entraves odieuses; en 1789, il fut déclaré libre, mais le Danemark s'en réserva le monopole exclusif. La conséquence toute naturelle de cet acte despotique est que les objets apportés par les bâtiments danois dans les entrepôts de l'Islande sont excessivement chers; que les habitants sont obligés, pour se procurer les denrées et les ustensiles dont ils ont besoin, d'abandonner à l'avide trafiquant tout le fruit de leurs sueurs et de leurs veilles, et qu'il leur est impossible de se ménager ces ressources pour les mauvaises années. Que de laine, de suif, de viande de mouton, de poisson, de pelleteries, et de duvet d'éder, ne faut-il pas que l'Islandais livre au marchand danois, pour obtenir seulement un peu de farine et de sel, quelques outils,

1 Terre de glace.

2 On en compte 65. 
et un petit baril d'eau-de-vie! Quant à l'argent, les Danois ayant intérèt à tout payer en marchandises, n'en donnent qu'avec beaucoup de répugnance et le moins possible.

Aussi le découragement paralyse l'activité et le bras de l'Islandais. Si, grâce aux leçons et à l'exemple de Biarin Haldorsen, l'Islande produit aujourd'hui quelques légumes, quels immenses espaces de sol susceptibles de culture sont encore en friche! Il est hors de doute que les districts méridionaux, soumis à une température plus douce que les provinces du nord, pourraient devenir plus riches et plus productifs qu'ils ne le sont, et cependant ils ne sont pas exploités. A quoi peut-on attribuer cette incurie, si ce n'est à cette espèce de fatigue morale qui s'empare de l'homme quand il sail que sa volonté rencontrera toujours des obstacles insurmontables?

Les IsLandaIs sont aujourd'hui, sous le rapport des usages, ce qu'ils étaient autrefois. Aucune nation n'a été aussi fidèle à ses traditions. Leur langue, leur costume et leur manière de vivre sont restés les mêmes pendant une période de neuf siècles, tandis que les autres peuples se sont modifiés sous l'influence des circonstances ou de certaines individualités puissantes. Habitués dès leur enfance à entendre vanter le caractère de leurs ancêtres, et sachant que leur île natale a été l'asile de la poésie et des sciences à une époque où l'Europe était plongée dans l'ignorance et la barbarie, les Islandais possèdent à un degré éminent le sentiment national, et l'on peut mème observer chez un grand nombre de paysans de cete contrée une certaine dignité de maintien qui révèle à la fois l'indépendance de caractère et la conscience de la valeur personnelle.

N'est-ce pas pour obéir à une habitude de leurs pères qu'ils s'obstinent à construire leurs inaisons au pied des hautes montagnes, en dépit des périls qui les menacent? Que leur imporle que des rochers énormes détachés du sommet, ou des masses de terre détrempées par la pluie, fondent sur leur frèle habitation et en dispersent au loin les débris? Les premiers colons norwégiens n'ont pas reculé devant ces dangers, et eux, leurs dignes enfants, ils ne reculent pas davantage.

En général, il ne faut pas chercher l'excentricilé dans les usages des Islandais; cependant quelques-uns sont assez singuliers. Leurs différentes manières de saluer, par exemple, ont presque toutes un caraclère oriental. Lorsqu'on se rencontre on s'aborde en se disant : Scelvertu, ce qui correspond directement au salut des Hébreux, schalom lach, et au bonjour arabe, salam aleik; ni l'une ni l'autre de ces expressions ne signifie paix, dans le sens qu'on attache à ce mot en Occident, mais bien, soyez heureux. Il paraîtrait, d'après l'Edda, que les anciens Scandinaves employaient le mot heill, au lieu de scell, d'où, par suite des modifications de l'idiome anglo-saxon, les Anglais ont fait hail (Dieu vous conserve!), expression employée comme mode de salutation dans plusieurs passages de la Bible. En s'abordant et en se quittant, un affectueux baiser sur la bouche est, sans distinction de rang, d'âge ni de sexe, le seul genre de salut usité en Islande. Seulement, dans le voisinage des factoreries, l'homme du peuple salue un étranger qu'il regarde comme son supérieur, en plaçant sa main droite sur sa bouche ou sur son cœur, et en s'inclinant profondément. Lorsque vous visitez une famille islandaise, il faut la saluer suivant l'àge et le rang de chaque individu, en commençant par le chef et en finissant par le moins respectable, sans en excepter les domestiques; mais, en prenant congé, cet ordre est complétement renversé, c'est-à-dire que le salut doit être d'abord adressé aux serviteurs, puis aux enfants, et enfin à la maîtresse et au maître du logis.

Henderson parle d'une coutume encore plus originale. Qu'il nous soit permis de traduire textuellement le curieux passage où il en fait mention :

"Le maître et la maîtresse de la maison m'ayant souhaité une bonne nuit, se retirèrent 
et laissèrent auprès de moi leur fille aînée, pour m'aider à òter mon pantalon et mes bas. Je leur aurais bien fait grâce de cette ètrange politesse qui contrastait avec les sentiments de délicatesse auxquels un Européen est habitué. En vain fis-je observer à la jeune Islandaise que son ministère m'était parfaitement inutile, elle persista en disant que c'était l'usage et qu'il était du devoir d'un chrétien de venir en aide au voyageur fatigué. Il fallut donc se résigner. Quand je fus couché, elle plaça devant mon lit une longue planche pour m'empêcher de tomber, et après avoir mis une jatte de lait sur une table près de mon chevet, elle se retira en me disant bonsoir. Cet usage est répandu dans toute l'Islande. Quand il n'y a point de filles dans la famille, c'est la maîtresse de la maison elle-même qui se charge de cette singulière corvée, et elle se trouve trèshonorée de donner cette preuve de déférence à l'étranger qui est venu s'asseoir sous son toit hospitalier."

Get usage prouve en faveur des Islandais, car il révèle une grande pureté de mœurs et une chasteté qu'on n'observe plus nulle part en Europe. Mais hâtons-nous de dire qu'il fait exception, sous le rapport de la bizarrerie, à la règle générale que nous avons posée, et que tout ce que les voyageurs nous apprennent sur les autres habitudes nationales de ce peuple est, comme nous l'avons dit, fort terre-à-terre.

Comment pourrait-il en être autrement? Leurs occupations n'ont-elles pas une teinte uniforme et essentiellement monotone? La pèche, la préparation du poisson et des peaux de phoque, le tissage du drap ou wadmel, la garde des troupcaux et la fenaison, tels sont leurs uniques travaux. Et les amusements par lesquels ils font diversion à ces tristes labeurs, ont à peu près le même caractère. La lutte, les échecs et les dames, sont leurs jeux de prédilection. Y a-t-il rien de moins excentrique?

Le paysan islandais fait ses trois repas par jour : il déjeune à sept heures du matin, dìne à deux heures de l'après-midi, et soupe à neuf heures du soir. Le déjeuner se compose de skyr, ou lait caillé aigre, qu'on accompagne d'une grande quantité de crème donce. Quelquefois on lui donne une saveur particulière en y mêlant du jus de baies de genièvre. Leur dîner consiste en poisson sec ou gelé, et en beurre aigre, car les Islandais se servent très-rarement de beurre frais ou salé. Ils le laissent aigrir, et le conservent ainsi vingt ans et plus; ils croient ce beurre plus sain et le trouvent meilleur.que celui auquel nous donnons la préférence. Plus il est vieux, plus il flatte leur goût. La livre de ce beurre vaut deux livres de beurre frais. A souper, ils mangent, soit du skyr avec un peu de biscuit et de fromage, soit une soupe faite avec de la mousse islandaise, espèce de lichen bien connu en Europe. Ce dernier mels est le plus agréable et le plus salutaire. La boisson ordinaire est le blandà, petit-lait mêlé avec de l'eau. Ils boivent aussi du petit-lait pur et du lait, qu'ils ne prennent guère que chaud.

Tel est l'ordinaire des Islandais. Mais il est encore d'autres mets dont ils raffolent : par exemple, la viande salée ou fumée, ou bien encore conservée dans du petit-lait fermenté. Ils mangent aussi avec plaisir des os, des tendons de bœuf et de mouton, et des arêtes de morue, qu'ils font cuire dans du petit-lait jusyu'à dissolution. Ils les font ensuite fermenter et les servent dans du lait. Quant au poisson, il est certaines espèces qu'ils ne mangent que lorsque l'animal est sur le point d'entrer en putréfaction, et quand les fibres se détachent presque d'elles-mêmes. Ils en font quelquefois du bouillon qu'ils mêlent avec du petit-lait. Les paysans qui jouissent d'une certaine aisance se nourrissent aussi de viande bouillie, de veau marin et de chair de baleine.

I.e dimanche, la famiHe islandaise se régale de quelques mets extraordinaires; tels que du gruau d'orge ou de sarrasin cuit dans du lail, de la bouillie, de la soupe grasse et de la viande macérée dans du petit-lait. Aux grandes fêtes, comme Noël et Pàques, le plat de rigueur est de la viande fumée dont on extrait le jus en la mettant en presse. Il 
y a aussi dans le courant de l'année certains jours qu'il est d'usage de célébrer par des festins : c'est ainsi que, après la moisson, on mange le slagen-lamb (agneau gras), ou un mouton si la famille est trop nombreuse. Ils appellent la soirée du mardi saint sprengiou liveld, parce qu'on est obligé, ce jour-là, de donner aux ouvriers et aux domestiques autant de viande fumée qu'ils en demandent. Le lendemain, la viande est interdite jusqu'après Pâques, et, pendant tout le temps du carême, il faut bien se garder de prononcer même le mot viande. Celte coutume donne lieu à un singulier badinage : ils s'excitent les uns les autres afin que ce mot échappe à l'un d'eux, parce que le délinquant perd la portion de viande qui lui revient le mardi après Pâques ${ }^{x}$. Le premier jour d'été est aussi fêté par un régal de famille, auquel participent tous les gens de la maison.

Nous avons parlé plus haut du beurre aigre dont les Islandais font grand cas. Ce beurre, ainsi préparé, a sur le beurre salé l'avantage de pouvoir se conserver trèslongtemps sans devenir rance; lorsqu'on a soin de le bien presser, afin d'en faire sortir tout le petit-lait; quand on l'a bien pétri et soigneusement lavé, il se garde, comme nous l'avons dit, plus de vingt ans, sans perdre sa saveur acide. A l'époque où le catholicisme régnait en Islande, il y avait près des évêchés de vastes maisons qui servaient uniquement à emmagasiner de grandes provisions de ce beurre. Dans les années de disette, qui ne revenaient que trop fréquemment, on en distribuait à tous ceux qui en manquaient, et principalement aux vassaux de l'évêque.

Il est certain, du reste, que ce mets national était en usage dès la plus haute antiquité; ce qui confirme ce que nous avons dit de la fidélité des Islandais à leurs anciennes coutumes. On lit le passage suivant dans la satire Skida Rima, un des plus anciens poëmes du pays, et l'œuvre d'un Islandais poëte du roi Sigurd-Jorsalasard: a Skidi était le mendiant le plus misérable de l'Islande. Il rêva, une nuit, qu'il allait demander Freya en mariage, et prier en même temps Odin d'ajouter à cette faveur la permission de se faire remplir de beurre aigri une caisse qu'il portait avec lui. Friggia reçut ordre d'acquiescer à sa demande. Le pauvre Skidi réveillé, et revenu de son rêve dans un coin de la chétive cabane qu'il habitait dans le Hittardal (vallée d'Hittar), va, comme poussé par une suite de son délire, visiter une caisse où il enfermait sa mesquine provision. Quels furent son étonnement et sa joie en la voyant pleine de vieux beurre aigri!n

Quelques voyageurs prétendent que de pareils aliments ne nuisent en rien à la santé des Islandais. Cependant la raison dit qu'une nourriture aussi singulière n'est guère propre à soutenir les forces de ces hommes condamnés aux rudes travaux de la pêche el de la culture. On peut même ajouter, sans craindre de se tromper, qu'une semblable alimentation est tout à fait de nature à favoriser les horribles maladies dont ces insulaires portent le germe dans leur sang, telles que la lèpre, l'éléphantiasis et les scrofules. Heureusement la civilisation européenne leur vient peu à peu en aide. Déjà un certain nombre de paysans islandais se nourrissent un peu mieux, boivent des vins de France, du café, et se servent de meubles venus d'Europe.

Les Islandais se chauffen $\mathrm{i}$ avec de la tourbe, de la bruyère, des buissons de genièvre, des os des bestiaux tués pour la consommation, des os de poissons arrosés d'huile de baleine, et du fumier de vache desséché. Ils emploient aussi le bois jeté sur leurs côtes par la mer. Il en arrive tous les ans une grande quantité dans tout le nord de l'île. Ce bois vient en grande partie d'Amérique, d'où les vents et les courants les poussent dans ces parages. Le Saint-Laurent en charrie-beaucoup, ainsi que les fleuves qui se jettent

1 Celte interdiction de la viande après la semaine sainte est un reste de catholicisme. 
dans la baie d'Hudson. Mais il en vient de bien plus loin : on a trouvé plusieurs fois sur le littoral de l'Islande et du Groenland des arbres qui ne croissent que dans l'ouest des États-Unis, et qui, entraînés par les flots du Mississipi dans le golfe du Mexique, avaient flotté, sous l'impulsion des courants, jusque dans le voisinage des régions circompolaires arctiques.

Il existe en Islande un autre combustible, pIus précieux encore et d'une nature assez étrange; c'est le surturbrand ou bois noir fossilisé. On trouve cette substance enfouie sous terre à une certaine profondeur, dans plusieurs quartiers de l'île. Elle se présente sous la forme d'arbres ou de rameaux couchés horizontalement, et accumulés par grandes masses dans le même endroit. On a beaucoup discuté sur l'origine de ce bois à moitié fossile. Quelques auteurs pensent que les forêts dont cette contrée était autrefois couverte, ont pu être renversées par des torrents de lave et se transformer en surturbrand; mais si le bois eût été en contact avec la lave brûlante, il eût été infailliblement consumé; ou si la lave était assez refroidie pour ne pas brûler ce qu'elle rencontrait, elle eût arraché violemment les arbres et les eût dispersés dans le plus grand désordre; or les fragments de cette substance sont uniformément rangés dans une position longitudinale et dans un ordre remarquable. L'hypothèse la plus vraisemblable, c'est que les anciens bois de l'Islande ont été abattus par la force de l'eau, puis recouverts à plusieurs pieds de hauteur de matières volcaniques. Quoi qu'il en soit, cette matière combustible offre, par l'état auquel elle est parvenue, un phénomène singulier. On ne peut douter que ce ne soit du bois, car on y voit les veines et les couches concentriques, en plus ou moins grand nombre, suivant l'âge des arbres. Le surturbrand, exposé à l'air sec ou au soleil, tombe en petites parcelles et se détruit; tandis qu'il se conserve trèslongtemps dans les lieux humides. Mis au feu, il donne une petite flamme claire, et produit une chaleur très-intense. Les forgerons et les serruriers le préfèrent au charbon de terre, parce qu'il ne brûle pas tant le fer, et que l'odeur légèrement acide qu'il répand, en se consumant, n'est nullement malsaine. Du reste, ce n'est pas là le seul usage auquel on fasse servir le surturbrand. Les Islandais le travaillent avec une adresse merveilleuse et en font toute espèce d'ustensiles; car ce bois n'a pas seulement la couleur de l'ébène, il en a aussi la dureté. Réduit en poudre, il préserve les habits des vers, et les insulaires assurent que c'est un remède souverain contre les coliques violentes.

Ce que nous venons de dire des mœurs et des usages des Islandais est suffisamment caractéristique, et nous dispense de plus amples détails.

La langue islandaise est considérée avec raison comme le modèle et la souche primitive du grand dialecte en usage chez les nations septentrionales et tiré de la langue gothique. Tandis que le suédois, le danois, et même le norwégien, qui est une espèce de dialecte fort doux, subissaient plus ou moins l'influence de l'idiome teutonique ou allemand, la langue des anciens Scandinaves se conservait en Islande dans toute sa pureté. Cette langue était, durant le moyen âge, le dônsk tunga, ou langue danoise; les Islandais l'appelèrent d'abord norroena, parce qu'ils l'avaient importée de la Norwége : ce dernier nom ressemble à celui de norns ou norse, qui désigne le dialecte corrompu parlé dans les Orcades. C'est seulement depuis que le scandinave proprement dit a cessé d'être en usage sur le continent, qu'on l'appelle langue islandaise. L'éloignement de cette île, et le peu de relations qu'elle a, pendant longtemps, entretenues avec le reste du monde, ont en effet préservé de toute altération le caractère original de cette ancienne langue. Tandis que les archéologues cherchent quelquefois en vain l'explication d'un mot ou d'une phrase écrite dans une langue éteinte depuis quelques siècles seulement, il n'y a pas en Islande un paysan, et même une servante qui ne soit capable de lire les plus 
anciens documents scandinaves. Ce fait, au point de vue philologique, est aussi curieux qu'intéressant.

Il va sans dire toutefois que cette particularité ne se fait remarquer que dans l'intérieur de l'île, et que, sur les côtes, le contact des étrangers a fini par modifier l'idiome national.

La langue islandaise est d'une richesse et en même temps d'une simplicité remarquables. Elle admet les combinaisons grammaticales les plus compliquées et de nombreuses modifications de mots; ce qui lui donne un point de contact avec l'allemand. Elle a les trois genres, comme le grec, la déclinaison des noms propres, comme le latin, et, comme le danois, l'article déterminé qui se place à la fin des substantifs. Elle est douce et exempte de la prononciation si dure des idiomes germaniques. Elle participe à la fois du danois, du suédois, de l'allemand, du hollandais, de l'anglo-saxon et de l'anglais; elle offre aussi des affinités avec le grec et les langues slaves.

Les runes étaient autrefois les caractères d'écriture usités en Islande. Le mot rune signifie parole mystérieuse. Chez les Finnois, il désigne les chants populaires, et quelquefois aussi chez les Islandais. Les monuments historiques et littéraires du Nord ne nous apprennent rien ni sur l'époque où les runes furent introduites en Europe, ni sur celle où elles tombèrent en désuétude. Ce qu'il y a de certain, c'est qu'elles passaient, en Scandinavie, pour avoir été enseignées par Odin, qui les faisait servir à des mystères cabalistiques. La rune était un talisman, et la magie l'employait pour exprimer ses formules. Ce n'était quelquefois qu'un symbole; gravée sur le bras ou sur la poitrine, elle avait une valeur hiéroglyphique : par exemple, un $F$ désignait Freya, déesse de l'amour; un $i$, is, glace; un $n$, naud, nécessité; un $T h$, Thor, dieu de la force. Les runes servaient aussi comme simples lettres : elles formaient un alphabet de seize caractères. Une seule représentait les consonnes qui se prononcent à peu près de même, telles que le $g$ et le $k$ (dans les langues du Nord); le $d$ et le $t$, le $b$ et le $p$; l'u, le $v$, et l'y qui se prononçait comme l'u.

Après avoir résisté aux efforts des missionnaires chrétiens, l'usage des runes fit enfin place à l'alphabet européen; toutefois il se maintint parmi certaines populations septentrionales jusqu'au xiv' siècle.

L'application presque exclusive des runes aux choses mystiques se concoit mieux quand on réfléchit que les anciens Scandinaves, par suite de l'habitude où ils étaient de réciter de mémoire leurs chants populaires, n'avaient presque aucun besoin de l'écriture positive. Les poëtes créaient, et le peuple répétait leurs chants, qui se perpétuaient ainsi dans son souvenir de génération en génération. L'activité intellectuelle des Islandais favorisait l'usage de ces traditions orales. Cette activité était telle, qu'à l'époque où l'Europe était encore plongée dans les ténèbres, les habitants de cette île voisine du pôle cultivaient déjà la poésie et l'histoire, et s'initiaient à des connaissances qui devaient avoir pour résultat, non-seulement de hâter leur développement moral, mais encore de transmettre à la postérité des documents certains sur les antiquités du Nord.

Ce goût des Islandais pour la littérature et la science n'est pas difficile à expliquer : les Norwégiens qui peuplèrént ce pays appartenaient aux familles les plus distinguées de la mère patrie. Ils étaient dès leur enfance accoutumés à entendre le récit des choses d'autrefois; ils avaient fréquenté les assemblées publiques, où la voix des hommes éloquents avait plus d'une fois frappé leur oreille; enfin, ils avaient retiré de leurs expéditions maritimes une connaissance assez exacte de la situation politique, de l'histoire et des mœurs des autres contrées de l'Europe. Tout ce trésor intellectuel, ils l'apportèrent en Islande, et les hauts faits accomplis par eux-mêmes sur cette terre d'adoption leur fournirent l'occasion d'exercer leur verve littéraire. Ils chantèrent aussi ; ils racon- 
tèrent le présent comme le passé, et les loisirs de leurs longues nuits d'hiver ne firent qu'augmenter cet heureux penchant.

Le sort du clergé islandais est très-précaire; il ne reçoit rien du gouvernement. Il a pour tout bien la jouissance des fermes qui appartiennent à l'église, et le quart des dîmes payées par chaque paroisse. Le prêtre est en outre obligé d'abandonner une part du produit de sa ferme à la veuve de son prédécesseur, et quand la vieillesse ou les infirmités l'empêchent de faire son service, on lui donne un chapelain, avec lequel il partage encore son revenu. La taxe pour les diverses cérémonies du culte est trèslégère; les paysans la payent avec du beurre ou du poisson. Dans quelques églises, le produit de la dîme, du casuel et de la ferme est de 20 à 30 thalers (60 à 90 fr.). Les prêtres ne peuvent point exiger de corvée de leurs paroissiens; leur seule prérogative consiste à placer à la fin de l'automne, dans chaque bœr (ferme), un mouton que le paysan s'engage à nourrir pendant l'hiver. Ne pouvant vivre avec d'aussi faibles ressources, le prêtre est obligé de cultiver sa ferme, de ferrer ses chevaux, d'aller à la pêche pendant six jours de la semaine, comme le plus pauvre de ses paroissiens. 

<smiles>CCCCCCCC</smiles>

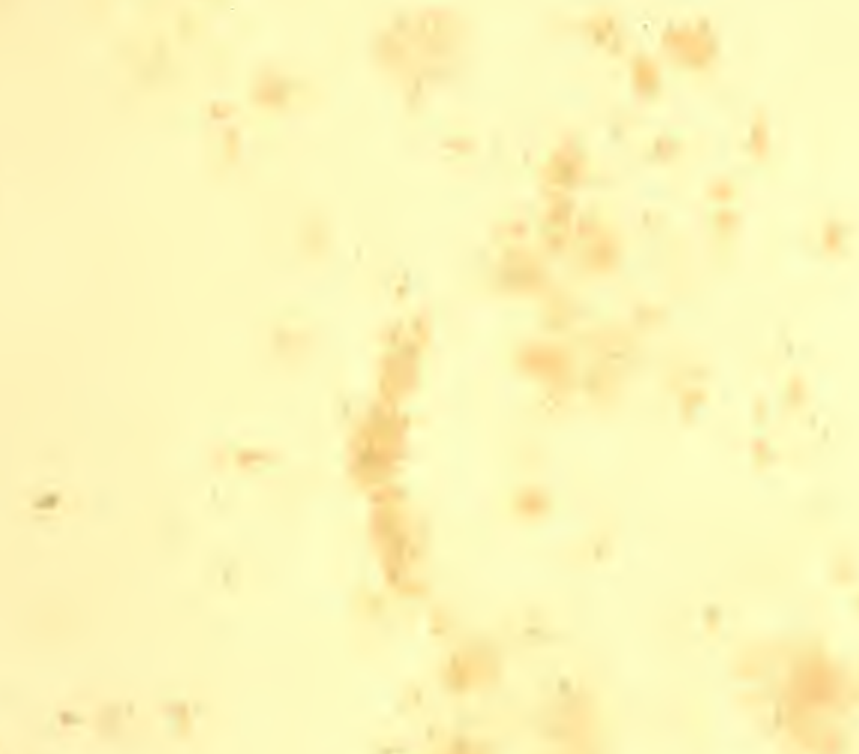

x

f

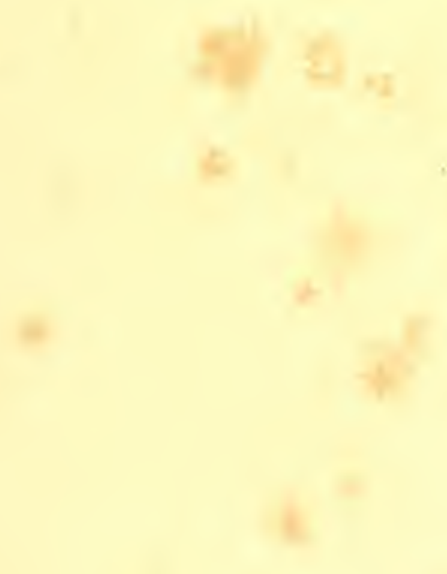

4 


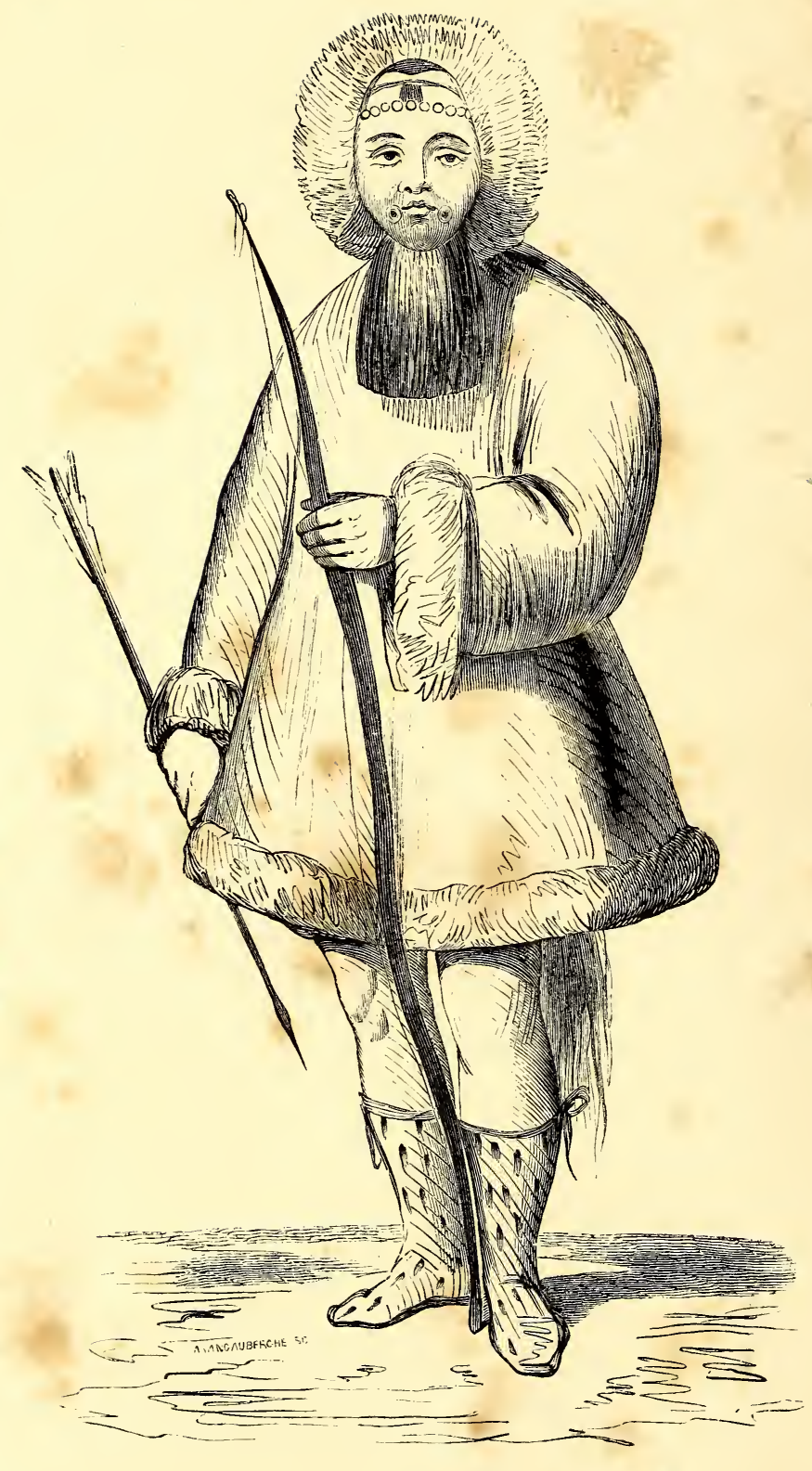

NATUREL DE L'ILE SARITCHEFF. 


\section{APPENDIGE.}

\section{ILE SARITSCHEFF.}

Cette île, qui fut découverte par Kotzebue, a sept milles de longueur et un mille dans sa plus grande largeur.

Nous laisserons parler Kotzebue qui, d'une éminence qu'il avait gravie, aperçut cinq ou six canots, montés chacun par une dizaine d'hommes et qui abordèrent près de lui.

Le capitaine russe s'exprime ainsi : ‘ J'ordonnai à mes gens de se tenir sur leurs gardes, et j'allai moi-même au-devant des Américains, qui, me voyant approcher, s'assirent à terre en rond à la manière des Turcs, pour indiquer sans doute que leurs intentions étaient amicales : deux chefs s'étaient assis un peu à l'écart des autres. J'entrai dans le cercle, bien armé, et je m'aperçus qu'ils avaient laissé la plupart de leurs armes dans leurs canots, mais qu'ils avaient de longs couteaux cachés dans les manches de leurs habits. La méfiance, la curiosité et l'étonnement étaient peints sur leurs figures; ils parlaient beaucoup, mais malheureusement je ne comprenais pas un mot. Pour tâcher de les rassurer, je leur distribuai du tabac; les deux chefs en reçurent double portion, et ils furent tous fort charmés de ce précieux cadeau. Ceux qui reçurent les premiers de mon tabac, furent assez fins pour changer secrètement de place afin d'en recevoir une seconde part. En effet, ces naturels attachent un prix extrème à cette plante, qu'ils trouvent autant de plaisir à mâcher qu'à fumer. C'était un curieux spectacle de voir cette horde sauvage assise en rond et fumant avec des pipes de pierre blanche dont le tuyau était de bois. Il est fort remarquable que l'usage du tabac ait déjà pénétré dans ces parties du monde qu'aucun Européen n'a encore visitées. Les Américains reçoivent cette plante ainsi que d'autres denrées européennes de Tschukutskoi. Aux deux chefs je donnai des couteaux et des ciseaux : ce dernier instrument, qu'ils parurent ne pas connaître, leur causa un extrême plaisir quand ils s'aperçurent qu'ils en pouvaient faire usage pour couper leurs cheveux; et aussitòt les ciseaux firent de mains en mains le tour du cercle, chacun les essayant sur sa propre tête. C'était probablement la première fois de leur vie que ces Américains voyaient des Européens; aussi nous regardions-nous les uns les autres avec surprise. Ils sont de taille moyenne, robustes et bien portants; leurs mouvements sont vifs; leurs figures, qui ont une expression d'insouciance et non de stupidité, sont laides et sales, caractérisées par de petits yeux et par des pommettes saillantes. Ils ont de chaque côté de la bouche des trous dans lesquels ils portent des dents de cheval marin ornées de grains 
de verre bleu, qui leur donnent un air tout à fait horrible. Leurs cheveux, courts sur le sommet de la tête, sont extrêmement longs des côtés. Leur tête et leurs oreilles sont aussi décorées par des grains de verre. Leurs habits, qui sont faits de peaux, ressemblent pour la forme à ceux qu'on porte au Kamtschatka : la seule différence est qu'ils descendent à peine ici jusqu'au genou. En outre, les naturels portent des pantalons et de petites bottines en peau de veau marin. $\triangleright$

Kotzebue nous fait aussi connaître les habitations de ces indigènes : "Nous entrâmes, dit-il, dans les iourtes qui sont rangées en ligne droite le long de la côte; mais d'abord nous fûmes seulement reçus par des chiens, qui ne s'alarmèrent aucunement de notre arrivée, et même vinrent mendier nos caresses. Ils me parureut être de la même espèce que ceux à qui on fait tirer les traîneaux au Kamtschatka. Nous avions déjà grimpé sur le toit des iourtes sans rencontrer personne; cependant des traces récentes que nous voyions de tous côtés nous montraient que les naturels étaient plus peureux que leurs chiens, et s'étaient enfuis à notre approche. Nous examinâmes alors l'intérieur de leurs demeures, que nous trouvâmes propre et commode. La porte, du côté sud-est, était une ouverture haute de trois pieds, que formait une pièce de bois posée transversalement sur des murs de terre. Nous entrâmes d'abord dans une pièce longue de dix pieds, large de sept et haute d'autant; les parois et le plafond étaient recouverts de bois. A gauche, dans une fosse qui régnait sur toute la longueur de la pièce, étaient des morceaux de baleine noire d'environ un pied carré, et auprès de ces morceaux des tamis à longs manches. A droite il y avait une fosse plus étroite, profonde de deux pieds et demi et longue de sept, par l'extrémité de laquelle nous pénétrâmes, en nous tenant presque à plat ventre, dans une chambre, il est vrai, haute de six pieds, mais aussi étroite que la fosse. Nous eûmes alors devant nous une cloison de bois, au milieu de laquelle était une ouverture ronde d'un pied et demi de diamètre, à travers laquelle il nous fallut passer pour arriver à un appartement dont les quatre murs avaient dix pieds de long et six de haut; la hauteur augmentait vers le milieu, et au plafond il y avait un petit trou carré, couvert d'une vessie, qui servait de fenêtre. Le long de la muraille opposée à la porte, de larges planches élevées d'un pied el demi au-dessus du plancher servaient de lits, et occupaient seulement un tiers de la pièce. Sur de petits dressoirs suspendus aux murs des côtés, nous vîmes différents ustensiles de ménage. Les planchers sont à trois pieds de terre, et dessous sont les magasins et peut-être les chenils. Toutes les habitations de ces naturels sont construites d'après le même plan.»

FIN DE L'AMÉRIQQUE. 


\section{TABLE}

\section{DES MATIERES.}

\section{AFRIQUE.}

Aperçu général.

Pages.

EGYPTE.

Géographie, topographie et histoire.

5) à 15

Gouvernement, lois, moeurs générales.

15 à 37

Différents peuples : Cophtes.

Juifs.

Arméniens.

Raïas.

ib.

Population franque.

40

NUBIE.

Géographie.

$43-44$

Différents peuples : Barabras ou Kenous.

Ababdèhs.

45

Habitants du Dongolah.

Chaykyéhs.

$i b$.

46

Habitants du Barbar ou Berber.

$i b$.

Peuples du Chendy.

Djemelyes, Hassanyeh's, Hetsenats, Mohamedyehs, Magdyehs, Hellahouyehs, Kererats, Kenaouys, Kemehabes, Kababychs, Choukryehs, Kaouahleh, Djaleyns.

Sennaariens.

AnNexes de La NUbie.

Différents peuples : Nègres de Dâr-el-Keyl et de Kamamyl.

Nègres de Denka, Dongolais, Noubahs, Arabes-Bédouins.

$i b$.

Habitants du Kourdofan.

51

$i b$.

ABYSSINIE.

Géographie et histoire.

$53-55$

Différents peuples : Falasjan (juifs abyssiniens).

Tribus du Condar, Gamaountes, etc.

$i b$.

\ du Gojam, de Maïcha, etc. 
Gallates, habitants du Choa, etc.

Mœurs des Abyssiniens.

Gallas, Changallas.

Agaouys, Gafates, Guragues.

Côte D'Habesch.

Différents peuples : Troglodytes des anciens.

Habitants de la côte Daza ou Bedjah.

ib.

Chohos, Danakils, Hazortas, etc.

61

Nébaras et autres tribus.

$i b$.

BARBARIE.

\section{Géographie.}

Différents peuples : Mores et Arabes.

Amazygh, Kabyles, Tibbous, Touariks.

Royaume DE Tripoli.

Barcah.

ib.

Fezzan.

Tripoli propre.

$i b$.

Régence de Tunis.

AlgÉRIE.

Differrents peuples : Mores algériens.

Tures.

Juifs.

$i b$.

Nègres, Arabes et Berbers.

$i b$.

Zouaves.

MAROC.

Ile et habitants de Gorée.

Royaumes de Cayor, de Dacar, de Baol, de Syn, de Yolof.

États de Kasson, Fouladou; peuplades Foulahs ou Poules.

Royaume et habitants de Bambouk et autres États; Papels, Bissagos, etc. $\quad 86$

Royaume de Fouini; tribus Feloups, de Mandings, etc. $\quad 87$

$\begin{array}{ll}\text { Serakhalès, Serawoulis, Ghialonkès, Sousous, Naloubès. } & 89 \\ & 91\end{array}$

GUINÉE.

Provinces, colonies, peuples : Sierra-Leone, Timanni.

Kourankoniens, Soulimas, Achantis (avec les Fantis et autres peuples tributaires).

Côte des Esclaves, royaume de Dahomey et ses habitants.

Royaumes et habitants de Benin, Lagos, Ouary, Calabar, Qua, Bonny, cap d'Esteiras, côte de Gabon.

NIGRITIE (Soudan ou TAKrour).

États et différents peuples : Nègres.

Bambarra (haut et bas) et ses habitants.

Massina et ses habitants.

Ludamar, Birou, Banan-Dagou, pays des Dirimans, Tembouctou, Kayry, Kong et autres, Fellatahs.

Mali, Sanghi, Haoussa, Yaouriens.

Bournou el Bournouais.

Mandarans, Kanembous, pays de Baghermeh, etc.

Dar-Four et Dar-Fouriens. 
États et peuples : Mayomba, Cacongo, N'Goyo, Congo, Ouando, Dembi, Angola,

Des Congues, de leurs mœurs, etc.

Anziquois.

CIMBEBASIE.

Les Damaras, les Namaquas (grands et petits), Kaboriquas, Geissiquas, Koranas, Gonaquas, Bosjesmans.

Cafrerie propre : des Cafres.

Pays des Betjouanas.

Borrolous, Machâous, Maroutzis, Sofala.

Monomotapa.

Tribus des Bororos, des Cazembes, des Moriza's, des Maravi's, des Monga's, des Merapoua's; pays de Jambara, de Mocanda, de Mouloua; tribu des Monjous.

Côte de Mozambique : ville de ce nom; nation des Makouas.

Zanguebar : Iles de Quiloa, de Zanzibar, de Pamba, et autres; peuplades de Mosegueyos, de Maracatas, de Magadoxo, d'Abyssiniens.

Côte d'Ajan : royaume d'Adel; les Jagas.

État et peuple de Gingiro.

Ile de Socotara : habitants divers.

Iles Comores : Anjouan, Angazija, Mouhilly, Mayotte; Comorois.

Madagascar : peuples divers.

Iles Mascareignes: Bourbon, lle de France, Rodrigue, Cargados.

Ile Sainte-Hélène : Jamestown, ville et port.

\section{AMÉRIQUE.}

Aperçu général.

AMÉRIQUE MÉRIDIONALE.

Géographie générale.

ILES MALOUINES (Falkland et Solidad). 
CHILI.

Géographie et histoire.

Peuples et villes : Aramans ou Molouches.

Chiliens.

Guassos.

Santiago.

Concepcion.

RÉPUBLIQUE ARGENTINE.

Position et histoire.

Topographie : Buenos-Ayres.

Corrientes.

Peuples : Mendozinos, Pampas.

Puelches, Capataz, Guachos ou Gauchos.

Indiens des missions.

Péons.

URUGUAY.

Position géographique.

Topographie : Montevideo.

Peuples : Charruas.

PARAGUAY.

Position géographique.

Topographie : Assompcion.

Peuples : Payaguas.

Guanas, Mbayas.

Tobas, Ayuilots, Pitilagas, Bocobis.

PÉROU, BOLIVIE.

Position géographique.

Topographie : Lima.

Cazeo, Callao, Chuquisaca, Aréquipa, Cerro.

Caxamarca.

Peuples : créoles, métis, mulâtres, quarterons, zambos, nègres créoles. 172

Quichuas ou Incas.

Aymaras, Atacamas.

Changos, Yuracarès.

Mocéténès, Tacanas.

Maropas, Apolistas.

BRÉSIL.

Géographie et histoire.

Topographie et peuples : Rio-de-Janeiro, Rio-Grande, San-Paulo.

Yameos (dans le district de Huarinas), Yaguas, Origones (dans la mission de Pebas), Maxourounas (aux environs de Tabatinga).

Mandrucus (dans la mission de Novo Monte Carmel do Canoma), Aponegi-Crus, Macama-Crus, Tupimambas ou Topinambous, Gamellas ou Acobas, Tenembas, Cayacas, Cupinbaros. 
Position géographique.

GuYane anglaise.

- Topographie : George-Town.

Pcuples : Warrows, Caraïbes, Arrowauks, Taïras, Piaunacotaus, Macoushis.

$i b$.

$i b$.

$i b$.

GuYane hollandaise.

199

Topographie : Paramaribo.

$i b$.

Peuples : Surinamois.

$i b$.

GUYANE FRANÇAISE.

Topographie : Cayenne.

$i b$.

Peuples : Galibis, Arouas, Palicoubs, Pricous, Cariacouyous, Noragues, Marawanes, Oyampis, Coussanis, Emerillons.

$i b$.

COLOMBIE.

Géographie et histoire.

Provinces, villes ou peuples : Colombiens.

RÉPUBLIQUE DE L'ÉQUATEUR : Quito (ville indienne de).

204

Indiens de Quito.

205

Nouvelle Grenade : Bogota (ville et habitants de). Mariquita.

$i b$.

206

Venezuela, Caracas.

207

Otomaques, Jarures, Amarizanos.

208

Macos, Salivas, Maquiritares, Carancucanas, Parecas, Guahibos, Chiricoas. 209

GUATEMALA. Guaraunos, Guahiros, Chaymas.

Géographie et histoire.

Divisions politiques. - Peuples : États de Guatemala (où se trouve Vera-Paz), SanSalvador, Honduras, Nicaragua, Costa-Rica; Guatemaliens. Mosquitos.

ARGHIPEL GOLOMBIEN OU GRANDES ET PETITES ANTILLES.

Cuba. - Position géographique.

Population.

Haїтr. - Position géographique.

Port Républicain ou Port-au-Prince.

Histoire, population.

Boucaniers.

Porto-Rico. - Géographie.

Topographie et population.

Bahana ou Lugayes (îles Turques et Caïques).

Martinique. - Géographie, histoire, population.

TABAGO.

Histoire. - Anciens peuples : Aztèques, Toltèques, Dolmèques, Xicalaugnes, Cores, 
Puentes del Rey, Xalapa, la Puebla.

Population.

Mecos, Apaches, Lipanis.

TEXAS.

Géographie et histoire.

Lappans ou Lipans, Comanches.

Tankoways, Cherokees. $\quad 257$

ÉTATS-UNIS.

Géographie.

États ou peuples : Maine, Penobscott (Indiens).

New-Hampshire, Vermont, Massachusets, Rhode-Island, Connecticut. 260

NEW-YoRk.

New-Jersey, Pensylvanie.

Philadelphie.

Delaware, Maryland, Columbia ou district fédéral. $\quad 269$

Virginie, Caroline du Nord. $\quad 270$

Caroline du sud, Géorgie, Illinois, Sawanees, Potowatomies. 271

Kentucky, Indiana. $\quad 272$

Floride, Cherokees, Michigan, Chippaways, Ottowas, Ohio. _.

Tennesee, Alabama, Mississipi, Louisiane, Nouvelle-Orléans. 275

Arkansas, Missouri, Indiens de Saint-Louis, Sacs, Renards. 280

Sioux, Minoa-Kantongs, Waspetongs, Sassitongs, Yanetongs, Titons, Waschpecontes. 282

Ayonas, Ménomènes, Mandans, Meunitarris. $\quad 283$

$\begin{array}{ll}\text { Chochonis. } & 301\end{array}$

Têtes-Plates (Killamoks, Clastops, Tchinnouks, Catlamahs) ; Konsas. 303

Osages, Panis. $\quad 364$

Omahas. $\quad$ \& 305

Poncars, Dacotas. $\quad \mathbf{5 0 6}$

Corbeaux. $\quad 308$

Assiniboins. $\quad 309$

Pjeds-Noirs. $\quad 310$

Ojibuais, Corneilles, Nez-Percés.

$\begin{array}{ll}\text { Shoshokors. } & \mathbf{3 1 8}\end{array}$

Indiens Dignes-de-Pitié, Traqueurs-Indépendants. $\quad 519$

CANADA.

Géographie.

États, villes ou peuples : Québec, Montréal, York, Kingston.

$\begin{array}{ll}\text { Population anglaise, Indiens vagabonds. } & 326 \\ \text { Canadiens. } & \end{array}$

$\begin{array}{ll}\text { Population française. } & \mathbf{3 2 7}\end{array}$

Hurons, Mississagues, Moharohs, Pikouagamis, Mistissinnys, Papinachois; Gaspé ou GASPÉSIE; Tummiskamings.

Nouveau-Brunswick, Maréchites, Nouvelle-Écosse, îles du Cap-Breton, du PrinceÉdouard, de Terre-Neuve.

Iles AlÉoutes : OunalachKa.

Archipels du Prince-de-Galles, de George-Trois, du Duc-d'York, de l'Amirauté; baie de Norfolk, péninsule d'Alaska-Tchouktchis.

Loniaghis, Kenaïts, Tchougatches ; Nouvelle-ArkHaNGEl.

Kalongiens. $\quad 334$

NouveluE-GÉorgie; Solkouks, Enouchours, Schillouts, Killamouks; Noutka; Wakas. 535 
TABLE DES MATIÈR ES.

363

Pages.

Nouvel-Havovre; Sloud-Couss, Nanscoud, Nagaïls, Atnahs, Carriers, Anwikumtes,

Kyltschanes, Inkalischluates.

339

RẺGION DU NORD ET DU NORD-EST.

$i b$.

Esquimaux.

340

Ghippeways.

ib.

- Indiens du Nord, Crihs.

311

Groenland.

ISLANDE.

349

Appendice : ILE DE SARITSChefF.

357 



\section{TABLE INDICATIVE DES PLANCHES}

\section{DE \\ L'AFRIQUE ET DE L'AMÉRIQUE.}

AFRIQUE.

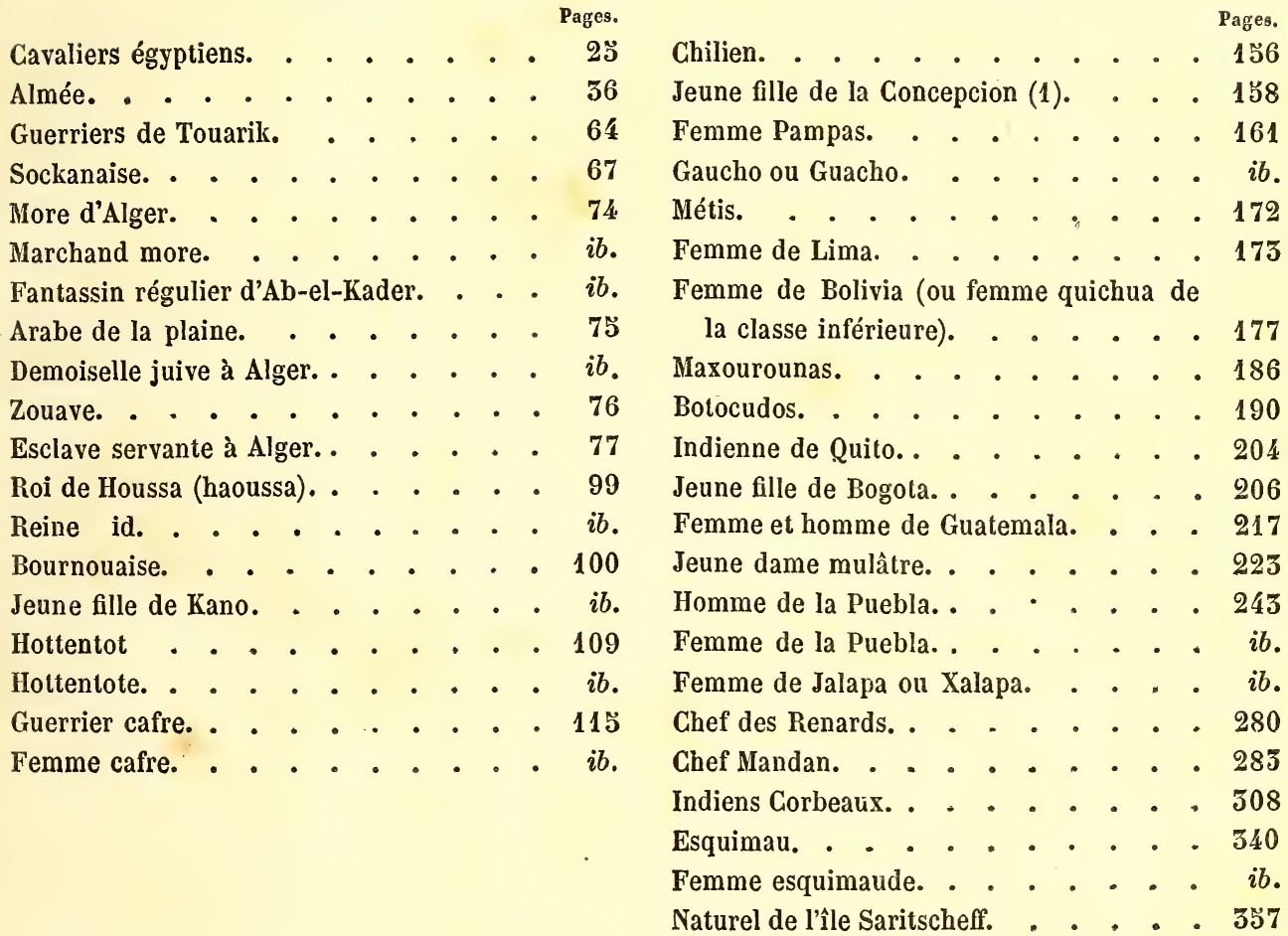

(1) C'est à tort que, au bas de la gravure, on a écrit Jeune fille de l'île de la Concepcion; il s'agit ici de la Concepcion, ville du Chili. 



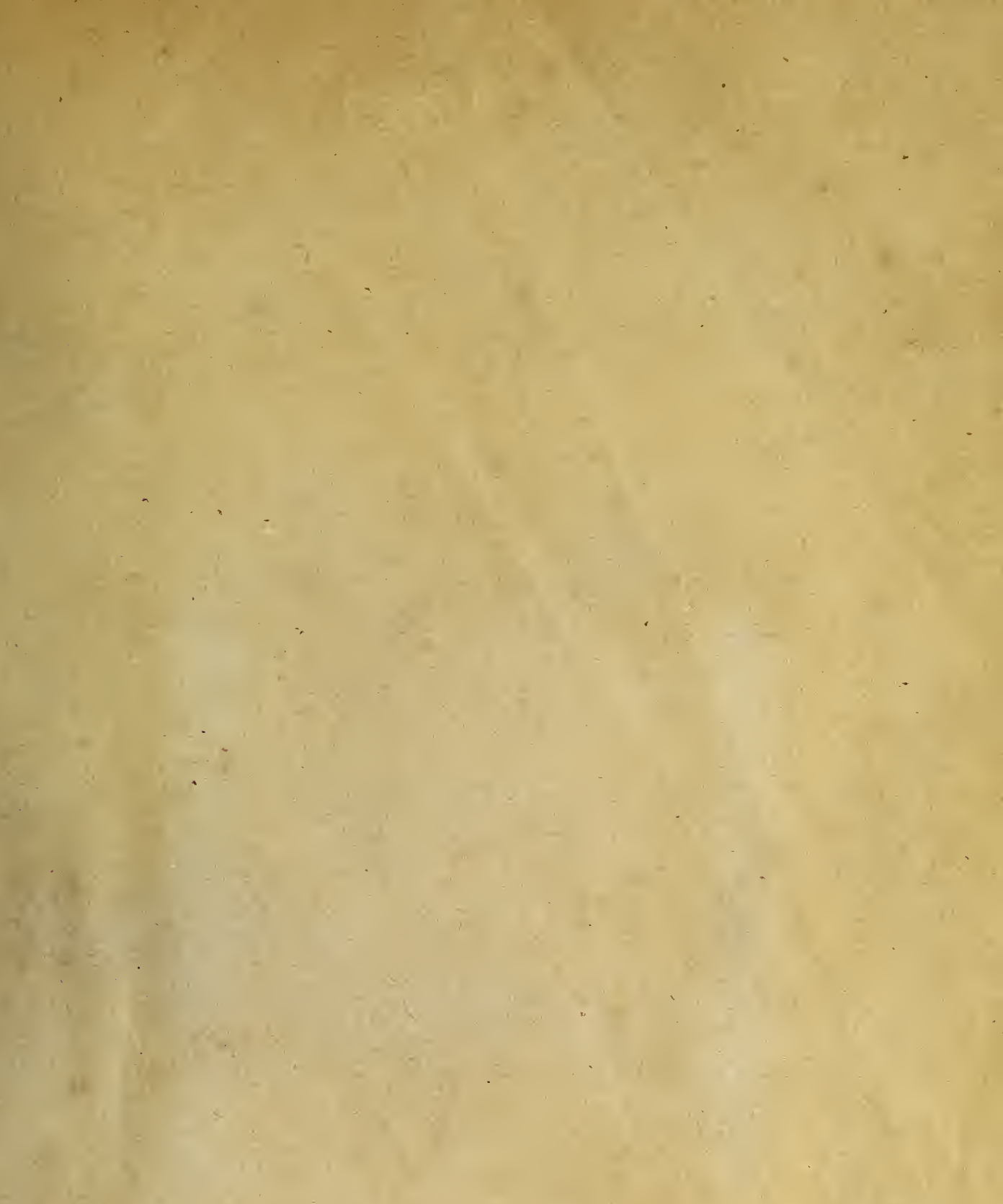




$$
P_{B S}
$$


Wahlen, Auguste.

Moeurs, usages et costumes...

GT70.W2X 1843 vol. 2 AFA 3049 
